intodes - The

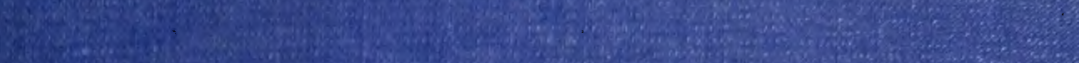

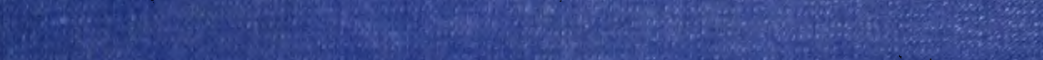

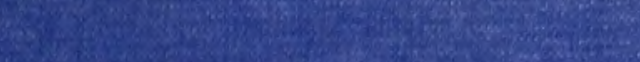
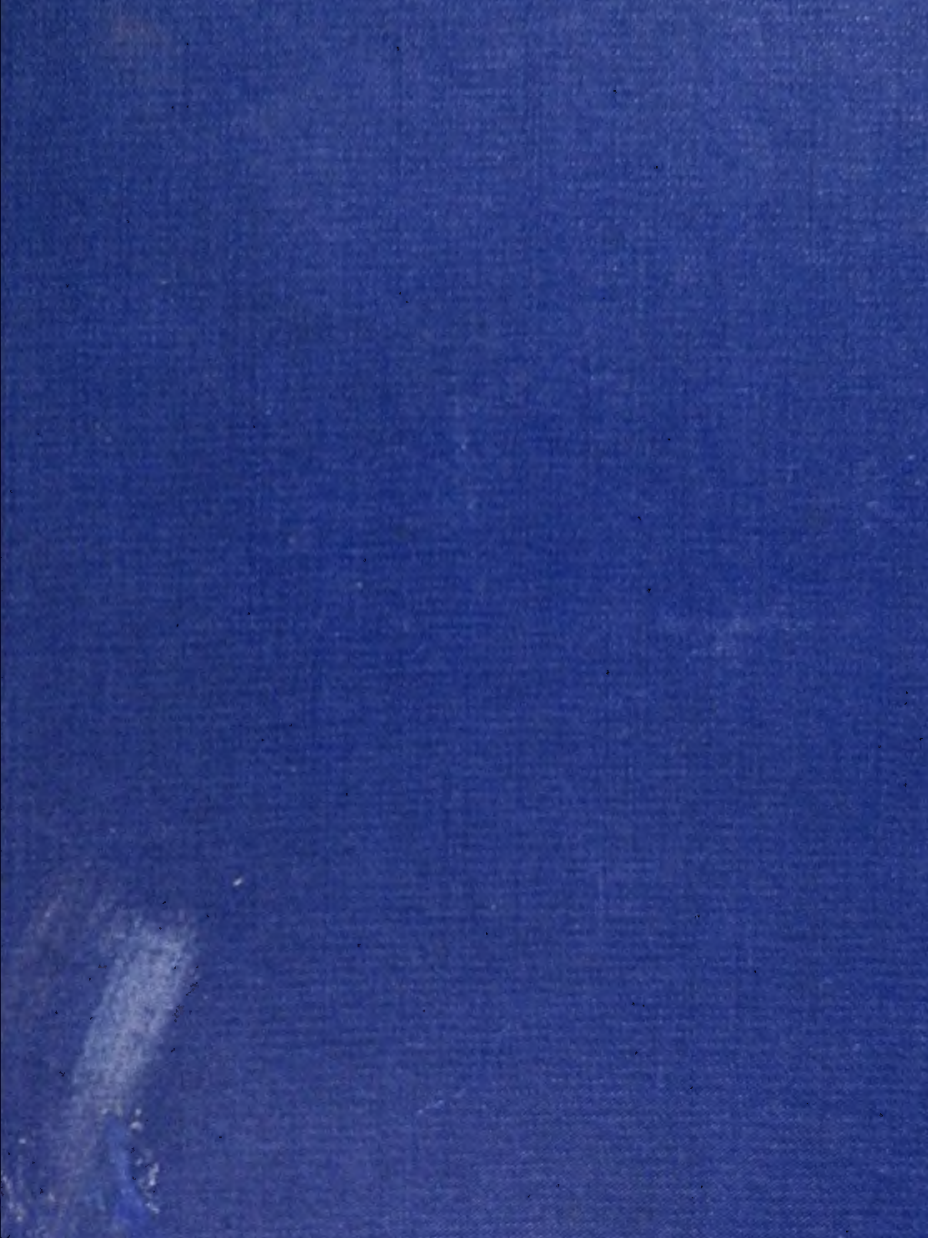

$\operatorname{igs} x+2$

as. 


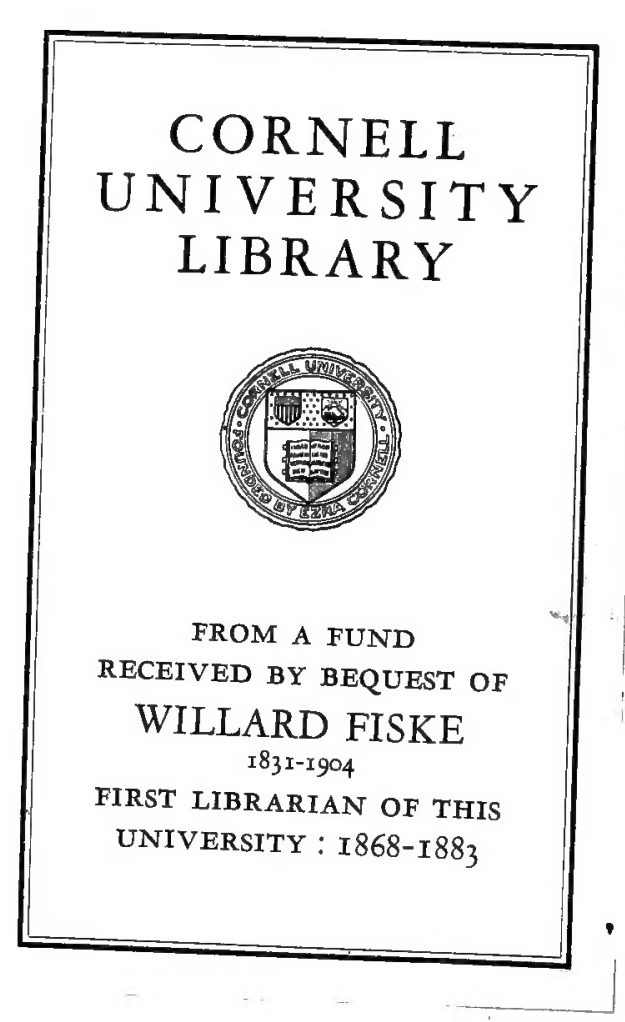




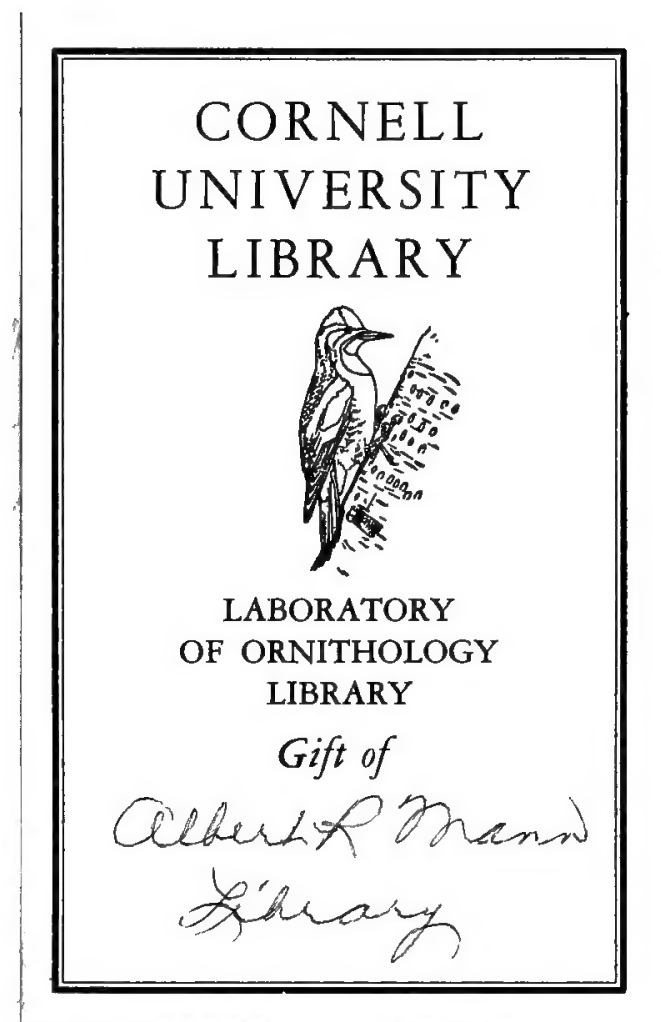




\section{DATE DUE}

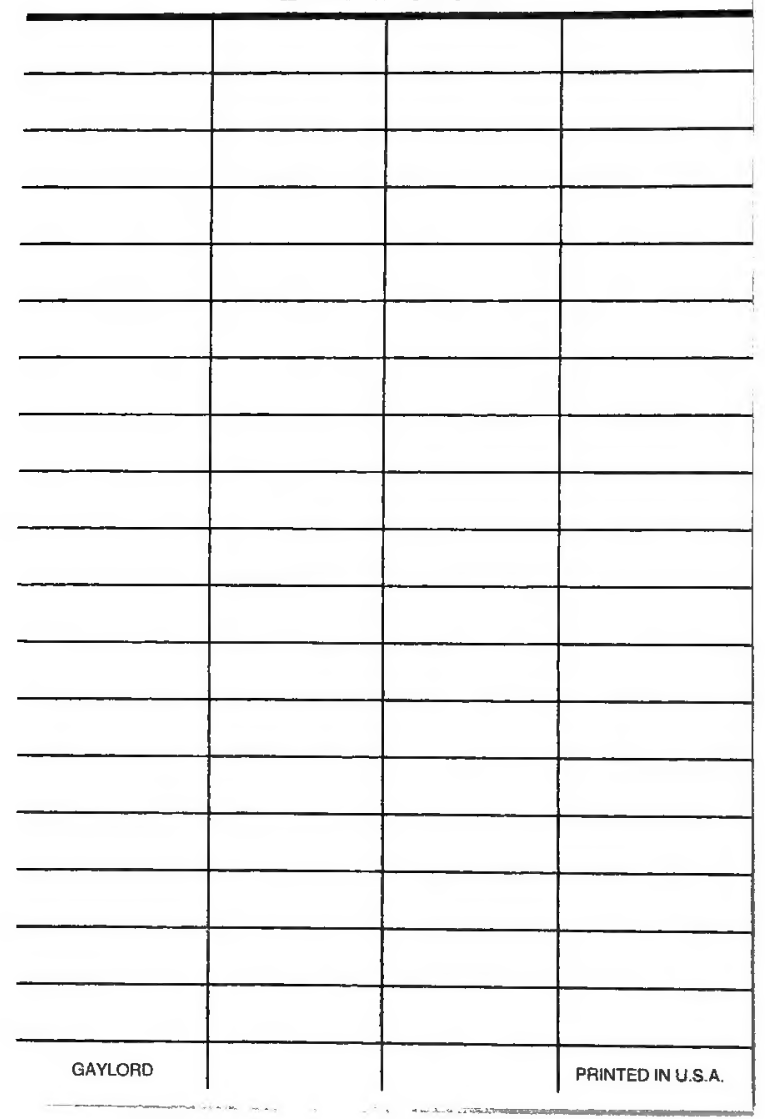




\section{ANIMAL LIFE}

AN EVOLUTIONARY NATURAL HISTORY

General Editor: W. P. PYCRAFT ZOOLOGIOAL DEPARTMANT, BRITIGH MUUEOM

VOL. II

A HISTORY OF BIRDS 


\section{Cornell University Library}

The original of this book is in the Cornell University Library.

There are no known copyright restrictions in the United States on the use of the text.

http://www.archive.org/details/cu31924022531242 



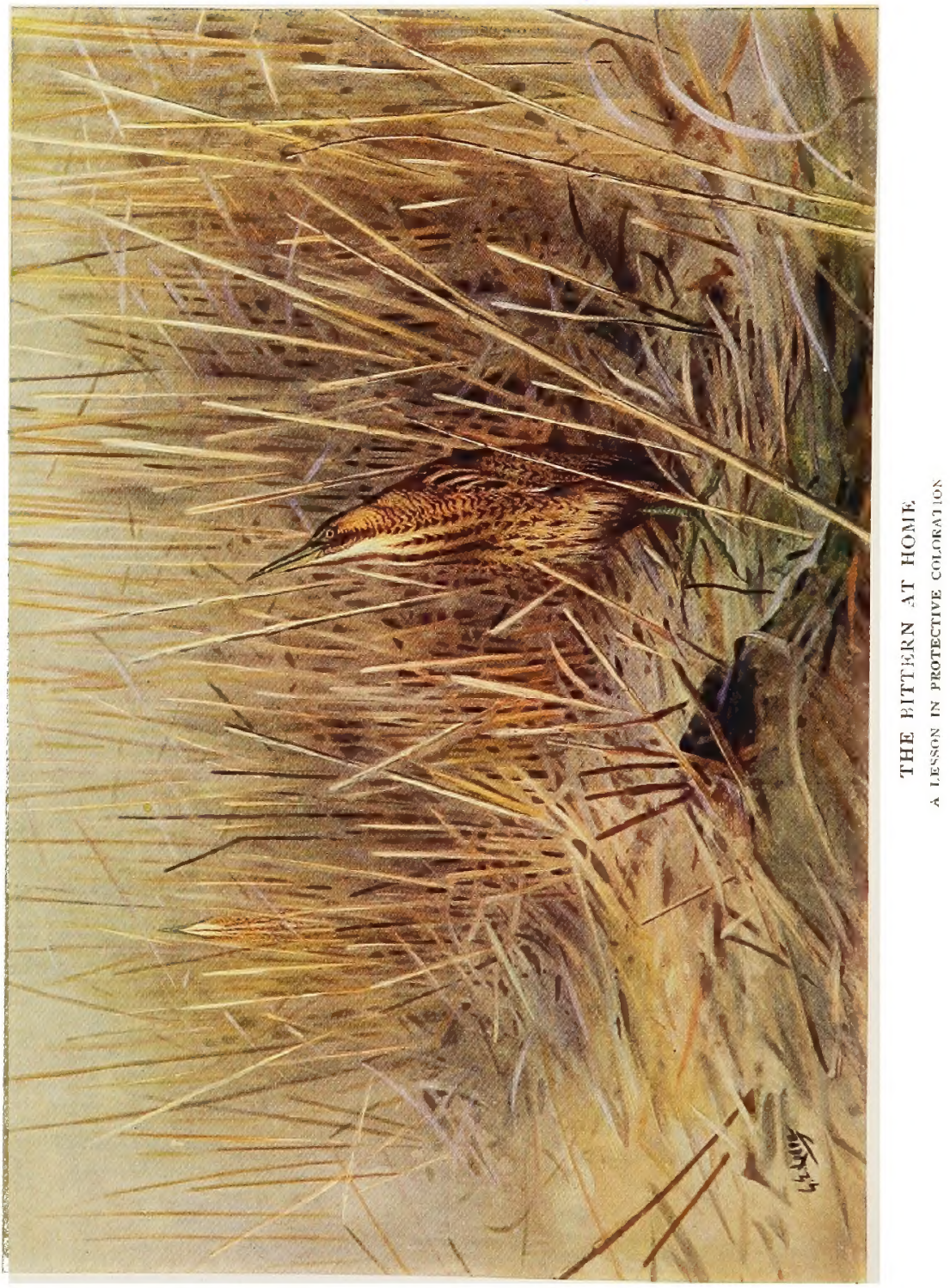




\title{
A HISTORY OF BIRDS
}

\author{
BY \\ W. P. PYCRAFT \\ ZOOLOGIOAL DEPARTMENT, BRITIBH MOSEUM
}

WITH AN INTRODUOTION BY

Sir RAY LANKES TER, K.C.B., F.R.S.

AND NUMEROUS ILLUSTRATIONS AND DIAGRAMS

METHUEN AND CO.

36 ESSEX STREET W.C.

LONDON

$\mathrm{H}$

LH 


\section{Ornith. \\ QL \\ 673}

p98

A 507670

First Published in 1910 


\section{CAROLO EDUARDO FAGAN}

PLURIMÂ ET JUCUNDISSIMÂ

MEMORIÂ DEDICATUS FST HIC LIBER 



\section{PREFACE}

$\mathrm{M}^{\mathrm{v}}$

$Y$ aim in writing this book is to present the study of Bird Life from the point of view of the Evolutionist; to set forth, in broad outline, the evidence now generally regarded as bearing on that most fascinating problem, the birth and growth of the various types of birdswhether regarded as large groups, or as geographical races.

The external beauty of form and colour which birds present, has so far proved a serious distraction, so that Ornithologists, captivated thereby, have paid but little heed to the possible factors to which these features are due. At any rate, since the master mind of Darwin himself laid the foundation for this wider study of Bird Life but little progress has been made. It is hoped, however, that this volume will prove a stimulus to renewed efforts to penetrate some, at least, of the many mysteries to which he called attention.

The purpose of this book, then, is obviously to present the Study of Birds as one of living organisms, moulded in part by an inherent constitution, and in part by that "struggle for existence" which is the lot of every living thing-a struggle with environment, animate and inanimate. This being so, it is obvious that anything more than the barest account of anatomical details would be out of place here. True, these "anatomical details" are the essence of the whole matter, but though this be so their bearing on the question at issue, at present, is not measurable; and accordingly those who seek in these pages for information of this kind will seek in vain.

My expert critics will doubtless discover many omissions in this book. I am aware of many: but I have had perforce to select, and I have chosen those facts which seemed best to 
serve my needs. Furthermore, I have written, not for the expert but rather for those who, like myself, have a keen love of birds-but who have so far had no opportunity of studying them from this point of view.

My friends being all busy men I have not dared to trouble them with appeals for help in my self-imposed task, but I am deeply indebted to Professor J. Arthur Thomson for help in laying the foundations, and to Mr. H. Eliot Howard for kindly criticism on my work in the course of its progress.

For many of the illustrations in these pages I am indebted to the courtesy of the Council of the Zoological and Linnean Societies, and of the Norfolk and Norwich Naturalists' Society. My thanks are also due to Mr. A. J. Bishop, Dr. Bumpus, Mr. J. G. Millais, Mr. A. R. Momber, the Hon. Walter Rothschild, Major Trevelyan, Miss E. L. Turner, and to Messrs. Black, Jack, Sotheran and Rowland Ward. Finally, I desire to accord my best thanks to my friend Mr. G. E. Lodge for his splendid interpretation of the themes illustrated by his brush ; these have never before been so vividly and realistically handled, and they should do much to bring home the lesson they are designed to teach.

W. P. PYCRAFT

LoNDON

November, 1909 


\section{CONTENTS}

\section{Preface}

PAGE

List of Illustrations in the TeXt

List of Plates

INTRODUCTION

List of AUTHORS QUOTED

\section{CHAPTER I}

INTRODUCTORY -

General characters of structure-feathers, glands, the skeleton, the respiratory system, the lungs and air-sacs, the digestive system, the circulatory system, the muscular systern, the nervous system, the senses.

\section{CHAPTER II}

Phylogenetic -

Birds and their position in the animal kingdom. Relationship to the reptiles, and the evidence thereof. Archæopteryx-the first bird. Hesperornis and early specialisation. Ichthyornis. The Pro-aves.

\section{CHAPTER III}

Phylogenetic (continued)-The Classification of Birds in Broad Outline-The Main Lines of the Evolution of the Class Aves

Archornithes and Neornithes. The position of the Ostrich tribe in the system. What the structure of the bony palate reveals. Palæognathæ and Neognathæ. The classification of the Palæognathæ and of the Neognathæ. A hypothetical ancestor. The Grebes and Divers, Penguins and Petrels, Steganopodous birds, the Accipitres, the Anseres, the Alectoromorphæ,-the Game-birds, Cranes and Rails, Plovers, Pigeons, the "Coraciiform" birds; the Passeres. Numerical strength.

\section{CHAPTER IV}

\section{E COLOGICAL}

Peculiarities of distribution. Continuous and discontinuous areas. Zoogeographical regions. The northern and southern hemispheres and the origin of life. Some British birds and the lessons they teach in regard to the migration of animal life from north to south. Factors in the formation of isolation areas. The haunts of birds. 


\section{CHAPTER V}

Seasonal Life. Relations to Morsture, Temperature, etc., and to Periodic Changes in the Cosmosphere

The bleaching effect of light. Desert forms. The effects of a saturated atmosphere. Arctic conditions. Size and latitude. Storms and drought.

\section{CHAPTER VI}

MrgRation

Kinds of migration. Routes. The beight at which birds fly. Speed. Lighthouses and their influence. Erratic migration. Causes of migration. Meaning of migration.

\section{CHAPTER VII}

Relations to the Animate Environment

Relation to plants. Birds and pollination. Birds and spread of seeds. Birds in relation to other animals. The perils of nestling birds. Birds and "civilisation".

\section{CHAPTER VIII}

Peculiar Interrelations

Ostriches and Zebras. Rheas and Guanacos. Oxpecker and big Game. Egrets and Elephants. Bee-eaters and Bustards. Penguins, Albatrosses and Petrels. Osprey and small birds. Chaffinch and Missel-thrush. Burrowing Owl and Prairie-dogs. Petrels and "Tuatera Lizard". Puffins and Rabbits. Skuas and Gulls. Frigate-birds and Gannets. Cuckoos and their dupes. The causes of parasitism.

\section{CHAPTER IX}

\section{Phases of Social Life}

Gregarious birds. Curious sleeping habits. Pelicans fishing. Woodpeckers and food stores. Significance of gregarious habits.

\section{CHAPTER X}

The Relations of the Sexes

The division of labour in nest-building. Manifestations of sexual activity. Forms of this activity. Plumage displays. "Sácaleli." Wind-bags and display. Tournaments. Weapons and their uses, Dancing. "Gardening." Song. Instrumental music. Where the sex role is reversed.

\section{CHAPTER XI}

\section{REPRODUCTION-NIDIFICATION -}

The first nest-builder. Origin of nests. Primitive nests. Burrowing. Simple nests. The nests of the Thrush tribe. Complex nests. Pensile nests. Mud nests. The remarkable nests of Tree-swifts. Colonies. Variability in nesting sites. Strange nesting sites. Nest-building and instinct. 


\section{CHAPTER XII}

REPRODUCTION-CONCERNING EGGS -

Number of eggs in a "clutch". Shape of the egg. Size, Texture and thickness of the shell. Colours of eggs. Origin of the colours. Patterns of coloration. Colours of eggs in relation to classification. Coloration in relation to environment. White eggs and their meaning. Structure and composition of the egg.

\section{CHAPTER XIII}

Reproduction (continued)-CARE of THE OFfsPring

Brooding and "brood-spots". Care for the sitting female. The remarkable case of the Hornbill. The brooding of the Emperor Penguin. Brooding of Egyptian Plover and of Megapodes. Forsaking eggs. Osprey and care of eggs. Transportation of eggs by parents. Precautions against floods.

\section{CHAPTER XIV}

CARe of Offspring (continued) - - -

The care of the young undertaken by the male alone, and by the female alone, or by both parents. The remarkable case of the Sand-grouse in procuring water for their young. The strange case of the transportation of the young in the Woodcock. Feeding customs. Sanitation of the nest. The callousness of Eagles. The coloration of nestlings.

\section{CHAPTER XV}

\section{Nestling Birds and what they Teach}

The differences between young birds and young reptiles. Nestling birds and the systematists. The clothing of nestlings. Primitive nestlings. Precocious flight. Helpless nestlings. The coloration of nestling birds and its significance.

\section{CHAPTER XVI}

\section{The Life-history of Birds-an Ecological Summary}

Embryology in outline. No hard-and-fast line between embryonic and post-embryonic characters. Plumage phases. Some puzzling facts with regard to adult characters. The plumage of Thrushes. Signs of maturity. Nuptial liveries. Coloration and its evolution. Moulting. Abrasion phenomena. The age of birds. Mortality. Play of birds.

\section{CHAPTER XVII}

Variation: Continuous and Discontinuous-Inter-Breeding

Paucity of information on variation in birds. The work of J. A. Allen. Relation of variation to natural selèction. Barrington's work. Colour variation. Dimorphism. Mutation. Albinism and Melanism. Swallows. 


\section{Acquired Characters-the Problem of Parental Modifications}

The remarkable case of the Hoatzin and the bearing thereof on the problem of parental modification. The results of feeding experiments, and changes of light and temperature on Flamingoes and Tanagers.

\section{CHAPTER XIX}

\section{Natural Selection as Applied to Birds}

The theory of "Natural Selection" applied to birds. Modes of selection. Inter-specific selection. Pigs and Penguins. Skuas and natural selection. Protective coloration. Winter whitening of Ptarmigan. Mimicry among birds. Protective resemblance and aggressive resemblance. Importance of inter-specific selection on the evolution of species. Intra-selection.

\section{CHAPTER XX}

\section{Artificial Selection}

The evolution of the domesticated races of Pigeons, Fowls, etc. Reversion of domesticated races to the wild, ancestral type. Physiological and morphological species. Fertility and the test of species.

\section{CHAPTER XXI}

Sexual Selection

Darwin and the theory of sexual selection. The evidence on which his theory was based. Objections to the theory of Alfred Russel Wallace, and of $\mathrm{H}$. Eliot Howard. Sexual selection in absence of secondary sexual characters. Consciousness in display of the effect produced, or to be produced. The factors which incite display. The part which sexual selection does play.

\section{CHAPTER XXII}

Isolation-Spatial and Physiological and Determinate Evolution -

Isolation and natural selection in evolution. Natural selection and the origin of species. Isolation and geographical distribution. Variations blastogenic. Romanes and Isolation. Physiological selection. Inter-breeding species. Island forms. Species formation in high altitudes. Discriminate isolation. Determinate evolution.

\section{CHAPTER XXIII}

Structural and Functional Adaptations-Shape and Symmetry

The factors determining shape. The remarkable asymmetry of Owls' ears. The wing. The shoulder-girdle and sternum. The pelvic girdle. The pelvic limb. Some puzzling features in the pelvis of Struthious birds. The pectineal process and its homologies. Types of feet. Feathers and adaptation to arboreal life. 


\section{CHAPTER XXIV}

Adaptations (continued)-Organs of Extreme Perfection -

The significance of certain peculiar modifications of the trachea. Reciprocity in development. The apparent over-elaboration of organs as illustrated by Woodpeckers and Kingfishers. Diastataxy.

\section{CHAPTER XXV}

Adaptatrons (continued)-The Alimentary Canal and Vascular Systems

The form of the beak in relation to the food. Modifications of the tongue. The alimentary canal. Modifications of the crop and gizzard. The convolutions of the intestines. Peculiarities of the vascular system.

\section{CHAPTER XXVI}

Convergent Evolution and Parallel Development

The evolution of the Owls and diurnal birds of prey. Night-jars and Owls, Swifts and Swallows. The Cariama, Cranes and Storks. The Plover tribe and the Rails. Gulls and Petrels. The Diving Petrels and the Auks. The remarkable transformation of the skeleton in the Auks and Diving Petrels. Homoplasy a factor in the evolution of birds. The problem of the New World Vultures. 



\section{LIST OF ILLUSTRATIONS IN THE TEXT}

ILLUSTRATION

I. Diagrams Illustrating the Structure of a Feather. (After Pycraft)

PAGE

From The Book of Nature Study.

2. Contour Feathers (Pheasant and Emu) showing the HypoRHACHis or After-shaft. (After Pycraft)

From The Book of Nature Study.

3. A Developing Filoplume showing the Rami which later disappear, and the MaIN Shaft Which remains to form the "Filoplume". (After Pycraft) -

From The Transactions of the Linnean Society.

4. Pterylosis of Acanthidositta chloris showing the Feather Tracts. (After Pycraft) - - -

By permission of the Editors of The Ibis.

5. Wing of a Bird, Slightly Diagrammatic, to show the ArrangeMent of the "Quill " or "Flight-Feathers". (After Pycraft)

6. Dissection showing the Lungs and Air-sacs of a Bird. (After Strasser)

Types of the Caca, or Blind Gut, of Rhea, Owl and Martineta Tinamou -

By permission of the Editors of The Ibis, and of the Zoological Society.

(1)


ILLUSTRATION

I4. Stages in the Evolution of the Avian Palate

15. Phylogenetic Tree of Descent

16. The Whale-Headed Stork (Balaniceps)

17. The Rufous Tinamou (Rhynchotus rufescens)

I8. Wing Feather of a Curlew showing the Initial Stages in the Disintegration of the White Parts: and a Portion of the Quill Feather of a Gull showing the same Process

ig. Hummingmird Fertilising Flowers of Marcgravia Nepenthoides. (After Wallace)

20. Devices to Secure a Permanent Food Supply

21. Pouch of Great Bustard Dissected to show its Relation to the Gullet and Windpipe. (After Pycraft)

22. The Display of the Great Bustard (Otis tarda) From Newton's Dictionary of Birds.

23. Types of Windpipes 167

24. Nest of the Hammer Head

From Newton's Dictionary of Birds.

25. Nest of THE HuMMING-BIRD (Phoethornis eurynome)

From Newton's Dictionary of Birds.

26. NEST OF OVEN-BIRD

From Newton's Dictionary of Birds.

27. HoATzIN (Opisthocomus cristatus)

From Newton's Dictionary of Birds.

28. Wings of Nestling Hoatzin and Common Fowl, Upper Surface

29. Wings of Nestling and Adult Hoatzin, and Nestima of Common Fowl, Upper Surface. (After Pycraft)

30. Dissection of Beak-sheath of Cormorant showing Vestiges of Narial Aperture. (After Pycraft)

3I. Throat of House-sparrow showing the Difference Produced by Abrasion between the "Winter" and "Summer" Plumages

32. Red Game Cockerel - - - - $33^{8}$

By permission of the Editors of The Ibis.

33. Black Polish Cock -

By permission of the Editors of The Ibis.

34. Types of Combs. (After H. S. Davenport)

35. The Sun-Bittern in Display -

From Newton's Dictionary of Birds.

36. Wing of ARch mopteryx, and HaNd of Young Ostrich to show THE STRUCTURE OF THE WRIST 
ILLUSTRATION

37. Wing of a Long-rared Owe showing the Pointed Type of Wing Associated with Strong Powers of Flight

From The Transactions of the Limnean Society.

38. Wing of a "Wood-OWL" showing the Rounded Type. (After ,Pycraft)

By permission of the Editors of The Ibis.

39. Shoulder-girdle and Sternum of an Eagle. (After Pycraft) From The Proceedings of the Zoological Society of London.

40. Shoulder-girdle and Sternum of a Cormorant. (After Pycraft) $3^{8 \mathbf{r}}$ From The Proceedings of the Zoological Society of London.

41. Shoulder-girdle and Sternum of A Boatswain-bird. (After Pycraft) By permission of the Zoological Society of London.

42. Types of Pelvic Girdles. (After Pycraft)

From The Proceedings of the Zoological Society of London.

43. Types of Birds' Feet. (After Pycraft)

From The Book of Nature Study.

44. TYPES OF SYRINX .

45. Forms of the Beak in the Genus Geospiza

From The Transactions of the Zoological Society of London.

46. UpPer Surface of the Wing of a Little Stint to show the Overlap of the Coverts; and Upper Surface of a Portion of the Wing of an OWL to show "Diastataxic" Condition. (After Pycraft)

From The Transactions of the Novfolk and Novwich Naturalists' Society.

47. TyPES OF BEAKS

48. Ear Apertures of the OwLs. (After D. Meinertzhagen) From The Transactions of the Linnean Society.

49. Skulls of OWLS, Showing the Asymmetry of the Skull of Tengmalm's OWl, and the Curious Differences in the Form of the Squamosal in the Young Tawny Owl and Young Burrowing OWL. (After Pycraft)

From The Transactions of the Linnean Society.

50. Types of Tongues. (After Lucas) 



\section{LIST OF PLATES}

The Bitrern at Home, a Lesson in Protective Coloration Frontispiece FACING PAGE

Powder-down Patches on the Breast of the Heron, Exposed by

Pulling aside the Breast Feathers

Io

By permission of the Editor of British Birds.

Wings of Eurylemus (A) and Colius (B) Dissected to show

Deltoideus Muscles

By permission of the Zoological Society.

Blue-necked Cassowary and the Secretary Bird

Map Showing Zoogeographical Areas, Illustrating the DistribuTION OF Birds

By permission of Dr. R. Bowdler Sharpe.

Cape Penguins (Speniscus Demersus)

From a Photograph by A. R. Momber, Esq.

\section{Elephants and Egrets}

By permission of Messrs. Rowland Ward, Ltd. From Neumann's Elephant Hunting in Equatorial Africa

BeE-Eaters and Bustard

By permission of Messrs, Rowland Ward, Ltd. From Neumann's Elephant Hurting in Equatorial Africa.

The Peacock in Display

From a Photograph by Reid, Wishaw.

A Stage in the Display of the Lesser Bird of Paradise

By permission of the Editors of the lbis.

The Nuptial Dance of the Prairie Hen

By permission of the American Museum of Natural History.

Black Cock on their Playing-ground

From Game-Birds and Shooting Sketohes. By permission of the Author.

Nest OF ReMEZia

From a Specimen in the British Museum.

Nests of the Edible Swift

From Specimens in the British Museum. 
From a Photograph by Mr. A. R. Bishop.

A Primitive Nest (Nest of the Ringed Plover)

From a Photograph by Major Trevelyan.

Emperor Penguin Brooding its Young

From a Drawing by Dr. A. E. Wilson.

Lapwing Setrting Down on its Eggs -

From a Photograph by the Rev. H. N. Bonar.

White-Throat Feeding its Young

From a Photograph by Miss E, L. Turner.

Meadow Pipit Removing Excreta from its Nest -

A Breeding Colony of Gannets -

From a Photograph by Messrs. Valentine \& Co.

A Nesting Colony of the White or Molly-mauk (Diomedea immutabilis) Albatross

From The Avifauna of Laysans. By permission of the Hon. Walter Rothschild.

Nestrings of Pigeon and Fledgling Barn Owl (from Photographs by Reid, Wishaw), and of Nestling Cape Barren or Cereopsis Goose

From Specimen in the British Museum of Natural History.

A Nestring Cassowary and a Nestling Emu

From Specimens in the British Museum.

\section{Mesoptyle Feathers of Tawny and Barn Owls}

By permission of the Editors of British Birds.

Shoulder-girdle and Sternum of the Hoatzin

From Specimens in the British Museum of Natural History.

A Factor in the Struggle for Existence (Peregrine)

From a drawing by G. E. Lodge. (Falcon Attacking a Rook.)

Artificial Selection as Illustrated by Varieties of the Common

Fowl (Red Cochin and Brown Leghorn)

From Photographs by Reid, Wishaw.

The Amherst Pheasant in Display

From a Painting by G. E. Lodge.

The Grasshopper Warbler in Display

From The British Wavblevs. By permission of the Author.

The Kagu in Display

From a Photograph in the British Museum. 


\section{LIST OF ILLUSTRATIONS}

$\mathrm{xxi}$

The Evolution of the Paddle of the Penguin After Pycraft.

Section of the Head of the Helmet Hornbill, showing the

Dense layer of Horn and Bony Tissue forming the Casque 422 From a Specimen in the British Museum.

The Trunk Skeletons of Chionis, the Diving Petrel and the Fork-tailed Petrel

From Specimens in the British Museum of Natural History.

The Trunk Skeletons of the Guillemot and Diver, showing Modifications Induced by Diving-habits

From Specimens in the British Museum of Natural History.

Shank of the Leg of the Red-throated Diver and of The Great

Crested Grebe

From Specimens in the British Museum of Natural History. 



\section{INTRODUCTION}

$\mathrm{L}$

IVING things form an inexhaustible field of interest and delight to Man, who is the outcome of an age-long process which has culminated in the production of the human mind with its unique powers of thought. This process has left, as it were, on the way to man, all the varied crowd of lower animals and plants which still survive to tell him whence he has come, and to enable him to arrive at an understanding of the secrets of his own nature. No wonder that natural history, the knowledge of animals, plants and stones, has from the earliest times been a serious pursuit, and perhaps we ought not to be astonished when the intimate and deep-seated relations of man with other living things is borne in mind, that the most fantastic beliefs about natural history have been current, and that it took a longer time to enable men to investigate animals without prejudice and the domination of childish and preposterous imaginings than it did to start a reasonable examination of less elusive and exciting things, such as plants and the non-living objects of which our senses give us cognisance.

The study of animals can never lose its special hold on the human mind, due to the animal's direct appeal to man, its saying, as it were, "You are one of us, you know. We are close to you-very close to you: if you can understand my nature, my mechanism and xxiii 
origin-snail, robin, squirrel, whichever I am-you will be near to understanding man's nature, mechanism and origin-near to understanding-yourself!" And so there are endless books on the natural history of animals, their kinds, their structure, their mode of action, their habits, growth, reproduction, food, their relations to one another and to other living things. Any one book treating of animals in every possible way would be too large ; moreover, our knowledge about animals is always growing and receiving quite new accessions, so that no one should complain of the number of such books, and every new one, if it is really a new one and written by a real "Knower" of animals, should be welcome.

Mr. Pycraft's series of four volumes called Animal Life is a really new book on animals, and its novelty and excellence is exhibited in the volume on Birds written by Mr. Pycraft himself.

In the first place, let me say what may not be known to every reader, though well-known to all scientific zoologists-that Mr. Pycraft is a most competent authority on birds; he has devoted his life to them, and has studied with specially favourable opportunities their skeletons and their plumage and the stages in their growth, so as to add greatly to our knowledge. From the museum at Leicester he came to assist me in the University Museum at Oxford in 1892, and later was appointed to the staff of the Zoological Department of the British Museum, where I again had the opportunity of seeing and appreciating his work.

In the second place, the plan of the book on Birds (which will be followed in the other volumes on Mammals, on Reptiles, Amphibia and Fishes and on Invertebrates) is original. We do not start with a scheme of classification and then take up the groups one by one 
and examine the different kinds included in each, but boldly, after an introduction on the general structure of birds, the phylogeny of birds is discussed, that is to say, their genetic relationship to the reptiles and the evidences thereof, and a "family tree" showing the main lines of the descent of birds and the relationships to one another of the numerous groups of birds is given. Then we have a chapter on Geographical Distribution followed by others on the Seasonal Life of Birds, on Migration, on Peculiar Interrelations (such as those of the Cuckoos), on the Relations of the Sexes (including courting, display, fighting, song and music). Then we come to chapters on Nidification, Eggs, Care of Offspring, Nestling Birds and what they teach (a subject greatly studied by Mr. Pycraft), the Life-history of Birds, Variation, Natural Selection and Artificial Selection in the case of Birds, Sexual Selection, Adaptations and Convergence of form in distinct groups (the latter better called " homoplasy"). These and similar topics are discussed by Mr. Pycraft at greater length than would be possible in a systematic treatise on birds of the usual scope. The survey of bird-life thus given is a very complete one, and many interesting features of it, liable to be too briefly treated in a book arranged on classificatory lines, are here duly dealt with. The illustrations are of great value, for they are not old but new, and they are admirably executed.

I may cite here a few of the more interesting views which Mr. Pycraft advances in the present volume. In regard to the subject of migration (see page 89), he has promulgated one or two new ideas. He holds that the trend of migration is, throughout the world, due north and south, as far as physical conditions render this possible. It appears as a consequence of this that 
our Swallows (for example) do not, as is supposed, on reaching Africa disperse some to West Africa as far south as the Gold Coast whilst others continue down the East Coast to the Cape. But that, on the contrary, our British birds, and those of France and Spain, go to West Africa only. Those that are found along the East Coast of that continent are birds which have been bred in Eastern Europe. It is significant in this connection that the Swallows of Northern Asia go south to India and Burma, those of North America to South Brazil.

Our British migrants are held by Mr. Pycraft to be so many "local" races of their species. Hence, he believes, has come about the extinction of many of our "British" birds-Avocets, Spoonbills, Ospreys, Ruffs, Bitterns, etc. As the parent stock is killed down, here and abroad, no descendants are left to return to the old haunts, for the Avocets, Spoonbills, Storks, etc., of the Continent are similarly so many "local" races, having no "inherent knowledge" (if one may use the term) of land outside their particular routes. That migration was and is possible only to such species as can obtain a livelihood outside their place of origin is very justly asserted by our author. Hornbills, Toucans, Birds of Paradise cannot migrate : outside their homerange they would starve. Hence when the areas they inhabit become over-stocked the surplus must perish. Those birds more fortunate, because less specialised in the matter of food, which find salvation in migration, were driven back periodically to the land of their origin by climatic conditions. Having, however, extended their range and hence their breeding area, they returned in greater numbers than those which departed. Hence the land of origin was less able than before to support 
the returning host, and hence migration became a fixed and necessary habit. The range and increased breeding area increased in waves mechanically. The exodus would naturally be to the new-found land of plenty. The birds of last year would return to their old breeding station: their young also. But these would be driven by the old birds further a-field and establish new colonies; for it is well known that birds will drive away their young and jealously defend their appropriated breeding territory against all-comers.

Mr. Pycraft makes a laudable attempt to combat the contention, which has been and still is urged, to the effect that small variations in animal colour and form can have no value as features for selection in the struggle for existence. He urges that even if this be true in many cases, yet such small variations will not be suppressed by selection adverse to them. They are free to take their course unless and until of such magnitude as to be either checked by natural selection or favoured by it. In illustration of his contention, he cites various facts in regard to the evolution of the skull and of particular skull bones and other skeletal structures in birds. This view appears to me to be well worthy of consideration.

In regard to the theory of sexual selection the original views of Darwin and those of Wallace are cited as well as the more serious criticisms of these views advanced by other observers. In the light of some recent work, $\mathrm{Mr}$. Pycraft is led to hold that some slight re-setting of Darwin's views in their application to birds is necessary. Without endorsing his view of the absence of selective action in certain cases, I may draw the reader's attention to his argument. Since it is now known that birds of the most sober hues affect displays of a character in- 
distinguishable from those of birds in which such displays are made apparently for the sole purpose of exhibiting to the best advantage some specially modified or beautifully coloured patterns, it seems (our author contends) probable that such resplendent dress is to be regarded rather as a by-product of sexual selection-as a variation allowed to assume a more or less extravagant form because unchecked by natural selection.

That display is the result of sexual selection is not doubted by Mr. Pycraft, for even the most inconspicuously coloured birds indulge in antics, more or less grotesque, when dominated by sexual desire. Any variation in the direction of more resplendent plumage would thus of course be free to fulfil its potentiality unless, and until, checked by natural selection. The view advanced by Mr. Pycraft is in short this-that the "display" is older than the resplendent plumage, and is not the consequence of its presence. Sexual selection is still regarded as operative, for there must have been degrees of splendour among the ancestors of the now resplendent species, and the brighter coloured would excite the females more effectively.

Mr. Pycraft considers at some length the coloration of desert-dwelling forms of birds. He emphasises the contention that natural selection is not the agent which has in the first instance determined that coloration. I confess that I should not have supposed that any one would contend that it has done so, any more than that the view could be supported that "natural selection" has primarily started any of the variations of colour or form upon which it operates. Mr. Pycraft holds that there can be no question but that the peculiar physical conditions of a desert environment exercise a direct influence on pigmentation. It is very possible that 
such a direct effect of one kind or another is in many instances produced. But in all such matters one would like to see experimental proof and to have full chemical explanation of the details of the coloration and the way in which external conditions directly modify it. $\mathrm{Mr}$. Pycraft thinks that a humid atmosphere undoubtedly causes an intensification of pigment inclining to melanism. That would be very important if it were experimentally demonstrated, but that seems not to be the case, nor is the chemical change by which such intensification of pigment, or the production of independent black pigment, could be arrived at by the action of a humid atmosphere as yet suggested. Our author says that of course natural selection "may have" acted by securing elimination of all those individuals which were not physiologically affected by desert conditions, viz., intense light and heat, or (I should be inclined to add) were not, owing to other causes, variations in the direction of sand-colour.

In regard to the life-history of birds, Mr. Pycraft has drawn attention to a host of facts which have hitherto been ignored by leading Darwinians, though of first-rate importance from their point of view. Such are his own observations as to the coloration of nestlings and of immature birds showing the significance of striped nestlings and of the brilliantly coloured mouths of certain species. He gives very cogent reasons for regarding the ancestral bird as arboreal, and as gradually acquiring flight by "parachuting". The view that the earliest birds were aquatic and that the wing was at one time a paddle is, however, still capable of defence. To arrive at anything like a preference between the two theories requires a very extensive survey of anatomical and palæontological facts, as well as a consideration of the 
various mechanisms of flight in animals and their relation to other locomotor organs.

It is distinctly a feature of Mr. Pycraft's book that he has given a larger number of illustrative examples of adaptation to environment, of homoplasy and parallelism, than is to be found in any other book on birds.

E. RAY LANKESTER 


\section{LIST OF AUTHORS QUOTED}

Alcock, Dr., II6.

Alexander, Capt. Boyd, 82.

Allen, J. A., 83, 85, 292.

Andrews, Dr. C., II2, I5O, 290.

Barrington, R. M., 294.

Bates, 423.

Beebe, C. W., 8I, 3 I5.

Beddard, F. E., 47.

Bonhote, J. L., 272.

Bumpus, Dr., 293.

Butler, A. G., 234.

Chapman, A., 326.

Chapman, F. M., 95 .

Clarke, Eagle, 96.

Cunningham, J. G., $3^{\text {I } 5}$.

DARWIN, C., 32I, 335, 337, 4 II.

Davidson, W. R., 146 .

De Varigny, 346.

Dwight, Dr. J., $28 \mathrm{I}$.

ELlrot T, Dr. D. G., I72.

FieldeN, Col., 298.

Finn, F., 328 .

Forbes, H. O., IIx.

Fürbringer, Prof. Max, 47.

Gadow, Dr. H., 47, 25I, 3Io, 3 I 2.

Gätke, 96,97 .

Giglioli, Prof., 303 .

Godman, Dr. F. D., 225.

Grant, Ogilvie, 147, 305 .

Günther, Dr. A. L., 232.

Harvie-Brown, J. A., 298.

Headley, F. W., $28 \mathrm{I}$.

Howard, H. E., 29o, 347, 348, 35 I.

Hudson, W. H., II $4, I_{3}, 323$.

JORDAN, 25 I.

KELLOGG, 25 I.

Kerner, A., I07, I I I.
LANKESTER, Sir Ray, 342, 453.

Latter, O., I3O.

Lucas, F. A., I22, 43 I.

Millais, J. G., I57, 345 .

Mitchell, Dr. Chalmers, 4 Io, 437.

Moseley, Prof., 449.

Murie, Dr., I49.

Nelson, E. W., I62.

Neumann, A., I25.

Newbigin, I99, 310.

Newton, Prof., 9o, I03, II9, I36, I80, 285 , 30.

Nicoll, M. J., II7.

Nutting, H., I62.

OsBorn, Dr. H. F., 453.

Palmen, Prof., 94.

Poulton, Prof. W. B., 323, 327.

Pycraft, W. P., 4Io.

RIDLEy, H. N., I Io.

Romanes, G., 355, 356, 357 .

Rothschild, Hon. W., I62, 308, 309.

SAUNDERS, H., 120, 297, 298, 301.

Sclater, Dr. P. L., 76.

Seth-Smith, D., I7I.

Sharpe, R. B., 92, IOI, IO2, 363, 443 .

Sorby, Dr., I98.

Tennant, S., 95 .

USSHER, R., 87.

VERNON, H. M., 3 I8.

Von Rosenberg, Dr., 218.

Waldo, Meade, 225, 285.

Wallace, A. R., I00, 147, 193, 208, 329, 330.

Warren, R., 345.

Whitaker, J. S., 8I, 86, go.

Wilson, Dr. A. E., 216, 217, 287, 320, 432. 



\title{
A HISTORY OF BIRDS
}

\author{
CHAPTER I \\ INTRODUCTORY
}

General characters of structure-feathers, glands, the skeleton, the respiratory system, the lungs and air-sacs, the digestive system, the circulatory system, the muscular system, the nervous system, the senses.

\section{Birds, in BRoAd OUtLine}

7 MOUGH the bird and the mammal are alike descendants of the scaly reptile, they present no points in common, save that both are "warm-blooded". Birds are essentially creatures of the air, mammals of the earth: yet, be it noted, some birds have lost the power of flight, while some mammals, in varying degrees, have acquired this; albeit only one group, the bats, have really mastered the art.

Birds, in short, from the first were destined by Nature to possess the air, while mammals were, on the other hand, developed along lines which made the earth their natural abiding place. And this fundamental difference explains the fact that, structurally, the birds present a remarkable degree of uniformity, while the mammals, on the other hand, display a wonderful diversity of form and structure. The mechanical requirements of flight rendered this structural uniformity inevitable; while, on the other hand, the terrestrial life of the mammals left open a wide range of variability in the matter of bodily shape, and this in time manifested itself, as the need arose, as, in the struggle for existence, some took to climbing trees, some to burrowing in the earth, some to the rivers, and some to the open sea, some to the burning deserts, and some to the wild fastnesses of the sombre mountains. 
By the accident of birth, so to speak, the career of the bird was determined by the shape of its fore-limbs. Though in course of time circumstances deprived these of all importance in certain species, so that they eventually became reduced to mere vestiges, as in many living birds, or even suppressed entirely as in the extinct Moas, the mammals, on the other hand, have in no case suffered a similar loss; but the hind-limbs, by way of contrast, have in not a few cases similarly vanished.

In birds the fore-limb has in all cases served as an organ of flight; even where this member has been reduced to the merest vestige, it is clear that the modelling thereof is that of a wing. In the mammal, on the other hand, the fore-limb presents the most varied forms. Similarly, in the case of the hind-limb, that of the bird presents a wonderful uniformity of structure, being always used for the carriage of the body when on terrafirma, but this is far from true of the mammal.

Notwithstanding the unquestionable uniformity of structure which birds present, this is apparent only when the fundamental structure is considered in relation to that of other groups. To the ornithologist birds display a marvellous range of variation, and in so far as coloration is concerned this is undoubtedly true. From the æsthetic point of view birds hold an unique position, and fill a place in the world that adds more than is generally realised to its charm and habitability. They seem to display a joyousness in existence, an intensity of emotion, that is infectious; though, it is needless to remark, this manifestation is not a universal characteristic of the group.

The factor which, more than any other, has secured for birds the high place which they hold in the affections of men, is unquestionably that of flight. Thereby they ever keep themselves, as it were, before the public, and give life and beauty to the world around them. And this is true more especially of such species as seek their daily bread in the open, on the wing, or indulge in ærial evolutions apparently out of the sheer exuberance of spirit. There must be few who have not gazed with admiration at the hovering feats of the Kestrel, and still fewer who have not felt moved at the wild, screaming flights of a flock of Swifts at dusk, while the marvellous spiral evolutions of the Skylark, accompanied by outpourings of song, have inspired some of the finest poets who have ever lived. 
The vivid hues which so many species display must be reckoned as only slightly less important in this respect than flight. This fatal gift of beauty has from earliest times subjected the wearers to a rigorous persecution, not only at the hands of savage races, but of peoples boasting themselves civilised, among whom women have always been the worst and most heartless offenders. On account of the ceaseless persecution to which these defenceless creatures have been subjected to meet the demands of fashion, savage and "civilised," many species have become wiped out of existence, and of many more the doom is sealed; the more beautiful of the Birds of Paradise and of the Humming-birds, for example, will, in another decade, have ceased to exist!

There is more in this colouring of the plumage than meets the eye of the unobservant; for whether we contemplate broad bands of vivid colours, sharply defined; or intricate patterns, fine as the most delicate lace work, we are confronted with a mystery which is so far insoluble-what determines the segregation and deposition of these pigments? The problem presents its greatest difficulties in such feathers as display, individually, intricate patterns, whether of sober shades or hues such as vie with, or even surpass, the rainbow in splendour. Take, for example, a feather displaying a series of fine concentric lines, divided by wider bands of white, or black, or red, as the case may be. These lines are not continuous, not organically complete, but formed by the exact relation, one to another, of a series of minute spots of pigment, each lodged in a separate filament, so that the several spots in each separate filament, when ranged side by side, form the several series of lines, straight or vermiculated, as the case may be. All that we can say is, that the spots in question are deposited simultaneously in each rod as the feather grows. But what controls the alternations of the deposition of the pigment necessary to bring about so simple a pattern as that to which we refer? And what determines the changes of pattern in the different areas of the body?

But birds have yet other attractions for us men. Graceful in their movements, and exquisite in their apparel, they are furthermore fascinating in their lives, for they display in their periods of courtship a singular vivacity, and in the care of their offspring a marvellous tenderness and solicitude. 
There is, in short, no single phase of their life-history which is not throbbing with interest. Nests, eggs, and young, adolescent and adult, at rest or in action, there is no phase which is not overflowing with matter for reflection, no single incident which is dull; and this is perhaps more than can be said for any other group of animals.

Birds, like mammals, display a wonderful plasticity to environment. There is no spot on the earth's surface which has not been made to provide a habitation for them, from the icy and storm-swept regions of the poles, to the equator: while by relatively slight structural changes, they have contrived to avail themselves of food supplies of the most varied description.

The general homogeneity which birds present, when compared with the mammals, or the reptiles, is generally attributed to the fact that they are less ancient than either: though they may yet claim a respectable antiquity, since the earliest known bird dates from the Jurassic epoch. It is supposed by some that enormous periods of time are necessary to bring about the extinction of connecting-links, and the consequent formation of sharply defined groups, such as are to be met with among the mammalia. But it may well be that this work of extermination among the birds has been largely evaded, and homogeneity preserved, by their ability to escape from unfavourable conditions. With the mammals the avoidance of periods of stress, of whatever kind, has always been restricted. Migration has been limited by unsurmountable barriers; at one time mountain ranges, at another of vast stretches of water.

To this evasion of Fate most modern taxonomers owe their difficulties in their attempts to classify birds, that is to say, those who desire merely to establish so many well-defined groups which can be readily summarised in the form of a "Key". Those, on the other hand, who have spent laborious days in the endeavour to trace the descent of the more or less well-marked groups of living and extinct birds, though hardly more successful than their less ambitious neighbours, must look to yet other and more subtle factors. First, and foremost, must be placed the fundamental modification due to the exigencies of flight, which all birds, without exception, share in common. Thereby the range of possible variation has been kept within very narrow limits, and secondly, there must be 
reckoned the phenomena of convergence and parallel development.

In taking a bird's-eye group of the Class Aves one may distinguish a number of apparently well-defined groups, such as the Ostrich tribe, Diving-birds, Penguins, Petrels, Steganopodousbirds, e.g., Gannets and Cormorants, the Goose tribe, Storks, Birds of Prey, "Game-birds," Cranes, and the Limicolæ or "Shore-birds": and against these may be set the Parrots, Cuckoos, a host of forms commonly known as "Picarians," including, for example, the gorgeously coloured Rollers, Kingfishers and Bee-eaters, and the bizarre Hornbills, the Owls and Night-jars, the Swifts, and the jewel-like Humming-birds, the gaudy Toucans, and the Woodpeckers. Finally, we have the most puzzling of all, the "Passerines," of which the crows may be taken as typical examples.

So far, any classification of this medley of forms, which shall express the lines of descent, has proved beyond attainment, though much towards this end has been done by the labours of such men as Huxley, Garrod, Forbes, Fürbringer, Gadow, Beddard and Chalmers Mitchell.

\section{General Characters of Structure}

\section{The Feathers}

For the purposes of these pages a very general survey of the structural characters of birds will suffice. And this survey cannot well begin better than with a general account of the feathers, since these, as we have already remarked, are unique structures.

In their nature they answer to the scales of Reptiles rather than to the hairs of Mammals. In addition to those which form the outer covering of the body, and hence are known as the "contour" feathers, there are several other forms of feathers. The most familiar of these are the "down feathers" which play so important a part in commerce. These form, in many birds, such as the Goose tribe, Gulls, and aquatic birds generally, a dense underclothing answering to the under-fur of mammals, such as, for instance, the "fur-seal," and after these come the "filo-plumes" and "powder-down" feathers to be described presently. 
into the skin. Tubular in shape and semi-transparent, it encloses a series of hollow, oblong cells fitting one into the other. During the growth of the feathers these cells contained the pulp, or nutrient matter out of which the feather is built up. The shrivelled end of the last of these cells projects from a small aperture-the upper umbilicus-at the point where the quill passes into the "rhachis" or shaft. This is formed by a process of continuous growth of the dorsal surface of the calamus, and the resultant lateral edges of this projecting outgrowth ultimately curl inwards, meeting in the middle line of the under surface of the feather and leaving a fine groove to mark the junction. The enclosed cavity is simultaneously filled with a closely packed mass of "pith"-cells, recalling "elder-pith," giving stability and elasticity to this region of the axis. Along each side of this rhachis, which has a quadrangular section, there runs, from the region of the upper umbilicus to the tip of the feather, a closely planted series of flattened laminæ, terminating in a point, and these in turn support a double row of smaller lamina. The former are known as the rami or "barbs," the latter as the "radii" or barbules. The whole form the remarkably elastic fringe which runs along each side of the shaft, and which together form the "vane" or "vexillum" of the feather.

This fringe must be more closely examined. On a superficial inspection it presents a homogeneous surface, but grooved withal by a number of fine, parallel lines. If an attempt be made to stretch this web in the direction of the long axis of the feather, it will be found that though at first resisting, it will eventually split, when, by drawing the fringe through the fingers the original unity will be restored. If a lens be now brought to bear on this surface, it will be found that the grooved or ribbed appearance of this vane is caused by the interspaces between the rami just described; interspaces which are more or less perfectly filled by the series of barbules which intercross. Under a high magnification of the microscope these barbules will be found to consist of two very distinct kinds, ranged one on either side of the barb. Those on the side of the barb pointing to the tip of the feather have the appearance-when examined separately- of flattened plates, cut up, from the middle outwards, into a number of long, hooked filaments, while those 
of the opposite side of the barb take the shape of long scrolls, whereof the upper edge is the more deeply curled. When in situ the two series are so arranged that the hooklets are thrust down between the scrolls so that their curled edges are caught thereby. A reference to the accompanying diagrams will make these points clear. The number of these rami or barbs

I

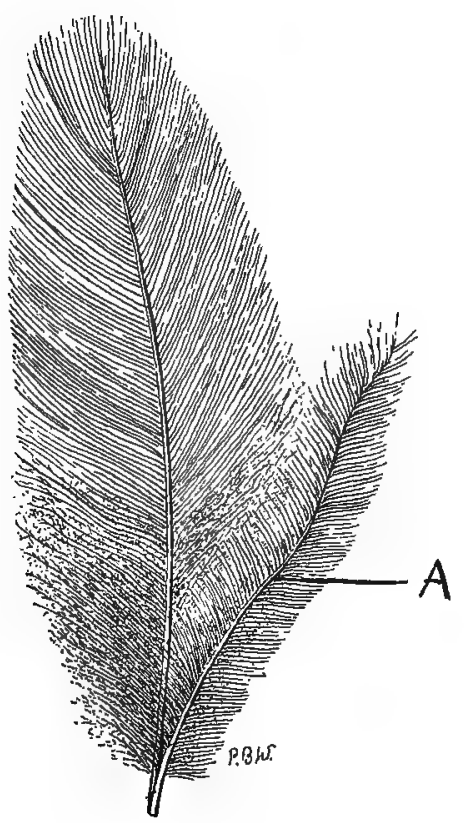

II

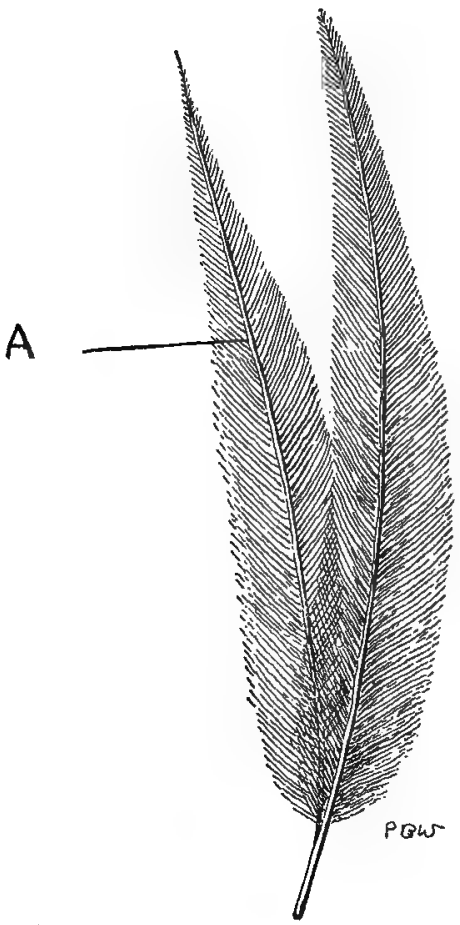

Ill. 2.-Contour Feathers showing the Hyporhachis or After-Shaft (A) I. Of a Pheasant.

II. Of an Emu.

depends mainly on the length of the feather. Along the inner web of a Crane's quill feather $38 \mathrm{~cm}$. long, Dr. Hans Gadow counted about 650 rami : he further estimated that every ramus of this feather bore about 600 pairs of radii (barbules), making nearly 800,000 radii for the inner web alone, and more than a million for the whole feather.

The contour feathers of most birds bear what is known 
as an aftershaft (hyporhachis). This is a duplicature of the main shaft, but much smaller and more delicate, and springs from the upper umbilicus of the main shaft. In the Gamebirds it is especially well developed, while in others it is reduced to a mere vestige, or is wanting altogether. In the great feathers which form the "quill" or "flight" feathers (remiges) of the wing, and in the tail feathers (rectrices) the after shaft is invariably wanting. Among the Ostrich tribe it is present only in the Emus and Cassowaries, and here it is of great size, as large indeed as the main shaft.

The contour feathers of the Ostrich tribe-save only in the Tinamous-it may be remarked, are peculiar in that their vanes are not held together to form a well-knit "web," the radii being degenerate, and failing to hold the vanes together; hence these vanes are said to be "discontinuous".

Down feathers differ from contour feathers in that the barbs, or rami, of the feathers are of great length and slenderness, and often all arise from a common base-the top of the calamus, instead of being ranged along each side of a long rhachis. The radii (barbules) of such feathers are represented by mere filaments, or sometimes by nodular swellings, which again may assume a pyramidal form.

As touching "filo-plumes" little is knownlas to their meaning or purpose. There are the long hair-like threads which remain sparsely distributed over the body of a fowl when plucked. They grow in clusters of five or six, or more, about the bases of the contour feathers, and when examined microscopically are found to consist of a simple, solid axis, terminating in a few weak barbs and barbules. An examination of the late stages of growth, just before development is complete, however, shows that these are degenerate feathers, inasmuch as there will then be found a considerable number of barbs, arranged much after the fashion of the barbs of a down feather. Among these one will be found stronger than the rest, and this eventually is left, the rest disappearing. In some birds these filo-plumes play a conspicuous part in the coloration of the surface of the body, since in such cases they attain a great length, and develop relatively large vanes. These project beyond the level of the contour feathers and may form large white patches, as in the thigh patches of the Cormorants, or 

powder-down is luminous, and that the birds take advantage of this luminosity by raising the contour feathers so as to shed this light on the water wherein they may be fishing, and thereby lure their prey to within striking distance. As these birds do not fish by night, and the glow would be invisible by day, this theory may be regarded as exploded.

The feathers of nestling birds do not differ structurally from those of adults in any essential particular, but they are remarkable for the very great range of degeneration which they display. On the varying number of successive plumages through which nestlings pass before attaining to a dress which is structurally equivalent to that of the adult much will be said later.

The nestling down feathers, it should be remarked, are known as "neossoptyles" to distinguish them from the "teleoptyles," or adult feathers-terms coined by Dr. Hans Gadow to serve a most useful purpose.

The neossoptyles are made up $(a)$ of feathers which immediately precede the contour feathers of the adult; and $(\beta)$ of feathers which are later succeeded by down feathers. The former are to be known as "pre-pennæe," the latter as "preplumulæ".

The pre-pennæ may further be divided into "protoptyles" and "mesoptyles"; and while the nestlings of some species develop both, in others the protoptyles have become suppressed, while the mesoptyles are degenerate, and may be represented by little more than a few straggling, hair-like filaments, as in young Pigeons, or the nestling may remain absolutely naked until the appearance of the first "teleoptyles".

Only in some species of Tinamous are the mesoptyles really well developed, and here they very closely approach teleoptyles in structure, but are peculiar in that the after shaft is almost as large as the main shaft, a point wherein they agree with the teleoptyles of the Emu and Cassowary. This is a very remarkable and puzzling fact, because in the adult Tinamou the after-shaft is either feebly developed or wanting, and in the nestlings of the Emu and Cassowary, and the Ostrich tribe in general, the after-shaft is degenerate, or absent! In the nestlings of certain Owls, e.g., Tawny and Eagle Owls, the mesoptyle plumage is worn until the first autumn, at least in so far as the trunk feathers are concerned, for the quill and tail 
feathers are of the true teleoptyle type before the birds leave the nest. These mesoptyles are, in such species, preceded by a peculiarly downy plumage made up of the protoptyle feathers. In the young Barn Owl the protoptyles are never developed, while the mesoptyles have so far degenerated as to be indistinguishable from protoptyles. That they are really mesoptyles is shown by the fact that, like all mesoptyles, they are thrust out upon the tips of the teleoptyles as soon as these develop (p. 27I).

In some birds, as in nestling Game-birds and Owls, prepennæ only are developed. In others, as in nestling Hawks, the pre-plumula are larger, and play a more important part than the pre-pennæ. And from this there is but a step to the suppression of the pre-pennæe altogether, as in the young of the Cormorant, wherein the nestling is clad only in pre-plumulæ.
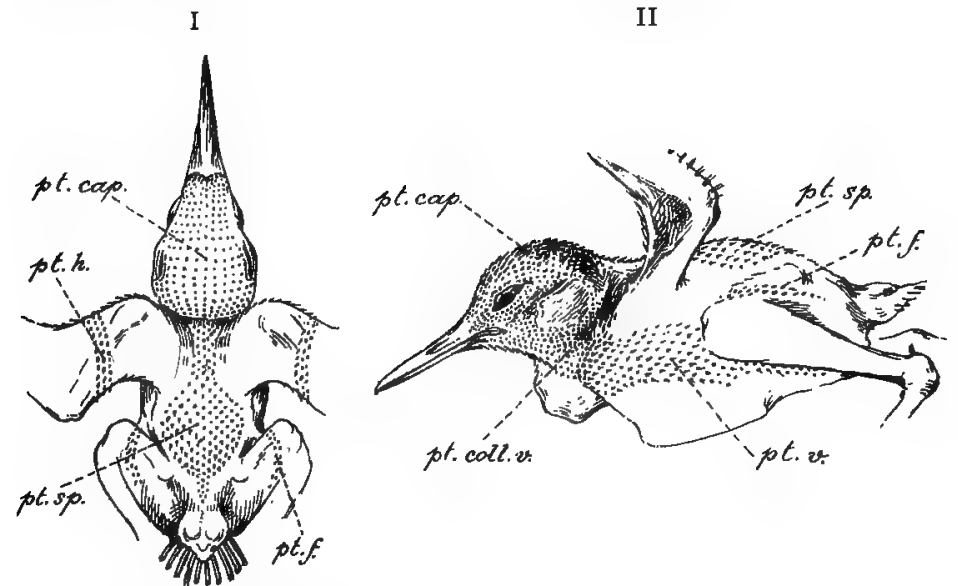

Ill. 4.-Pterylosis of Acanthidositta chloris showing the Feather Tracts

Pt. cap. = Pteryla capitis. Pt. h. = Pteryla humeralis. Pt. $s p_{.}=$Pteryla spirialis. Pt. $f .=P$ teryla femoralis. $P t$. coll. $v .=$ Pteryla colli vertralis. Pt.v. = Pteryla ventralis. (By permission of the Editors of The Ibis.)

The feathers of birds are not evenly distributed over the body, as are the hairs of, say, the horse, but are gathered together to form more or less sharply defined tracts (pterylæ), leaving large bare spaces or "apteria," though in many birds such apteria are covered with down feathers. The nature of these tracts may be seen in Ill. 4. Since they assume char- 
acteristic forms in different groups of birds they are of value for taxonomic purposes.

The feathers on the wings of birds have a quite peculiar

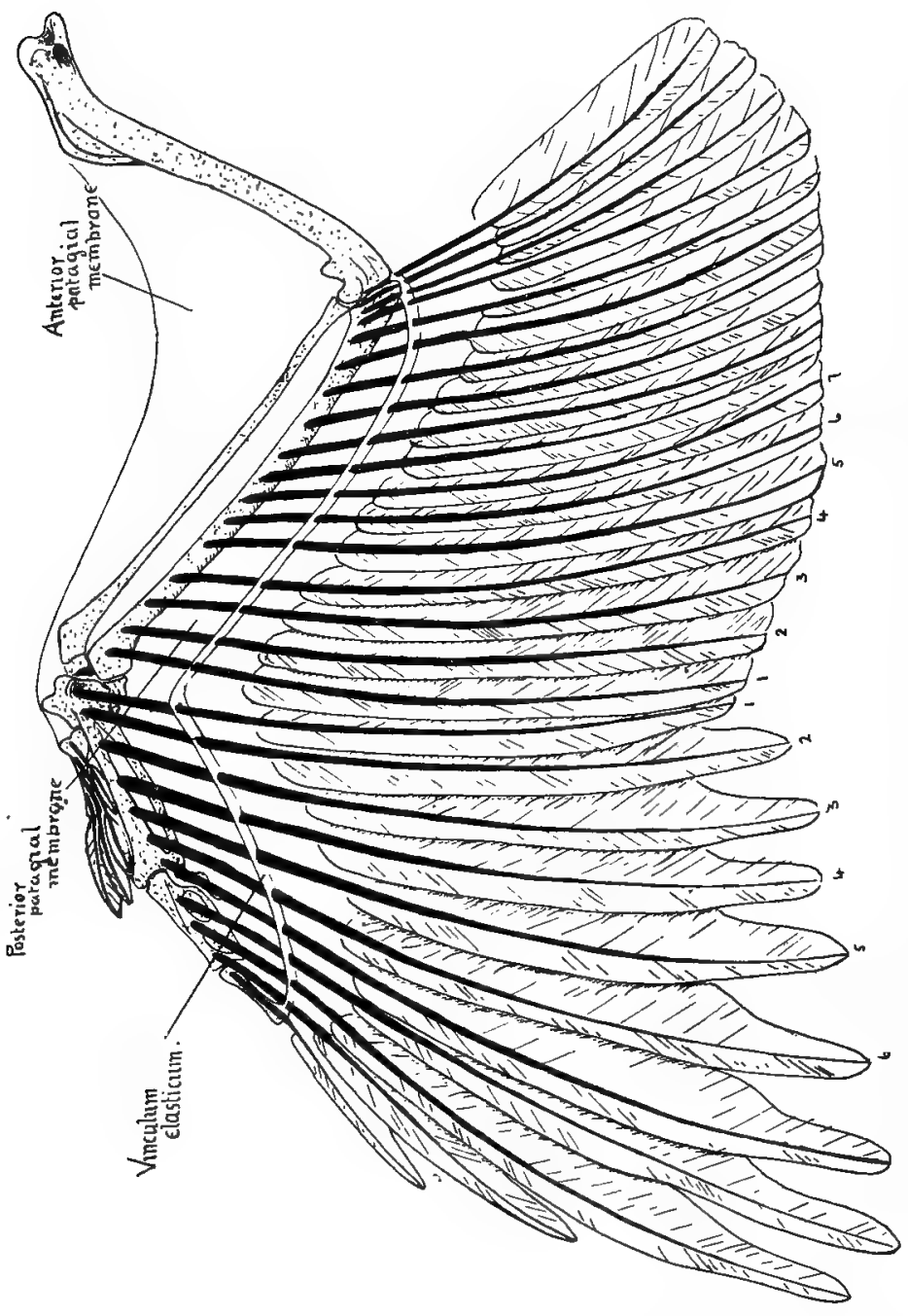

arrangement, and this is true more especially of the great "flight" feathers or quills. These are arranged along the upper surface of the skeleton of the fore-arm and hand, being 
fairly well spaced on the former, crowded together at their bases on the latter (Ill. 5). The quills of the fore-arm, or "secondaries," vary in number according to its length, never falling below six or exceeding thirty-seven. But the quills of the hand-the "primaries"-never exceed twelve in number among Neognathine birds, and never fall below ten, though the tenth may be reduced to a mere vestige, known as a "remicle".

The bases of these "quills," and the surface of the arm generally, are covered by feathers arranged in definite order. These are known as the coverts, whereof four distinct groups are distinguished. The first of these are the major coverts. These are always large and strong feathers, and are closely attached to the bases of the quill feathers; the next row are known as the median coverts; beyond these run from one to five - rows of minor coverts, while beyond these come the marginal coverts. The same rows are represented on the under surface of the wing.

Since these coverts present characteristic features in each of the great groups of birds, they are useful for taxonomic purposes; and this is more especially true of the manner in which those of the upper surface overlap one another. Thus, the major coverts always lie with their free edges turned towards the tip of the outstretched wing, and so also, very commonly, do the median series. The overlap is then said to be "distal". But the outermost median and minor coverts frequently have an opposite, or proximal overlap, that is to say, the free edges = of the feathers face towards the body. The marginal coverts always overlap distally. But the details of this matter should be sought for in the special treatises on this subject rather than in these pages.

While it seems impossible to discover any significance in the matter of this overlap in the smaller coverts, this is by no means the case with the great flight feathers and their coverts. With a distal overlap, as the broad surface of the wing is raised during the up-stroke in flight, the resistance of the air is reduced to a minimum, since it forces down the inner webs of these feathers and so escapes; but during the down-stroke, this resistance forces these inner webs upwards, driving one against another, and so forming a continuous, unyielding surface, as perfect as that afforded by the membrane of the wing of the bat. 
Where the arm (humerus) is long, as for example in the Albatross, the gap between the innermost quills of the fore-arm and the body, which would be formed during flight, is filled up by a series of long feathers which are related to the humerus much as are the secondaries to the fore-arm. But with this difference, in the arm this series is double, one running along the upper, and one along the under surface of the shaft. But for this bridging, flight would be impossible.

\section{Glands}

Birds have no sweat glands. Indeed the only skin gland they possess is that known as the Oil-gland or Uropygium, which is situated above the bases of the tail feathers, and secretes a fairly abundant quantity of clear oil. In some birds this gland ends in a pointed nipple, e.g., Owls; in others it bears a tuft of feathers, e.g., Ducks.

As to the use of this gland: it may be remarked that it is now universally believed to serve as a reservoir for the secretion of oil which is used by the bird for the purpose of dressing the feathers. It is supposed to be applied by the beak, the bird turning the head backwards, and gently squeezing the nipple of the gland. The oil thus expressed is then applied to the feathers, individually, by drawing them through the mandibles, and thereby it is believed aquatic birds make their plumage waterproof.

So deeply rooted is this belief, that he who would nowadays presume to question its truth would be branded as a heretic, or worse. The late Charles Waterton had the temerity to cast doubt upon this thypothesis, and was promptly scorned for his pains; nevertheless, there are grave doubts as to the function of this gland. And these can be briefly set forth by one or two striking cases.

To be of any use as a lubricant this oil must be very skilfully applied: yet there are many bircls wherein this gland is well developed which could not possibly take up and spread so much as one drop of this precious fluid. The Scissor-bill is perhaps the most striking instance of this, for in this bird the lower is not only longer than the upper jaw, but both jaws, from the gape of the mouth onwards, are compressed to form a single blade as flat as a paper-knife. The Pelican is tongueless, and 
has a long unwieldy beak: how could this seize upon and distribute oil over individual feathers drop by drop? Similarly, the Shoveller Duck and the Petrels of the Genus Prion have the edges of the jaws fringed by very long, delicate lamellæ: how, with such an armature, could drops of oil be expressed from the gland and spread over the feathers: or how could this be done by the serrated beaks of such birds as the "Saw-billed Ducks" and the Darters? The Anastomus, or Open-bill Stork, and the Whale-headed Stork again, would surely find such a feat impossible. And these, be it noted, are all aquatic birds.

On the other hand, the Bustards, many Pigeons and Parrots, and the Ostriches have no gland: yet they keep their feathers in as good condition as those birds which possess this organ. So copiously is this secretion said to be formed in the gland of the Concave-casqued Hornbill (Dichoceros bicornis) that the feathers of the neck! are said to be stained yellow thereby!

Nevertheless, ninety-nine out of every hundred Ornithologists are firmly convinced that they have seen the oil squeezed from the gland, and witnessed its application.

If, after all, it should be proved that this gland is not used as tradition assures us, what then is its purpose? So far no really satisfactory hypothesis presents itself. But the same is true of many other glands in other animals. It is possible, however, that it may have served, and may still serve, as a scent gland: though the odour may not be traceable by the olfactory nerves of the human subject, save in one or two cases. In the Hoopoes, for example, it gives forth a most offensive odour, while in the Musk Duck (Bizina lobata) it sends forth a musky smell. The peculiar smell of Petrels is also apparently due to the secretions of the oil-gland.

\section{The Skeleton}

Birds show their reptilian ancestry in the skeleton more clearly than in any other part of the body, though even here the evidence has been largely masked by the modifications due to flight.

The reptilian characters are more conspicuous in the pneumaticity of the bones, the structure of the skull, and the great number of the neck vertebræ, and the structure of the hip- 
girdle and hind-limb. The shoulder-girdles are unquestionably reptilian, but this is not so patent as are the other characters.

While in some birds, as in the Hornbills for instance, every bone in the skeleton contains spacious air-chambers, in others, the long bones at any rate- - the bones of the wings and legsare filled with marrow, and this is true even of such skilled performers on the wing as the Swallows. The peculiar characters of the shoulder-girdle, wing, and hind-limb will be discussed later in these pages.

\section{The Respiratory System}

The respiratory system of birds presents some points which demand a brief notice.

\section{The Lungs}

In the first place the lungs are not suspended freely within the body cavity, but are closely affixed to the dorsal wall of the anterior portion of the thorax. In the second place they differ from the lungs of other vertebrates in that the respiratory air is not simply drawn into the lungs and expelled again, but is rather drawn through them and passed into a series of large thin-walled chambers lying along each side of the body cavity, and known as the air-sacs. The air stored in these reservoirs serves not only for respiratory purposes, but also as regulators of the temperature, thereby compensating for the lack of sweat glands.

\section{The Pulmonary System of Air-sacs}

There are five pairs of these air-sacs. The first, or cervical pair, lie one on either side of the base of the neck and may give rise to a number of smaller cells which run up the neck, and even into the head; while small side branches may penetrate between the muscles of the neck, the vertebræ, and the various cranial cavities: or they may form large inflatable sacs in the region of the throat, as in the Prairie-fowl and Frigate-bird.

The second pair are known as the interclavicular sacs. In the Ducks they communicate one with another, while in the Storks they combine to form a single chamber. Lateral extensions of these sacs form large axillary chambers uitimately penetrating the humerus and other of the wing bones, the 
large pectoral muscles, and the body and keel of the sternum.

The third and fourth pair are the "anterior and posterior intermediate sacs," and are enclosed within the thoracic cavity, extending backwards more or less far into the abdominal cavity.

The fifth pair form the "abdo-

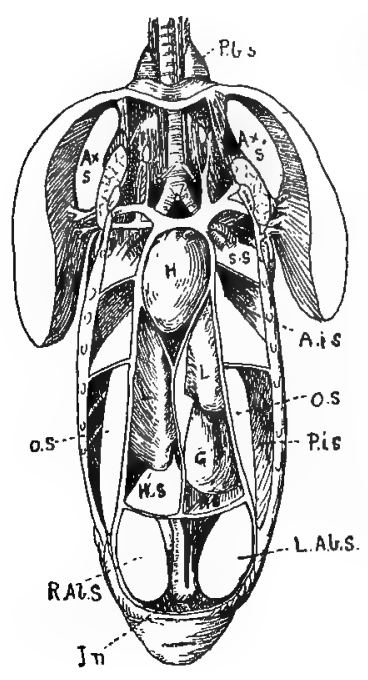

ILL. 6.-Dissection Showing THE LUNGS AND AIR-SACS OF A BIRD

$\mathrm{Pb} . \mathrm{s} .=$ Pre.bronchial sac. $A x_{1}=$ Axillary sac bounded externally by the breast-muscles, seen here in section. S. s. $=$ Partition dividing anterior intermediate sac (A.i.s.) from the sub-bronchial sac. P.i.s $n=$ Posterior intermediate sac. O.s. $=$ Oblique septum. H.s. $=$ Horizontal septum. L. Ab. s. = Left abdominal sac. $\mathrm{H}_{\mathrm{.}}=$ Heart. $\quad$ G. $=$ Gizzard. $\quad$ L. $=$ Liver. In. = Intestine. (After Strasser.) minal sacs". Of large size, they are continued backwards to the end of the abdominal cavity.

This elaborate system of airchambers is further complicated in many birds by an extensive system of pneumatic cells extending between the muscles, and between the muscles and the skin,so that the bird is absolutely encased in a layer of air enclosed between the skin and the body. This emphysematous condition is most perfectly developed in birds such as the Gannets, Screamers and Hornbills.

\section{The Naso-pharyngeal System of Air-sacs}

But there is yet another system of air-cells to be mentioned, which is known as the "tympanic" or "naso-pharyngeal system". While in the majority of birds this is concerned merely with the supply of air to the bones of the skull, in the Adjutant Storks it gives rise to a very remarkable pouch which runs down the front of the neck as far as its middle. It can be inflated and deflated at pleasure, communicating as it does with the nasal chamber through an aperture in the floor of the orbit.

The extraordinary air-pouches of the Great Bustard and the Emu may be mentioned here. That of the first-named forms 
a relatively enormous cavity, having extremely thin walls, lying immediately under the skin of the neck, and opening immediately under the tongue. Peculiar to the male, it must be regarded as a variation of the pouch described just now in the Adjutant. Only one other bird possesses a similar chamber, and this is the Musk Duck (Biziura lobata). But here the pouch is very small, and is lodged in a sac depending from the underside of the lower jaw.

The pouch of the Emu is formed by an evagination of the lining membrane of the windpipe, and makes its escape along the ventral aspect of the trachea, near its middle, where the tracheal rings for some distance are cut away, as it were, to permit of the exit of the pouch (p. 4OI).

The pulmonary system of air-sacs make their first appearance in the embryo at about the eleventh day, as small vesicles from the surface of the lungs, formed by dilations of branches of the bronchial tubes. As they develop they push the peritoneal membranes before them. Thus they acquire a twolayered wall - the outer serous layer formed by the peritoneum, the inner by the lining of the bronchial tubes from which they take origin.

\section{The Digestive System}

The digestive system of birds betrays its reptilian origin in many ways, but perhaps most markedly so in the arrangement of the annular and longitudinal muscular layers of the intestine, the longitudinal layer lying within the annular, while in. the mammals the reverse order obtains, the longitudinal layer, with the serosa, forming the outer wall of the tube.

In most birds the food is swallowed without any attempt at mastication, and passed backwards into the osophagus. As a rule this tube, in the region of the furcula, dilates to form a more or less globular or bi-lobed and thin-walled "crop". Here, mixed with saliva and water, and warmed by the heat of the body, the food is softened and passed on to the stomach. This again is divisible into two distinct portions, an anterior, the "Proventriculus," with thick glandular walls, and a posterior, the "Ventriculus" or "Gizzard," whereof the walls are thick and muscular, and furnished with a more or less rugous and indurated inner surface. In grain-eating birds the inner walls of the gizzard are furnished with a pair of apposed and greatly 
thickened pads, which, by means of spirally arranged muscular fibres, are made to rub together in opposite directions after the fashion of a pair of millstones. But this work of trituration is further aided by a mass of small stones swallowed, and retained by the gizzard, for this purpose. In the pigeons of the genus Ptilopus there are four such pads, so that the gizzard is crossshaped in section. In fish and flesh-eating, and in insectivorous and fruit-eating birds, the gizzard is feebly developed, the proventriculus and ventriculus passing insensibly the one into the other. The latter, in fish-eating birds, such as the Herons and Cormorants, may assume the form of a long oval sac extending along the whole length of the abdominal cavity; while, by way of contrast, it should be mentioned that in other piscivorous forms, such as the Tropic-birds, Pelicans and Gannets, the gizzard or ventriculus is much reduced, the proventriculus being in consequence of considerable size. In the Cassowaries and Emus and in Tanagers of the genus Euphones similar relations obtain between these two portions of the stomach; but in the Hoatzin, which has also a greatly reduced ventriculus, it is the crop which has become enlarged (p. 3I3).

The inner lining of the stomach is naturally constantly wearing away and being reproduced, but in some birds this lining is suddenly cast off and ejected through the mouth as in the Starling, Missel Thrush, Little Owl, Cuckoo and Hornbill. The Cuckoo and Trogons of the genus Harpactes are further peculiar in that the inner lining of the gizzard becomes beset with hairs, spirally arranged, derived from the caterpillars on which these birds feed.

In birds of prey the fur and feathers of the victim swallowed, and in some grain-eating birds the husks, are formed into "pellets" and ejected through the mouth.

The intestines, with the external digestive glands-the liver and pancreas-attached thereto demand little notice here. Suffice it to say that three portions thereof may be distinguished -the duodenum, a closed loop embracing the pancreas, and receiving the hepatic and gall-ducts; the ileum or "small intestines," the longest portion of the gut, and the rectum. The last-named is shut off from the ileum by a special valve, the "ileo-cæcal," which, while it permits of the contents of the gut passing into the rectum, hinders any return thereof, 
The convolutions into which the small intestine is thrown, for the purpose of securing a greater length of gut, and consequent increased digestive surface, are of considerable value for taxonomic purposes, as Dr. Hans Gadow and Dr. Chalmers Mitchell have successively shown (p. 436).

But the length of the gut, and the thickness of the walls thereof, are largely determined by the nature of the food to be assimilated. Thus, in purely frugivorous and insectivorous birds the gut is very short, while it reaches its maximum length in species which feed upon fish, carrion, grain and green vegetable matter.

The lumen of the gut in short-gutted forms is generally very wide, while in piscivorous birds the walls of this canal are always very thick-a possible contrivance to lessen the danger of perforation by fish-bones.

At the junction of the small and large intestines there may be found a pair of cæca or blind diverticula, guarded by a valve which allows the semi-fæcal matter to pass into these pouches, but prevents any backward movement into the small intestine (ileum).

In some birds, such as the African Ostrich, Rhea (IIl. 7, p. 23) and the Gallinæ these cæca are of relatively enormous size; they are also very large in some of the Wading-birds (Limicolæ), in Owls and in Night-jars, Rollers, Bee-eaters and Cuckoos which are insectivorous.

In fish-eating birds they are of relatively small size, and in some species are quite degenerate. In some species they are reduced to mere wart-like bodies, of which one may be wanting altogether, e.g., Herons and Petrels, or both may have completely disappeared as in many Pigeons, Parrots, Kingfishers and the Swifts, for example.

In Struthio and Rhea the aggregate volume of these appendages, as Dr. Hans Gadow has pointed out, may surpass that of the rest of the intestinal canal.

These pouches do not present any great range in the matter of shape. As a rule they are cylindrical. But in the Owls they assume the form of inverted Florence-flasks; while in the Martineta Tinamou (Calodromas elegans) they assume a truly remarkable form, having the semblance of a bunch of grapes! (Ill. 7, p. 22). 
The cæca appear to function as digestive organs when fully developed; but in some cases they seem to have assumed a new character. Such instances appear to obtain in many cases where these organs would seem, judged solely by their small size, to be degenerate, as, for example, in Passeres. But here, as Dr. Chalmers Mitchell has pointed out, the walls of these extremely reduced organs contain lymphoid tissue, though what function they serve, whether secretory or excretory, is yet unknown. The cæca of the Owls similarly, at their ends, contain masses of lymphoid tissue, while in Ducks and Fowls this occurs in scattered patches. Thus, while some reduced cæca are certainly degenerate and functionless, others, though reduced, still play a more or less important rôle in the metabolism of the body.

But the presence of these organs presents some curious anomalies, which seem to show that although their development is correlated with certain kinds of diet, this relation is by no means always maintained. The diurnal birds of prey and the Owls afford the most striking illustration of this peculiarity. Both are now flesh eaters, and the former have apparently in consequence lost them, yet in the latter they are of large size. Some of the Owls, it is true, still partake freely of insect food, but so also do many of the smaller Falcons, which indeed live exclusively on this diet, yet they, like their larger brethren, are minus these organs. One must assume that they were lost before the insect diet became fixed, and so could not be redeveloped. But it is clear that they are not essential to the digestion of insect food, and equally clear that the substitution of a carnivorous diet need not bring about their dissolution.

The rectum, like that of reptiles, terminates in a cloaca divided into a series of more or less distinct chambers, the coprodæum, urodæum and proctodæum, into which last opens the "Bursa Fabricii," an organ of unknown function, peculiar to birds, and largest in nestlings; into the urodæum open the kidney and the genital-ducts. The coprodæum retains the fæcal and urinary matter until ready for expulsion.

\section{The Circulatory System}

The main features of the circulatory system may be very briefly summarised. 


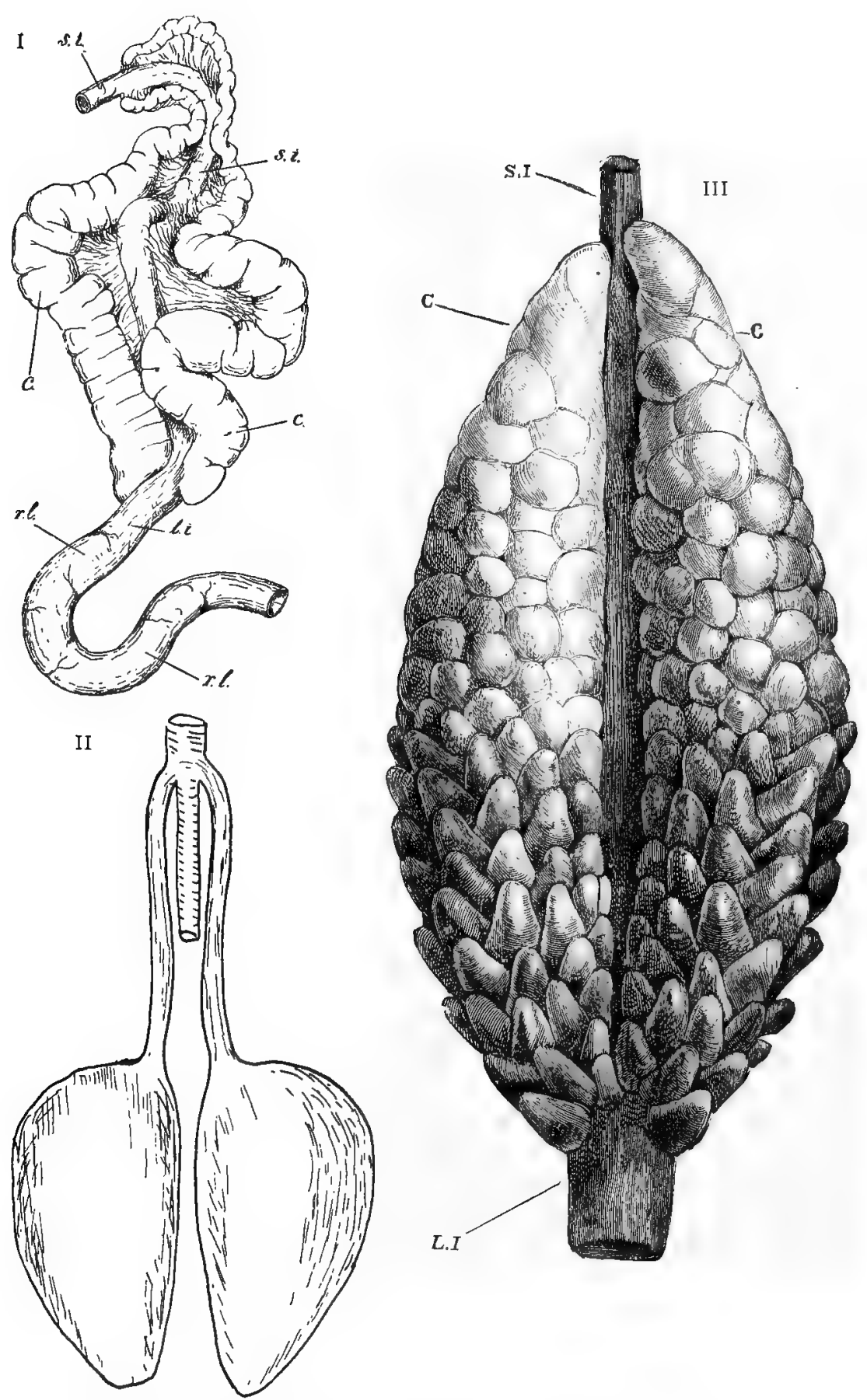

Ill. 7.-Types of the Caeca, or Blind Gut, of I. Rhea. II. OWL. III. Martineta Tinamou 

Birds differ from Reptiles and agree with the Mammalia in having a completely four-chambered heart, whereby the admixture of arterial and venous blood is prevented. The heart of birds, however, differs in important respects from that of mammals.

Owing to their excessive activity the heart-beats of the bird are quicker than in any other animals, numbering I 20 to the minute during rest, and during flight reaching a far higher figure. In a bird which has just alighted the pulsations are beyond the count of the ear.

Birds, like mammals, have but a single aortic arch, but while in the former this is the left, in the latter it is the right of the originally double arch which persists. The corresponding arch of the opposite side, in both cases, gives rise to part of the subclavian artery. The carotid arteries exhibit some interesting modifications, but these appear, like so many other characters, to have no bearing, no traceable bearing, on the struggle for existence. And the same remarks apply to the femoral arteries which may be supplanted by the sciatic. Though attempts have been made to use these vessels for taxonomic purposes, they have been only partially successful. The Penguins alone among birds develop a rete mirable, which is, of course, connected with their diving habits, though other diving birds, it is to be remarked, have not developed a similar arrangement of the blood-vessels, which is met with again in the Cetacea among the mammals. An ingenious use of the veins supplying the intestinal mesentry has been made by Dr. Chalmers Mitchell, but the discussion of this, as of other peculiarities of the vascular system, does not come within the scope of this work.

During the work of brooding it is to be remarked the blood-vessels of the abdomen become greatly distended, and form large "inflamed" areas known as brood spots, which, applied to the surface of the egg during incubation, generate the heat necessary for the development of the growing chick.

\section{The Muscular System}

The muscular system of birds presents no characters which have any really important bearing on the problems with which this book is concerned. Nevertheless, interesting illustrations 

this purpose into three separate tendinous branches. In a number of species, however, wherein the ambiens was supposed to be wanting, Dr. Chalmers Mitchell found striking proofs that this muscle had suffered extensive degeneration, but that traces thereof were to be found in the shape of a tendinous band attached to the fibula and sending off three tendinous slips to the perforated flexors. More than this, in a dissection of two specimens of that aberrant bird the Hoatzin, he found in one case no ambiens above the knee, but the, so to speak, dismembered, distal end thereof forming a round ligament attached to the fibula, whilst its opposite extremity was split up into three branches, inserted after the manner just described. In the other specimen the belly of the ambiens was present, but the tendon thereof lost itself on the knee. The dismembered extremity thereof was found attached, as in the first-named specimen, to the fibula at the one end, and to the branches of the perforated flexor at the other. Thus there could be no doubt as to the evidence showing that the dissolution of the ambiens was accomplished by slow degrees, the first stages commencing with the disappearance of the region between the knee and the crossing at the fibula. In a precisely similar way, it may be remarked, the hindmost thoracic ribs disappear, till at last nothing but the head attached to the synsacrum, and the terminal portion attached to the sternal rib next in front remains; finally, the head also disappears, leaving but a spicule of bone representing the sternal segment of the rib.

\section{Nervous System and Senses}

Though birds display a high order of intelligence the brain is devoid of superficial convolutions such as are found in the brains of the higher mammals. A slight furrow, however, apparently answering to the sylvian fissure of the Mammalian brain, may be traced in many birds.

In the size of the brain, however, birds are in advance of reptiles; both the cerebrum and cerebellum being relatively much larger in the former.

The sense of sight in birds is highly developed; thereby the soaring vulture detects the presence of food at immense distances, guided largely, no doubt, by the movements of others of its species nearer the feast, though these may be so far apart 
as to be invisible to human eyes. The hovering Kestrel again from a considerable height is enabled to detect the presence of creatures so small as mice on the ground beneath him.

In the structure of the eye birds resemble the reptiles. In both the sclerotic coat is more or less cartilaginous, while the region surrounding the face of the eyeball lodges a number of overlapping, bony plates, which in Accipitres and Owls attain a large size, and gives this region of the eye a tubular shape. In the Woodpeckers and their allies, and in the Passeres, the region surrounding the entrance of the optic nerve also lodges bony plates. In the Lammergeier the outer surface of the sclerotic region immediately surrounding the iris is of a vivid vermilion colour. No other bird has this region similarly coloured, and this may be cited as another of the many characters which birds-in common with other animals-display that appear to have no direct relation to the struggle for existence.

In addition to the fovea centralis, answering to the "yellow spot" of mammals, the spot of most acute visuality, "many birds," says Dr. Gadow, "possess a second foveæ more towards the outer or temporal side of the eye. One pair of these fover seems to be used for monocular, the other for binocular sight, so that the whole field of vision of birds possesses three points where vision is most acute."

The exposed surface of the eye in birds is protected by a large semi-transparent membrane known as the nictitating membrane. This is formed by a reduplication of the conjunctiva, and worked by two muscles whereby the membrane is drawn over the eye from the outer lower towards the upper inner angle. In some birds, as in Owls, this is kept in constant motion, so that the iris is incessantly being covered and uncovered by this curious curtain. In other birds it is less often used, but in many, as in Corvidæ, for example, it appears to be employed extensively during moments of pleasurable excitement.

The eyelids are not conspicuous, and, as a rule, the lower lid only is movable, rising upwards to close the eye. Only in a few species are eyelashes present, such, for example, as the Ostrich and the Hornbills, where they are of exceptional length, and in the Amazon Parrots. 
The sense of hearing is acute in most birds, though there is no external auricle, such as is met with in most mammals; and herein birds and reptiles again agree. But in the Owls there are some species which develop prominent folds of skin of a very remarkable character, such as will be found described in chapter XXIII, p. 369. The structure of the ear will not be described in these pages, since this is a subject which belongs to the domain of comparative anatomy and is foreign to the purpose of this book.

The sense of smell in birds is not, apparently, as a rule, very strongly developed. The evidence so far collected on this head is conflicting. The South American Vultures and the Petrels have both an unusually large olfactory chamber, yet, in the first-named at any rate, it has been satisfactorily demonstrated that their sense of smell is practically nil. They find their prey by sight. The Apteryx has the most complicated nasal labyrinth of all birds, and during feeding keeps up a constant sniffing sound, as if seeking to make up for its deficient sight by the use of its olfactory sense; and a piece of further evidence that this sense is well developed is the fact that the nostrils are placed at the extreme tip of the beak-a position found in no other bird. Nevertheless, experiments on captive specimens have produced no very striking evidence to show that their sense of smell is much better, if at all, than in other birds. Ducks are credited with a keen sense of smell, and in the days when duck-decoys were worked, it was the custom of the decoy-men to burn a sod of peat or other vegetable matter when the wind was blowing towards the fowl, in order that any suspicion of human scent might thereby be covered.

Birds certainly possess a sense of taste, as is shown by the predilections of captive birds, for example, and the way in which gaudily coloured and nauseous insects are avoided. How much the tongue is used in this matter, and whether tongueless birds like Cormorants and Pelicans also possess a sense of taste, there is no evidence at present to show.

The sense of touch in birds is confined chiefly to the beak: in reptiles, it may be remembered, the tongue is often used for this purpose. The beak of the Snipe, and of its near relatives, is singularly sensitive, being used as a probe for the discovery of food hidden in mud and swampy ground. 


\section{CHAPTER II}

\section{PHYLOGENETIC}

Birds and their position in the animal kingdom. Relationship to the reptiles, and the evidence thereof. Archæopteryx-the first bird. Hesperornis and early specialisation. Ichthyornis. The Pro-aves.

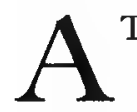

$\mathrm{T}$ the outset it is well that a clear conception should be gained as to the relationship of birds with regard to. other classes of the Vertebrate kingdom: and this relationship can be established more clearly perhaps with regard to the birds than in any other group.

Agile and restless to a degree unequalled perhaps in the animal kingdom, it may seem surprising to many to learn that nevertheless they owe their descent to the sluggish and coldblooded reptiles : yet such is the case. Like the reptiles they are oviparous, though, unlike the reptiles, none avoviviparous. Furthermore, they differ from their humbler allies in that their eggs require a higher temperature to incubate. This is generally obtained by the brooding of the parent, though in certain exceptional cases this is secured by depositing the eggs in fermenting vegetable matter, or by the aid of sand heated by warm springs (p. 218).

Structurally their reptilian character is abundantly plain. In the skeleton this is manifested in several ways.

The skull alone would furnish sufficient evidence to prove this relationship, but happily many other parts of the skeleton can be made to bear no less striking evidence. These characters may profitably be reviewed, though briefly, here.

First of all as to the skull. As in the reptiles this articulates with the vertebral column, or backbone, by means of a single condyle - a rounded boss of bone projecting from the floor of the skull immediately below the aperture for the exit of the spinal cord-while the bones of the palate and of the cranium 
are arranged on the same general plan as those of the reptile. In so far as the bones of the palate are concerned, this can be

I

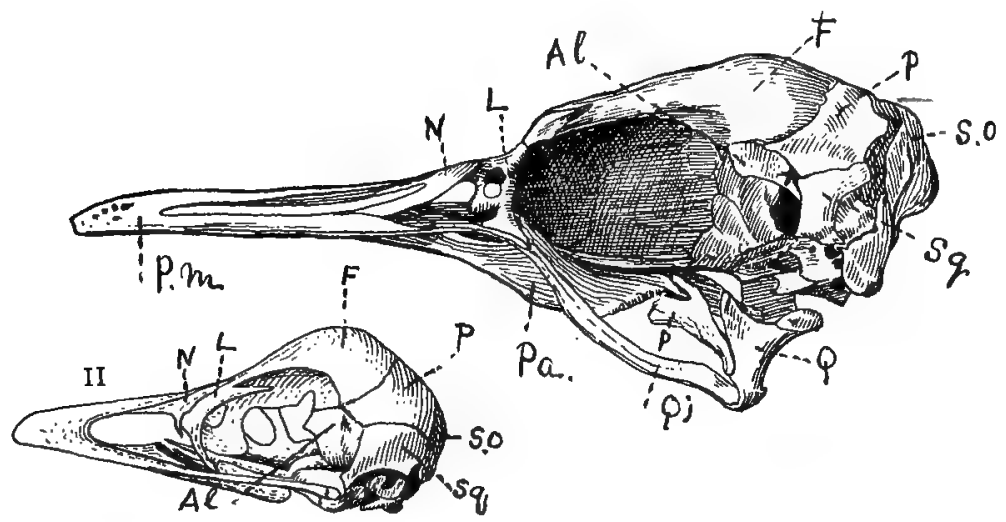

III

IV
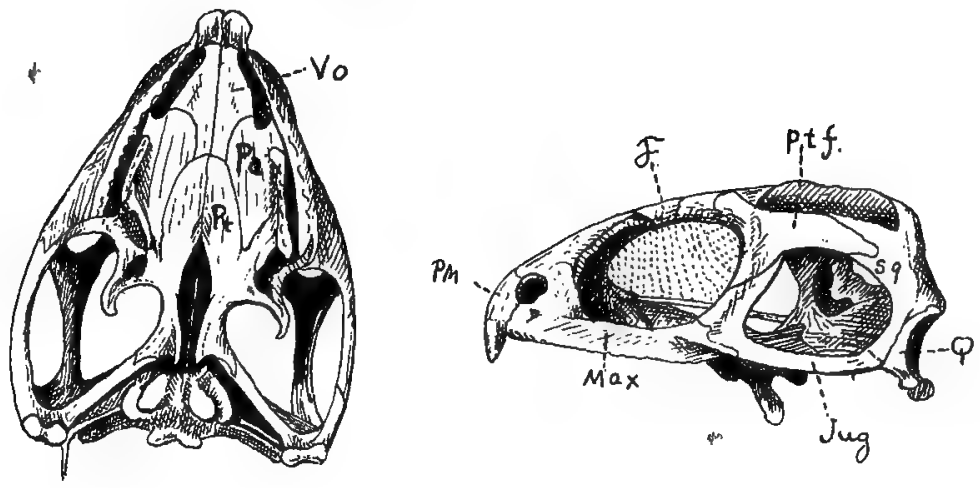

Ill. 8.-Skulls of Nestling Penguin (I.) and Emu (II.) to Show the Suture Dividing the Separate Elements of the Cranium

The quadrate has been displaced in the case of the Penguin to show the base of the skull. These should be compared with that of Sphenodon, III., IV., the most primitive living Reptile.

Al. = Alisphenoid. P. = Parietal, F. $=$ Frontal. Sq. $=$ Squamosal. S.o. = Supra-occipital. Q. = Quadrate. Qj.=Quadrato-jugal. Pt. = Pterygoid. Pa. = Palatine. Pm. = Premaxilla. Pt.f. = Post frontal. L. = Lachrymal. N. = Nasal. Jug. = Jugular. Max. $=$ Maxilla. Vo. $=$ Vomer.

readily demonstrated at all ages in the bird's life-history; but

. this is not the case with the cranial bones, that is to say, with the elements which make up the brain case, inasmuch as these rapidly coalesce after birth obliterating all traces of their separate 
existence, and forming a smooth, highly polished box whose walls are permeated with air spaces. But in the ripe embryo, or better still, generally, in the nestling, this cranial box is found to be composed of a number of separate pieces corresponding closely with those of the reptile. Of these separate elements there is no need to do more than give a very general account of those which have a direct bearing on the question at issue. As in the reptile, the fore-part of the floor of the skull is prolonged into a long parasphenoidal rostrum, at the base of which, in the majority of birds, will be found a pair of "basipterygoid processes". These are peculiar to reptiles and birds. Largest in the more primitive types, such as the Ostrich tribe, Game-birds and Ducks for example, they have disappeared entirely among some groups, as in the Parrots for example; while in others some members possess vestiges thereof, and others no trace at all, as for instance among the birds of prey and the song-birds. The lower jaw articulates with the skull by means of an anvil-shaped bone, the quadrate, and this again occurs only among reptiles and birds.

But owing to the relatively enormous increase in the size of the brain, the cranium of the bird differs markedly from that of the reptile, inasmuch as the parietal bones, before fusion, have the whole posterior border interlocked by suture with the supraoccipital and lateral occipital bones, and to these the squamosal is attached, being fitted in, as it were, puzzle fashion, to fill up the gap left where they meet, and serving at the same time to partly cover the bones of the internal ear (I1l. 8). In the reptile, on the contrary, the brain is relatively small, so that the outer angle of the hinder border of the parietal is produced backwards into a long "flying buttress" to serve for the attachment of the squamosal which is thus completely divorced from all participation in the cranial wall. In this particular then the bird really more closely resembles the mammal. The structure of the ear and the lower jaw are other characters which must be cited in this connection.

Evidence of no less importance is to be had by a study of the developing skull, but this is of an extremely technical character, and need not be cited here.

Turning now to the skeleton of the trunk, we find that, in the young bird at least, the neck vertebræ bear free ribs-in 
the adult they coalesce with the centrum, while in the nature of the ends of the body, or centrum, of the vertebra, reptilian blood is also evident. But this evidence might not, at first, appear so plainly as in the characters just referred to, since the majority of birds have now acquired what are known as "saddle-shaped" vertebræ, or heterocœlous vertebræ; that is to say, the two ends are unlike. Anteriorly the articular surface is columnar, posteriorly transversely hollowed, so that the columnar surface of the vertebra moves, laterally, on the hollowed surface of that next in front of it. But in the old Ichthyornis like the modern reptile Hatteria, these surfaces were cup-shaped; while the Parrots, Penguins and Gulls have cup and ball articulations to the vertebræ, in the region of the thorax, and these are quite reptilian in type. Young birds, however, furnish much more emphatic "testimony on this point, for, in addition to the movable ribs of the neck vertebra, we have the fact that, as in reptiles, these vertebræ do not possess, at any stage, "Epiphyses," as in the mammals. These epiphyses are flat discs of bone fitting on to the ends of the vertebræ, enabling new bony matter to be added between the enclosed space: growth com-

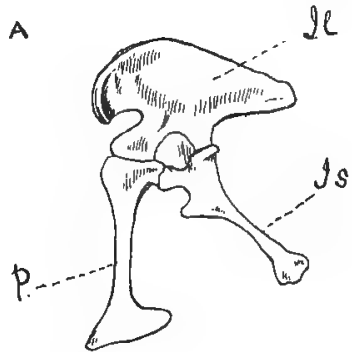

B

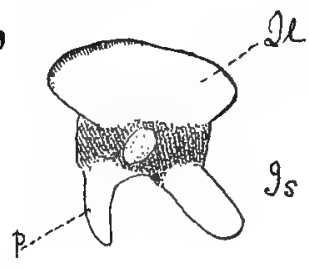

C

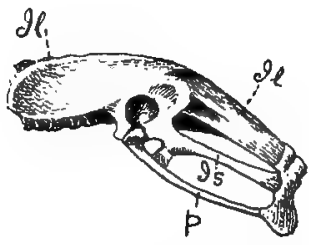

Ill. 9.-Hip-girdles of a Dinosaur (A), AN Embryo Bird (B), AND a Nestling Emu (C)

The hip-girdle of the embryo in the shape of the Ilium (Il.) and the position of the Pubis (P.) and Ischium (Is.) resembles that of the Dinosaura primitive or ancestral phase of development. In the nestling Emu the Ilium has greatly increased in length, and the Pubis and Ischium have rotated backwards. In less primitive birds the fissure between the Ilium and Ischium becomes almost completely closed. pleted, these plates fuse with the main body of the centrum. The hip-girdle, especially during its embryonic stages, pre- 
sents a very striking resemblance to that of the Dinosaurian reptiles; and the shoulder-girdle no less emphatically bespeaks. a reptilian descent. The hind-limb again is built on a completely reptilian model, and this is seen in the peculiar character of the ankle-joint, and the nature of the tarso-metatarsal segment. Both in reptiles and birds the joint between the foot and the shank of the leg is formed by a hinge passing between the two rows of ankle-bones, and not, as in the mammals, by a hinge between the shank and the first or uppermost row. In the adult bird, however, no separate ankle-bones are traceable. To find these the embryo, or at least the nestling, must be examined. In the former several distinct tarsals can be made out, but in

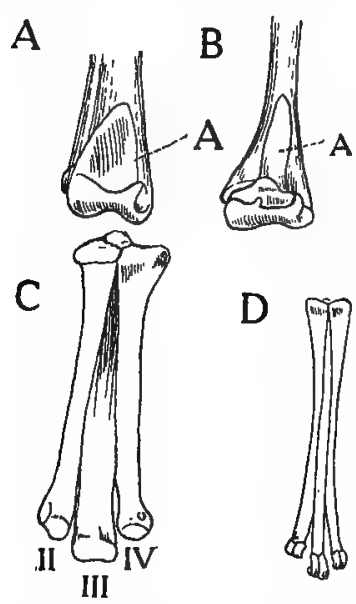

ILL. IO.-The END OF THE Shank, AND Middle Bones of THE Foot (Tarsometatarsus) OF A Young Bird (B, D) CoMPaRed With THE SAME Bones in an Adult Reptile (DinoSAUR) (A, C)

A. = Astragalus. the nestling these are represented (a) by a mallet-shaped bone, and (b) by a flat disc. The first, or astragalus, fits on to the end of the shank, up the front of the shaft of which it sends a short spur; in a few weeks after hatching this astragalus fuses completely with the end of the shank, when all trace of its former existence is lost. The second is applied to the surfaces of the three metapodial or foot-bones, and this similarly fusing therewith disappears rapidly as an independent element. This plate, as may be seen in the embryo, is made up of distinct elements, but these rapidly coalesce to form the plate, which in turn disappears to form the top of the "cannon-bone".

This "cannon-bone" or tarsometatarsus-the "tarsus" or scalecovered portion of the leg, in works on Ornithology-in the embryo, or nestling bird, is seen to be made up of three separate shafts or rods, answering to the similar bones extending from the ankle to the base of the toes in the human foot, for example, and consequently corresponding in number to the number of the toes. The dividing lines in the nestling bird 
are extremely fine, but they can easily be seen. By the time the adolescent stage has been reached all trace of these separate bones has vanished, leaving the hard, pillar-like "cannon-bone," which reveals no evidence of its earlier compound character.

So much for the reptilian characters of the skeleton. But the Brain, Vascular and Urino-genital Systems similarly furnish proofs of the same derivation.

So. closely do the birds and reptiles agree, indeed, that Huxley included them together under the term Sauropsida.

But apart from the indubitable evidence to be obtained from existing birds, other and even more striking evidence is to be obtained from the remains of fossil forms.

This evidence carries us back to Jurassic times, the oldest known fossil bird, Archæopteryx, having been obtained from the Lithographic slate of Solenhofen in Bavaria.

This bird more nearly resembles the reptiles than any other known form. So much so, that undue and unwarrantable use has been made of the fact, many writers having endeavoured to show that it was more reptile than bird, a contention which becomes ridiculous when the facts are carefully considered. Two specimens only of this remarkable bird are knownbelonging to as many species-the first to be discovered being now in the British Museum of Natural History, the second in the National Collection of Berlin. With their specific distinctions we have nothing to do here, but both agree in having the jaws armed with teeth and a long tapering, lizard-like tail, but this, like the rest of the body, bore feathers.

Of all the accounts, and there are many, that have been given of this patriarch of the bird-world only one can be regarded as accurate, though on many occasions one or other of them have been described by men whose powers of interpretation have in other ways been more severely tried. It is on their descriptions that the inaccurate, and sometimes grotesque figures which adorn text-books of comparative anatomy have been based. So profoundly impressed do these authorities appear to have been by the presence of the teeth, the long tail, the armature of claws on the wings-concerning which we shall have more to say-and the fact that traces remain only of the wing and tail feathers, and of the feathers of the leg, that they contended that these ancient types must have been clothed 
with scales as to the head, neck and trunk, the feathers being restricted to the parts on which they occur in the fossil! A contention as wildly improbable surely as it would be to insist that from the absence of all traces of muscles these primitive creatures had not yet acquired muscular tissue!

Nevertheless, we have, in this primitive type, not only a remarkable link in the chain of evidence as to the source from which birds derived their origin, but also a most valuable key to some essentially avian characters which would otherwise have had to be explained on mere conjecture. In so far as the reptilian characters are concerned the principal features are

A.

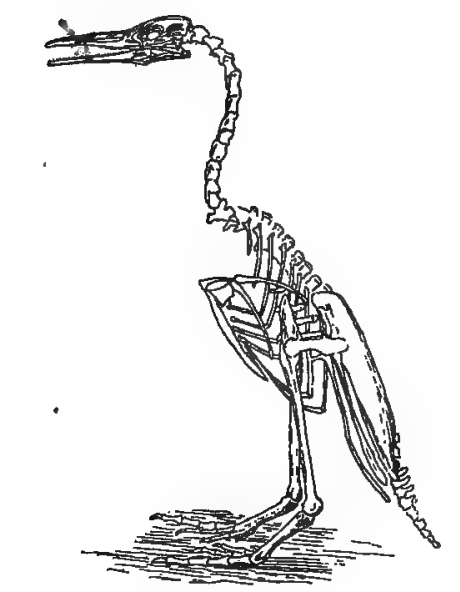

B

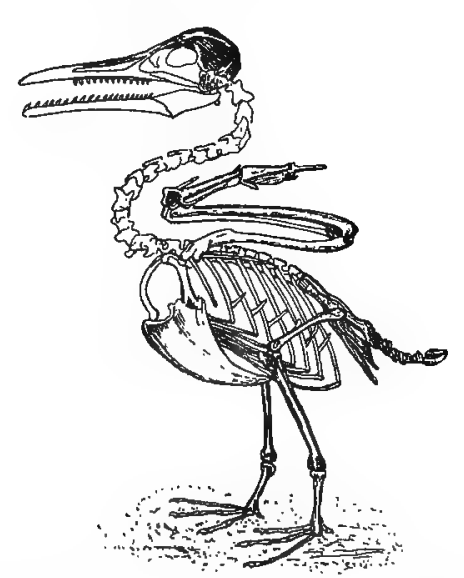

Ill. II.-The Skeletons of Two Extinct Fossil Birds, Hesperornis (A) AND ICHTHYORNIS (B)

In Hesperornis all that remains of the wing vestige of the humerus, seen in the figure lying across the ribs.

the teeth and tail. The former were small and appear to have been lodged in sockets, while the tail, on account of its length and the number of the vertebræ, must unquestionably be regarded as reptilian. As to the avian characters, these will be dealt with later (p. 263).

Not, unfortunately, until the cretaceous period do we meet again with bird remains, and these have now become stamped with the stereotyped avian characters in all save that the jaws still bore teeth.

The two most conspicuous and most perfectly preserved of 
these ancient birds were Ichthyornis and Hesperornis, from the cretaceous shales of Kansas.

On account of the presence of teeth in the jaws these have been placed in a distinct "Sub-class" of birds-the "Odontornithes," but it is open to question whether on such grounds this is justified.

Ichthyornis maytperhaps be, and generally is, regarded as the ancestral type of the present Steganopodes-the Gannets, Cormorants, Pelicans, Tropic and Frigate-birds. In all save the teeth and the peculiar character of its vertebræ, which were amphicœlous-reptilian characters-the skeleton of this bird had acquired all the characteristic peculiarities of the Class Aves, though we should expect, by the way, when the structure of the palate is better known, to find that it presents even more reptilian characters than are to be found in the living Struthious . birds.

Hesperornis, on the other hand, represents one of the most highly specialised of all birds, after the toothed jaws are taken into consideration, having undergone the most radical changes of structure in adaptation to an aquatic life (p. 385).

These two birds, Ichthyornis and Hesperornis, though not the only birds known from cretaceous rocks, represent the only complete skeletons yet discovered, and it is significant that they had already not only become adapted to different modes of life, but that, in the case of Hesperomis, this adaptation had attained a degree of specialisation exceeding that of any other known bird, with the exception of the Moa, fossil or recent.

The existence of these two very different types-the one a bird of powerful flight, the other not only flightless but wingless, only a vestige the upper arm remaining-points conclusively to a very extensive bird fauna at this remote period, though of the land birds naturally but few would be preserved, and these have not yet been discovered.

Furthermore, when the whole of the available fossil material comes to be examined, it is evident that the differentiation into land and water birds took place in very remote times indeed, dating from the Jurassic period, if not earlier. It is to the earlier Jurassic formations then that we must look for traces of the pro-avian types, for an insight into the beginnings of the evolution of the bird. And here, probably, if anywhere, we 
must turn to find that process of differentiation at work which evolved the several types of land and water birds, of which our bird fauna to-day are the descendants.

What these "pro-aves" were like we can only dimly surmise; and all our inferences must be inspired by and based upon that strange, kite-tailed form, Archæopteryx.

From what we know of the evolution of other types of vertebrates, we may safely assume that these ancestral birds were of small size, and were almost certainly also arboreal. And from the unmistakable signs of the shortening of the body in modern birds, the trunk, we may assume, was also relatively longer, as it certainly was in Archæopteryx. From these two inferences we may conclude with some degree of probability that these creatures, these birds " in the making," had substituted leaping for climbing about the trees, and from this there was but a short passage to leaping from tree to tree. In these movements we may reasonably suppose the fore-limbs were used for grasping at the end of the leap. The use of the forelimb for this work would naturally throw more work upon the inner digits, I-3, so that the process of selection would rapidly tend to the increased development of these, and the gradual decrease of the two outer and now useless members. Correlated with this trend in the evolution, the axillary membrane, the skin between the inner border of the upper arm and the body, became drawn out into a fold, while a similar fold came to extend from the shoulder to the wrist, as the fore-limb, in adaptation to this new function, became more and more flexed. While the fingers upon which safety now depended were increasing in length, and growing more and more efficient, they were at the same time losing the power of lateral extension and becoming more and more drawn together by ligament and muscle, and more and more tending to become flexed upon the fore-arm. And the growth in this direction was probably accompanied by the development of connective tissue and membrane along the post-axial or hinder border of the whole limb, tending to increase the breadth of the limb when extended preparatory to parachuting through space from one tree to another, long claws being used to effect a hold at the end of the leap; though to a less extent, the hind-limbs were also affected by this leaping method of locomotion, resulting in the 
reduction of the toes to four, and the lengthening and approximation of the metatarsals, $2-4$, to form a "cannon-bone".

The body clothing at this time was probably scaly, but with scales of relatively large size. Those covering the hinder border of the incipient wing, growing longer, would still retain their original overlapping arrangement, and along its hinder border would, in their arrangement, ap-

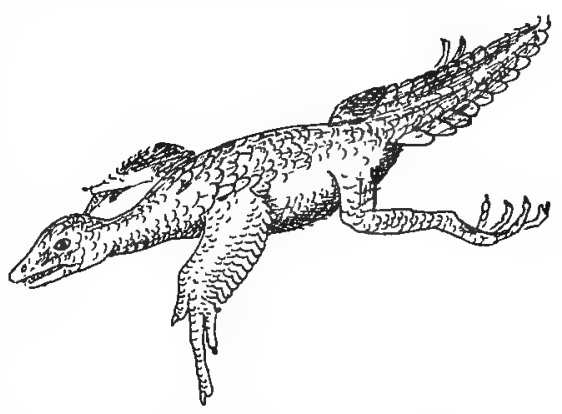

Ill. I2.-One of the Pro-Aves pearance, and function, simulate the quills of modern birds; as their length increased they became also fimbriated and more and more efficient in the work of carrying the body through space.

There is less of imagination than might be supposed in this attempt at reconstructing the primitive feather, inasmuch as there is a stage in the development of the highly complex feather of to-day which may well represent the first stage in this process of evolution.

Creatures such as are here conjured up would bear a somewhat close resemblance to the Archæopteryx; and it is contended that the discovery of earlier phases of avian development, the phases preceding Archæopteryx, will show that this forecast was well founded. But in Archæopteryx it is to be noted the feathers, so far as the impressions on the slab containing the remains of this bird enable us to see, differ in no way from the most perfectly developed feathers known to us.

While the external form and mode of life of these primitive, hypothetical types was slowly changing, no less fundamental changes must have been taking place with regard to the internal organs, more especially to the nervous, respiratory and vascular systems, changes in the direction of a larger brain in the one, and a more perfect system of oxygenating the blood in the other. This last was effected by the acquisition of a four-chambered heart, an approach to which has been made only in the Crocodiles among living reptiles. By the addition of this 
fourth chamber the high temperature and phenomenal activity of the birds came into being; but for reasons for which no explanation is yet forthcoming, the reptilian character of the blood corpuscles has been retained. That is to say, the red corpuscles still retain the nucleus in common with all the lower vertebrates, while in the warm-blooded Mammalia-also of reptilian descent-these nuclei have been lost.

But whether these pro-aves are to be regarded as descended, in common with the reptiles, as a collateral branch of the same stock; or whether they sprang from some primitive but true reptile, is a point too subtle to be determined. 


\section{CHAPTER III}

PHYLOGENETIC (continued)-THE CLASSIFICATION OF BIRDS IN BROAD OUTLINE-THE MAIN LINES OF THE EVOLUTION OF THE CLASS AVES.

Archornithes and Neornithes. The position of the Ostrich tribe in the system. What the structure of the bony palate reveals. Palæognathæ and Neognathæ. The classification of the Palæognathæ and of the Neognathæ. A hypothetical ancestor. The Grebes and Divers, Penguins and Petrels, Steganopodous birds, the Accipitres, the Anseres, the Alectoromorphæ, -the Gamebirds, Cranes and Rails, Plovers, Pigeons, the "Coraciiform" birds; the Passeres. Numerical strength.

RCH EOPTERYX naturally forms the starting-point
in any comprehensive system of avian classification,
since it represents the lowest, because most reptilian, of the whole Class Aves. Moreover, on account of its many structural and peculiar characters, it is by common consent set apart in a separate sub-class-Archornithes-as distinct from the Neornithes, the sub-class which embraces all other known forms.

Though the Struthious or Ostrich-like birds are, by modern systematists, regarded as the lowest, most primitive of this Neornithine branch or sub-class, they are not, by many, on this account looked upon as a natural group of birds; that is to say, as a group having a common origin. Rather it is held they must be considered as descendants of several distinct stocks-four, or perhaps five isolated groups whose relationship to the remainder of the birds is necessarily a matter for conjecture rather than dogmatism.

One of the strongest reasons among the older systematists for regarding this assemblage as one bound by ties of affinity was that all the members thereof had lost the power of flight, and with it the characteristic median plate, or keel, which, in flying birds, runs down the under surface of the sternum. Hence they were placed together to form the "Order Ratitæ" 
or "raft-breasted" birds. And, by way of qualifying this arrangement, it was pointed out that in the structure of the palate these "Ratitæ" differed fundamentally from all other birds, past and present. As a matter of fact the raft-like character of the breast-bone is of no real importance, no guide as to questions of affinity: it is a secondary, degenerate char-

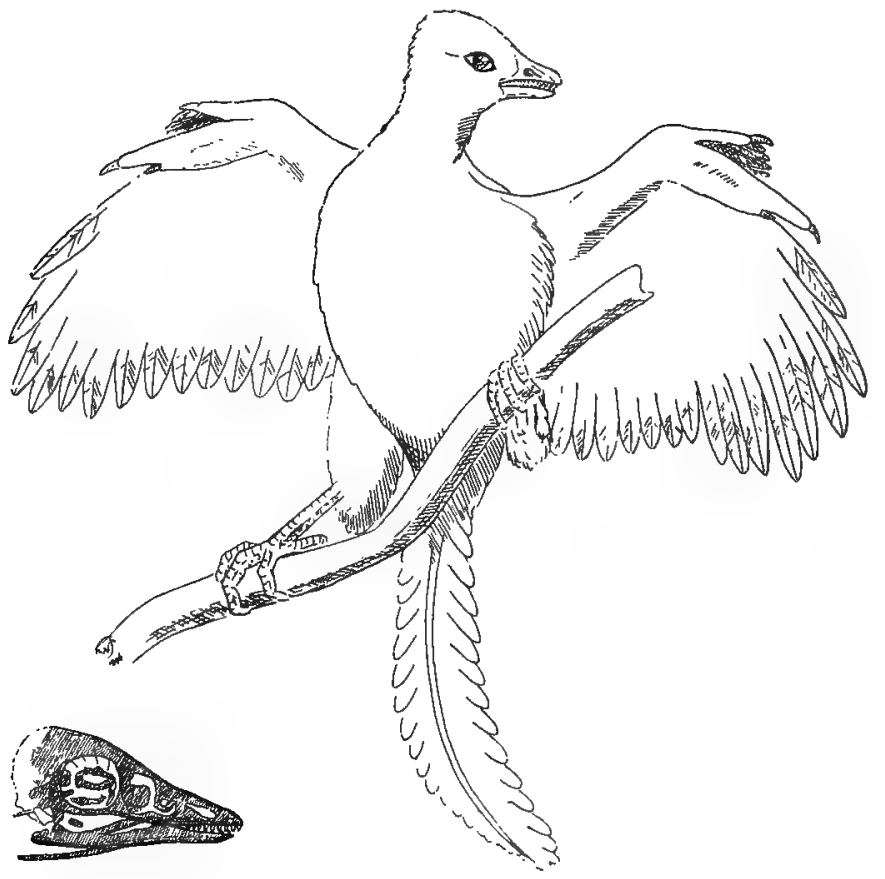

ILl. 13.-Restoration of ARChagopteryx (after Pycraft)

acter, which has been independently acquired by many birds, though in no case so completely as in the "Ratita". The structure of the palate is, on the other hand, of supreme importance in this connection. So far from being fundamentally different from that of flying birds, it is now clear, as the present writer has shown, that the palate in the flightless and flying forms is fundamentally similar. That this is so-a brief review of the main features of this palate, and its evolution, will make clear.

In the Emu and Cassowary we have this palate in its simplest form. Its chief characteristic is the enormous size of 
the vomer which is of considerable width, and extends forwards over the premaxillary and backwards as far as the middle of the pterygoids, embracing the anterior half of each by a pair of broad "feet". The palatines, it will be noticed (IIl. I4), are short, articulating on the one hand with the vomer and pterygoid where they overlap, and on the other with the maxillo-palatines, which are of great size.

The next phase of development is furnished by Rhea. The vomer is here also of great size but is deeply cleft in front, while the "feet" posteriorly are nearer together. Their relation to the vomer is precisely similar to that which obtains in Dromæus (Emu), though this fact is masked by the movement of the palatines which have shifted inwards, and in so.doing have come to rest under the junction between the vomer and pterygoid, concealing this when the skull is seen from the ventral aspect. In their relative size and shape the palatines differ but little from those of the Emu, but the maxillo-palatines are relatively much wider as the palatine processes of the premaxilla are also much longer.

The palate of the Tinamous carries us a stage further. The vomer is still large, and in its general conformation closely resembles that of Rhea. The palatines have, however, become relatively longer and rod-like: and while posteriorly, in their relation to the vomer and pterygoid, they agree with those of Rhea, anteriorly they have come into touch with the palatine processes of the premaxilla. The maxillo-palatines, it should be noted, have become relatively smaller than in $\mathrm{Rhea}$. So much for these three stages in brief outline.

Now compare any, or all three, of these palates with those of, say, a Gull and a Common Fowl. For clearness' sake let the comparison be made with the skull of the Fowl (Ill. I4). One of the first things to be noted will be the greatly reduced size of the vomer, which indeed is now little more than a vestige. It will next be noted that this reduced vomer has lost all relation with the pterygoid, and is borne by an ingrowing pair of plates from the palatines. These, moreover, it will be noticed, have now greatly changed, both in their relative position as well as in length and shape. Compared with those of Rhea and the Tinamous, they will be found to have extended forwards in the form of a pair of slender rods, wedged in between the palatine 
process of the premaxilla and the maxillo-palatine processes, in this last matter resembling the Tinamous. Finally, they
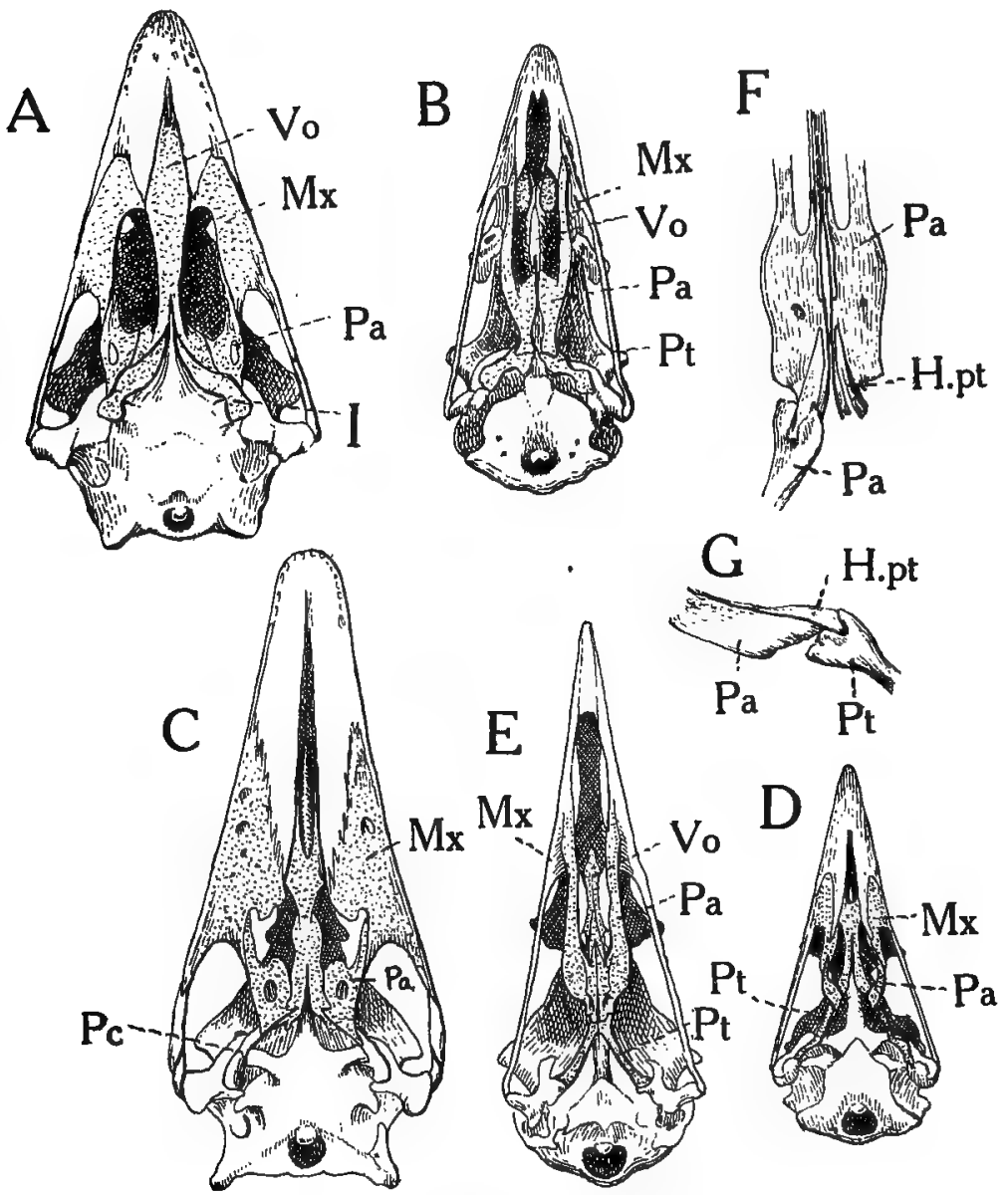

ILl. I4,-Stages in the Evolution of the Avian Palate

A, Dromæus. B, Gallus. C, Rhea. D, Tinamou. E, Larus. F, Portion of the palate of a Penguin to show the hemipterygoid, G, The hemipterygoid, side-view. $\quad$ Vo. $=$ Vomer. Mx. = Maxillo-palatine. Pt. = Pterygoid (I, Ill. A. Pc., Ill. $\mathrm{C}=$ Pterygoid). Pa. $=$ Palatine. H. pt. $=$ Hemipterygoid.

will be found to articulate with the pterygoids by means of a true joint-opposed bones having glenoid surfaces.

Now between the type of palate, as we have remarked, 
exhibited by the Struthious birds and that of the "Carinate" or flying birds, such as is seen in the Fowl, for instance, there appears to be a very wide gap.

A study of the palate of the nestlings of the "Carinate" or Neognathine group, however, will show conclusively that this gap is apparent only, and not real. In the skull of the young Penguin, for example, the palatine and the pterygoid articulate, not by a joint, but by overlapping suture ; the pterygoid terminating, moreover, in a spike which just reaches the forked ends of the vomer ; so that, in so far as this contact between vomer and pterygoid is concerned, Carinate and Struthious birds agree. But as growth proceeds the pterygoid segments, at a point corresponding with the level of the hinder end of the palatine, and shortly after this segmentation the spike-like anterior extremity of the pterygoid fuses with the palatine on which it rests, while a true joint is formed between the segmented surfaces. When this process is complete, all record of the earlier connection between vomer and pterygoid is lost, so that the palate appears to differ fundamentally from that met with in the Struthious birds. In some other species, as for example in the Petrels, the joint formed after the segmentation of the pterygoids is formed between the pterygoid on the one part and the pterygoid and palatine on the other: that is to say, the anterior end of the pterygoid segments at the level of the hinder end of the palatine instead of tail-wards of this point (compare illustrations.)

These two types of palate have been named by the author the Struthious "Palæognathine" and the Carinate "Neognathine". Concerning the latter more must be said later: for the present it is sufficient to point out the fact that the one has been derived from the other-the Neognathine from the Palæognathine.

But this by way of a digression. We must return to the question of the relationship of these Palæognathine forms one to arother. Owing to the paucity of material this is a peculiarly difficult problem, and one which, for the present at least, must be regarded as unsolved. That the Emu represents the most primitive member of the group few will doubt. And with the Emus we must reckon the Cassowaries. The Ostrich of Africa is probably nearly related. In the palate it shows degenerate 
characters, while in the matter of the hind-limbs and hip-girdle it has undergone extreme specialisation (p. 39I). In the pterylosis of the wing it shows more primitive characters, probably, than any other group. By many, the extinct Apyornis of Madagascar is regarded as a close ally of Struthio: but until more is known of the palate this must remain open to question; especially since the form of the hip-girdle, and of the nature of the hind-limbs differs so conspicuously from that of Struthio, and agrees rather with that which obtains in the New Zealand Dinornis.

The Rheas in the nature of the palate bear a striking similarity to Dinornis; but in the matter of the hip-girdle the two types differ fundamentally, Rhea, indeed, exhibiting characters in this region of the body that are absolutely unique (p. 392). By many, including the present writer, the Tinamous of the South American Continent are also to be included among the Palæognathæ, being possibly allied to the Rheas.

The remarkable Apteryx of New Zealand must, it would seem, be regarded as one of the mostaberrant of the Palæognathæ, though, by some, it is regarded as allied to the Moas (Dinornis).

The discovery of further and more complete remains, especially of the skull, of an extinct type from the Lower Eocene of Western Europe, now known as Gastornis, promises to throw a flood of light on the subject of the evolution of the Palæognathæ (Ratitæ), though according to some these remains are those of an Anserine bird, a conclusion which is probably wrong. Only a part of the skull is known, but this shows that the cranial sutures were persistent, or at least slow to close, and further, that the post-orbital region of the skull, as in the Cassowaries, was of considerable length.

The birds which exhibit the arrangement of palatine bones, here designated Palaognathine, should probably be regarded as representing some six or seven sub-orders (including Gastornis) of an Order Palæognathæ. Time may show that these sub-orders must be further reduced, since Rhea, the Tinamous, Æpyornis and Dinornis may prove to be descended from a common stock.

With the possible exception of Gastornis, the Palæognathr, both fossil and recent, are represented only by flightless forms, excepting only the Tinamous, which still retain the power of 
flight. Gastornis may also have retained this power: at any rate it possessed a complete furcula.

We must turn now to a broad survey of the "Carinate" or, as we prefer to call them, "Neognathine" birds-a formidable array, inasmuch as the remainder of the Class Aves is included in this review.

By the older systematists these were fancifully arranged so as to form a linear series. That is to say, they believed it possible to group the forms with which we are now concerned in a continuous series, the several types being supposed to pass the one into the other. But in such schemes, it must be remarked, the Struthious types were generally also included. Such schemes were of course founded on external characters alone.

More philosophical methods of investigation have shown, however, that no such continuity exists; but that we are dealing, not with a linear series, but with an intricate and at present tangled system of branching. To trace out these ramifications endless patience and research is necessary; indeed, the classification of the Class Aves on phylogenetic lines is one of the most difficult tasks which the ornithologist can be called upon to undertake. The attempt made by Dr. Gadow, based on, and inspired by, the monumental work of Professor Max Fürbringer, has much to recommend it; and no less valuable is the later work of Dr. Chalmers Mitchell. Though founded on a single set of characters-the convolutions of the intestines-and not offered as a solution of the problem of descent, this work shows a very remarkable grasp of facts and power of interpretation.

The writer of these pages has endeavoured to blend the labours of these investigators in setting forth the main principles of the classification of the Neognathæ, a classification which it is believed expresses more or less truthfully the phylogeny of the several groups.

Briefly the Neognathæ may be regarded as divisible into two great branches, traceable to a common stock. Each of these two branches again divides into two, giving us on the one hand what we must describe as the Colymbo- and Pelargomorphine branches, and on the other the Alectoro- and Coraciomorphine branches.

What the ancestral stock may have been like which gave 
rise to these two great branches we cannot, from lack of material, say as yet. That it was an offshoot from the Palæognathine stock is certain, and Dr. Mitchell contends that it is represented to-day by the remarkable aberrant Goose-like birds, Palamedea and Chauna, more commonly known as the "Screamers," natives of South America.

The descendants of this hypothetical Palamedia-like ancestor would seem to have given rise to a stock of great potentiality, which under the stress of the struggle for existence became more and more differentiated, more and more specialised as the necessity for adaptation to environment became more acute. These descendants, in short, gave rise to what we know to-day as the Neognathine birds, which, as we have already remarked, are divisible into two great groups.

Let us pass, in brief review, the essential features of the differentiation of the Colymbo-pelargomorphine group.

Of these, the oldest, the first to become differentiated from this generalised stock, appear to have been the Penguins, Grebes and Divers, including the extinct, giant, toothed Diver of the cretaceous epoch (p. 37), and the Petrels on the one hand; and the Anserine birds, Storks, and Accipitrine birds on the other. While these were in the making, yet a third group was developing which gave rise to types which are represented to-day by the Steganopodes-Pelicans, Gannets, Cormorants and Darters, Frigate and Tropic-birds. Dr. Mitchell contends that it was this same Steganopodous stock which gave rise to the Penguins, the Petrels, the Stork tribe and Accipitres, but this is a matter for debate.

Of the Penguins and Petrels we need say little here, the salient points in their evolution being discussed elsewhere in these pages. But of the Stork tribe it is necessary to say that this includes, besides the familiar Storks and Herons-commonly confounded with the Cranes-several less familiar and aberrant types; the Flamingoes, Hammer-head (Scopus), Open-bill (Anastonus), Spoon-bills (Platalea), Ibises and Tantalus Storks. being among the more or less isolated ciconiine or Stork-like forms, and the Whale-headed Stork (Balanicepo) and Boat-bill (Cancroma) among the Ardeine or Heron-like forms.

To return for a moment to the Steganopodous birds, it should be mentioned that it is to this group, in all probability, 



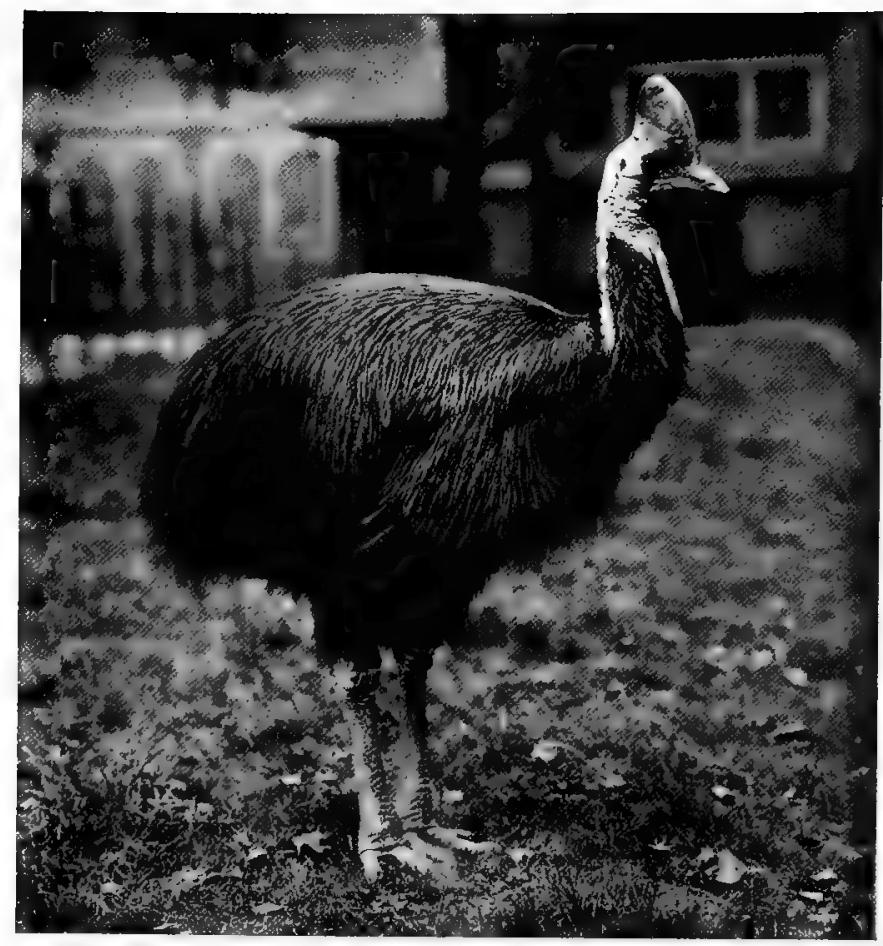

THE BLUE.NECKED CASSOWAKY

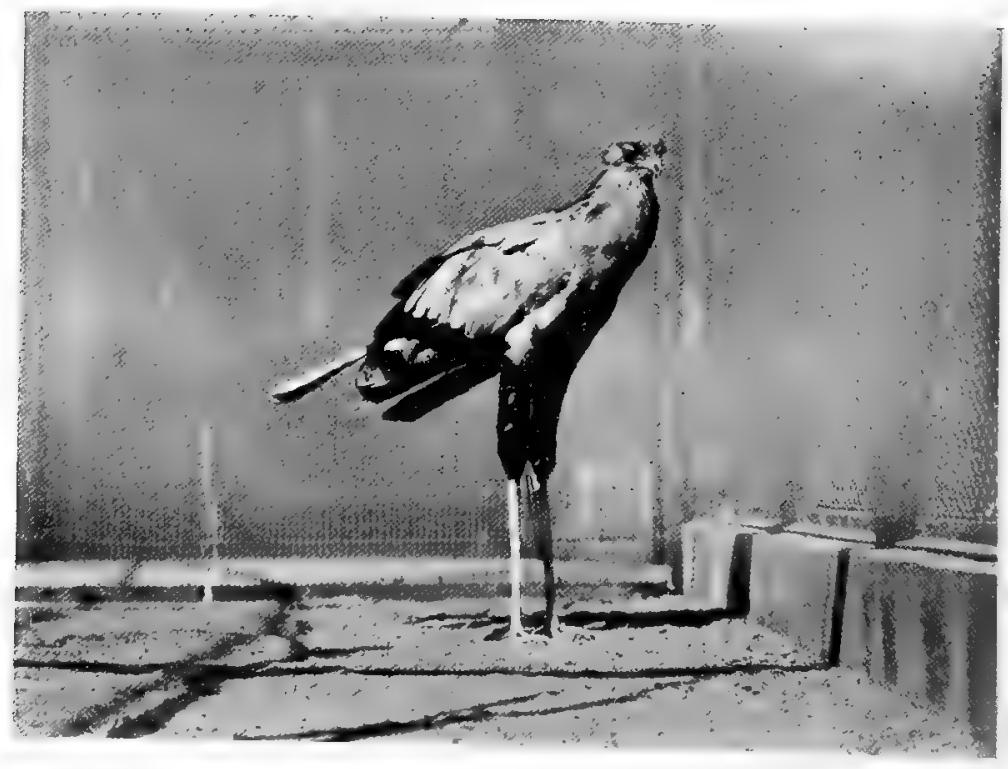

THE SECRETARX-BIRD 
that the extinct Ichthyornis and Odontopteryx belong. The first-named, as we have already remarked (p.37), was a bird of powerful flight, whose jaws were provided with a formidable armature of teeth, while of the Odontopteryx of the London Clay but little is known, save that the jaws were deeply serrated by a series of bony outgrowths of the edges of the jaw which were encased in horn.

According to some authorities the Accipitres are descended not from the Ciconiiformes but from a Gruiform stock, of which more presently. On the whole, however, the evidence seems to support the origin here indicated. The strange Secretary-bird (Serpentarius) on the one hand, and the Cathartæ or New World Vultures on the other, represent the most aberrant and puzzling of the group, and both have preserved many proofs of their primitive character. Of the more strictly, or more specialised, Accipitrine types we have three more or less distinct groups-the typical Eagles, Buzzards, Kites and Hawks; the Vultures; and the Falcons; the last being the most highly specialised of all.

The Cathartæ or New World Vultures probably represent a distinct branch, running parallel with the rest of the Accipitres, and descended from the same stock.

The origin of the Anseres, as we have already remarked, is not difficult to trace; inasmuch as they are probably descendants, if not of the archaic Screamers-Palamedea and Chauna-at least of the stock from which these arose. That is to say, the Screamers may either be regarded as the living representatives of the actual ancestors of the Anseres, more or less modified by time, or as an offshoot of these ancestors retaining most of the original characters thereof.

In two important characters the Screamers differ from the Anseres however. In the first place they lack the peculiar fleshy, horn-fringed tongue and the lamella along the edges of the beak, so characteristic of the Anseres; and in the second they have an extremely emphysematous skin, a character met with again, it is to be noted, among the Steganopodes. As to absence of the horny lamellæ of the beak and tongue. This is really not very important. Incipient lamellæ may well have been present in the earlier generations and have become eliminated later, while in the true Anseres they gradually 
gained in size in adaptation to the peculiar feeding habits of their possessors. That this is so a study of the jaws and tongues of the Anseres will show. The lamellæ in question are largest in the surface-feeding-ducks, reaching their maximum development in the Shovellers. In the Geese, which are vegetivorous, the lamellæ take the form of horny teeth, and these become still more tooth-like in the piscivorous Ducks. The fact, therefore, that lamella of the kind which obtain in the surface-feeding-ducks are found also along the jaws of the Flamingoes may mean, either that they have been acquired from the common ancestor of the Storks and Anseres, or that they have been independently acquired. This last alternative seems to have been the case among the Petrels, some of which, as in Prion, have lamellated beaks as well developed as in many Ducks.

In their pterylosis the Screamers are certainly primitive in that the apteria are but feebly developed, as in the Struthious birds, Divers, and Penguins. They furthermore resemble the Struthious birds in the convolutions of the intestines, and in the structure of the genital organs of the male. But this last character, be it noted, also obtains among the Anseres but not in the Flamingoes, which, according to some, are to be reckoned, as we have seen, among the Anseres.

As to the Anseres proper but little need be said here. Starting with the primitive Palamedea and Chauna we pass to the more typical Anseres which fall into three more or less sharply defined groups-the Swans, Geese and Ducks. Of these probably the Geese are the more ancient, for in one shape or another they retain many characters which must be regarded as primitive. Thus in some genera, e.g., Clophaga, the nestling wears a striped mesoptyle plumage: Anseranas has only partially webbed feet, and presents other characters indicative of a low position both in the skeleton and the convolutions of the intestines, though in the matter of its strangely convoluted trachea it is highly specialised. The Swans on the one hand, however, and the Ducks on the other must be regarded as offshoots of this Anserine stock.

We proceed now to a survey of the second great division of the Neognathre; and commence with that branch which constitutes what Dr. Gadow calls the Alectoromorphine legion. First of all must come the Galliformes-Gallinaceous types- 
which are divisible into two groups, according to the structure of the feet-A. Peristeropodes, B. Alectoropodes. In the first the hallux is large, and arises low down the metatarsal shaft, so that all four toes are on the same level; but besides this the skeleton displays less specialisation than is met with in group B., and this applies more especially to the sternum, shoulder and pelvic girdles.

Probably the most lowly of the Peristeropod forms are the Megapodes of the Austro-Malayan region. They are generally regarded as forming a distinct Family, the Megapodiidæ, while a second Family is made up of the Cracidæ-the Curassows and Guans of Central and South America, comprising some four genera and fifty species in all.

The group Alectoropodes embraces all the remaining Gallinaceous birds, which may well be included in a single Family divided into sub-Families, though this practice is not generally followed, the custom being to form several Families, and to divide these again into sub-Families. The more important types herein embraced are the Turkeys, Guinea-fowls, Grouse, Partridges, Francolins, Quails, Pheasants and Peacocks.

Anatomically the Galliformes are a very sharply defined group, and on this account it is curious that the Tinamous should so persistently be associated therewith, though this is generally done by those systematists who are guided only by superficial characters. As we have already shown, these birds should probably be regarded as Palæognathæ, though this view is not accepted by authorities of such weight as Professor Max Fürbringer and Dr. Chalmers Mitchell.

Two other types of doubtful affinity are commonly associated with the Galliformes. These are the Turnices and the aberrant Opisthocomus of South America. The former are small, Quail-like birds occurring throughout the warmer regions of the Old World. Presenting characters in common with the Galline birds, the Sand-grouse and the Rails, these birds should perhaps be regarded as an offshoot from the Galliform stock, though there is much to be said in favour of the contention urged by Fürbringer that these birds should be regarded as an aberrant type of the Charadriiformes.

As touching Opisthocomus, the Hoatzin of British Guiana, the evidence is conflicting, as may be judged by the fact that 
this most puzzling bird has been associated during recent years with the Galli, the Rails, the Pigeons, the Musophagi (Plantaineaters) and Cuculi, while earlier writers have made yet other attempts to indicate its place in the system.

The more remarkable characteristics of this bird are elsewhere discussed in this work, so that here it will be necessary to say but little. Osteologically it appears to stand near to the Galli, but Dr. Mitchell, on the evidence of the intestinal convolutions, considers it more nearly akin to the Pigeons. Into the bearing of other anatomical characters we do not propose to enter, since they have not been made to reveal any material evidence either one way or another.

The many-sided character of this bird is plain evidence of its isolated position, and we shall probably be near the truth if we regard it as an offshoot from the very base of the Alectoromorphine stem: hence the many resemblances between these now more or less sharply differentiated forms-the Cuculi, Galli and Pigeons, for all must be regarded as descendants of the same common stock.

The undifferentiated or "generalised" stock which gave rise to the Galliformes, developing along other lines, gave rise also on the one hand to the Gruiformes and on the other to the Charadriiformes.

The Gruiformes-Rails and Cranes-contain many aberrant and extremely interesting types. The Rails must be regarded as the more ancient of the two; thereof we may cite as examples the familiar Water-rail, Land-rail, Moor-hen and Coot, while besides these there are a number of flightless forms, as the Weka-rail (Ocydromus) and the extinct Aphanapteryx and Aptomis, and Gypsornis, not to mention others. The curious South American "Courlans" (Aramus) appear to represent the half-way house between the Rails and Cranes, though on this border line we must probably also reckon such archaic forms as the South American Trumpeters (Psophia), the Kagu (Rhinochetus) of New Caledonia, the Sun-bitterns (Eurypyga) of Central and South America, and the "Fin-foots" (Heliornis and Podica) of South America, West Africa and India (Assam to Sumatra). More remarkable in this connection is the Cariama or "Seriema" (Dicholophus), inasmuch as this bird by most of the older systematists was regarded as 
one of the Accipitres, and this on account of its rather close resemblance to the long-legged "Secretary-bird" (Serpentarius). There can be no doubt, however, as to its Gruine character, and it would seem that it is to be regarded as a near ally of the extinct giant Phororhacus, also of South America.

The Bustards (Ortalide) are certainly aberrant and isolated members of the Crane tribe, though by the older Ornithologists they were regarded as giant Plovers.

The true Cranes alone remain to be mentioned, and of them but little need be said here. The earlier systematists associated these stately birds with the Storks, a mistake which is commonly made to-day by those who judge merely from superficial appearances. Even by external characters, however, they may be distinguished, the Cranes having a relatively shorter, less cone-shaped beak, which is deeply grooved on either side, and has the nostrils placed nearer the middle than the base. Anatomically the difference between Storks and Cranes is so wide that there can be no question as to the distinctness of the two types.

The Charadriiformes, as has already been remarked, are close allies both of the Crane tribe (Gruiformes) and Fowl tribe (Galliformes), these three great groups being probably descendants of a common stock: though Dr. Chalmers Mitchell -the latest original contributor to this subject-prefers to regard the Gruiformes as an offshoot from the Charadriiform stem. But it must be stated, in justice to him, that this conclusion is based only on the evidence of the intestinal convolutions, and was never intended to be regarded as a definite decision. No one, indeed, would be less likely to allow the deductions from a single character to form the sole basis for determining so difficult a problem.

But be this as it may, this group appears to present two or three more or less sharply defined grades of development, and these again present within themselves many phases of specialisation.

There seems to be but little doubt but that the Curlews, Dunlins, Sandpipers, Avocets and Plovers, for example, must be regarded as the final stages in the evolution of the typical Plovers. More primitive are the Thick-knees or Stone-curlews (Edicnemida), Pratincoles and Coursers (Glareolide), Seed- 
plovers (Thinocorida) and Jacanas (Parrida), Crab-plovers (Dromadide), "Sheath-bills" (Chionidide) and the Gulls and Auks (Laridee and Alcide). With the exception of the Stonecurlews and the Gulls and Auks, these more ancient types are not generally very well known, save to the expert.

The Stone-curlews, by all the older Ornithologists, were recorded as closely allied to the Bustards, some of the smaller species of which they approach not only in size but also in their general coloration, and in the shortness of the toes. Nevertheless, there can be no question but that they are to be regarded as Plovers, in a wide sense, and not as members of the Gruiformes. The likeness which they bear to the Bustards is due in part to convergence, to the moulding influence of a like environment-dry heaths and wastes-and in part to their common origin. The Pratincoles are certainly not very Ploverlike in their general appearance, indeed they have been associated more than once with the Night-jars, and even with the Swallows! As might be supposed, they bear a superficial likeness to the Swallows on account of the length and shape of their wings; but a very cursory examination is sufficient to show their Pluvialine affinity. Nearly allied to these birds are the long-legged "Coursers" (Cursorius) of Europe, Africa and tropical Asia, one species indeed occurring as an occasional visitant to the shores of Great Britain.

The "Seed-plovers" or "Seed-snipes" of South America are no less un-plover like in their general appearance. Indeed from their general appearance they might well pass for some sombre-coloured member of the Fowl tribe, or Sand-grouse. In many of their habits indeed they also recall the Gallinaceous birds, nevertheless they are unquestionably aberrant Plovers.

The "Jacanas" (Parrida) again serve as pitfalls to the unwary, inasmuch as superficially they bear a much closer resemblance to Rails; and this likeness is rendered the more striking on account of the great length of the toes, which is further exaggerated by claws of enormous length.

Almost as puzzling, at first sight, are the Crab-plovers and Sheath-bills. The former are long-legged, black and white birds with a short, heavy beak. Maritime in habit they occur commonly along the East Coast of Africa from the Red Sea to Natal, as well as along the northern and western shores of 
the Indian Ocean. The "Sheath-bill" or "Kelp-pigeon" bears, as its name implies, a by-no-means Plover-like aspect, but rather a likeness to the Pigeons, which birds it further resembles in its flight and methods of courtship. Snow-white in plumage, it is remarkable in many ways, and especially on account of the peculiar tubular sheath which covers the base of the beak, giving the bird, in this particular, a semblance to the Petrels. Natives of the extreme south of South America, the Falklands, Crozets and Kerguelen, this Plover is essentially a bird of the seashore; it is frequently indeed found far out at sea, where it appears to be as much at ease in the water as more aquatic types, such as the Gulls for example. But this bird is further referred to elsewhere (p. 446).

These aberrant types are of extreme interest, representing, as it were, Nature's experiments at Plover-making. They are at any rate offshoots which started on their several roads to specialisation before the more typical Plovers began their evolution. And this also is true of the Gulls and Auks. By the older systematists, and some modern Ornithologists who judge solely by appearances, regarded as allies of the Petrels, the Gulls are nevertheless to be regarded as archaic but highly specialised Plovers, the Skuas representing the earlier and the Terns the latest phases of evolution.

Just as the Gulls were, and still are by some, regarded as allies of the Petrels, so the Auk tribe were, and are, regarded as related to the Divers (Colymbi). Yet they have not the remotest relation to these birds, but are on the contrary intensely modified Plovers adapted for an aquatic mode of life (p. 450).

By most authorities, and we think rightly, the Pigeons and the Sand-grouse are included in this assemblage of Plover-like birds. It is possible, however, that the older workers in this case were right who saw in these birds Gallinaceous characters. At any rate Dr. Mitchell holds that in so far as the evidence of the convolutions of the intestines is concerned the Pigeons and Sand-grouse, and that paradox the Hoatzin (Opisthocomus) of South America, are all derived from a common stem, running parallel with branches which gave rise to the Gallinaceous birds, Tinamous and Turnices (p. 75). We cannot, however, agree that other anatomical facts lend support to this view. 
The characters which the Pigeons and Sand-grouse share in common with the Plover tribe are indicative of a common descent. The several stems, in short, represent the splitting up of a common ancestral stock, indicated in the diagram by $B$ II., I, and this sufficiently explains the fact that the Pigeons would seem to incline more towards the Galli than towards the Plovers in the matter of intestinal convolutions.

We have arrived now at a very critical point in the problem of avian descent - the question of the relationship of the "Coraciiform" birds to the "Passeres," and the position of both with regard to the rest of the Neognathine birds.

As to the wider question: the weight of evidence seems to show that the members of this great group, collectively known as the Coraciomorphæ, must be regarded not so much as an offshoot of any other of the groups so far considered, as an independent stem of great antiquity: a derivative of that generalised stock whose descendants represent the Neognathine types so far reviewed. Yet there seems to be some sort of affinity, though remote, between the Coraciomorphre and the Gallinaceous birds, as if the two were to be regarded as having had a common origin, such as is indicated in the diagram B II., 2. If it be admitted that this interpretation is correct, there still remains for settlement the position of the Passeres. So far the evidence seems to show that they are to be regarded as derivatives of a Caprimulgine stock. But to this point we must refer again after passing in review the principal groups of the Coraciomorphæ.

\section{Main Lines of Evolution}

Before proceeding to the further sections of this work it would be well to briefly review the main lines of evolution which the avian stock has undergone. The earliest bird known, it will be remembered, was of a strictly arboreal type, and we have shown that it is almost certain that this had been evolved from an arboreal reptile stock. In other words, the Class Aves began its development as a forest haunting tribe. From this environment it appears to have spread to more open country. This migration must have been followed by material changes of form in adaptation to the new environment, the avoidance of new enemies, the capture of new food, the forma- 


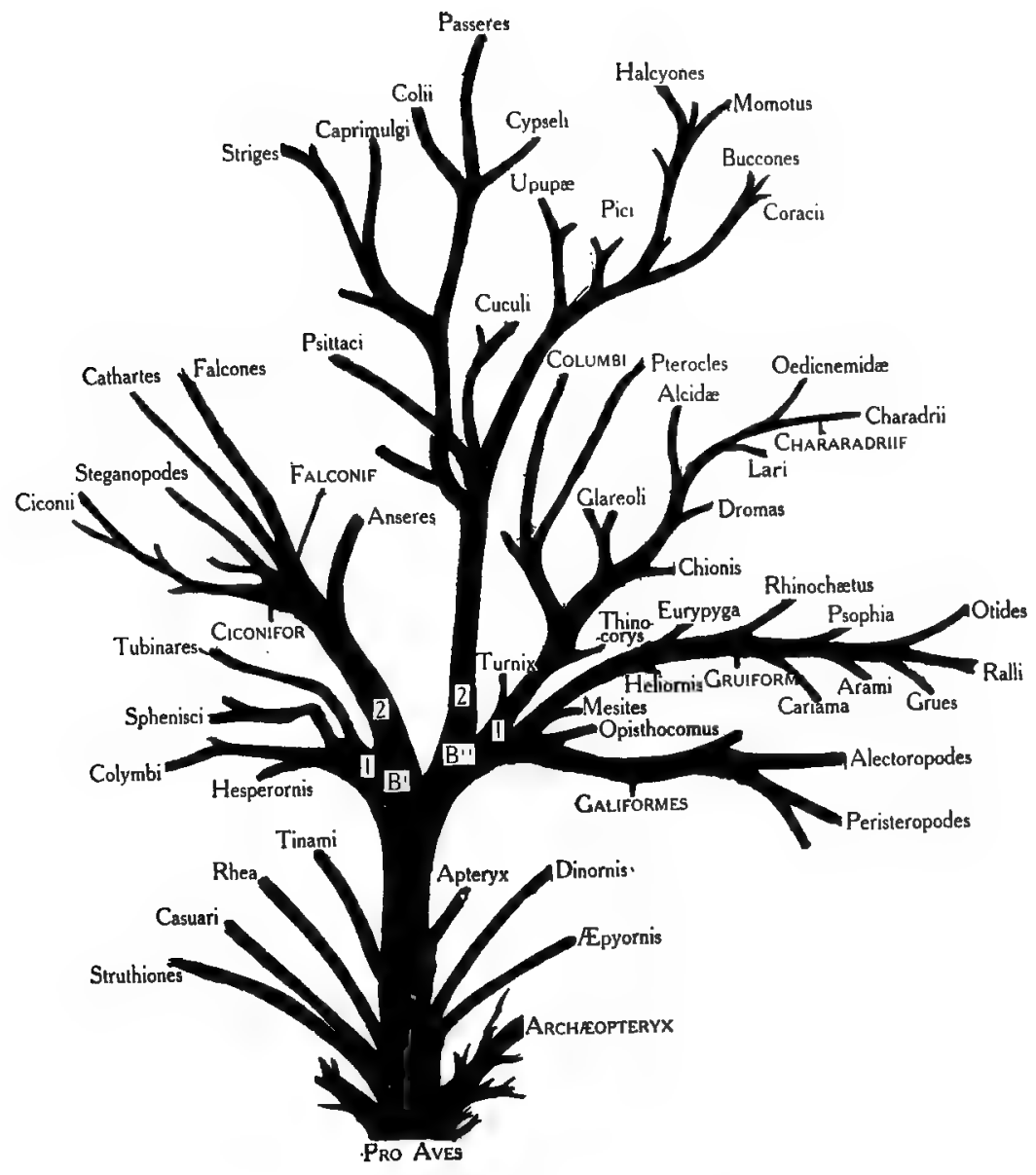

Ile. 15.-Phylogenetic Tree of Descent 

tion of new nesting habits, and so on. But of all this we have little or no evidence, except that, in all probability, the Ostrich tribe of to-day are the most primitive survivors thereof. So far as the evidence of fossil forms goes, however, it would seem that some of these terrestrial types must have found very early that the neighbourhood of water furnished the most suitable conditions of life, since, after Archæopteryx, the earliest known fossils are of aquatic birds, and this too of a remarkably specialised, intensified type. And it is significant that aquatic and semi-aquatic types dominate to-day, for, except the Gallinaceous and Raptorial types and the forms presently to be considered, all the rest of modern birds are either waders or swimmers, in greater or less degree, though here and there are isolated exceptions-such as the Bustards among the Crane tribe on the one hand, or the curious Dippers among the Passerine birds on the other. The principal types of these waders and swimmers we have already cursorily outlined, and they will be dealt with later in greater detail as occasion demands. As to the Gallinaceous birds, they are still essentially forest birds, or birds which frequent thick undergrowth; while the birds of prey have adopted a roving life, they are essentially birds of the air.

The Coraciomorphæ, to which reference has been made, make up a very heterogeneous collection, which may be divided into Passerine and non-Passerine, derived, there seems good reason to believe, from a stock nearly akin to the Gallinaceous birds, and this stock apparently split up at a very early date, inasmuch as their present-day descendants are for the most part separable into a number of sharply defined groups affording no very decided connecting links. Probably the oldest are the Cuculi-Cuckoos, and Plantain-eaters (Musophagi)-and the Parrots (Psittaci). They may be safely regarded as divergent branches of a common stem, which may be assumed to have its roots in that which gave rise to the Gallinaceous birds. In common with these two branches-the Cuculine and Psittacine, there came off a third, which, splitting up, gave rise to the Upupidæ (Hoopoes and Hornbills), the Pici (Woodpeckers), Capitoniidæ (Barbets) and the Coraciiformes, this last branching into the Coraciidx and Bucconidx (Rollers, Puff-birds), the Meropidæ (Bee-eaters), Momotidæ (Motmots) and Halcyones (Kingfishers). 
From the Caprimulgine stem there arose a branch which gave rise to the Striges (Owls), Cypseli (Swifts and Hummingbirds), Colii (Mouse-birds) and the "Passeres".

The Coraciomorphine stem should probably be regarded as extremely ancient. It is highly probable indeed that we should be near the truth, as we have already hinted, in considering it as arising from the same generalised stock as that which gave rise to the Pelargocolymbomorphine, and Alectoromorphine trunks.

Finally, the gradual splitting up and differentiation of this great Coraciomorphine stem has been largely due to adaptation and to the pursuit of food. And these adaptations we shall discuss in due course, at least in their more salient features.

\section{Numerical Strength}

In the matter of numbers the Class Aves far outnumbers all other vertebrates, since about I9,000 species are now known to science. It is significant to note that the Fishes approach nearest to the Birds in this matter, since between 8,000 and 9,000 living species are known. Of the Amphibia there are probably not more than I,000 species. Of Reptiles some 3,500 have been described, and of Mammals between 2,000 and 3,000.

This numerical superiority of the Birds and Fishes must be ascribed to the comparative absence of barriers to their distribution.

As to their past history there is little to be said, for the records of the rocks have revealed less on this head than on any other group of'vertebrates. Such fossils as are of importance, however, are described later in this work. 


\title{
CHAPTER IV
}

\author{
EECOLOGICAL
}

Peculiarities of distribution. Continuous and discontinuous areas. Zoogeographical regions. The northern and southern hemispheres and the origin of life. Some British birds and the lessons they teach in regard to the migration of animal life from north to south. Factors in the formation of isolation areas. The baunts of birds.

\section{Geographical Distribution}

$\mathrm{I}$

$T$ is a matter of common knowledge that in passing from one region of the world to another strange types of birds are sure to be met with, and it is commonly supposed that the tropics are especially rich in this respect. This, however, is by no means true, nor are the differences between the various types encountered in the different regions of the world correlated with the distance which separates these several regions. Thus, as has been more than once pointed out, the birds of Great Britain and Japan bear a remarkable likeness one to another, a much greater likeness than obtains between the birds of Africa and the adjacent island of Madagascar. Yet one-fourth of the circumference of the globe separates the first two countries, while the last two are divided only by a few miles!

Again, a very varied avifauna may be found within the confines of the same country; and this especially where the surface of the land is diversified by mountain and moor, forests, swamps and lakes. And when this avifauna as a whole comes to be more closely studied, it will be found to contain more or fewer types met with in no other part of the world, so that the area over which such forms are spread is to be regarded as forming a distinct zoological province.

The differences between the birds met with in any given country are due to gne or other, or a combination of several 
causes-temperature, food and physical peculiarities. Thus Woodpeckers, for example, will be confined to the forests, Bustards to the dry plains, Grebes and Divers to the lakes. In other words, any given species is to be sought for only in suitable spots within the distributional area, and these spots are known as the "stations" of the species within that area. Thus a clear distinction is to be drawn between the area of distributionthe "locality" or "habitat" of the species_and its "station". This last, as we have already hinted, is more often represented by a series of discontinuous areas-or isolated stations-than by one continuous tract.

Passing now to some of the more general peculiarities of distribution it is to be remarked that though, in surveying the habitat of any particular species one may expect to find that species in more or fewer numbers wherever suitable conditions occur, this expectation is by no means always realised. The curiously local distribution of birds like the Nightingale, Redstart and Stonechat, for example, among our British birds well illustrate this point, since these birds may be tolerably abundant in one place and yet appear to shun areas in the immediate neighbourhood which seem in every way suitable to their needs.

More remarkable still are those cases where the "stations" are not so many isolated spots dotted over a continuous area, or zoological province, but are separated by enormous distances, are scattered, in short, over one or more separate zoological provinces. These cases of "discontinuous distribution" are of peculiar interest, for they show, in the first place, that, in the majority of cases, species so isolated must have become so by the extinction of more or fewer intermediate "stations". Such widely sundered sanctuaries, so to speak, as isolation areas, play an even more potent part in the evolution of species than do stations dotted over a continuous zoogeographical area. But of this more anon.

Thus, then, it has come to pass that the Ornithologist, in studying the birds of the world--as one might study the people of the world-ignores political boundaries, and divides the surface of the earth according to the dominant and peculiar types of birds which are characteristic of such and such areas. The governing factors in this distribution are many-climate, 



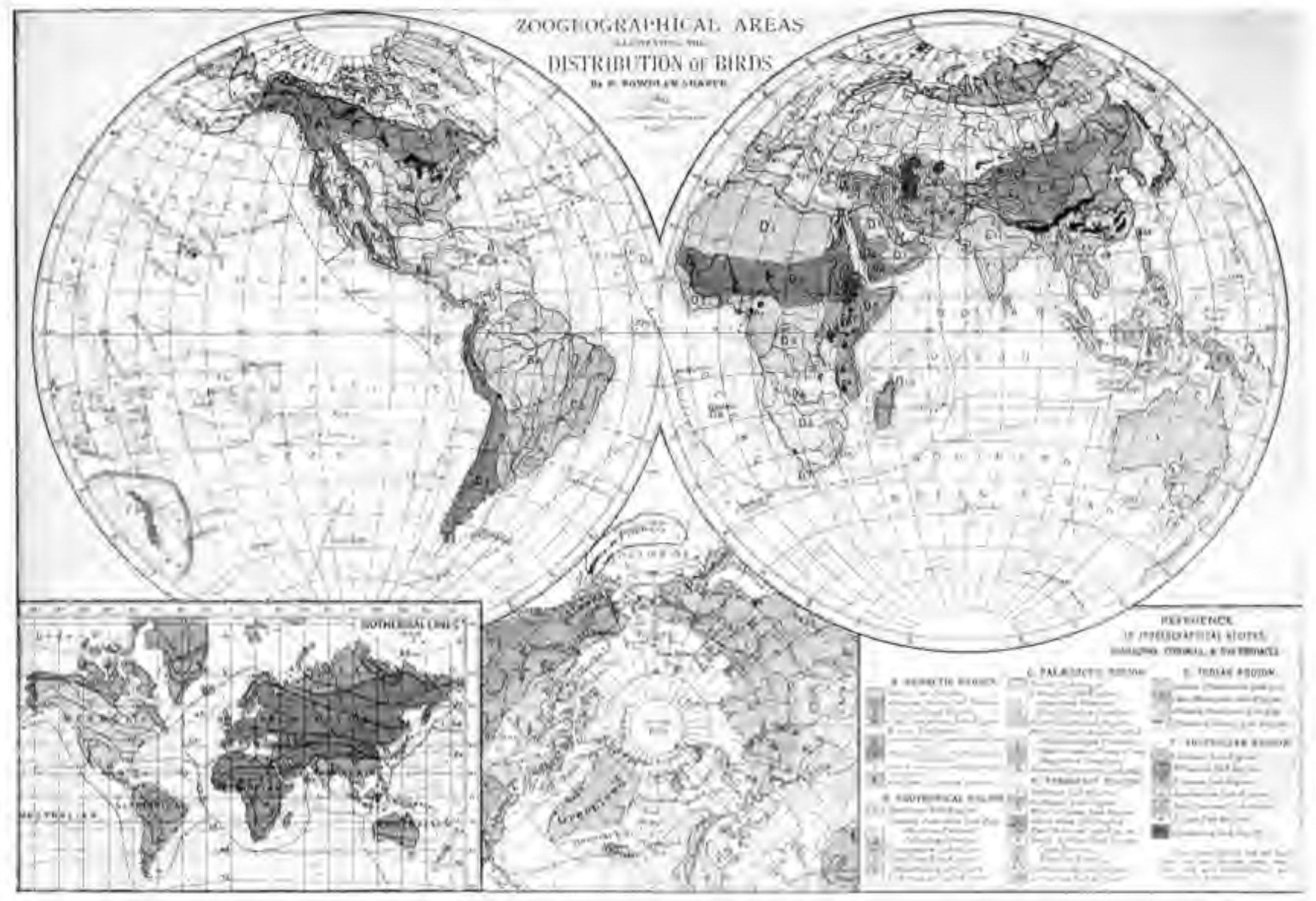


temperature, rainfall, vegetation, altitude; while lastly, but by no means leastly, we must reckon with the past-the upheavals and subsidences, and changes of climate which have done so much to change the relative proportions of land and water during the last million years or so. As the history of the rocks bear testimony, land was where now an ocean heaves and swells: what are now continents have more than once been submerged areas. And these upheavals and depressions, as the sequel will show, are responsible for many of the enigmas of distribution to-day.

There seems good reason to believe that birds, in common with other vertebrates, originated in the northern hemisphere and gradually travelled southwards, forming, as they moved, so many fresh centres of evolution and distribution. This hypothesis explains much that would otherwise appear inexplicable, and furthermore is supported by the fact that the earliest known fossil birds have been unearthed either in Northern Europe or Northern America.

With the formation of the existing continents migration became restricted, and new evolutionary centres came into being; and the number of these increased as the sea, from one cause or another, cut off more or less extensive areas of these continents to form islands, or as oceanic islands came into being and afforded new areas for colonisation. And thus it is that, as a general survey of the larger groups of birds will show, certain more or less distinct ornitho-geographical areas or "regions" may be distinguished. At the present time the regions generally recognised are the:-
I. Palæarctic.
2. Ethiopian.
3. Indian.
4. Australian.
5. Nearctic.
6. Neotropical.

By some authorities, and with much reason, the Palæarctic and Nearctic Regions are regarded as forming but one great " $\mathrm{Hol}$ arctic" Region. But be this as it may, these several regions are further divided into numerous sub-regions and provinces, the more important of which we shall now proceed to define. 
The Palæarctic Region embraces the whole of Europe and Northern Asia, its southern limit corresponding roughly with the $30^{\circ}$ Parallel of N. Latitude.

What may be called the typical birds of this region are the Grouse, Pheasants and Capercailzie.

It is divided by Dr. Bowdler Sharpe into five sub-regions :-

The Arctic Sub-region.-The first in this list comprises the inhospitable land above the Arctic Circle, with the northern islands such as Kolguev, Nova Zembla, Spitzbergen and Franz Joseph Land; while it extends southwards of the Arctic Circle to include Central Siberia and the mountain districts of Siberia. That is to say, this area is not determined merely by latitude, but by physical conditions-altitude, temperature, vegetation. Here dwell the Gyr Falcon, Steller's Eider-duck, Bewick's Swan, the Little Auk and Brunnich's Guillemot, while the Knot and Curlew Sandpiper, among the waders, continue to find, in this apparently forbidding environment, a safe breeding place, spending the winter in more southerly regions ; the Hawk Owl and Snowy Owl and the Snow Bunting, on the other hand, are permanent residents.

The Eurasian Sub-region includes the rest of Europe, most of Central Asia and Siberia to the Pacific at about Lat. $55^{\circ}$. No very remarkable types are characteristic of this sub-region. All the "British" birds occur here, as well as many continental types which do not occur in these islands.

In the Mediterraneo-Asiatic Sub-region are included the Mediterranean countries south of the Alps, and Carpathians, Persia, Central Asia and Thibet. As might be expected, in addition to typically Palæarctic birds, such as Crows, Chats (Saxicola), Warblers, Tits, Buntings and Larks, a mingling of African, Indian and Chinese forms are met with, such as the Glossy Starling (Hagiospar tristrami) and a Sun-bird (Cinnyris osea), which are African, and the Fishing Owl (Ketupa), which is Indian.

As touching the Manchurian Sub-region, Dr. Sharpe remarks: "From the Yangtze Valley north to about $55^{\circ} \mathrm{N}$. Lat. and eastwards to about Long. $100^{\circ}$ there are found so many remarkable forms of birds that a natural sub-region must be assigned to the area they inhabit". Not the least interesting feature of the birds herein met with is the fact that they closely 
resemble European birds, but yet differ sufficiently to be regarded as distinct species. Our British Rook, for instance, has become replaced by, or shall we not say, transformed into, the Chinese Rook (Trypanocorax pastinator), and our Jackdaw into the White-necked Jackdaw (Colous dauricus), while some forms, such as Pericrocotus and the curious Suthora, are met with in this sub-region, as also are the tropical Black-headed Kingfisher (Halcyon pileata) and the Blue Roller (Eurystomus calonyx).

The Himalo-Caucasian Sub-region is regarded by Dr. Sharpe as a well-defined sub-region of great importance. Herein he includes the Himalayas, in the higher ranges of which, above 8,000 feet, several genera are met with that occur nowhere else, such as the Snow-cocks (Tetraogallus) and the Hill Partridge (Lerwa). Since the Snow-cocks occur also in the lofty ranges of the Altai Mountains, as well as in the mountains of Northern Persia, the Caucasus and Asia Minor, these ranges are also included in this sub-region.

\section{The Ethiopian Region}

This great region includes the whole of Africa south of the Tropic of Cancer, and the islands adjacent to the Continent. The territory to the north of the Tropic of Cancer is regarded as belonging to the Palaarctic Region. Some authorities, however, contend that the Palæarctic area should not be extended beyond the Atlas Mountains.

Quite a number of peculiar types belong to this great region, such, for example, as the Ox-peckers (Buphagide), Madagascar "Starling" (Euryceros), the Wattled Ant-thrush (Philepitta), Plantain-eaters (Musophagide), Kirombo (Leptosoma), Colies (Colizda), the Secretary-bird (Serpentarius), the Guinea-fowls (Numidide), and last, but not least, the Ostrich (Struthio).

The Ostrich, indeed, is the most characteristic bird of the Ethiopian Region. Though at one time regarded as representing but a single species, at the present at least three are recognised-Struthio camelus, $S$. australis and $S$. molybdophanes. Some authorities further admit a fourth, S. massaicus. Since the distribution of these several species at the present day does not quite accord with the sub-regions presently to be described, they are referred to here as birds characteristic of the regions 
as a whole. "The Common or Northern Ostrich," writes Mr. Ogilvie Grant, " is found in Northern and Western Africa, and ranges eastwards to Abyssinia, Arabia and South Palestine; ... S. massaicus is found in East Africa, S. molybdophanes in Somaliland and Central Africa, and $S$. australis in South Africa." But it must be remembered that the Ostrich, though the characteristic bird of Africa to-day, was not always confined to this great Continent, since fossil remains thereof have been found in India and in Europe, a point to which we shall have occasion to refer later.

As to the number of sub-regions into which the great area should be divided opinions are divided. Dr. Sharpe recognises eight. These are :-

\author{
I. The Saharan. \\ II. Sudanese. \\ III. West African. \\ IV. Abyssinian. \\ V. East African. \\ VI. South African. \\ VII. Cameroonian. \\ VIII. Lemurian.
}

Of the Saharan and Sudanese Sub-regions the ornithology if practically unknown. So far we may say of the Saharan Subregion that it is the land of peculiar desert forms, conspicuous among which are Larks and Chats.

The Sudanese Sub-region includes the country to the south of the Sahara, extending northwards to Nubia below the Nile Delta and including the western and southern shores of Arabia, and the east coast thereof as far as the Straits of Ormuz. "There is evidently," remarks Dr. Sharpe, "a connection between the avifaina of Senegambia and that of Abyssinia evidenced by the occurrence in both countries of such birds as the Abyssinian Roller (Coracias abyssinica) and by certain of the Game-birds. It is a country of Francolins, Quails and Bustards. Many species of birds are peculiar to this sub-region, and here too many European migrants pass the winter.

The West African Sub-region extends from the forest regions of Southern Senegambia to the Gold Coast, and after a small gap çaused by the interposition of the Sudanese Sub-region at 
Accra, is continued practically without a break to the Cameroons, Gaboon and the Congo as far south as the river Coanza in Angola. Inland it extends to the western watershed of the Nile.

The genera and species of birds peculiar to this subregion are many, and of these the most interesting are perhaps the Cuckoo-falcon (Baza cuculoides), and the curious Black and Turkey-like Guinea-fowls of the Genera Phasidus and Agelastes respectively.

But beside these, in this sub-region we meet with genera both of Malayan and Indian types. Thus, of Malayan birds the curious Genus Turdinus is represented by several species. The Ant-thrushes (Pittida) are eastern types, occurring in greatest plenty in the Indian peninsula and the Himalayas eastwards to China and Formosa, and throughout the Malayan Archipelago as far south as New Guinea and Australia. The Flower-peckers (Dicade) again are Indian and Malayan forms, but they also occur in West Africa.

The limits of the Abyssinian Sub-region are by no means well defined, nor are the precise features of its avifauna easily demonstrated, though some 200 or more species are peculiar thereto. The most interesting of these is the bizarre-looking Shoe-billed Stork (Balceniceps). But perhaps the most interesting feature of the birds of this area is the occurrence there, as actual residents of its mountains, of the Alpine and Cornish Choughs! birds which occur elsewhere only in the Palæarctic Region. Here again is another instance of discontinuous distribution, another instance of the important part played by physical conditions in avian distribution.

Whether the East and South African Sub-regions will prove to be natural and well-defined areas is open to question. Time may prove that they will have to be ignored.

The Cameroonian Sub-region is remarkable in many ways, and especially in that it is made up of a series of isolated areas, consisting of the elevated mountains of Central East Africa, and extending north and south from the highlands of the lake regions and across to the peaks of the Cameroons on the west coast! Some of the more remarkable forms met with in this region have already been referred to.

The Lemurian Sub-region is characterised by a number of 
very remarkable forms, indicating a long and complete isolation for the areas here included. It is made up of the large island of Madagascar, and the adjacent Mascarene Islands-Reunion, Mauritius and Rodriguez, and the islands to the north, including

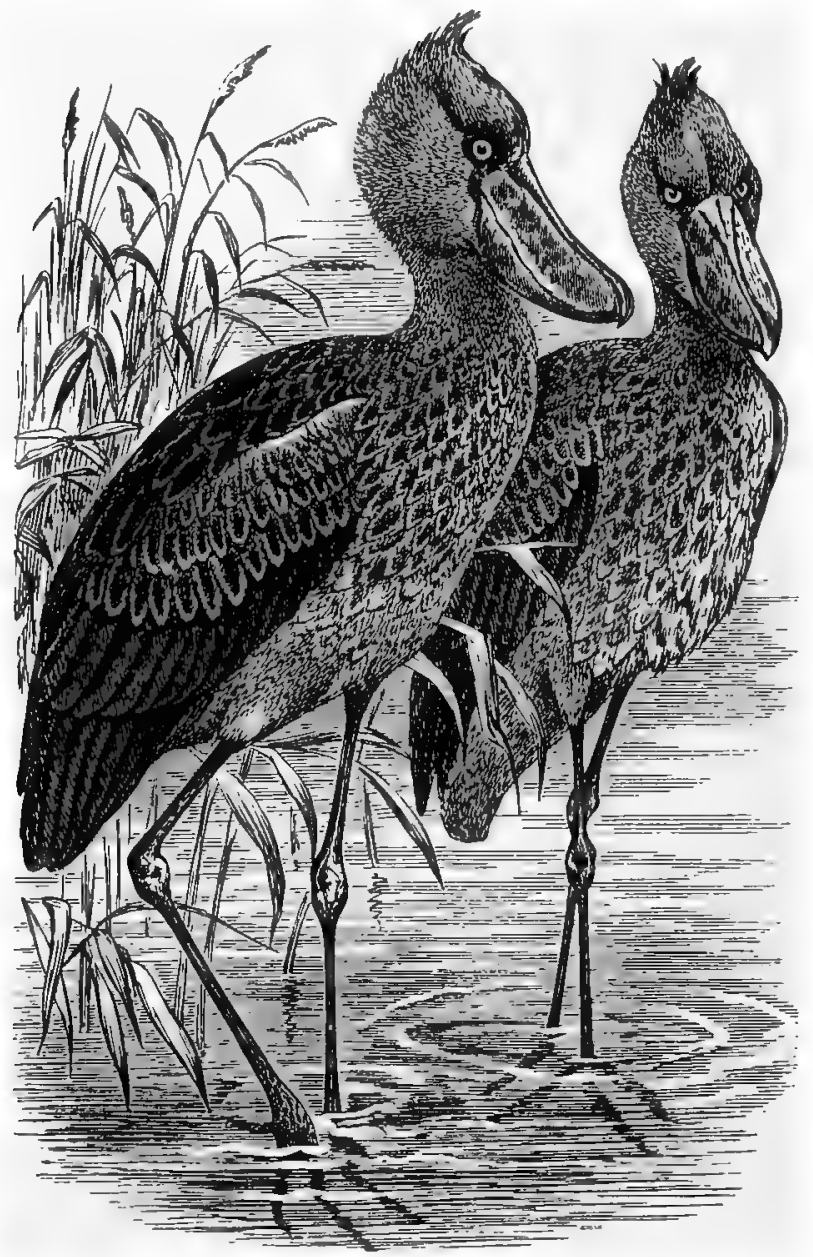

Ild. I6.-The Whale-headed Stork (Balaniceps)

the Seychelles. Of living and extinct birds the islands included in this sub-region possess a richer collection of distinct and peculiar types than any other region in the world, on which 
account some authorities regard the Lemurian as a separate, primary region.

Among extinct types may be mentioned the Giant Epyornis of Madagascar and the aberrant Giant Pigeons--the Dodo and the Solitaire of Mauritius and Rodriguez respectively. No less remarkable was the extinct Starling (Fregilupus) of Reunion. But beside these must be mentioned an extinct crested Parrot (Lophopsittacus mauritians) of Mauritius, and a very remarkable flightless Rail (Aphanapteryx) of the same island. On Rodriguez lived a Rail closely resembling Aphanapteryx (Miserythrus equati), a large brevipennate Heron (Ardea megacephala), a big Parrot (Necropsittacus rodericanus) and a small but peculiar Owl (Athene murivora).

Turning now to the living species, we have in Madagascar some 240 species, of which 129 are peculiar to it, and among these are no fewer than 35 peculiar genera. The so-called Madagascar Starling (Euryceros), more nearly allied to the Shrikes, the curious Philepitta, and the still more remarkable Mesites are found only in Madagascar. The Ground-rollers (Atelornis) and the aberrant Leptosoma also occur here.

The indigenous fauna of the Mascarene Islands has been practically "wiped out" by the inroads of civilisation. Mauritius and Reunion, lying within sight of each other, seem to have but three species in common, and there is one genus Oxynotus which is peculiar to these two islands, each possessing its own species. Rodriguez has now left to it but three species, all peculiar, and of which the Parrot (Palcornis exsul) is the most noteworthy. The land birds of the Seychelles are sixteen in number, and of these fourteen are peculiar.

\section{THE INDIAN REgION}

Though the Indian Region embraces an enormous area, and presents extremely varied physical and climatic conditions, yet it has produced no strikingly peculiar groups. Its avifauna indeed is made up, almost entirely, of genera and species to be met with in other regions, notably the Palæarctic and Ethiopian. The most aberrant group which occurs here is that of the "Broad-bills" (Eurylami), which represent the most primitive known Passeres; while the remarkable Paradoxornis, an 
aberrant Tit, and the strange Pink-headed Duck (Rhodonessa caryophyllacea) also belong to this region, and are met with nowhere else.

Nevertheless, when the fauna is studied as a whole more or less distinctly defined zoogeographical areas can be made out, though as to their number and boundaries authorities differ. Dr. Bowdler Sharpe, for instance, recognises no less than five Sub-regions, while the late Professor Newton admitted but three-the Himalo-Chinese, the Indian (proper), and the IndoMalayan. In the first and last, as may readily be perceived, Chinese and Malayan species respectively are conspicuous.

The Himalo-Chinese Sub-region includes the southern slopes of the Himalayas, from their base to the limit of the growth of trees, and beginning with Cashmere extends through Nepal and Bhutan, thence to the coast of China. It includes all Burma as far as the middle of Tennasserim, and for the rest its southern and eastern boundaries are those of the Asiatic Continent, while to the Chinese portion belong the islands of Hainan and Formosa.

This great sub-region is to be regarded as the great centre of distribution of the Pheasants, which include a number of striking though generally unfamiliar forms. For the most part strange in appearance, and often of marvellous beauty, they deserve more space than can be allotted them in these pages. It would be impossible, however, to do them justice in anything less than a monograph, and after all, this chapter is mainly concerned with the distribution of the various types of birds, and the relation which this distribution bears to the subject of evolution. The number of Pheasant-like birds which occur in this region, and are confined to this region, is remarkable; and not the least noticeable fact is the conspicuous place which the Himalayas hold as a distribution centre. A large proportion of the genera now to be enumerated is to be met with here. Here, for example, are to be found the curious Blood-pheasants (Ithagenes), and from thence they may be traced to the allied chains of mountains in North-West China. They are forest birds, living at a great altitude near the snowline. The wonderful Horned-pheasants of the Genus Tragopan are met with both in the Himalayas and in the hills of Assam and South-East China; while the marvellously beautiful 
Moonals or Impeyan-pheasants are confined to the Himalayas and the mountains of Assam and West China. The curious Fire-backed-pheasants of the Genus Acomus and Lophura are inhabitants of the mountains of the Indo-Chinese provinces and Malayan Peninsula and Islands. One of the most remarkable of all the Game-birds-the Lobed-pheasant (Lobiphasis) occurs only on the high mountains of North-West Borneo, the Lawas River, and the region of Mount Dulit. The Eared-pheasants of the Genus Crossoptilum-the sexes of which are peculiar among other things in being alike in plumage-inhabit the woods clothing the high mountains of Thibet, West China and Manchuria, living in flocks. The Silver and Kalij Pheasants inhabit the Himalayas and the hills of Assam and Burma, ranging from $I, 000$ to 9,000 feet. Besides these, mention must be made of the curious Koklass Pheasants (Pucrasia) and the Barred-backed-pheasant (Callophasis). The former range along the Himalayan chain from Afghanistan eastwards to Thibet, and the mountain ranges of South China and Fokien and Manchuria. The latter are represented by two species only; one, $C$. ellioti, from the mountains of South-East China, and the other, C. humia, from the Shan States.

The beautiful Golden-pheasant (Chrysolophus pictus) and the even more remarkable Amherst-pheasant ( $C$. amherstice) are conspicuous ornaments of this region, the Golden-pheasant inhabiting South and West China and Kokonoor, Lady Amherst's West China and Thibet. The wonderful Peacockpheasants belong to the Himalayan system of mountains extending from Sikkim to Tennasserim and Cochin-China, and thence to the Malayan Peninsula, Sumatra and Borneo, affecting forest country up to 6,000 feet.

Here is the home of the Pea-fowl which are represented by two species, the Common Peacock of India and Ceylon, and the Javan Peacock (Pavo muticus) of Indo-China and the Malay Peninsula. These are birds of the plains rather than of the mountains, which they ascend, however, occasionally. Plentiful in the plains of North-West India they will not long remain so unless some restriction is placed on their slaughter for decorative purposes.

Passing now to the Indian region proper, which includes the whole of the Peninsula from the base of the Himalayas to 
Ceylon, little to any profit can be said, for though much has been written on the avifauna of separate districts of this great area no general summary and analysis thereof has so far been made.

The Indo-Malayan Sub-region, which is made up of the Peninsula of Malacca, the great Islands of Sumatra, Java and Borneo, and the Philippine Archipelago, possesses a rich and interesting avifauna, though, it is to be noticed, it is remarkable not as the home of any peculiar groups of birds, but rather for striking species and genera, which are represented either in the Indian region proper, or in regions more or less remote therefrom.

Perhaps the most remarkable of all the birds to be met with in this sub-region are the Argus-pheasants, the Common Argus (Argusianus argus) of the Malay Peninsula ; Gray's Argus ( $A$. grayi) of Borneo, and $A$. bi-punctatus, the habitat of which so far remains a mystery. In Tonquin the allied crested Argus (Rheinhardius ocellatus) occurs.

\section{The Australian Region}

The Australian Region is one of peculiar interest since it is pre-eminently a region of islands, a region of isolation areas. It embraces not only the vast Continent of Australia, but all the islands of the Pacific lying between the Tropics of Cancer and Capricorn, except those lying to the west of a line passing between Lombok and Celebes and south of the Philippines.

The narrow strait indicated by the line just referred to does not exceed twenty miles in breadth, yet it must be regarded as one of great antiquity, and this because it is of great depth: the avifauna east and west thereof presents entirely different characters. The faunas of the two areas are-east and west of this line-as distinct as those of South America and Africa. A certain amount of interchange has taken place between the land areas adjacent to the dividing strait, but this was to be expected. The avifauna to the west of the strait is Indian, that to the east Australian.

Space forbids anything like an analysis of the genera and species peculiar to the Australian Region, or even of the Subregions Australian, Papuan and Polynesian, which some author- 
ities recognise. Let it suffice to say that here is the home of the Birds of Paradise and of the Bower-birds; of the remarkable Lyre-bird, and of the Emus and Cassowaries, concerning which last we have already had something to say. Many peculiar forms of Parrots occur here, and this region is also to be regarded as the headquarters of the remarkable "Brush Turkeys," or Megapodes. Some of the most remarkable of known Kingfishers and Divers belong to this region, and here also occurs that aberrant Crane the Kagu (Rhinochetus)a very strange form confined to the Island of New Caledoniaand that anomalous bird the Black Swan.

\section{The New Zealand Region}

While some choose to regard New Zealand as an Australian sub-region, others prefer to regard it as entitled to rank as an independent region, since it harbours the most remarkable and interesting of insular faunas.

Here, almost within historic times, lived the Moa; and here to-day dwells the curious and aberrant Apteryx. The remarkable and flightless Weka-rail, and the still more remarkable flightless Giant Gallinule Notornis are products of this region. The last-named was first described from fossil remains. A year or two later, to the delight and surprise of Ornithologists, a living example was found, and since, three others have been obtained. By some, however, the fossil remains are regarded as specifically distinct from these later captures. This determination, however, is open to question. The flightless Parrot known as the Kakapo is another of New Zealand's peculiar birds. This region, indeed, possesses a larger number of flightless birds than any other in the world; and this because the conditions of existence all tended to favour the development of such types, there being no carnivorous mammals to contend with, an abundance of food; and an equable climate. The Giant Moas, it must be remembered, were flightless; indeed, so long had they thriven in this condition that the fore-limb had actually become so completely suppressed as to leave not a trace of its existence behind. And besides this, we have to record a giant flightless Goose (Cnemiornis) allied to the Cereopsis Goose of Australia. The curious Wrybill Plover (Anarhynchus) and the equally strange Huia-bird must also be 
mentioned here. The Kakapo or Owl Parrot, by the way, is not the only peculiar Parrot of New Zealand, for here is the home of the Kea or Kaka, a bird which has acquired an evil reputation among the flock-masters of New Zealand on account of its alleged attacks on sheep.

Such, in brief, are the more striking forms of the New Zealand regions, but there are besides a number of peculiar genera and species which bear out what has already been said as to island faunas. We pass now to the

\section{NeARCtic REgION.}

The Nearctic Region, according to some authorities, as we have already remarked, should be regarded as forming, with the Palæarctic Region, one great zoological area known as the Holarctic Region. For convenience sake, however, it may be well to consider the Palæ- and Nearctic Regions as distinct, though the faunas thereof present a remarkable similarity.

Though by some the Nearctic Region extends southwards to Mexico, by others it is regarded as terminating at about Lat. $38^{\circ} \mathrm{N}$; ; the area south of this line to Mexico being distinguished as a separate region, or sub-region, according to fancy-the "Sonoran" Region. There are, however, no natural boundaries along the northern frontier of the Sonoran Region, and much intermingling of the faunas thereof naturally takes place. It is in short a by-no-means well-defined region.

A considerable number of the Passerine birds of the Nearctic Region occur also in the Palæarctic: such, for example, are the Tits (Parus), Creepers (Certhiicle), Wrens (Anorthura), Shorelark (Otocorys) and Wax-wing (Ampelus). But this region possesses a number of peculiar types, quite unknown in the Palaarctic Region. Such are the Hang-nests (Icteride), Greenlets (Vireonida), American Warblers (Minotiltide) and Tanagers (Tanagrida); and besides these there are others, such as Humming-birds and the "New World" Vultures, which are common to the Nearctic and Neotropical Regions, to the consideration of which we shall now pass.

\section{The NeOtropical Region}

The Neotropical Region includes the West Indian Islands and the whole of the American Continent from Mexico south- 
wards. In the richness of its bird-life the Neotropical surpasses all the other regions of the world.

Here are found the Ostrich-like Rheas and Tinamous, the curious Game-birds known as the Guans and Currassows, and the Hoatzin, the aberrant Goose-like birds known as the Screamers (Palamedea and Chauna), and those aberrant Cranes (Psophia and Aramus), the Seriemas and the Sun-bittern (Eury-

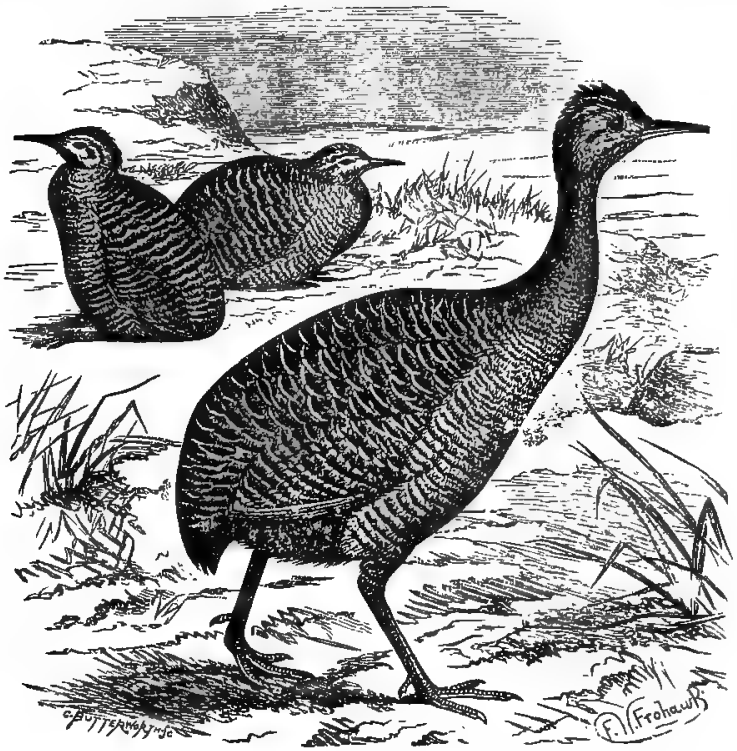

lLL. I7. - The Rufous Tinamou (Rhynchoins rufescens)

pyga). Among the Plover-like birds we find the Seed-snipe (Thinocorys) and Chionis. A host of peculiar Parrots, Cuckoos and Kingfishers occur here, and to these must be added Jacamars and Puff-birds, Toucans, Motmots, and a vast number of primitive Passerine types, such as the Manakins (Pipride), Chatterers (Cotingide), Plant-cutters (Phytotomida), Woodhewers (Dendrocolaptida), Ant-birds (Formicariida), Ant-wrens (Camopophagide) and Tapacolas (Pteroptochide).

But besides the foregoing we have the primitive Passerine Tyrant-birds (Tyrannidce), the Humming-birds and the "New World" Vultures (p. 454), which occur also in the Nearctic Region, and a number of other peculiar types which are found 
also in Africa, India and the Malayan Region, the distribution of which we propose to speak of presently.

Such, in brief, are the main outlines of the Zoogeographical Regions of the world. To have worked this out in fuller detail a whole volume would be required, and those who desire to acquaint themselves more fully with this subject should consult the works of such exponents of the subject as Russel Wallace, Sclater, Lydekker, Beddard, Heilprin, Sharpe and others.

In the earlier part of this chapter a reference was made to the phenomena of continuous and discontinuous distribution. Let us return now to a more careful, if brief, consideration thereof. The older writers held that similar forms occupying isolated areas were to be regarded as independently created forms, but this, in the light of modern biological science, cannot be regarded as a tenable hypothesis.

How, then, are we to explain the fact that certain families and genera of birds are confined to certain well-defined areas in Africa and South America, for example, on the one hand, and to Africa, India, the Indo-Malay Peninsula and Australia on the other?

This question has already been discussed by other writers at various times, and many interpretations of the riddle have been offered. Space forbids anything more than a bare outline of the two most probable of the suggested explanations of this matter.

Briefly, according to one hypothesis, these forms, in common with others of cosmopolitan range, originated in a great southern land area, circumpolar in extent, which, extending northwards, served during tertiary times to link together the several Continents concerned in this discussion. For this Continent Dr. H. O. Forbes-the originator of the hypothesis-suggested the name "Antarctica". It apparently followed the 2,000 fathom line extending northwards by broad expansions to join an old New Zealand continental island (including the Antipodes, Macquaries, New Zealand and Chatham, Lord Howe, Norfolk and the Kermadec and Fiji Islands); a second to East Australia and Tasmania ; a third to the Mascarene and adjacent islands; perhaps one to South Africa and finally one to South America.

The Trogons, Parrots and Struthious birds were cited by 
Dr. Forbes as groups which supported his contentions as to the southern origin of animal life, these groups, at the present day, being still essentially southern types. Dr. Forbes' contentions were, it should be remarked, not, however, based on the distribution of birds only, but of other groups of vertebrates as well. We are, however, concerned here only with the birds, and these do not support the theory of an Antarctic Continent.

In the first place, so far from the Trogons, Parrots and Struthious birds being southern forms which later spread more or less northwards, there is evidence to show that they are northern forms which have spread southwards, for fossilised remains of Trogons and Parrots have been found in Oligocene beds in France, while fossil fragments of Struthious birds, allied to the existing Ostrich, have been obtained from the Pliocene of the Siwalik Hills, the Government of Cherson, Russia, the Lower Pliocene of Pikermi, Greece, and from that of the Island of Samos in the Turkish Archipelago. The Secretary-bird (Serpentarius), now confined to South Africa, is represented by remains from the Miocene of Allies. More than this, the earliest known bird, the Jurassic Archæopteryx, was obtained from the Solenhofen States of Bavaria, while the only other remains of toothed birds have come from the cretaceous formations of North America, e.g., Hesperornis and Ichthyornis, and the Enaliornis from the Cambridge Greensand (Upper Cretaceous) of England. Besides these we have the curious Odontopteryx-a bird with strongly serrated jaws -apparently related to the Gannet and Cormorant, from the London Clay (Lower Eocene) of Sheppey, Kent, and fragments of apparently Ostrich-like birds, Gastornis, from the Lower Eocene of Western Europe; Dasornis, from the London Clay of Sheppey and Diatryma from the Eocene of New Mexico.

All these facts go to show that the northern hemisphere from remote times has been inhabited by a very rich and varied bird-fauna. And thence, in all probability, this fauna gradually spread southwards. The Penguins seem to be the only group of importance which has had a southern origin, and no species appear ever to have wandered north of the Equator.

That Africa and South America were at one period joined by a land bridge there is but little room for doubt, but this connection was probably between the westernmost portion of 
North Africa and the easternmost extremity of South America. Into the evidence for this, however, there is no need to enter here, as this evidence is supplied by the facts of mammalian distribution, and will be dealt with in the volume dealing with this group.

The peculiarities of avian distribution with which we are here concerned can be explained without the aid of a Southern Antarctic Continent.

There are some significant facts, furnished by existing species, which support this contention, and these are provided by some of our commonest British birds. The Nuthatches, for example, represented in Great Britain by the Common Nuthatch (Sitta coesia), ranges throughout Europe, North Asia, North America, India, China, Indo-Malaya and Australia. The Gold-crests (Regulida), represented by two species in Great Britain, range throughout Europe, North Asia and North and Central America. The Wax-wings in Europe and Asiaessentially northern types-pass into North America and then southwards into Central America. The Dippers (Cinclide) range throughout Europe and Asia, and crossing into North America-via North Asia-pass into South America.

Now it is significant to note that there are certain Families which occur in Southern Europe which range into Africa and India, pass by the Indo-Malay Peninsula into Australia, but which do not occur in America, as for example, the Bee-eaters (Meropida), and others, as the Bulbuls, Hornbills and Trogons, which are met with only in Africa, India and the Indo-Malay Peninsula. These possibly originated in southern latitudes, and hence did not find their way into America, as did those which originated in Northern Europe.

But there are some Families, such as the Barbets (Capitones) and Jacanas (Parra) which are found in Africa, India, the Indo-Malay Peninsula and Australia, and South America. The occurrence of these birds in South America may be due to the land bridge between Africa and South America referred to already.

Into the details of the distribution of these Families it is not the province of this chapter to enter, nor into the several species and sub-species, or geographical races, by which these Families are represented: our aim being to account for the discontinuous 
distribution which they present. The factors which caused the breaks in the continuity are naturally impossible to trace with any certainty, though occasional glimpses may be caught which may some day be turned to account.

A very potent influence in the formation of isolation areas is undoubtedly to be ascribed to changes in the plant world, caused in turn by river systems, and changes in the level of the earth's surface and consequent alteration in the condition of temperature, moisture and so on. Both insectivorous and vegetivorous birds are naturally vitally affected thereby, more particularly those which perform but limited migrations, or are non-migratory.

The study of the haunts of birds is the study of geographical distribution on a minute scale. Just as we look for Hummingbirds and Toucans only in America, Secretary-birds and Ostriches in Africa, and Lyre-birds and Emus in Australia, so we look for Petrels and Auks only in the immediate neighbourhood of the sea, Grebes and Water-hens in fresh waters, Grouse on moors, and so on. And we know that while some birds may vary their haunts according to the season, others appear unable to affect any change whatever, and are consequently the more endangered in times of stress. Little then can with profit be said with regard to the haunts of birds, for the theme is too discursive. But one point is certainly worth considering, and this relates to the bird-life of large woods and forests. One would expect that such areas would teem with bird-life, yet such is not usually the case. Forests of deciduous trees such as are to be met with only in temperate climates are notoriously poor in bird-life, only the outer fringe being at all thickly populated. But here the tree-dwellers are free to scour the surrounding open country in search of food, for within the gloomy interior of such forests insect-life is scarce, and edible fruits are rare. Coniferous forests harbour a few highly specialised species, such as Nutcrackers, Cross-bills and Wood-peckers. Tropical forests, from their more luxuriant growth, and the abundance of trailing, flower-bearing creepers, support a far larger and more varied avian population; but these dwell on the forest, rather than in it, as we shall show. 


\section{CHAPTER V}

SEASONAL LIFE. RELATIONS TO MOISTURE, TEMPERATURE, ETC., AND TO PERIODIC CHANGES IN THE COSMOSPHERE.

The bieaching effect of light. Desert forms. The effects of a saturated atmosphere. Arctic conditions. Size and latitude. Storms and drought.

\section{LTHOUGH much valuable information has been ac- cumulated as to the effect of light, moisture and temperature on the lower invertebrate animals, but} little in the way of close observation or experiment has been carried out with regard to the higher animals, and to birds in particular. In the following short account an attempt is made to bring together some of the more important facts which have been collected on this subject. These do not refer, however, to periodic, seasonal, climatic conditions, which will be discussed in another chapter.

As to the direct effect of the action of light, and weathering, on the feathers of living birds little seems to be known. It would appear, however, to have a decidedly destructive influence, not only destroying the colour, but also bringing about the disintegration of the horny tissue of the feather. This is well seen in the large quill or flight feathers of birds, such as those of the Plover tribe, which spend much time in exposed situations. These feathers, in the first place, if examined just before the annual moult takes place, will be found to have faded in just those areas which are left uncovered when the wings are closed, each feather, when the wing is extended, showing a silhouette of the feather next above it, a dark area representing the portion covered, and a distal light area representing the part subjected to "weathering". Disintegration seems to accompany this fading, and to take place most rapidly in those parts of the feather which are unpigmented. Thus, in many waders, as in the Curlew, where the darkly pigmented areas of the feathers 
have deeply incised margins filled in with white, the latter disappears, leaving a dull rusty brown feather with a serrated edge as is shown in Ill. 18. But Mr. Beebe, of the New York Zoological Gardens, made some experiments which seem to show, on the other hand, that strong light, in itself, may have the effect of intensifying colour. "I transferred," he says, "a male Purple Finch, which had for several years moulted yellow, from a dark cage to one which was exposed to bright sunlight, and in one moult the bird assumed his original normal colour". But this may have been due rather to the more vigorous health of the bird, following on the improved conditions of captivity. Loss of colour certainly cannot invariably be set down to the action of light, for it is well known that many brilliantly coloured birds become more or less pallid in captivity. This is especially noticeable in the case of Flamingoes which lose their wonderful rose colour and become almost white in Zoological Gardens.

The curiously bleached appearance of desert forms may possibly prove to be the result of intense light, or more probably light and a dry

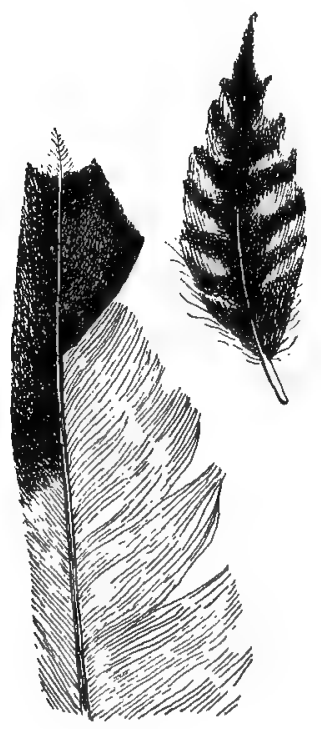
atmosphere accompanied by a high temperature, since the most pallid forms appear always to occur where the temperature is very high, and the air free from moisture. And it is well known that a sandy desert heats the atmosphere above it much more than a fertile tract or a watery expanse. As to the bleaching and the opposite effect of intensification, Mr. J. S. Whitaker, in describing the various races of crested Larks met with in Tunisia, remarks : "In their coloration and marking they vary according to the particular district inhabited; thus, 
roughly speaking, the birds frequenting the mountainous and more humid regions of the north are dark in colour, those found in the lower lying and drier central districts, paler, while those inhabiting the arid desert country of the south are isabelline or sand-coloured."

Captain Boyd,Alexander, on his return in 1907 from his remarkable journey across Africa, showed me a particularly interesting case of bleaching. This was furnished by a Nightjar (Caprimulgus claudi) which presented two phases-a light and a dark phase. The former is found only in open country away from the forest region-by Lake Albert-on ironstone rocks. The birds which exhibit this pallid hue are never found among grass or other vegetation, but pass their whole lives amid the rocks, which they so closely resemble in colour that they are invisible until approached within a couple of feet or less. The darker phase of this bird occurs towards the Gold Coast, on the borders of the forest, where there is a heavy rainfall.

Since desert conditions beget bleached forms it is not surprising to find that the opposite-a moist atmosphere-should produce dark-coloured types. A case in point we have just referred to, in the Night-jar. White-throated Sparrows and Wood-thrushes are said by $\mathrm{Mr}$. Beebe to become "almost like Blackbirds in colour when confined in a bird-house where the air was constantly moist". "A South American Pipit," he continues, "the individuals of which passed their lives on very circumscribed plots of earth, exhibit two colour forms entirely different, and thought to be due solely to the amount of moisture in the ground on which it lives. Very dark coloured and very pale individuals live within a few hundred yards of each other, in dry and swampy stations respectively, each, it is said, keeping entirely to its own little beat!"

Mr. Whitaker has drawn attention to the fact that the Skylark (Alauda arvensis), which is found in the marshy Roman Campagna, is exceedingly dark in colour, so much so as to form a distinct race.

Similarly in the Galapagos Islands, where the climate is damp, the birds are remarkable for their dark coloration. That this is due to the humidity of the climate is clearly demonstrated in the case of two species-a Short-eared Owl (Asio galapagoensis) and a Night-heron (Nycticorax pauper), inasmuch 
as the former is, save for its darker hue, indistinguishable from the Common Short-eared Owl (Asio brachyotus), a bird which ranges over well-nigh the whole world, and is known in Great Britain as the Woodcock Owl, while the Night-heron is similarly only distinguished from the South American Violaceus Night-heron ( $N$. violaceus).

Mr. J. A. Allen has brought to light some extremely interesting facts with regard to the relation between changes of colour and meteorological conditions. An intensity of pigmentation occurs, he points out, with regard to American animals, from North to South, coinciding with the intensity of the sun's rays and the increase of humidity. The increase in colour observed in birds on passing from East to West points to the same factors, "the darker representatives of any species occurring where the annual rainfall is greatest, and palest where it is least". In Europe the same phenomena obtain. Birds from the Scandinavian coast are much darker than in Central Europe, where the rainfall is only half as great. And similarly, British races of birds are darker than the Continental forms.

Wallace, among others, has contended that light, heat and moisture have no influence on the coloration of animals. Without in this place entering further into the reasons he advances in support of his views, we may remark that the evidence is overwhelmingly against him. That wherever individuals of a widely distributed species settle down and become more or less sedentary, there that species takes on the characters of "local" or "geographical" races, paler or darker, than the parent form, according as they settle in a desert or a marshy area. There is no need here to add to the number of cases which could be cited to show the importance of the action of light and dry heat, and of the effects of a deficiency of sunlight and excess of moisture on coloration. We have chosen the Galapagos to serve as an illustration for other reasons which will be apparent later.

It is generally believed that the bleached appearance of desert forms is the result of the action of natural selection, whereby all dark coloured, and therefore conspicuous forms, have become weeded out by predatory foes, while those individuals which tended towards the development of light plumage survived, in proportion as they harmonised with their surround- 
ings. To this we shall return in a later chapter. But here we would remark that the evidence seems rather to show that the action of natural selection followed another line-the physiological reaction of the organism to heat and a dry atmosphere, which seem, in some way, inimical to the production of pigment, except in a dilute form such as would give rise to pale coloration. How much is due to the direct action of the sun's rays on the ceratin which forms so large a portion of the superficial part of the feather remains to be discovered. But it would seem that this is a factor to be seriously considered. That there is a direct relation between high temperature and a dry atmosphere on the one hand, and weak pigmentation on the other, seems certain.

To suppose that the phenomenon of bleaching as here set forth is a concession to Lamarckism would be to fall into a grievous error. The reduction of colour is due either to the selection of individuals with reduced powers of pigment secretion which may be correlated with other qualities necessary for. such an environment, and therefore be of blastogenetic origin; or it may be somatogenic, that is to say, a purely physiological phenomenon, impressed anew upon each generation; in other words this coloration is not transmissible.

Let us pass now to a review of the evidence as to the opposite relation between extreme cold and pigmentation.

As is well known, the birds of Alpine and Arctic Regions are commonly white, at least during the winter months, while during the rest of the year they may wear a plumage quite richly coloured. The Ptarmigan and Willow-grouse are cases in point. These birds, at the approach of winter, gradually discard their richly mottled plumage and assume a dress of pure white, though it has been stated that this white dress is assumed, not by a moult, but by the ingestion of the pigment of the feathers by phagocytes. This, however, does not appear to be supported by fact, for in the first place the moulting has been watched repeatedly, and in the second it seems improbable that phagocytes would be able to make their way up the tissue of a feather. That this whiteness is the direct result of a nicely sensitive reaction to cold is shown by the fact that the change varies in completeness according to the intensity of the stimulus. But since it does not manifest itself in all Alpine and Arctic 
birds there must be some other governing cause at work demanding this change, but this so far has eluded discovery.

The naturalist Allen, to whom we have already referred, showed that in the birds of North America there is increase in size from the southern towards the northern regions, where, in the northern forms, this increase is correlated with an appreciable decrease in colour. This increase in size from the south northwards appears to be true not only of individuals of the same species, but also, as a rule, the largest species of each genus are to be met with in the north. But there are some exceptional cases, however, in which the increase in size is in the opposite direction. This apparent contradiction Allen suggests may be explained by assuming that the largest forms are found in the area from which the species took its originthat is, if the species arise in the north then the northern forms will be largest, if in the south then the reverse is the case. The increase in size northward is, however, less common than in the opposite direction. In species whose breeding area covers a wide range of latitude the northern birds are not only smaller, but have a different coloration, as in the Common Quail, Meadow Lark, Purple Crackle, Red-winged Blackbird, Blue Jay, Crow, Titmouse, and numerous species of Finches, Warblers and Thrushes, the variation amounting to as much as from Io to 5 per cent. of the average size of the species.

Possibly this decline in size as the species wanders further from its area of origin is due to the fact that the new conditions encountered during the migration grow less favourable as the distance between the ancestral home is increased. That is to say, those which remain in the area of origin have become so completely adapted to their environment that an increased size has become possible. And the huge bulk attained by certain island forms which have become largely freed from the struggle for existence seems to support this view.

But Allen further contends that in birds the peripheral parts-the beak, claws and tail-also increase towards the south. That in passing from New England to Florida the beak in slender-billed forms becomes larger, longer, more attenuated and more decurved; while in short-beaked forms the southern individuals have larger and thicker beaks, although 
the birds themselves are smaller. This increase, however, is not so much due surely to climatic conditions as to adaptation to feeding and other inevitable changes in the environment. In supporting this view we may cite an instance of this kind given by Mr. J. S. Whitaker. Writing in his Birds of Tunisia, he says of one of the crested Larks (Galerida cristata macrorhyncha) it "shows considerable variation in its colouring, according to the particular district it inhabits. To a certain extent it varies in other ways as well, notably in the size and shape of its bill, the modification of which is presumably brought about by the nature of the soil in which the bird finds its subsistence, a soft sandy soil calling for a long, fine-pointed bill, while a hard gravel or rocky soil requires a shorter and blunter bill." $\mathrm{He}$ further points out that the small-beaked group of crested Larks shows a greater variability generally than the large-beaked group. And this he says "is no doubt due to the fact of the former having a wider and more extended range in the Regency (Tunisia) than the latter. The smallbilled crested Larks are to be found universally throughout the country, and frequent the hills and high plateaux, as well as the lower ground, whereas the larger-billed birds are confined to certain districts, and are, as a rule, only to be met with in the plains."

The foregoing facts seem to leave but little room for doubt but that birds are directly affected by climatic conditions, that they react to the stimuli of temperature and moisture, for example, when long continued. Moreover, it seems clear that similar stimuli produce similar results in widely different species, when, be it noted, these are sedentary species, though all are not affected to the same degree.

But the climatic conditions here referred to are such as are uniform and long-sustained. Climatic conditions, however, are nowhere absolutely stable. Periodic or seasonal changes and sporadic, meteorological periods of inclemency occur everywhere, and these two factors exercise a very important part on avian life the world over. They play an important part in the geographical distribution of species; and they further serve to eliminate all but the most perfectly developed individuals, all but those which are exceptionally well adjusted to their environment, or those which can contrive to tide over times of 
stress by superior cunning or intelligence; or by sensibly reducing the number of a species which in other ways affect the balance of nature.

A few illustrations relative to this aspect of the effect of natural conditions will contribute more towards indicating what is meant by the influence of climate and weather than a long dissertation.

After great storms along our coasts great numbers, sometimes thousands, of Razor-bills, Puffins, Guillemots and Little Auks are picked up along the shore, or are found floating at sea. These victims succumbed either to the buffeting of the wind and waves when fishing, or to their inability to procure any food at all. Only the very strongest birds survive such visitations; while young birds of the year are especially noticeable among these dead.

During the winter months great numbers of Starlings cross over from Great Britain into Ireland, and should severe weather-frost and snow-set in, these numbers are enormously increased. As the cold wave moves westwards the birds flee before it. "All day long," remarks Mr. Ussher in his Birds of Ireland, "the race for life has been watched streaming towards Kerry, whose peninsulas and islands enjoy that freedom from frost which makes them the last resort of the refugees. After the snowstorm of February, I895, the Rev. W. S. Green, on visiting the cliffs of Moher, in Clare, found cartloads of dead Starlings, chiefly on the landward side of the fence that ran along the top of the cliff . . . but the strangest observations made at this, the most western island of Donegal, and at Eagle Island and Blackrock, west of Mayo, are of flocks flying west, as though to perish in the Atlantic."

Periods of drought are no less disastrous; and the same is true of volcanic eruptions, though these last are happily extremely rare. Nevertheless, within the last few years several species of birds are known to have been exterminated from this cause only. Thus, the eruption of Mount Pelée on Martinique and La Soufrière on St. Vincent have exterminated the Thrushes (Myadestes sibilans) of St. Vincent, Myadestes genibarbis of Martinique, Cinclocerthia gutturalis and Rhamphocinclus brachyurus of Martinique, as well as the magnificent Parrot (Chrysotis guildingi) of St. Vincent. 
Storms and droughts, and cataclysmal disturbance, however, though they very materially affect bird-life, do so for the most part only indirectly. That is to say, the shifting from one area to another, and the mortality to which reference has been made, are not so much due to these adversities as to the lack of food or the inability to procure it.

Since birds neither æstivate nor hybernate-though the older naturalists were convinced that the Swallows and some other birds really did hybernate-such species as cannot obtain a sufficiency must wander till they find this. With some species such wanderings are limited to a relatively small area, but with others vast distances are annually traversed on this account: though there are many cases, to which reference will be made in due course, which seem to be prompted by some other motive.

These periodic movements constitute the study of migration. 


\section{CHAPTER VI}

\section{MIGRATION}

Kinds of migration. Routes. The height at which birds fly, Speed. Lighthouses and their influence. Erratic migration. Causes of migration. Meaning of migration.

T $\mathrm{N}$ whatever part of the world the Ornithologist may live there he will find birds : and further that the birds of any given area may be divided into two more or less well-defined classes-the resident and the migratory. That is to say, that the ranks of the resident population are constantly receiving new-comers, either in the shape of stragglers which appear suddenly and as suddenly vanish, or of large bodies of more or fewer species whose appearance and disappearance is periodic and apparently governed by the seasons. Of these larger bodies of wanderers, some may stay but a short time, others may remain for months. And thus there will inevitably arise the question-What governs the movements of these migrants? To this at present no really satisfactory answer is forthcoming, we must perforce remain content with speculation.

For reasons more or less obvious, it will be best, in considering this difficult subject, to confine our remarks, in the main at any rate, to observations on this theme made on the birds of the British Islands : they may safely be regarded as a guide to what obtains in more remote regions of the world.

First of all as to casual vagrants. The ever-increasing list of birds new to the British list shows that these are fairly numerous. With the largely increased army of keen observers the number of species of birds new to Great Britain is not only steadily increasing, but the number of records for each of these "new species" seems to be increasing also. The spring and autumn, it is to be noticed, are the seasons when these vagrants most generally make their appearance, and it is further to be 
noticed that immature birds occur the most frequently. Such wanderers would appear to have been blown out of their course while journeying towards some distant goal. They may represent species common in parts of Europe in close proximity to our own shores, or individuals from the far distant North America. These latter, as the late Professor Newton has remarked, are of species which breed in somewhat high northern latitudes. "On their way thence to their winter-quarters, some are driven out to sea by violent westerly gales-the strongest winds, be it remembered, that prevail in the North Atlantic, and thus strike the coast of Norway.... Such storm-beaten wanderers there consort with the allied species to be found at that season in abundance on its shores, and in their company pursue the same southerly course. With them they cross to the east of Great Britain, and once arrived here are speedily picked out and secured by the practised gunner. But should they even escape his notice, they with their comrades follow the shore-line, where they obtain the best supply of food, until passing round the South Coast they find themselves at the western extremity of England-the district of the Land's End in which, next to Norfolk and Suffolk, the greatest number of these Transatlantic stragglers have been obtained. This suggestion may serve to show what most likely goes on in other parts of the world, though the materials for establishing its general truth are not forthcoming."

Time may prove the truth of this suggestion. But even so there will remain a greater mystery to be explained, a problem which seems at the present day well-nigh insoluble. And this refers to the regular and orderly movements of a large number of totally unrelated species whereof every member participates-movements which compel the attention of even the most unobservant, while at the same time it excites the wonder of those who find in the study of Nature a never-ending delight. As the late Professor Newton eloquently puts it: "The Hawk that stretches her wings towards the south is as familiar to the latest Nile-boat traveller or dweller in the Bosphorus as of old to the author of the book of Job. The autumnal thronging of the myriads of Water-fowl by the rivers of Asia is witnessed by the modern sportsman as it was of old by Homer. Anacreon welcomed the returning Swallow in numbers which his imitators 
of the colder north, to whom the associations connected with it are doubly strong, have tried in vain to excel. The Indian of the Fur-Countries in forming his rude calendar names the recurring moons after the Birds-of-passage whose arrival is coincident with their changes. But there is no need to multiply instances. The flow and ebb of the feathered tide has been sung by poets and discussed by philosophers, has given rise to proverbs and entered into popular superstitions, and yet we must say of it still that "our ignorance is immense'."

The wandering hordes to which reference is here made are all bent on the same errand. In the spring they seek their breeding quarters, in the autumn they are hastening away to more congenial climes wherein they may pass the winter. Great Britain harbours large numbers of such migrants, which find here a suitable breeding ground, or come to us in the autumn to tide over the winter; while some species merely pass through on their way to other lands. Thus, from March to May, while the birds that wintered with us silently steal away for more northern latitudes, others crowd in to take their place. In the autumn these movements are reversed.

Before we endeavour to analyse the possible meaning and origin of these movements, let us trace, so far as may be, the extent of the journeys which some of these wanderers take.

Than the Swallow it would be difficult to find a more instructive example. The species known in Great Britain as the Common Swallow (Hirundo rustica) occurs also all over Europe, Northern Asia and North America, but presenting in each of these great areas characters sufficiently distinct to warrant recognition as sub-specific, or geographical races, though some prefer to regard them as true species. Be this as it may, these birds in their seasonal wanderings all agree, as do migrants in general for that matter, in taking a course due north and south. Thus then the Swallows of these several regions keep each to the land areas lying more or less directly north and south of their range. That is to say, their latitudinal range is relatively limited. The Swallows of Northern Europe go south to Africa, those of Northern Asia (H. gutturalis and H. tytleri) to India and Burma, and even farther southwards, occasionally reaching Australia and New Zealand, while those of North 
America (H. erythrogaster) extend their wanderings to Southern Brazil.

Out of these broad facts an attempt has been made to trace the wanderings of the Common Swallow (Hirundo rustica) in more detail. And it is found that while some go to West Africa, as far south as the Gold Coast, others extend down the whole of the eastern portion of that continent as far as the Cape. Now Dr. Bowdler Sharpe, in discussing these facts, assumes that the migrant hosts wintering in these two areas are made up indiscriminately of British-bred birds, as well as of birds bred on the Continent of Europe. But this assumption, we venture to suggest, is possibly incorrect. However, let this pass for the moment. With this interpretation before him he proceeds to ask by what routes do these two main bodiesWest and South African-travel. Do those making for West Africa go across the Mediterranean direct or by the short cut to Gibraltar, or from Italy to Malta, and so to Algeria and across the Sahara? Or do they follow the coast-line and so come to Liberia and the Gold Coast? As a yet further alternative he suggests that the whole migratory army may travel together to the Nile Valley when it breaks up into two great bodies, one making for the West Coast, and the other continuing its southern journey which ends in the Transvaal and the Cape.

Bearing in mind the evidence as to the tendency to travel as far as possible due north and south it seems probable, we venture to think, that we shall eventually prove be right in assuming that the Swallows which winter on the Gold Coast of Africa are those which make their breeding quarters in Great Britain, France and Spain, and that they reach their winter resort by the shortest and most direct route possible. This being so, we may assume that those which reach the Transvaal and the Cape have been bred in Eastern and South-Eastern Europe.

A large proportion of the summer migrants to Great Britain, even the frail Warblers and Chats, winter in Africa. Our Common Night-jar (Caprimulgus europreus) goes to East Africa by way of the Great Lakes. But nearly allied species which may occur together in their breeding quarters often adopt very different winter quarters. This is true of two European Shrikes -the Red-backed Shrike (Lanius collurio) and the Woodchat 
Shrike (L.poneranus). The former "extends its winter range," says Dr. Sharpe, "to the Cape Colony. Not so the Woodchat, which goes to North-Eastern Africa and to Somaliland, but then reappears in West Africa. Failing information that it crosses the Sahara direct, we can only imagine that it turns westward from the Nile. Valley, skirts the Sahara . . . and reappears in West Africa."

The most ambitious attempt to map out the migration routes of European birds is that made by Professor Palmen. These are nine in number. The first leaving the Siberian shores of the Polar Sea, Nova Zembla and the north of Russia, passes down the West Coast of Norway to the North Sea and the British Islands. The second, proceeding from Spitzbergen and the neighbouring islands, follows much the same course, but is prolonged past France, Spain and Portugal to the West Coast of Africa. The third starts from Northern Russia, and, threading the White Sea and the Great Lakes of Onega and Ladoga, skirts the Gulf of Finland and the southern part of the Baltic to Holstein, and so to Holland, where it divides-one branch uniting with the second main route, while the other, running up the valley of the Rhine and crossing to that of the Rhone, splits up on reaching the Mediterranean, where one path passes down the Western Coast of Italy and Sicily, a second takes the line by Corsica and Sardinia, and a third follows the South Coast of France and Eastern Coast of Spain -all three paths ending in North Africa. The fourth, fifth and sixth main routes depart from the extreme north of Siberia. The fourth ascending the river Obi, branches out near Tobolsk -one track, diverging to the Volga, descends that river and so passes to the Sea of Azov, the Black Sea, and thence, by the Bosphorus and Agean to Egypt; another track makes for the Caspian by way of the Ural River and so leads to the Persian Gulf, while two more are lost sight of on the Steppes. The fifth mounts the Yennesei to Lake Baikal and so passes into Mongolia. The sixth ascends the Lena and striking the Upper Amoor reaches the Sea of Japan, where it coalesces with the seventh and eighth, which run from the eastern portion of Siberia and Kamschatka. Besides these the ninth, starting from Greenland and Iceland, passes by the Faroes to the British Islands, and so joining the second and third runs down the French coast. 
These are Professor Palmen's main routes, the minor channels of these vast streams being formed by river-courses.

The great migration routes, as we have already remarked, run north and south, but there are cases where an exceptionally wide easterly or westerly trend is to be noted. These, it is significant to notice, occur mainly where the migrants are compelled to follow a shelving coast-line, where a course due north or south, as the case may be, would carry them out into trackless wastes of ocean. Tytler's Swallow, for example, nests in Kamschatka and winters in Burma. "In New Zealand," wrote Professor Newton, "there are two Cuckoos which are annual visitors; one, a species of Chrysacoccyx, probably has its winter quarters in New Guinea, though commonly supposed to come from Australia, the other, Eudynamys taitensis, is widely spread throughout Polynesia. . . ." Here are two nearly allied forms which take opposite directions-east and west-yet each following land routes, and the objective of each, be it noted, being north or south as the season may determine.

More remarkable is the case of the Red-footed Kestrel (Erythropus amurensis) of Eastern Siberia, which winters in Eastern South Africa, more especially, apparently, in the Zambesi region. So far as can be made out at present this enormous journey is not made westward through Arabia and by way of the Nile Valley and the Great Lakes, but across the Indian Ocean. This conclusion has been arrived at, because so far no specimens of this species have yet been taken on the route just referred to, but examples have been taken in the Indian Peninsula, in Cachar and in Canada. This is the more inexplicable because the nearly allied European Red-footed Kestrel (Erythropus vespertinus) — which differs from its Siberian relative only in having the under wing coverts grey instead of white-nests in South-Eastern Europe and winters in SouthWestern Africa, though the two species are occasionally found together in their winter quarters. Time may show that the Siberian bird after all follows an overland route, but eastwards by the Nile and the Great Lakes, while those birds found in the Indian Peninsula stray no farther south wards. But on the whole it seems clear that though an east to west course, and vice-versá, is followed by some species when on migration, the ultimate goal of all is always north and south. 
Although the migratory movements such as we have just described take place, as a rule, on a stupendous scale they attract comparatively little attention. A few stragglers tell us that the arrival of our guests is at hand, or remind us that they have departed, but the main body of these wandering hordes is seen but by a few privileged ones. And this largely because, as a rule, they come in rushes, and come, very commonly, by night, leaving in a like manner. This, however, is largely determined by the conditions of the weather. But whether they travel by day or night, as a rule they appear to prefer to perform their journeys at high altitudes, perhaps because less wearisome. Often they betray their presence only by their whistling, though it would appear that as a rule they travel in silence, save only on dark, foggy nights, when their constant cries serve to keep the troop together.

American naturalists have made some interesting observations by directing a telescope against the sky. Thus Mr. Frank Chapman, by turning his instrument towards the full moon, has seen birds passing at night at an altitude, according to his computation, of five miles, while Mr. W. E. D. Scott saw, through an astronomical telescope at Princeton, in New Jersey, great numbers of birds passing across the face of the moon. Most of these were the smaller land birds, among which he recognised Warblers, Finches, Woodpeckers and Icterida (Quiscalus purpureus). These, it is computed, were travelling at heights varying from one to two miles. Mr. Chapman again, on another occasion, when in New Jersey, during three hours saw no less than 262 birds pass over the field of the telescope at a height of from $\mathrm{r}, 500$ to $\mathrm{I} 5$, I00 feet; and the most remarkable thing of all was the fact that the lowest birds were flying upward, as if they had risen from the immediate neighbourhood and were seeking the proper elevation at which to continue their flight. Mr. S. Tennant has recorded the fact that through a telescope turned towards the sun, at Roorkee, he saw birds, apparently Kites, frequently pass over its face, some of which were in focus with the sun itself and must therefore have been several miles high, while the nearest must have been quite a mile above the earth's surface. These birds, it should be remarked, were soaring in search of prey, and not migrating. More than once doubt has been expressed as to whether 
birds can maintain themselves at an altitude of five miles, or whether indeed they can attain this height, and this partly on account of the low temperature which would be there encountered, and partly because the rarefied air would not serve to sustain flight. This last is perhaps the more serious objection, for cold would scarcely be felt by birds engaged in such violent exercise as flight, while the clothing of feathers would be a further protection.

Birds on migration do not always, however, travel at a great height, for there are occasions indeed when the exact opposite is the case. Mr. W. Eagle Clarke, one of our greatest authorities on all that pertains to these mysterious wanderings, has recorded more than one occasion when enormous numbers of Larks, Starlings, Thrushes and other small birds were crossing the North Sea flying so low that they barely topped the crests of the waves. On one such occasion when on the Kentish Knock Lighthouse, during a gale accompanied by a downpour of rain, the birds were scudding along after this fashion, apparently to escape, so far as was possible, the force of the wind. And this continued throughout the day, thousands and thousands passing during this time.

Estimates as to the height at which birds migrate sometimes make large demands upon our faith, and this is no less true of calculations as to the speed attained during their journeys. Thus the late Herr Gätke, of Heligoland, one of the pioneers of the study of migration, believed that the little Arctic Blue-throat (Cyanecula suecica) could leave Africa at dusk one evening and arrive in Heligoland nine hours later, having travelled I,600 geographical miles in a single night at the astounding velocity of I 80 miles per hour! According to another estimate of his, Curlews, Godwits and Plovers crossed from Heligoland to the oyster-beds lying to the eastwards, a known distance of rather more than four English miles, in one minute, or at a rate of over 240 miles an hour! Against such extravagant estimates it is hardly necessary to attempt to bring rebutting evidence, but if any be demanded this may be furnished by the Carrier Pigeon, which has been known to maintain a speed of fifty-five miles for four hours in succession; and it is extremely unlikely that this is much, if at all exceeded by wild species during long-distance flights. 
Not until the erection of lighthouses along our coasts did we gain an opportunity of realising the magnitude of migratory movements, and of the astounding numbers of the birds which participate therein. But by a strange irony these beacons of safety to the human race have become veritable death-traps to the birds, for the lanterns, when sending forth their beams for the guidance of those who go down to the sea in ships, exert at the same time a fascination for the winged wanderers which seems to be absolutely irresistible. In thousands they dash themselves against the blinding light, and in thousands they fall stunned on to the rocks below, or into the surging sea, so making an annual death-roll which is positively appalling. On clear and moonlit nights such tragedies are largely, if not entirely averted, but cloudy skies and a mist-like rain are fatal, for the light reflected on the latter gains a peculiar brilliancy which appears to exert a dazzling effect which these birds cannot escape. Two of many instances given by Gätke show the extent of these visitations. From ten o'clock on the night of the 28th of October, I882, to the next morning, Goldcrests eddied thick as flakes in a heavy snowfall round the lighthouse on the little island of Heligoland ; on the morrow they literally swarmed over every square foot of the island; and twelve months later Hawks in myriads thronged to its bright beams for four nights in succession, accompanied by Starlings in hardly fewer numbers. But "these great hosts," remarks Professor Newton, " consist usually of many kinds of birds congruous only in their congress-Larks and Lapwings, Starlings and Sandpipers, Fieldfares and Curlews, Golden-crested Wrens and Golden Plovers, Oyster-catchers and Owls-while the air is filled with their cries, among which are several that are wholly unrecognisable, for it would seem that some birds have a language that they use only when migrating. Otherwise is it with the return of the wanderers in spring, when the exciting scenes of autumn are seldom if ever presented, yet under a moonless and clouded sky the wakeful ear may often catch positive evidence of what is going on aloft, though owing to the smaller numbers (for at that season it is only the birds which are about to breed that pass) and the shorter nights, the movements attract far less attention. Generally troop after troop of the travellers succeeds in orderly, and what has been called 
'wave-like' fashion, varying indeed in rapidity according to the species, but taken as a whole in comparatively little else."

Only where the lighthouses show a red light do the migrants pass unharmed, the ruddy beams failing to exert any influence over them. One cannot help expressing a wish that the lighthouses which lie in the more frequented routes of these tired travellers could accordingly exchange their white for red lights, could this be done without diminishing their value as guides to mariners.

Reference has already been made in this chapter to casual migrants to our shores, vagrants swept hither by adverse winds. But at times such visitants make their appearance not in twos and threes, or as solitary individuals, but in large flocks. Among the most remarkable of such visitations are to be reckoned the sporadic irruptions of Pallas's Sand-grouse (Syrrhaptes paradoxus). These birds, natives of the vast Gobi deserts, occasionally make their appearance in Europe in enormous numbers and for reasons which as yet are absolutely inexplicable. During the last forty years three separate invasions of this handsome species have occurred in Great Britain. The first of these took place in 1863 , the last in 1888 , when both previous records were totally eclipsed, vast hordes making their way across Europe, following on the routes taken by their predecessors; of these, thousands finally reached Great Britain only to be speedily exterminated by the "Collector". The Wax-wing and the Nutcracker, similarly, at rare intervals, sally forth in their thousands apparently in search of fields and pastures new. "The inroads of the Wax-wing" (Ampelis garrulus), wrote Professor Newton, "have been the subject of interest for more than 300 years, and by persons prone to superstitious auguries were regarded as the forerunners of dire calamity. Sometimes years have passed without its being seen at all in Central, Western or Southern Europe, and then, perhaps for two or three seasons in succession vast flocks have suddenly appeared. Later observation has shown that this species is as inconstant in the choice of its summer as of its winter quarters . . ., " the cause, he suggests, of this irregularity may possibly be due to lack of food; and this also may have been the inciting cause of the invasion of Western and Central Europe in the autumn of 1844 
by a great band of Nutcrackers (Nucifraga caryocatactes). But nothing whatever on this head is known.

And this brings us to the question-Why do birds migrate? To attempt an answer to this question is, at present, to attempt a very difficult task. But before proceeding to make the endeavour it would be well to draw attention to one or two further mysteries of migration which have long excited the comments of Ornithologists but as yet defy all attempts at solution.

Why, for example, in so many species do males usually arrive in advance of females? This is true of the Warblers, for example, males of which reach their breeding quarters some days in advance of the females. More extraordinary still in a large number of species, the adults leave before the young birds, while with the Swallow the young leave first, undertaking their stupendous journey without guides. That is to say, birds which have but recently left the nest are left to find their way, apparently unaided, to the winter quarters in Africa! The young Cuckoo, for example, accomplishes this feat, and so also, apparently, do the young of the Red-backed Shrike.

Yet another remarkable feature of our annual migrants is the wonderful regularity with which they make their appearance and disappearance. Thus of the Puffin (Fratercula arctica) Professor Newton wrote: "Foul weather or fair, heat or cold, the Puffins repair to some of their stations punctually on a given day as if their movements were regulated by clockwork, Whether they have come from far or from near we know not, but other birds certainly come from a great distance, and yet make their appearance with scarcely less exactness."

Such, in brief outline, are the main features of the migration of birds. In the space of a single chapter no room can be found to describe the laborious work that has been expended on this subject by workers abroad, nor of the splendid work of Barrington and Eagle Clarke and others in Great Britain. During the last year or so some most valuable work has been done by a committee of the British Ornithologists Union, the aim being to gain an insight into the lines of migration and dispersal in Great Britain; and it is certain that if this work is carried on most important results will follow. But we are yet as far off as ever with regard to the crux of the whole matter--Why do birds migrate? 
On this theme much has already been written, but little to any purpose. An American writer of good repute would have us believe that when Professor Newton wrote that on this theme "our ignorance is immense" he was really making mystery where no mystery was. The whole matter, he assures us, is simply one of securing suitable breeding sites; and adduced in evidence the migration of the shad and the salmon, which for this purpose, and none other, leave the sea and ascend the rivers, there to lay their eggs, just as the fresh-water eel for a like purpose leaves the rivers to perform the duties of reproduction in the sea. Even so, what impels the one to seek the fresh and the other the salt water? When they start on their perilous journeys have they any fixed ideas as to the relative merits of fresh or salt water as repositories for their eggs? The fresh-water eel and the species of salmon of which he wrote perform these journeys but once. Reproduction over, they die-every one, like Pharaoh's host, perishes. He further seems to commit the very grave mistake of supposing that what may be true of fishes is true of all other migrants.

The veteran Darwinian, Alfred Russel Wallace, took a more serious view of the matter. He says-in reference to birds(Nature, x., p. 459): "It appears to me probable that here, as in so many other cases, 'survival of the fittest' will be found to have had a powerful influence. Let us suppose that in any species of migratory bird breeding can as a rule be safely accomplished only in a given area; and further, that during a great part of the rest of the year sufficient food cannot be obtained in that area. It will follow that those birds which do not leave the breeding area at the proper season will suffer, and ultimately become extinct; which will also be the fate of those which do not leave the feeding area at the proper time. Now, if we suppose that the two areas were (for some remote ancestor of the existing species) coincident, but by geological and climatic changes gradually diverged from each other, we can easily understand how the habit of incipient and partial migration at the proper seasons would at last become hereditary, and so fixed as to be what we term an instinct. It will probably be found that every gradation still exists in various parts of the world, from a complete coincidence to a complete separation of the breeding and the subsistence areas; and that 
when the Natural History of a sufficient number of species is thoroughly worked out, we may find every link between species which never leave a restricted area in which they breed and live the whole year round, to those other cases in which the two areas are absolutely separated."

That migration among birds is, and has been, largely if not entirely connected with the problem of food supply would seem to be highly probable. A strong point in favour of such an interpretation is the fact that birds which have a sufficient and constant food supply do not migrate. Whole groups of birds, it must be remembered, either do not migrate at all, or confine their wanderings to small areas. The majority of tropical and sub-tropical species, for example, do not migrate; while of typically migratory species not a few will be found which have become stationary in some part of their range throughout the year, having found an abundant and unfailing food supply. There is no more typically migratory bird than the Common Swallow (Hirundo mustica), yet a closely allied species, differing only in a few slight particulars (H. savignii) is resident in Egypt. The tropical and sub-tropical species to which reference has just been made, are, be it noted, relatively far less numerous in individuals than are such migratory species as Warblers and Swallows. And this because they have become adapted to live on a peculiar kind of diet to be met with only in their own particular neighbourhood. For such species migration would be suicide: thus the numerical strength of such species is determined by the food supply; a shortage spells famine, and the consequent reduction of the species to limits which the area can support. Migration is possible only so far from the original centre of dispersal as food is obtainable. And it would seem that migratory species follow their food more than is supposed. So far as is possible, overland routes appear to be followed just because of the need of food all along the route. "It is well known," writes Dr. Sharpe, " that in certain parts of Africa, during the northern winter, vast flocks of birds of prey are observed. They consist of Kites, Eagles, Hobbies, Kestrels, etc., and they follow the swarms of locusts, or appear in numbers where grass-fires take place." Migratory birds, in short, have acquired this power to shift from place to place, and the consequent advantage to the species, just because 
they have not become too highly specialised in the matter of food, and so can avail themselves of supplies that in some form or another are universal.

That these migratory birds are the descendants of a line of forebears of similar habits extending far back in time none can doubt, extending back indeed to a time when the physical geography of the world, in the matter of the distribution of land and water, differed materially to what obtains at the present day. This is a fact which is not only commonly recognised by students of bird migration, but which is also made to play what to some must seem rather too imaginary a part. Thus it has been contended that many present-day migration routes are taken irrespective of present areas of land and water, and in conformity with the route followed by their ancestors when these areas were otherwise than now. That is to say, they cross such and such areas of water not because they afford short cuts, but because these areas were traversed ages ago when what is now a sea was then dry land.

And just as submerged areas are now traversed purely for traditional motives, so it is held certain land areas are now skirted rather than crossed because they represent areas once covered by sea. Thus Dr. Sharpe, in describing the route of the Woodchat Shrike on its way to its winter quarters in Africa, remarks that it "skirts the Sahara as if it were still a sea . . ."; yet he shows that the Willow Warbler, on the other hand, "winters in the oases of the Northern Sahara," whence it appears some individuals perform a further flight to Senegambia, this species being found during the winter months both in West and South Africa. The inference seems rather to be that while the Willow Warbler can safely enter the Sahara, being sure of food, the Woodchat cannot. Of course it is open to argument that the Willow Warbler is the more recent species, and therefore entertains no hereditary prejudices against this region, but of this there is no evidence.

Ancient and now submerged land surfaces, however, are undoubtedly to be reckoned with in considering the subject of migratory birds, for these submerged areas would seem to act as barriers of a hitherto unsuspected kind. But before this hypothesis can be profitably developed it will be necessary to say a few words anent what has been called the "homing 
instinct " in migrants. This theme has been most admirably yet briefly handled by the late Professor Newton. By way of illustration he cited the case of a "pair of Stone Curlews (Edicnemus crepitans)-a very migratory species, affecting almost exclusively the most open country-which were in the habit of breeding for many years in the same spot, though its character had undergone a complete change. It had been part of an extensive and barren rabbit-warren, and was now become the centre of a large and flourishing plantation." Two other instances quoted by Newton are scarcely less remarkable. Of these oneconcerned "the nest of a Falcon (Falco peregrinus) on Avasaxa -a hill in Finland . . - -is mentioned by the French astronomer Maupertuis as having been observed by him in 1736 . In 1799 the nest was discovered by Skjoldebrand and Ascerbi. In 1853 Wolley found it tenanted, and from inquiries he made of the neighbours it was evident that such had yearly been the case so far as any one could remember, and so it was in 1855 , as I myself can testify." Continuing, he remarks: "In I779 according to one account, in 1785 according to another, a pair of the Blue Titmouse (Parus ceruleus) built their nest in a large earthenware bottle placed in the branches of a tree in a garden at Oxbridge, near Stockton-on-Tees. With two exceptions only, this bottle, or a second which had been placed close to it, was tenanted by a pair of birds of this species from the year it was first occupied until I873, when I saw it; . . . but I regret to add that I learnt through Canon Tristram in 1892 that the occupancy had ceased for four years."

Bearing these facts in mind, and applying them to British birds, it seems to the writer of these pages that our annual migratory visitants may be regarded with a tolerable degree of probability as the direct descendants of the migrating hosts which made their way to these islands when they formed part of the mainland of Europe. The invading sea made its way by slow imperceptible inroads. Though with the cycle of the seasons the successive generations of these ancestral migrants saw more and more water stretched across their path to the summer breeding-home they heeded not, because the change was so slow that none took note of it. By such gradual stages was the barrier thrown across that no confidence was shaken. The birds passed on, sure of what was beyond: and for this 
reason their descendants continue in the same unshaken faith. In other words, our summer migrants are so many British races of their species, though indistinguishable from their continental relatives. Now for the sequel to this. As, by human interference-drainage, agriculture, persecution at the hands of game-preservers and collectors-these British races become reduced, their numbers are not replaced. The Bittern, Avocet, Ruff, Spoon-bill, Harriers, Ospreys, and the dozen or so more of our vanishing native avifauna that turn up year by year among us are the last survivors of these old races. When they are gone their places will be taken only by occasional, accidental stragglers blown out of their course by adverse winds. Their place will not be taken by annual visitants because the representatives of these species on the mainland of Europe have similarly become "local" races-using this term in the wide sense-which therefore return year by year to their accustomed breeding spots, and as their ranks in turn become depleted so will they too become rare, then vanish.

The intimate relation between migration and food supply is demonstrated annually within the confines of the British Islands during such visitations of "hard" weather as occur during the winter months: and on this head both Barrington and Eagle Clarke, our foremost authorities, have furnished some remarkable evidence.

Though we must still regard the origin and survival of the migratory habit as a problem never likely to be certainly solved, we may yet find some satisfaction in hypothesis.

Thus then it is to be noticed that migratory species, individually, vastly outnumber sedentary species, and this because of the enormous breeding areas which this wandering habit secures. But migration is only possible where a sufficient supply of food is to be secured; both on the journey and at its terminus-and this is true even where great distances can be covered without food. Very well. We may assume that the migratory species owe their origin to the matter of food supply. Composed of individuals subsisting on a food of universal range, but limited in supply, they were enabled to roam farther afield as their numbers strained this supply in their immediate neighbourhood. Annually, however, a check was placed on further extensions of range by the cares of breeding and by 
the diminution of food at the end of the breeding seasonwhether caused by climate or otherwise-while behind them the supply was increasing. Thus they were drawn back towards their starting-point. Again threatened by famine, they once more turned outwards, finding the earlier depleted area restocked. These movements, in short, were doubtless then, as now, periodic, and determined largely, if not entirely, by seasonal changes. Such species increasing numerically with their increase in range were naturally automatically compelled to still further extend this to obtain the means of sustenance. That each individual would return by the route he came by is but a natural inference, and the same is true of the offspring of each pair-hence the "homing instinct" and the formation of British_or other races-of migrating species.

The range of a migratory species, "in fact, would seem to increase of necessity-so long as no severe check is placed on the annual increase in numbers of that species, and this because the younger generations have to stake out new claims for territory, so to speak: since the older birds will return to the breeding spots annexed by them previously, and will drive away any younger would-be settlers, which must therefore settle outside the range of the earlier occupiers of these sites.

Thus is explained the fact that the Common Swallow (Hirundo rustica), for example, is found breeding throughout the whole of its range from Southern Europe northwards, those breeding farthest north having been forced thither by the settlement of the earlier migrants : and thus is explained the general rule that species which go farthest north in summer go farthest south in winter. 


\section{CHAPTER VII}

\section{RELATIONS TO THE ANIMATE ENVIRONMENT}

Relation to plants. Birds and pollination. Birds and spread of seeds. Birds in relation to other animals. The perils of nestling birds. Birds and "civilisation".

$7 \mathrm{HE}$ fact that birds in any way modify their animate environment is generally, if at all, but vaguely realised; whereby it is plain that this influence is too subtle, or too small, to make itself felt. Nevertheless, careful observation will show that though the part they play may be a small one, birds do indeed leave their mark upon the organic world, though it be but a ripple-mark on the surface of the great ocean of life.

In the plant world such

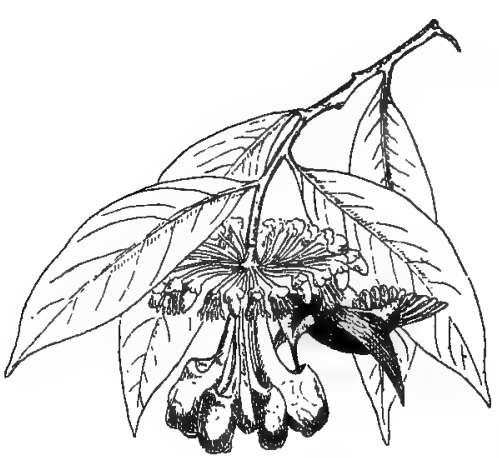

ILl. I9.-HUMming-BiRd Fertilising FLOWERS OF MARCGRAVIA NEPENTHOIDES. (After Wallace) forms as the Sun-birds and the Humming-birds play the part of insects in the pollination of flowers. But since it does not appear that these flowers are absolutely dependent upon the birds for pollinationthat is to say, these same flowers are probably more commonly visited by insects which perform the work of pollination quite as effectually-we may turn with more profit to the facts which have been collected with regard to the part played by birds in the dispersal of seeds.

Here there can be no doubt but that, in a large number of 
cases, the evolution of many plants has been very materially affected, in so far as the fruit and its dispersal are concerned, by the agency of birds.

The eminent botanist Kerner carried out a series of interesting experiments designed to test the vitality of seeds after having been swallowed by birds. As a result he found that birds are in this respect divisible into three groups. The first . group includes those which grind up even the hardest fruits and seeds in their muscular gizzards by the aid of small stones and grit. Amongst these some strip the fruits and seeds when they first lay hold of them, and thereby condemn them to destruction. Such were, he found in his experiments, the Turkey, Common Fowl, Pigeon, Duck, Cross-bill, Bullfinch, Goldfinch, Siskin, Serin-finch, Nutcracker and Titmouse. No seed, under ordinary conditions, was found capable of germination in the excrement of these birds. The seeds used were those of Arenaria serpyllifolia, Papaver rhoas, Sisymbrium sophia, Ribes rubum, ligustrum vulgare, Fragrare indica and some other species. Ravens and Jackdaws form a second group, wherein the stones of the drupes and hard-coated seeds of the berries which they ate passed uninjured through the intestine, whilst soft-coated seeds and fruits were all destroyed. Kerner draws particular attention to the fact that after these birds had been fed with cherries their excrements contained cherry-stones $15 \mathrm{~mm}$. in diameter, every one of which was able to germinate. The Blackbird, Song-thrush, Rock-thrush and Robin formed a third group. Of these the Blackbird proved to be the least fastidious about its food. It even swallowed the fruits of the yew without afterwards relieving its crop of the stony seeds, and it never rejected a single fruit that was mixed with its food. The Song-thrush rejected all dry fruits of $5 \mathrm{~mm}$. diameter or more, even when they were mixed with the finely chopped meat with which the bird was fed. They also avoided such strong-smelling fruits as those of the yarrow. On the other hand, the aromatic fruits of umbelliferæ were eaten with great avidity. The seeds of the tobacco plant, henbane and foxglove mixed with the food were not rejected and caused no ill effects, neither did the berries of the deadly nightshade which were greedily devoured. On the other hand, however, a Song-thrush sickened after eating 
berries of Phytolacca. One species of this genus, $P$. decandra, a native of North America, is used as a source of colouring matter in the making of wine, and for other purposes. When fleshy fruits with seeds of a diameter exceeding $5 \mathrm{~mm}$., such as those of Berberis, Ligustrum, Opuntia and Viburnum, were introduced into the crop, the pulp passed into the gizzard, but all the seeds were thrown up. And the seeds of fleshy fruits which were greedily devoured were thrown up if the stones which they enclosed measured as much as $3 \mathrm{~mm}$. In some cases seeds, as those of Lychnis flos-Jovis, were carefully removed from the rest of the food with which they had been mixed.

The interval of time between ingestion and evacuation in the birds of this third group (Thrushes) was very short. A Thrush fed with Ribes petraum at 8 A.M. excreted numbers of seeds after the lapse of three-quarters of an hour, and seeds of Sambucus nigra passed through the alimentary canal in half an hour; but the majority of seeds took from one and a half to three hours to perform this journey; though, curiously enough, the small seeds of Myosotis sylvatica and Panicum diffusum were retained for the longer period.

Of the fruits and seeds which passed through the intestine of one or other of these birds 75 per cent. germinated in the case of the Blackbird, 85 per cent. in the Thrush, 88 per cent. from the Rock-thrush, and 80 per cent. with the Robin. But the germinating power of these seeds seems, as a rule, to suffer a check-in from 74 to 79 per cent. of the cases examined by Kerner-though the ultimate vitality of the seed does not appear to suffer in any way. This point was established by control experiments, the seeds of similar fruits, and we presume from the same plant, which were sown directly germinating quicker than those which had been swallowed. In a few cases, however, as in the case of a few berries, e.g., Ribes, Berberis, Lonicera, germination was hastened by this ingestion; while the seeds of such plants as grow on richly manured soil, e.g., $\mathrm{Am}$ aranthus, Polygonum, Urtica, after passing through the intestines of birds actually produced stronger seedlings than did those which were cultivated without having passed this test.

Thus then we may assume that the brightly coloured fruits which distinguish so many plants have been evolved by the 
agency of birds. That is to say, these bright colours are, so to speak, a device on the part of the plants to secure the dissemination of their seeds. Thereby intraspecific competition is reduced, and an extended range and continuance of the species is secured. Some plants, indeed, appear to owe their very existence to the agency of birds; as, for example, in the case of the mistletoe. The part played by Thrushes in this distribution is well known, as witness the name "Mistle-thrush". But it is generally believed that the seeds of these viscous berries are deposited in the crannies of the bark of trees by the bird's beak. To this it is supposed they become attached as they escape from the sticky pulp when this is squeezed. And to rid itself of the annoyance the bird is said to rub the beak vigorously across the bough until successful in transferring the offending particle to the bark.

As a matter of fact, however, the berry is swallowed whole and the seed escapes when the fæces are expelled. In support of this one has only to note that only occasionally do mistletoe plants spring from the upper surface of a bough. As a rule they start off from the side, or hang down from the under surface thereof. And this because the fæcal matter being semifluid, it runs some little way across the bough until stopped by some flake of bark. Here the seed is deposited; occasionally the fluid excreta may run on until it forms a drop beneath the bough.

The nutmeg again appears to be largely dependent on fruit Pigeons to carry on the work distributing its seeds. The fruit is yellow, in shape resembles a peach, but is firm and not edible. When quite ripe it splits open and exposes the seed, which is of a glossy black colour, partly concealed by a bright scarlet laciniated sheath or "arillus," known commercially as "mace". The fruit Pigeons greedily seek out these seeds and swallow them entire for the sake of the mace. Later the nutmeg is said to be expelled with the fæces, and thus wild nutmegs have been spread over New Guinea and the surrounding islands. More probably, however, the mace is removed while in the crop, and the nutmeg is then thrown up, as other birds eject pellets.

Nutcrackers, Jays, Magpies, Rooks and Woodpeckers, which keep stores of food in hiding-places-which they appear very 
frequently to forget-do much towards distributing the nuts of such trees as beeches, oaks and hazels.

Some valuable evidence as to the important part birds play in the dispersal of seeds has been brought together by $\mathrm{Mr}$. H. N. Ridley, who found that in the Malay Archipelago the principal carriers were Bulbuls, the dark-blue Starling (Calornis chalybea), the Minah (Mainatus savatus), and the Horn-bills (Buceros, Anthracoceros, etc.), the latter being especially fond of the nutmeg. The Parrots of the Genus Palceornis also aided in this work. The granivorous Finches of the Genus Munia he found aided considerably in the dispersal of adhesive seeds which were carried about by the feathers and finally dropped. He states that, on the authority of Mr. G. Clunies Ross, on Cocos Islands "when Boobies are not nesting, and have con. sequently left, the Frigate-birds (Tachypetes aquila) are unable to procure their ordinary food, which consists of fish taken from the Boobies, and that they then swallow seeds of Guilandina and beans which they find floating on the sea, and on flying to the land vomit them up again, apparently merely using them to fill up temporarily empty crops!" He further shows that while the bulk of the seeds dispersed by birds are highly coloured, dull-coloured seeds are dispersed by nocturnal mammals who seek their food by smell and not by sight.

The mud adhering to the feet of birds furnishes another source of seed dispersal, for seed becomes embedded therein and may be transported over vast distances, though this, probably, plays no very important part in the distribution of plants. Not infrequently, perhaps, small seeds are carried in the plumage. Instances of the latter kind rest, however, rather upon circumstantial evidence than upon established cases. The granivorous birds are supposed to act as seed distributors in this fashion. Certainly, small Finches and Gallinaceous birds which love to dust themselves in dry earth, may well enclose small seeds between the feathers during this operation. Migrant waders, it has been suggested, carry seeds of marsh plants about in this manner, and one observer-Mr. H. N. Ridley-has recorded the fact that a number of plants of Rhynchosposa aurea suddenly appeared in a stone tank in the Botanic Gardens at Singapore after the visit of a small Sandpiper.

The evidence as to seed borne in mud adherent to the feet 
of birds is much more satisfactory. We may begin with the now historic case, cited by Darwin, of the leg of a Red-legged Partridge which was found encased in a ball of earth, as a result of injury to the foot. This foot was submitted to Darwin by Professor Newton, who suggested that it might afford some interesting facts in the matter of the relation of birds to seed dispersal. And this proved to be the case, for, as is recorded in the Origin of Species, this ball of earth, which weighed six ounces, and had been kept for no less than three years, "when broken, watered, and placed under a bell-glass, [produced] no less than eighty-two plants ... : these consisted of twelve monocotyledons, including the common oat, and at least one kind of grass, and of seventy dicotyledons, which consisted, judging from the young leaves, of at least three distinct species". This, of course, was a quite abnormal case ; but Darwin had already collected much evidence on this point. Thus he in one case removed sixtyone grains, and in another twenty-two grains of dry argillaceous earth from the foot of a Partridge. And again, from the shank of a Woodcock, he removed a little cake of earth, weighing only nine grains, and this contained a seed of the toad-rush (Juncus bufonis) which germinated and flowered.

The botantist Kerner has since brought to light additional evidence on this subject. He remarks: "The extraordinary occurrence on the edges of ponds in Southern Bohemia of the tiny Coleanthus subtilis, which is indigenous to India, and the sudden appearance of the same species of grass in the West of France about twenty years ago, may be unhesitatingly attributed to the mode of dispersion in question; as may also the occurrence of the tropical Scirpus atropurpureus on the shores of the Lake of Geneva, and that of the southern native Anagallis tenella on the shores of the Schwarzsee at Kitzbühel in North Tyrol." He also gives an instance of the case of a Little Owl (Athene noctua), which in catching mice brushed against wormwood-bushes (Artemisia), and when it flew away was all besmeared with the fruits which had been rendered sticky by a previous shower of rain. A similar case is recorded by Dr. H. O. Forbes in his Wanderings in the Eastern Archipelago, where two species of Heron (Herodias nigripes) and Demiegretta sacra breeding in "West Island"-Cocos Keeling Group Islands-nest on high Pisonia trees, and often, in consequence, 
died from the number of the glutinous seeds which clogged their feathers. Again, Dr. C. W. Andrews, of the British Museum, has shown that Pisonia seeds are constantly being distributed over Christmas Island (Indian Ocean) by sea-birds whose feathers become so clogged thereby that flight is considerably impeded.

Birds of prey aid in this work of seed dispersal in another way. Vegetivorous fishes, when eaten by piscivorous birdsHawks, Owls, Kingfishers and so on-frequently contain seeds in the stomach. These are either torn from the body of the victim on the margin of the stream, or are ingested by the bird with the prey; but in either case many germinate, sometimes being deposited far from the place whence they were taken, and from the habits of the bird, the chances that they will be set free in a favourable spot are considerable. Similarly, when granivorous birds are eaten by Hawks and Owls, the seeds contained in the victim's crop are either scattered over the ground at once, or are sown in the excreta of the slayer.

Thus, then, it is clear that the influence of birds on the plant world, though not perhaps very great, is by no means a negligible quantity. But some plants, such as the mistletoe and its allies, are dependent for their very existence to the agency of birds, and it seems certain that the brightly coloured fruits of our hedgerows have come into existence through the same cause. That is to say, they have been developed to serve as allurements to bring about seed dispersal and the spread of the species. More correctly, perhaps, the factors which brought about the initial stages in the development of this fruit -whether mutation or the cumulative action of definite variation-secured to these plants material advantages in the struggle for existence; and hence the increasing perfection in the device, if device it may be called. On the other hand, the birds have also profited, for fruit-eating birds certainly owe their existence to this evolution of fruit-bearing plants. In distributing the seeds of these they are sowing for their future use, as much as when men sow a corn-field. In favour of the mutation theory we may remark that, whatever may have originally served as the inducement to birds to swallow the seeds of these plants, served at the same time, in all probability, to encourage mutation, inasmuch as it has been shown that, as a rule, the growth 
of ingested seeds is retarded, and this fact, as De Vries has shown, tends to produce mutation.

While, in considering the relation of birds to their animate environment, it is easy to show that they undoubtedly exert a modifying influence upon the plant world, it is by no means so easy to demonstrate the fact that they play a similar part with regard to the animal world, including their influence on one another. Yet such is the case, though from the nature of the evidence this influence rests largely rather on deduction than on an array of stereotyped facts.

That many groups of invertebrates with enormous powers of multiplication are kept in check by birds, there can be no doubt, and nowhere is this more certain than in the case of the Insecta, for a vast number of species of birds subsist entirely on an insect diet; and to these must be added a number of species which during the breeding season at least become insect destroyers.

No less important is the part played by birds in keeping down the numbers of such prolific Mammalia as the rodents. How real is this check may be seen during times, when, generally from man's stupid interference in killing off these police of nature, these mammals increase till they become a veritable plague. The recurrent vole plagues in Great Britain may serve as a case in point. In the last of these, which occurred in the South of Scotland and North of England during 1890-92, the common field-vole (Microtus agrestis) multiplied to such an appalling extent as to threaten the farmers of the infested districts with ruin. And by far the most powerful agent in the final suppression of these invaders was the work of birds of prey, especially of Kestrels and Short-eared Owls. The latter indeed developed a remarkable fecundity under the stimulus of this plenty. Normally laying from four to eight eggs, clutches of thirteen now appeared. And before the end of the plague it was estimated that no less than 400 pairs of Short-eared Owls alone were finding sustenance in the stricken area. Further, it is said that not only were clutches of eggs enormously increased in size, but that at least two broods were produced by each female during this time.

But for the work of these birds the whole face of the country round might well have been changed. 
Incidentally this remarkable case serves also to illustrate the fact that the numerical level of a species is dependent largely upon the supply of food. And that this is so we may point out, on the authority of $\mathrm{Mr}$. W. H. Hudson, that the Caracaras or Carrion Hawks of South America have largely increased in numbers since the introduction of large herds of cattle into the plains of this vast cattle-raising region. They find abundant food in the offal from the carcasses of the cattle slain for European markets.

By way of further illustration of the influence of birds on their animal environment, take such a case as that cited by Darwin, of the absence of feral cattle, horses and dogs in Paraguay owing to the abundance of a certain fly which lays its eggs in the navels of these animals as soon as they are born and so destroys them. Darwin contended that these flies must be held in check by insectivorous birds, and that these were in turn kept down by Hawks; but for which, he argues, the insectivorous birds might increase sufficiently to hold the pestiferous flies in check, and so render existence possible for these persecuted mammals. It may well be, indeed, that the navelbreeding insects owe their amazing abundance to this chain of circumstances. But, be this as it may, the main point-the inability for these mammals to maintain a hold on life in this region-remains the same, and this materially affects, as he shows, the whole face of the country in so far as its vegetation is concerned.

A similar case affecting sheep in New Zealand is furnished by the Kea Parrot, if all accounts are true. This bird, originally vegetivorous, has taken to a carnivorous diet, feeding on the backs of the huge flocks of sheep kept by the colonists. The Parrot is said to tear away the wool, and burrow down through the flesh for the sake of devouring the kidneys, though this part of the story savours of the ridiculous, since the bird would certainly never succeed in obtaining these morsels. Nevertheless, if, as the flock-owners avow, these birds actually devour any part of the flesh of the back, death would certainly ensue. And after such fashion birds may well have played an important part in the past in determining or controlling the mammalian life in different parts of the world.

Before man took it upon himself to regulate the balance of 
nature, birds must have played no inappreciable part in keeping in check the prodigious fecundity of gregarious fishes, both fresh and salt water; and blundering efforts made to-day by certain ill-informed would-be legislators to keep down fish-eating birds, on the ground that they lessen our food supply, fail of their purpose. For should they succeed in appreciably reducing the numbers of these birds, they will but give a fresh impetus to the shoals of predaceous fishes which would profit by the increased abundance, and over these they have no control whatever.

The Secretary-bird, the New-World Vultures, and certain species of Kingfishers may serve as examples of birds which contribute more or less effectually to keep in check the undue increase of reptiles.

The Secretary-bird (Serpentarius reptilivorus) of S. Africa, from its fondness for poisonous snakes, has during the last few years been carefully protected by law. Standing nearly four feet in height and of powerful build, this remarkable bird-an aberrant member of the Hawk tribe-displays no small skill and caution in attacking its venomous prey, shielding itself by means of the wings, and kicking violently with both feet until its victim is vanquished. The "Turkey-buzzard" of the Genus Cathartes-more commonly known as the Turkey-buzzard or Turkey-vulture-like the Secretary-bird is an aberrant member of the Accipitres. By preference a Carrion-feeder, this bird, however, confers yet other benefits by its fondness for the eggs of the alligator. In this it displays great cunning, watching the process of deposition, and pouncing down upon the prize so soon as the unsuspecting reptile has taken to the water.

We have been considering birds in relation to their animate environment only in so far as they directly influence this, in so far as they may be regarded as affecting the balance of organisms other than birds. But we may turn now to another aspect of the picture, or rather, to the complementary picture, which shows us how this animate environment reacts upon the birds.

This reaction appears to obtain only between the birds and their animal environment, and different groups of birds on one another. And instances of this phase of bird-life will only be cited where this reaction is exhibited in what may be called a measurable quantity. 
The keenness of the struggle for existence between different organisms occupying the same area is, and can only be, appreciated by us in part; we get but occasional glimpses of what is going on in this direction. And thus it seems as though the conflict between birds and their animal neighbours is confined mainly to the brooding parents and their offspring. During the breeding season birds are subjected to a very heavy toll. Snakes and lizards and rats devour their eggs. Squirrels and prowling carnivores destroy their young, while the sitting bird is always in danger of being surprised and seized when brooding, though the mortality from this last source is trifling compared with that which overtakes the eggs and young. When the critical period of reproduction is passed in the neighbourhood of human communities, the destruction, especially with regard to eggs, is appalling, and it appears to attain its highest intensity where civilisation is most advanced. This is largely due to the ravages made for economic purposes.

The young birds, from the moment they leave the egg till the time they have learned to fly, run the gauntlet of a host of enemies, even invertebrates taking part in the carnage. For Dr. Alcock has recorded in his charming book, $A$ Naturalist in Indian Seas, how when landing on Pitti Island, in the Laccadive Sea, he found "every foot of the ground above high water-mark literally carpeted with young Terns of two species, many living and nearly full-fledged, many dead and rotting, and many reduced to clean-picked skeletons with only the quill feathers still sticking to the wing-bones. . . . We soon discovered that one great cause of the wholesale destruction of young birds was the voracity of swarms of large hermit crabs (Canobita), for again and again we found recently killed birds in all the beauty of their first speckled plumage being torn to pieces by a writhing pack of these ghostly crustaceans. There were plenty of large ocypode crabs too ( $O$. ceratophthalmus) aiding in the carnage." And he continues: "Moseley, in his Notes of a Naturalist on the Challenger, made mention of a grapsus crab that he saw on St. Paul's Rocks carrying off a newly hatched Tern, but such an accident does not shock one's feelings nearly so much as does the thought of full-grown young birds, nearly ready to fly out into the world and to exercise their intelligence, being overpowered by force of numbers 



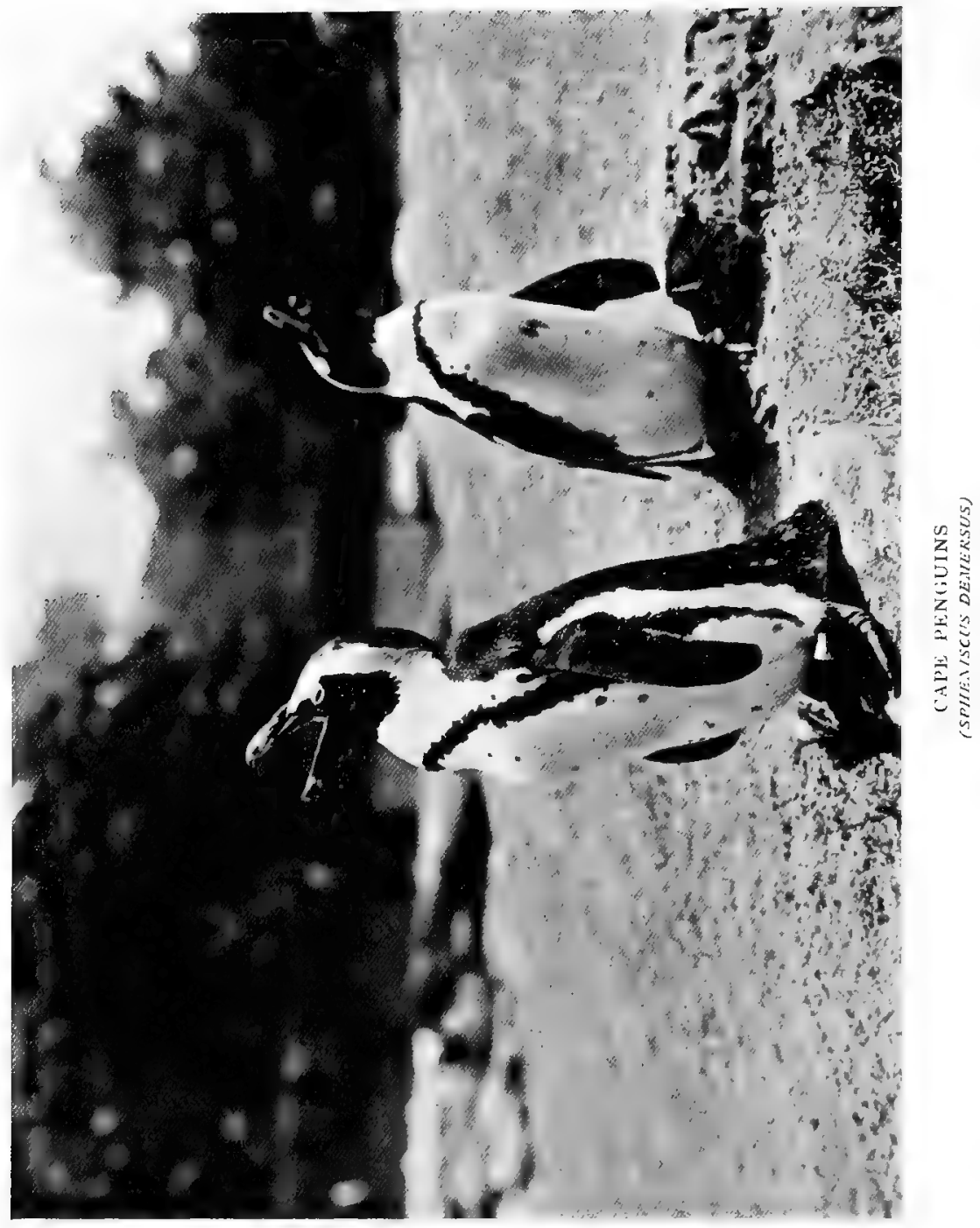


and slowly eaten alive by animals so far inferior in the scale."

Strangely enough, the nestlings of the Booby (Sula leucogaster) and of the Noddies (Anous stolidus and A. melanogenys) which Moseley found on St. Paul's Rocks, defended themselves vigorously and successfully from the similar attacks of this crab (Grapsus strigosus).

It may here be noted that while many birds appear to suffer the spoliation of their nests and the slaughter of their young by their more rapacious neighbours, if not with indifference, at least with but a feeble show of resistance, others profiting by experience have adopted measures whereby they may escape these unwelcome attentions. Thus Moseley on his visit to Inaccessible Island found that feral pigs had nearly exterminated a Penguin rookery on the south side of the island, but a few Penguins remained which had saved themselves by building in holes under stones where the pigs could not reach them.

Similarly, the Barn Owl (Strix flammea) in Texas and in India, and the Short-eared Owl in the Aleutian Islands, breed in fairly deep burrows, though the causes which have led to this appear to be unknown.

But besides enemies from without, a very heavy infant mortality is inflicted by ravages from within, by the depredations of predatory birds, which contrive to support themselves and their families by preying upon the eggs and nestlings of their more helpless neighbours.

An instance of this is furnished by the great breeding colonies of Penguins and Cormorants on Dassen Island, off the Cape of Good Hope. Mr. M. J. Nicoll, a naturalist who visited this island in 1906, found in addition to vast hordes of Jackass Penguins (Spheniscus demersus);-it was estimated that about nine millions of these birds were breeding here, laying their eggs in holes-an enormous colony of Cormorants, and considerable numbers of Sacred Ibises and Gulls. The Gulls and Ibises seem to subsist, during the breeding season, on the eggs and young of the Cormorants. The Gulls displayed a most extraordinary watchfulness over the sitting Cormorants, seizing the eggs with a devilish dexterity if for a moment they were left unguarded: later they took the young. The Ibises appear 
to content themselves with preying upon the young only, which they seized for the sustenance of their own offspring, feeding them upon the entrails of their victims.

Wherever large breeding colonies of marine species are to be found the larger Gulls and Skuas are sure to be met with, these living almost entirely on the eggs and young of their more helpless neighbours. Of the depredations caused by Skuas among the Penguin colonies of the Antarctic, Dr. E. A. Wilson, one of the naturalists of the Discovery expedition, tells some lurid stories. Writing of McCormick's Skua and the colonies of the Adélie Penguin he says: "Hanging round the rookery, with the unmistakable look of a thief, the Skua will run up to a chicken almost as big as himself, drag it by degrees away from the more crowded part of the rookery, and then gradually worry it to death. . . . The Penguin chick pipes his loudest, but the old birds standing round take very little notice. Occasionally one in passing will make a run at the Skua, drive him off for a moment, but the chick is separated from the rest, and the old Penguin has no mind to stop and shelter him, so back the Skua comes to complete his work. Literally, in a rookery such as that of Cape Crozier, one cannot walk ten yards without coming on a dead Penguin chick. Many of these ... are dried and flattened mummies, trodden down and flattened into the stones and guano that cover the ground. But an enormous proportion are seen to be fresh victims, if one visits a rookery in January, when the Skuas have not only themselves but their young to feed." "But," he also remarks, "the Skua even robs its own kind, and in a nesting colony of some twenty or thirty birds, the numbers that have apparently lost their eggs, or one at least, by robbery is always fairly large." This fact, coupled with the pugnacity of the young (p. 320), tends to keep down the numbers of these predaceous birds, which otherwise would long since have exterminated the Penguins.

The foregoing illustrations of the severity of the struggle for existence deals only with a struggle sustained by species which yet contrive to maintain a hold on life. But we must pass now to another aspect of this theme-to an aspect which shows how the extermination and extinction of species is brought about as soon as such species become too highly specialised to respond to changes in their environment. 
Unfortunately, Great Britain furnishes us with many instances of this process of extermination, which is the first step to extinction. The recital of this history makes a melancholy story which has been told at length, and with uncommon force and weight by Professor Newton, than whom none have ever excelled in all that pertains to the history of birds. From his account the following instances are for the most part selected.

First of all we have the Crane, which was described by Turner as breeding in our fens in 1544 , but soon after this date this magnificent bird seems to have forsaken its breeding haunts and to have been met with only as a winter visitant. Though we have no record of the fact, this must be inferred from an observation of Sir Thomas Browne, who speaks of it, in 1682 , as being found in the open parts of Norfolk in winter, the county in which it formerly bred in considerable numbers. In 1678 Willoughby was still able to say : "They come to us often in England, and in the fen-counties, Lincolnshire and Cambridgeshire, there are great flocks of them; but whether or no they breed in England I cannot determine. . . ." Their disappearance is to be attributed to the drainage of the marshes, the increase of the population, and the use of firearms. With the dying out of the original breeding stock the number of annual visitants slowly declined, till now it occurs only sporadically -a single bird being seen and generally killed at once-every ten years or so. The same is true of the Spoon-bill (Platalea leucorodia), and of its near relative the Glossy Ibis (Ibis falcinellus). And to these we must add the Great Bustard (Otis tarda), the Ruff (Machetes pugnax), the Avocet (Avocetta recurvirostra) and the Capercailzie, which has been successfully reintroduced, while others, such as the Bearded Tit (Panurus biarmicus) and the Great Skua, are fast disappearing. Among birds of prey the havoc has been even more striking, and this is owing to the zeal of game-preservers who, in their slaughter of so-called "vermin," have exhibited a combination of greed and ignorance such as cannot be described in temperate language.

The insane vanity of women has brought about a desperate condition of things with regard to birds in other lands. The ends of the earth have been searched to provide birds of beautiful plumage for the trade of the milliner; and this traffic has 
led to the perpetration of atrocious barbarities. The total extinction of some species, such as Birds of Paradise, Egrets and Humming-birds, will surely come to pass unless legislation steps into the breach, while the reduction of others has already reached such a pass that their doom is sealed.

A distinction has been drawn, it will be noticed, between extermination and extinction. The former term is here used to indicate species which have been extirpated over large geographical areas, but still survive elsewhere; extinction marks the final disappearance of that particular species throughout the world, though in most cases extinction has befallen only such species whose range was limited-for the most part island forms.

The most familiar instance of the extinction of a bird enjoying a fairly wide distribution is that of the Great Auk or Gare-fowl, nearly allied to and closely resembling the Razorbill, still common along the British coasts. This bird ranged from our shores eastwards as far as Denmark and northwards and westwards to Iceland, Greenland and Newfoundland. Yet it had absolutely lost the power of flight. As large as a Goose-measuring about two feet eight inches in length-its wings were actually smaller than those of the Razor-bill which does not exceed seventeen inches from the tip of its beak to the tip of its tail. Entirely aquatic in its habits, and free from enemies at sea; the wings slowly degenerated, and it is possible that they would in course of time have completely disappeared, as in the case of the wingless fossil Hesperonis, of the cretaceous epoch. When, however, man appeared upon the scene, and discovered that Great Auks were at least palatable, the fate of this bird was sealed. This war of destruction appears to have been chiefly waged in the neighbourhood of Newfoundland, which was apparently the headquarters of this bird, inasmuch as it occurred here in great numbers, as may be gathered from the narratives of the early travellers, according to whom it was much sought after by French fishermen, who victualled themselves with, and salted down, the wretched victims. Mr. Howard Saunders records that in A Discourse and Discovery of Newfoundland written by Captaine Richard Whitbourne of Exmouth, in the county of Devon, published in I620, it is stated that among the Water-fowl, which are very plentiful, are "Penguins" which "are as big as Geese and flye not, 
for they have but a little short wing, and they multiply so infinitely upon a certain flat Iland, that men drive them from thence upon a boord, into their boates by hundreds at a time, as if God had made the innocency of so poore a creature, to become such an admirable instrument for the sustentation of man". "How long," Mr. Saunders remarks, "this slaughter continued it is impossible to say, but Auspach, writing in I8I9, speaks of 'the Penguin' as exterminated in that quarter." On Funk Island these birds were discovered in I534, and could then be reckoned by thousands. For more than 200 years they were subjected to a ceaseless persecution, till at last they were exterminated. On this island, it is said, it was the custom for the crews of several vessels to spend the summer for the sole purpose of killing "Gare-fowl" for the sake of their feathers. Stone pens were erected into which the birds were driven like sheep, to be slain by millions and their bodies left to rot where they lay.

As a British bird it appears to have been nowhere plentiful during the two or three centuries of its existence. Earlier, however, it must have been commonly used for food, inasmuch as its bones occur in the kitchen-middens of Caithness and Oronsay, and in a cave near Durham. Similarly, its bones occur in kitchen-middens in Denmark. Hence we may suppose that the cause of its extermination in this part of the world was the same as that which culminated in extinction some hundreds of years later in Newfoundland. The last Great Auk in Britain was taken alive in Waterford Harbour in 1834 .

The Islands of Mauritius and Rodriguez furnish us with two further illustrations of the work of extermination due to man's handiwork. Mauritius was the home of a gigantic Pigeon-the Dodo, a bird as large as a small swan, but absolutely incapable of flight. This combination of great stature with flightlessness was the outcome of an abundance of food, and the freedom from all necessity of procuring this food by flight, or by resorting to the use of the wings for the purpose of avoiding enemies. The atrophy of the wing had proceeded so far when man entered into this paradise that it had become so reduced as to be inferior in size to that of our common Rock Pigeon. Thus pinioned, it was at the mercy of the invader; who, however, accomplished the work of destruction unwittingly, 
and this by the introduction of pigs which devoured the eggs and young. The sister island of Rodriguez harboured another Pigeon scarcely inferior in size to the Dodo. This was known as the Solitaire; but somehow or other the fame of this bird has been quite eclipsed by that of its relative the Dodo, yet, in many respects it was the more interesting bird of the two. Most of our knowledge of this bird we owe to the traveller Leguat, who published an account of his wanderings in 1708 .

Indiscriminate slaughter, under the pretext of killing for food, has wiped out many other species, of which not more than one or two can be mentioned here.

First of all we may take the case of the Labrador or Piedduck (Somateria labradoria), which occurred in plenty, in summer, about the mouth of the St. Lawrence and the coast of Labrador, migrating in winter to the shores of Nova Scotia, New Brunswick and New England. This bird, which closely resembled the Eider-duck, was at one time as commonly displayed in American markets as Mallard or Wigeon are in England. Suddenly the supply ceased, and inquiry soon showed that it had ceased for ever. Those who had so long found its capture profitable had not wit enough to see that the policy pursued of plundering the nests and mercilessly shooting the birds, must soon end in putting an end to this source of income, the wretched victims being flightless, and therefore restricted as to their breeding area. About thirty-eight specimens are all that are known to exist in museums.

A similar case is that of the largest known species of Cormorant (Phalacrocorax perspicillatus), which, according to Dr. Steijneger, became extinct about the middle of the nineteenth century. This bird was formerly abundant in Behring Island in the North Pacific, but was exterminated by incessant slaughter for the purposes of food, though one would hardly have supposed that Cormorant, in any shape, would prove a sufficiently palatable dish to bring about the extinction of the bird. Only four skins and a tew bones are all that remain of this bird.

Finally let us take the case of the giant flightless Moa of New Zealand. "Although Moas were still numerous," says Mr. F. A. Lucas, the distinguished American Ornithologist, "when man made his appearance in this part of the world, the 
large deposits of their bones indicate that they were on the wane, and that natural causes had already reduced the feathered population of these islands. A glacial period is believed to have wrought their destruction, and in one great morass, abounding in springs, their bones occur in such enormous numbers, layer upon layer, that it is thought the birds sought the place where the flowing springs might afford their feet at least some respite from the biting cold, and there perished miserably by thousands.

"What Nature spared man finished, and legends of Moa hunts and Moa feasts still lingered among the Maoris when the white man came and began the extermination of the Maori."

That these gigantic birds-the largest species being far larger than an Ostrich-owe their final extinction to man there can be no doubt; for masses of charred bones and egg-shells show that they were hunted for the purposes of food.

Further illustrations of this work of extermination and extinction could be shown, but enough has surely been quoted for the purpose of this chapter, since our aim is more especially to show that birds, by close adaptation to any particular environment, become too highly specialised to respond to any further changes therein, and consequently must die out. Nowhere is this fact more strikingly illustrated than in the case of flightless birds. Here, from an abundance of food procurable on the ground, and freedom from enemies, flight becomes unnecessary. As a consequence, in the course of a few generations the wings have so decreased that flight has become impossible. Should these times of abundance and peace continue, the wings, as in the case of the Moa, vanish completely. The introduction of carnivorous animals now introduces ${ }^{*}$ a new factor into this Edenic environment, to which it is impossible to respond further. Return to flight is impossible, and before any devices for avoiding or meeting the new conditions can be developed, extinction has overwhelmed the victims. 


\section{CHAPTER VIII}

\section{PECULIAR INTERRELATIONS}

Ostriches and Zebras. Rheas and Guanacos. Oxpecker and big Game. Egrets and Elephants. Bee-eaters and Bustards. Penguins, Albatrosses and Petrels. Osprey and small birds. Chaffinch and Missel-thrush. Burrowing Owl and Prairie-dogs. Petrels and "Tuatera Lizard". Puffins and Rabbits. Skuas and Gulls. Frigate-birds and Gannets. Cuckoos and their dupes. The causes of parasitism.

$7 \mathrm{HE}$ subject of the last chapter leads us insensibly up to the consideration of those remarkable interrelationships which exist between different species of birds, or more commonly, between different species of birds and of other animals, though the part these interrelationships play in evolution is not very obvious.

For example, it is not easy to see why the Ostrich in Africa and the Rhea in South America should commonly associate with herds of the larger ungulates of their respective countries. Thus the Ostrich commonly consorts in troops of from thirty to forty with herds of Zebras or the larger Antelopes; while the Common Rhea similarly associates with herds of Deer, and the smaller Darwin's Rhea with herds of Guanacos (Lamx huanacos). In this association there is no apparent advantage to be gained, but there are many similar cases which are less enigmatical. Take, for example, the case of the Oxpecker or Rhinoceros-bird (Buphaga Africanus), a native of South Africa, and generally regarded as a species of Starling. This bird is commonly found in intimate association with basking herds of cattle and big game, running about all over the bodies of these creatures in their search for the ticks and other parasites which harbour there. Lately, however, this bird has fallen into disgrace, since it has extended its attentions to the horses and cattle of the colonists with anything but happy results. It would seem that in removing ticks 


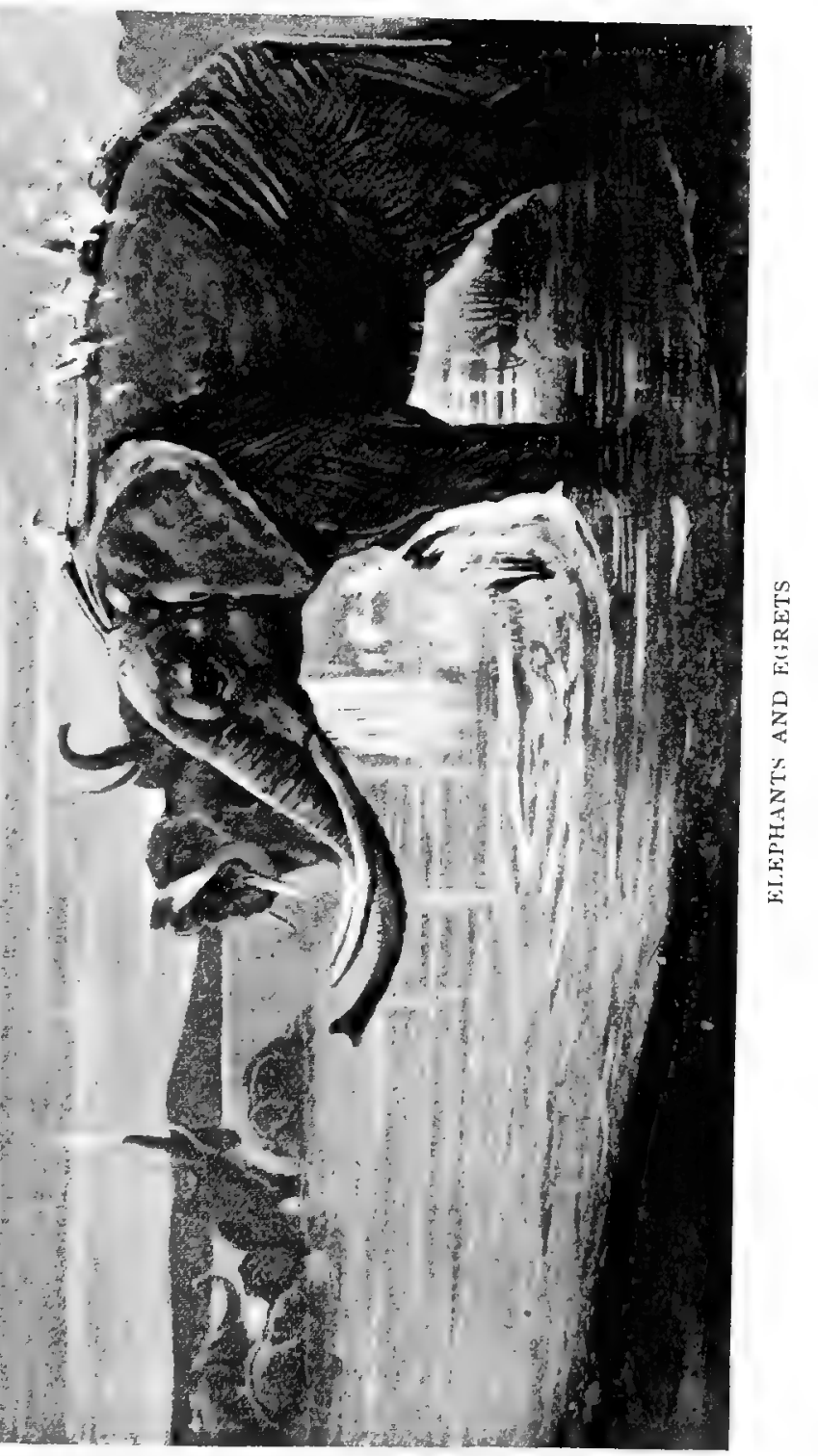






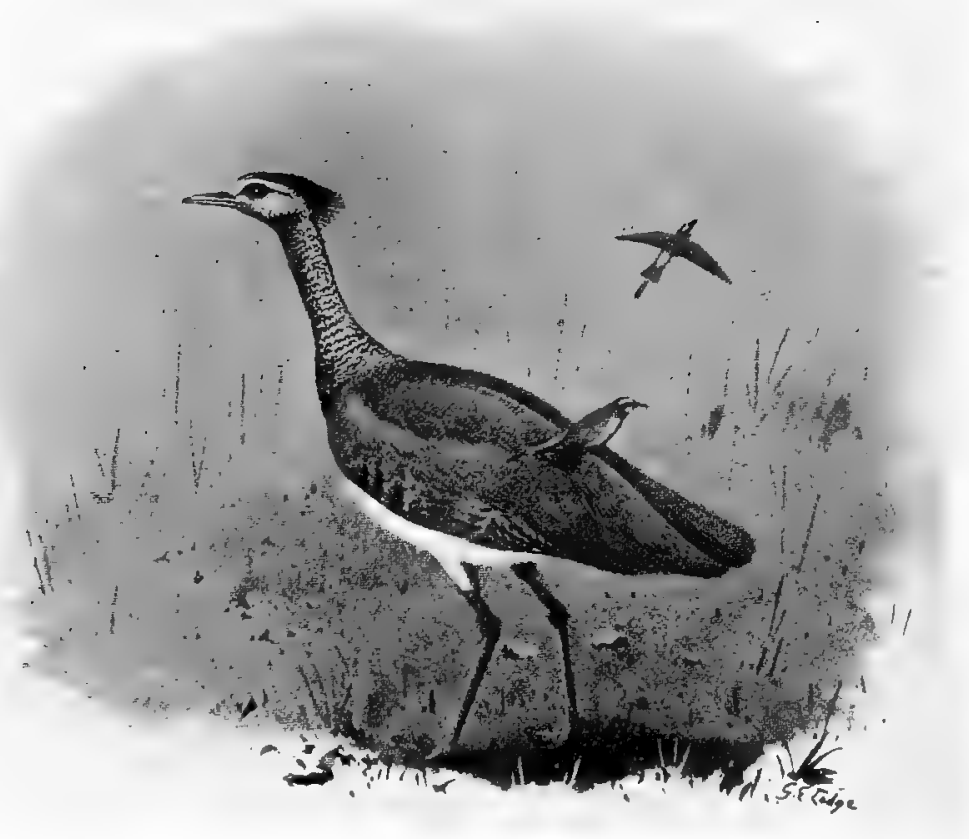

BEE-EATERS AND BUSTARD

FROM "ELEPHANT HUNTING IN EQQUATORIAL AFRICA" 
from the more tender hides of these animals the birds caused wounds, and at the same time gained a taste for blood, with the result that, where horses and cattle are at all numerous, they become severely persecuted by these birds, who now seek, not so much to prey upon the ticks as the hosts thereof, which suffer considerably in consequence. Thus we see how easily long-rooted habits may become changed, and how an originally useful instinct may become depraved. The tough hide of the rhinoceros was proof against the beaks of these birds, and consequently nothing but good resulted from their presence, but, as we have shown, a very different state of things began when the hides of the imported domesticated animals became subjected to a similar inspection. On account of the damage they do the restrictions imposed by Government for their protection have now been removed, but the Oxpecker will doubtless long contrive to hold his own in this vast country. The work of the Rhinoceros-bird in England is performed by the Common Starling, and so far no harm to cattle has been done by reason of injuries inflicted on the hides. Similarly, in East Africa, Egrets swarm over the bodies of elephants when they approach the neighbourhood of water, apparently, as it has been suggested, for the sake of capturing the various kinds of insects put up by the elephants as they move about. In like manner the Rosy Bee-eater (Merops nubicus) in East Africa is described by Mr. Arthur Neumann as habitually riding about "on the back of the large crested Bustard or 'Pauw' (Eupodotis kori) which is common about the northeast extremity of Bassu. It sits far back on the rump of its mount, as a boy rides a donkey. The Pauw does not seem to resent this liberty, but stalks majestically along, while its brilliantly clad little jockey keeps a lookout, sitting sideways, and now and again flies up after an insect it has espied, returning again after the chase to 'its camel' as Juma [his native servant] not inaptly called it. . . . I have also noticed this pretty little bird sitting on the backs of goats, sheep and antelopes, but the Pauw seems its favourite steed. I imagine it gets more flights in this way at game put up by its bearer, which also affords it a point of vantage whence to sight and pursue its prey in a country where suitable sticks to perch on are few."

Much more curious are the associations formed by birds 
during the breeding season. In the case of aquatic birds which have perforce to congregate in great numbers on a small area of land, this phase is presented in a very striking manner. Moseley cites a case of this kind, where, when visiting Nightingale Island-one of the Tristan $\mathrm{Da}$ Cunha group-he found vast numbers of Penguins (Catarrhactes chrysocome) and Yellowbilled Albatrosses (Diomedea culminata) breeding together on the open ground, and with these were many nestling pairs of Skuas (Stercorarius antarcticus), while the soil beneath was riddled with holes burrowed by various species of Petrels.

Similarly, the huge nests of large birds of prey, such as those of the Secretary-bird (Serpentarius) and of the Osprey (Pandion), invariably lodge within their walls numbers of nests of small Passerine birds - and even Night-herons in the case of the Osprey-these nests being built into the outer walls, much as birds build nests in the thatched roofs of houses. This peculiar site is chosen, however, not so much for convenience as for the sake of freedom from molestation which they gain by thus seeking the protection of their powerful neighbours. Similarly, in France the Chaffinch is said to build its nest, whenever possible, as near as may be to that of the Misselthrush, a bird which is exceedingly pugnacious and intolerant of the presence of Magpies which have rather a fondness for the eggs of small birds.

But instances of this kind could be multiplied with ease. Let as pass on to stranger associations. One of the most familiar examples of the kind to which we refer is that afforded by the Burrowing Owl (Speotyto) of America. In North America this bird shares the burrows of " prairie-dogs," rats, ground-squirrels or badgers, and in South America those of the Viscacha, Patagonian hare, and, it is said, even of armadillos and large lizards, constructing therein a nest of grass and feathers. Where ready-made burrows are not to be had, however, they will dig for themselves. Similarly, various species of Petrels in New Zealand share the burrows of the "Tuatera Lizard" (Sphenodon). The Petrel seems generally to live on the left, the Tuatera on the right side of the burrow!

The amicable terms which these birds seem to have established with the occupants of these burrows is the more striking because the British Puffin which, whenever possible, 
selects rabbit burrows for its nursery, will not tolerate the presence of the rightful owners of the burrow.

Without doubt the most interesting and most puzzling of all the interrelationships displayed by birds relate to the phenomena of parasitism which is manifested in two distinct ways.

The first of these is illustrated by birds which waylay others for the sake of robbing them of their food, and among these the Skua-gulls and the Frigate-birds hold perhaps the foremost place. "Woe to the Gull or other sea-bird," says Brehm, " which seizes its prey within sight of a Skua! With arrow-like swiftness he follows the fortunate possessor uttering barking cries, dances, as if playfully, round him on all sides, cunningly prevents any attempts at flight, resists all defence, and untiringly and ceaselessly teases him till he gives up his prize, even though it has to be regurgitated from his crop." It is this habit of catching the food of the persecuted bird which has given the Skua the unenviable name of dung-eater, the common notion being that the bird in its fright voided excrement! The Frigate-bird is a no less persistent robber. Dr. C. W. Andrews, during his exploration of Christmas Island (Indian Ocean) had plenty of opportunities of watching these birds. They "by no means depend for food," he says, "on the fish they catch themselves, but systematically rob the Gannets which feed in great numbers on the island. Towards sunset many Frigate-birds may be seen sailing along the coast, watching for the return of the Gannets full-fed from the fishing grounds. The birds being well aware of what is in store for them, and knowing that if they can reach the shelter of the trees they are safe, approach the island at a great speed, flying as low down as possible. Usually, while they are still at some distance, two or three Frigate-birds give chase, and hunt the Gannet backwards and forwards, continually trying to get beneath it and to cut off its retreat to the trees. The chase may last several minutes, but at length the exhausted bird disgorges some of the fish it had swallowed, and this is immediately caught in mid-air by one of the pursuers."

Before proceeding further it would be well to point out that neither in the cases which have been cited, nor in those which are to follow on the subject of parasitism, are these inter- 
relationships so close as is the case with the lower animals. Commensalism and symbiosis are unknown among the birds, while the parasitism of which instances have been given, and of which we are presently to speak, is of a very different kind to that which obtains among invertebrates.

As may have been surmised, the parasitism of the Cuckoos and some other birds is now to be discussed. In this form of parasitism the female has adopted the practice of depositing her eggs in the nests of other birds and there leaving them, without further care, to be hatched by her dupes, who, unconscious of the trick which has been played, perform the duties the immoral parent has contrived to shirk.

First of all as to the Cuckoos. Though the broad facts of the case, as illustrated by the Common Cuckoo (Cuculus canorus), are well known, they will be repeated here for the sake of the bearing they have on less widely known facts which have been brought to light during recent years, facts which are of the highest importance.

This bird then, which reaches the shores of Great Britain in the month of April, deposits its eggs, singly, in the nests of the smaller Passerines, though occasionally, by an error of judgment, other species are selected. No less than eighty-four different species of birds are known to have been victimised in this way-including Eider-ducks and Grebes! — but the majority of such eggs are distributed among Robins, Hedge-sparrows, Wagtails, Meadow-pipits, Tree-pipits, Warblers, Thrushes and Red-backed Shrikes.

The egg is duly brooded by the dupe with her own eggs, and in due time is hatched. Within an hour or so of this event a gruesome domestic tragedy is invariably enacted; for, prompted perchance by the overmastering instinct of selfpreservation, the foundling proceeds to eject from the nest the offspring of its foster-parents, as though conscious that they would be utterly unable to provide sufficient food to satisfy its insatiable appetite while these competitors remained alive. Accordingly, with a most diabolical persistence and ingenuity, this blind and naked hooligan proceeds to the work of eviction, one after another being pitched over the edge of the nest. This feat is performed by burrowing under the victim until the body thereof rests upon the middle of the little murderer's back, 
when, raising the wings to keep its burden in position, it climbs up the nest backwards. Little by little, with widely spread legs, and the use of the beak as a lever, the journey to the top of the nest is made, when, with a supreme effort the helpless little Robin or Hedge-sparrow, as the case may be, is sent sprawling, to die very shortly after of exposure. Not until the last is ejected does this extraordinary little criminal relax its efforts; but so soon as all is over it settles down contentedly to enjoy life, developing a most ravenous appetite, and making the most exacting demands upon its foster-parents.

Without for the present discussing the factors which have resulted in this most successful fraud on the part of the Cuckoo, we may refer next to another very remarkable phase of this life-history, and this concerns the coloration of the Cuckoo's egg, which, as a rule, bears a very close resemblance to those of the nest in which it is laid. In other words, the eggs of the Cuckoo show a very remarkable range of variation, or rather of coloration, corresponding, roughly, with the number of species which are used as dupes.

Evidence has now accumulated to show, however, that this range of colours becomes manifest only when the eggs of a large series of Cuckoos are examined. In other words, the eggs of any particular Cuckoo are all of the same type, both in colour and markings; and this is true when all the eggs laid by a single female throughout each season for a number of years are examined-and such series have been found, by reason of certain peculiarities of colour and pattern. Further, it is now almost conclusively established that the colour and pattern of any given egg bears a more or less close resemblance to the eggs of the host in whose nest they are placed. Where this rule is broken it is more than probable that the disparity is due to untoward circumstances, to the fact that the Cuckoo at the time she deposited her egg was unable to find a suitable nest, and so dropped the egg into the nearest likely nest available to take its chance. How this curious resemblance came about it is not easy to see at first; for it is certain that the bird cannot in any way voluntarily influence the colour of her egg, nor can we suppose that she carries her egg in her mouth while she makes the round of nests in the neighbourhood for the purpose of selecting that as a nursery which contains eggs most 
like her own. The most probable explanation is that which has been formulated by the late Professor Newton-though he does not claim the discovery as wholly his own-who suggests that the Cuckoo has split up into a number of distinct "gens". Thus he recognises Robin Cuckoos, Meadow-pipit Cuckoos, Wagtail Cuckoos, Reed-warbler Cuckoos, and so on-Cuckoo-types whose eggs resemble the several species just enumerated. This formation of Cuckoo "gens" has, he suggests, been brought about by selection. When the Cuckoo first began to shirk the duties of incubation by dropping its eggs into the nests of other birds, only those were hatched which sufficiently matched those of the dupe, the others being ejected from the nests by the owners thereof. A further process of selection took place, moreover, if, on hatching, the food of the dupe proved unsuitable to the needs of the foundling. Thus, it would come about that female Cuckoos reared in Robins or Wagtails' nests would seek the nests of these birds in which, in turn, to lay their own eggs. The probability of this explanation of the evolution of the resemblance between the eggs of the Cuckoo and those of its host has recently been exhaustively investigated by $\mathrm{Mr}$. Oswald Latter, and though he at first felt sceptical about the matter, he has come to the conclusion, after examining many hundreds of eggs, that the theory is well founded.

A most serious objection, however, it has been urged, to the stability of this theory is the certainty that female "Robin Cuckoos" must frequently mate with male "Wagtail Cuckoos," and so on, and that this being so we must assume that the inherited habits and characters of every female Cuckoo must follow only the female line of descent. But this objection is based on a confusion of the facts of the case. It appears to be forgotten that these "Robin Cuckoos" and "Wagtail Cuckoos" are not hybrids between the foster-parent and the Cuckoo. What the female Cuckoo has inherited is the instinct to seek out, whenever possible, nests of birds of the species by which it was reared. And there is nothing more wonderful in this than in the remarkable inherited instincts of many female insects which make peculiar provisions for their offspring: in the case of the Cuckoo we are dealing with inherited instinct prompted by memory.

That the Cuckoo must keep a careful watch on birds likely 
to prove suitable victims is evident from the position of many of the nests which are found to contain young Cuckoos. As a case in point mention may be made of an instance where a young Cuckoo was found in the nest of a Pied Wagtail which had built in a flower-pot containing a plant trained over an intricate trellis-work, leaving but small interspaces just big enough to allow the passage of so small a bird, and this flowerpot, it is to be noted, was placed in a greenhouse. Thus then the Cuckoo must have noticed the Wagtails collecting nesting materials, and have watched their destination. Then, having deposited its egg on the ground somewhere in the vicinity, it must have picked it up and gone straight to the flower-pot, thrust in its head and dropped the egg into the nest.

The Common Cuckoo (Cuculus canorus) is not the only species of the Cuckoo tribe which is addicted to parasitism. Thus, the great Spotted Cuckoo (Coccystes glandarius)--a rare visitor to Great Britain, but common in Southern Spain and North Africa-foists its eggs upon various species of the Crow tribe. In Spain, its choice falls upon the Magpie, in Egypt the Hooded Crow, and in Algeria the Moorish Magpie. In this restriction to birds of the Crow tribe this Cuckoo differs remarkably from the Common Cuckoo, which levies service on a large number of species of widely different families. It is further peculiar in that at least two eggs are laid in each nestsometimes as many as four-while the newly hatched birds live amicably with the rightful occupants of the nest. So closely, it may be remarked, do the eggs of this Cuckoo resemble those of the Crows in whose nests they are placed, that even oologists have been deceived by the resemblance.

Many other species of Cuckoos have also become parasitic, and so far as the evidence goes, it would appear that, like the Great Spotted Cuckoo, the young have not developed the remarkable, one might almost say criminal, instincts displayed by the Common Cuckoo. The Cuckoos of the Genus Endynamys are parasitic. Thus the Koel of Palawan (E. orientalis) victimises a Mynah (Eulabes javanicus), while the Indian Koel ( $E$. honorata) chooses Crows for this purpose. Similarly, the New Caledonian Cuckoo (Caccomantis bronzinus) lays its eggs in the nest of a Flycatcher (Pseudogerygone flavilateralis). The case of the Drongo Cuckoo (Surniculus lugubris) of India is still 
more remarkable, since this bird lays its eggs in the nest of the Black-drongo (Buchanga atra), a feat which it apparently could not accomplish but for the fact that it has acquired a most extraordinary resemblance to this bird, thereby enabling it to evade the notice of the owners of the nest when about to thrust upon them the doubtful privilege of incubating its eggs. But of this particulars will be given elsewhere in these pages (p. 327). In Java, however, it appears to dupe the Bulbul (Pycnonotus aurigaster), at any rate two eggs in the British Museum were obtained from the nests of this bird.

Though Cuckoos all over the world, and of widely different genera, have acquired parasitic habits, some species build nests and incubate their eggs in normal fashion, though, as a rule, these nests are but indifferently constructed. This does not apply, however, to the Lark-heeled Cuckoos of the Genus Centropus, which build a large globular nest, generally with an entrance at the side.

One or two species at least, though commonly parasitic, appear occasionally to build a nest and incubate. This is the case, for example, with the Hawk Cuckoo (Hierococcyx sparveroides) of the Himalayas and East Asia, which appears to be normally parasitic, but in the Nilgiris to build a nest and rear its young.

This strange aberration of the parental instinct is, however, not confined to the Cuckoos, since it is met with also among the South American "Hangnests," birds belonging to a widely different group-being true Passeres. Thus one species (Cassidix oryzivorus) in Pará appears always to leave the incubation of its eggs and care of its young to an allied species, C. persicus, while farther south it victimises others of about its own size, such as the Crested Cassique (Ostiniops decumanus) or the Yellow Cassique (Cassicus hamorrhous).

The nearly allied polyandrous "Cow-birds," belonging to the Genus Molobrus, are yet more interesting from this point of view, inasmuch as this parasitism appears to have brought about a state of disorganisation of the parental instinct which threatens all the species concerned with extinction. Only one species, Molobrus badius, appears to have retained the normal reproductive instincts. The rest seem to share in common the habit of dropping a considerable number of their eggs in empty 
nests, or abandoning them by the wayside. But a few are laid in the nests of other birds, by them to be hatched. The only care they appear to take to secure any degree of safety for their offspring is when they pick holes in some, at least, of the eggs they find in the nests they visit for their nefarious purposes. Should any of these eggs succeed in hatching, the young Cow bird quickly seals the fate at any rate of most of the callow-young, by sitting on them until they are smothered, when the dead bodies appear to be thrown out by the Cowbirds' foster-parents. Even when these strange birds exhibit sense enough to deposit their eggs in nests where incubation is going on they not seldom exhibit a curious lack of discernment, since several females will deposit their eggs in the same nest, or they will stupidly stab and break their own egg while destroying those of their dupes! The only respectable member of the family, Molobrus badius, is victimised by its near ally $M$. rufoaxillaris, though strangely enough another species, $M$. bonariensis, which is found in this same region-Buenos Ayresis always detected and repulsed when it similarly attempts to rid itself of the ties of parentage.

While among the Cuckoos the majority appear to be parasitic some at least retain their normal parental instincts, while in others, aberration has taken another course, which, in some ways, recalls features which obtain among the Cowbirds. Thus certain New World Cuckoos, known as the White Ani (Guira) and the Black Ani (Crotophaga), the former represented by only a single species (Guira piriviqua), the latter by at least three species (Crotophaga ani, $C$. major and $C$. sulcirostris), exhibit a most remarkable prolificness in the number of eggs produced, as many apparently, or more, being dropped about promiscuously as are deposited in nests. But these Cuckoos are not parasitic. Instead they perform their maternal duties on the co-operative system. A number of females combine to build a large nest of twigs which is placed in a tree, and lined with moss and green leaves. Herein each deposits about five eggs, to the number of twenty or more, and upon these, according to some accounts, all proceed to sit, huddled together, until the eggs are hatched, when the company of mothers proceed to the work of feeding. So flimsily are these nests constructed, however, that not seldom the eggs fall through the nest as they are laid, while 
many other eggs appear to be carelessly dropped outside the nest. According to another version, these eggs are arranged in layers, with leaves between each layer, and are then abandoned, incubation taking place from the fermentation of the decaying vegetable matter aided by the sun.

Be this as it may it would seem that the Ani Cuckoos, like their parasitic neighbours and relatives, owe the decadence of their parental instincts to the fact that they are polyandrous, and this because the males largely outnumber the females. But for the fact that the parasitic types have succeeded in producing eggs which, for the most part, are sufficiently like those of their dupes to pass muster, they would have become extinct. There seems to be no doubt about this mimicry of the eggs-to which reference will be made again-and in this connection it is of importance to note that the European Cuckoo (Cuculus canorus) in India, chooses birds of European types as its victims.

That parasitism is due to polyandry-and to a less extent to polygamy-we believe is almost certain. And this because such a sexual relationship tends inevitably to lower the parental instincts, just as monogamy tends to strengthen them. Among the polygamous Game-birds there are not wanting signs of degeneracy in the parental instinct. Thus the males commonly leave the care of their offspring entirely to the female, which, indeed, often have to guard them against the violence of the paternal jealousy: while two females will frequently share a common nest, a custom which offers an easy means of shelving responsibility altogether, as in the case of parasitic species. 


\section{CHAPTER IX}

\section{PHASES OF SOCIAL LIFE}

Gregarious birds. Curious sleeping habits. Pelicans fishing. Woodpeckers and food stores. Significance of gregarious habits.

$W^{\text {n }}$

HILE the facts related in the previous chapters with regard to the relationships of birds one to another are well known, they are facts which can only be verified by close and careful observation. But the most casual observer needs not to be reminded that many birds are gregarious. What advantages may accrue from this relationship, and what modifications thereof have been evolved are, however, by no means so obvious, and it will be the purpose of this chapter to trace these, at any rate in outline.

No better example of a gregarious bird could be found than that of the Rook, which the year round herds together in larger or smaller bands. The Limicoline birds afford another good example. But though they commonly keep together to breed in colonies, sometimes of enormous size, in many cases they elect to perform their parental duties in seclusion. Herons breed in colonies but are otherwise extremely solitary birds. While commonly birds of gregarious habits associate in small parties, they may, in the case of some species, as in Flamingoes, the Rice-bird (Dolichonyx oryzivorus) and Starlings, roam in huge flocks. But these numbers are never so great as in the vast assemblages of birds which gather together during the breeding season. 'This is especially true of Penguins, Albatrosses and Terns, which may number millions of birds. Among land birds the only parallel is, or rather was, that afforded by the Passenger Pigeon (Ectopistes migratorius). A breeding colony of this species was discovered in 1876 by the naturalist Brewster. It began near Petosky and extended north-east, past Crooked Lake for twenty-eight miles, averaging three or 
four miles wide. The birds arrived in two separate bodies, one directly from the south by land, the other following the east coast of Wisconsin, and crossing Manitou Island, the latter body forming an army at least five miles long and one mile broad. The birds at once began the work of nest-building, and in a very short time this colony extended for a distance of about twenty-eight miles of forest, every tree having one or more nests, and some being filled therewith!

It is clear that large assemblages of the same species are only possible when there is an abundance of food for all, and the gregariousness of some birds is probably due to this fact alone, as in the case of Gannets and Guillemots, for example, or the large gatherings of birds of prey, as when following the hordes of migrating Lemmings. It does not seem that such assemblages are bound by any ties of mutual affection or for desire of protection, though these several inducements cannot by any means be sharply divided. Parrots, for example, appear to roam in bands for the mere pleasure of company; while Rooks find in association security against surprise while engrossed in feeding, since one or other of the flock is constantly performing the rôle of sentinel. The vagrant bands of the Long-tailed Titmouse, which lend such a charm to our woods during the autumn and winter months, are held together very largely at any rate by their common needs. The discovery of insect food at this time is an arduous task, and if undertaken individually many would starve. As Professor Newton remarks : "A single Titmouse searching alone might hunt for a whole day without meeting with a sufficiency, while if a dozen are united by the same motive, it is hardly possible for the place in which the food is lodged to escape their detection, and when discovered a few call-notes from the lucky finder are enough to assemble the whole company to share the feast. . . . One tree after another is visited by the active little rovers, and its branches examined: if nothing be forthcoming, away goes the explorer to the next that presents itself, merely giving utterance to the usual twitter that serves to keep the body together. But if the object of the search be found, another kind of chirp is emitted, and the next moment the several members of the band are flitting in succession to the tree, and eagerly engaged with the spoil." 
That the gregarious habit is formed originally not so much by community of interests as by the common attraction of an abundance of food is, as we have already hinted, indisputable. Thus it is that birds of prey are rarely gregarious. An exception is found in the case of the little Red-footed Falcon (Falco vespertinus) -a summer visitor to Europe-which just before migration assembles in immense flocks, reuniting in autumn previous to departure for its African winter quarters. But it also forms small breeding communities, and further assembles together in some number to roost. This is possible because the food of this species consists almost entirely of insects, such as dragon-flies, large moths, beetles and grasshoppers, varied by lizards, shrews and field-mice. The Osprey again breeds in enormous colonies wherever the food supply admits. As many as three hundred pairs are described as nesting together in North America, and large colonies are formed in parts of Europe, as in Pomerania. Thus we see, in the case of the Red-footed Falcon, how a species, assembling at first merely because drawn by a bountiful food supply, may later develop more social instincts.

While among some birds the gregarious instinct is deeply rooted, in others it forms but the slenderest of ties. Some species, for example, appear to associate during migration and disperse immediately on their arrival at their destination.

With most gregarious species the flocks are made up of birds of both sexes, but in some cases the males and females, during a part of the year at least, form separate companies. This is true, for instance, of the Chaffinch, which, in some localities at any rate, passes the winter after this fashion.

Speaking generally, it would appear that gregarious species hold their own best in the struggle for existence, and this is most noticeable where the development of the social instinct is highest. Such species are certainly numerically stronger than solitary species. Thus Rooks and Jackdaws are far more abundant than Ravens, though the last species has been mercilessly persecuted by many and so further reduced. Swifts are more numerous than Night-jars, Plovers than Rails. Nuthatches and Titmice are nearly allied, yet the latter are more numerous than the former, which is a solitary bird. This difference is certainly not due to the relative abundance of food 
demanded by these several species, for in those between which these comparisons are made the food is practically the same. Nor can it be attributed to relative differences in fertility, the shy and retiring Rail, for example, having a far larger progeny than the Plovers. It would seem then, that on the whole the evidence favours the superiority of gregarious over solitary habits.

Among gregarious species some display a much more intimate association than others-are more social in their relationships. And this is shown very clearly in the devices which some species have adopted for their mutual protection during sleep. The Common Partridge, as is well known, lives in small companies, or "coveys," which scatter only while feeding, and then not far enough to be beyond call. Late in the day, as soon "as the beetles begin to buzz," says Professor Newton, the whole move away together to some spot where they jug, as it is called-that is, squat and nestle close together for the night; and from the appearance of the mutings, or droppings, which are generally deposited in a circle of only a few inches in diameter, it would appear that the birds arrange themselves also in a circle, of which their tails form the centre, all the heads being outwards-a disposition which instinct has suggested as the best for observing the approach of any of their numerous enemies, whatever may be the direction, and thus increase their security by enabling them to avoid a surprise. Ducks similarly take special precautions to secure safety during sleep, when this must be taken in exposed situations, as when, for example, they desire to doze between the intervals of feeding during the night, which they pass afloat. At such times they keep close together, and to avoid drifting ashore keep one leg slowly paddling and thus drive themselves round in circles.

More remarkable still are those cases where a number of birds crowd together in ball-like masses during sleep. Our British Long-tailed Titmouse furnishes an example of this strange habit. Similarly, the Crested Tree-swift of India roosts in this fashion, forming feathery balls. The Wood-swallows (Artamide) have also adopted this practice. But the Australian species seem to have carried it a stage further, inasmuch as instead of forming a ball on the upper side of the bough, they are said to cling together suspended from the under side. If this be so, one can 
only wonder how those clinging to the bough manage to sustain the weight of their fellows for so long a time. By way of corroboration we may remark that the Mouse-birds or Colies also sleep after this fashion.

This reversed position during sleep, by the way, is still more marked in the little Hanging Parrots. Numbering some twenty species, and ranging from India and the Philippine Islands, through the Malayan region as far east as Duke of York Island, these little birds, which do not exceed five inches in length, all share the habit of sleeping suspended by their feet from the under surface of the bough, hanging for hours at a time head downwards, after the fashion of bats. Not only during sleep, however, do they thus hang, for in confinement they will so hang crowding together and caressing one another after the fashion so common among Parrots.

The good comradeship displayed in these curious sleeping communities is exhibited in other directions among birds, and especially in the co-operation many display in the capture of agile prey. Thus the Golden Eagle (Aquila chryscetos) will sometimes at any rate hunt in concert for game. On such occasions one bird glides over the ground beating the bushes and undergrowth with its wings, while the other remains on the lookout at a slight elevation, pouncing at once upon whatever game is driven out, and sharing with its companion. Similarly, Pelicans, when fishing in a lake or bay, combine to form a semicircular cordon, driving a shoal of fish before them to the bank. As soon as they have succeeded in getting their victims sufficiently massed they set about reaping the fruits of their shepherding, filling their large pouches as one might fill a landing-net. Cormorants are said, occasionally at any rate, to adopt similar methods of hunting.

Gregarious habits are, as we have seen, fostered and developed where the food supply is unlimited; but wherever a sufficiency is obtainable only by strenuous hunting, segregation and competition result. These factors, however, are not so obvious, and cannot be seen at work as the opposite to this picture can be seen. Flocks of birds feeding in harmony impress us: those that lead solitary lives escape our attention, and the fact that this isolation is more or less enforced does not easily admit of demonstration. As a rule, probably, it is taken for granted that 
the pugnacity which species which lead solitary lives cunningly exhibit, is due to an inherent moroseness of disposition. As a matter of fact it is rather begotten by stern necessity. An area which would provide an abundance for a pair of birds would spell famine if occupied by a flock, and hence the instinct of self-preservation develops pugnacity. Competition for whatever is to be had results, and the most aggressive species will prevail. Yet all this is to be gathered rather by inference than by observation, for this struggle between individuals of the same species, or between two or more allied species of sinilar habits, is carried on decently, as it were: there is no parade by the conquerors before the public. Consequently, we only realise what has taken place by inference, as a rule. That one gregarious species will invade the territory of another nearly related species and more or less totally supplant it, is shown, for instance, in the case of the Lesser Kestrel, which since I877 has annually invaded the district of Orenberg, Russia, in thousands, displacing the Red-footed Falcon, which has retreated to the northern provinces of Russia.

Although earlier in this chapter it was suggested that gregarious species, on the whole, hold their own best, inasmuch as they are numerically stronger than species which lead solitary lives, it may well be that this is not really the correct interpretation of the facts. That is to say, this numerical superiority may be the result of a uniformly abundant food supply, so that the formation of large colonies may be not so much the consequence of the evolution of a sense of comradeship, or of a more or less intelligent sense of the many advantages gained thereby, as of a lessened mortality due to the lightening of the struggle for food.

Birds, as a rule, do not lay up stores of food for use during times of scarcity, and, strangely enough, the only exceptions to this rule appear to be made in the case of certain Woodpeckers which band together for this purpose. Thus the Californian Woodpecker (Melanerpes formicivorus) is said to band together in considerable numbers, and, selecting an oak-tree suitable to the purpose, proceed to riddle the bark with holes. This done they set to work to collect acorns which are then thrust each into a separate hole. For some unknown reason only one tree in an area of several miles is selected, and having been duly stocked is left for some considerable time. At irregular intervals 
stragglers of the original party return to inspect the store, and disperse again. Finally, at a time apparently agreed upon, all return to feast upon the hoard. But whether these nuts are stored till they ripen, or for the sake of attracting and harbouring insect grubs, is not known.

No less interesting are the accounts given of the Red-headed Woodpecker, which is abundant in Indiana only when beechnuts are plentiful. From the time these begin to ripen the Woodpeckers are constantly at work in storing nuts, which they
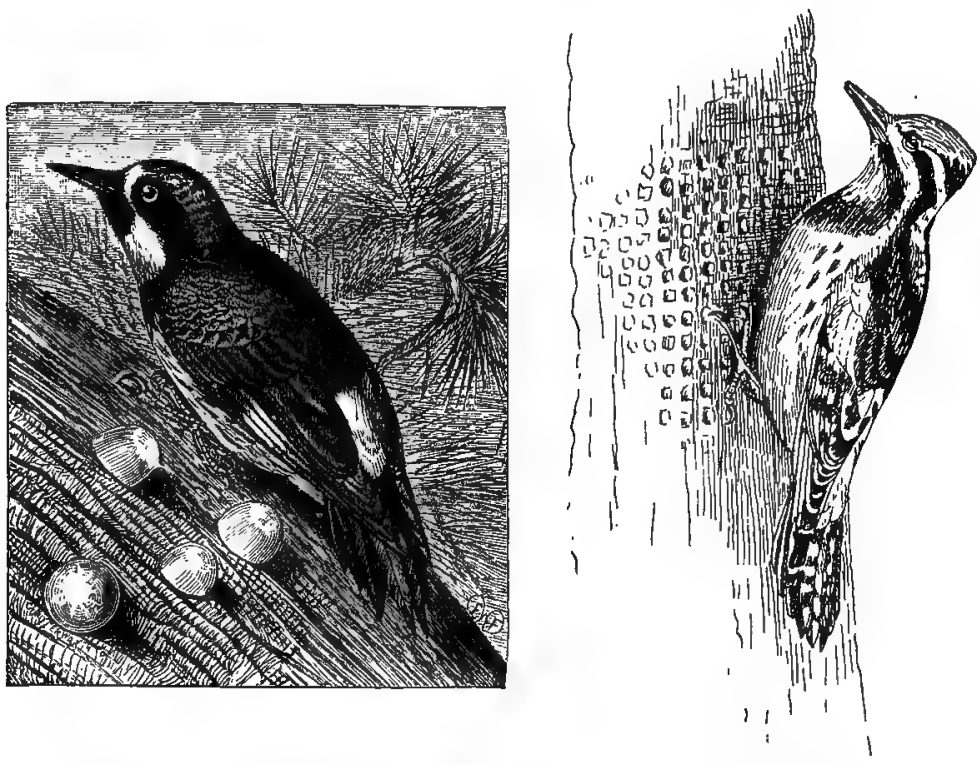

Ill. 20.-Devices to Secure a Permanent Food Supply

The right-hand figure is that of the Sapsucker or Yellow-bellied Woodpecker; the left-hand the Californian Woodpecker.

deposit in every conceivable situation-the cavities of decayed trees, clefts in gateposts, and even into the thatches of houses! The felling of a tree in such a neighbourhood is always sure to disclose several pints of these small nuts. In one instance where they had been dropped into a crevice, pieces of bark and wood had been driven into the aperture to conceal the treasure from poachers! These birds have also formed a habit of storing grasshoppers in the way that the Californian Woodpecker 
stores nuts. These insects are captured with as little injury as possible, borne to some old oak post or tree, and there wedged in between the crevices of the bark and left struggling vainly to get free. As many as a hundred grasshoppers have been found so wedged at one time. Later the birds return to devour their victims.

This record loses something of its importance at present, since it does not appear to have been ascertained whether the stores referred to are made by individuals or by a number of birds banded together for a common purpose.

In this connection mention may be made of the case of the American Yellow-bellied Woodpecker (Sphyrapicus varius) which has developed a great fondness for the sap of trees, to obtain which it pierces a system of more or less symmetrically disposed holes through the bark so as to tap the source of the sap. This soon collects in the holes prepared for its reception, and, incidentally, attracts large numbers of insects which are also devoured by the Woodpecker. There is no record to show whether this species also works in concert with its neighbours, after the fashion of the Californian Woodpecker just referred to.

The taste for sap is probably an acquired one, possibly gained in the first instance when this was tapped in searching for insects. The fact that insects became attracted to the sweet juice issuing from these originally more or less accidental wounds in the tree made by the bird, would soon, it may be imagined, be associated by the bird with the fact that only certain trees-apple and maple, and one or two others-yielded this exudation, and the consequent fly-decoy, as a result of vigorous hammering. At any rate only profitable trees are so punctured, and hence this bird in orchards is not much welcomed! 


\section{CHAPTER $\mathrm{X}$}

\section{THE RELATIONS OF THE SEXES}

The division of labour in nest-building. Manifestations of sexual activity. Forms of this activity. Plumage displays. "Sácaleli." Wind-bags and display. Tournaments. Weapons and their uses. Dancing. "Gardening." Song. Ínstrumental music. Where the sex rôle is reversed.

7 HE high degree of individuality which birds, in common with the rest of the higher animals, have attained, has rendered them independent of one another to a very large extent.

Combinations of individuals each with a limited rôle to play, such as is met with among the lower and less intelligent animals, have passed away, and individualism with its greater responsibilities and greater possibilities has asserted itself.

But in studying the relations of the sexes it will be found that the principle of division of labour has to a limited extent been revived. Thus in the work of nest-building, of the incubation of the eggs, and of the feeding of the young, the two sexes often take equal shares, though in a very large number of instances the whole of these labours are undertaken entirely by the female, and in a few striking exceptions by the male alone. This phase of bird-life, however, will be dealt with in the next chapter. Here it is proposed to review a very different aspect of this matter of the relations of the sexes. In short, we shall survey, as briefly as may be, some of the more remarkable of the facts which have been collected relating to that stormy period of life during which the fateful choice of mates takes place.

In some species this choice is accompanied by most extraordinary behaviour, and in all peculiarities of conduct are to be remarked, which for the rest of the year are dormant. The mass of facts which have been accumulated on this theme is bewildering, the more so since the most conflicting theories 
have been built up by way of interpreting the significance of what has been observed.

Ignoring, for the moment, these interpretations, let us take a brief survey of the more striking facts which have been recorded on this head.

In the first place, sexual activity in birds manifests itself in many ways, sometimes indeed in a complex of emotions not easy of analysis. But roughly we may divide the phenomena into (I) periodic outbursts of ecstatic frenzy, during which strange postures are assumed, generally in the presence of the opposite sex; (2) outbursts of jealous rage which vents itself in fighting all possible rivals who may appear upon the scene. Such conflicts are often severe, one or other of the combatants often being badly mauled, or left dead upon the field ; and (3) in vocal or instrumental music, often of great beauty.

But the living bird defies systematic definitions; many, for example, contrive to combine all three of these phases. As a rule, in the vast majority of cases indeed, the males alone are the performers, but in a few species the tables are turned, the rôle of the male being played by the female.

Considerations of space forbid anything like an exhaustive analysis of this aspect of bird-life ; indeed little more than a very brief survey thereof is possible. And this shall commence with an indication of the nature of displays of the kind indicated in Section I.

\section{Plumage Displays}

Of these no more familiar example could be found than that furnished by the ridiculous antics of the common Housesparrow, which are generally preceded by unseemly brawls, such as are, however, quite in harmony with the life of this street arab among birds. The grotesque manner in which he struts with drooping wings and outspread, upraised tail, around his chosen mate are, however, but feeble performances compared with what many of his betters indulge in; though these last have contrived to mask the grotesque element by the splendour of their plumage.

The Turkey and the Peacock may serve us as examples of this. The gorgeous dress of the latter bird is so familiar that any description thereof is unnecessary, but it may be well to remark 



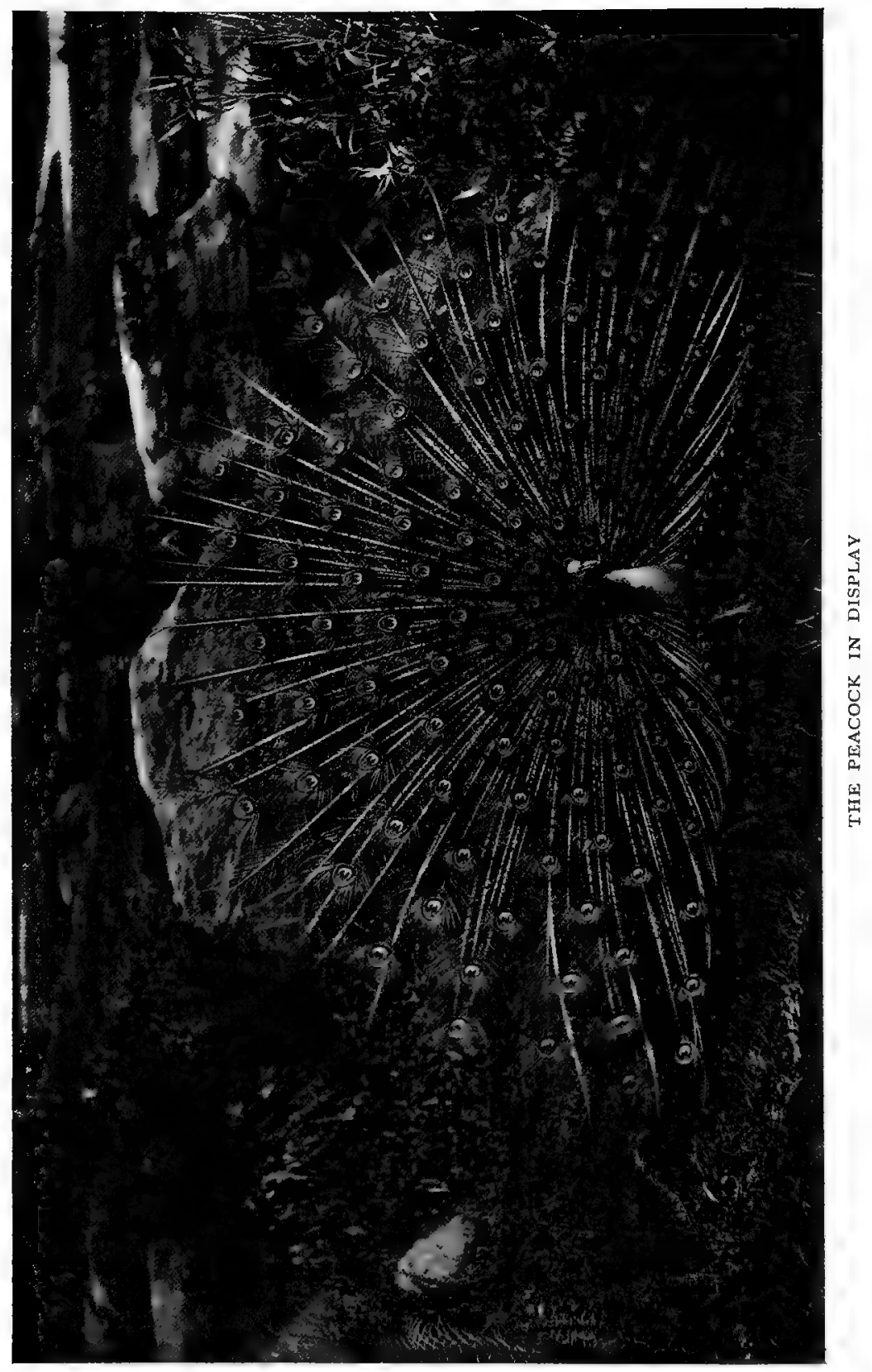


that the wonderful "train," which is the Peacock's crowning glory, is composed partly of the feathers of the back and partly of the coverts of the tail feathers, which latter are used as a support to the train. The long ocellated feathers, by the way, are the covert feathers. This magnificent appendage, this marvellous train, is made to play a most important part in the Peacock's courtship, though whether he is as conscious of its beauty as some imagine is a debatable point.

If he be carefully watched it will be seen that he first places himself more or less in front of her, but at some distance off; then watching his opportunity, turns round, and in turning effectually conceals the beauties which it is his desire at the right moment should overcome her! Walking rapidly backwards and going faster and faster, and faster still, till, arrived within a foot of her, he suddenly, like a flash, swings round and displays to the full his truly gorgeous vestments. This turning movement is accompanied by a violent shaking of the train, the quills of which rattle like the pattering of rain upon leaves. Often this movement is followed by a loud scream. But the curious part of it is that the female, for whom all this elaborate display is made, appears to remain supremely indifferent, and offers him no encouragement whatever.

In some ways the display of the Argus Pheasant (Argusianus argus) is even more remarkable. This bird, a native of the Indo-Malay mainland and Sumatra, has the secondary quill feathers of the wings enormously elongated and of great breadth, while they are furthermore remarkable for the great beauty of their coloration. This consists of a number of large eye-like spots, so coloured that when the feathers are held with their free ends upwards, the ocelli appear like so many balls lying each within a cup or socket. But, furthermore, the primary quills are also extremely beautiful, being of a soft brown tint sprinkled with small dark spots, while the shaft of the quill is dark blue. Running along the outer margin of this blue shaft is a band of a paler colour than the rest of the vane, and this is thickly spotted with minute white points. It is this band which gives the final touch of perfection to the whole feather. Lastly, the tail of this bird is like the wing feathers, of enormous length, and also possesses a rare beauty of coloration. 
While the bird is at rest there is little or no evidence of this beauty; it appears to be remarkable only on account of the great length of the wing and tail feathers. But during the courting season the utmost seems to be made of this wonderful livery.

A great deal, however, is yet to be discovered with regard to the habits of this bird at this time. It would seem, from the observations of the late $\mathrm{Mr}$. W. R. Davidson, that the Argus Pheasant leads a very solitary life, the sexes living apart. During the breeding season the male appears to choose some open, level spot in the depths of the forests-which this bird never leaves-from which he clears all the dead leaves and weeds for a space of some six or eight yards square, until nothing but the bare clean earth remains, and thereafter he keeps this area scrupulously clean, removing every dead leaf and twig that may drop from the trees above. Here, in solitary state, this gorgeous creature spends his days, calling at short intervals "how-how, how, how, how," and this note is repeated some ten or a dozen times. It is an intensely penetrating call, and is repeated apparently until answered by the female who calls "howowoo, how-owoo," the last syllable much prolonged. This call, as in the case of the male, is repeated many times, ending in a series of "owoos" run together! But in this way the sexes discover the whereabouts of one another; and the female apparently comes to the call of the male, and ultimately enters his "parlour," as the cleared space is called. Once in, it would seem, she is entertained by a very remarkable performance, which has been graphically described by Darwin.

Having obtained an audience, it appears the bird erects his tail and expands his huge wing feathers "into a great, almost upright, circular fan or shield, which is carried in front of the body. The neck and head are held on one side so that they are concealed by the fan; but the bird, in order to see the female before whom he is displaying himself, sometimes pushes his head between two of the long wing feathers . . . and then presents a grotesque appearance. This must be a frequent habit with the bird in a state of nature, for . . . on examining some perfect skins sent from the East, [there was] found a place between two of the feathers which was much frayed, as if the head had here frequently been pushed through." 



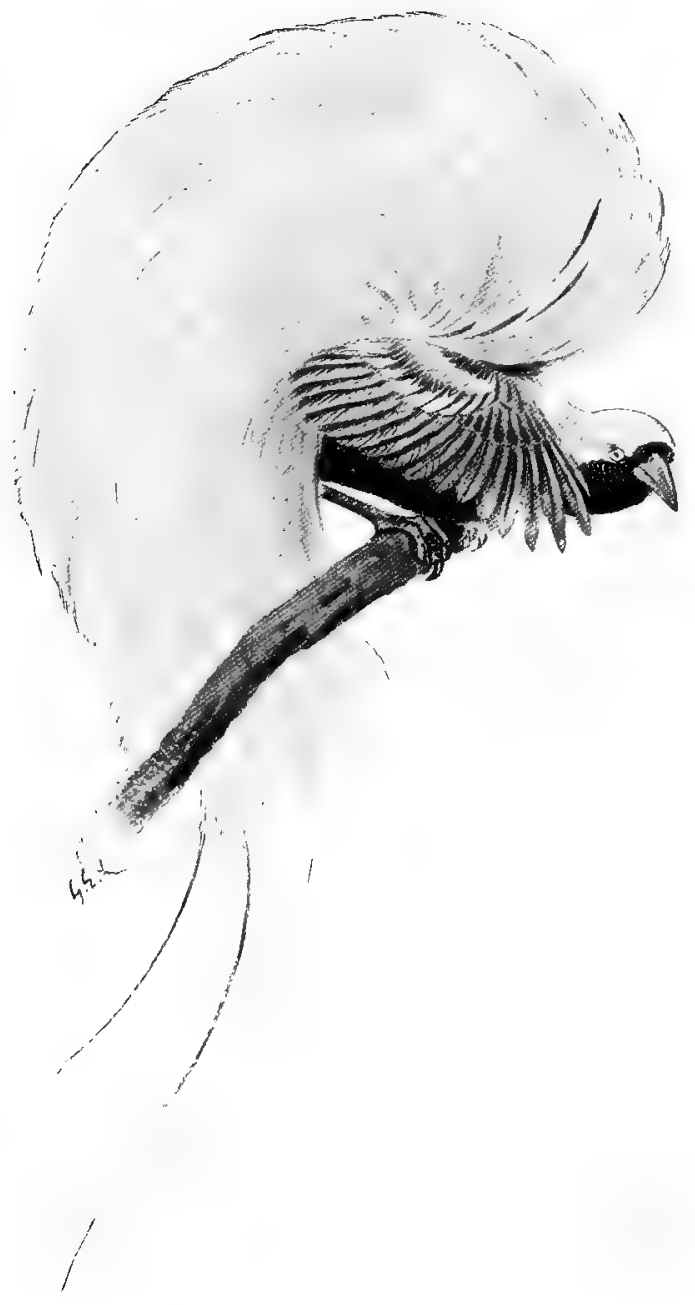

A STAGE IN THE DISPLAY OF THE LESSER BIRD OF PARADISE 
By way of contrast with the several displays just described it would be hard to find a more striking illustration than that afforded by the great Bird of Paradise (Paradisea apoda), inasmuch as here the display is associated with rivalry between a number of individuals. For much of our knowledge on this matter we have to depend upon the descriptions of natives, collected on the spot by Mr. Alfred Russel Wallace, but happily this has now been supplemented by observations made by Mr. Ogilvie Grant on a captive in the Gardens of the Zoological Society of London.

It appears then, that during the period of courtship these birds at frequent intervals gather together, up to the number of twenty, on certain of the forest trees of the Aru Islands, selected apparently on account of the fact that they have an immense head of spreading branches, and large but scattered leaves, thus affording plenty of space for the revels, which take the form of "Sácaleli," or dancing parties.

By the time the ball opens the birds appear to have worked themselves up to a state of great excitement, and each commences his performance with quivering, wings and a loud cry"wāā ! wāā ! wāā! wāà !" Then the wings are suddenly held out in a semi-vertical position on either side of the body, the tail is bent forward under the branch, and with a quick shuffle of the plumage, the side plumes are erected, forming an arched cascade over the back, meeting one another in the middle line. With every muscle tense the bird will remain in this attitude from ten to twenty seconds, slightly quivering his wings, and from time to time hitching up his long plumes, which are raised somewhat above the level of the top of the head.

Then a second stage commences. Each bird, seemingly gone mad, commences to dance and hop wildly backwards and forwards along the bough, and with head bent down, wings fully extended horizontally, and side plumes erected to their utmost, he utters loud harsh cries_c "cā! cā ! cā! cā!"

For some seconds he remains in a sort of ecstasy, rubbing his beak on the bough, and occasionally glancing backwards below his feet with the back fully arched. Then, the climax passed, he reverts once more to the first and more erect stage of the display, when the paroxysm either gradually subsides, or is renewed, and after an interval of about half a minute again 
reaches an acute stage and the wild dance is in full swing once more!

Although in the earlier part of the chapter it was implied that the strange antics of which examples have just been cited were performed in the presence of the opposite sex, this appears by no means to be a general rule. It does not seem to be known, for example, whether the females of the Paradise-birds are witnesses, at a respectful distance, of the strange dances in which their respective lords engage, or whether these are indulged in by the males alone for their own delight. But with some species at any rate, as will be shown presently, the presence of the female seems to be all-important.

Since, in the light of modern discovery, all birds appear to indulge in antics more or less remarkable during the season of courtship, it is obviously impossible to do more than select some of the more important of such displays, and the further accompaniments which in a large number of instances are to be met with.

So far we have cited cases where this accompaniment takes the form of brilliant and highly specialised plumage, using the Sparrow as a foil, so to speak, inasmuch as here, though the antics are grotesque enough, the plumage presents no striking features.

But there are a number of species which at this critical period develop special organs, or for the nonce make temporary use of existing organs, apparently for the sole purpose of enhancing their suit with the opposite sex. Anatomical changes, in short, of a more or less complex character, make their appearance at this time, and disappear, or at any rate remain dormant, for the rest of the year. The most remarkable of these organs are those which take the form of wind-bags, or inflatable sacs, and they are used solely in displays of a peaceable character. But there are some species which, during the season of courtship, become extremely pugnacious, and among these many are provided with formidable weapons of offence, weapons which, unlike the antlers of the stag, are permanent. On the other hand, there are a few species which become more markedly social and indulge in the most curious dances. These several phases will now be discussed.

The displays which depend on the use of wind-bags shall be taken first. And of such displays the most familiar is that 



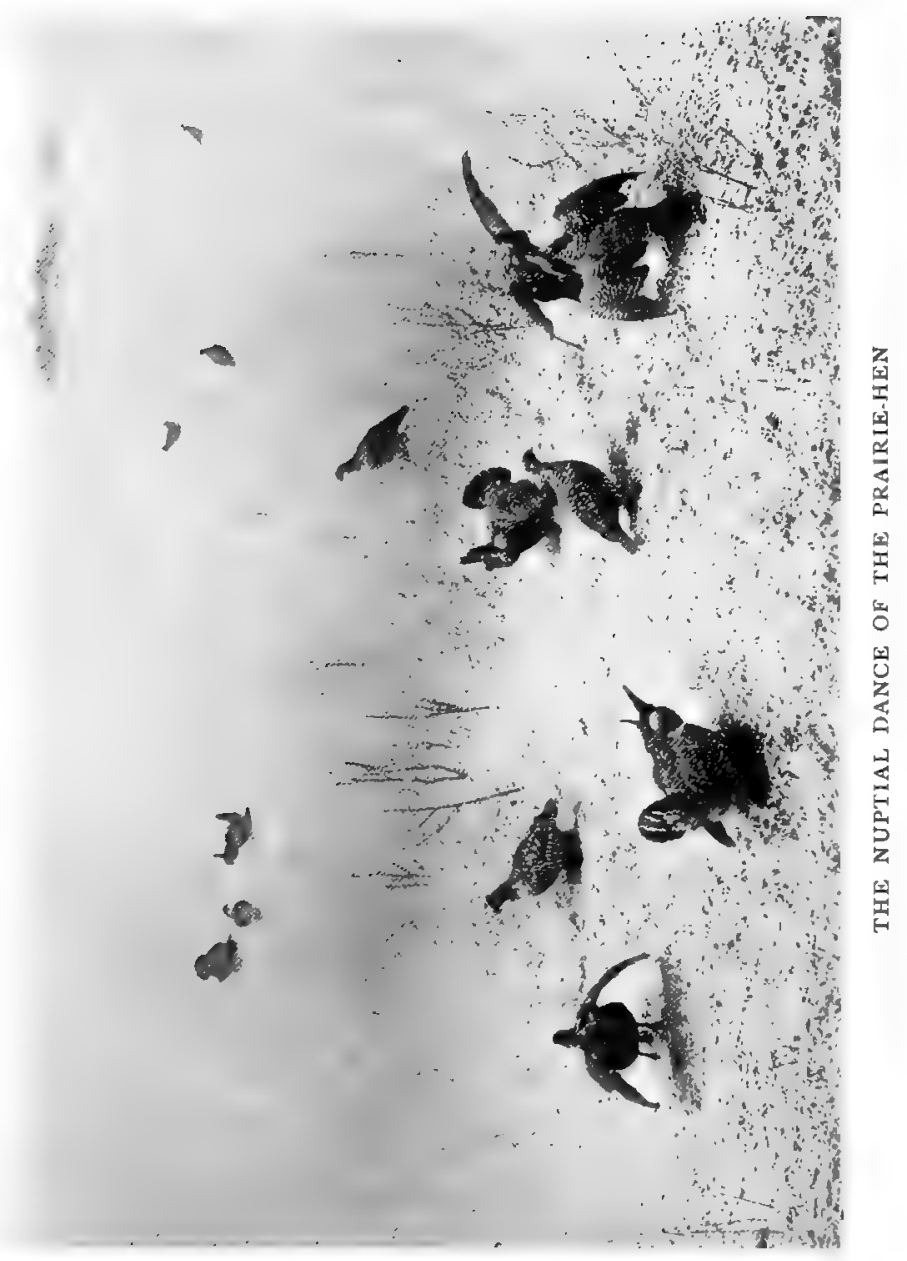


of many of the Pigeon tribe. Herein the bird inflates the gullet, and more especially the crop, and this done, proceeds to pay his vows of everlasting constancy to his mate by keeping up an incessant "cooing" accompanied by a succession of most courtly bows. The great Australian Bustard (Eupodotis australis) similarly inflates its gullet. "The premonitory symptoms," says Dr. Murie, "observable when [this] Bustard is about to exhibit himself in the pride of lust . . . is a slight swelling of the infra-mandibular portion of the throat, while the head is thrown upwards. Immediately afterwards the neck swells, and the feathers of the lower parts concomitantly bulge out and descend gradually downwards in the form of a bag, oftentimes nearly reaching the ground.

"If the paroxysm is a strong one, then the tail is shot upwards and forwards over the back, the rectrices coming almost in contact with the neck.

"In this peculiar attitude, with bloated neck, hanging, baggy chest, elevated tail, and stiff, stilt-like legs, the creature struts about in a somewhat waddling manner, the elongated pouch swaying to and fro. The feathers of the throat start out on end, those of the depending sac are also raised but less upright. While all this has taken place the bird seems to have gulped in air, or rather, with partly opened gape, to have taken a long, deep and forced inspiration.

"The acme of inspiratory effort and strange attitude attained, the Bustard begins to snap the mandibles together in a loud manner and utter a series of cooing sounds for a short interval of time. Usually and more frequently he struts towards the female Bustards in a most dignified manner. . . ."

No less remarkable are the displays of the American Ruffedgrouse (Tympanuchus americanus) and the Frigate-bird.

In the case of the Ruffed-grouse the inflatable sac appears to be formed by specially modified air-sacs running up the neck. But the effect is heightened by the fact that the featherless spaces which normally occur on each side of the neck are deeply pigmented with bright yellow, so that, when the sacs are distended with air the bare yellow skin is thrust out in the form of a pair of globular swellings, which have been compared to oranges. Above these sacs have been developed a frill of long narrow feathers which during the time that the sacs are 
in use stand out like a ruff just below the head, while, as if in sympathy, the whole of the body feathers are set on end, and the wings are dropped, as in the Turkey and Peacock.

The displays appear to take place early in the morning, when parties of from a dozen to fifty of both sexes assemble on some high dry knolls where the grass is short. Having gathered together, the more eager males immediately begin to set themselves in order for the morning's revels, the first part of the performance apparently consisting in the passive displaythe inflation of the sacs and erection of the feathers.

Next, some "proud cock, in order to complete his triumph, will rush forward at his best speed for two or three rods through the midst of the love-sick damsels, pouring out as he goes a booming noise, almost a hoarse roar, only more subdued, which may be heard for at least two miles in the still morning air. This heavy booming sound is by no means harsh or unpleasant, on the contrary, it is soft and even harmonious. When standing in the open prairie at early dawn listening to hundreds of different voices pitched on different keys, coming from every direction and from various distances, the listener is rather soothed than excited.

"Every" few minutes this display is repeated. I have seen not only one, but more than twenty cocks going through this funny operation at once, but then they seem careful not to run against each other, for they have not yet got to the fighting point. After a little while the lady-birds begin to show an interest in the proceedings by moving about quickly, a few yards at a time, and then standing still a short time.

"The party breaks up when the sun is half an hour high to be repeated the next morning and every morning for a week or two before all make satisfactory matches. It is toward the latter part of the love-season that the fighting takes place among the cocks, probably by two who have fallen in love with the same sweetheart whose modesty prevents her from selecting between them."

The display of the Frigate-bird, though of a very different kind, is no less remarkable. And we owe to Dr. C. W. Andrews the best account of this which has yet been published. His descriptions are based on observations made upon Fregata 



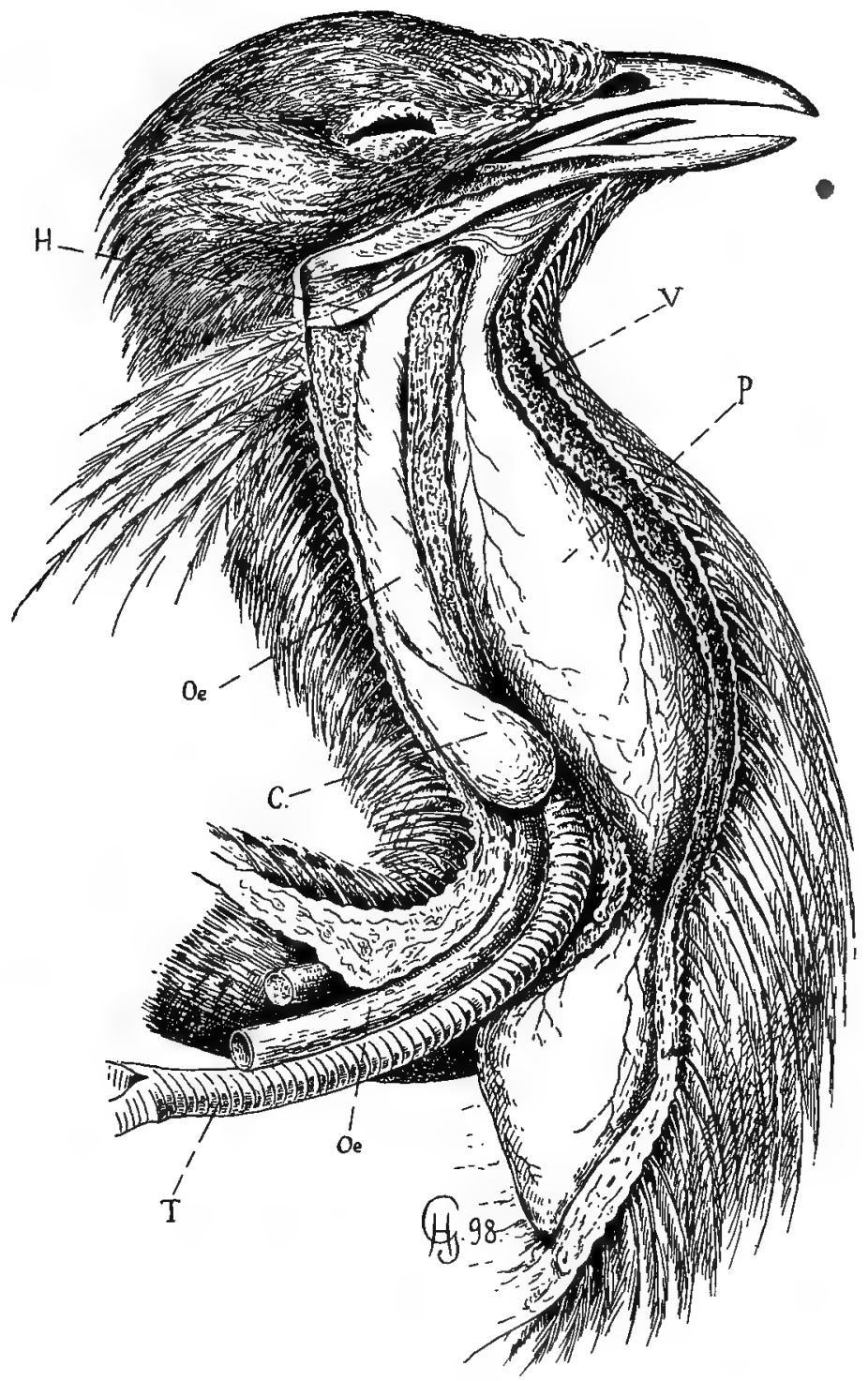

Ill. 2I.-Pouch of Great Bustard, Dissected to Show its Relation to THE GULleT AND WindPIPE
P. $=$ Pouch.
E. = CEsophagus.
T. $=$ Trachea.
$H_{0}=$ Hyoid. $\quad V_{.}=$ Vascular tissue. 

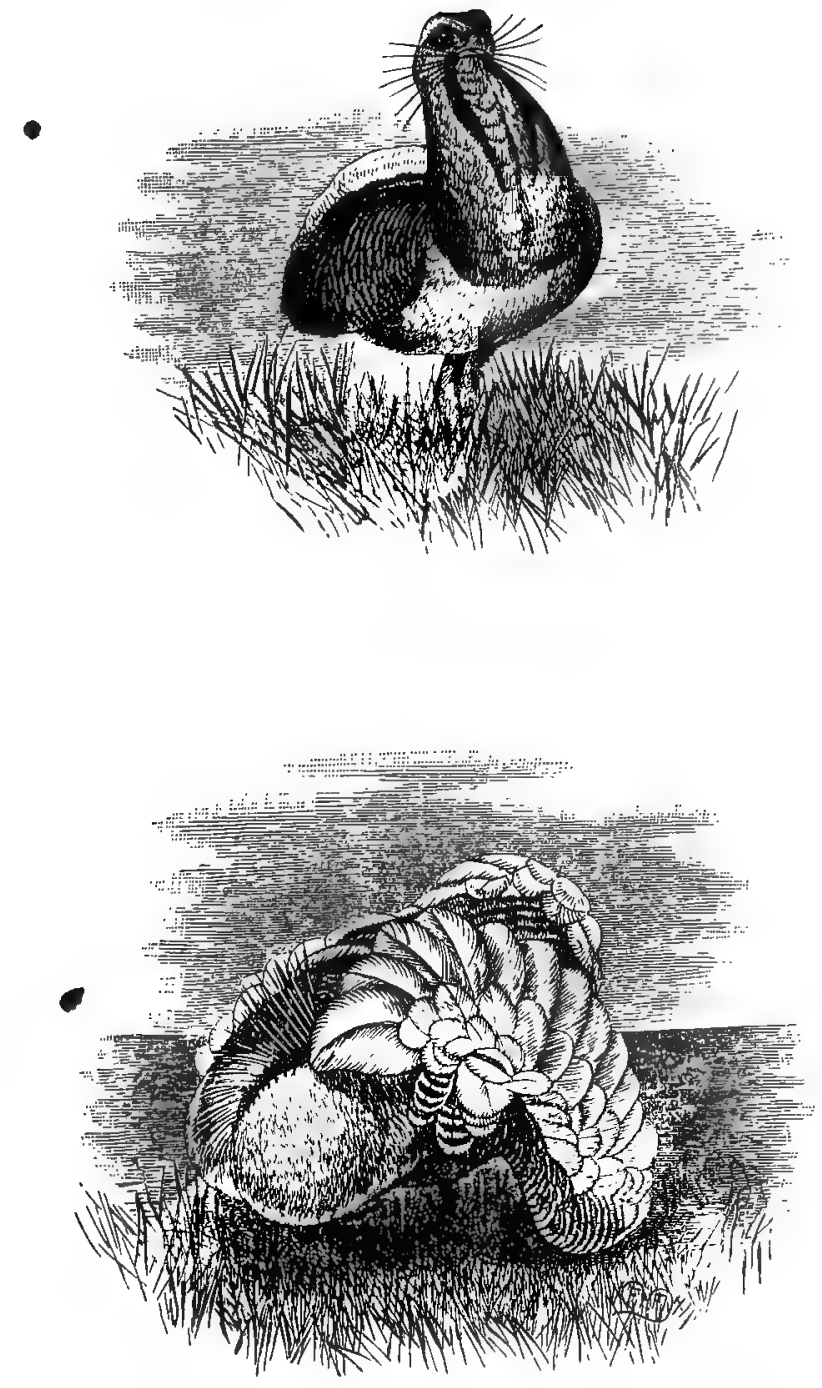

Ill. 22.-The Display of the Great Bustard (Otis tarda) The upper figure shows one of the preparatory stages of the display. 

aquila during the time that he was engaged in the exploration of Christmas Island (Indian Ocean).

"About the beginning of January," he remarks, "the adult males begin to acquire [a] remarkable pouch of scarlet skin beneath their throat. This they can inflate till it is nearly as large as the rest of the body, and a dozen or more of these birds sitting on a tree with outstretched drooping wings and this great scarlet bladder under their heads are a most remarkable sight. When a hen-bird approaches the tree the males utter a peculiar cry, a sort of 'wow-wow-wow-wow' and clatter their beaks like castanets, at the same time shaking the wings. When they take to flight the air is allowed to escape from the pouch, but occasionally they might be seen flying with it partly inflated."

This pouch, it should be remarked, is not formed by inflating the gullet, but, as in the case of the Ruffed-grouse, by certain enlarged air-sacs of the cervical system.

Two other instances of inflatable pouches and the rôle they play in courtship must suffice for the purposes of this chapter.

The first of these is that furnished by the Great Bustard (Otis tarda), a bird at one time common on the heaths of England.

The pouch in this bird is a quite remarkable structure, being formed by a long sac running down the front of the neck just beneath the skin, and opening above by a narrow slit just beneath the free end of the tongue. Its walls are extremely delicate, and just between the furcula are constricted, as may be seen in Ill. 21. How it is filled is not yet known, but the performance of the bird after the work of inflation is completed is remarkable.

The neck is then drawn downwards and backwards so as to rest on the back, while the tail is raised and drawn forwards.

Unlike so many of the displays already described, that of the Great Bustard is apparently addressed very directly to the female. Approaching her with a mincing gait and rustling wings, he draws the neck backwards and downwards till it rests upon the back, while the tail is raised and drawn forwards and downwards, and is there held in place by the aid of the tips of the long quill feathers of the wings. Simultaneously the scapular feathers are set on end, and with these 
the long white inner secondary quill feathers. The head, meanwhile, is drawn down on to the pouch, while the long, spike-like feathers which normally project backwards on either side of the head now stand erect like a row of slender palisades on each side of the partly hidden beak. Behind the head is a great billowy mass of white feathers formed by the under-tail coverts, and brought into view by the overturning of the tail feathers. The feathered contortionist having completed this complex series of movements, now stands solemnly facing his mate, uttering now and again a low grunt like "oak, oak, oak!" and then slowly returns to his normal shape again.

Of the display of the Adjutant Stork there appears to be no record. But this bird is provided with a pouch in some respects more peculiar than that of the Bustards, inasmuch as it can be filled and emptied with remarkable rapidity. Deflated it is hardly visible, but may be detected in the shape of a conical swelling of bare skin in front of the neck. Suddenly it shoots out, or rather downwards, in the form of a large, naked wind-bag of considerable size, and again disappears with magical rapidity. This sac is filled through the naso-pharyngeal system, that is, from air-sacs opening into the nose. How that of the Great Bustard is filled is, by the way, unknown.

\section{TOURNAMENTS}

During the time that birds are under the stimulus of sexual excitement mutual jealousies, leading to more or less violent encounters between rivals, are common among all species. But there are some species which, of set purpose, appear to gather together for the purpose of "sparring," apparently by way of displaying their prowess in the presence of the females, but without any desire to come to actual blows, though this occasionally happens. These fight unarmed. On the other hand, there are several species, especially among the Gamebirds, the Plover tribe and the Anatidæ, which have developed formidable weapons of offence, and these are used in deadly earnest on every possible opportunity, at any rate during the period now under discussion. There is, however, no hard and fast line between these harmless encounters and duels to the death, as we shall presently show. 

There is, in fact, no better illustration of this than is furnished by the "gathering of the clans," so to speak, described so graphically and so vividly by $\mathrm{Mr}$. J. G. Millais, anent Black game in Scotland.

Their arrival at the tourney-ground, he remarks, which begins soon after daybreak, is preceded by the almost continuous whirring calls of the cocks, calls which he likens to the sounds produced by a luggage train passing over loose metals at a distance, and which are audible at two miles. This call rouses the Grey hens. Soon after, one or two Black cocks put in an appearance on the field, and at once begin to attack one another. Both birds simultaneously lower their heads and arch their tails, the beautiful curled feathers almost touching the ground, while the primary feathers are trailed. This posture may be assumed when the birds are as far as thirty yards apart, when they advance till separated only by a few feet. "Then the actual fighting, if there is to be any, begins. It, however, often happens that, as with our bombastic race, it is all 'gas,' and the two, after skirmishing up to one another with every apparent gesture of rage and fury, by the time that close quarters are arrived at have come to the conclusion that another occasion will do just as well as the present for fighting it out. . . . More often they stand and fence, after the manner of bantams, until one, by superior tact and rapidity, suddenly seizes his adversary by the 'scruff' of the neck, and gives him a right good dusting, handling him in no gentle manner with his strong bill, whilst he beats him over the head with both his wings, the latter making a loud noise. When he who hath come off second best eventually gets clear, he has generally had about enough for the time being, and is either chased ignominiously off the ground to hide his diminished head in some quiet corner, or wings it off altogether to the nearest wood. This is only temporary, however, for he does not consider that he is altogether vanquished till he has made at least another attempt to display his prowess. The victor gives his plumage a shake, and calmly proceeds to select for himself a position of vantage in the shape of a grassy mound, the possession of which he is now prepared to contest with any opponent who may be bold enough to tackle him; and if the birds are at all numerous he is not long in having his wish gratified. He seats 
himself composedly on his little hillock and again commences his song of war, at which some wandering knight, who has yet his laurels to win, soon takes offence, and at once challenges him. Now in preparation for this coming battle the victor of the former strife entirely alters his tactics, and his attitude is one purely of a defensive nature; for after rising to his feet, he simply watches the advance of his adversary with lowered head, allowing the latter to waste his energies in futile attempts at getting above or behind his guard, till the process of fencing wearies him, when, with one quick movement, he repeats the lesson he gave his former antagonist.

"At intervals during each separate fight, Black cocks emit a curious call; it is a hoarse screech, resembling the noise too painfully familiar to us, namely, that of cats on house-tops, supplemented by the said animals being afflicted with sore throats. The sound is both wild and un-musical in the extreme.

"We will suppose that the observer has come early on the scene, before the Grey hens have made their appearance. The approach of one of the latter is the signal for an immediate cessation of hostilities on all sides, and intense excitement prevails amongst the assembled Black cocks. Her approach has been observed by a single bird, who has been sharper than the rest in detecting the lady afar off . . . [he will] suddenly draw himself up to a rigid position of attention, till he is sure she is really coming. Having settled this in his mind to his own satisfaction, he throws himself into the air and flutters up a few feet, uttering the while hoarse notes with all the power and effect he can muster. This is, of course, done to impress the lady in his favour, and arouse in her breast a proper sense of admiration which he considers his due. His example is immediately followed by all the others, who on alighting dance about in the most absurd manner, each one trying to see who can screech the loudest and be the most ridiculous in his antics.

"When a hen has alighted on the playing-ground, the male that is nearest to her pairs with her and fights off any other that disputes his possession. She then meanwhile walks sedately round her lord and master, picking about the grass coquettishly and pretending to be feeding. Each hen on 
arrival causes the same general excitement, and is appropriated by one or other of the successful cocks, till the harems are filled up, one cock having at times as many as six or seven hens. As the season advances, after the first few mornings of the hens coming to the ground, they resort to the same spot each day, and stay with the same cock who has previously trodden them, and are not interfered with afterwards by other cocks, who acknowledge the superior claims of the male to whom they rightfully belong."

The tournaments of the Ruffs may serve as our second illustration of these weaponless duels.

The term "Ruff" is more particularly applied to the males of a species of Sandpiper (Pavoncella pugnax), the females being distinguished as "Reeves". The male bird derives its name from the fact that during the spring it develops a very remarkable nuptial dress, the most conspicuous feature of which is formed by a large frill of feathers which, encircling the upper part of the neck, can be erected or depressed at will. But besides these, certain feathers from the occipital region of the head become greatly elongated, forming a pair of tufts known as the "ears". This frill, which, as we have elsewhere remarked, presents a most wonderful variety in its coloration, is made to play a very important part in the critical work of courtship.

During this time the Ruffs select such eminences as the fenlands afford whereon to assemble and display their finery. At the break of day, as in the case of the Black game, the performers assemble at the favoured spot and commence at once to disport themselves, now sparring one with another, and now standing one in front of another with outspread frill and head bent down till the beak rests upon the ground, immovable, only to commence again to spar. Now and again some display of temper is shown, one bird endeavouring to seize another by the beak and administer a rain of blows with its wings; or the two will rise in the air and strike at each other with their feet. The more vigorous appear to take possession of certain definite areas and to hold these against all comers.

Sooner or later the females appear upon the scene, when they are courted vigorously by the males, who display their frills assiduously. And, so far as can be made out, it would seem that the more active, excitable and strikingly coloured 
birds are generally the favoured ones in securing mates. Polygamy, as might be supposed, is here the rule, but the females appear to be allowed, or to insist on, a very considerable amount of liberty in their choice of a mate. They may be said to abandon themselves to, rather than be taken possession of by, the master males of the community.

\section{WEAPONS AND THEIR USES}

The males of all birds, during the period covering the time of courtship and the helplessness of the young, are more or less pugnacious towards other males of the same species, furious battles being the result; and these not seldom result in the death of one or other of the combatants. With some species this pugnacity exhausts itself in contests for the possession of the females, while with others it appears to be reserved for the defence of the sitting hen and young.

The "dove of peace" at this time of the year appears in a new and not always pleasing light, for not only will he fight his neighbours, but he does not always show that gentleness towards his wife which tradition has credited him with. The tiny Humming-bird would seem to be as little capable of fighting as a bird could be, yet few birds are more pugnacious. Robins and Titmice, too, fight savagely. And certain species of Quails, and a Rail (Gallicrex cristatus), nearly related to the Moor-hen, are commonly kept by the natives for the sake of setting them to fight one another.

In all these cases, however, no special weapons are used, the birds seizing one another by the beak, and buffeting with the wings, or striking with the feet. Such as have stout beaks endeavour to beat out their opponents' brains, and in this they are frequently successful.

A considerable number of species, however, notably among the Game-birds, have developed powerful weapons in the shape of long, pointed spurs upon the legs, some, such as Pheasants and Jungle-fowl, having but a single pair, others, as in Francolins, having several pairs. And these birds are notorious for the ferocity of their encounters. It is said that in the Indian Swamp Francolin (Francolinus gularis) nearly every individual is marked by scars and wounds received in such combats. These battles appear to be fought in defence of, or rather, perhaps, 
for the retention of, their females. But there is some evidence to show that they not seldom occur as the outcome of displays at preconcerted meeting-places such as have already been described in these pages as occurring among Grouse and Ruffs for example,

Certain members of the Plover tribe, and certain Anserine birds have, however, developed spurs of a very formidable character on the wings.

Among the Plover tribe the best example is that furnished by the Egyptian Spur-winged Plover (Hoplopterus). These birds fight, after the manner of our common English Lapwing, by turning suddenly in the air and striking with the wings. In the case of the formidably armed Egyptian bird the result is often fatal. In our own birds a fatal result is rarely the case, since slightly swollen knobs take the place of spurs. In Hoplopterus and in the Jacana this spur arises from the base of the thumb, but in the Spur-winged Goose (Plectropterus) it is borne by the radial carpal bone, while in the Screamers (Palamedea and Chauna) there are two spurs on each wing, one at each end of the metacarpus. That these formidable weapons have been developed for the purposes of offence and defence there can be no doubt, but there are no detailed records as to the frequency of such encounters.

No less remarkable is the form of the weapon which has been developed by another Plover, one of the Jacanas (Metopidius). In this bird the radius has been broadened out from its middle onwards, in the form of a flat plate, or blade, but the manner in which this is used seems to be unknown.

The dearth of facts with regard to the time and place of the use of these weapons is deplorable; but this is partly to be explained by the fact that these birds live in regions little visited by observing naturalists, and when encountered by collectors are promptly shot, life-histories having for them no interest.

We may pass now to a brief outline of the more important facts which have been recorded with regard to the peaceful arts of dancing and music among birds.

As touching dancing among birds. This curious exercise is practised by many different birds belonging to widely different groups, and in parts of the world remote from one another. One of the Manakins-small South American birds belonging to the Family Pipridæ-and perhaps others, is an expert dancer, 
practising the art, apparently, as a means of winning the favour of the females. "The natives call this bird the 'bailidor' or 'dancer," "says Mr. Nutting, "but 1t was not until I had been in the region for some time that I understood why it was called by that name. One day, when hunting through the dense forest, the profound silence was suddenly broken by the regularly repeated note of 'El Bailidor,' and softly making my way to the spot I witnessed one of the most remarkable performances it has ever been my lot to see. Upon a bare twig which overhung the trail at a distance of about four feet from the ground two male 'bailidors' were engaged in a 'song and dance' act that simply astonished me. The two birds were about a foot and a half apart, and were alternately jumping about two feet in the air, and alighting exactly upon the spot whence they jumped. The tune was as regular as clockwork, one bird jumping up the instant the other alighted, each bird accompanying himself to the tune of 'to-lé-do-to-lé-do-to-lé-do' sounding the syllable ' to' as he crouched to spring, 'le' while in the air, and 'do' as he alighted. This performance was kept up without intermission for more than a minute, when the birds suddenly discovered that they had an audience, and made off."

The stately Albatross even indulges in dancing when overwrought with excitement! The Hon. Walter Rothschild, in his Avifauna of Laysan gives a vivid word-picture of the antics of this bird: "First they stand face to face, then they begin nodding and bowing vigorously, then rub their bills together with a whistling cry. After this they begin shaking their heads and snapping their bills with marvellous rapidity, occasionally lifting one wing, straightening themselves out and blowing out their breasts; then they put their bill under the wing or toss it in the air with a groaning scream, and walk round each other, often for fifteen minutes at a time."

Even more remarkable are the performances of Cranes. Mr. Nelson, in his Birds of Alaska, gives a striking illustration of this: "On I8th May I lay in a hunting blind and was much amused by the performances of two Cranes which alighted near by. The first-comer remained alone but a short time, when a second bird came along, uttering his loud note at short intervals, until he espied the bird on the ground, when he made 
a slight circuit, and dropped close by. Both birds then joined in a series of loud rolling cries in quick succession. Suddenly the new-comer, which appeared to be a male, wheeled his back towards the female and made a low bow, his head nearly touching the ground, and ending by a quick leap into the air. Another pirouette brought him facing his charmer, whom he greeted with a still deeper bow, his wings meanwhile hanging loosely by his side. She replied by an answering bow and hop, and then each tried to outdo the other in a series of spasmodic hops and starts, mixed with a set of comically grave and ceremonious bows. The pair stood for some moments bowing right and left, when their legs appeared to become envious of the large share taken in the performance by the neck, and then would ensue a series of skilled hops and skips, which are more like the steps of a burlesque minuet than anything else I can think of. Frequently others join, and the dance keeps up until all are exhausted."

Similarly, according to Mr. W. H. Hudson, the South American Cayenne Lapwing indulges in dances of an elaborate description. These birds, which are known in the Pampas by the name of "teru-teru," generally live in pairs. "Any one watching a pair," says Mr. Hudson, "will see an individual from another pair rise and fly to them. Advancing to receive their visitor, the pair place themselves behind it; then, all three keeping step, begin a rapid march uttering resonant drumming notes in time with their movements, the notes of the pair behind being emitted in a stream like a drum-roll, while the leader utters loud single notes at regular intervals. The march ceases, the leader elevates his wings and stands erect and motionless, still uttering loud notes; while the other two, with puffed-out plumage and standing exactly abreast, stoop forward and downward, until the tips of their beaks touch the ground, and sinking their rhythmical voices to a low murmur, remain for some time in this posture. The performance is then over, and the visitor goes back to his own ground and mate to receive a visitor himself later on."

Another South American species of Spur-winged Plover, which indulges in dances of this kind is the Jacana, a bird remarkable for the enormous length of the toe-nails. Herein both sexes participate. These birds go about in pairs, but 
"occasionally," says Mr. Hudson, "in response to a note of invitation, they all in a moment leave off feeding and fly to one spot, and, forming a close cluster, and emitting a short, excited, rapidly repeated note, display their wings, like beautiful flags grouped loosely together; some hold the wings up vertically and motionless; others half open and vibrating rapidly, while still others wave them up and down with a slow, measured motion."

Such, then, are a few of the more striking cases of dances among birds. But there remains yet to be described another form of play connected with the period of sexual activity which must be briefly referred to here. This concerns the remarkable performances of the "Bower-birds" of Australia, of which there are several species, all displaying similar habits; consequently space can be found here only for a single detailed illustration. This shall be furnished by the " Gardener Bowerbird" (Amblyornis inornatus). This species builds at the foot of a small tree a kind of hut or cabin, some two feet in height, roofed with orchid stems that slope to the ground, regularly radiating from the central support, which is covered with a conical mass of moss sheltering a gallery round it. One side of this hut is left open, and in front of it is arranged a bed of verdant moss, bedecked with blossoms and berries of the brightest colour. As the ornaments wither they are removed to a heap behind the hut, and replaced by others that are fresh. The hut is circular and some three feet in diameter, and the mossy lawn in front of it is nearly twice that expanse. Each hut and garden are believed to be the work of a single pair of birds. The use of the hut, it appears, is solely to serve the purpose of a playing-ground, or as a place wherein to pay court to the female, since it, like the bowers built by its near relatives, are built long before the nest is begun, this, by the way, being placed in a tree.

The less elaborate "bower" of the Satin-bower bird (Ptilonorhynchus holosericus) indicates an earlier stage in the evolution of this remarkable custom. Herein a long gallery or avenue is constructed of fine twigs placed on end, and roofless. The entrance to this is decorated with snail shells, bleached bones and bright feathers. When complete the male uses the bower, as we have indicated, as a courting-ground. In 
his moments of ecstasy he seizes a leaf or other object in his beak, and with feathers on end and quivering wings chases his mate in and out of the bower till both are tired! The Spotted Bower-birds provide a roof to this avenue, which may be of considerable length, and confine their decorations almost entirely to shells, which are often collected on the sea-shore some miles away from the site of the bower.

This, by the way, appears to be almost entirely constructed by the males, though in all cases the females are believed to assist.

\section{Song and Instrumental Music}

It will scarcely be necessary in this place to dilate upon the marvellous perfection to which some birds have attained in the matter of song. The exquisite performances of the Skylark, Nightingale, Blackcap, Thrush and Blackbird, and a dozen others, must be known to all who will read these pages. Rather, we are concerned here with the nature and purpose of song among birds.

It is commonly supposed that Passerine birds alone sing; and further, that among these only those of sober-coloured plumage are so gifted. Both these suppositions, however, have no foundation in fact, though it is true the more brilliantly coloured birds are rarely good songsters. But it is equally true that a large proportion of dull-plumaged birds, even among the Passerines, have no song, or at least can give forth but a short musical refrain. No bird is absolutely mute, but some species are extraordinarily silent, and at most give forth but monosyllabic sounds.

No hard and fast line can be drawn between call-notes, uttered to keep individuals or flocks together, or to give warning of the approach of danger, and true song. Nor can any hard and fast line be drawn between the times and occasions when song is practised.

In many cases it would seem to play a very important part in courtship, the male seeking this means whereby to gain a mate: but long after this important event has been accomplished, singing is continued, apparently in sheer exuberance of spirits. Some birds, on the other hand, sing but little after the courtship is over. That song plays an important part in the task of 
procuring mates is shown in the case of the British Warblers, where the males arrive before the females, and take up their position for the summer. This done, the females on their arrival are attracted to the chosen sites by the sound of the familiar song, probably electing to alight within the area of the troubadour which pleases most.

That the song of any given species varies with the geographical range of that species has often been denied; but nevertheless it would seem to be true.

Although it is commonly supposed that true song-birds sing only when extremely happy, only when possessed by some spasm of exaltation, so to speak, this is by no means altogether the case. The most famous singer of all, for example, the Nightingale, will sing when alarmed, or under the emotion of a great shock, as when its nest and eggs are destroyed, or when roused from sleep by some sudden alarm.

\section{Instrumental MUSiC}

Though by no means generally known, it is nevertheless a fact that many birds possess the power of making sounds by mechanical means: sounds which may not be musical to cultivated ears, but which are nevertheless at least as worthy of this designation as the music of savage peoples.

We can distinguish wind-instruments and instruments of percussion. And while in some cases the males alone play, in others both sexes appear to be equally skilled performers.

Among wind-instruments one of the most remarkable is that of the Emu. In both sexes of this bird the outer wall of the windpipe is pierced near the middle of its length for a space of several inches; and through this aperture the inner lining of the windpipe escapes to form a large inflatable sac lying immediately under the skin. Therewith these birds make a very remarkable sound which resembles the "rolling" of a big drum. But whether this noise is made only during the courting season, as a kind of music, or whether it is used as a call-note at all seasons, does not appear to be known.

In many species of Cranes and Swans the windpipe has undergone a no less remarkable modification. Herein it has greatly increased in length, the additional inches being stowed away in a long chamber formed by the keel of the breast-bone, 


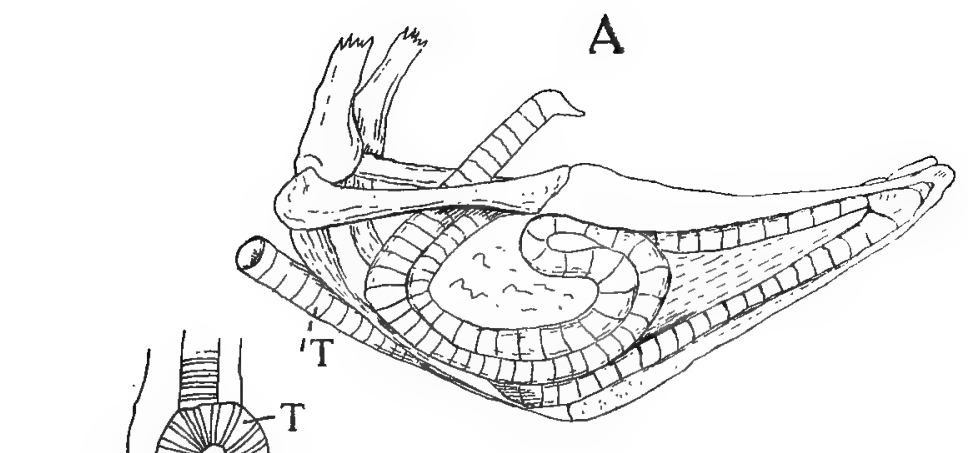

D
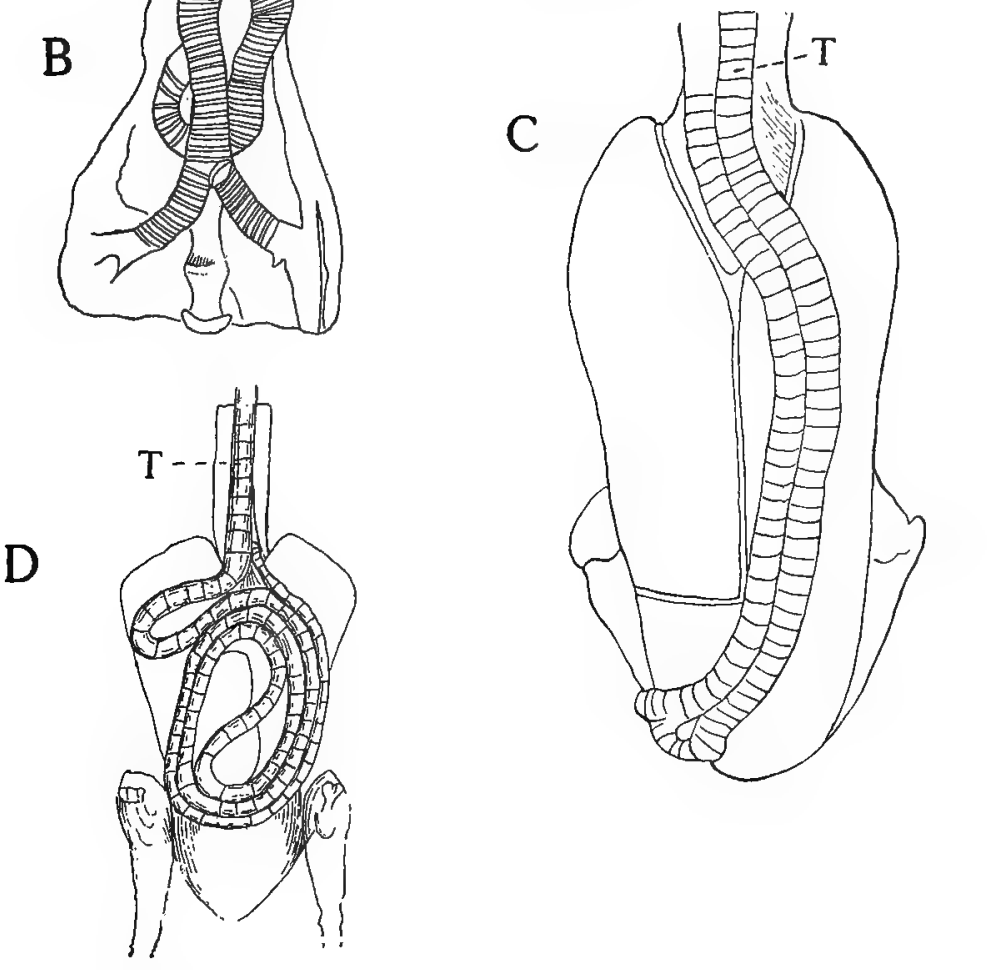

ILL. 23.-TyPes OF WINDPIPES

A, Crane. B, Spoonbill. C, Manucodia. D, Manucodia keraudreni. 

after the fashion shown in Ill. 23. Confined to the males alone, this lengthening of the tube seems to have been acquired for the sake of increasing the resonance of the voice.

Though it is undoubtedly remarkable that in two such completely distinct groups the same structural modification should have taken place, we meet with an exact parallel in another fashion of disposing of an elongated windpipe.

Herein the increased length is disposed of in a series of coils lying between the breast muscles and the skin! This obtains in certain Passerine birds-related to the Birds of Paradise, many Game-birds, e.g., Curassows, the curious Goose Anseranas, and the Sandpipers known as "Painted Snipes" (Rhynchea). The nature of these coils are shown in Ills. 23. Though we must assume that in all these modifications increased resonance of the voice has been secured, either to enhance the performer in the eyes of its mate during the courting season, or for the more prosaic purpose of indicating the whereabouts of individuals which have got separated, there is but little concrete evidence obtainable at present bearing on the problem. That such elaborate devices should have come about is somewhat puzzling, since many birds continue to make exceedingly powerful and penetrating sounds though possessed of no special sound-producing apparatus whatever. The Ostrich and the Cassowary may serve as striking examples of this, for in both the windpipe and voice organ generally is of a most primitive character.

We must pass now to a brief review of what we may call instruments of percussion whose purpose is the production of sound. Some of these, however, scarcely come within this category, since the sounds they give forth are due to vibrations set up by their rapid motion through the air.

The simplest form of percussion music is perhaps that produced by the White Stork. Throwing the head backwards till the point of the beak almost touches the back, the jaws are set rapidly in motion, clashing one against another and producing a curious rattling sound, which has been compared to castanets. As the sound is being produced the head is slowly turned into its normal position; but not until the beak has described a half-circle and rests almost on the ground does the music cease. This sound, so far as can be made out, 
appears to be made at all times of the year, and by both sexes, but especially during the courting season, when two or more birds join together keeping the most perfect tune.

Pigeons and Night-jars when on the wing can produce at will a curious snapping sound by bringing the wings together smartly over the back; and this appears to be most frequently indulged in during the period of courtship.

Similarly, certain small South American Passerine birds, known as Manakins, have the shafts of the secondary quill feathers curiously thickened to an extraordinary degree, so as to form solid, horny lumps. Therewith, by bringing the two wings sharply together over the back, a peculiar noise, not unlike the crack of a whip, is produced. One of the Gamebirds-the Black Penelope (Penelope nigrina) of Guatemalawhile on the wing will occasionally pitch suddenly earthwards with outstretched wings, and at such times a crashing, rushing, sound is produced, which has been likened to the sound of a falling tree. This is peculiar inasmuch as there seems to be no modification of the wing feathers which would account for such a noise, while, on the other hand, certain relatives of this bird have the three outermost primary quills curiously excised along their inner webs, yet, as far as is known, they produce no peculiar sounds.

Better known, and more easily verified, is the strange "drumming" or "bleating" practised by various species of Snipe, and especially the Common Snipe (Gallinago media), during the courting season. It is now known that these remarkable sounds are produced by both sexes, and by means of the tail feathers. Mounting to a great height, these birds suddenly turn and descend with prodigious speed, meanwhile holding the tail fully expanded. The outermost pair of feathers are, however, specially modified, so that, in the first place, during this descent, they stand at right angles to the long axis of the body, and well away from all the rest of the tail feathers. This alone, however, would not produce the sound, which is due to the fact that the shafts of the feathers are somewhat thickened and peculiarly curved, while the vane or web of the inner side of the feather is of great width, and structurally differs from the vanes of the other feathers. This difference consists in a greater number of hooklets, and in the larger size of those 
belonging to the barbs of this region of the feather, whereby the vane becomes more resistant to the rush of air caused by the wings during the descent.

The fact that this curious musical instrument occurs in both sexes makes its interpretation the more difficult; for there is little difference in the performance of the two sexes, though that of the male is said to be the more resonant.

The tail of the best performer of all, the Common Snipe, is, it is to be noticed, superficially, but little or not at all modified either in shape or size for the production of this sound. But there are other species of Snipe, e.g., G. stenura, which have greatly increased the number of the tail feathers, and at the same time has reduced the vanes or webs of these to the vanishing-point. Yet these birds are unable to produce any sounds appreciable to human ears.

\section{Where the Sexual ROLE IS Reversed}

Before bringing this chapter to a close it is necessary briefly to refer to a most remarkable collection of facts, which show that, in several widely different and unrelated species of birds, the position of the sexes with regard to courtship, the brooding of the eggs, and the care of the young is entirely reversed, the female playing the part of the male in all these particulars. In consonance with this fundamental reversal of the sexual relations, the females are in every case the more brightly coloured! Nature has few other such striking illustrations of hen-pecked males among the vertebrates!

The Quail-like Hemipodes, the Tinamous, !the Painted Snipe (Rhynchea) and the Phalaropes, afford the best-known examples of this, though other instances are on record.

All these birds appear to be polyandrous, indeed there is little room for doubt in the matter.

A recent writer, Mr. D. Seth-Smith, has added much to our knowledge of this matter from his observation on captive species of the Australian Hemipode (Turnix varia). The courting of the female recalls that of the male of the Common Pigeon, the crop being inflated with air, the while the proud suitor bows and "coos" to her chosen mate. He describes the courting thus:..." The male squats upon the ground amongst short grass, and the female runs round him in a circle with tail 
more or less erected, and crop puffed out. She then stops and faces him, and commences 'booming' or 'cooing' to him . . . the while stamping and scratching on the ground with her feet. The male meanwhile answers her with low crooning notes.

"At this time the female would very frequently pick up a dainty morsel, such as a grub or grain of seed, and holding it at the tip of her bill, would call her mate and present it to him."

So soon as all the eggs were laid the cock commenced to sit, and the hen took no more notice of him, but commenced to boom as if to call another mate.

The Tinamous, similarly, have been kept in confinement, and from this it has been found that the female, after laying clutches for two different cocks to brood, seeks yet a third husband, and in a wild state probably more.

Of Wilson's Phalarope, an American writer, Dr. D. G. Elliott, remarks: "The female is the larger and altogether the handsomer bird, the male having very little of the brilliant tints which render his mate so attractive when arrayed in her full summer dress. Upon him too devolves the duty of incubation, . . . the female amusing herself upon or near the water. Like the other species of Phalarope, she makes all the advances at pairing season, and sometimes more than one female fixes her attention on the same male, who thereupon has but little peace, as he is pursued from place to place by rival suitors." From the nature of the case there would seem to be some error of interpretation here, since rival females would almost certainly fight. Instead, the choice, according to this author, seems to be left to the male. If he pairs with both hens it is obvious that one clutch of eggs at least would be wasted. 


\section{CHAPTER XI \\ REPRODUCTION-NIDIFICATION}

The first nest-builder. Origin of nests. Primitive nests. Burrowing. Simple nests. The nest of the Thrush tribe. Complex nests. Pensile nests. Mud nests. The remarkable nests of Tree-swifts. Colonies. Variability in nesting sites. Strange nesting sites. Nest-building and instinct,

7 HOUGH some birds are content to deposit their eggs on the bare ground, the majority construct a receptacle of some kind in which to lay them, displaying in this work every imaginable degree of skill; for while some contrive to manage with the merest apology for a nursery, others exhibit the most marvellous ingenuity in its architecture. At no time perhaps, except just before and during this time of nest-building, are the inherent peculiarities of birds more evident. And in no phase of their life-history do they show their racial characteristics more strikingly. Species at other times social enough now steal away in pairs to work out in seclusion the command laid on them by Nature, to increase and multiply; while on the other hand, birds usually of solitary habits combine to form huge communities, where, as is usual in communities, robbery, battle and murder, and sudden death, are hourly occurrences. Only at this time having any really fixed dwelling-place, idiosyncrasies in the choice of the site thereof are not rare; and so too we meet at this time with curious departures in this matter on the part of some species from the common traditions of the tribe; departures the more puzzling and the more instructive, because they appear, as a rule, to be prompted rather by a love of eccentricity than by motives of expediency.

This phase of bird-life, the prelude to the crowning work of every living thing-reproduction-is by no means to be regarded as the measure of the birds' parental affection. We do not find in short that those birds which build no nests prove but indifferent parents, and that the parental instinct grows 
with the increasing perfection of their procreant cradles. As the following facts will show, nidification, in its broad outlines at least, is determined by environment, though there can be no doubt but that other factors are at work, some of which perhaps we can at least indicate while others yet remain to be discovered.

That the earliest birds were arboreal there can be little room for doubt, and we may assume that they brooded their eggs either in the holes of trees or on the stumps of decaying treeferns, or amid the crowns of evergreen oaks, and similar trees which had, with the appearance of the first bird-Archæopteryx -already come into existence. It may be objected however, that the long and peculiarly formed tail of Archæopteryx was but ill-suited to the cramped quarters of a hollow tree-trunk -though the long-tailed modern Hornbills contrive to overcome the difficulty--and that the work of hatching was carried on in the open. But be this as it may, with the gradual spread of the race some became denizens of the open country, and these would probably at first have deposited their eggs on the bare ground without making any special preparations for their safety or protection. Two new selective factors would now come into operation, one tending to eliminate all eggs which were not protectively coloured (p. 206), and on the other, all such as suffered from contact with cold or moist earth. It is not diffcult to imagine that sooner or later more or fewer of the birds nesting in such sites would hit upon the plan of collecting bits of grass and stick or small stones into a small heap whereon to lay their eggs, prompted not so much by any conscious desire to protect the eggs from injury as to keep warm and dry when sitting where the ground was damp. Only those birds which had sufficient intelligence to adopt this expedient would rear offspring, and this offspring would probably inherit the same instinct. Thus were the first nests built. The habit of building a nest once fixed, wherever the eggs were laid, some receptacle would be first constructed, and thus the way was prepared for those birds which, to avoid enemies, took to laying their eggs amid the branches of shrubs and trees.

The possibility that the earliest nesting sites were holes in trees receives some little support from the fact that many birds still retain this habit, and lay white eggs (p. 208). As the primitive, arboreal bird left the forest regions some sought the 
dark recesses of caves or the deserted burrows of other animals. Not finding these in all cases sufficiently roomy, they naturally enlarged the end of the burrow which was to form the brooding chamber, and thus they acquired the first lessons in excavation, to be turned to account when no ready-made burrows were to be found.

A survey of the various types of living birds will show that in nearly every group some select either burrows or caves for the work of incubation. Thus one of the "Rock-hopper" Penguins (Catarrhacteschry socome) in Kerguelen's Land nests in caves, though in Prince Edward Island it must be remarked they breed in the open, laying a single egg on a small heap of stones. The Magellan "Jackass" Penguin (Spheniscus magellanicus) digs large and deep burrows in the peat banks by the sea, often constructing one large chamber to serve for several pairs of birds; and similarly the little Blue Penguins of the Genus Endyptula breeds in dark recesses of caves. All the Petrels, save the Albatrosses and the Giant Petrels (Ossifiagagigantea), build either in deep crevices or in burrows, though but the merest apology for a nest is ever made, and this may be wanting. The Tropicbirds (Phathon) nests in holes in cliffs, e.g., P. mubricauda, or, when these are wanting, in holes in trees, $e g$., $P$. fulus. Among the Anserine birds we find the Golden-eye duck (Clangula glaucion) breeding in holes in trees, and the Sheld-ducks (Tadorna) in burrows, usually those excavated by rabbits. But these birds will also, when ready-made holes are wanting, dig for themselves. Where rabbit-burrows are used it appears to be a common practice to lengthen the tunnel leading to the brood chamber, and in one instance this was found nearly sixteen feet from the entrance, and seven feet below the surface! The Puffins again, among the Auk-tribe, breed in rabbit-burrows, or in burrows of their own making, or in crevices of rocks. Where rabbit-burrows are to be had they will not scruple to eject the rightful owners should there be no deserted tenements in the neighourhood. Among the Pigeons we find the Rock-dove breeding in caves or deep fissures, and the Stock-dove in-rabbitburrows, or holes in trees, and also in deserted squirrel "dreys," or thick ivy on old walls. The Parrots all breed in holes, save only the Quaker-parrot (Myopsittacus monachus), which builds a nest of sticks, a huge pile, containing a central chamber, so that 
the bird may almost be said to build a hole! Turning now to the "Coraciiform" birds we find that the majority breed in holes in trees, or in burrows. The Kingfishers, Bee-eaters, Hoopoes, Owls and the Woodpeckers and their allies serve as good examples in this connection. The Bee-eaters especially deserve mention, since these birds dig for themselves deep shafts sloping obliquely from the surface and descending as much as ten feet, at the bottom of which a slight nest of feathers is constructed. Among the perching birds a considerable number breed in holes, while the most striking burrower is the Sand-martin, whose nesting colonies must be familiar even to those who are not particularly interested in Ornithology.

It would only be wearisome to describe in detail the nature of the preparations made for the reception of the eggs. Suffice it to say that in the majority of cases little or no nest is made, the eggs, when laid in hollow trees, being deposited on the rotten wood at the bottom of the hole; but where a burrow is made, in sandbanks, for example, a few leaves or grass are commonly introduced. It would seem, however, that in some cases the practice of nesting in a hole is of comparatively recent date, as for instance, with the Golden-eye and Sheld-ducks, which still make a nest of vegetable matter, lined with down plucked by the female from her breast. "The Kingfishers again differ among themselves. The fish-eating species build no nest, but lay their eggs on the disgorged remains, the hard parts of the fish and crustacea on which they feed; but those which feed on insects or fruit appear to lay their eggs on a roughly constructed bed of leaves and straws (see also p. I92).

Another and more important aspect of this subject is the fact that not only do the burrowing species exhibit no sort of special adaptation for the work of burrowing, but some even appear to suffer therefrom: the beaks of the Bee-eaters, for example, being quite worn down by their labours, a fact which becomes the more remarkable when we reflect that the most fragile of all these shaft-driving birds, the Sand-martins, appear to suffer in no way by their digging operations, even though they have the smallest of beaks.

As a rule, probably, the work of excavation is carried on by the aid of the feet, as in the case of the Sheld-duck and Iurrowing-owl (Speotyto), but with the Kingfishers and the 
fragile Bee-eaters and Sand-martins, the beak alone is employed in digging, but the feet eject the loose earth, the feet indeed of these birds being remarkably small and delicate. The two last-named species, for their size, bore really remarkably long tunnels, those of the Sand-martins extending in an upward direction for a distance of four or five feet, or even longer, when the tunnel terminates in a chamber of some six inches in diameter, the floor of which is covered with a little grass, or, if near the sea, with sea-weed and a few feathers. Both sexes combine in the work of excavation, which is carried on only during the early hours of the morning. Bit by bit the soil is removed, and often when the work is almost half-way through a stone will be encountered, and if this be too large, then there is nothing for it but to make a fresh start in another place. Once completed, however, the burrow is used year after year. The sides of a sand-pit are chosen for preference, but the middle of a bluff a hundred feet high, or a thin layer of mould of some eighteen inches thick, capping the side of a chalkcutting, will serve the purpose equally well. Nay, further, they will, as in Norway, utilise the turf-roof of a hut, or a hole in a wall, and they have been known to take advantage of huge heaps of sawdust! That most enthusiastic naturalist Waterton even induced them to take possession of a series of drainpipes.

The common Kingfisher, unlike the Sand-martin, is a solitary bird. Whenever possible choosing the deserted burrow of a water-vole, it will, when such a ready-made tenement is not to be had, dig for itself. According to some indeed this practice is invariably followed. The length of the burrow is roughly about the same as that of the Sand-martin, and similarly this terminates in a wide chamber, which, as we have already stated, is soon covered with a laver of fish-bones and other indigestible matter ejected by the builders, and on this the eggs are laid. Though in course of time this mass gets beaten down and forms, by the adherence of the débris, a more or less coherent mass, no real nest is ever built by these birds.

It would seem, as we have already remarked, that nestbuilding had its origin in an attempt to secure comfort in brooding where the eggs were laid on cold or damp ground. This being so, it is easy to understand how birds which had thus 
acquired this habit should continue to make similar preparations for brooding when for some other reason-to escape floods or enemies-they elected to build in trees, instead of reverting to the older custom of seeking a hole in the trunk thereof. Such a nest would necessarily be of a loose and rough character, but, since it served its purpose, many to this present day have not improved thereon. The Crows, Pigeons, Herons, and Accipitrine birds, such as the Eagles, for example, build only a rough platform of sticks. In the case of the Pigeons it is so frail indeed that daylight can be seen through it. Nevertheless, these structures are much more durable than one might suppose, and in successive seasons are often either repaired or a fresh nest is built upon the top of the old one, a practice followed by many birds of prey, until at last, as in the case of the Osprey, for instance, the accumulated mass, if built in a tree, falls of its own weight.

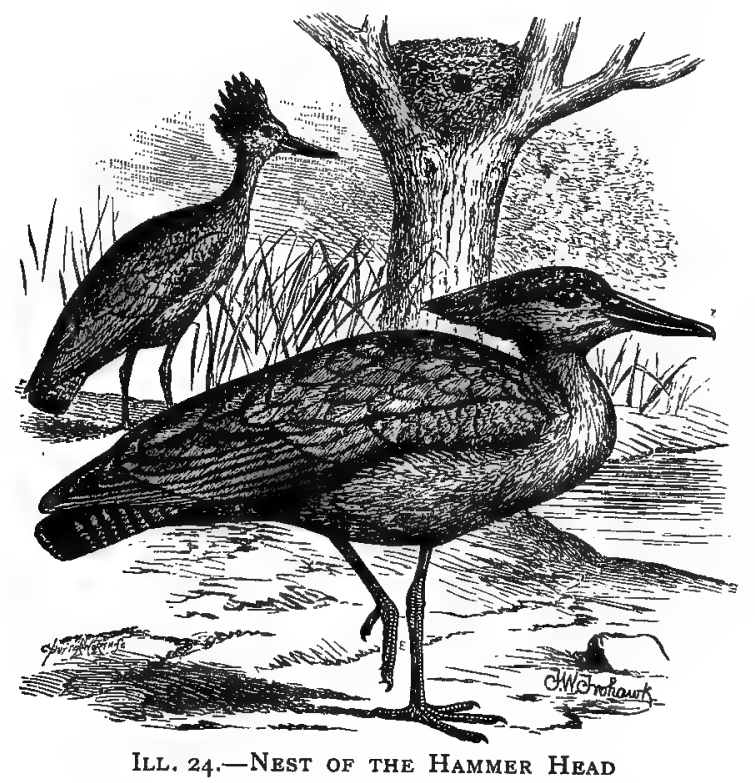

Some species, however, have improved upon this platform structure, piling up sticks to form a roof or dome, such as, for example, may be seen in the nests of the Magpie, the African "Hammer-head" (Scopus umbretta) and the Quaker-parrot 
(Myopsittacus monachus), the only Parrot, by the way, which builds a nest, all other members of the order nesting in holes in trees; thus the domed nest in this case is significant.

The transition from the platform of twigs to the more highly finished nests such as we must now pass on to examine may well be studied in the work of the Hawfinch (Coccothraustes vulgaris) and the Bullinch (Pyrrhula vulgaris), which to a platform of twigs adds a neatly wrought central cup composed of rootlets and fine hair. From nests such as these we may pass, by a series of infinite gradations, to cup-shaped structures of exquisite beauty, composed entirely of the finest materials. To follow up these gradations in detail would be an almost impossible task; suffice it to say that we find in the earlier phases of this evolution that mud is a material commonly used. This fact is of no small significance, since, as we shall show later, it is to this habit that the use of mud exclusively for building material owes its origin.

The larger Thrushes all employ mud as an agent in the construction of their nests, which are composed of sticks, roots and moss, held together by an admixture of clay, while the interior of the nest is cup-shaped and lined with fine roots and grass. But the Common Thrush (Turdus musicus) has become an expert mason, lining its nest with an admixture of mud, rotten wood and cow-dung in varying proportions. So perfectly is this plaster-work done that during wet seasons the nest often becomes filled with water, to the destruction of the eggs of course. As the evolution of the nest proceeds the use both of sticks and mud is discarded, the whole structure being composed simply of deftly interwoven root-fibres, grass and moss, with a lining of feathers and fine hairs, commonly procured from the tails of horses. The nest of our Common Redstart (Ruticilla phoenicurus) answers to this description. More perfect and more beautiful are the nests of the Goldfinch (Carduelis elegans) and of the Chaffinch (Fringilla coelebs), the former choosing fine twigs of fir, fine roots and wool, lining the whole with willow-down, feathers and hair. The last-named species is a yet more skilful architect. Wool appears to form the staple building material, and into this moss and lichens of various colours are dexterously woven, producing a shapely cup of uniform texture and singular beauty. Extern- 
ally it is studded with such lichens as best accord with the surroundings of the nest, and bits of birch-bark, these final additions being held in position by the aid of spiders' webs. Inside the wool is still more closely felted and interwoven with fine hairs, while the final touches are given by a few feathers deftly arranged, often so as to curl over and partly conceal the eggs. This exquisite fabric appears to be the work of the female only, and takes about three or four days in the weaving.

No less beautiful is the nest of the Long-tailed Tit (Acredula caudata). It has indeed been justly described by the late Professor Newton as "a marvel of construction, combining beauty with safety and warmth". Nearly oval in shape, and with a small hole on one side by way of a door, it is composed mainly of moss and wool, held together by spiders' webs; externally it is encrusted with lichens so as to harmonise with its surroundings, while it is lined with feathers. This lining would appear to entail a prodigious amount of labour, since Macgillivray found in one of these nests no less than 2,379 feathers, chiefly those of the Pheasant, Wood-pigeon, Rook and Partridge. Generally this wonderful nursery is placed in the middle of a thick bush, and so firmly is it bound to the supporting branches that these must be removed with the nest if the latter is to be taken intact. The cock and hen appear to work alternately in its construction, which may be completed in as short a time as twelve days, but a longer period is usually required for this purpose.

Usually nests which are built amid bushes or trees either rest upon some big bough just where it leaves the trunk, or are lodged between the parting-ways of several small branches. Often, however, these branches are included within the framework of the nest, as in the case of the Long-tailed Tit, for example. And herein we probably have the origin of pensile nests, of which a few examples shall be described here. But. before proceeding to these it will be necessary to refer to a type of nest which, fixed between vertical pillars, occupies an intermediate place between nests interwoven between forking branches and suspended nests. A good example of such a nest is found in that of the Reed-warbler (Acrocephalus streperus). The building material selected by this little bird consists of the seed-heads of reeds and long grass mixed with wool. The 
grass seems to form the foundation, and is wound horizontally round about the stems of three or four tall reeds, while the seedheads and wool are used to fill up the interstices. The complete nest measures about five inches in depth, three inches across the top, enclosing a cavity of some three inches in depth, lined with very fine grass and long hairs. So securely is this cradle fixed, and so great is its depth, that even when the supporting reeds are bent low by the wind, so low that the nest may almost touch the water, the eggs will not roll out, nor is the sitting bird apparently discomfited.

Pensile nests are built by many species, though the more remarkable instances must be studied in the birds of other lands. At least one good example, however, may not infrequently be met with in Great Britain, the builder thereof being the smallest of our native birds-the Golden-crested Wren (Regulus cristatus). The materials chosen are the softest moss and wool, held together by means of spiders' webs and long grasses, while small feathers are finally added to form the lining. The whole structure is suspended after the fashion of a hammock, to the under side of the slender twigs at the end of a branch of such trees as fir, yew or cedar, only with this difference, that while the hammocks swing at the ends of long cords this nest is braced up close to the branch. The Golden Oriole similarly suspends its nest, which is built up of sheep's wool, fibres of roots and long slender stems of grass beautifully interwoven, while flowering heads of grasses are used to form a lining in the place of feathers. But while the Oriole appears always to suspend its nest, this rule is not so closely followed by the Goldencrested Wren, which will occasionally build upon the upper surface of a branch, or against the trunk of a tree upon the base of a diverging branch, thus reverting to the more normal habit.

The purse-like nests of the Flower Peckers (Diceum) and of the Penduline Tits (p. I84) and Humming-birds (p. I82) are even more beautiful examples of nest-building, being made almost entirely of cotton-down, as also are those of the Crowned Titmice (Agithalus).

It has already been shown that species which commonly build a pensile nest will on occasion revert to the normal fashion of resting the nest on the bough. Similarly, when a number of distinct species are found to have acquired the 
practice of building a pensile nest, it will often be found that other species of the same group build after the older fashion, as witness the Weaver-birds (p. 183) and Humming-birds, for example. The nests of the latter, of whichever type, are of

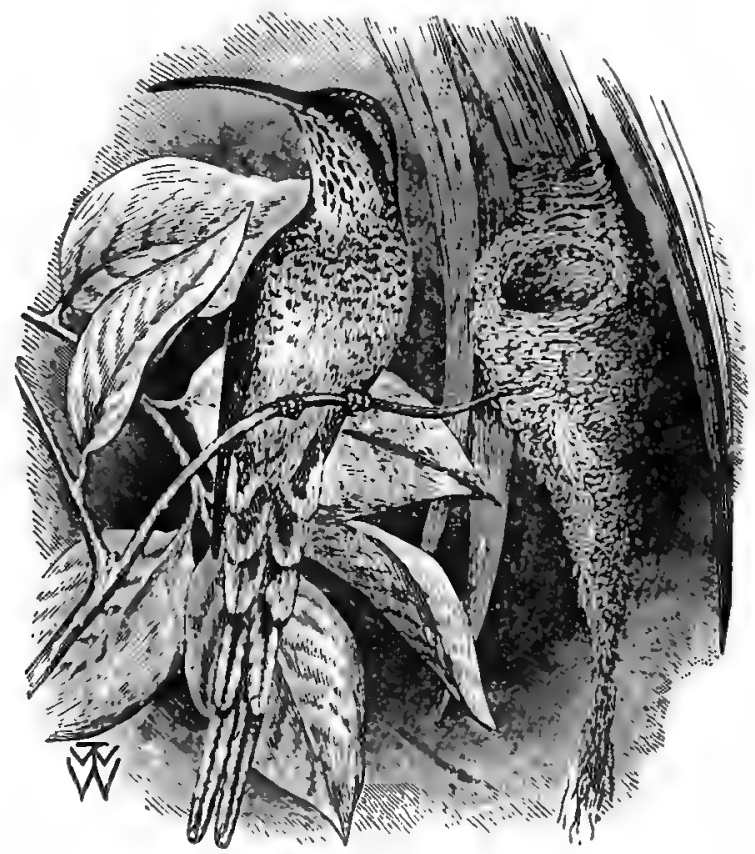

Ilc. 25.-Nest of The Hummina-Bird (Phathornis eurynome). Pensile Type.

great beauty, and formed principally of a felting of cottondown and spiders' webs. Mostly cup-shaped, and often bestudded externally with lichen, they are small even relatively to the size of the bird, so much so that in one instance it is recorded that as the young grew in size the walls were heightened by the parents, until at last the nest was more than twice as big as when the eggs were laid and hatched! Where the nest is suspended it is attached either to the tendril or stem of some climbing plant, or to the side of a drooping palm leaf. When hanging freely some species, it is said, load one side of the nest with a stone or bits of earth to secure a proper balance, and this device is again met with in the case of some of the Weaverbirds. 
More remarkable structures than any we have yet noticed are the hanging nests of many of the Sun-birds, Hangnests, Weaver-birds and Jastly the "Tailor-bird". These nests afford us a forcible illustration of the apathy of Ornithologists for anything more than mere collecting or species-making, or the record of bald or obvious statements of fact; inasmuch as among the Hangnests (Icterida) a great diversity in the form of the nest and in its site is exhibited, some species nesting on the ground, others in reeds or tussocks of grass, and others again in trees, these last presenting a very remarkable degree of specialisation in their architecture, while those of the first of this series are simple in type. Yet no attempt has been made to trace out the several stages in the evolution from the one extreme to the other. Unfortunately, this cannot be done here, as owing to neglect of this most interesting question sufficient material has not been collected to make the chain complete.

The Sun-birds appear always to suspend their nests, which are built of fine hair-like roots, fine grass and wool. They are pocket-shaped structures provided with a more or less steeplelike dome, the apex of which seems to suspend the whole, while above the entrance it is produced to form deep overhanging eaves.

The Hangnests of North and South America (Icterida) build, as we have just remarked, various kinds of nests, but we can here refer only to the very highly specialised suspended type, which have the shape of a Florence-flask with an enormously long neck. These nests are made of long, fine grass with an entrance hole near the middle of the flask. Yet more wonderful are the nests of some of the Weaver-birds-and here also transitional types of increasing complexity are to be found-the typical forms of which may be described as retortshaped. Strongly wrought of fine grass stems or fine roots, these nests are globular in form and suspended by a long rope, while entrance is gained by a tubular aperture generally placed at the bottom of the nest; it forms indeed a sort of covered way added on to the more normal pocket-shaped structures of this kind built by other species. Both sexes are said to take part in the work of building, the rope-like suspensory portion being first formed, and this is continued downwards to end in a large loop, the inner entrance to the nest, From this loop the sides 
of the chamber are started, the female receiving the ends of the threads pushed through from the outside by her mate. One species, Ploceipasser mahali, make two "spouts" or covered ways to the brood chamber, while Ploceus baya balances its nursery by means of lumps of clay, as is also done by some Humming-birds (p. 1 82).

It would seem that the addition of this tubular entrance is a contrivance to prevent the entrance of snakes. To achieve this end Salvin's Swift and the Penduline Tits add a false, blind entrance, their nests being exposed to the attacks of lizards. The nest of Salvin's Swifts, Panyptila Sancti-hieronomyi, is to be reckoned among the most remarkable of the pendant nests, being constructed entirely of seeds collected in mid-air, held together by a salivary secretion, which is also used as a cement for the attachment of this curious tubular structure. The felted nests of the Penduline Tits of the Genus Remiza deserve some special notice. In texture the walls of this nursery, both in appearance and to the touch, resemble that of the finest felt carpet, being made of cotton and seed-down. Towards the upper end of the nest is a funnel-shaped opening leading to the chamber, and bejow this a small pocket which is supposed by some to be a roosting place for the male. On the other hand, according to others, the sitting bird draws in the tubular entrance before going to sleep so that snakes or lizards fumbling about the pocket or false entrance give the alarm, when the bird escapes by pushing a hole through the back of the nest.

One other example of pendant nests and we must conclude this section: this is furnished by the Tailor-bird (Sutoria longicauda). It is an extraordinary cradle that this creature makes, inasmuch as it draws together the edges of a leaf and holds them in position by stitching them, either by vegetable fibres or threads spun by man-when the nest is built near human habitations. Sometimes two leaves are similarly held. The pocket thus formed is then filled with cotton-down and other vegetable matter and soft material. Just as various stages in the evolution of the highly finished nests of the Hangnests and Weaver-birds are to be met with, so in the case of the Tailor-bird we find an allied species, the Fan-tailed Warbler (Cisticola cursitans) building a globular nest amid grass stems and binding the free end's together above it. 


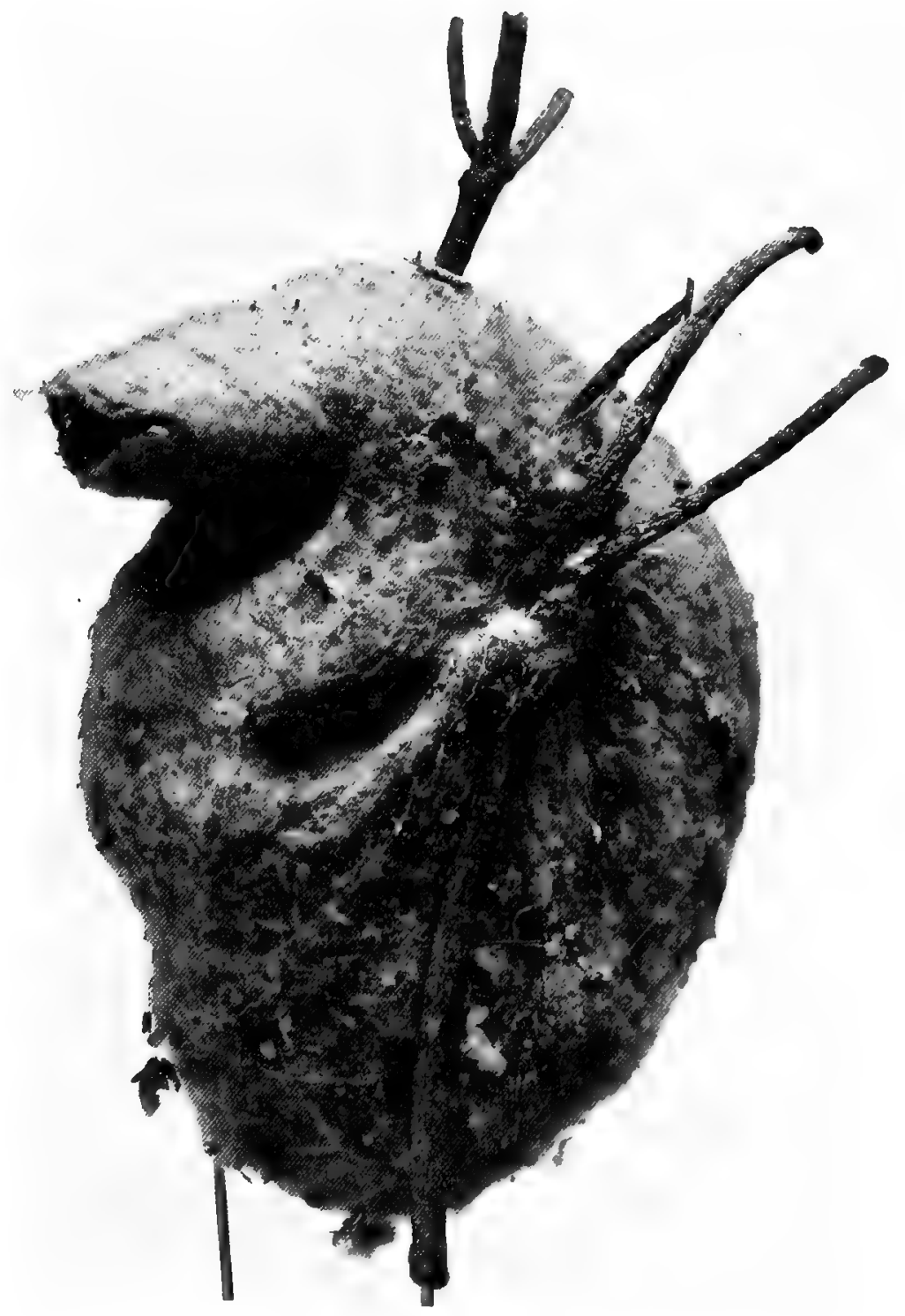

THE NEST OF REMEZIA 

We must pass now to a brief survey of such nests as are built of mud, wherein it will be seen that the selection of this material has been independently made by the most diverse orders of birds, some of which have acquired the most wonderful skill and ingenuity in the use of this material.

Mud is employed, as the foregoing pages have shown, by many birds either to form a cement in holding together other materials, or more remarkable still, to serve as a balance to nests suspended by a single strand. Originally used as a cement only, it is easy to see how, when the normal stable materials were hard to come by, mud alone came to be employed. But whether the shapes of the mud-nests of to-day are replicas of the older nests built of a mixture of materials, or whether the evolution in intricacy which is to be met with is independent of such models, we cannot say.

The simplest types of mud-nests are cup-shaped, or rather basin-shaped structures such as those built by the Grey Struthidea and Corcorax of Australia on the branches of trees; or of the huge columnar piles hollowed at the top built by the Flamingo in swamps. The mud-nests of the Swallow and Martin need no description here, but it is to be noted the other mud-building members of this tribe show a wonderful ingenuity in the construction of their nurseries, some of those of the Cliffswallows of the Genus Petrochelidon, for example, building retortshaped nests of no little beauty. It would seem, however, that, like the Swallows generally, they originally built in holes, inasmuch as a North American species, $P$. pyrrhonota, will frequently build in holes, around the entrance of which they construct a rim of clay. Probably the size of this rim was increased in proportion to the smallness of the hole, until at last the entire nest came to be of mud whenever holes were wanting. The nests of Australian Cliff-swallows are said to be constructed by several birds working together, one remaining inside the nest and receiving the pellets as they are brought by its companions. The entrance tubes to these nests are often eight or nine inches in length. But observations are wanting as to whether these birds build their nests on this principle of mutual help, or whether they are polygamous, each nest being built by the male and his mates. But the most noteworthy of nests of this kind is that built by the Oven-bird (Furnarius) 
of South America. It is a remarkable structure, thick-walled, globular and of great size. For the most part made of clay and dung, the builders, however, evidently understand the value of hair and long grass as binding materials, for these are worked into the mass just as hair is used in mortar in the construction of human dwellings. In section it is found to contain a central chamber, with a long passage running partly round it, the inner chamber being lined with fine grass. Since the materials for building can only be obtained in damp weather this edifice takes several months to build. It is further to be noted that while three distinct species all build precisely similar nests, two adopt a more conventional style of nursery. One of these, Furnarius figulus, builds a nest of sticks, while the other, $F$. torridus, breeds in holes in banks.

Among the builders of the more elaborate nests where finely divided materials are used, cement, in the form of a secretion of the salivary glands, is commonly employed. This is the case, as we have already seen, in the nests of Salvin's Swift (p. I84). But there are certain Swifts, of the Genus Collocalia-a genus extending from the Indo-Malayan countries and Australiawhich build their nests almost, or entirely, of inspissated saliva. These birds attach their small saucer-shaped cradles to the walls of caves, generally mixing grass or feathers with this secreted matter. But the species known as the Esculent Swiftlet (Collocalia fuciphaga) commonly dispenses with all foreign materials and uses the proqucts of the salivary glands entirely, and it is these nests which furnish the material for the "birds'-nest soup" considered so great a delicacy by the Chinese. The collection of these nests constitutes an important industry, as may be seen from the fact that from Borneo alone, over three and a half million nests have been exported in a single year. As might be supposed, these birds build in huge colonies, and while in some cases the caves are approached by water, in others the floor is dry and covered with a deposit of guano varying from eighteen to thirty feet thick !

No less remarkable are the nests of some of the Tree-swifts of the Genus Macropteryx since these are made up of a salivary secretion intermixed with bits of bark, while in point of size they represent the smallest nests known-relatively to the size of the builders. About an inch and three-quarters across and half an 


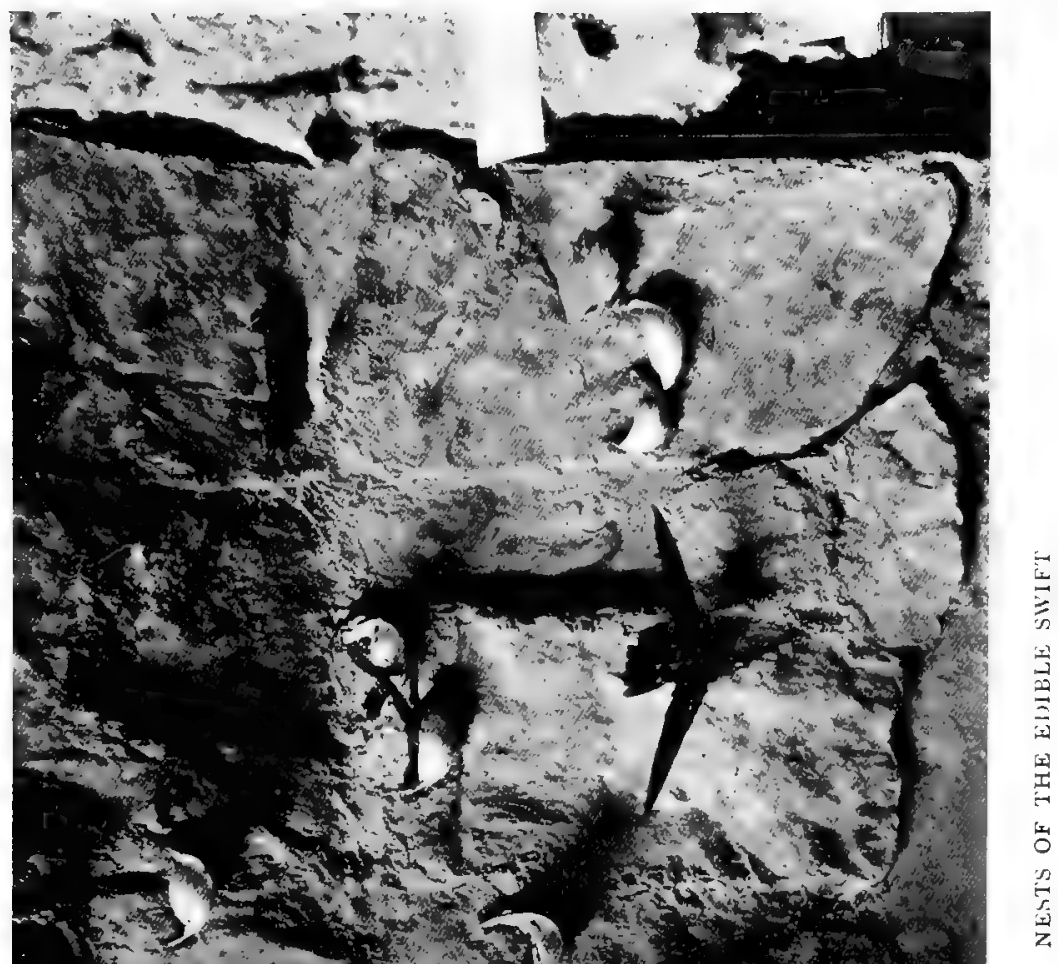




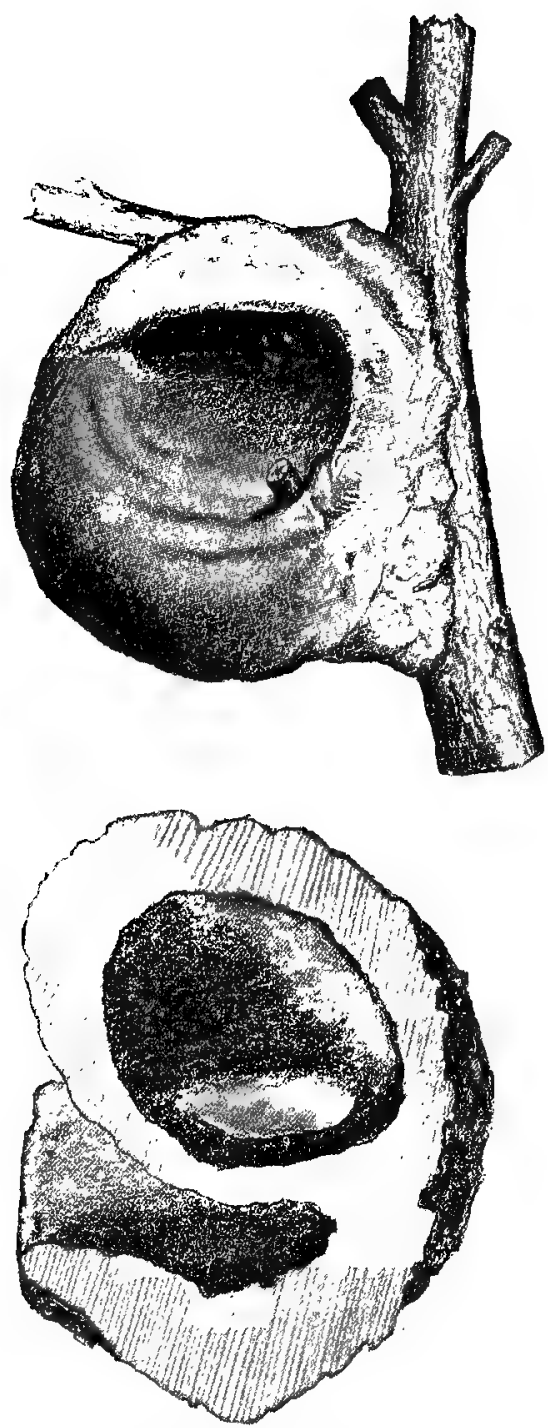

ILL, 26.-NEST OF OVEN-BIRD 

inch in depth, the walls of this fragile structure do not exceed an eighth of an inch in thickness. In this tiny space a single egg is laid which, in most species of the genus, appears to be incubated in the usual manner, though at this time, owing to the large size of the bird, the nest becomes invisible. But one species, the Javan Tree-swift ( $M$. longipennis), builds so flimsily-the walls of the nest being no thicker than parchment-that the sitting bird has to rest her weight upon the bough, to the side of which the nest is attached, contriving so that the abdomen is in contact with the egg.

We have already alluded to the fact that many birds breed in colonies, often of vast extent, as in the case of Penguins, Albatrosses, Flamingoes and the members of the Gull tribe, which may often be numbered by millions. Here the nests, often but the rudest structures, are all separate, though they may be divided only by a few inches. Smaller colonies are formed by many species, notably by the Swifts and Swallows, where the nests, sometimes to the number of several hundreds, are frequently so crowded as to touch one another. And thus we find the way paved for the evolution of a yet more intimate relation between associated nests. Yet but two species appear to have adopted the practice. One of these is a Weaver-bird (Ploceide), the other the Sociable Grosbeak of Africa (Philhatcrus socius). The enormous umbrella-shaped, thatch-like masses which these birds combine to erect in trees have been known to contain as many as three hundred and twenty-seven separate nests, but whether the whole is produced by the packing together of separately constructed nests, or whether the nesting tunnels and chambers are driven through after the common foundation has been built, does not seem to be known!

Probably this arboreal "warren" is formed by the interlocking of separate nests, since this method of building is also practised by the Wax-wing of San Domingo (Dulus dominicus), several pairs of which will often join their nests, made of twigs, into a circular mass.

'The huge nests of the Osprey and Secretary-bird present us with yet another aspect of colony formation among birds; for both species permit small Passerine birds to build their nests within the outer walls of the castles of their overlords, much in 
the same way as Sparrows, Starlings and Swifts build within the roofs of human dwellings.

In broad outline the main facts concerning the construction of nests, and the sites in which they are placed, have now been surveyed, and here and there exceptions to the rule have been cited. To these exceptional cases it is proposed to add a few others, inasmuch as while some yet seem inexplicable, others throw some light at least on the question of the evolution of nest-building.

That some species are remarkably conservative in the construction of their nests, and in the selection of its site, while others are not a little erratic in these matters, is well known. But most of these instances will be found on examination to be determined by circumstances. Thus Rooks have been known to build their nests of wire, of which an abundant supply was to be obtained from refuse heaps in the neighbourhood, while sticks were probably scarce, possibly having been appropriated by earlier builders. Robins and Blue Titmice choose most curious places wherein to build; and here again we have an explanation in that both these birds seek the neighbourhood of human dwellings during the nesting period, thereby displaying a confidence that happily is not often abused.

Similarly, the fact that Cormorants and Herons, and even the lordly Eagle, will build either in trees, precipitous rocks, or on the ground is explained by the nature of the environment. Where lofty trees are available all seem to prefer the security they offer.

But the exceptions to which reference is here particularly made are those which break with the traditions of the tribe in a much more striking fashion, inasmuch as, in the case of large groups of birds especially, some species are found which have developed idiosyncrasies in this matter which seem to defy solution; and while with some species these departures are sporadic, it is often found that with others of the same group they have become normal. Thus among the Duck tribe the ground is the normal nesting-place, but the Mallard often elects to nest in a hole in a tree thirty or forty feet from the ground; with the Golden-eye Duck (Clangula glaucion) such a site is invariably chosen.

Among the Plover tribe there is a remarkable lack of 



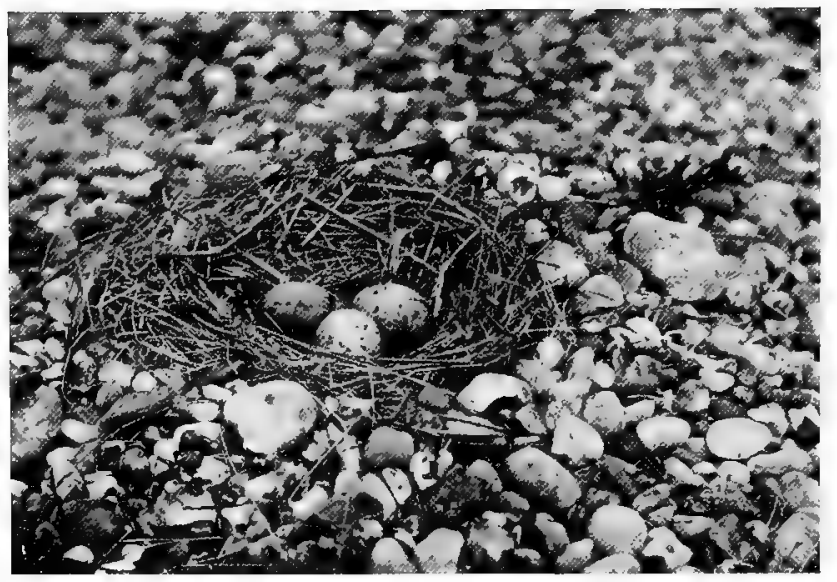

NEST OF THE HERRING GULL

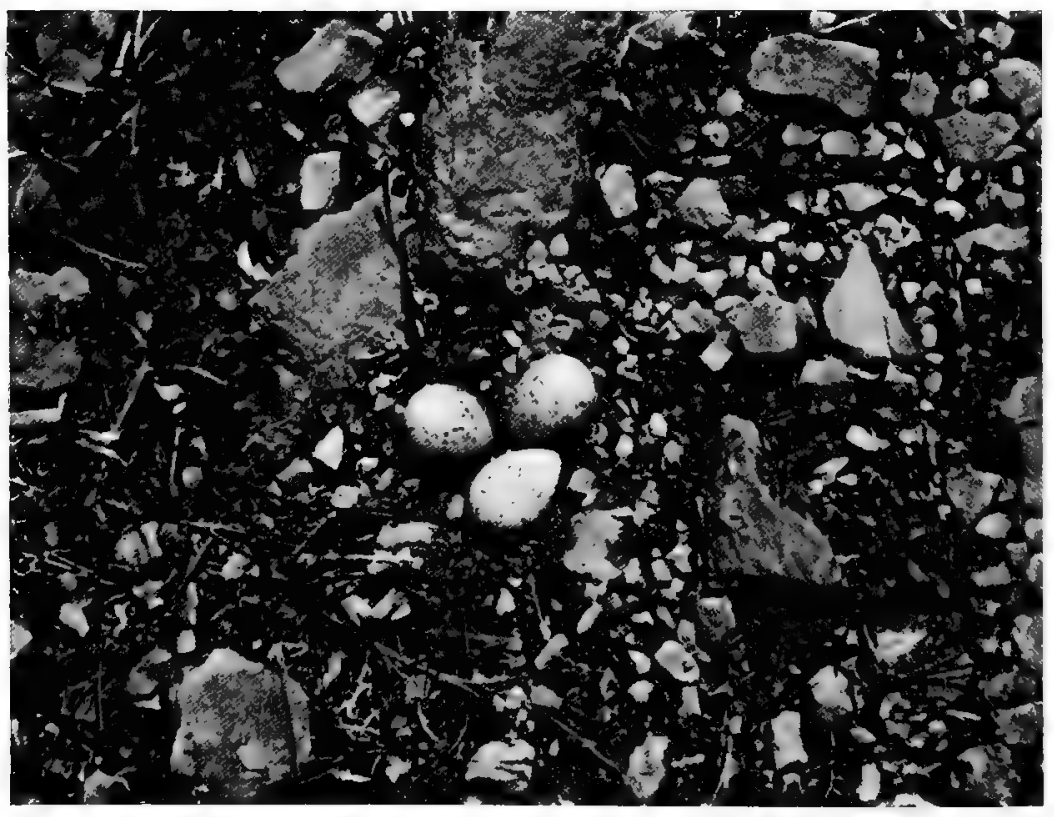

A PRIMITIVE NEST: NEST OF THE RINGED PLOVER 
uniformity and tradition, so to speak, in the matter of nestbuilding.

The majority lay their eggs on the bare ground, in a slight natural depression, or in a shallow cup formed by the birds themselves. The site chosen may be meadow-land or barren heath, or sandy or shingly beaches.

The Redshank alone among the Plovers weaves a dome of growing grass above its eggs. The Little Ringed Plover, on the other hand, trusts to the protective resemblance of its eggs to their immediate surroundings. In some cases these eggs are deposited in the bare sand or shingle; in others a pavement of small stones or shells is prepared for their reception.

The Wood Sandpiper (Totanus glareola) and the Green Sandpiper ( $T$. ochropus) differ in yet more striking fashion from their congeners. The former appears generally to fashion a rude nest on the ground, near water, but in Siberia it generally uses the deserted nests of Fieldfares high up in trees ! Similarly, the Green Sandpiper nests occasionally on the ground or on moss-covered stumps, but more usually the eggs are laid in old squirrels' "dreys," the nests of Song and Missel-thrushes, Blackbirds, Jays and Ring-doves!

The Gull tribe normally nest on the ground, content with the merest apology for a nursery, yet, on occasion, they will build in trees thirty feet or more from the ground.

The Terns again, as may be seen on a visit to any breeding colony on our coasts, display considerable individual differences in this respect. The Common Tern, for example (Sterna fuviatilis), may be content with a bare scrape in the sand, or may build a quite bulky nest of weeds. These differences seem to be inexplicable, to be due to individual idiosyncrasies, since various gradations of perfection, from a mere bare depression to a relatively elaborate nest, may be found in the same colony, and within a relatively small area.

The innate capacity for building displayed by the British species of Tern is possessed in a more highly developed and more stable degree in some exotic species, as for example in the Noddy-tern (Anous stolidus). This bird commonly rears its young in trees or low bushes, building a nest of mud, sea-weed and grass. More curious still, the White-tern (Gygis candida) will lay its single egg on a coral reef, or any slight cavity of 
a branch, or at the base of a broad leaf-stalk. Thus Dr. H. O. Forbes, describing the nesting of this bird in the Cocos Keeling Islands, remarks: "Its solitary egg is deposited on the leaf of a young cocoa-nut palm, at the time when the leaf has rotated from its vertical position to one nearly at right angles to the stem. The egg is laid in the narrow angular gape between two leaflets on the summit of the arch of the leaf, where it rests securely, without a scrap of nest, ... yet defying the heaving and twisting of the leaves in the strongest winds. The leaf, as in all palms, goes on drooping further and further till it falls; and among the settlers it is a subject of keen betting, when they see a Tern sitting on an ominously withered leaf, whether the young bird will be hatched or not before the leaf falls. The result . . . has always been in favour of the bird: if the leaf falls in the afternoon, the Tern will have escaped from the egg in the morning!" More commonly, it would seem, however, that this bird deposits its egg on the bare limb of a tree without any attempt at safeguarding whatever, yet accidents seem rarely, if ever, to happen.

Motives of security probably prompt the Dipper (Cinclus aquaticus) of our northern streams to build its dome-shaped nest of moss in some cranny behind a cascade, so that the bird must dash through the water every time it enters or leaves the nest; but there is no evidence to show whether this site is invariably chosen when cascades are to be met with. Similarly, security may be the reason why the Ruddy Kingfisher (Halcyon coromandus) of North-West Borneo places its eggs in the pendulous nest of a peculiarly vicious bee, for certainly the eggs can only be taken after the destruction of the bees! The Rufous Woodpecker (Micropterus phoeoceps) has been taken near Darjiling from the deserted nests of ants, nests resembling in shape those of the wasp (Vespa brittanica). It would seem that the builders are summarily ejected by the birds, and since ants form their staple food it is probable that the victims are eaten as they surrender! Deserted ant-hills are commonly used by many species of insectivorous Kingfishers, but this is not surprising when it is remembered that so many select sandbanks wherein to tunnel their nurseries.

This list of peculiar nesting sites might be greatly extended, but sufficient instances have perhaps been cited to draw atten- 
tion to this aspect of nest-building among birds. Whether we shall ever learn anything of the factors which have brought about these departures depends entirely upon the observations,of those fortunate enough to be able to study the facts in the field.

This chapter would be incomplete without a brief comment on the question raised by Dr. Alfred Russel Wallace, years ago, as to whether birds build by instinct or by imitation. Without doubt he did much to confuse the issues at stake by comparing the nest-building of birds with the house-building of man: an obviously false analogy. In spite of the dogmatic assertions of this eminent naturalist, there is absolutely not only no evidence in support of his contention that birds build by imitation, but all the known facts are directly against him. He first argued that the art of nest-building was acquired by the young bird while in the nest. That is to say, between the intervals of sleep and feeding it takes mental notes of the construction of its cradle, against the day when these notes may be useful! Relinquishing this, he next suggests that the young bird, just before building its first nest, makes a survey of the cradles of others of its own species; and finally, that young birds must pair with old birds and so learn the secret from their more experienced mates! But it is all very well to talk of imitation, but who set the fashion of each type of nest originally? No, there can be no question of imitation. Nestbuilding is a product of selection and is instinctive. This is shown by the fact that wild birds taken from the nest before they can see, and kept in captivity under suitable conditions, will, at the appropriate time, build a nest typical of their species. That a bird's first nest is less perfect than succeeding nests has often been urged, and this is probable; for practice necessarily leads to perfection. There is nothing remarkable, indeed, about the part played by instinct in this matter. Young spiders yet but an hour old will at once proceed to spin a web as perfect as that of an adult, and there can be no question of imitation here. A caterpillar when full-grown will spin for itself a most elaborate cocoon, or suspend itself by the tail, and place a girdle round its body to bear its weight in the chrysalis stage, yet there can be no factor other than "instinct" at work to guide it. For this act is performed but once in its life, and is carried out in isolation. 
But Dr. Wallace also implies that birds employ a certain amount of reasoning in their building, or rather, perhaps, that they act on suggestion, on the stimulus of their environment. That when impelled to build they seize on the materials nearest at hand. Thus the Wren "frequenting hedgerows and low thickets, builds its nest generally of moss, a material always found where it lives. . . ." "Rooks dig in pastures and ploughed fields for grubs, and in doing so must continually encounter roots and fibres. These are used to line its nest." But what about the foundation of the nest? And again: "Swallows use clay and mud from the margins of the ponds and rivers over which they find their insect food. The materials of birds' nests . . . are, then, those which come first to hand." But the Sandmartin is equally partial to streams, yet this bird does not build a nest of mud, but laboriously drives tunnels in sandbanks and lines the further chamber with feathers! Finally, he remarks: "The clumsy hooked bills, short necks and feet and heavy bodies of Parrots, render them quite incapable of building a nest. ..." But the Quaker-parrot (Myopsittacus monachus) builds a large domed nest of sticks, and is, moreover, no mean craftsman at weaving.

The origin of nest-building, as we have suggested (p. 174), began probably with the ground-builders, which hit upon the device of collecting twigs or grass to form a dry bed while brooding, thereby preserving their eggs, while those less intelligent failed to rear offspring. The young of these more intelligent parents, inheriting this variation in the direction of increased intelligence, would, stimulated by the sexual impulse at the proper season, repeat the same tactics. With changes in the environment new needs arose and were similarly met by at least a few individuals, and thus, by slow increments the gradual evolution of complex nests arose. Even to-day many stages can be traced in the growth and perfection of the more complex nests of any particular type, such as the pendant nests of the Weaver-birds, and Hangnests, for example (p. 183). While, as in the case of the Cliff-swallows (p. I 85), we may even have a reversion of the older type of nests, inasmuch as when suitable holes are to be found a mud-rim around the entrance is all that is constructed, the typical retort-shaped nest growing in inverse proportion to the size of the hole. 


\section{CHAPTER XII \\ REPRODUCTION-CONCERNING EGGS}

Number of eggs in a "clutch". Shape of the egg. Size. Texture and thickness of the shell. Colours of eggs. Origin of the colours. Patterns of coloration. Colours of eggs in relation to classification. Coloration in relation to environment. White eggs and their meaning. Structure and composition of the egg.

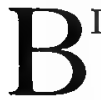

IRDS, like their cousins the reptiles, are oviparous: but they differ markedly from the reptile in the relative fewness of the eggs laid in each "clutch" as well as in the fact that these eggs are commonly coloured externally.

With regard to number it is to be noted that this may vary from a single egg, as in the case of the Guillemot, for example, to as many as twelve or even twenty, as in the Common Partridge. That is to say, except when more than one brood is reared in each year, this number is not exceeded; but if the eggs be removed or destroyed, more are laid to replace them, and this may be repeated many times during each season, until the maternal instincts are gratified, or the bird becomes exhausted.

Man has taken advantage of this fact to supply himself with food, or for other less excusable ends. Thus the Lapwing, one of our most useful birds, is mercilessly robbed year by year to supply "delicacies" for the table, and similarly the colonies of Gulls and Guillemots are systematically plundered, the former supplying the shortage in the market of "Plovers'" eggs, the latter furnishing their ova for commercial purposes. As a rule, however, a few eggs are left to hatch, for the purpose of preserving the stock. The Eider-duck and the Goldeneye Duck are still more systematically victimised, the latter even being induced to lay in artificial nest-boxes.

While in many species the number in each "clutch" varies considerably, as in the case of the Partridge, in others it is very 
constant, as for example in the Plover tribe, which lay three or four, or in the Gulls and Terns, which lay two or three, or of the Pigeons, which never exceed two.

In form birds' eggs present certain peculiarities; thus in the Owls, Bee-eaters and Diving Petrel they are spheroidal, and bi-conical in the Night-jar and Sand-grouse; in the Cormorants they present a long ellipse, while in many of the Plovers and Guillemots they are pyriform. Only in the case of pyriform eggs does shape appear to have any significance. Thus in the case of the Guillemot, which deposits a single egg on a bare ledge of rock in the face of some cliff, this shape is obviously advantageous, since, if blown by the wind, or struck by the bird as in diving off the ledge, instead of rolling over into the sea or on to the rocks below, it will revolve in a circle on its own axis; though in spite of their shape thousands of eggs are annually lost, either because laid on too small or sloping a ledge, or because they are struck too violently by the sitting bird, as when it leaves the work of incubation through fright. In the case of the pyriform eggs of the Plovers this shape is of advantage, since it allows the eggs to be more closely packed - the sharp ends inwards-and so more easily covered by the sitting bird. This being so, it is a little surprising to find that even among nearly allied birds of this group pyriform eggs are by no means the rule.

The size of the egg does not by any means always correspond in proportion with the size of the bird which laid it, but depends rather on the relative development of the newly hatched chick. Thus where the eggs are relatively large-compared with the size of the parent-the chick at hatching is able to run about and feed itself, under guidance, while on the other hand, when the egg is small the chick is hatched in an extremely helpless state-before the eyes have opened, or the body has developed a covering of any sort (p. 246). In proportion to its size perhaps the Apteryx lays the largest egg. This bird indeed was described on one occasion as "the bird which lays eggs bigger than itself"! By way of contrast a comparison is often made between the egg of the Humming-bird and that of the extinct Æpyornis, the cubic contents of whose egg equalled about three gallons. The Curlew, Raven and Guillemot are birds of similar size, and so also are the Snipe and 
Blackbird, but the contrast in the sizes of their eggs is enormous.

Besides the variation as between different species, there are to be found numerous instances of specific variations of a very considerable range which have become normal to such species. Of course variation within small limits occurs in eggs of all species: to these we do not refer here, nor have we in mind those abnormalities of size which so frequently occur. Remarkably small eggs containing no yolk, for example, frequently mark the first efforts of immature birds. But the variations to which we refer are such as are afforded by the great White Heron." This species occurs both in Europe and India, birds from the two regions being indistinguishable, yet the eggs of the European birds are always much larger than those taken in India. European eggs in the collections of the British Museum measure from $2 \cdot 35$ to 2.7 in. in length, while Indian specimens range from $\mathrm{I} \cdot 88$ to $2 \cdot 38$. *

Birds' eggs differ very considerably in the texture and relative thickness of the shell. In the matter of texture some, as in the case of the Tinamous, have their surface so highly polished as to look like burnished metal or highly glazed porcelain, while a very considerable gloss is commonly met with, as in the case of the Kingfishers and Woodpeckers. Ducks' eggs are remarkable for their peculiarly smooth, "greasy" surface, though the eggs of the Genus Erismatura must be taken as exceptions to this rule, since they are covered with coarse granulations; and, curiously enough, the eggs of the allied Genus Biziura, represented only by the Australian Musk-duck, are frequently similarly granulated, and when this is not the case they are of the normal Anserine type. The eggs of the Ibises offer similar differences, since in some genera they have a smooth surface, while in others it is rough. So far no explanation for these differences appears possible. This roughness of texture attains its maximum among the Grebes, Flamingoes and certain Cuckoos. The eggs of these birds have the shell incrusted with a chalky layer often of considerable thickness: often when this crust is scraped away a rich colouring is revealed, as in the case of the Cuckoos of the Genus Crotophaga. In the allied Guira Cuckoo this chalky layer is deposited in the form of a coarse and irregular meshwork forming a 
tracery of white over a deep blue ground. Nothing appears to be known as to the possible use of this chalky layer, but in one case at least a possible explanation may be found. This case is furnished by the Razor-bill, but the interpretation offered may be more conveniently considered later (p. 209).

The thickness of the shell varies within certain limits; thus in some cases, especially among the smaller birds, the shell is so thin that the egg becomes translucent, as in the case of the Kingfisher, while among the Ostrich tribe it is relatively thick.

While as a rule the surface of the egg is smooth, in some cases, especially among the Ostriches, the egg is deeply pitted, the Apteryx and Tinamous excepted.

It has been stated that the texture and colour of the shell of eggs of hybrids can be distinguished from those of the pure species. It is conceivable that this may be so, but the contention that the eggs of a hen mated with a cock of another species are similarly affected is lacking in support, and will almost certainly prove to be wrong, for it must be remembered that the shell is a purely extraneous product, that is to say, it is a secretion of the glands of the oviduct, and has nothing to do with the germ cells, which are alone affected by such crossing.

We must pass now to the colours of eggs, or rather, of the shells thereof. First of all, let us dismiss certain technical but important facts concerning the composition of these colours. We are indebted for most of what we know of the pigments colouring eggs to the late Dr. H. C. Sorby who by spectrum analysis differentiates seven distinct colours :-

I. Oorhodeine-a very permanent, and very common, redbrown pigment.

2. Oocyan $\{$ blue pigments probably closely related,

3. Banded oocyan $\{$ though the second only yields a banded spectrum.

4. Yellow ooxanthine-a bright yellow pigment which, mixed with oocyan gives the beautiful green colour seen in the egg of the Emu.

5. Rufous ooxanthine-a reddish-yellow pigment possibly peculiar to the eggs of the Tinamous. 
6.

- - a pigment giving a banded spectrum but otherwise little known.

7. Lichen ooxanthine-a brick-red pigment, possibly due to the growth of minute fungi.

In some respects we must regard Lichen ooxanthine as the most remarkable of all, that is, if it is really of fungoid origin. This pigment, it seems, occurs in almost all kinds of plants, but especially in lichen and fungi. Dr. Sorby, however, believed that it is a normal constituent of the shell of eggs having a peculiar brick-red colour. Some of the most valuable work in recent years on the nature of the pigments of animals has been done by Miss Newbigin-to whom, and to Professor Newton, we are indebted for this summary-but she has apparently not yet investigated the point.

The other pigments here mentioned are apparently blood secretions, derivatives of hæmoglobin. According to Wickmann they originate from the blood which contributes to the formation of the corpus luteum, the "yellow body" which is formed by the escape of blood from the capsule in which the egg is formed, after the expulsion of the egg. This "yellow body" appears later to undergo decomposition, or rather a retrogressive metamorphosis, which results in the formation of pigments. These pigments thus formed within the ovary are shed, according to Wickmann, into the oviduct and mingled with the materials of the shell in its uterine portion, the varying and characteristic hues being due to the difference in the composition of the blood in each particular species.

That these pigments are blood-pigments rather than bilepigments is more than probable, but it is open to question whether they are derived and disposed of in the manner suggested by Wickmann; rather, if they are really derived from the corpus luteum, it would seem that the products of the metamorphosis must be absorbed and redeposited in the tissues of the oviduct, where they become set free after the shell has reached a somewhat advanced stage of development; and for the following reasons: "If a bird," says Professor Newton, "bearing in its oviduct a fully formed egg, be captured, that egg will speedily be laid under any circumstances of inconvenience to which its producer shall be subjected, but such an egg is usually 
deficient in coloration-fright and over-excitement having arrested the natural secretions." Again, in birds which normally lay two richly coloured eggs, it sometimes happens, as in the case of two pairs of eggs of the Golden Eagle, that one egg is colourless. In one instance the coloured, in the other the uncoloured egg was first laid. In the matter of intensity also the colour varies, increasing with age up to the bird's prime and then declining. Finally, if the products of this "yellow body" are simply shed into the oviduct, there to mingle with the growing tissues of the shell, it is difficult to account for the existence of patterns of coloration, as in eggs with zones of colour or streaks, for example, and still more difficult to account for the existence of white eggs, since the "yellow body" will be found in all cases.

We may assume then, that however derived, this pigment is deposited by the walls of the oviduct, and it would seem that in many cases this deposition takes place in two different regions of the duct, first on the formation of the earlier layers of the shell, where little more than a slight staining is affected, and later when the shell is nearly complete; in most cases there is no coloration until the egg has passed some way down the oviduct. It would then appear that the ground colour is first deposited, and after this the peculiar markings of the particular egg. When these are formed while the egg is at rest a sharply defined spot is the result: but it commonly happens that the deposit of pigment takes place while the egg is in motion, smears and blotches being the result; and it would further appear that the egg in its passage rotates, inasmuch as these streaks and lines show a decided spiral arrangement. These various evidences of the process of coloration can be well seen in eggs of many birds of prey, as well as in such strongly marked eggs as those of the Guillemot, for example.

When there is a difference in the size of the two ends of the egg, as is commonly the case, the larger appears first, as has been proved by experiment.

He would be a bold man who would attempt to describe all the varied hues and patterns which birds' eggs display, and his labour would be lost in the interminable, repellant descriptions in which such an attempt to achieve the impossible would involve him. But two points must necessarily strike any one confronted 
with a large and representative collection of eggs. Firstiy, that the colours displayed bore no sort of relation to those of the birds which laid them, and secondly, that there was little about these shells that would enable him to decide the particular species, or even genus, to which such and such an egg belonged, rare cases only excepted.

At the first blush it may seem curious that since the pigments of egg-shell and of feather are alike derived from the blood, there should be such striking contrast between the colours of a bird and the eggs which it lays. This contrast is marked indeed in such species, for example, as the Hedge-sparrow and the Thrush, whose eggs are blue, yet in the matter of plumage they are the most sober-coloured of birds; while the gorgeously clad Kingfishers and the Bee-eaters lay milk-white eggs. But the explanation of these things is not far to seek. In the first place, the colours of feathers are often due, not to pigment, but to structure (p. 284). This is never the case with eggs. The wonderful iridescent blue of the Kingfisher is a case in point, for the blue colours of the feathers are never due to pigment. In the second place, the coloration of the shell is, on the whole, as much governed by natural selection as are the colours of the feathers of the bird which laid them. To this point we shall return presently. For the moment we must pass to the question of markings of the shell, though there is unfortunately at present little enough that can be said on this head. We have indicated already the process by which these markings are made, and all that can further be said on the subject may now be briefly summarised. They range then from minute frecklings, such as are met with in some Game-birds, through sharply defined dots, to blotches and smears, and irregular lines and streaks which sug-. gest hieroglyphics of some sort, as in the eggs of Buntings and the Jacanas among the Plovers; while many eggs are what is called "double-spotted" on account of the fact that many of these spots are but faintly indicated, "and evidently deposited in a deeper layer of the shell. In some eggs, as in those of certain Petrels, the pigment is almost, and sometimes entirely, confined to a zone around the larger end. But perhaps the most striking fact about this coloration is the lack of uniformity which prevails among even closely allied species, species which in plumage bear an exceedingly close resemblance, while birds in no way 
related may lay very similar eggs. Not only indeed do nearly allied species lay eggs of widely different coloration, but instances are numerous where differences no less striking obtain between eggs of the same species, of which the Guillemot affords one of the most striking and familiar instances. And much the same is true of the shapes of eggs. Nevertheless, there are not wanting Ornithologists who, in the face of these facts, employ the coloration, or lack of it, as a factor in classification!

Contradictory though it may seem, it is yet true, however, that in broad outline we may distinguish the eggs of the larger groups, though, as might be expected, exceptions are frequent.

Thus, for example, the eggs of the Tinamous are distinguished by their extraordinary burnished appearance, met with nowhere else, except in one or two isolated cases among the Passeres (Burnesia), but from which they can of course readily be distinguished by their size. Among the Petrels, such eggs as are coloured have the pigment deposited in the form of a cap, or of a zone around the larger end, though this peculiar distribution is not confined to the eggs of this group. Among'the Steganopodes the Tropicbirds lay richly coloured eggs, those of the remaining families are more or less thickly incrusted with a white chalky deposit concealing, as in the Cormorants and Gannets, a shell of a beautiful blue colour. The Anserine birds, without exception, lay whole-coloured, unspotted eggs; and so also do the Stork tribe, whose eggs are generally blue or green in colour, though in some cases, as in the Ibises and Flamingoes, they are white and chalk incrusted. The eggs of the birds of prey are either wholly white, or have a ground colour of white, bluish-white or cream colour, spotted with red of various shades, and purplish pigment being distributed in the form of blotches varying in number and intensity, so that the colour ranges from a pale rust-red to a rich sienna-red, or inky purple, the blotches being sometimes so thickly clustered as to entirely suppress the paler ground colour. Thus the eggs of birds of this group are often of rare beauty. They also exhibit a marvellous range of variability in the matter of coloration, those of the Indian Kite (Milvus govinda), for example, in this respect are said by Mr. Hume, whose authority is great, to defy description. While the Game-birds, as a rule, lay whole-coloured eggs, generally cream or buff 
coloured, there are a few whose eggs are spotted and sometimes double-spotted.

The Grouse, Snow-cocks (Tetraogallus); and Red-legged Partridges lay spotted eggs : so also do the Quails and Hemipodes-if these last be true Game-birds. The eggs of the Gamebirds are noteworthy as presenting a perfect gradation from whole coloured, through minute freckles of pigment to spots, and from spots to blotches. Further, in some species they present a really wonderful range of variation, as, for example, in the Australian Swamp Quail, no two clutches being alike either in size or coloration. Some are white, others cream coloured, and others again sparingly or thickly freckled and blotched with grey, rufous or brown. Occasionally, as in the case of the Chukar Partridge (Caccabis chukar), the coloration varies with the geographical range. Thus eggs taken in Greece are frequently unspotted; those from the Grecian Archipelago and Cyprus are generally slightly and sometimes boldly spotted; more to the eastward they are invariably spotted, and frequently blotched with purplish, reddish or yellowish-brown, grey and pink.

It is little to the credit of the "field-naturalist" that we have no information as to the nature of the environment of the birds in these different areas.

The eggs of the Cranes and Rails are always more or less spotted. In the Rails these spots are usually small and of various shades of Indian red on a cream or white ground. Sharpe's Crake (Saurothrura insularis) lays a white egg. In the Cranes the coloration is stronger, forming large spots and blotches of various shades of brown and purple on a darkoccasionally light-ground.

Few hobbies perhaps have engendered more enthusiasm, have called forth more enterprise, pluck and hardihood, than egg-collecting. Yet, it must be confessed, the gain to science, for all this expenditure, has been pitifully small. The collector has furnished the raw material for the more serious student it is true, but he has made little enough use thereof himself. To his credit at any rate be it said, that he was the first to point out the striking resemblance between the eggs of the Plover tribe and of the Gulls, birds hitherto believed to be quite unrelated. Since then it has been shown, on anatomical grounds, that this resemblance between the eggs is no mere coincidence, but one 
of many links in the chain of evidence showing that the two groups are really very intimately related indeed.

With the exception of the Jacanas these eggs are all spotted with various shades of brown and black on a groundwork varying in hue from white, cream, brown, to blue and green. The Jacanas are remarkable. The Pheasant-tailed Jacana (Hydrophasianus chirurgus) is the only species of the group which lays a white egg; while the remainder have the shell covered with inextricably twisted lines forming a sort of tangled meshwork all over the egg.

But in the matter of variability none can compare with the eggs of the Guillemot (Uria troile), which are often of extreme beauty. No less than thirty well-marked variations of these eggs are exhibited in a special show-case at the British Museum of Natural History. The great range in pigmentation is really wonderful, but still more wonderful is the variability of the size and distribution and shape of the markings. No mere description could do justice to these eggs; suffice it to say in the ground colour they may be white, blue, green, brown, yellow, buff or pink, while the markings consist of blotches, spots, streaks and lines of every conceivable shape, and ranging in colour through different shades of brown, reddish, chocolate, and black; while some eggs have scarcely any markings at all, others have the surface of the shell thickly covered. But there can be no doubt but that, as in other cases, the eggs laid in successive seasons by each individual are always of the same type, i.e., a Guillemot which lays a green or a red egg for the first time of laying, will produce eggs of the same type in successive years so long as it lives.

The significance of such extreme variability is far from apparent, but it has been suggested that this individuality is the outcome of selection, the end gained being to enable each bird in the colony-for these are social birds-to recognise its own egg.

The remarkable pyriform shape of the Guillemot's egg we have already referred to; the Lapwing and many other Plovers lay eggs of a similar shape. On the other hand, no inconsiderable number lay eggs of the more typical form. Even among birds of the same genus and even of the same species great differences in this respect obtain. Among the Snipe many 
instances of this occur; thus the eggs of the Common Snipe are usually pyriform, but examples of an oval shape are common; the eggs of the Himalayan Solitary Snipe (Gallinago solitaria) are extremely pointed in shape, while those of Strickland's Snipe (G. stricklandi) are remarkably long, narrow and blunt-pointed. As a rule where these markedly pyriform eggs occur they are laid four in a clutch, and with the narrow ends turned inwards, thus economising space, or what is more to the point, are more perfectly covered by the sitting bird. Thus it would be of great interest if observations could be kept on such nests of the Common Snipe as are found containing the less specialised type of eggs with a view to discover whether incubation is in any way affected thereby.

We may bring this survey to a close with a few comments on the eggs of that great assemblage of forms which has been aptly grouped under the collective term "Pico-passeres". It is interesting to note here that while among the "Picarian" or "Coraciiform" types white eggs are the rule, among the Passerines such are very rare, e.g., Dipper, Sand and House Martin. As touching the significance of this lack of colour we shall speak elsewhere (p. 207).

Although many thousands of species are included in this great brigade - the Passeres which includes more than half of all the known species of the Class Aves-it is a somewhat remarkable fact that in so far as their eggs are concerned, they present a wonderful uniformity.

True, indeed, they present variety enough in their coloration, which is often of great beauty, but eggs precisely alike are laid by species not even remotely related. Where markings are present they take the form for the most part of small spots and freckles, such, for example, as in typical eggs of our Common Thrush or of the Blackbird; or the pigment may be deposited in the form of a cap or of a band, or yet again in hair-like irregular lines, as in the Buntings.

As among species outside the assemblage now under discussion, the eggs of some of these "Pico-passeres" are subject to remarkable ranges of variation. In the case of the Common Cuckoo this variation has a definite and peculiar significance, but this is certainly not apparent in such cases as are met with, for example, in our Common Blackbird (Turdus merula) 
or some of the Babbling Thrushes, e.g., Alcippe nipalensis, though numerous instances of such variations could be quoted. The eggs of the Black-cap (Sylvia atricapilla) again, in common with many other species, exhibit three distinct types: in one the ground colour is greyish-white or grey smudged and mottled with brown and lavender; in another the ground colour is salmon-pink smudged with darker pink and grey, and spotted with reddish-brown; while in the third type the shell is white, blotched and speckled with chestnut and lavender. Not even a plausible explanation of this variability has yet been found. All three types may occur in the same locality, and they are not correlated in this or any other cases-and they are numerous-either with peculiarities of plumage or of the construction of the nest or of its site.

Yet, generally speaking, the coloration of eggs has a real significance, inasmuch as it is undoubtedly determined to a large extent by the nature of the environment. That is to say, the coloration can be shown to be protective in a very large number of instances. Nowhere is this more certainly true than in the case of such eggs as are deposited on the ground and left for longer or shorter periods completely exposed. The eggs of the Plover and Gull tribe constitute the most striking examples of this fact, as those who have tried to find them know well. The eggs of the Marsh-dwellers, since they deposit their treasures on dark, damp ground, have the ground colour of the shell of some dark hue, with darker blotches and spots, while among such as nest on sandy or shingly beaches the ground colour of the shell is correspondingly pale, with similar dark markings, and so perfectly do these frail bodies match their surroundings that they are discovered by accident rather than design; even expert egg-collectors are reduced to adopting various devices to aid them in their search.

Thus then the curious dissimilarity, the unlikeness which obtains between the coloration of the eggs and of the bird which lays them, becomes no longer a matter for wonderment; in both instances they are the outcome of the needs of the environment, of mechanical selection. Both eggs and birds have enemies, and the device--if "device" it may be calledof protective coloration is one of several ways for circumventing these enemies. As the size and shape and relation to the 
ground of the two bodies-egg and bird-differ, so each demands a special kind of coloration, where this serves.

With a strange perversity, many who have discussed this question seem to find insuperable difficulties in explaining the lack of protective coloration which obtains in the great majority of coloured eggs. But in such cases, almost without exception, these eggs are deposited in a nest, itself not infrequently a a conspicuous object. This being so, protective coloration avails nothing for the eggs. Where protection for these has become necessary it is the nest which has undergone the necessary transformation (p. I79). Yet the question naturally arises as to why such eggs are coloured. If the pigmentation of the shell neither confers protection nor courts destruction, it would certainly almost seem as though it should, in such cases, have disappeared as a result of the cessation of selection. But this by no means follows, since these varied hues may serve other purposes, where they are not actually protective. On the other hand, the coloration may represent a more or less modified form of an earlier protective type, white eggs being due to the action of selection; and on this last point we have sure evidence. But to appreciate this, it is necessary that the broad outlines of the evolution of coloured eggs should first be traced.

It is almost certain that the eggs of the earliest birds were white, like those of their forebears, the reptiles; and further since these primitive birds were arboreal, that they were laid in holes of trees or under other cover. Later, when some migrated from the forest region to the plains or meadows colour became necessary: firstly, for protective purposes, and secondly, probably, as a defence against the action of light, which in excess is inimical to protoplasm. It is not really difficult to see how the varied coloration seen in birds' eggs to-day may have been evolved, and in all probability egg-eating animals largely aided its development. We may assume that, as in the case of the Sphenodon or Tuatera Lizard of to-day, there was a tendency to develop rust-coloured stains on the shell, some eggs being more decidedly marked in this way than others. Now with the migration to exposed localities, these eggs, unless constantly brooded by one of the parents, would have to remain exposed for longer or shorter periods, when sooner or later various creatures in the new environment would 
make the discovery that these white, hard bodies contained very luscious meat, and with this discovery the work of selection would begin.

White eggs, at the beginning of this process of weeding out, would be the dominant type. Consequently, the taste for white eggs would be the first to be acquired, and their enemies would pass coloured so long as white eggs were to be had; and so, in course of time, the birds which laid these would die, and die without leaving offspring; while those which produced blotched and spotted eggs would produce more vigorous offspring because they would escape the constant strain of laying a large number of eggs in each season, and year after year, to replace the loss by robbery. Such offspring would, in turn, inherit the tendency from their parents, lay more and more strongly coloured eggs, which more and more would tend to resemble their environment, or, in other words, would become protectively coloured.

And now we come to the problem of the significance of the white eggs met with to-day. If the foregoing arguments are sound, then few birds laying white eggs could maintain a hold on life as a species, save those which deposited their eggs in holes or burrows. The exception to this sweeping rule shall be considered presently. Among these troglodytes then, selection has been at work eliminating any but white eggs, since colour, rendering them invisible in the dark, would tend to their destruction by the sitting bird when entering the nest.

Thus then white eggs are as much the result of selection as coloured. Birds, in short, lay white eggs to-day because they lay them in holes. In a large number of birds, in all probability, none but white eggs have ever been laid since their race began, while in other cases, as we shall see, this whiteness has been secondarily or re-acquired. This view, however, is quite at variance with that generally adopted, which was first propounded by Dr. Alfred Russel Wallace. This being so, it would be well to state his views. He contends then that birds whose eggs are white resort to holes wherein to hide them. Such, for example, are the Petrels, Kingfishers, Bee-eaters, Parrots, Woodpeckers, Hornbills, Hoopes, Trogons and Owls. But surely the more reasonable interpretation of this rule is exactly the opposite of that suggested by Wallace. That is to 
say, that birds lay white eggs because they lay them in holes, inasmuch as in such dimly lighted places coloured eggs, from their lower refractive power, would run grave risks of being broken whenever the bird entered the nest, while white eggs, in this dim religious light, are just visible. For a somewhat similar reason plants that are fertilised by night-feeding insects have white flowers, white being conspicuous in the dark, whilst colour is invisible. We ourselves adopt a similar expedient for making objects conspicuous in dark places. Thus in the dark corridors of the British Museum of Natural History a piece of white paper is pasted around the keyholes of doors to serve as a guide thereto, while on underground railways the edges of the platforms and the stairs leading thereto are similarly painted white. By way of supporting this hypothesis as to the significance of white eggs, we may cite the case of the British Puffin whose eggs are white, and deposited in burrows. But if these eggs be examined they will be found to be but thinly covered with a layer of white over a coloured surface, recalling that of the eggs of the Guillemot and Razor-bill. Here then it would seem the custom of laying in burrows is of recent origin, and that selection has begun the work of suppressing the colour, and we may therefore assume, with some justification, that the white eggs of other hole-breeders have similarly acquired a secondary colourlessness, or in other words, have re-acquired the primitive white colour: or it may be that this has been brought about not as in the Puffin but by reversion, though in the majority of cases, as we have already suggested, this development of colour may never have taken place since the race began.

But some birds, it may be objected, whose eggs are remarkable for the richness and beauty of their coloration, yet lay them in holes. The Snow-bunting (Plectrophanes nivalis) would appear to be a case in point. When, however, we come to examine this, we find that though such nesting sites are used in Scotland, in the tundra of Siberia they deposit their eggs on the ground, concealed amid tussocks of grass. Thus the breeding habit of Scotch birds is exceptional, and determined by the nature of the environment. It may well happen that in course of time those which persist in breeding in holes will come to lay white eggs like the Puffin. Another objection which may be raised is that many birds, as the Pigeons, for example, lay white eggs 
in open nests. According to some oologists this is a protective device, the structure of the nest being of so loose a character that the light can be seen through when viewed from below, and the white eggs are mistaken for light patches. This is a farfetched explanation. Such creatures as may prey on these eggs must be able to gain access to the nest from above, whence the eggs would be conspicuous enough. Probably the surrounding leaves of the overhanging boughs afford protection enough from such enemies, or they are not sufficiently numerous to be seriously harmful, for it must be remembered that even protective coloration is not an absolute protection.

Finally, it is a matter for comment that there are no blackshelled eggs, inasmuch as black frequently occurs in the form of spots.

As touching the structure and composition of the egg we need say but little here, yet a few words on this subject are necessary.

To begin with, what is popularly called the egg is this, and something more. What is this "something more," and what is this egg? If, say, a hen's egg be carefully broken into a cup there will be found a large yellow mass, surrounded by a clear jelly-like elastic coat. On the top of the yellow yolk, in the centre of the field, there will be noticed a small white spot. This represents the germinal protoplasm destined to form the chick; the cushion on which it rests constitutes an enormous food store which is gradually absorbed as the development of the chick proceeds. The eggs of the lower forms of life, as is pointed out in vol. iv. of this series, though extremely minute in size, consist of a similar mass of germinal protoplasm, including only a very small quantity of food yolk. Hence the developing organism is thrown upon the world in an extremely undeveloped condition, bearing no sort of resemblance to the adult form. Owing to the scanty supply of food material with which it is provided, the microscopic creature has to obtain its food from the surrounding medium, hence it begins life as an aquatic animal or "larva," though it does not always necessarily remain there.

But to return to our point- the egg in the cup. The cushion of yolk to which we referred is enclosed by an extremely thin and delicate skin, the vitelline membrane, while the yolk within, if examined in a section of a hard-boiled egg, will show that it is not 
of uniform structure throughout, but that there is a portion of it having the shape of a flask with a funnel-shaped neck, and containing a quantity of more or less fluid matter. The expanded neck of this flask-shaped space is situated immediately under the small white spot or disc, while its bulbous portion extends to the middle of the egg. The fluid contents of this flask are known as the "white yolk," and similar white yolk will be found throughout the rest of the yellow yolk, disposed in the form of concentric layers enclosing yellow yolk between them, the final layer lying immediately under the vitelline membrane, and becoming continuous with the expanded neck of the flask just described. The "white yolk" differs, as might be expected, from the yellow yoke in its microscopic characters, but into these differences we need not enter.

The clear jelly-like outer investment of the yellow yolk constitutes the "albumen" of the egg, and from its appearance when boiled is known as the "white" of the egg. If carefully examined in the unboiled egg there will be found at each pole, embedded within this albumen and extending from the vitelline membrane, a little spirally twisted "cord" of denser structure, that at the narrow end of the egg being more or less firmly fixed to the shell, or rather to the membrane lining this. These bodies serve to keep the yolk in position, as well as the purpose of pads to reduce the effect of shock. From the fact that the interior of these cords presents the appearance of a succession of white knots, these cords are known as "chalazæ" (hailstones).

If an opening be cut through the side of the shell of a fresh egg, the germinal portion will always be found at the top. This is due to the lighter specific gravity of the yolk in the neighbourhood of the disc, and not to the control of the chalazæ.

In birds the left ovary alone is functional. Each egg is enclosed in a capsule, and on the completion of its store of yolk, that is to say when ripe, bursts its capsule and escapes into the oviduct, and here the completion of its growth commences. This consists in the addition of the albumen and the shell membranes and the shell, which are formed by the glands of the walls of the oviduct.

The true egg then consists only of the germinal protoplasm and the yolk, since these only are produced by the ovary. The 
white and the shell are accessory structures, though it is to be noted the former is finally absorbed by the developing chick.

These accessory portions-the albumen, shell membrane and shell-are added in the lower part of the oviduct, the membrane lining the shell being formed by the transformation of the outermost layer of albumen, while the shell itself is formed by the secretion of a thick white fluid, in which, finally, the pigment, when this is present, is mingled. The albumen and the shell membrane are formed in about three hours, while the completion of the shell takes about eighteen hours.

With regard to the membrane adherent to the shell we may remark that this is double, and that at the larger end of the egg the two layers part company, the space between being filled with air drawn in through the porous shell. As incubation proceeds this space grows larger, and thus the necessary supply of oxygen for the developing chick is obtained.

Such then is the answer to the questions, what is an egg? and what is this "something more"?

The fertilisation of the egg takes place immediately after its escape from the capsule in which it was developed, into the oviduct; so soon as this is effected the early stages of development begin, but these cease so soon as the egg is laid and becomes cold, to be resumed again by the brooding of the parent. 


\section{CHAPTER XIII}

\section{REPRODUCTION (continued)-CARE OF THE OFFSPRING}

Brooding and "brood-spots". Care for the sitting female. The remarkable case of the Horn-bill. The brooding of the Emperor Penguin. Brooding of Egyptian Plover and of Megapodes. Forsaking eggs. Osprey and care of eggs. Transportation of eggs by parents. Precautions against floods.

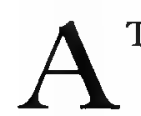

T first sight it may seem that the jealous care which birds bestow on their offspring originated with the necessity for brooding the eggs. But this is clearly not the case, since among the invertebrates there are numerous instances to be found where a high degree of concern appears to be bestowed upon the eggs and young to ensure their safety, and these instances become more numerous as we pass in our survey to the lower vertebrates. With the birds and mammals, however, this care develops into something higher, entailing personal sacrifice in a high degree, so much so that we should perhaps rather speak of the love for their offspring which these creatures exhibit, though there are some striking exceptions to this rule.

With the birds the cares of the family begin at an earlier stage than with the mammals, inasmuch as it commences with the brooding of the eggs, while the mammals, being viviparous, are necessarily relieved of this responsibility until after the birth of the young.

To this necessity for brooding the eggs we may ascribe the relative fewness of the young produced at a time, as compared with the reptiles, since no more eggs can be hatched than can be effectually covered by the sitting parent.

Among the mammals but little preparation, as a rule, is necessary for the reception of the young. And this is true of many birds: in the majority of cases, however, a more or less elaborate receptacle, or nest, has to be constructed to contain the eggs during the process of hatching (see p. 176). 
It would seem that the "field-naturalists" as a general rulefor there are notable exceptions-find more pleasure in nestrobbing than in nest-watching; for though they have been assiduous in recording the number of eggs in a clutch, variations in colour and size, and in the choice of nesting site, their contributions towards our knowledge of the brooding habits of birds are singularly few and miserably incomplete.

The early stages of the development of the chick begins within the body of the parent, but all further growth is suspended directly the egg is laid, to start afresh with the brooding of the parent. While in the majority of birds this does not begin until the whole complement of eggs has been laid, in some cases incubation begins with the first egg, as among the diurnal birds of prey and the Owl, for example, so that the late eggs are partly incubated by the earlier hatched nestlings.

Monogamous species would appear generally to share the duties of incubation, as may be seen by the bare and somewhat inflamed area of the abdominal wall of the body of the sitting bird due to the increased flow of blood to this area, whereby the necessary warmth for the developing chick is supplied. But a careful analysis of the species in which this division of labour obtains is yet wanting. In many cases, however, the work of incubation is performed by the hen only, who, forsaken by her mate, sits assiduously, leaving her charge only at distant intervals for the purpose of procuring food and for defecation. This last act is performed as far as possible away from the nest, and is delayed until the cloaca becomes unable to bear further strain. With some species, however, the hen is constantly supplied with food at this time by her mate. In the case of Montagu's Harrier, for example, the cock so waits upon the hen. At his approach with food she flies out to meet him, whereupon he drops his spoils, to be caught by her in midair and borne back to the neighbourhood of the nest to be devoured. The little Red-backed Shrike is most attentive at this time, feeding her as she sits upon her nest. Similarly, the female Blue-tit, and indeed quite a number of species, are fed, when sitting, by the male. Where both parents sit, however, no feeding appears to be done, each providing for itself when released from the cares of incubation. The hen Hoopoe, save when moved by necessity, does not stir from the nest 
during the whole period of incubation, during which time she is fed by the cock. In the nearly allied Hornbills this peculiar division of labour reaches a very remarkable and unique climax. Among these birds-there are several species-but a single egg is laid, and this is deposited within a hollow tree. Directly afterwards the male proceeds to close up the entrance to the nest, leaving but a narrow slit; but except for this aperture, through which she thrusts her bill to receive the food brought by her indefatigable mate, there is no communication with the outer world. She is a prisoner, we presume voluntarily, until the egg is hatched! The substance used in this walling-in operation would seem to differ among different species, varying doubtless according to the materials available in the different parts of the breeding range. Dr. Hose, a keen naturalist, and for many years one of the resident magistrates of Sarawak, carefully examined the plaster used by the Rhinoceros-hornbill (Buceros rhinoceros), and found it composed of a substance resembling vegetable resin-probably a salivary secretion-mixed with the woody fragments of fruit. Some species appear to use the undigested skeletons of centipedes in addition.

During her period of solitary confinement, as we have remarked, she is assiduously fed by her mate. And thereby hangs a tale, as wonderful as anything in nature-wonderful because her daily: rations are passed to her in the form of a bolus, the investing coat being furnished by the inner lining of the gizzard of the male! At least this is the commonly accepted explanation of the structure of this capsule, though it is probable that it may prove to be formed by a special glandular secretion when the matter is further investigated. This is the more likely interpretation, because, according to other accounts, each meal is divided into from two to four pelletscontaining fruit, seeds, insects and portions of reptiles-which the devoted cock transfers into the gaping mouth of his fair prisoner by a series of jerks. No wonder that by the time the egg is hatched she has become a "mass of fat," while he is reduced to a mere skeleton, so lowered in vitality that on a sudden fall in the temperature, such as takes place after rain, he not seldom falls down exhausted and dies!

Speaking broadly, the hens alone sit among the Game-birds, 
Ducks, Birds of Prey, Storks, Cranes, Rails and Wading birds, and probably in many other cases, concerning which, however, we appear to have no records-while in a few cases, as in the Cassowary, Rhea, Tinamous, Painted Snipe, Hemipodes and Phalaropes, the whole work of incubation is performed by the male alone. There are, of course, exceptions to the rule; thus, among the birds of prey the female only incubates in the case of the Harriers, both parents in that of the Buzzards. Among the Sand-grouse the hen broods by day, the cock by night. Where the hen alone sits the males, as in the Ducks, for example, betake themselves off to some distant spot to return on the hatching of the young; in other cases, as among the birds of prey, the cock remains near at hand to protect his mate and home.

There are two species of birds which enjoy a unique distinction in the matter of brooding. These are the King and Emperor Penguins. Laying but a single egg, this is most tenderly nursed by both parents alternately, and on the back of the feet. That is to say, the egg, instead of resting on the ground, is supported on the upper surface of the feet, where, pressed close to the body, it is covered by the loose skin of the abdomen and the feathers. Dr. A. E. Wilson, one of the naturalists of the Discovery expedition to the Antarctic during I9OI-I904, made a most careful study of the nursing habits of these wonderful birds. A most shrewd and accurate observer, his vivid account of the terrible struggle of these birds to maintain a hold on life will ever remain a model as to how and what to observe in studying the life-histories of animals, and will be the more impressive because of the unusual difficulties and hardships attending these observations. While the bulk of the work would appear to fall on the hen, the cock, as we have hinted, bears his share. But the work of transferring the precious egg is evidently regarded by these fond parents as one of no small importance and delicacy. Consequently a certain amount of ceremonial attends the transfer. The cock, when about to relieve guard, approaches his mate, when both bow one to another. He then proceeds to inspect the egg before taking it over, and having satisfied himself that all is in order, assumes charge of the burden. In spite of Dr. Wilson's endeavours, however, he never succeeded in witnessing the method 


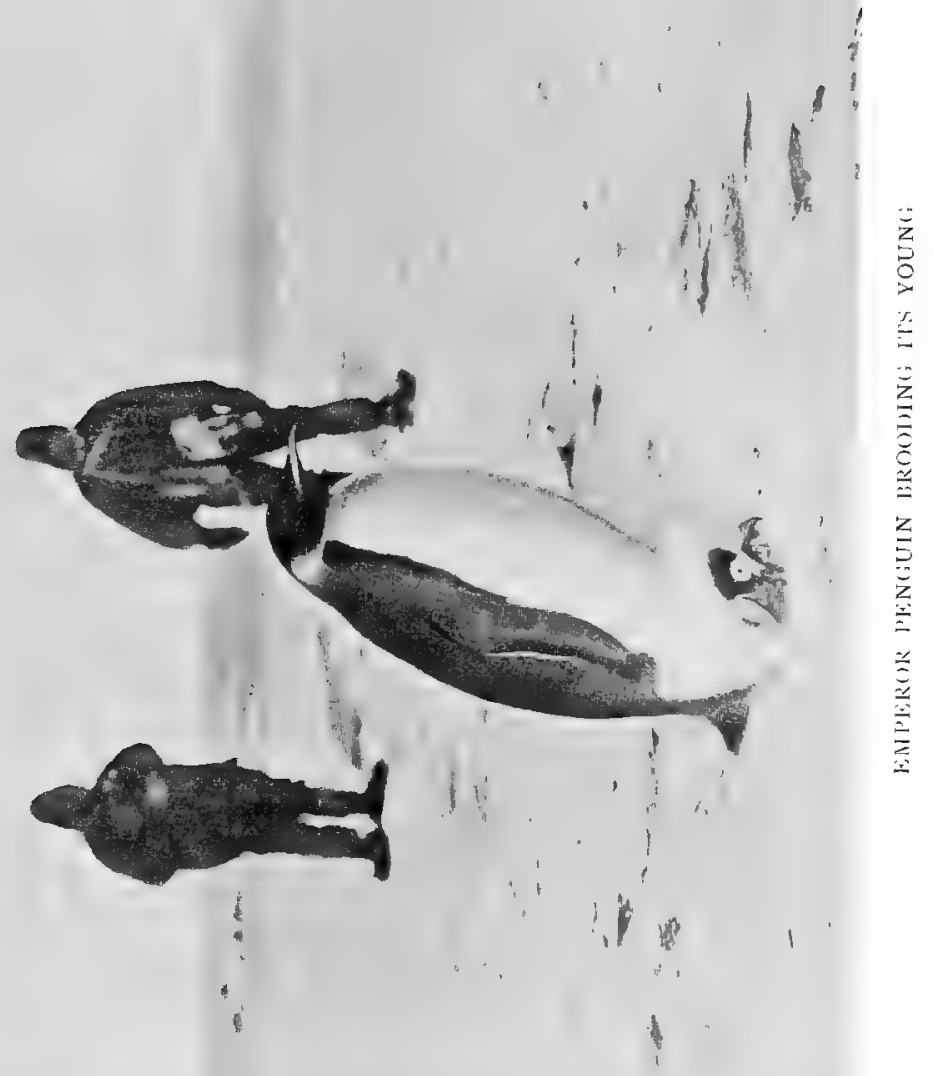


by which the transfer was effected. Six lonely weeks, in darkness of mid-winter, are thus passed before the chick appears, bringing with it increased cares and responsibilities (p. 287).

Dr. Wilson exploded one curious myth concerning the brooding habits of the King Penguins, a myth all the more remarkable because created by a naturalist of no less standing than the late Professor Moseley. He it was who, in his account of the Voyage of the Challenger-which he accompanied in its now famous journey round the world in the capacity of naturalist-stated that the King Penguin carried its egg in a pouch between its legs. It is strange that the probability of his having been mistaken as to the pouch should not have occurred to him, and that he should not have inquired further into the matter, by way at any rate of comparing this with that of the marsupial Mammalia.

While incubation among the birds is almost universally performed by brooding, there are one or two noteworthy exceptions to this rule. Thus the little Egyptian Plover (Egyptius pluvialis) buries its eggs in the sand, brooding them only during the chill hours of night. The Ostrich has been said to adopt a similar device for escaping the irksome work of brooding. As a matter of fact, however, the hen broods by day and the cock by night; but during wet weather, be it noted, the cock sits by day as well as by night, while in the more tropical parts of its breeding range the eggs are said to be left during the day to the sun's rays, covered only by a layer of sand. But the Megapodes have utterly abandoned all brooding habits, and leave their eggs entirely to natural agencies to hatch, the methods by which this is accomplished varying with the different species. Thus the "Maleo" (Megacephalum maleo) of Celebes "come down in pairs," says Wallace, from the interior to the beach, where they "scratch holes in the coarse black volcanic sand three or four feet deep and four to five feet wide, just above high-water mark," therein an egg is laid, then covered with about a foot of sand. At the end of ten or twelve days the journey is repeated, and so on until from six to eight eggs have been buried within this pit. Not seldom, however, several birds continue to lay in the same hole, as many as a dozen eggs having been found together. After the last eggs are laid the birds return no more, and the young, on hatching, work their way up through the 
sand and run off at once into the forest. Wallace's Megapode (Megapodius wallacei), which inhabits Gilolo, Ternate and Bourou, has similar nesting habits, and so also have Brenchley's Megapode (Megapodius brenchleyi) of New Britain and Solomon Islands, and Pritchard's Megapode ( $M$. pritchardi) of Hope Island. It would seem, however, that in Celebes the Maleo occasionally breeds inland, and in this case the birds seek out, in the highlands of the island and in the forest regions, spots in the immediate neighbourhood of hot springs, thereby finding compensation for the lack of the sun's rays.

Yet other species adopt different methods. The Australian Brush-turkey, for instance, lays its egg in a mound of decaying and fermenting vegetable matter. Two or more females commonly combine, scraping together by means of their enormous and powerful feet a mass of twigs and rotten leaves and other débris, till a heap is raised as much as six feet high and twelve or fourteen yards in diameter at the base. The rotten leaves and fine materials are placed in the centre, while the outside is composed of sticks, leaves and twigs recently gathered. The heap made, the birds dig down deep into the centre and there deposit their eggs, in the fine leaf mould. From examination of these mounds it would seem that the eggs are laid with the pointed ends downwards, often in a circle, with three or four in the centre, about six inches apart. As many as thirty-six eggs have been taken from a mound of this description. The mound of the Dark-billed Brush-turkey (Talegallus fuscirostris) of Southern New Guinea has been described by Von Rosenberg. It is, he says, "composed of earth, mixed with sticks and leaves, the whole forming a truncate cone eleven feet high and twenty-five feet round the base. In the summit of the cone we found the openings of five burrows which went down perpendicularly to a depth of four feet, and were filled with earth. In four of these I found eggs which were placed vertically . . . and were in various stages of development. In the mound the thermometer rose to $93^{\circ} \mathrm{Fahr}$., while the surrounding atmosphere was only $85^{\circ}$ in the shade." Of Duperry's Megapode the traveller-naturalist Gilbert writes of a visit to Knocker's Bay in search of this bird: "I suddenly found myself beside a mound of gigantic proportions. It was fifteen feet in height and sixty in circumference at the base, the upper part being about a third 
less, and was entirely composed of the richest description of light vegetable mould: on the top were very recent marks of the birds' feet. The native and myself ... . after an hour's work . . . succeeded in obtaining an egg from a depth of about five feet; it was in a perpendicular position, with the earth very lightly touching it on all sides, and without any other material to impart warmth, which indeed did not appear necessary, the mound being quite warm to the hands. The holes in this mound commenced at the outer edge of the summit, and ran obliquely towards the centre: their direction there fore is not uniform. Like the majority of mounds I have seen this was so thickly enveloped in foliaged trees as to preclude the possibility of the sun's rays reaching any part of it. . . . The mounds are doubtless the work of many years, and of many birds in succession: some of them are evidently very ancient, trees being often seen growing from their sides : in one instance I found a tree growing from the middle of a mound which was a foot in diameter. .. . The natives say that only a single pair of birds are ever found at one mound at a time. . . . They also affirm that the eggs are deposited at night, at intervals of several days."

Concerning the significance of this remarkable habit of incubation we have elsewhere commented (p. 248), but we may remark here that the vertical position of the egg is somewhat curious. 'All who have examined such mounds agree in that this is the universal position of these eggs, and interesting testimony of the accuracy of these observations was obtained during 1904 at the Zoological Gardens in London, where a pair of Brush-turkeys (Talegalla lathami) built a perfectly typical mound, and from which in due time young emerged. From observations made on this mound, it seems probable that the young do not force their way until about thirty-six hours after hatching, the chicks remaining within the shattered shell until sufficiently strong to make the necessary efforts to escape from this living tomb.

Either the dread of man is much greater in some birds than others, or they have less of that mysterious love for their offspring which, in some birds, as among the human species, amounts to an overmastering passion. For while some species forsake their eggs on the slightest of pretexts afforded them by 
their ancient enemy, others appear to set all danger at defiance to save these precious pledges of joys to come. Thus while some species will leave their eggs, when necessity demands, fully exposed, trusting apparently to their protective coloration when this exists, others carefully conceal them, covering them, as in the case of the Grebes, with decaying vegetable matter, or burying them in the sand, as with the little Egyptian Plover. In this latter instance it does not appear-to be certainly known whether the eggs are buried in the hot sand to save, or at least reduce the work of incubation, or whether they are normally incubated, and covered only when danger compels the sitting bird to seek safety in flight. But among the Ducks this regard appears to reach its maximum, inasmuch as the mother plucks the down from her breast to form both a lining for the nest and a covering for the eggs during her enforced absences.

The Eider-duck, if suddenly alarmed when sitting, will instantly leave her eggs, but before doing so discharges over them a quantity of fluid excrement having a peculiarly offensive smell, which probably contributes in no small degree to disgust intending robbers. Though this discharge is probably involuntary, it forms nevertheless a device which must be of no little service in the preservation of the species.

The Osprey again (Pandion haliatus) appears to regard her eggs with great solicitude, inasmuch as she has apparently a habit of leaving them exposed for a few hours daily to the sun while she basks therein on a neighbouring branch, ever and anon rousing herself to take a plunge into the lake below, rising therefrom to shake her dripping plumage over the Ospreys that are to be.

Here then we have the rudiments of that instinct for the preservation of the eggs of which so many wonderful instances have been recorded.

Thus, for example, a case is on record of a pair of Merlins which transported their eggs from a nest in a tree to a bank forty yards distant where they improvised a nest of leaves for their reception; and this because the sitting bird had been repeatedly shot at while on the nest-to the shame of the shooter, be it said. It must, however, be recorded to the credit of those who instigated this attempted murder, that the birds were allowed to hatch off their young in safety. No less re- 
markable is the case of a Common Partridge, which was discovered sitting on a nest of eggs in a field that was being ploughed. The bird was first noticed as the horses passed it, so near that it narrowly escaped being crushed. The owner of the field, who happened to be paying a visit of inspection, quite accidentally descried the bird immediately the plough had passed, and found that she was sitting on a nest of twenty-one eggs, near the point of hatching, for some were beginning to chip. Returning with the plough, to his surprise he found the nest empty; and after careful search, suspecting that she must in the meanwhile have removed her eggs, he found them under the hedge about forty yards off; a task which, probably with the assistance of the cock, had been performed in about twenty minutes! A similar case is recorded by the naturalist Selby of a Moor-hen which had built a nest on the edge of an ornamental pond, into which the water from another pond was occasionally admitted. This was done while the bird was sitting; and as the nest had been built while the water level was low the sudden influx caused a rise of several inches, threatening the speedy submersion of nest and eggs. This the birds apparently realised, for when a gardener who knew of the nest went to it, expecting to find it destroyed, he found the birds adding fresh material thereto by way of raising it above the level of the flood, and further search revealed the eggs, which had been deposited on the grass a foot or so from the water's edge. Fearing that he might alarm the birds, he did not remain to watch their further proceedings; but returning in less than an hour found the hen comfortably sitting on the newly raised nest. A few days afterwards the young were successfully hatched.

A similar case has been recorded of a Swan which, while sitting on a nest of four or five eggs, was observed to be "very busy collecting weeds and grasses to raise her nest. A farming man was ordered to take down half a load of haulm, with which she most industriously raised her nest and eggs two feet and a half. That very night there came down a tremendous fall of rain, which flooded all the malt-shops and did great damage. Man made no preparation, the bird did; instinct prevailed over reason. Her eggs were above, and only just above the water." 
It must not be supposed that the number of such instances are confined to those here recorded. Romanes has brought together many similar cases, some of which refer to cage-birds, but sufficient have surely been mentioned here to show how great is the love of some birds for their as yet unborn young. 


\section{CHAPTER XIV}

\section{CARE OF OFFSPRING (continued)}

The care of the young undertaken by the male alone, and by the female alone, or by both parents. The remarkable case of the Sand-grouse in procuring water for their young. The strange case of the transportation of the young in the Woodcock. Feeding customs. Sanitation of the nest. The callousness of Eagles. The coloration of nestlings.

ITH the hatching of the eggs and the advent of the young the cares and labours of the parents enter a new and more exacting phase. Where the female has been left to carry out the work of incubation alone she is now often joined by her mate, no longer able to ignore his responsibilities, or perhaps roused into activity by the sight of his offspring. In some cases, however, the hen has to shield her young from the vicious onslaughts of the cock, who, however, soon appears to accept the inevitable and settles down to aid in the work of feeding. In the Emu (Dromaus), on the contrary, the reverse is the fact, but here, it must be remembered, the duties of incubation and the care of the young devolve entirely on the male. But where the cock takes the task of incubation entirely upon himself the maternal instincts seem to be degenerate, inasmuch as the care of the young, as of the eggs, devolves entirely upon him, as, for instance, in the case of the Rhea and the Emu. By way of contrast, we find that among the Pelicans and the Ducks, for example, the care of the family falls on the female only.

But the arduousness of parental cares varies not so much in proportion to the number of offspring as in relation to the condition of this offspring at hatching. Thus young Ostriches, Game-birds or Ducks, which are able to run about almost immediately they leave the egg, also feed themselves under the parents' guidance; while young Thrushes, Rooks or Pigeons, for example, are what we may call prematurely hatched (p. 246), 
and for a long while are utterly unable to leave the nest or to feed themselves.

It is curious that while parental responsibilities of a complex character are undertaken even among the lowest invertebrates, the practice of feeding the young obtains only with the ants and bees among the invertebrates, and is not met with again till we come to the birds and the Mammalia.

The labour entailed in this among the birds varies with the nature of the food required and its preparation. The active young of graminivorous birds, such as the Game-birds for instance, or of the Plover tribe, which feed upon small crustacea, snails, worms and so on, or of the Duck tribe, which live upon vegetable matter and small animal organisms, follow their parents to feed under their direction. But where, as in the case of the Grebes, for example, the food is obtained only by chase, and for the most part by diving, the young swim out after the parents, and are fed by them on a diet consisting of very small fish, crustacea and a small quantity of vegetable matter.

The Dabchick or,Little Grebe (Tachybaptes fuviatilis), however, appears to differ from its larger relative in this matter, in that the young remain for many hours daily in the nest perched on the back of the mother and covered by her wings, and during this time are assiduously fed by the male, who has been seen to make as many as forty journeys with food in the space of a little less than an hour. Later, as the young gather strength, they are fed on the water, the diet being at least partly vegetable. The food appears to be dropped on the water and picked by the youngsters.

The Sand-grouse afford perhaps one of the most remarkable instances yet discovered of the care displayed by birds for their offspring. These birds are dwellers in arid deserts and consequently have to make long journeys night and morning to procure water. During the time that the young are helpless their drinking water is supplied by the cock, and this in an absolutely unique fashion. After having slaked his thirst at the customary drinking pool, generally many miles distant from the feeding ground and young, he proceeds to wallow in the water after the fashion of a bird dusting its plumage, remaining until the feathers of the under parts are thoroughly saturated. 



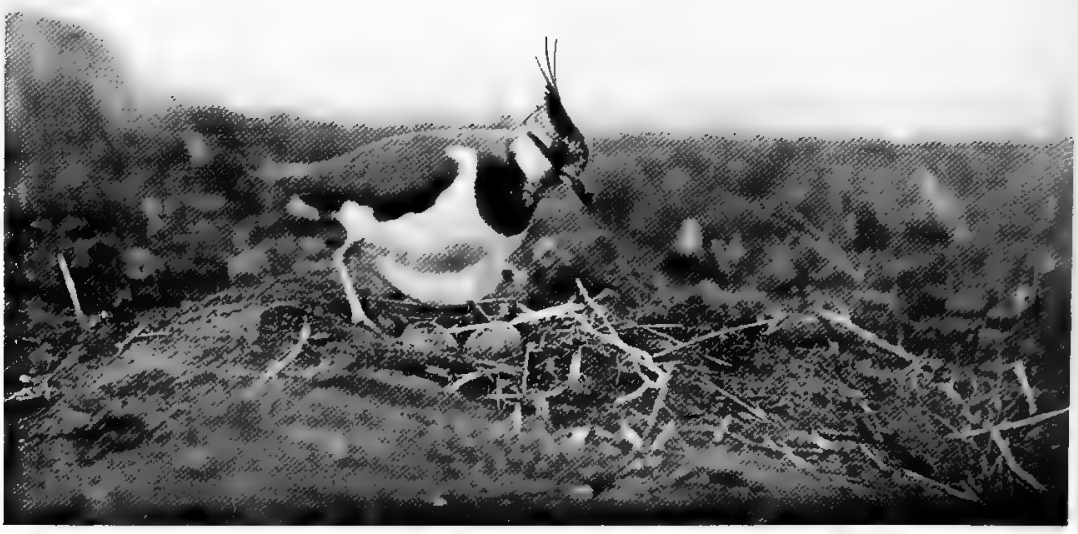

LAPWING SETTLING DOWN ON ITS EGCSS

NOTE THE LOWERED CREST FEATHERS

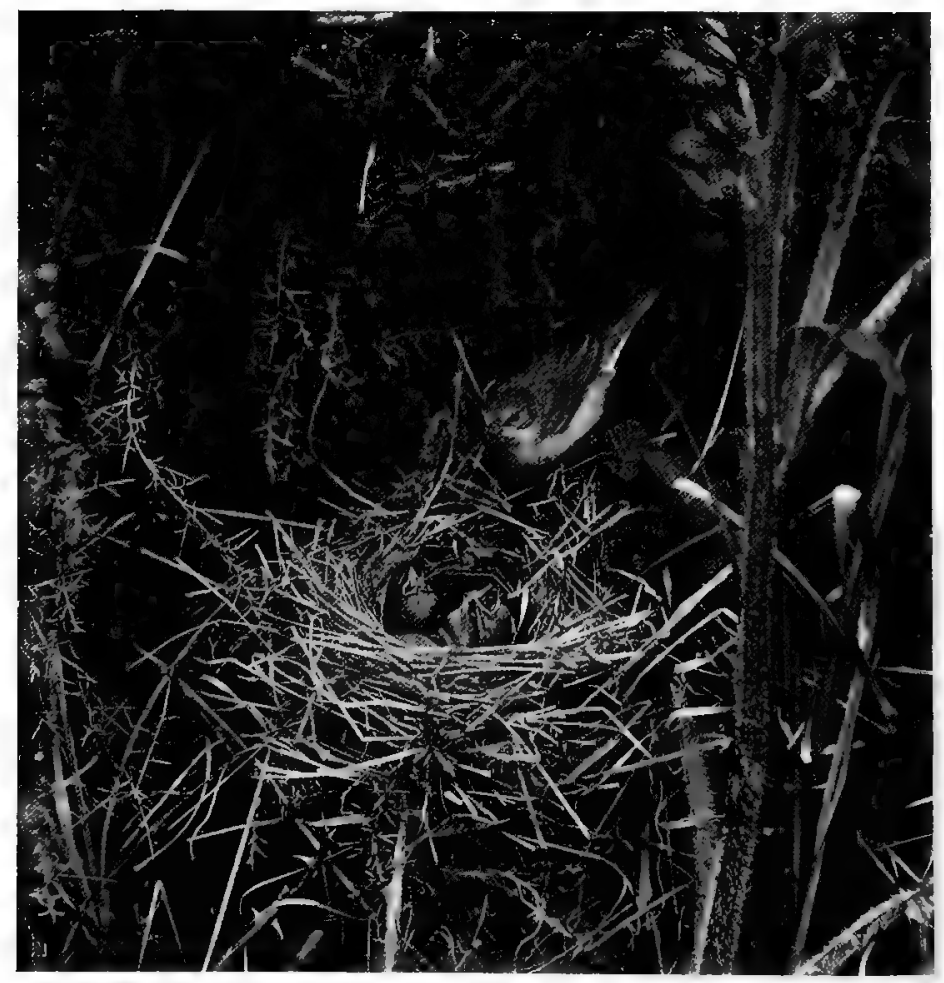

NEST OF THE WHITE THROAT 
As soon as this end is attained he makes all speed back again, when he calls loudly to the young who run to meet him. As soon as he alights they thrust their heads amongst the breast feathers and under tail coverts, and drawing them through their beaks suck out the water they contain, moving to fresh places as the supply becomes exhausted! This most interesting discovery we owe to the observations of Mr. Meade Waldo. Whether the young in some way communicate their desire to drink to the parents, or whether they observe signs of thirst in the young, is of course a matter which cannot be determined.

No less extraordinary is the case of the Woodcock which frequently nests on high ground at some considerable distance from the marshy swamps where alone food is procurable. When this is the case, the parents carry the young down, at dusk, from the high ground to the swamp, and bear them back again at dawn, carrying them held between the legs. St. John in his Highland Sports refers to this fact, and Dr. F. D. Godman, an Ornithologist of wide experience, has described the same habit to me in the case of Woodcocks nesting in the Azores. But this appears to be the only known instance among birds where the young are periodically carried from place to place.

Where the young remain long in a helpless state in the nest the work of feeding is increased tenfold, entailing as it does long and frequent forage for food. Nor is the physical strain less when this food is elaborated within the crop of the parent and conveyed to the young by a process of regurgitation.

Family cares weigh heavily upon all birds, but heaviest upon those whose young are helpless. To feed them the fond parents must rise early and work late : their toil is incessant. A pair of Blue Titmice have been observed, for example, to make no less than 475 journeys to the nest in the space of seventeen hours. Even Sparrows, for whom little good can be said, at this time excite our admiration on account of their devotion to their young. While daylight lasts indeed they can know but little rest, for the insatiable appetites of their callow brood keep them almost ceaselessly at work. During the first few days, as with other Finches, they feed their brood on insects, many of them, as has been proved, extremely injurious to crops. Thus for a few days in the year at any rate these pugnacious 
and mischievous birds make some atonement for the injury they do the farmer and the gardener, to say nothing of the birdlover, during the rest of the year. But in a very little while a vegetable diet of regurgitated seeds take the place of insect food; and in this particular the Sparrow follows the traditions of his tribe-the Finches.

The offspring of the Cormorants are fed after a fashion which savours a little of nastiness, inasmuch as the young bird thrusts its head down the parent's throat and helps himself to as much as he can swallow of his parent's last meal! Similarly, the young Pelican helps himself to fish from his mother's pouch. To assist him she presses the pouch against her breast and raises the upper jaw. According to the legend indeed she feeds her young on her own blood! This curious and touching conceit probably arose from the fact that a certain amount of blood from the captured fish escapes at this time. This fashion of feeding practised by the Cormorant and its near relative the Pelican is the more curious because no other members of the group to which these birds belong, except perhaps the Gannet, appear to adopt the practice. And this brings us to the subject of feeding by regurgitation, which is practised by numbers of birds of quite different orders, so that it must suffice here to quote a few instances thereof.

The Petrels appear always-though exceptions will probably be found-to feed their young on oil, which is distilled from the fish on which they live, in large quantities, and this is injected into the mouths of their offspring. This oil is also used, by the way, as a weapon of offence both by old and young, being squirted out from the mouth and nostrils whenever they are alarmed.

Unappetising as such a diet may seem, it would nevertheless appear to be wonderfully sustaining, and no more striking proof of this could be found than that furnished by the Albatross. In the species known to science as Diomedea exulans, at any rate, if in no other species, the nestling is at first assiduously fed until it becomes a mass of fat, even exceeding the adult in weight! It is then deserted by its parents, who roam the winter over the ocean, leaving their down-clad and helpless offspring to the tender mercies of Fate for the space of about four months! At last they return to the nest to find the young 
hopeful standing, fully fledged but helpless on its edge. But this reunion is but of brief duration, inasmuch as the youngster is straightway driven off and a new nest is commenced. Nevertheless, he seems loth to leave the parental dwelling, remaining in the vicinity for some months longer, but from time to time taking short trips to sea, probably accompanied by one of the parents, who plays the part of instructor.

Parrots feed their offspring on regurgitated food, and also be it noted, feed one another during the process of courtship, a fact which may throw some light on the origin of this method of feeding the young. The White Stork-and probably other species-feeds its young after this fashion also, placing its beak within that of the nestling during the operation. The members of the Finch tribe, as we have just remarked, feed their young at first on insects, but later on regurgitated seeds. For the preparation of this pabulum green seeds are chosen. The Night-jar feeds by regurgitation, and so also does the Housemartin, though the remaining members of the Swallow tribe feed their young on insects. This fact is interesting, showing, as it does, how careful one must be in forming conclusions as to the feeding habits of nearly allied birds based on the observations of a single species. Similarly again, the Green Woodpecker (Gecinus viridis) regurgitates, while the Greater and Lesser Spotted species retain the more primitive method of rearing their young on the undigested insects. This regurgitated food, it should be remarked, differs among different birds in this respect, that whereas in the majority of cases it is injected into the mouth of the chick but little if at all changed, in others it is considerably changed, as in the Petrels and the Green Woodpecker. In the Pigeons again, at least during the earlier period of feeding, the regurgitated food takes the form of a milky secretion-known as "Pigeons' milk"-formed by the disintegration of the mucous membrane of the crop.

The method of conveying this food also varies. Thus in the Penguin and Cormorant, for example, the young thrusts its head down the throat of the parent; in like manner the young Pigeon thrusts its beak within that of the parent, but it would appear that in the case of the Martin the operation is reversed. On this point, however, as in much else that concerns the feeding of the young, more observations are sadly needed. 
Where the young are fed on insects, either in the form of grubs or imagos, it is amazing to see the number of victims which the parents will contrive, in some mysterious way, to gather up and hold within their beaks before flying off to the nursery. The Starling and the Wagtail may be taken as examples of this custom. The Puffin, which feeds its young on fish, has acquired a marvellous skill in holding several fish in the bill at once. One can understand easily enough how one or two can be held, but how a dozen or so victims can be gathered up without the earlier ones being dropped is a mystery.

Among Passerine birds both sexes share the work of feeding, and though the female is generally most assiduous, the male occasionally exceeds his mate in zeal. Mr. Farren describes the case of a pair of Chaffinches in which the male bore the brunt of the work. He generally brought food (insects) entirely concealed in his mouth. This was then regurgitated, and distributed to the young according to their needs, or according to their clamour. If any inability, or disinclination, to swallow was observed he carefully readjusted the food in the mouth of the youngster, or transferred it to one more hungry! With regard to the Stone Chat he noticed that while the female always brought small insects, generally spiders, and sometimes butterflies and moths, the male always brought large caterpillars. Miss E. L. Turner, an Ornithologist of rare zeal and great discrimination, tells a most amusing story of a scene she saw enacted on the edge of the nest of a Red-backed Shrike. The male had brought to the nest a young bird, and pulling off its head proceeded to ram it down the throat of a very clamant youngster. But the morsel was too big and had to be readjusted, not once, but several times, and finally, was rammed down its throat with such success that the wretched bird was in imminent danger of death from choking. At this the female, who had been sitting on the opposite edge of the nest looking on, and making, apparently, very sarcastic remarks on the awkwardness of her lord, seized the offending head and dragging it from the throat of the choking offspring, proceeded to tear it into small pieces, giving each of her brood a piece. And during this time the male looked on in what appeared to be a very subdued fashion!

With regard to the feeding of Passerine birds much has yet 



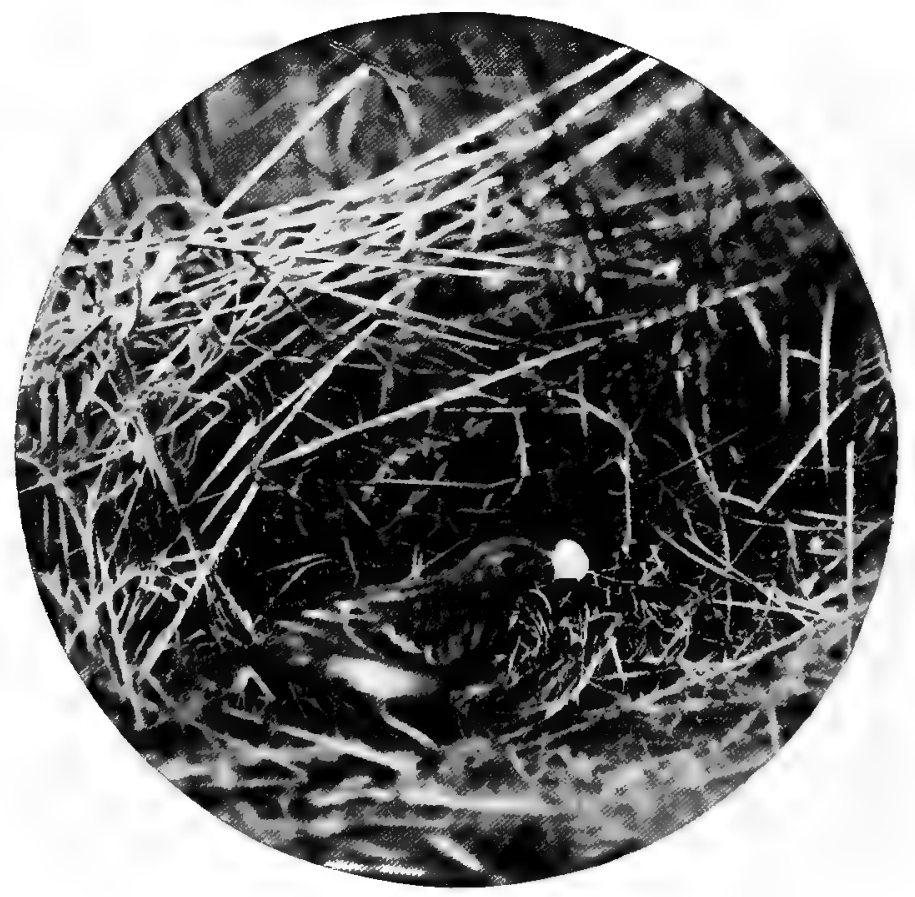

MALE TREE PIPIT REMOVING EXCRETA FROM ITS NEST 
to be learned. But it would seem that the majority of species feed their young during the first few hours after hatching on regurgitated food; later this is varied by a few insects, which soon become the staple diet, to be finally succeeded, in the case of grain and seed-eating birds, by a vegetable diet.

In the case of birds of prey which capture relatively large animals, the victim is borne to the nest and torn in pieces, each nestling receiving its due share. But it would seem that more victims are occasionally caught than is absolutely necessary, inasmuch as bodies more or less putrefying are commonly found in the immediate neighbourhood of the nest, and within reach of the young.

When the young remain for some time helpless within a nest the work of the parents, as we have remarked, becomes arduous in the extreme, and this because of the endless journeys to and fro that must be made during the day to keep their voracious offspring from dying of hunger. The sanitation of the nest has also to be attended to, though fortunately nature has provided a method by which this task is simplified, inasmuch as the excrement of the nestling is enclosed within a capsule so that it may be picked up in the beak of the parents, and carried away to a distance from the nest before being dropped. It would seem, however, that occasionally, whether as a consequence of a depraved appetite, or for some as yet unexplained reason, this excrement is swallowed. Certainly Thrushes have been seen so to dispose of this fæcal matter. As the young grow and gather strength, however, they relieve the parents of this work of sanitation by raising the tail above the edge of the nest and expelling the fæces. Among the Kingfishers of the Genus Alcedo, which are hatched in holes, the cloaca appears to be unusually muscular, since the nestlings are enabled, by turning the hinder end of the body towards the entrance to the nest, to expel the fæcal matter clear of the tunnel. The care indeed which birds take in this matter is widely known, hence the proverb, "no bird fouls its own nest". But there are, however, exceptions to this rule, and perhaps the most striking is that afforded by the Hoopoe, a bird which in spite of its great beauty seems to be animated by a strangely depraved character, seeking its food among filth, and taking no sort of trouble to secure the cleanliness of its nest : and the young similarly lack this instinct. 
Consequently the nursery of this bird, by the time the young are ready to leave, has become indescribably filthy.

While those birds whose young are active from birth escape for the most part the labour of carrying food, they, on the other hand, are called upon to meet grave anxieties in the protection of their offspring from enemies.

The singular habit which such birds have of luring away enemies by feigning madness will occur to the memory of many who read these pages, and concerning this comment will be found elsewhere (p. 245). For the moment we refer more particularly to the methods adopted by the anxious parents to remove the chicks from the nesting area when threatened by danger such as cannot be averted by the device of feigning wounded, or of transportation when the nesting site is high above ground and must be quitted before the young are able to fly.

That the Woodcock will transport its young from place to place is well known, though the precise method by which they are carried is still a matter for debate. According to the older naturalists she was supposed to carry them, one at a time, by the aid of her beak, the precious burden being pressed against the breast thereby. Later observers have shown that this is not the correct interpretation of what takes place. Some are confident that the chick is grasped by the toes of the parent and carried as in a basket attached to a parachute, or better, a flying machine; but yet other observers contend that the little one is pressed between the thighs of the parent, and further guarded against a fall by means of the beak, which is placed underneath, and this is perhaps the correct interpretation.

Similarly the Dabchick, when suddenly alarmed on the nest with her young ones ( $p .232$ ), has been seen to take to the water, the chicks following. Unable to keep up with her, she stopped, and one going to one side of her and one to the other, she raised her wings, under which they crept, when, pressing these shields lightly down, she bore them off in safety.

The dangers which beset the young of nidifugous birds are, however, by no means confined to attacks from enemies. Thus the Mallard or Wild-duck (Anas boschas) on occasion will nest high up in a tree, and in consequence, within an hour or two of hatching, the young must be brought to the ground, since 
they will not rest contentedly together till the wings have grown, as do the young of those birds which leave the shell with eyes unopened, naked, and altogether helpless. How this transportation is accomplished is not certainly known; it has been surmised that they are brought down by the aid of the parent's beak. In two or three instances, however, this descent has been witnessed by careful observers, and in each case the youngsters launched themselves into space, falling unhurt, some twenty feet, to the ground, when they were triumphantly led off to the water by the female parent, who, by loud quackings, apparently encouraged them to take this wonderful plunge! Possibly this is the normal method of descent. The Eider-duck similarly will sometimes choose an abnormal nesting site of this kind. But the Tree-ducks, of the Genus Dendrocygni, and the Golden-eye Duck (Clangula glaucion) invariably nest in trees, the latter choosing a hole in the trunk of some decayed giant, some twelve feet or more from the ground. In this case it would seem to be obviously more easy to raise the young from such a nest when held between the legs, as Woodcock are said to do, than when pressed close to the body by the aid of the beak. Yet, according to the observation of a Lap clergyman, the latter method is that actually adopted. He watched a female while she made no less than five journeys to the nest, and on each occasion saw her leave the hole with a nestling, which he was certain was held under the beak, and supported against the neck. Nevertheless this requires confirmation.

That the Duck tribe feel great affection towards their young is certain. And a good instance of this is furnished by the case of a Teal which came under the notice of Sir Ralph PayneGallway. A farm-boy fell in with a brood of nestlings and drove them before him to Lord Cavan's lodge, the mother following after, and keeping close at hand the whole way. $\mathrm{He}$ drove them into the yard, and into a shed, but even here the undaunted mother followed, and this in spite of the presence of dogs and people!

To return to the question of the transportation of helpless young from considerable heights to the ground, we need but mention the Auk tribe by way of further illustration. Here there is rarely need for carrying, as the young do not leave the 
rock-ledge on which they were hatched until the wings have grown sufficiently large to act as a parachute, though not large enough for flight. They are enticed to spring into space by the parents, who tempt them with food. But occasionally it would seem, when obstinacy is displayed, the exasperated parent seizes her progeny by the back of the neck and flies down to the water with it, to acquire the art of swimming and diving (p. 230). Dr. Günther tells me, however, that he once had the good fortune to watch a young Guillemot taking his first trip to the sea. Here the young was thrust off the rock by its parents, who broke its fall by continuously darting underneath it, and partly supporting it till the water was reached.

After these instances of the care and affection which birds almost universally display towards their offspring, it is somewhat surprising to find that cases of what appear to be the most brutal callousness on the part of the parents are not infrequently to be met with. Thus, it commonly happens, in the case of the Golden Eagle, for example, that the last bird to be hatched is smaller than the rest, and very commonly appears to be so much weaker that its more vigorous bed-fellows are fledged and ready to fly before the "runt" has lost its down plumage. When this is the case it is not infrequently left in the nest to starve, or fed in so desultory and perfunctory a fashion that death from neglect soon results. This fact would seem to be due either to the pride which the parents take in teaching their first-born to fly and capture food, or to the irksomeness of this labour which leaves them little or no time to forage for the backward bird. Similarly, late-hatched Swallows and Martins are commonly left in the nest to die, and this apparently because the parents are unable to resist the migratory impulse which seems to possess all alike as autumn wanes.

Again, parental love apparently disappears so soon as the young are able to fend for themselves, inasmuch as they are then driven away from the locality in which they were reared to seek fresh pastures. As a matter of fact, however, this action is really dictated by stern necessity. But for this dispersal overcrowding and inter-breeding would inevitably follow, and these are two of the greatest evils that could overtake the species. 
The significance of the striped coloration of nestling birds will be discussed in Chap. XV., but there are other facts concerning the development of highly coloured areas which may well be discussed here, even though the exact interpretation of some is not yet known.

The young of the Water-hen, for example, have the beak as brilliantly coloured-vermilion and yellow-as in the adults, yet by the time the first plumage of contour feathers has been developed this coloration has given place to a dingy green, and so far this fact is inexplicable. But it is significant to note that the young of the Great Crested Grebe (Podicepes cristatus) when in its downy state has a vermilion-coloured, heart-shaped patch of bare skin on the crown of the head, and of this there is no trace in the adult. Has this red colour any special significance? Perchance it is a "recognition" mark, enabling the parents to find the young after they have dispersed into hiding to avoid an enemy. Though this be so, it is hard to see why a similar mark should not have been developed in other species of Grebes. Again, young Coots in down have the forepart of the face covered with small warty, or rather fleshy, papillæ exactly resembling the papillæ on the face of the Pheasant, and some other Game-birds, and these papillæe, in the Coot as in the Pheasant, are vermilion coloured, therein again, so far as colour is concerned, resembling the young Grebe and Waterhen.

Among the nidicolous birds bright colours occur around and in the mouth. But these have an obvious purpose, inasmuch as they serve as a guide to the parents when feeding their young. In the Passerine birds the aperture of the mouth is made to appear abnormally large by the development on either side of the gape of fleshy flanges, generally of a bright yellow colour. In the young Jackdaw, which, be it noted, is hatched in dark places, this flange is white, just as eggs laid in dark places are white (p. 208), while in the Jay, Rook and Crow, for instance, this flange is but feebly developed and is not brightly coloured. But the most remarkable feature of this kind is the brilliant coloration of the inside of the mouth. The colour varies, being generally yellow, as in the young of Wagtails, Larks and Thrushes, or purplish-red as in the Chaffinch. Sometimes, as in the Hedge-sparrow, for example, the tongue and the roof of the 
mouth are spotted with black, while in the Bearded Titmouse the inside of the mouth is of a bright cornelian red, surrounded by a band of yellow, and relieved by a double row of white, glistening, tooth-like conical processes resembling palatal teeth. The nestling of the Red-tailed Weaver-finch of Samoa has a red wattle at the gape. But the high-water mark of ornament in this matter has been reached by the young of the Gouldian Weaver-finch. Here, the angle of the mouth is ornamented with three bead-like bodies of a brilliant opalescent emerald green and blue, while the roof of the mouth is marked with five black spots perfectly symmetrically disposed, and a black bar crosses the tongue. The young of the Crimson-eared Waxbill or "Cordon-bleu" and of the Parrot-finches are similarly marked. These peculiar markings have a special purpose, inasmuch as the young so ornamented are invariably hatched in places where there is but little light, so that the parents use these markings as guides to the mouth when feeding. This interpretation I owe to my friend Dr. A. G. Butler. 


\section{CHAPTER XV}

\section{NESTLING BIRDS AND WHAT THEY TEACH}

The differences between young birds and young reptiles. Nestling birds and the systematists. The clothing of nestlings. Primitive nestlings. Precocious flight. Helpless nestlings. The coloration of nestling birds and its significance.

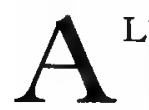

LTHOUGH the young of birds and reptiles agree in that they are developed from an ovum provided with a greater or less amount of food yolk enclosed within a hard case or shell-and are not nourished by the maternal tissues as in the higher Mammalia-they differ conspicuously in one important particular. Among the reptiles it is no uncommon occurrence for the young to emerge from the shell while still within the body of the parent, or immediately after the eggs are laid. With the birds the egg is invariably hatched only after a prolonged period of incubation, which is performed, save in some rare instances, by the brooding of one or both parents.

The young reptile invariably comes into the world in a fully developed condition. With the birds this is never the case. In a very considerable number of species it is true the newly hatched bird is sufficiently advanced to be able to run about, and to accompany its parents in the search for food, but the clothing of the body differs from that of adult life (p. 237), and certain exceptions apart, the remiges or quill feathers, which subserve the purposes of flight, are wanting. The young of other species differ still more widely, in that they leave the shell in a perfectly blind, naked and helpless condition. Between these two extremes of activity and helplessness every possible gradation can be met with.

The failure of the older Ornithologists to interpret the true meaning of the varying conditions „of the young at hatching may be set down to the fact that this precocious or helpless condition, as the case may be, is characteristic of large groups of birds, which on other grounds seem to be, and often are, 
intimately related. Thus the young of the Ostrich tribe, the. Game-birds, Gulls, Plovers, Sand-grouse, Bustards, Cranes and Rails, Geese, Swans and Ducks, Grebes and Divers, are all precocious (nidifugous). On the other hand, the Penguins, Gannets and Cormorants, and their allies, the Petrel tribe, Hawks, Pigeons, Owls, Cuckoos, Hornbills, Swifts and Woodpeckers, for example, and the Passeres, are all born helpless (nidicolous).

But no hard and fast line between nidifugous and nidicolous birds can be drawn in the first place, and as we shall show presently these two states are really due to adaptation and have no genetic connection.

In the matter of clothing the helpless forms present every possible gradation from a complete investment of down-like feathers to absolute nakedness. Some are hatched naked and later acquire a downy covering, others remain naked until the feathers appear; and in this no sort of order seems to be traceable. In the precocious types the downy covering of the nestling seems to have attained its full growth at hatching.

Among the helpless forms this appears to be but rarely, if ever, the case. Young Hawks and Owls, for example, at hatching are but scantily clothed. In a very short time, however, an abundant crop of long and very soft down feathers is developed. So too with young Penguins. The young Pelican

$?$ and Cormorant leave the shell quite naked, and never develop more than short, downy tufts which barely conceal the skin. The young Gannet differs in this respect inasmuch as on leaving the egg the body is covered by an exceedingly short down, which rapidly acquires considerable length. The down of the young of the Petrels, and especially of the Albatross, grows to a great length. The young of the closely allied Storks and Herons differ markedly in the length of the down feathers, that of the Heron being of a peculiarly hair-like nature, whilst the Stork's covering is of the more typical kind-short and woolly. The down of the nestling Pigeon is peculiarly thread-like in appearance, and sparsely distributed. The Kingfishers, Hornbills, Swifts and Hummingmbirds never develop nestling down, so that the growing feathers give these birds somewhat the appearance of Hedgehogs. The young of many Passeres are aggressively naked, others develop an apology for a covering, in 
the shape of a few tufts of filamentous and extremely delicate down, which serves rather to exaggerate the nakedness of the body than as a covering.

It is difficult to account for this variability, which is often made the more striking by reason of the fact that closely allied birds like the Gannet and the Cormorant, the Heron and the Stork, though living in the same environment, yet differ extremely in this particular. Exceptions to the rule indeed turn up in the most unexpected places. Thus, though the Passeres may be said never to develop more than a vestigial downy covering, yet the young Lyre-bird (Menura) is abundantly provided for in this matter.

That the more loose and fragile down of the nidicolous types is intimately connected with a sedentary habit there can be little doubt. The Pigeon and the Sand-grouse illustrate this point extremely well. These two forms are undoubtedly closely allied. Yet the young of the Sand-grouse is precocious and clad in a dense and very thick coat of down; while the young $\mathrm{P}$ igeon is helpless and but scantily invested in down feathers of a degenerate and filamentous character.

The fact that the young of indubitably close allies-like the Sand-grouse and Pigeon-may differ very conspicuously, and that birds, in no way related to one another-as in the case of the Owls and Hawks-may in their nestling stages bear a very striking resemblance, shows at once the unreliability of this character for systematic purposes. At the same time it raises the question-what is the significance of these two conditions?

There can be no doubt but that the nidifugous or precocious type of nestling is the more primitive, since it is nearer to the reptilian condition out of which the birds have risen. Yet it is not the apparently most active which are nearest to this primitive stock.

The correct interpretation of this problem is to be found, probably, in the early stages of the life-history of an extremely aberrant type, whose affinities are still a matter for conjecture. This bird is the Hoatzin (Opisthocomus cristatus), a native of the Amazon valley. Perhaps more exclusively arboreal than any other bird ( $p .50$ ), both in its adult and nestling life, this species may be regarded-in so far as its habits are concerned, as well as in some structural features to be discussed immedi- 
ately-as more nearly approaching Archæopteryx (p. 250), and the proto-avian types, than any other living member of the Class Aves.

But it is in the nestling that these primitive features stand revealed. Had the adult alone been known they would never have been,suspected. The nestling, however, presents the key to the whole question concerning the evolution of the two types of nidifugous and nidicolous young, and furthermore, explains the true meaning of the vestigial claws which occur on the wings of adults of the most diverse types.

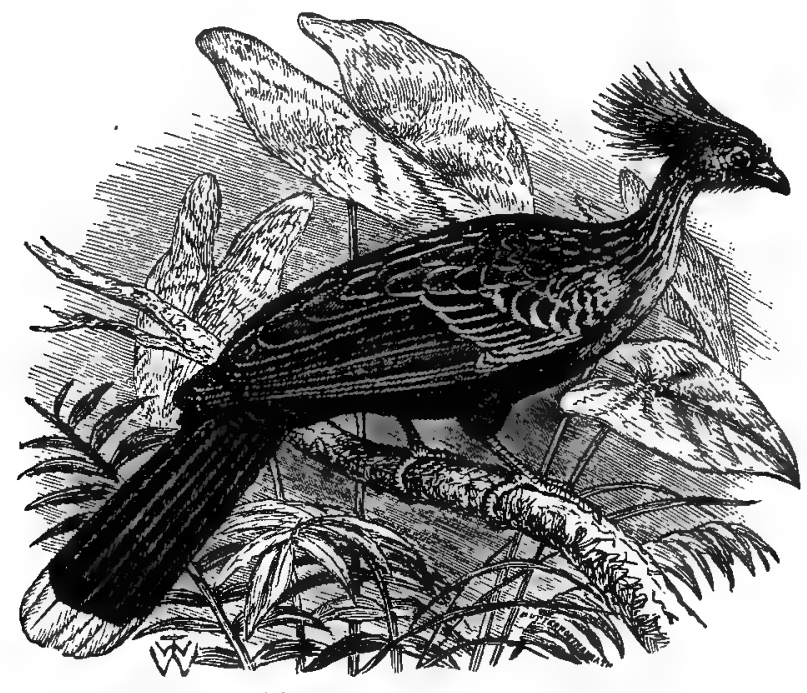

ILL, 27.-HoATzIN (Opisthocomus cristatus)

Briefly, the history of the nestling of this strange bird is as follows. Nidifugous, or, to use the simpler term, precocious it is hatched in a rough nest of sticks placed amid the boughs of a tree overhanging the water. How long after the escape from the egg it and its nest-fellows remain in the nest is not known, but they probably use this, after the first few hours of independent life, only as a roosting-place where they can be "brooded" by the mother. The hours of daylight appear to be passed in rambling about the tree in which the nest is placed. The method of progression is so far unique, since not only are the feet and the beak used Parrot-fashion, but the wings are 


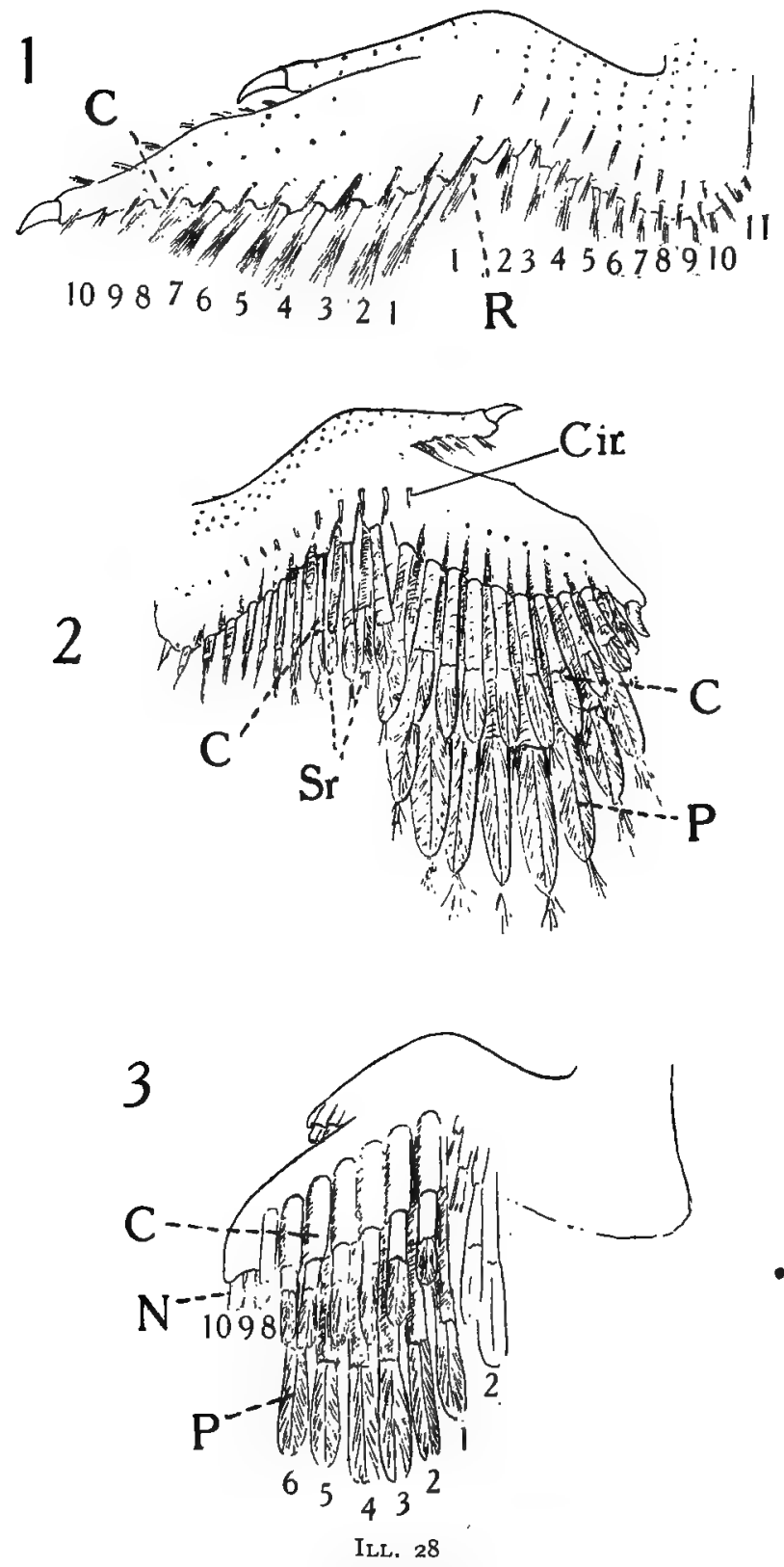

The two upper figures represent two stages in the development of the wingquills of the nestling Hoatzin; the lower of the wing of the nestling Common Fowl. Note the arrested development of the three outermost quills $=\mathbf{N}$. $\quad$ C. $=$ Coverts. $R_{.}=$Remiges or "quills". r, $2,3,4$, etc. = the quills of the forearm and hand. P. = Primaries. S. $x_{0}=$ Secondary remiges. (After Pycraft.) 
also employed. Thus locomotion is quadrupedal at this stage, the creeping movements of the earlier reptilian phase being used in combination with the more avian fashion as practised by the Parrots.

As might be expected, the wing while used as a climbing organ presents features not to be found in later development when it has assumed its proper function.

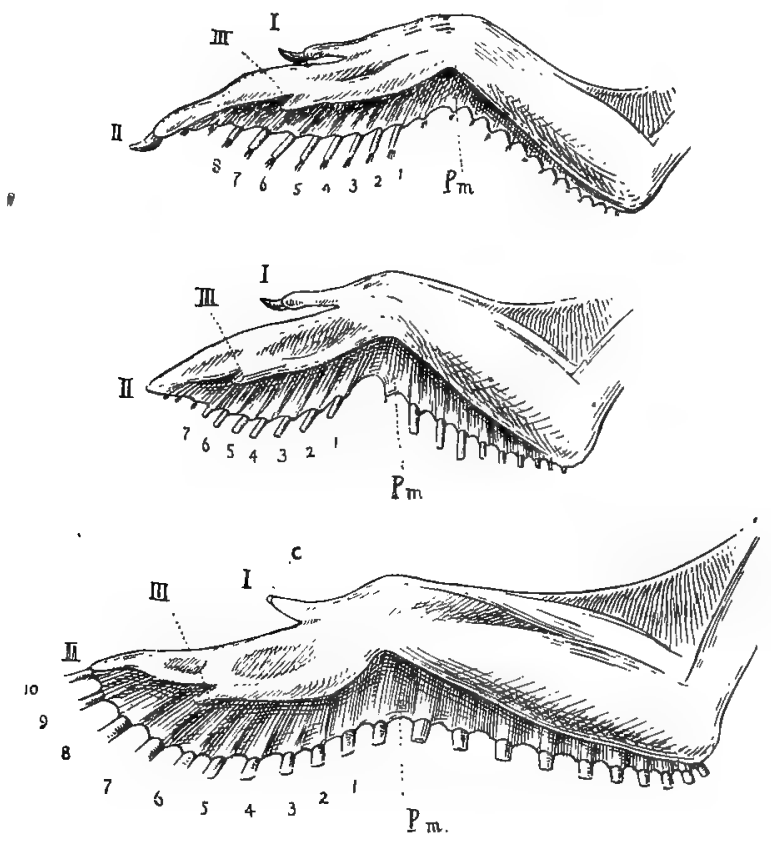

ILL. 29

The upper and lower figures represent the under surface of the wings of the nestling and adult Hoatzin; the middle figure that of a nestling of the Common Fowl (Gallus barkiva). The hand of the nestling Hoatzin is seen to be relatively much longer than in the adult, which has also lost the claws.

The wing of the nestling fowl shows an arrested development of the outermost quills, just as in the Hoatzin. (After Pycraft.)

One of the first things to attract attention in the examination of this wing is the presence of unusually large claws on the thumb and first finger, and the great length of the hand which is conspicuously longer than the forearm (I11. 29). The thumb is found to be unusually long, and to extend beyond the level of 
the tip of the third digit. Both thumb and finger are armed with large claws. The index finger is furthermore remarkable in that it is produced beyond the fold of skin which runs along the hinder or post-axial border of the wing for the support of the quill feathers. Examined further, the palmar surface of the thumb and second finger are found to be swollen into little cushions, resembling the cushion-like under-surface of the fingertips of the human hand. Next the budding quill feathers attract attention, and if a series of young is being examined, probably the first point to be noted is the fact that the development of the quill feathers of the hand is peculiar, inasmuch as in the older forms whilst the inner quills are found to have pushed their way out some considerable distance the outer quills are only represented by simple down feathers (IIl. 28). Thus, a long, free finger-tip is left beyond the quills. The thumb also, as yet, bears only down feathers, the future quills being conspicuous by their absence. On a little reflection the meaning of this becomes clear.

The arrested development of the quills of the thumb and the tip of the finger is an adaptation to the bird's peculiar needs, albeit a deep-seated character, dating probably from the very dawn of avian development. If all the quills were to grow at an equal rate a stage would soon arrive when the wing would be useless as a climbing organ by reason of the developing feathers, and so expose the bird to constant danger of falling before the quills had sufficiently developed to break the force of such a fall. This hypothesis of the signification of the arrested development of the quills receives the strongest testimony when still older specimens are examined. In them we find that as soon as the inner primaries have grown sufficiently long to enable the bird to recover itself in falling, the hand begins to shorten, and the claw to diminish, till at the time of puberty the hand has become shorter than the forearm, the claws, both of the thumb and the finger, have disappeared, the thumb no longer extends to the level of the third digit, and the second finger no longer projects beyond the hinder wing fold (post-patagium).

That the structural peculiarities observable in the wing of the Hoatzin are not recently acquired characters cannot be doubted. The presence of the claws is almost sufficient to. 
prove this, for having once become vestigial it is unlikely they would reacquire their primitive size.

But we have other evidence affording the strongest confirmation of the contention that the wing of the Hoatzin represents an ancient order of things once common to all birds. ${ }^{1}$ This evidence is "writ large" upon the wing of those allies of the Hoatzin, the Common Fowl, the Turkey or the Pheasants, for example.

Although these birds are no longer hatched in trees we find in them the same developmental stages as those met with in the Hoatzin, but with certain modifications easy to interpret.

If the wing of a chick of, say, sixteen hours old (Ill. 29) be compared with that of a young Hoatzin of the same age, it will be found that the same relative proportion between the hand and forearm exists, but that the claws are now reduced to one - that on the thumb-and this is but a mere vestige. The claw of the finger appears only during embryonic life, and is absorbed before the chick is hatched. Passing on to an examination of the developing quills in the chick with relation to the hand, we find that, as in the Hoatzin, these are at this stage restricted to the wristward region of the hand so as to leave a free fingertip, but this and the thumb lack the cushion-like pads of the Hoatzin. Now the arrested development of these terminal quill or flight feathers is absolutely inexplicable in a bird hatched on the ground, and only becomes intelligible when viewed in the light revealed by the Hoatzin. In other words, it can only be explained on the hypothesis that at an earlier period in the life-history of this bird the wing was used as a climbing organ. The remoteness of this period accounts for the disappearance of the claws and the relatively shorter hand, though, as we have already remarked, this is still longer than the forearm. As in the Hoatzin, moreover, by the time that maturity is reached the relative lengths between hand and forearm have changed, the latter being longer than the former. But in one particular the wing of the young Fowl differs

1 There is good reason to believe that the young of the Turacos, when more is known of the nesting habits of these birds, will prove to follow very closely the peculiarities of the young Hoatzin. The only known nestling of this bird, described in the Avicultural Magazine for January, Ig05, when a month old, had enormous wings, the quills of which had not completed their growth, while the body was still invested in a short, black down, sparsely distributed over the body. 
conspicuously from that of the young Hoatzin. This is in the remarkably rapid development of the flight feathers or quills. The growth of these in the Hoatzin is a comparatively slow process, occupying many days, but in the Fowl and its allies they are beginning to unfold when the chick is but sixteen hours old, and in three days they form an efficient organ of flight. The explanation of this accelerated development of the quills is not far to seek-it is the result of adaptation to the changed environment. The descent from the trees to the ground was a descent from comparative security from enemies into a world where enemies were numerous. Precocious flight was the method of escape adopted, though, as we shall see presently, not the only method.

But how comes it, some may ask, that the arboreal nursery was forsaken, if it afforded such security from enemies? And, further, how is it that the young of all birds hatched in trees at the present time-save only the Hoatzin-are so singularly helpless at birth? What is the origin of the altricial or helpless type of young?

As touching the migration from the forest to more open ground, we may surmise that this probably took place as a result of overcrowding. The old habitat left behind, the young in response to the new environment underwent modification, now in one direction, now in another, to bring them into harmony with their particular environment.

Among the forms known as Game-birds, and the Tinamous, the most striking of these changes is that affecting the wings, the nature of which we have just described in the wing of the Common Fowl. But we would draw special attention to one further point concerning the accelerated development of the quills. This forcing, it is instructive to note, affected only those quills originally concerned in the precocious flight; those at the tip of the wing, whose development was retarded so as to leave the claw free for climbing purposes, still remaining unaffected. This is as we might expect, for just as these inner quills were sufficient during the arboreal phase, they remained, and still remain, equally so for all the early demands of the terrestrial life.

The fact that similar traces of an arboreal life are rarely to be found in the precocious young of birds other than Game- 
birds, is a curious and extremely interesting point, and not only reveals a change in the tactics adopted for the escape of enemies, but draws attention to another, and what we may regard as a second string to the bow, practised by the Gamebirds themselves. It must be remembered then that these latter are reared in comparatively large families, and that they in consequence afford a conspicuous and tempting prey to prowling carnivora. Accordingly, as soon as danger is realised by the parent, the alarm is given and the young scatter in all directions. Halting at last, they then fall back upon this "second string" - protective coloration. That is to say, they have, in addition to the remarkably accelerated flight, also acquired a peculiar type of plumage which enables them to assimilate with the surrounding objects. Now it would seem that this precocious power of flight has not proved a really satisfactory method of escape, inasmuch as in fleeing from immediate danger the young either strayed too far to render recall possible, or they fled into new danger. Consequently, the young in other groups have come to rely either on protective coloration alone, or at most run but a few yards and then squat down. Or, as in the case of one of the Coursers, the parents cover the young with earth. On this account, then, other groups have discarded the doubtful refuge afforded by precocious flight, and with it the evidence of these earlier arboreal habits. The young of aquatic birds obviously do not need to seek safety in flight. Concealment amid reed-beds or other vegetation affords ample protection. Among all these non-flying young we find the development of the quills has been retarded rather than accelerated, so that they appear together with the rest of the body plumage. Among the Ducks, indeed, the quills do not appear till extremely late, so that the body has attained almost its full size before the wing begins to attain its adult form.

The wing of the nestling Rhea-the South American Ostrich-still retains traces of evidence of a developmental history precisely similar to that of the forms which we have been discussing. Whether such traces will be found in the other flightless members of the Ostrich tribe, remains to be seen. In the Tinamous, the only Ostrich-like birds which have retained the power of flight, the development of the wing 
is precisely similar to that which obtains among the Gamebirds.

This is a point of some considerable importance, since it shows that, as we have reason to believe on other grounds, the giant members of the Ostrich tribe have attained their present conspicuous bulk comparatively recently, that is to say, since they became flightless. That they are primitive types there can be no pcssibility of doubt, but like other primitive types, their great size is the last developmental phase in their lifehistory, and precedes extinction.

It is time that we turned to the opposite side of this picture -to the consideration of those types of nestlings which are ushered into the world blind, naked and helpless. According to the terms of our argument, birds were originally a strictly arboreal group, and their young, like those of reptiles, were extremely active from the moment they left the shell.

Without doubt, such activity in an arboreal nursery must have been attended by considerable infant mortality through the young falling to the ground. Many, probably, would fall through weakness; the habit of dispersing themselves among the branches of the trees in which the nest was placed, resulting in a loss of regular food supply owing to the difficulty of being on the spot when the parents returned with food.

Now two courses were open whereby this infant mortality could be reduced. Either the eggs could be deposited on the ground, or the activity of the young could be curtailed. The Game-birds, Ducks and Geese, Rails, Cranes and Plovers, may serve for eximples of those species which have descended from the trees to the ground for nesting purposes. Although, as a consequence, such young have undergone considerable changes in adaptation to their new environment, these changes are not so striking as those which have taken place among the young of the species which, retaining the ancient practice of nesting in the tree tops, have adopted the alternative of currtailing the activity of their offspring. This curtailment was accomplished by reducing the amount of food-yolk enclosed within the egg. As a consequence of this reduction the embryonic period of development has become relatively shortened, and the young accordingly emerge from the shell in the helpless condition to which we have referred already. 
The number of species which have adopted this expedient outnumber those which have not, and this speaks volumes for its success. As examples we may cite the vast army of songbirds, the Pigeons, Parrots, Cuckoos and birds of prey.

The amount of food-yolk once reduced, return to the older fashion of active young became impossible; and this explains why the young of so many species hatched on the ground are as helpless as those reared in the topmost boughs of the highest trees. These young are the descendants of birds whose young had become adapted to the requirement of an arboreal nursery, and though this was later forsaken it is obviously impossible to return to the earlier precocious condition.

The young of the Skylarks, Pipits and Wagtails, among the Passeres, and of the Bee-eaters, Kingfishers and Night-jars among the Coraciiformes (p. 59) are cases in point. Though these are now hatched in a nest on the ground, or as in the case of many Kingfishers and of Bee-eaters, in burrows, they have all undoubtedly undergone this adaptation to the needs of an arboreal nursery. The factors at work which determined the change in the nesting site are discussed elsewhere.

On the other hand, there are a number of instances where precocious young, specially adapted to meet the requirements of a terrestrial nursery, are reared in trees, as in the cases of the young of the Green Sandpiper (Totanus ochropus) and of the Noddy (Anous stolidus) and White Tern (Gygis candida). The condition of these nestlings leaves no room for doubt that they have only lately ceased to become actually precocious; in form they are still scarcely distinguishable from the still active young of their immediate allies. They are apparently on the way to become as helpless as the young of the Gannets, Cormorants, Pelicans and their allies, which, in the early stages of development are now peculiarly helpless. This stage has probably been reached by a series of gradual transitions similar to those now in progress by the Terns just described. Like these birds and the Green Sandpiper, the Gannets and Cormorants, Frigatebirds and Pelicans, now, either sporadically, or in the case of some species, constantly nest in trees. Such a nesting-place, doubtless, has only lately been resorted to-it is a reversion to an ancient custom and not a survival, as in the case of the Hoatzin. 
Various intermediate stages in this process of "hobbling" may be studied in the case of those species which, having young of the precocious type, breed in colonies, often of vast size, or on ledges of precipitous cliffs. The reduction of the food-yolk, and the consequent premature hatching observable in the young of such species, are undoubtedly advantageous. This is the case in so far at least as the preservation of the species is concerned, since, when reared in colonies affording a free space to roam, they would, if active, become lost amid a general crowd of nestlings, and hence soon starve-even if the parent birds had acquired the habit of feeding indiscriminately any nestling in the colony which clamoured for food. In the case of cliff-breeding species like the Guillemots and Razorbills, and many Gulls, this quiescence, at first enforced by sheer inability to move and later adhered to by habit, saves an enormous mortality through falls from the cliffs.

Whilst a large number of birds have adopted the expedient of curtailing the activity of the young, and thereby have increased the burden of family cares, there are a few species of - Game-birds known as Megapodes, or mound-builders, which have succeeded in reducing the ties of offspring to the smallest possible limits—without descending to parasitism-by enormously increasing the size of the egg so as to include a proportionately large amount of food material for the developing embryo. As a consequence, the whole of the normal nestling period is passed within the shell, and the young bird emerges fully feathered and able to fly. The parental instinct seems in consequence of this habit to have become well-nigh extinguished, for there is no brooding of the eggs, and little or no care displayed for the chicks which are hatched after the fashion of many reptiles-by the warmth generated by decaying vegetable matter in which the eggs had been placed? (Chap. XIII., p. 217).

${ }^{3}$ Although numerous facts have been recorded concerning the disposition of the eggs of the various species of Megapodes there appears to be no published account of the discovery of young immediately after hatching and before working their way out of the natural incubator in which these birds are hatched.

From observations made at the Gardens of the Zoological Society on the nesting of the Australian Brush-turkey (Catheturus lathami), it would seem that the nestling remains in the mound raised by the parents for about thirty-six hours, and then makes its way up to the outer world. During this time the quills of the wing appear to complete their growth, since, though at the moment the 


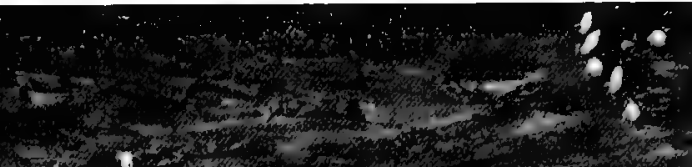

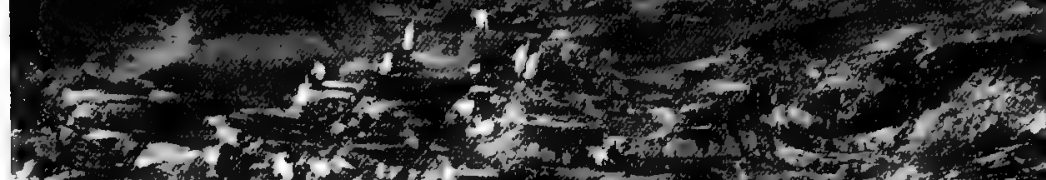

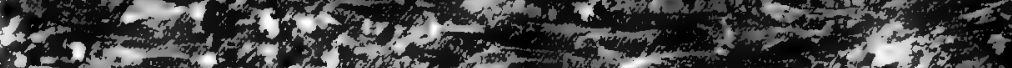

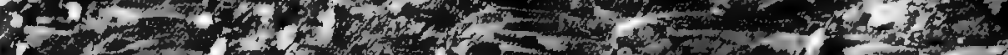

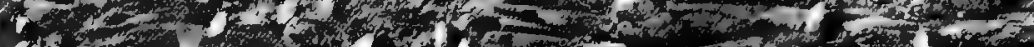

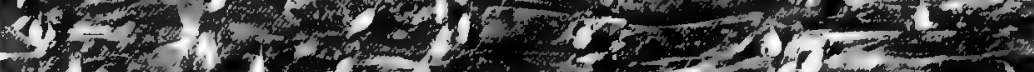

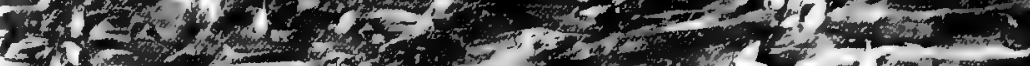

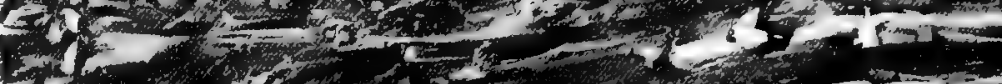

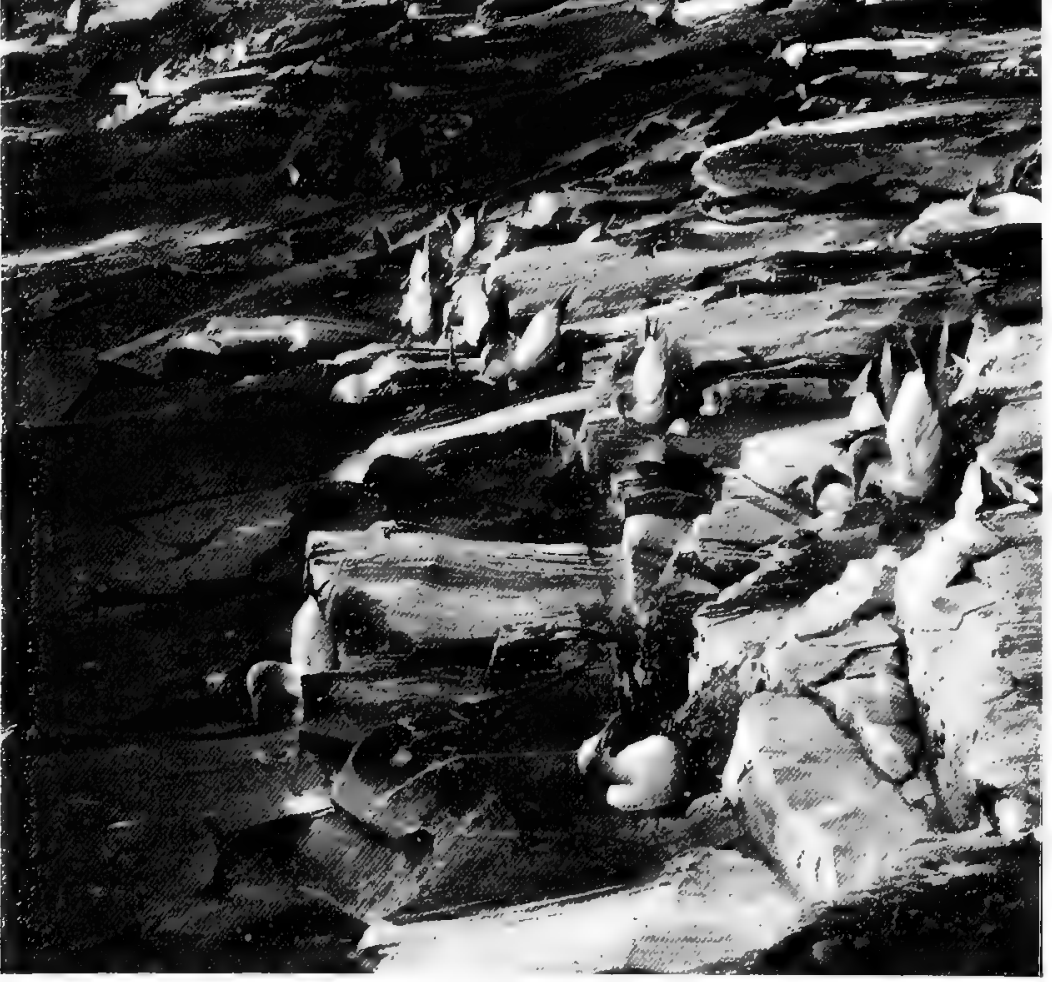






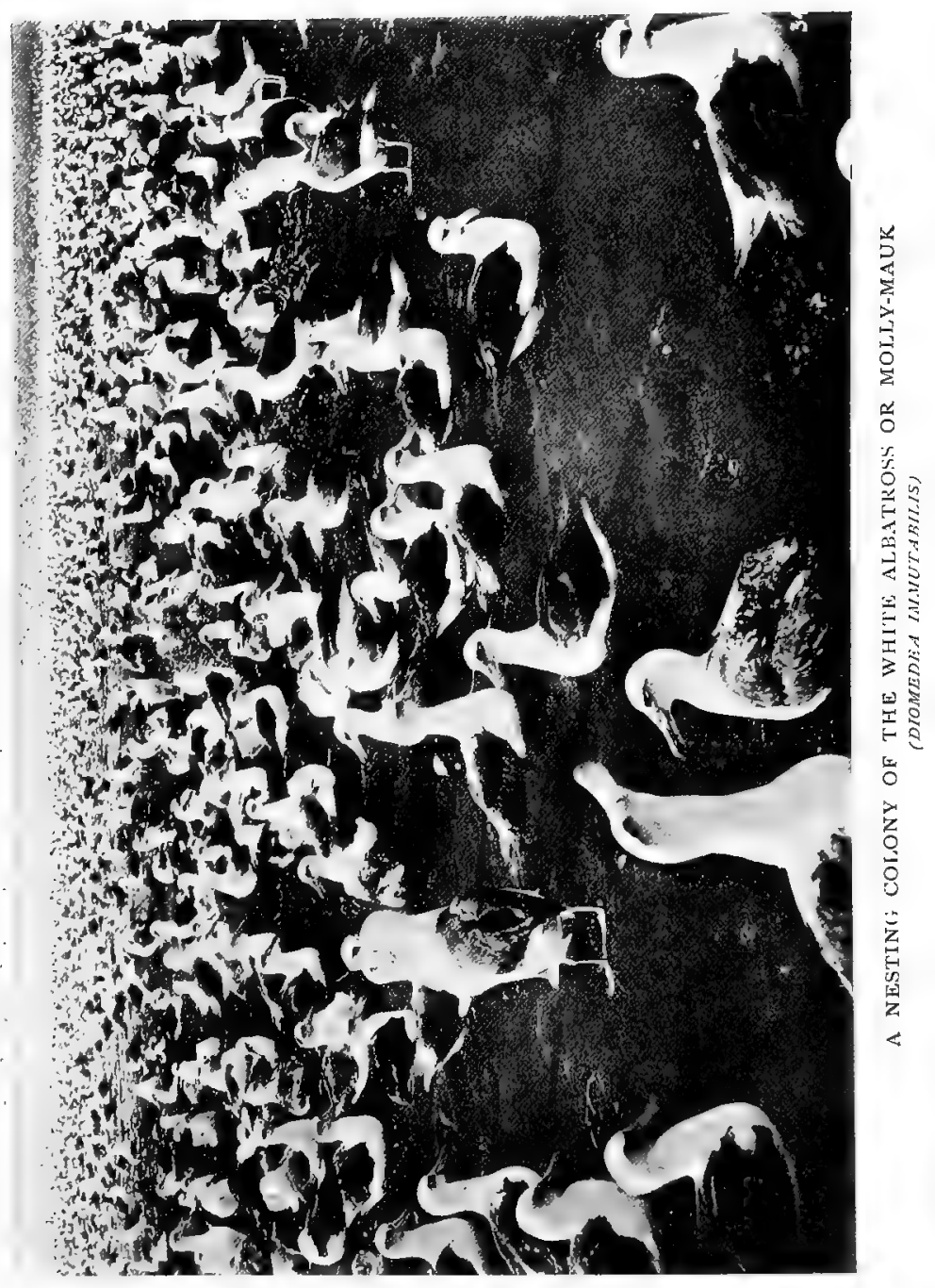


That the Megapodes were originally hatched in trees, like the young Hoatzin, there can be little doubt, since, like the latter, the wing of the young shows a free finger-tip, and the arrested development of the outer quills, characters which, as we have already seen, are direct adaptations to the peculiar locomotion of tree-climbing nestlings. Further, we may feel sure that the increase in the amount of food-yolk did not take place until some time after the descent to the ground for nestling purposes, since the wing of the young Megapode forms an exact counterpart to that of the young Fowl or Turkey. Had the increase taken place earlier, the wing would have resembled that of the Hoatzin in the possession of large claws. These are now present only during embryonic life.

The increase in the food-yolk, allowing the earlier nestling stages to be passed within the egg, must be accounted for by supposing the adult Megapode to have been obliged to adopt this expedient to avoid perils attendant on normal incubation, perils which may since have passed away, leaving no record of their nature. A return to the normal method of incubation is now impossible, the instinct therefor having been replaced by that which induces the birds to bury their eggs and leave them to be hatched by heat other than their bodies.

This remarkable habit of burying the eggs has received a very different explanation to that adopted here, one which seems to show that the effect has been mistaken for the cause. The great size of the egg, say the supporters of this hypothesis, takes up so much room within the body cavity that only one can ripen at a time, and consequently, long intervals must elapse between the deposition of each egg. To wait till all were laid would be dangerous, and furthermore, they could not all be covered by the sitting bird. Consequently, each is deposited as it is laid, in an incubator, and left to take its chance just as among reptiles. They hold, in short, that the Megapodes lay their eggs in mounds because of their size, whilst the converse appears to be the case-the large egg has been produced because of the need of depositing it in some

chick leaves the egg these are of considerable length, they are still enveloped in the sheath common to growing feathers. In a few hours this sheath crumbles away, and when this process of disintegration is complete, the quills are ready for use. Then, and not until then, the young nestling makes its way out of its premature grave! 
natural incubator, the parent being unable to undertake this duty.

That the extremes of precocious development on the one hand, and of helplessness on the other, are traceable to a common origin represented to-day in the young Hoatzin there can be no doubt.

That the peculiar features which distinguish this bird during the nestling period are distinct survivals from the very remotest times may be regarded as proved by the evidence afforded by the remains of the earliest known bird Archæopteryx (p. 266).

The long hand and claws of this bird, when compared with the hand and claws of the wing of the Hoatzin, display a resemblance too close to be regarded as the result of convergence (p. 240). Having regard to all the factors in the case, they leave little room for doubt but that the two wings are genetically connected-that of the modern bird is a direct survival from the most ancient times.

According to the views hitherto expressed the claws, both in this fossil and in living birds, were simply vestiges-indices of the reptilian stock from which the Class Aves was derived. The correct interpretation appears to be, however, that these structures are something more than this-that they were retained by the developing birds because they vere inseparably linked with a number of other intimately associated adaptations of vital importance to the preservation of the species, at least during the nestling period; for there can be no doubt but that Archæopteryx was as absolutely pledged to an arboreal life as in the Hoatzin to-day, and stood in the same need of special modification of structure to make this possible.

Among living birds the majority have adopted other modes of life, or other means of accomplishing the same end, and have in consequence lost the peculiar characters preserved in their integrity only in the Hoatzin, and leaving more or less blurred records in some other species, the distinctness of the record being the rough measure of the time which has elapsed since the old habits were forsaken.

These conclusions at which we have arrived seem almost irresistible; but they would never have been reached but for the combined study both of fossil and recent forms. Each helps to explain the other. 
The interpretation so far submitted of the facts in question differs materially from the conclusions of earlier writers.

According to Dr. Gadow ${ }^{1}$ three deductions are possible: (I) That the developmental period (embryonic + nestling stage) stands in direct relation to the ultimate perfection in development which is attained. That is to the relatively "high" or "low" position they hold with the class. (2) That it is profitable because safer both for mother and offspring for the embryonic and brooding periods to be as short as possible. (3) That the helpless types, and among these especially the Passeres, are the most perfectly developed types, and these have absolutely the shortest brooding and the longest nestling period.

If it be admitted, he concludes, that the preponderance of the nestling over the incubation period is a sign of higher development, then the Passeres must be allowed the highest position in the system, for these have, relatively, the longest post-embryonic and shortest incubation period of all birds.

Similar views have been expressed by later writers. Thus, Messrs. Jordan and Kellogg, in their work on Animal Life, assert that "among the lower or more coarsely organised birds, such as the Chicken, the Duck, and the Auk as with reptiles, the young animal is hatched with well-developed muscular system and sense organs, and is capable of feeding itself," but the offspring of the more highly organised forms, such as the Thrushes, Doves. and Song-birds generally, "are hatched in a wholly helpless condition, with ineffective muscles, deficient senses, and wholly dependent on the parent".

We must pass now to a brief review of the facts appertaining to the coloration of nestling birds.

This subject falls under two different heads: $(a)$ the coloration of the body as a whole, and $(\beta)$ the coloration of definite regions of the body. Under the first section we have all those birds which are nidifugous, or active from the moment they leave the shell, and some nidicolous or helpless birds. These all agree in that they are downy, but they present different types of coloration, all of which, however, belong to the protective resemblance group. Under the second we have some of the downy forms, and those nidicolous or helpless types, which,

${ }^{1}$ Gadow, Bronns Their. reichs. Vogel., p. 698. 
though generally coming into the world blind, naked and helpless, yet frequently exhibit brilliantly coloured markings, generally confined to the mouth. These coloured areas belong to another category, and will be discussed later.

The down-clad nestling, there can be no doubt, represents the more primitive condition, but it is not so easy to determine whether in any case the primitive type of coloration has also been retained, or whether what appear to be instances of primitive coloration are really cases of adaptation to environment independently acquired.

That the dominant type of coloration among primitive animals took the form of longitudinal stripes seems to be a very widespread belief. These stripes are next supposed to have given way to spots, and these latter either became re-arranged to form transverse stripes, or mottlings, or disappeared altogether, leaving a perfectly uniform coloration unrelieved by any markings, or at least any very conspicuous markings such as form a pattern. This orderly sequence seems to imply that these patterns have followed an inherent line of development, determined in the germ plasm, and encouraged, so to speak, by natural selection.

Eimer supposes "that the fact of the original prevalence of longitudinal striping might be connected with the original predominance of the monocotyledonous plants, whose linear organs and linear shadows would have corresponded with the linear stripes of the animals; and further that the conversion of the striping into a spot marking might be connected with the development of a vegetation which cast spotted shadows. It is a fact that several indications exist that in earlier periods the animal kingdom contained many more striped forms than is the case to-day. "This supposition," he goes on to say, "is also supported somewhat by the fact "that at present strongly spotted forms mostly occur in places with spotted shadows, the longitudinally striped more in grassy regions. . . . Crossmarking is perhaps to be connected with the shadows, for example, of the branches of woody plants-thus the marking of the wild cat escapes notice among the branches of trees.'"

That these several types of markings are, in many cases, direct survivals enjoying a transient existence, like many other vestigial characters, is highly probable, but in others they, with 
almost equal certainty, represent comparatively recent developments.

Thus the spots in the young lion and the faint traces thereof in the adult female are almost certainly remnants of an earlier and more emphatically spotted phase common to the adults of both sexes. But it is also possible that in many cases these markings may be remnants of an earlier spotted immature stage when the young derived, and may still derive, benefit from the protection accruing from these markings. In such cases the adults may have been quite differently coloured as they commonly now are.

According to the prevailing opinion, we have something like a recapitulation of past types of coloration, the markings of ancestral adult stages being reproduced in the immature stages of to-day. On this assumption we must suppose either that this immature coloration is now merely reminiscent and of no protective value, or that the descendants of these spotted or striped forms, as the case may be, require the ancestral adult protective colours only during the period of immaturity.

But even this view cannot be reconciled with Eimer's interpretation of the significance of these markings. If longitudinal stripes are the result of adaptations to foliage of monocotyledonous plants, and spot marking to an adaptation to foliage of vegetation which cast spotted shadows, then the longitudinal markings of many animals of to-day must be quite out of harmony with their environment, and their survival shows that in these cases at least the correspondence between the markings and the type of foliage need not be a very close one, since the longitudinal stripes developed to harmonise with linear foliage serves equally well amid foliage which casts spotted shadows.

Transverse stripes, at least, apparently owe their origin to adaptation to totally different environments. Originally developed for the sake of affording protection amid linear foliage, as in the tiger, for instance, they have almost certainly been acquired de novo in the case of the zebra, where they serve to protect the animal on account of the absence of foliage of any sort.

The contention that longitudinal striping was developed in response to linear foliage is lacking in cogency. Vertical stripes would have served the purpose better, supposing that the 
direction of the stripes was a matter of prime importance. The widespread occurrence of longitudinal stripes probably depends on a deeper stimulus.

The definite and orderly sequence of colour, which many animals exhibit in the course of development, seems to show that in many cases the markings of the immature stages are really reproductions of an ancestral adult livery. This is well seen in cases where the male and female have a distinct livery. Here the females and young are often precisely similar in dress, and bear a remarkably close resemblance to the adult stages of both sexes of more primitive but closely allied species. Among birds there are many illustrations of this. A large number of animals, however, afford no clue as to whether the colour of the immature individual is ancestral or newly acquired; whether it is an ancestral adult or an ancestral juvenile coloration. The larval Alpine Newt, for example, is conspicuously longitudinally striped. Even while still within the egg these markings can be seen. There is a median dorsal black stripe, which bifurcates on the head, and a lateral stripe, also black. Later, black pigment cells wander into the transparent ground colour, and eventually the black upper and red under-surface of the adult is acquired. The stripes of caterpillars are not easily accounted for. Are these independently acquired markings, or inherited ancestral larval markings? They certainly can have nothing to do with the adult coloration.

With the birds the problem becomes still more complex, inasmuch as, in the precocious types at least, we may have three separate plumages: $(a)$ the nestling; $(b)$ of the fully-fledged "immature" stage, which may be the same as that of the female; and (c) the adult stage, i.e., the plumage worn by the male only, or by both sexes.

With regard to the "immature" stage it is worthy of comment that, as Professor Newton has pointed out, "Throughout the Class Aves it is observable that the young, when first fledged, generally assume a spotted plumage of a peculiar characternearly each of the body feathers having a light-coloured spot at its tip-and this is particularly to be marked in many groups of the oscines. . ..."

There seems to be strong presumptive evidence to show that the primitive coloration of young birds took the form of 


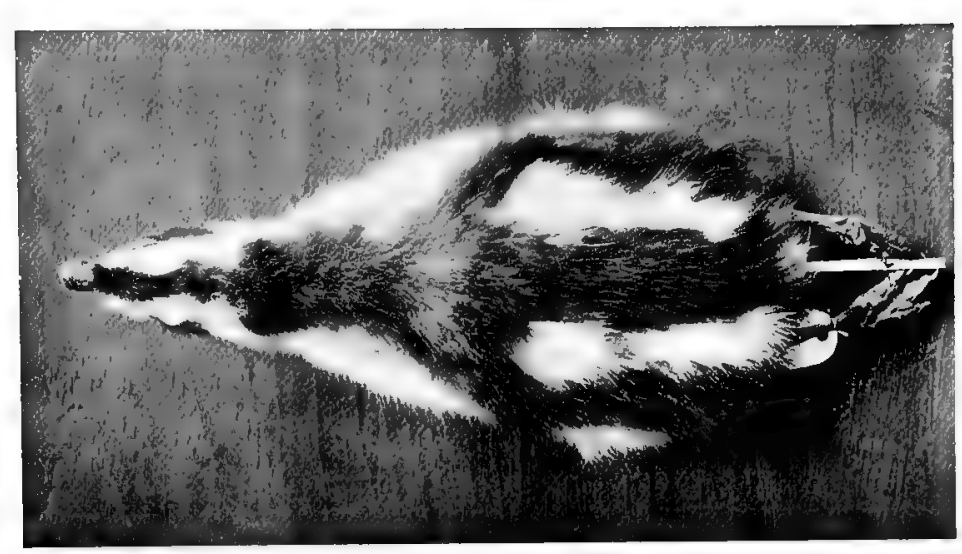

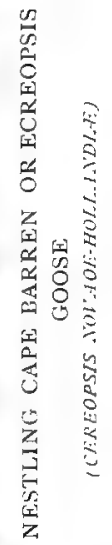
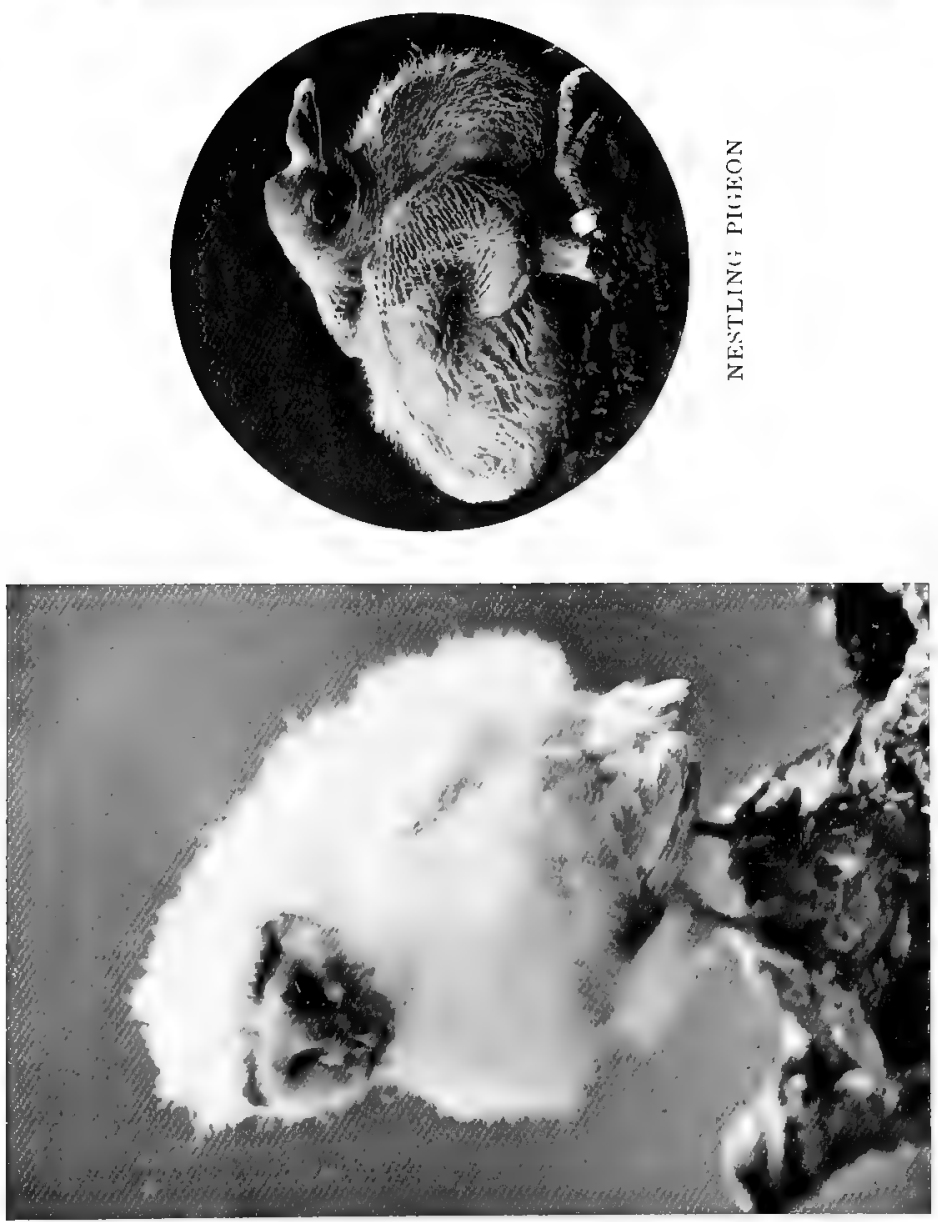

ह 

longitudinal stripes. Nowhere are these stripes seen to better perfection than in the young of the Emu. Here, in the very young bird, we find a long, thin, white stripe extending from the head down the back of the neck, and tailwards along the back on either side of the middle line. Beluw the trunk-stripe a second occurs, but towards the end of the nestling period it is interesting to notice these stripes appear to increase in number. The second, inferior trunk-stripe of the newly hatched bird extends forward to join the neck-stripe just described; and beneath the second, now elongated stripe, a third appears, and this runs upwayls to form a second neck-stripe, running parallel with the first; below this third a fourth stripe appears; this extends from the end of the tibia, upwards and forwards along the flanks, terminating at the base of the neck. The continuous neck-stripe, No. I, breaks up at the base of the skull into a number of dots in the older birds. In the very early stages the legs bear curious mottled markings, but these rapidly vanish.

In the young Cassowary (p. 258), at an age roughly corresponding to the second stage of the Emu, only the faintest traces of spots on the head and neck are traceable. On the trunk we find five white bands sharply defined, and set off by a darker ground than in the Emu. The fifth corresponds to the leg and flank stripe of the Emu, but is shorter.

In the nestling Rhea stripes also occur, but these are less conspicuous and fewer in number than those of the genera just described. The neck-stripes are obsolete.

The nestling Ostrich appears to differ from the other "Ratites" in having a uniform coloration. The trunk, it will be remembered, presents a curiously grizzled appearance, and this is due to the fact that the tips of the rami of each down feather are produced into long ribbon-like horny processes. But there can be little doubt but that this peculiar structural modification of the down feathers is comparatively recent, since, though these no longer display a pattern, the down feathers of the neck agree precisely with those of the Emu, in that they are coloured so as to form very strongly marked longitudinal stripes down the back of the neck, while along the front of the neck and the sides of the head these stripes give place to rows of dots. 
Apteryx, it may be mentioned, has a uniform grey coloration.

There is no reason to believe that the Grebes are even remotely related to the Ostriches, yet the nestlings of these birds display a precisely similar style of coloration-light longitudinal stripes on a dark ground.

It is interesting to note that while in the nestling plumage of the "Ratite" birds and the Grebes we find a relatively large number of stripes, in all the forms now to be considered the pattern is almost invariably formed by a median and two lateral stripes. In some species these stripes are strongly marked, in others barely traceable.

But great variability in this matter obtains, even among the several species of a single family. In the Tinamous, for example, a median stripe along the back, extending forwards up the neck on to the head, and a dark stripe behind the eye, occurs with some frequency. Others of this group are uniformly coloured, or have a dark occipital patch (Nothocercus). In Rhynchotus the head and neck are spotted, as in the nestlings of the Ostriches.

The Game-birds are undoubtedly, as a group, striped when nestlings, though in many this striping is giving way to mottling by the breaking up of the stripes.

The nestling Curassow, e.g., Crax alector, is conspicuously banded. The mid-dorsal line is marked with a broad chestnut band, bounded on either side by a conspicuous white stripe, the band commencing on the head and widening backwards. The white bars also commence on the head. Again, in the young Argus Pheasant we have a similar dark median band bounded by white stripes. In the young Blackcock (Lyrurus tetrix) the general ground colour is buff, the back of the neck bears a median stripe which bifurcates at the trunk to run down on either side of the middle line in the form of two indistinct lines. The occiput and the rump are of a warm chestnut colour. But the general effect of this pattern is mottled rather than striped. This mottling is more pronounced in the Capercailzie nestlings, and in those of the Pheasant and Partridge; probably this mottling is derived from the breaking up of stripes, the last phase of the striped dress being seen in the nestling Red Grouse. 
The nestling stages of the Chardriiformes, or at least the Limicolæ and Lari, appear to have been originally striped. Today these stripes are most apparent in the Redshank, Woodcock and Norfolk Plover (Edicnemus crepitans). In the Redshank we find a narrow median dorsal stripe extending forwards up the neck and bifurcating on the crown of the head. On either side of the median stripe are three lateral stripesthese stripes are dark on a buff ground. In the Woodcock the median stripe takes the form of a broad chestnut band. The lateral stripes are wanting.

The Snipe, on the other hand, is distinctly striped. In Gallinago coelestis (the Common Snipe), for example, the general colour of the down is of a rich dark chestnut, relieved by three very distinct white stripes. The adult is also, it may be remarked, longitudinally striped. The Norfolk Plover has the ground colour of the body of a pale yellowish-grey, relieved by two narrow black bars or lines along the back, and a black stripe through the wing and down the middle of the head.

In the other Plovers the stripes have broken up to form mottlings as in the Gulls. But the general coloration is obviously adaptive-procryptic. Thus, in the Knot-which breeds in the snow-the down is white, mottled with grey; the young Kentish Plover has the upper parts very pale buff, powered with black; and so on. The under parts, as in the case of nearly all nestlings, are either pure white or nearly so. The Jacana bears strongly defined narrow black stripes on a bright chestnut ground.

The Gulls, like the Plovers, show both striped and mottled forms, the former being rare. Indeed, so far, the only striped form I have come across is the nestling of the Little Tern. The ground colour in this species is pale relieved by a median and two lateral stripes. From this we pass to the mottled type, and in many cases, e.g., Common Gull, the median and lateral stripes are still plainly visible; the neck, too, is spotted just as in the young of Dromaus, also indicating the derivation of the spots from stripes. The young Sooty Tern is almost unicoloured, powered with minute white points; and from this we pass to the completely unicoloured and dark young of the Skuas. The Skuas, it is to be noted, are of a uniform dusky colour when adult. 
The Gruiformes would appear to have been originally striped, inasmuch as traces of a broad median band are visible in the young Japanese Crane, while the young Bustard (Otis tarda) bears a close resemblance to the young Gull, being pale coloured with dark mottlings.

The young of the Turnices are striped.

The nestling Rails at the present day are all dusky in colour, yet the young of the Black-tailed Water-hen (Microtribonyx ventralis) shows distinct traces of a median and two lateral stripes.

The Anseriformes, like the Rails, have now typically uniformly coloured nestlings. As a rule the upper parts are dark, the ventral light. But the young of the Mallard and its near allies have the upper parts relieved by light-coloured spots -one over the thigh and one behind the wing, which are obviously discontinuous bands. In many Anatidæ there is a strongly marked superciliary streak, and a streak passing from the lores to the eye, and behind this to the base of the skull, markings which are evidently remnants of an earlier striped condition. The Sheldrakes depart from this type, having a broad dark median band which passes upwards along the neck and invests the whole of the upper part of the head. A dark patch behind the wing gives the semblance of a white streak on either side of this median band. In the Variegated Sheldrake (Casarca variegata) the dark median band expands over the shoulders to form a transverse band. Whether this peculiar coloration of the downy Sheldrake is a modification of an earlier striped condition or a specialised condition it is not easy to say, but it seems probable that the latter is the case. The under parts, as in all the other Ducks, are white. The downy young of Swans and Geese and of Chauna display no markings, and are either pale grey or pale yellow in colour. But the downy young of the more primitive Geese of the Genera Cereopsis and Clophaga have, however, it is significant to note, preserved the primitive striping, and the same is true of the Ducks of the Genus Merganetta, thus justifying the inference that the white spots described in more specialised species are remnants of once continuous bands.

In a number of groups the young are invariably uniformly coloured. But, it is to be noted, these young are all nidicolous; 


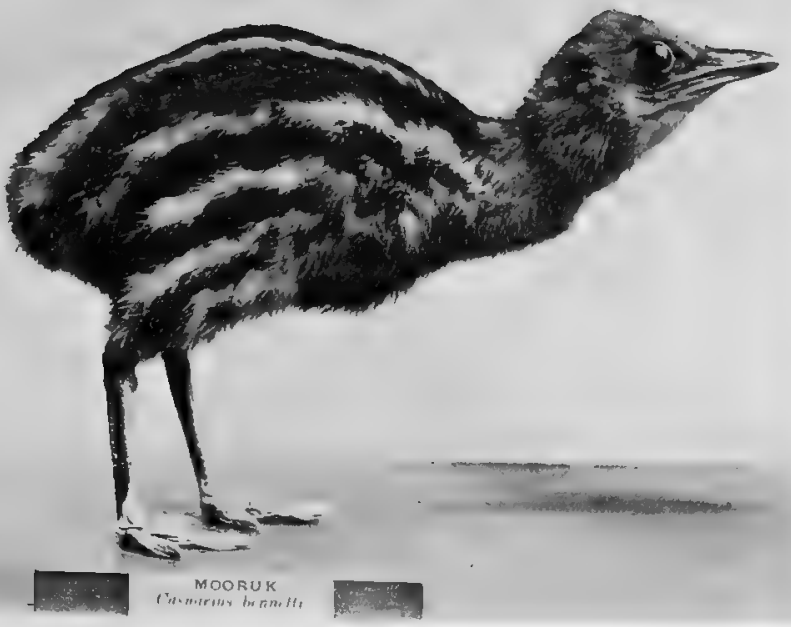

A NESTLING CASSOWARY

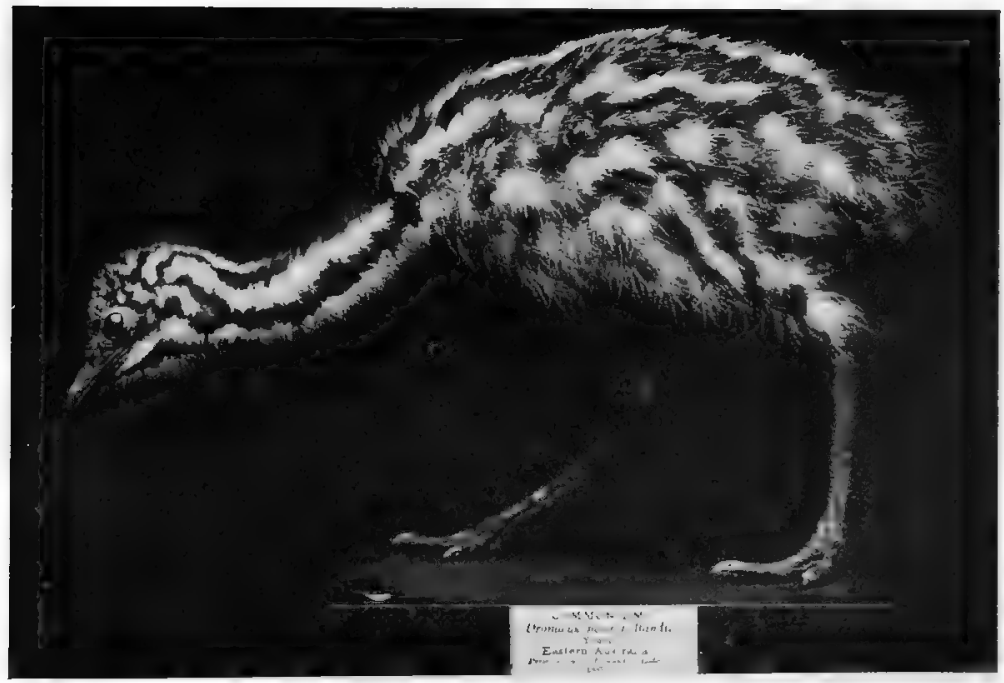

A NESTLING EMU 

and it may well be that these have long since lost the ancestral striping. Many are reared in holes, and in those which lay in open nests the striped pattern of the down would probably afford no protection.

A mong the birds, as in other vertebrate groups, longitudinal stripes do not necessarily give place to a spotted livery, and this to a uniform coloration. In the nestlings of the Emu, Cassowary and Grebe, for example, the striped dress gives place to one without markings, and this again to a patternless plumage in the adult stage. The Game-birds furnish us with two very interesting stages of development. In some, e.g., Quails, the young are striped ; the first pennaceous plumageas distinct from the downy plumage-may be described as a brown or buff colour relieved by various shades of darker brown arranged in the form of streaks, spots and bars. The adult plumage for both sexes is similar. In others, e.g., many Pheasants, the striped downy plumage is succeeded by a dress resembling the immature and adult dress of the Quails. This dress is retained by the female, but in the male is succeeded by a more or less resplendent livery. In other Pheasants, e.g., Eared Pheasants (Crossoptilon), the speckled dress of immaturity is discarded by both sexes for one of more or less brilliancy.

The same order of coloration, which obtains in the life of the individual in one group, is found in another group only in studying the history of the race. This may appear to be only another way of saying that the history of the species is a recapitulation of the history of the race. But in the present connection, it is to be noted, the most primitive species pass through all the possible phases in the course of their growth, while the individuals of the "race" to which we have referred are of comparatively recent origin and have eliminated the earlier phases of development, or have replaced them by new "adaptive" characters. Among the Limicolæ, for example, we find striped forms like the Redshank or the Snipe, mottled forms like the Gulls and Terns and some Plovers, and unicoloured dusky forms like the Skuas and Alcidæ, e.g., Guillemots. In the Terns and Gulls the mottled nestling gives place to a brown first plumage, which is succeeded by a more or less unicoloured adult dress worn by both sexes alike.

Longitudinal markings occur but rarely among adult birds. 
Instances thereof are seen in the Snipe, Avocet, Black-throated Diver, Herons and Bitterns. Now it is worthy of note that in the Snipe and the Bitterns, at least, these peculiar markings are known to be used for protective purposes. The Bitterns when desiring to conceal themselves adopt a perfectly vertical position, throwing the head and neck upwards and holding the body perfectly still so that the dark lines down the neck harmonise with the dark inter-spaces between the reeds which form its cover. The Snipe reverses this position, holding the head downwards and presenting the longitudinally marked back so that the tail points directly upwards.

From the rtiological side it must be admitted we have much yet to learn in the matter of these stripes.

Where both nestling and adult wear a protective plumage, it seems strange that in many cases a distinct livery should be necessary for each stage. But this may be due to the fact that the environment of the nestling is quite different to the normal environment of the adult. The downy young Ringed Plover, for example (Egialitis hiaticula), is almost white with dark mottlings; the adult is buff coloured above, white below, and barred across the head and breast with black. These bars are apparently protective devices, for while the khaki-coloured body is invisible, the dark bars are conspicuous, but they bear a curious resemblance to mussels, the empty shells of which occur on every tide-wash, where these birds commonly feed.

But there is no need to expect a very close connection between the two stages in the life-history, for while in many cases the stripes of the downy plumage may well be ancestral, and, therefore, of extreme antiquity, the plumage of the species is necessarily of more recent origin, and is determined by the requirements of the environment amid which it has developed.

There are yet other peculiarities of nestling birds which demand at least a brief notice in these pages.

The first of these concern the " egg-tooth," which is a small calcareous. conical mass developed on the tip of the upper jaw during late embryonic life, and is used for the purpose of cutting away the shell for the purpose of escape therefrom. As a rule this drops off soon after hatching. In the Ostrich tribe (Palaognathe) the egg-tooth is never so conspicuously 
developed as in the rest of the Aves (Neognathe), and is absorbed later instead of becoming detached.

In the Barbets (Cyanops) and other related forms, and in the Wry-necks-and probably also the Woodpeckers-the "heel" is protected by a curiously roughened pad, which disappears soon after the nestlings leave the nursery. The use of this pad is not quite clear, but it will perhaps be found to be present in the young of all birds which are reared in holes on the bare ground, or in hollow trees, when no real nest is made. 


\section{CHAPTER XVI}

\section{THE LIFE-HISTORY OF BIRDS-AN ECOLOGICAL SUMMARY}

Embryology in outline. No hard-and-fast line between embryonic and post-embryonic characters. Plumage phases. Some puzzling facts with regard to adult characters. The plumage of Thrushes. Signs of maturity. Nuptial liveries. Coloration and its evolution. Moulting. Abrasion phenomena. The age of birds. Mortality. Play of birds.

$T \mathrm{~T}$ is proposed in this chapter to give a general summary of the œcological side of bird-life before proceeding to discuss the retiological-before we attempt to consider the problem of the origin and causes of the evolutionary data so far dealt with.

In tracing the life-history of birds it is the common practice to take up only the post-embryonic portion thereof. But there is no hard-and-fast line to be drawn between embryonic and post-embryonic life, as will be shown presently: though it will be sufficient for the purposes of the present book to give but the barest outline of the embryonic stages ; only such, in short, as bear upon post-embryonic life will be considered.

Briefly, the later stages of development reveal, not seldom, indications of earlier, more primitive structural characters. That is to say, passing phases in embryonic life often represent conditions which obtained during adult life in more remote ancestors. In other words the phylogeny is repeated in the ontogeny-more or less.

Thus in embryology we have, as it were, the mirror of the past, in which we may see in more or less vague procession the several phases through which any given animal has passed in the course of its evolution, while if we follow the same animal through its post-embryonic life we may witness the acquisition of new characters in this life-history, now at one stage now at another. Thus it has been said that every animal during its 
development climbs its own genealogical tree or recapitulates the essential characters of its ancestors as it passes on to acquire those which are peculiar to itself. But this record is notoriously incomplete. Short cuts are often taken, and whole passages are left out. In some cases these gaps appear to be due to the exhaustion of the "stirp," as in the last remaining vestiges of organs, where only enough of the material originally set aside to form that organ now remains to briefly indicate the foundations thereof, and this is later absorbed: in others it may be that the apparent gaps are really so many records of discontinuous variation (p. 29I).

By way of example we may take the case of the developing wing. In the embryo the hand is at first short and the digits, four in number, are enclosed in a web-at least vestiges of a fourth digit remain - while in the wrist more elements may be traced than are to be met with in the adult. Similarly, in the post-embryonic state, the wing of the young chick passes through a stage which was once characteristic of an ancestral adult condition. In this stage there are two free proximal carpals - radial and ulnar - and a separate semilunar mass of bone closely approximated to the bases of the metacarpals which at this stage, though closely apposed, are free. This is but a transitory stage in living birds, but in the ancient Archæopteryx it persisted throughout life. In modern birds this semilunar mass fuses with the metacarpals, while at an earlier stage than that described as corresponding with the Archæopteryx, this distal row of carpals was made up of three distinct elements, while a third-the intermedium - is sometimes met with in the proximal row wedged in between the radius and ulna, as in many reptiles. And so again with the digits. In the Ostrich occasionally, and in the Penguin, each of the digits in the embryo terminates in a claw, while in many birds the thumb and index finger are so furnished. Yet in the adults these claws are generally wanting at least in the index finger. But in the Ducks, for example, and in many birds of prey and in the Water-hens, a claw will be found on both digits. In the aberrant Opisthocomus these claws are large and functional during the nestling period (p. 240), but disappear entirely during adolescence. In the hind-limb of the embryo, similarly, there will be found traces of five digits, while only four persist in the 
adult, and these may be reduced to two, as in the Ostrich. The tarsal or ankle bones also pass during their development through a stage reminiscent of an earlier condition of things. Here the proximal row is represented by a cylindrical mass of cartilage supporting a vertical shaft which is closely applied to the lower end of the tibia. In the old Dinosaurs this mass remained distinct throughout life, in the bird it fuses soon after hatching with the shaft of the tibia. A distal row of carpal bones can be plainly made out in the embryo, but in the chick these fuse to form a tabular mass closely applied to the bases of the tarsals which form three distinct bones. Later these become welded to form a "cannon" bone, and with the base thereof the tabular mass of fused tarsals becomes indistinguishably blended. Thus the ankle joint is "intertarsal," as in reptiles.

In the skull much evidence of a similar kind is to be met with. Basipterygoid processes, or buttresses of bone projecting from the base of the skull for the support of the pterygoid bones, are invariably present among reptiles. In birds they are large only in the Ostrich tribe. Among the more modern types they are small, or absent altogether in adults, yet where not even a vestige in the adult remains traces will often be found in the embryo. Again, though the earliest birds, like reptiles, possessed teeth, these are conspicuous by their absence in modern birds, though traces of these structures are said to be met with in the beak of the embryo Parrot, and tooth-like denticles are met with in the jaws of young Tinamous. On the other hand, recently acquired characters, like the long beak of the Avocet, the flat beak of the Spoon-bill, the crossed beak of the Cross-bill, the serrated beak of the Darter and Gannet, are sought for in vain in the embryo. The long, slender, rod-like beak of the Humming-bird is a quite late development. In the nestling the beak is short like that of a Swift. Similarly, in the Cormorant, Gannet, Pelican and Penguin the external nares have become suppressed, the fossa, therefor, in the skull having become filled up by bone in all save the Penguin; but in the embryo and very young nestling this fossa is as well developed as in normal birds. In Sphenisus only, among the Penguins strangely enough, is there any tendency to similarly close up this fossa, though the aperture in the horny sheath is completely closed in all the Penguins. 
The Long and Short-eared Owls furnish yet another illustration of the recapitulation theory, since in the adult the ears of these birds differ in a most remarkable way from those of all other Owls-or indeed of all other birds-while the embryonic ear differs in no way from those of, say, the Eagle Owls, which are normal. The young Cassowary furnishes a similar

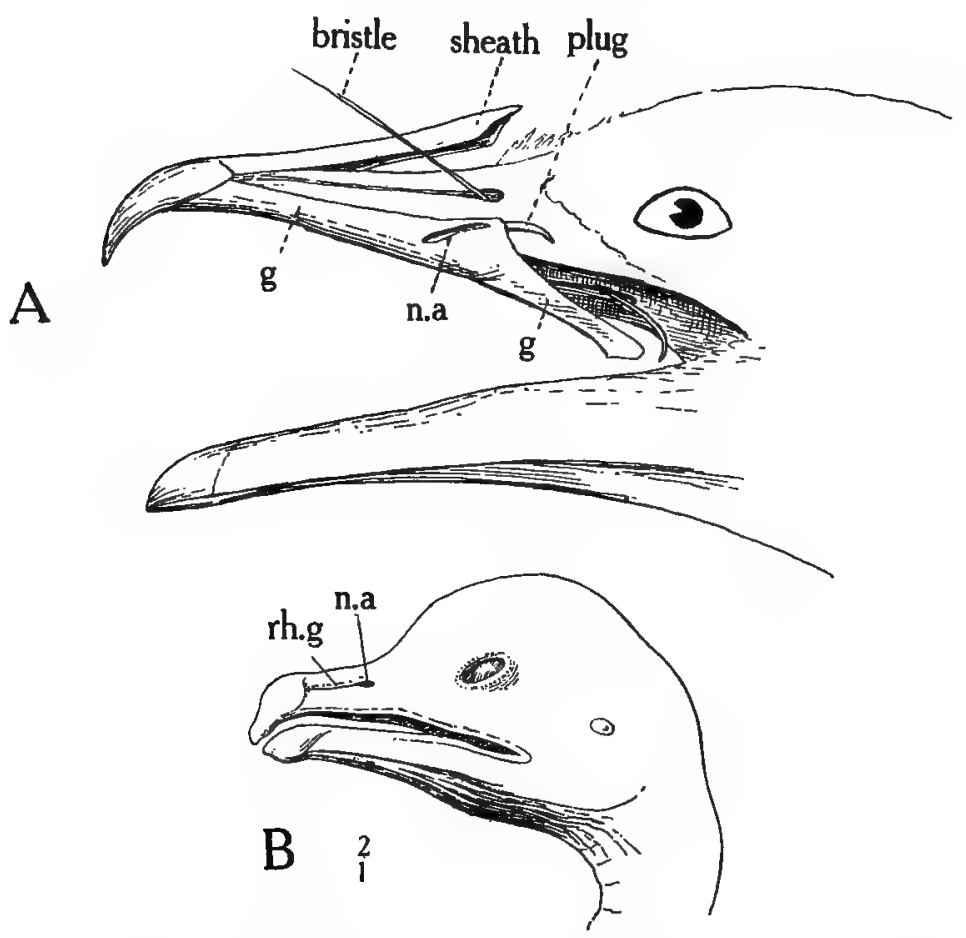

ILL. 30

A, Dissection of the beak-sheath of a Cormorant showing the last trace of the once open narial aperture-a bristle has been passed through to the opening in the roof of the mouth. During life this aperture is closed by a plug, formed by an ingrowth of the bony sheath. In the Embryo (B) the aperture is still open.

example at a later stage of development. This we find in the history of the growth of the curious spine-like quills of the wing. In the nestling these resemble the less degenerate quills of the Apteryx, having a distinct quill and vexillum : later this latter portion is shed while the lower portion, or quill, increases enormously in length, and becomes solid, forming some five or 
six rod-like stalks which apparently serve the purpose neither of use nor ornament.

In the development of the skull again we find in the very young nestling that the squamosal, in the more primitive forms, is a relatively large bone attached comparatively loosely to the skull wall, and finding no place within the skull, thus approaching the reptiles. In the more highly specialised forms the squamosal appears to have slowly absorbed the underlying bones so that before the sutures marking the separate bones disappear the squamosal will be found to have forced its way, as it were, to the interior of the skull cavity.

Though the history of the development of the bird's wing, from the embryonic to the adult organ, shows but few traces of a phase earlier than that seen in the earliest known bird, Archæopteryx, this is not true of the tail. And this perhaps because in Archæopteryx this organ had not yet shaken off its reptilian character, being of considerable length and composed of a series of tapering vertebræ, each of which supported a pair of elongated feathers. As time went on these vertebræ became reduced in length, more especially the terminal members of the series, which to-day make up the "ploughshare" element or "pygostyle" which forms the termination of the tail of all living species. This element in the adult supports the tail feathers, as we shall show presently. In the embryo and nestling it is found to be made up of several separate vertebræ, varying between six and seven in number; but these have now become reduced to mere rings of bone closely pressed together, and recalling the similar reduction of the neck vertebræ in whales. But the tail of living birds has also undergone reduction in number, by the loss of vertebræ from the free end of the tail, since in Archæopteryx eleven vertebræ were concerned in the support of the tail feathers, whereas in modern birds not more than seven - those included in the "pygostyle"-of these remain. The "pygostyle" in the adult is a blade-shaped bone, sometimes developing a disc-shaped plate on its inferior surface -as in the Falcons and Woodpeckers, birds which make much use of their tails, the one as a "brake" in flight, the other as an organ of support in climbing. By the gradual shortening of the bodies of these vertebræ the tail feathers became brought nearer and nearer together, till at last, in place of forming a series of 
paired structures one behind the other, they came to take up a fan-shaped arrangement; a process of evolution which may be compared to the development of the "compositz" flower-head from a primitive "spike".

There is no hard-and-fast line, no set order, in the chain of of these events. Some appear and disappear before the completion of embryonic life; some begin at the close of this period and terminate soon after hatching, while others do not appear till near the end of the nestling period, or at the beginning or end of the adolescent period, while, finally, others are what we call "adult characters". These last, it may have been remarked, seem to be subject to the same laws of growthadolescence, maturity and senility-which govern the body as a whole: the senile character being represented by vestiges, embryonic or adult.

It is obvious then that we cannot regard the embryonic period as a phase of development sharply divided from the post-embryonic, and this is nowhere more evident than among the birds. By way of an illustration let us take the case of the Megapodes. These birds while yet within the shell develop and shed the nestling down plumage characteristic of the Gamebirds to which the Megapodes belong, so that the young emerge from the egg fully fledged, and with the wing quills so completely developed that they are enabled to fly therewith within an hour of leaving the shell.

Of the characters which are peculiar to embryonic life, characters developed solely to serve the ends of development, we need mention here but one or two-the egg-tooth and the em-. bryonic membranes. The former is a small, conical, calcareous body generally loosely attached to the tip of the upper jaw and used by the young bird to break away the shell wall in order to escape therefrom. Soon after hatching this drops off.

The embryonic membranes are the allantois and the amnion. The former is a specially developed sac arising from the gut which, pushing its way outwards, ultimately curves over the embryo to underlie the shell, serving at one and the same time as a receptacle for the urine and a respiratory organ, the latter function being performed by reason of the fact that it is richly supplied with blood-vessels which absorb oxygen through the porous shell. Towards the end of the incubation, when the em- 
bryo is able to breathe by means of its lungs, the allantois shrivels up and is ultimately cast off with the shell: but its narrowed stalk, from the gut to the navel, remains for some time as the "urachus" upon the inside of the body wall.

The amnion is a delicate membrane enveloping the embryo, so that it lies within a closed sac which is filled with fluid, the liquor amniz, whose purpose is to preserve the embryo from injury and pressure, and to permit the free use of the growing limbs.

We cannot, it is contended, draw any hard-and-fast line between embryonic and post-embryonic development, since, as we have already seen, phases of development which in some birds are post-embryonic are in others embryonic. Consequently, the phases usually considered as belonging to embryology are here dealt with as phases in the common life-history (ontogeny) which begins with the fertilisation of the egg.

Concerning embryological characters little is said here, inasmuch as these demand intimate knowledge of abstruse facts that only indirectly concern the theme of this book. But in the course of development birds pass through many stages reminiscent of earlier ancestors, and carrying us back even beyond the reptiles, the stock from which the birds are evidently derived. Thus the presence of gill arches in the embryo must be regarded as survivals of an amphibian stage common to both reptiles and birds. And similarly in the development of organs such as the heart, brain and kidneys - to go no furtherwe have like evidence of pre-reptilian stages.

We may proceed then to review the essential phases of the life-history which are strictly post-embryonic.

The first of these phases is that presented by the nestling, which as we have seen may leave the egg in a relatively advanced stage of development, or in a condition of utter helplessness; while between the two extremes there are many gradations.

The time required to attain maturity varies enormously. Thus some species, as in the Penguins, Albatrosses and Secretary-birds, may remain "nestlings" for many months-the larger Penguins, as the King Penguin, for example, remaining in the downy stage for as long as twelve months; and the 
Albatross would appear to retain this covering for nearly as long a period, while the Secretary-bird does not leave the nest till six months old. On the other hand, the Quails and Hemipodes are fully feathered in about three weeks, while some of the smaller perching birds are sexually mature when six weeks old!

In this procession from the cradle to the grave birds may pass through several phases of plumage. The first of these is downy in texture, and differs in many ways from the later covering of feathers. The precise significance of the downy stage is not easy to grasp. Presumably it represents a somewhat degenerate ancestral plumage. In support of this there is evidence to show that the body covering of Archæopteryxwhich must always be taken as the standard in questions of this kind-was of a loose, semiplumous character, only the wingquills and tail feathers having acquired the characteristic feather-like structure. The absence of these last in nestlings is easily explained by the supposition that development has been retarded for safety's sake until the young birds had acquired the necessary intelligence to fend for themselves, flight being dangerous until then. The young of the Gamebirds alone represent such an ancestral stage, and it has already been shown that in them the power of flight at this tender age is a source of danger. But this comparison is not quite exact, since it would appear that the downy covering of the body in these birds really answers to a later plumage. And for this reason: In the Penguins the typical feathers are preceded by two distinct, successive plumages of nestling down. The first of these barely covers the skin, being almost hair-like in appearance-though microscopically indubitable down featherswhile the second is longer and of a peculiarly "woolly" texture. These last down feathers begin their growth before those of the first plumage have ceased to grow, hence the bases thereof are in direct, organic connection with the tips of the feathers of the second plumage, and in course of time, when these appear through the skin, it is found that each is surmounted by the down feather which preceded it. Similarly, and for the same reason, when: the typical or "definitive" contour feathers appear, they are found to bear upon their tips the down feathers of the second generation. Sometimes all these feathers will be found in direct connection. Among one or 
two of the more primitive Geese, e.g., Clophaga, a precisely similar sequence obtains, but the second generation of down feathers are here of a more typical feather-like structure, showing a well-developed shaft, bearing a number of paired branches or rami. These, later, are succeeded by the "definitive feathers". Now the down feathers of the Game-birds answer to the feathers of the second generation of the Penguin and those primitive Geese. In some of the Tinamous, e.g., Martineta Tinamou (Caladromus elegans), the down feathers yet more closely resemble definitive feathers. Consequently, we may infer that these two generations of down feathers represent degenerate plumages, while in some, or rather most species, one-the first -has become entirely suppressed. This view is the more probable since among the Owls, for example, two generations of feathers precede the typical adult feather as in the Tawny Owl, while in the Barn Owl only one is developed. The down feathers of the Tinamous answer to those of the second generation. In the Megapodes the down feathers of the first generation are extremely degenerate in structure, and are shed before the bird leaves the shell. At hatching it is clothed in feathers of the second generation. From the varying degrees of degeneracy which the feathers of the second generation display, especially among the Game-birds-as in the Turkey and Grouse, for example-we may infer that those of the first generation were of a higher type than in any modern bird, though they probably never attained the perfection seen in the contour feathers of living birds. If this is so, then we have in nestling birds to-day another of the many relics of past conditions which a study of life history reveals. But as yet there appears to be no clue obtainable as to the meaning of this degeneracy in the earlier plumages, unless, indeed, it be that each represents a distinct phase, not so much after all in the structural perfection of the feathers, as of coloration; for it is a curious fact that, as has already been pointed out, and as we shall have occasion to remark again, this nestling plumage, when not of a monotone, is striped or marked with mottlings obviously derived from stripes, and stripes in the plumage of adult birds are rare. Thus it may be that, for reasons not yet apparent, these suppressed down-plumages may represent so many eliminated, because injurious, colour-phases. 


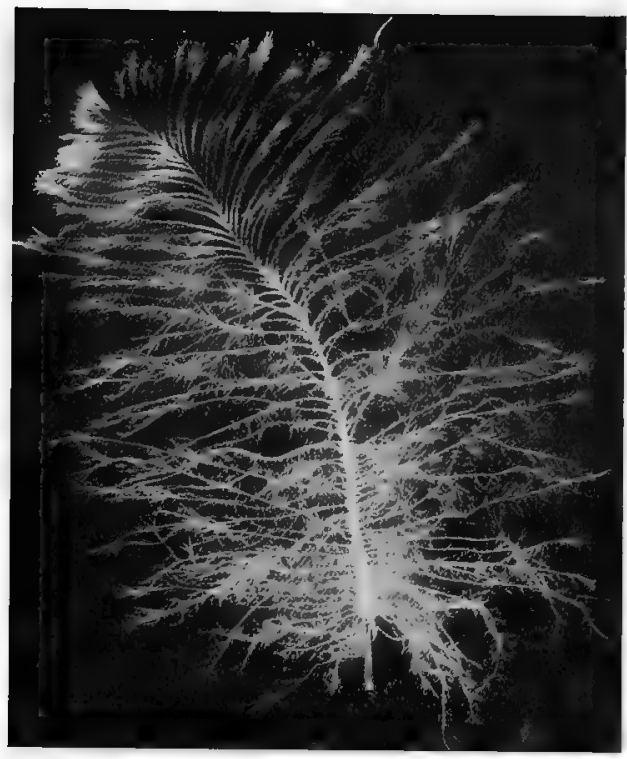

MESOPTYLE FEATHER OF TAWNY OWL

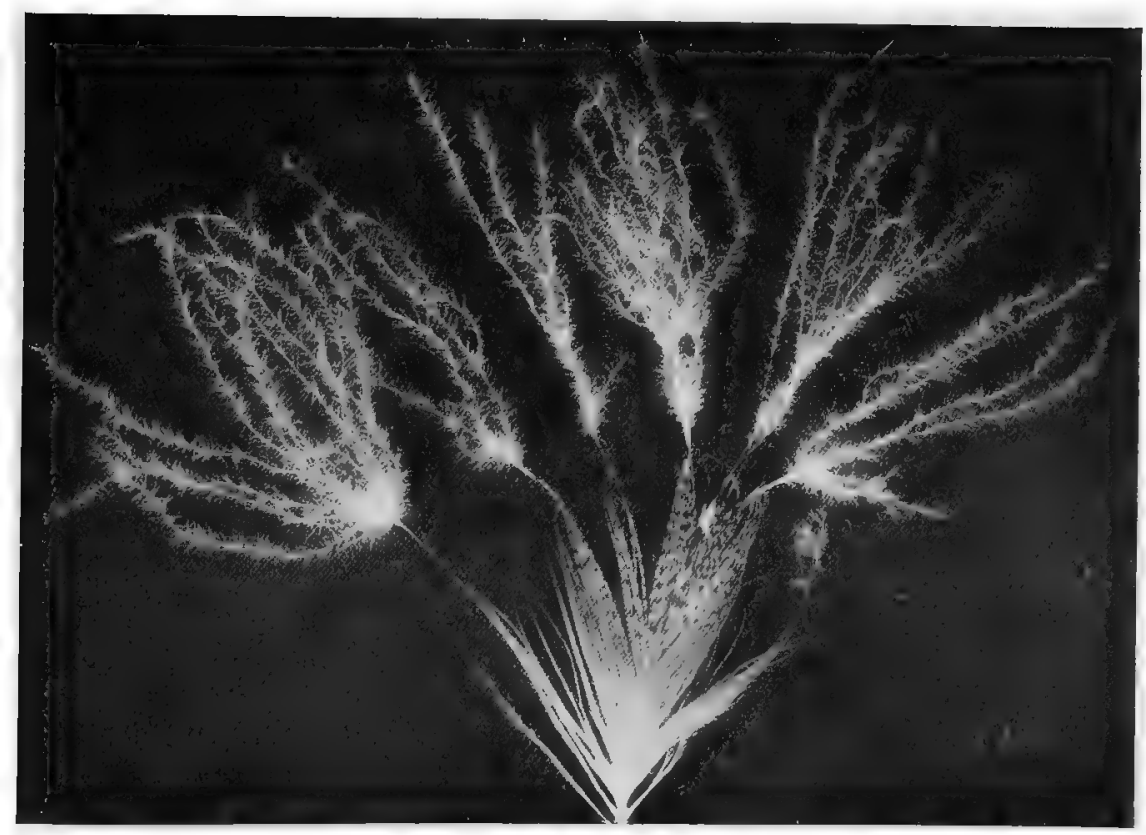

MESOPTYLE FEATHER OF THE BARN-OWL 

The Passerine birds present us with the other extreme of nestling plumage, in that the down feathers are here but feebly developed, or are absolutely wanting, as in the Sparrow and Crow tribe. Young Larks and Wagtails have more down than Thrushes, but this is never developed save in certain restricted areas. That is to say, instead of every contour feather being preceded by a down feather, as in the young of nidifugous birds, only a few have these fore-runners. Thus a row of down feathers occurs over each eye and a few around the back of the head, while a row of downy tufts runs down the scapular tract, and a similar row along the spinal and femoral tracts. But the under-surface is always bare. That this condition has been derived from a more complete covering is shown by the fact that the Lyre-birds alone among the Passeres have a complete downy covering, and these birds represent, probably, the most primitive members of the group. Thus we have, among the Passeres, every gradation from a thick, woolly covering to absolute nakedness, and the specialisation in this matter runs hand in hand with specialisation in other particulars.

The passage from the downy to the feathered stage is often very gradual, as may be seen, for example, in the young of Game-birds, where the head and neck, the middle of the breast and the lower part of the back retain their down until after the rest of the body is clothed with typical feathers.

The first plumage of true feathers is instructive. Where the sexes of the adults differ in coloration the young resemble the female, though this resemblance may be only very approximate. On the other hand, as in the Koel (Eudynamis orientalis) -a Cuckoo-and in a Starling (Amydrus blythi) the young of both sexes wear the plumage of the male, the females later assuming the dress characteristic of their sex. The adult female, in the case of the Koel, it may be remarked, is brown, the male black; while in the Starling the female is glossy black with a pure grey head and neck, the male entirely black. So that, while in the case of the Cuckoo the female apparently retains an ancestral livery, in the Starling the female would seem to have assumed a more highly specialised, resplendent livery, independently of the male, unless indeed this female dress represents an earlier male dress. Where the adults of both sexes are similarly coloured the young either differ from both parents, 
as in the case of the Starling, and the Gulls and Gannets, or they don a livery differing from that of the parents only in a lack of brilliancy, as in Kingfishers and Crows, for instance. But, in rare cases, the young may even be more brightly coloured than the parents, as for example, in the case of many of the Warblers. In this connection it has been pointed out by $\mathrm{Mr}$. J. L. Bonhote, that the young of many of the Wading-birds (Limicolæ) tend to reproduce the rich colours of the adult breeding dress, instead of, as might be expected, the duller colours of the winter dress. But to this point we must return later. So far attention does not seem to have been specially drawn to the fact that features peculiar to the summer or breeding dress of one species may be reproduced by an allied species only during its immature stages, as, for example, in the case of the "hood" of the Black-headed Gull (Larus ridibundus), which is worn only by this bird for a few weeks preceding and during the nesting season, and is therefore a certain sign of maturity; while in Scoresby's Gull (Leucophaus scoresbii) it is as certainly a sign of immaturity, since it is worn only by young birds in their first year. Underlying these facts, however, are certain others for which no explanation is forthcoming at present. Briefly they are as follows: The Black-headed Gull (Larus ridibundus) when immature has, among other characters, a dark subterminal bar across the tail, and in the adult a wholly white tail, with, as we have remarked, a brown hood during the breeding season. In the Large-billed Gull (Larus crassirostris) of China and Japan the adult has a dark subterminal tail bar and a white head throughout the year, but the young have the head striated to form a more or less distinct hood. This last character is recalled in the winter dress of the Herring-gull (Larus argentatus) and appears again as the summer dress of the Common Gull (Larus canus), though the streaks are sparse, and cannot be said exactly to form a hood in these two birds.

Similarly, among the Cormorants we find that the Common Cormorant (Phalacrocorax graculus) in its breeding plumagewhich is assumed in February and lasts till May-develops a crest and a white throat, white filoplumes on the neck and a white patch on the thigh. But in the closely allied Shag, in the nuptial dress-which is also worn from February till May- 
white feathers are wanting, but a white throat band is assumed after the nuptial dress is discarded.

The crimson patches in the plumage of our British Woodpeckers is, in this connection, no less interesting. Thus, in the Great-spotted Woodpecker the male-there is no special nuptial dress-has a crimson nape, while the female has no such badge. But young birds of both sexes, in their first year, have a patch of red on the crown. In the Lesser-spotted Woodpecker the male has the crimson on the crown instead of the nape, while the female has white in place of the crimson. The young birds, however, resemble those of the Greater-spotted species in having the crown crimson, though in the females this colour is confined to the forepart of the crown. Finally, in the Green Woodpecker the crown and nape feathers are crimson in both sexes, though this colour is less vivid in the females; while in the young birds crimson appears only on the tips of the occipital feathers.

From this it would seem that in the life-histories of these three species we have an insight into a very interesting phase of evolution, one in which a character, probably first acquired by the male, has become, as is so often the case, transferred to the female, and to the young of both sexes. The Green Woodpecker serves as a case in point, but here the female and young birds have as yet only imperfectly assumed this feature. The evidence seems to show that the two first-named species in like manner assumed the vivid colour patches of the male which were transmitted both to the adult female and to the young. Later, apparently, evolution favoured the development of a differentiation between the sexes which is being acquired, or being transmitted, perhaps we should say, to the young females, inasmuch as these in the Lesser-spotted species now have the red confined to the forepart of the crown. Furthermore, the crimson crown was apparently common to adults of all three species. To-day the Greater-spotted species has reduced this colour to a patch on the nape, while, as we might expect, the young birds still pass through the originally adult condition. Thus the colour, in its evolution, is acquired first by the males, then by the females, and lastly by the young, possibly beginning with the young male. And as the young are the last to acquire new characters, so they are the last to lose old 
ones: and by this token we are often enabled to trace relationships between forms which may, in adult life, show no very great similarity.

No better instance of this can be found than that afforded by the young of the Thrush and Flycatcher tribe where the young are invariably spotted, while the adults are for the most part whole coloured above, save among a comparatively few species, e.g., Thrushes of the Genus Geochichla, the adults of which are also spotted. These last, then, we may assume, represent the older type of coloration once common to all the species of these groups but now reappearing in the more specialised species only during the earlier stages of the lifehistory. By way of corroboration we find that it is only among the species which are spotted when adult, species which have never lost the primitive type of coloration, that vestiges of basipterygoid processes appear in the skull. These processes are heritages from reptilian ancestors, and are largest in the most primitive groups, e.g., Ostrich tribe.

The Thrushes and Flycatchers are, however, not alone in passing from an immature spotted to an adult whole-coloured plumage. A striking example of this fact is furnished by the Common Gannet, wherein the first teleoptyle plumage is of a dark-brown colour heavily spotted with white, while the adult dress is pure white tinged with buff on the head, and neck. Here, however, though the spotted plumage may, and probably does, represent an earlier adult livery, there is no evidence at present which would justify the assumption that this spotted livery was once common to all the Gannets, inasmuch as all the other species of this Family when immature are whole coloured and dark.

A striped plumage no less than a spotted, when it appears in immature birds, must, it would seem, be regarded as a heritage from originally striped ancestors, and because, in so many cases, these stripes are later replaced by transverse bars. This has long been recognised in the case of the diurnal birds of prey, for example. Thus, in the Falcons young birds have the under parts conspicuously striped with broad longitudinal lines, while in the adult these give place to transverse barrings.

The period of adolescence can be measured only, in the case of birds, by the differences in plumage between the 
immature and adult liveries, and consequently, wherever this livery is assumed early, all trace of the age of the wearer is lost after the first autumn. When, as so often happens, the young assume the livery of the parents at once, e.g., Corvidæ and Kingfisher, they can only be distinguished by the lack of gloss and brilliancy. Thus, although for general purposes we assume that the characteristic full plumage is a sign that adult life has been attained, this is not necessarily always the case. Many of the Gulls, for example, take at least three years to attain the full dress of the species, the change from the "immature" to the mature dress being. made by almost insensible gradations; similarly, the birds of prey are known to take several years in arriving at maturity.

Sexual maturity can no more be regarded as an index of physical maturity than the plumage, for with birds, as with many other animals, reproduction often begins before the fully adult condition has been reached, e.g., Golden Oriole, Black Redstart, Night-heron, Tantalus Ibis.

Maturity attained, in a large number of species two sharply distinct liveries are worn during each year, and these are generally, but not always happily, described as the "summer" and "winter" plumages. More correctly the "summer" dress is now designated by many the "nuptial" dress, since it is assumed prior to, and worn during the breeding season. In cases of this nature both sexes alike very commonly assume these wedding garmer ts, though the male is usually distinguishable by the greater vividness of his colours ; in many instances, however, only the males don this distinctive dress. The Wading-birds present instances of both kinds. Thus in the Dunlins, Knots, Godwits and the Grey and Golden Plovers, and the kindred Auks, Guillemots and Puffins, both sexes put on this characteristic dress, while in the case of the Ruff (Machetes pugnax) only the male is so distinguished. Among the Gulls, however, many species adopt no special change. But the Plover tribe, it is hardly necessary to say, are by no means the only birds which assume a special nuptial plumage, and there is neither reason nor space to enumerate all those which display this phenomenon.

But a very striking case of this sequence of plumages is seen in the Scarlet Tanager (Pyranga erythrumelas), wherein 
the young of both sexes, in their first teleoptyle plumage, are of a greyish-fawn colour streaked with a darker shade; while the adults in "winter" plumage are green, the male being distinguished by his jet-black wings and tail. But in the spring he assumes a nuptial dress wherein the whole body, save only the wings and tail, which retain their black hue, takes on a rich crimson colour.

Herein is a case wherein the male, female and young are all different, though in the winter dress the adults differ mainly in the colour of the wings. But, here, as in other cases, the very old female shows a tendency to assume the livery of the male, her plumage taking on an orange hue, and the wings becoming more or less black, while the young, in their first autumn, by a moult acquire a distinctly greenish colour, resembling that of the female. Thus, in course of time, are ancestral plumages dropped and new liveries assumed, the male being the first to change, then the adult female, then the young male which resembles the female in her approximation towards the livery of the male.

With profit we may briefly summarise the several phases in the evolution of this plumage, since these seem to show that current notions on the question of "summer" plumage need revision.

These phases seem to fall into five main groups, and to show that the ancestral plumage was longitudinally striped, this later in time giving place to a dull brown or buff-coloured livery relieved by darker markings.

The phases repeated to-day-neglecting nestling plumages -are briefly as follows:--

I. A dull brown plumage worn by both sexes throughout the year.

2. A dull brown plumage worn by both sexes throughout greater part of the year, but replaced-generally in the males alone, but often in both sexes-by a decorative plumage assumed just before and worn during the breeding season, and hence, generally known at the "summer" dress. More properly it should be called the "nuptial" dress. The Limicolæ, Tanagers and Weaver-birds (Ploceince) furnish the best instances of this kind.

3. A dull plumage worn till after the first moult by both 
sexes, succeeded by a decorative dress worn by the males only during the greater part of the year, as in most of the Ducks. The Game-birds belong to this section, or rather have just emerged therefrom, some species, e.g., Blackcock and Jungle Fowl, retaining traces of the fleeting, dull plumage on the head and neck only.

4. A dull plumage worn by both sexes till after the first moult, and then succeeded by a decorative plumage worn throughout the whole year, e.g., Starling.

5. A decorative, brilliantly coloured plumage assumed on leaving the nest, without any preceding dull dress, as in Parrots and many Kingfishers.

Thus then we have a series of ascending phases terminating in a brilliantly coloured, permanent livery. As might be expected, in each of these groups we find exceptions to the rule, though these exceptions, far from tending to confute these arguments, tend rather to lend them weight.

Certain periodic or "seasonal" changes of plumage, which are generally regarded as especially protective in character, stand a little apart from the cases just described. The first of these is that of the so-called "eclipse" plumage of the Ducks, a name very appropriately coined by the celebrated Charles Waterton. And this because the male, as soon as his expectations of a family are realised, that is to say, in June, doffs his coat of many colours and puts on a livery very closely resembling that of his spouse, and so closely that it takes an expert to distinguish the sexes at this time. Now it is believed that this dress has been adopted to secure to him for a season the same measure of protection from prowling enemies that this sombre garb assures to the female, whose life is important at this time on account of her family. This protection he requires because of the fact that the annual renewal of the quill or flight feathers takes place, not by the substitution of new feathers for old in pairs, but by the loss of the whole series at once; so that, until the new feathers have completed their growth, he is helpless, or at most can escape only by swimming - a refuge of no avail when overtaken on land, and equally unavailing when overtaken on the water by such birds of prey as the Eagle. Hence it was supposed that this "eclipse" plumage was an interpolated plumage, brought about by the agency of natural 
selection, whereby the bird might, by its more sombre hues, escape these dangers until the power of flight returned again.

A closer examination of the facts, however, serves to show that this interpretation must go, or must at least be largely modified. It would seem that this "eclipse" dress, worn for some few weeks only, answers really to the "winter" plumage or postnuptial dress of the Limicolæ, for example. In the two groups the period of the two liveries is reversed then. That is to say, the bright colours of the one are donned for a very few weeks only, and discarded for a more sombre garb, worn during the rest of the year; while in the other they are worn during the greater part of the year, so that it is the dull garb which is evanescent. In short, the differences between these two groups are really two phases, two links in the chain of the evolution from a dull to a brightly coloured plumage, the latter tending more and more towards persistence until it becomes permanent, the older, dull plumage, appearing only in the young, and finally becoming eliminated from the life-history altogether, as in the Parrots and Kingfishers, for example. Even among those groups which have acquired a permanently brightly coloured plumage remains of the older, dull plumage still persists, appearing for a season during the annual moult. Thus in Gallus the neck-hackles are for a time discarded, and similarly in the Blackcock, during the late summer, the head and neck puts on a dull brown covering, to be replaced immediately by the normal colours. That the head and neck should be the last to put off the final relics of the older, dull-coloured plumage is interesting, since here too the last traces of the down plumage remain while the rest of the body is fully feathered. That the "eclipse" plumage of the Duck is protective is highly probable; and but for the need for some such protection it is also probable it would have been eliminated altogether.

Much light will doubtless be thrown on the problems of this evolution of plumage when more material has been collected on the subject of moulting among birds. At present our knowledge of this subject is of the most meagre description.

That birds from time to time renew their plumage by the process known as moulting is matter of common knowledge; and in this periodic change of raiment they agree with the amphibia, reptiles and mammals. But it is not so generally 
known that whereas in many birds this ecdysis takes place but once annually, in others, a second, more or less complete change of feathers take place during the year; while in some exceptional cases even a third moult may take place.

It is highly probable that among the more primitive birds three or four moults annually were the rule; and that the number became reduced as the feathers gained increased perfection and ability to withstand the wear and tear of life. Moreover, the development of new feathers entails a serious drain on the system, to which domesticated birds, at any rate, not infrequently succumb.

So far as the known facts go, it would seem, and this is significant, that birds which have reached, approximately, their maximum in the matter of brilliancy of plumage, moult but once annually; as, for example, in Kingfishers, Parrots, Passerine birds; the Swans and Geese among the Anatidæ; the Gulls among the Great Plover tribe; the Cranes and Bustards; the Birds of Prey; Steganopodous birds and Storks, Petrels and Struthious birds. This list of course might be greatly extended, though, doubtless, many exceptions will be found on further investigation to have been included in those given herewith.

Where this maximum has not been reached, the more or less gaily coloured dress is exchanged for a longer or shorter period for a duller dress, which is assumed by a moult.

Since, whatever the number of moults, the quills are shed but once annually, two kinds of moult are distinguished-complete and partial. The former takes place after the breeding season, but the period of the latter is not so fixed. As a rule, it takes place just before the breeding season, when a special nuptial dress of bright colours is assumed, as in the case of a large number of the Plover tribe. Among the Ducks, where the sexes differ in plumage, both sexes undergo the usual complete moult after the breeding season, the new plumage in both being dull. In the autumn, however, the male assumes what answers to the "nuptial" dress of the Plover tribe, as we have already remarked, and this does not appear to undergo any heightening of colour as the critical period of courtship begins. But in many brightly coloured species which now have but a single, post-nuptial moult, a very pronounced brightening up of the plumage takes place in the spring, not, however, be it 
noted, by moulting, but by shedding the tips to the feathers, and also the outer surface of the barbs and barbules, as in the Linnet, Chaffirch, Brambling, House-sparrow and Snow Bunting, for instance (p. 284).

In these birds the feathers assumed at the autumn moult have long brown or grey tips, as the case may be, which impart to the bird the sober colours of winter. If the plumage be carefully examined, however, the greater part of the feather will be found to present the colours characteristic of spring, but dulled. As the breeding season approaches these dull-coloured tips are shed, thereby exposing the surface previously overlapped. These tips, in short, have served the purpose of a "dust-cloak," keeping the spring dress clean during the winter months, and so saving a new dress!

So far, it would appear, a double moult is mainly-and perhaps we shall find always, when we arrive at a correct interpretation of the facts-confined to those species which assume alternately a dull and a brightly coloured livery. Further, as we have already hinted, the facts seem to show that there is a tendency to eliminate the dull-coloured phase of plumage, as may be seen in the Ducks, which put on what answers to the "nuptial" dress of the Plovers in the autumn, wearing the dull plumage for a few weeks only.

On the assumption that the double moult is a primitive character-and this seems tolerably certain-it is curious that, in species where the males develop alternately a dull with a multi-coloured plumage, the males alone seem to go through this double moult.

A very definite order in the succession of the new feathers is met with, an order which will probably be found to differ with different species. As to the variations thereof we know little enough. Whether this order corresponds with the original appearance of the feathers in the assumption of the first plumage remains to be seen; but, as a general rule, it would appear to do so, except, at any rate, in so far as the quills are concerned. Even here, however, this rule is followed by the Ducks, Rails and Grebes where the quills are shed all at once, leaving the birds for a time helpless as to flight. Selection, however, has in the majority of birds brought about an arrangement whereby the power of flight is retained throughout the 
year, the quills being shed and renewed in pairs. This method of renewing the quills is best illustrated perhaps by the birds of prey. Owing to the need of preserving absolutely unimpaired the full powers of flight, the work of renewing worn-out feathers is spread over a long period, almost the whole year, in fact. In Pigeons the renewal of the quills appears to take about six months. "About Ioth May," says Headley, "the tenth of the eleven primaries counting from the outermost is lost. A month later the ninth goes. By that time the tenth has grown nearly to its full size; when the ninth is about half its proper length the eighth falls; the others follow at intervals of from eight to fifteen days." The tail feathers being of considerable importance are similarly moulted in pairs. The first to go are those on either side of the central pair of the twelve which make up the complete tail series. When the new feathers are about threequarters grown the central pair are shed; then follow the third pair, counting from the centre outwards, next the fourth, then the sixth or outermost pair, and lastly the fifth pair. As to the order of the coming of the rest of the plumage nothing seems to be known! The order of the ecdysis of the "quills" among Passerine birds has been very little studied. In the Australian Piping Crow (Gymnorhina tibicen) this matter was made the subject of an elaborate monograph, wherein it was shown that the quills are moulted in pairs, and in a very definite order, the primary quills moulting from the wrist outwards and the secondaries from the wrist inwards.

But as to the moulting of Passerine birds generally, ridiculously little is known, and for most of our knowledge of this subject we are indebted to the labours of an American Ornithologist-Dr. Dwight. Of the vast number of species included in this group observations have been recorded on a few small groups only. Thus, among the Warblers the Blackcap (Sylvia atricapilla) is said to moult but once annually, while the Garden Warbler ( $S$. salicaria) and the White-throats ( $S$. rufa and $S$. curruca) are commonly believed to moult twice. The Buntings (Emberizida) again seem to show similar differences, some species changing their raiment once, some twice, annually. If this is true it will be interesting to see whether, for instance, a dull-coloured species, like the Corn Bunting, belongs to the first, and the Yellow-ammer (E. citrinella) to 
the second category. The Larks moult but once, the Pipits and Wagtails twice annually, the quills, in all cases, as we have remarked, alone excepted.

Litfle indeed appears to be known as to the order of the moulting of the body feathers in any group. But in the Ducks, for example, the feathers of the wings are the first to be renewed, next flanks and under parts, then those of the lower part of the neck and back, and finally of the head and neck, and this applies not only to the renewal of the adult dress but to the appearance of the feathers in the young birds, as may be seen by studying the changes which mark the assumption of the nuptial dress. These begin to be apparent during the middle of August and are completed by the end of September, or early in October. The new feathers, by the way, appear one or two at a time among those of the plumage which is being replaced, not in uniformly affected patches.

The appearance of the feathers of the first teleoptyle plumage of young birds appears to follow the same order successively in the same areas as the later plumages. In the Game-birds, for instance, the head is the last part to assume feathers, being still down-clad while the rest of the body is fully feathered. Whereas the adults undergo an autumn moult the young would appear to effect a similar change, often then assuming the adult livery. And in the case of males of brightly coloured species, as in the Pheasant, for instance, the striking differences in the two plumages-first and second teleoptyle plumage-well shows the order in which the feathers of the new dress appear.

Here again, as in the assumption of the first dress, the head and neck are the last to acquire the new feathers; the flanks, wings and tail the first. But, as we have already remarked, the facts recorded from observation on this head are of the most meagre description.

Among the Passerine birds it would seem the first plumage is shed within from thirty to forty days after its development, at about the time of the annual moult of the parents. The Accipitrine birds keep their first plumage, according to $\mathrm{Mr}$. Headley, till the next summer. But anything like a general knowledge of what obtains in this matter among the different groups is wanting. 
Finally, there remain two or three curious facts concerning moulting and feather growth requiring further investigation.

It is stated that in birds which have not paired the moult is considerably delayed - that is to say, the period between the moults is increased; and it is believed that by some means of arresting the moult discovered by the Japanese, the shedding of the tail feathers of a certain breed of domesticated fowl is retarded until the central feathers attain a length of from seventeen to eighteen feet! This bird, which recalls the wild Jungle Fowl (Gallus bankiva), is very carefully tended, and for the greater part of the day is kept tethered to a high perch to prevent injury to the feathers. Once a day at least the birds are taken down for exercise, and the precious train is gathered up and carefully wrapped in tissue paper to prevent damage. A failure to fulfil the autumn moult probably accounts for the so-called "hairy" Water-hens that from time to time occur in the country. The "hairiness" of the plumage would appear to be due to the wear and abrasion of the feathers from long use.

This same question of wear and abrasion, however, requires further investigation. As we have already remarked (p. 274), certain birds undergo in the spring more or less of a transformation in the coloration of the plumage assumed in the autumn. Since this change of colour makes its appearance more or less suddenly it would appear that something more than mere wear and tear is to be sought for. The feathers concerned in the change which results in the rose-pink of the Linnet's breast and the black throat of the House-sparrow, for example, will be found to have shed the tips of the rami at a perfectly definite point, so that the feather as a whole preserves a rounded tip, though now appreciably reduced in length.

Captive Linnets, it should be noted, for some mysterious reason do not thus become red, save in cases of birds caught just after the autumn moult. In the spring such birds assume the normal colours proper to the season, but these never appear after subsequent moults in captivity. In Madeira, on the other hand, the red colour is worn throughout the year by wild birds. The spotless and glossy plumage of the Common Starling is similarly acquired by "abrasion," which produces the long, 
pointed feathers of the breast and neck. At any rate, by this tendency of the feathers and autotomy at a certain definite period, revealing at the nuptial season a hitherto concealed "nuptial dress," the necessity of a weakening and dangerous moult is obviated.

We may have a clue to the mystery in the abrasion phenomena which obtains in such birds as the Curlew or the tail feathers of the Duck, for example. Here, as in the long inner secondaries of the Curlew, the pale-coloured areas of each feather drop away just before the annual moult sets in. The darker central areas are unaffected, and hence the edge of each feather ultimately assumes a peculiar jagged appearance. It would seem, therefore, as though the increased pigmentation was
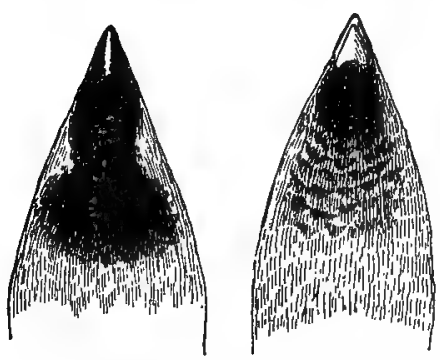

ILL. 3I.-THROAT OF HOUSE-SPARROW Showing the Difference ProDUCED BY ABRASION BETWEEN THE "WINTER" (RIGHT-HAND) AND "SUMMer" (LEFT-HAND FIGURE) Plumages correlated with increased wearing powers. Thus, if the normal life of slightly pigmented feathers is, say, six months, by an increase in the quantity of colouring matter, the lasting powers of the feathers are extended, and in some way secure the bird against the necessity of a double moult. The less pigmented portions fall off at the end of the normal life of the feather, say, six months; while the more vividly coloured would appear to retain vitality longer, and so delay the stimulus to moulting.

While there can be no question but that the vast majority of birds which assume a nuptial dress do so through the agency of moulting, it is stoutly maintained by many that a considerable number of species assume the nuptial livery not by moulting but by the infusion of pigment into feathers till then uncoloured. Thus the brown hood of the "Black-headed" Gull is supposed to be acquired. According to Gatke the dark pigment appears first at the edges of the feathers and gradually extends.inwards until the whole feather is darkened. The black breast of the Dunlin is said to be acquired after a similar fashion, but as a matter of fact it is not, but is acquired by moulting. 
But this ecdysis is not necessarily confined to the feathers, for in some species the beak-sheath is partly shed periodically, and in others the claws are similarly renewed. In the Common Puffin, for example, after the breeding season, a pair of plates on either side of the beak are shed, together with a pair of conical horny spurs which are developed on the rim of the upper eyelid. The White Pelican (Pelicanus erythrorhynchus) of North America bears during the breeding season on the ridge of the beak, in the male, a curious, horny, laterally compressed, and roughly triangular excrescence. At the end of the breeding season these growths fall off, and may be gathered by the bushel in the nesting colonies of the species. Some of the Grouse, e.g., Red Grouse, shed the claws of the toes. These claws attain a great length during the winter-possibly to assist in supporting the weight of the body when on deep snow, but they are replaced later-in the breeding season-by short claws.

As touching the age to which birds live but little can be said, for but little is known. From observations made on birds kept in captivity it would seem that some species are extremely long-lived. Thus a White-headed Vulture is said to have lived I 8 years in the Zoological Gardens at Vienna. An Eagle Owl in the possession of Mr E. G. B. Meade Waldo lived ninety years in captivity; and at fifty began to lay eggs, rearing young from this date onwards till within a year or two of death. The Magpie has been known to live twenty years in captivity; while many of the smaller Passeres have died, apparently, at the ripe old age of sixteen years. Parrots are said to live 100 years, Ravens 200. The Common Gannet takes five years to reach maturity, and probably some of the Gulls take as long. The Eagle probably reaches roo years, taking ten years to reach maturity. But there are no external signs by which we can judge the age of wild birds after once the adult plumage has been acquired.

In rare cases it is believed the intensity of the colouring of the egg may prove an index as to the age of the bird which laid it. The late Professor Newton cited the case of a Golden Eagle, whose history was known, in this connection. He had, in his collection, a number of eggs of this bird laid during twelve successive years, and these show a gradual increase, followed by a gradual decline, in the intensity of pigmentation. From 
this we might infer that this species at say from fifteen to twenty years has become worn out and shortly afterwards dies; since among the lower animals the exhaustion of the reproductive period is more or less speedily followed by death, a necessary sequence to prevent the competition of the now useless-to the species-individuals with the younger and fruitful members. But it is known that the Eagle is a long-lived bird, attaining an age of from sixty to one hundred years, and requiring, according to some authorities, ten years to reach maturity. So far then, the value of the pigmentation of the shell, in so far as it concerns this species, does not seem to be of any very reliable character, though it must not be forgotten that this calculation is based on a single instance. But it is doubtful whether in any case it will ever prove of value.

So far, then, once the adult plumage has been assumed, there is no possibility of estimating the age to which a bird lives, save the rough index afforded by the number of young produced annually by each species.

Though but few of us realise it, the death-rate among birds is a very high one, and is especially high during the first few weeks of life, as we shall show presently (p. 288). So then, for any given species to maintain itself one of two courses must be followed. The members thereof must annually produce a large number of offspring during a few years and die; or they must live long and produce annually but few offspring. It has been calculated that, at the lowest figure, the life of the Golden Eagle is sixty years, and that it will retain its reproductive activity for fifty years. During this time, of three nestlings produced annually by any given pair more than two will rarely, if ever, leave the nest; so that, estimating the number of young which they succeed in launching on the world during fifty years at a hundred, not more than one pair will arrive at maturity! The fecundity of a species is an approximate index of its longevity in short; while the estimated longevity and the number of young produced annually give a rough index of the mortality which any given species has to provide against.

Few grasp, probably, the huge numbers of the birds which die violent deaths, compared with which the inroads made by disease are insignificant, while death from senescence is probably rare indeed. 
Let us lift the veil on a few scenes where Death is at work among the nurseries of the bird-world.

The most striking of all is that presented by the Emperor Penguin of the Antarctic. For the remarkable facts a study of this bird has revealed, we are indebted to Dr. E. A. Wilson, one of the naturalists who accompanied the Discovery Antarctic Expedition of Igor.

These birds perform the work of incubation, strange as it may appear, during the Antarctic mid-winter, forming, for this purpose, vast colonies on the sea-ice, and as the brooding birds are at this time in excellent condition, Dr. Wilson observes, "it is obvious that the same bird does not sit on the same egg for seven weeks". And he continues: "It would appear that the incubation is carried out, not by one bird only, or by a single pair, but by a dozen or more, which stand patiently waiting round for a chance to seize either a chicken or an egg as the post of incubator becomes vacant: every adult bird, both male and female, in the whole rookery has a desire to sit on something. Certainly not more than one egg, and so one chicken, is produced to every ten or twelve adults, though why this should be the case is more than one can say; possibly it is a condition of things evolved in an exacting climate to allow each adult to obtain sufficient food through so long a period of incubation.

"Not only do the barren females take their turn with the hens that lay the eggs, but the male birds also help, and so every individual ... has the same bare patch of skin in the median line of the lower part of the abdomen against which the egg is closely held for warmth. What we actually saw, again and again, was the wild dash made by a dozen adults, each weighing anything up to ninety pounds, to take possession of any chicken that happened to find itself deserted on the ice. It can be compared to nothing better than a football 'scrimmage' in which the first bird to seize the chicken is hustled and worried on all sides by the others while it rapidly tries to push the infant in between its legs with the help of its pointed beak, shrugging up the loose skin of the abdomen the while to cover it. Although the transfer of the egg was never actually seen, there is every reason to believe that when the sitting bird feels hungry it hands over its treasure to the nearest neighbour that will undertake the duty of incubation. 
"That no great care is taken to save the chick from injury is obvious from an examination of the dead ones lying on the ice. All had rents and claw marks in the skin, and we saw this not only in the dead but in the living. The chicks are fully alive to the inconvenience of being fought for by so many clumsy nurses, and I have seen them not only make the best use of their legs in avoiding so much attention, but remain to starve and freeze in preference to being nursed. Undoubtedly, I think that of the 77 per cent. that die before they shed their down, quite half are killed by kindness. . . ." So overmastering is this parental instinct that birds having neither eggs nor chicks will persistently endeavour to coax a frozen infant into a comfortable position between its legs, in a vain endeavour to nurse it back to life!

With the Adelié Penguins the struggle for life among the chicks is hardly less severe though it begins later and takes a different form, whereby, as Dr. Wilson remarks, one may see exemplified in a direct and indisputable manner the far-reaching law of the survival of the fittest, "the cruelty, the pathos, the humour, and yet the admirable perfection of the whole system being irresistibly brought home to the observer.

"The sooty-grey young ones in the third week in January were almost as big as their parents and quite as active. Of these young birds there were literally thousands, and all were hungry, many very hungry. Moreover, each individual chicken acted upon the assumption that every old bird, as it came from the shore, was full of shrimps. On this assumption it had no choice but to run the gauntlet. Chased incontinently... by the unfortunate infants, the fond parent ran hither and thither with a keen eye for the chicken it had once called its own. Driven at last to bay, it could only turn to swear and silence its persecuting followers, for the moment, with a vicious peck, but the moment its search again commenced it would be caught up and followed and worried in precisely the same way by a fresh relay of young ones, all belonging to some one else. . . The more robust of the young thus worried an adult, until, because of his importunity, he was fed. But with the less robust a much more pathetic ending was the rule. A chick that had fallen behind in this literal race for life, starving and weak, and getting daily weaker because it could not run 
fast enough to insist on being fed, again and again ran off pursuing with the rest. Again and again it stumbled and fell, persistently whining out its hunger in a shrill and melancholy pipe, till at last the race was given up. Forced thus by sheer exhaustion to stop and rest, it had no chance of getting food. Each hurrying parent with its little following of hungry chicks, intent on one thing only, rushed quickly by, and the starveling dropped behind to gather strength for one more effort. Again it fails, a robuster bird has forced the pace, and again success is wanting to the runt. Sleepily it stands there with half-shut eyes, in a torpor resulting from exhaustion, cold and hunger ... a dirty dishevelled dot, in the race for life a failure, deserted by its parents, who have hunted vainly for their own offspring round the nest in which they hatched it, but from which it may now have wandered half a mile. And so it stands, lost to everything around, till a Skua in its beat drops down beside it, and with a few strong vicious pecks puts an end to the failing life.

"Not once or twice, but a thousand times this happens, and the kindness of Nature's seeming cruelty is borne in upon us as we watched its working. All round the rookery are Skuas' nests with their young; the conditions of life are hard, and failures must be many where the standard of efficiency is high. Not 50 per cent. of the Skuas themselves survive their infancy; not 30 per cent. of Emperor Penguin chicks survive; and from the corpse-strewn condition of the acres occupied by an Adelie Penguin rookery ... mangled chicken remains by the many hundred lie trodden into frozen dust and muddy guano... [showing that] even in these communities the death-rate is excessive." And "it is not only the youngest chickens that die, but .... a very large proportion are birds which have already shed their down and have assumed the plumage which enables them to take to the water. Why, one wonders, did these birds die on shore? The parents left them, true, but they were ready to be left, and yet apparently they never dared the water, where alone they could escape starvation. Once again the uncompromising character of Nature's laws was brought home to us as we realised that death was the one aiternative to a creature that refused to learn."

But dozens of such instances might be quoted, some others 
indeed have already been given in these pages. A sudden fall of temperature, bush-fires, and other, climatic variations cause great havoc among nestlings: but these tend to eliminate all but the strongest, all but the most receptive, all, in short, but the fittest.

From the melancholy aspect of death it is fitting that we should pass to the brighter side of the picture, revealing birds at play, by way of bringing this chapter to a close.

Unfortunately, but few facts have been collected on this theme. Mr. H. E. Howard, in his masterly study of the Warblers, has brought to light some interesting facts on this head. Thus young Sedge-warblers, just after having left the nest, he tells us, are very playful, "their games sometimes taking the form of a tilting match. Three take part, two sit on convenient twigs facing one another, and the third, from his central position, might almost be called an umpire. Numbers one and two then lower their heads, each in anticipation of the other moving; one of them, call him number one, then springs into the air, and darts at number two; number two dodges and occupies the position vacated by number one; each of them then face round ready to continue the fray, the change of positions becoming quite rapid."

Dr. C. W. Andrews has similarly recorded the play of young Frigate-birds observed by him on Christmas Island. "Groups of them," he says, "could often be seen near the coast stooping to the water, one after the other, to pick up leaves and other floating objects, and then dropping them, apparently practising the method by which their parents obtain their food, which consists of surface-fish and cephalopods."

As in the cases of play in other groups of animals, young birds perform in pantomime those evolutions which are to be matters of life and death in after-life, and here, doubtless, the work of selection begins. The more clumsy will later, in all probability, prove the more indifferent performers, and so suffer in competition with their more agile neighbours.

So far the number of observations on this subject with regard to birds is pitifully meagre, so much so, that in these two instances we have exhausted the list of cases known to us ! 


\section{CHAPTER XVII}

\section{VARIATION : CONTINUOUS AND DISCONTINUOUS. INTER- BREEDING}

Paucity of information on variation in birds. The work of J. A. Allen. Relation of variation to natural selection. Barrington's work. Colour variation. Dimorphism. Mutation. Albinism and Melanism. Swallows.

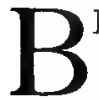

EARING in mind the immense amount of work which has been expended in recording observations on birds, it is astonishing to find how little has been set down with regard to the deeper problems of avian evolution. It might have been expected that the stimulus to patient inquiry given by Darwin's magnificent work would have borne some fruit among the vast army of those who profess an interest in Ornithology. Yet the most laborious research among the formidable array of books on birds which have been written since the Darwinian theory was given to the world, yields but a miserable reward. While splendid work has been done, and vast sums have been expended, in hunting for new species, there have been few who have availed themselves of this harvest. Those who are most enthusiastic in this task of heaping up novelties, care least for the problems which these novelties. present. This need not surprise us; but it is certainly strange that the study of Ornithology should have produced no philosophic mind bent on making use of such a wealth of material.

One might have expected, at least, that some attention would have been paid to the phenomena of variation among birds. Yet less has been brought to light on this subject perhaps than any other. Though more than 19,000 species have been described, and though the descriptions of every species have entailed measurements, nowhere will there be found anything more than the bald statement that such measurements as are given are "average" measurements; and generally even this is not done. The range of variation is nowhere given in 
such descriptions. Happily, however, a few workers have paid some attention to this matter, but such observations are, necessarily, extremely limited. And the same is true with regard to the variations of colour and pattern of the plumage.

Those who fall under this indictment may plead that variation among birds is a negligible quantity; and it must be admitted that, in so far as most species are concerned, variation appears to be but slight. It is probable, however, that when closer attention is paid to this matter even the most uniform types will be found to vary more than has been supposed.

In summarising what has been done towards the collection of data on the subject of variation, continuous and discontinuous, we may begin with the facts collected by Mr. J. A. Allen who some six-and-thirty years ago published a series of most valuable observations which have been used by every writer on evolutionary problems since they first appeared. They refer to the subject of continuous variation among birds, and are based on certain external characters. After carefully measuring a large series of each of several species he found " that a variation of from I 5 to 20 per cent. in general size, and an equal degree of variation in the relative size of different parts, may be ordinarily expected among specimens of the same species and sex, taken at the same locality, while in some cases the variation is even greater than this". Each part, he further shows, varies independently of the other parts, so that when the size varies, the proportions of all the parts vary, often to a much greater amount. Thus the wing and the wing and tail vary not only in actual length, but in the relative proportions of the feathers, so that the contours of the outspread wing and tail vary in shape. Similarly, the bill and the legs vary in length, averaging one-sixth of the whole length, and often reaching one-fourth.

Dr. Alfred Russel Wallace gives, in his Darwinism, an able summary of Mr. Allen's work, and adds thereto a mass of evidence of his own collecting. This study of variation was carried out on a few species of Passerine birds, from twenty to fifty or sixty examples being taken at random from each species for this purpose. Dr. Wallace, in his summary of the work, points out that, in this matter of measurements if large numbers-thousands or millions-were subjected to the same 
process of measurement it would be found " that a very large proportion of the total number of individuals constituting a species would diverge considerably from its average condition as regards each part or organ; and as we know ... that each part varies to a considerable extent, independently, the materials constantly ready for natural selection to act upon are abundant in quantity and very varied in kind. Almost any combination of variations of distinct parts will be available where required, and this ... obviates one of the most weighty objections which have been urged against the efficiency of natural selection in producing new species, genera and higher groups".

An actual illustration of the relation of variation to natural selection has been given by an American naturalist-Mr. Bumpus. This was furnished by the Common English Sparrow (Passer domesticus) which some years since was introduced into the United States. One hundred and thirty-six of these Sparrows were collected after a very severe storm of snow, sleet and rain. Of these seventy-two revived, while sixty-four perished. On comparing the survivors with the eliminated individuals, very appreciable differences were found. The average characters differed but little. But the eliminated individuals were 1.27 per cent. greater in length, and 2.38 per cent. greater in weight, while they were about I per cent. smaller than the survivors in respect of most of the other characters measured. The variability, or range of variation of the eliminated birds about their mean was, however, very much greater than in the case of the survivors. Of the nine characters measured, the variability is greater in eight, the average excess being no less than I 8.8 per cent. The variability was less in respect of the sternum alone, and then only by $3^{\circ}$ I per cent. The struggle for existence appeared to fall heaviest on the very long individuals, as of the eighteen birds obtained in which the length was $164 \mathrm{~mm}$. and upwards, no less than fourteen perished. Also the two shortest birds perished. The conclusion drawn by Bumpus from these observations was that " natural selection is most destructive of those birds which have departed most from the ideal type; and its activity raises the general standard of excellence by favouring those birds which approach the structural ideal". But Mr. H. M. Vernon, 
to whom I am indebted for the foregoing summary, taken from his most valuable work, Variation in Animals and Plants, remarks: "The observations really show more than this, however. It is true that, as a rule, the most extreme individuals in either direction are eliminated, but if the distribution of the various characters be plotted out ... . it will be seen that in the case of some of the other characters, as in that of length, the eliminating process acts much more on the extreme individuals in one direction than in those in the other... the eliminated birds were, on an average, heavier. This conclusion has already been obtained by the simple process of taking averages; but the curves show in addition that it is the very heavy birds which were more especially eliminated. Thus of fourteen birds of 27.3 grms. and upwards obtained, only three survived. Similarly, also in respect of the femur measurements it was found that of the nineteen birds obtained with a known length of 6.85 inch or less, only seven survived, whilst twelve were eliminated.

"The next generation of birds collected in the storm-swept area would accordingly be shorter in length, weigh less, have longer legs, a longer sternum and a greater brain capacity than the former generation, supposing, of course, that the variations existing in these characters were partly of blastogenic and not wholly of somatogenic origin; and this could scarcely fail to be the case."

Some birds vary more, in regard to certain parts, than others; and this is especially the case with organs that are of great importance in procuring food. The Curlew, for example, shows a striking range of variability in regard to the length of the beak, ranging from $4^{\circ} 6$ to 7 inches. The Common Heron (Ardea cinera) affords a no less striking instance in the variation of the length of the tarso-metatarsus, though no measurements illustrating the extremes of length appear to have been recorded. But the Limicoline birds all appear to be variable in the matter of size, and this is especially noticeable in such species as the Dunlin (Tringa alpina).

Some valuable and striking facts have been brought to light with regard to this matter of variation by $\mathrm{Mr} . \mathrm{R} . \mathrm{M}$. Barrington, who in his monumental work on The Migration of Birds at Irish Light Stations made a large collection of facts which have not received the attention they deserve. 
These observations concern one character only-the length of the wing. But they are of considerable interest since they reveal a remarkably wide range of variation in this particular in one or two species; while in closely allied species this range is often surprising. Further, he shows that, in many cases, in times of stress, as in unusual inclemency in the weather, the shortest winged forms are the first to succumb.

The Willow-wren and the Skylark he found to be the most variable among British birds in, this matter. In the former species the wings of eighty-two specimens gave the following measurements :-

Willow-wren-

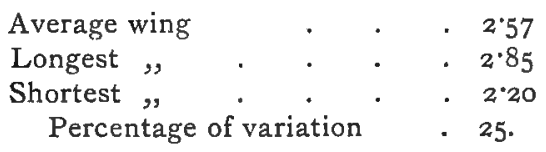

Lark-

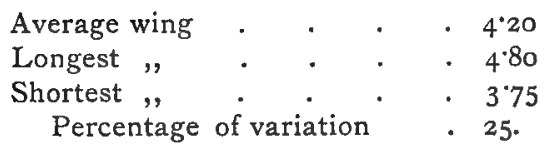

The Wheat-ear and the Whin-chat are very closely allied, yet the following table shows they differ greatly in the stability of their measurements :-

Whin-chat-

$$
\begin{aligned}
& \text { Average wing . . . . } 2.98 \\
& \text { Longest , . . . . 3'I0 } \\
& \text { Shortest ,, . . . } 2.85 \\
& \text { Percentage of variation - } 8 \frac{1}{2} \text {. }
\end{aligned}
$$

Wheat-ear-

$$
\begin{aligned}
& \text { Average wing } \quad \cdot \quad \cdot \quad \cdot 378 \\
& \text { Longest ", . • } 4^{*} \text { I5 } \\
& \text { Shortest ,, . . . . } 33^{2} \\
& \text { Percentage of variation . } 16 \frac{7}{2} \text {. }
\end{aligned}
$$

Among the Finch tribe the range is interesting; thus from specimens taken at Irish Lighthouses Mr. Barrington found the following differences-to take but a few cases :- 
Chaffinch-

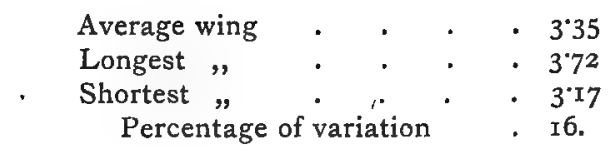

Siskin-

$$
\begin{aligned}
& \text { Average wing . . . } 2 \cdot 85 \\
& \text { Longest, . . . 3.00 } \\
& \text { Shortest , . . . . } 257 \\
& \text { Percentage of variation . I5. }
\end{aligned}
$$

\begin{tabular}{|c|c|c|}
\hline Average wing & . & . \\
\hline Longest, & . & - \\
\hline $\begin{array}{l}\text { Shortest , } \\
\text { Percentage }\end{array}$ & variation & - \\
\hline
\end{tabular}

Brambling-

\begin{tabular}{|c|c|c|}
\hline Average wing & - & \\
\hline Longest, & • & \\
\hline $\begin{array}{l}\text { Shortest , } \\
\text { Percentag }\end{array}$ & $\dot{f}$ variatio & . \\
\hline
\end{tabular}

Greenfinch-

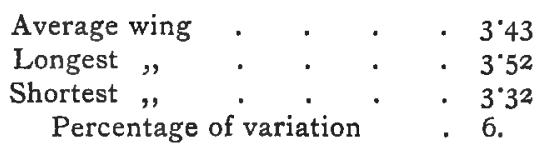

Linnet-

The Dunlin (Tringa alpina) is, as we have already remarked, an extremely variable species, and in its wing measurements it is no less so :-

\begin{tabular}{|c|c|c|}
\hline Average & gth wing & \\
\hline Longest & $"$ & 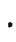 \\
\hline Shortest & $"$ & • \\
\hline
\end{tabular}

$$
\begin{aligned}
& \text { Average wing . . . . } 44^{\circ} 54 \\
& \text { Longest " . . . . } 4.87 \\
& \text { Shortest , . . . . 3.95 } \\
& \text { Percentage of variation } 207 \frac{7}{2} \text {. }
\end{aligned}
$$

These measurements are the more striking when compared with similar ones in allied species, such as the following :-

Common Sandpiper- 
Purple Sandpiper-

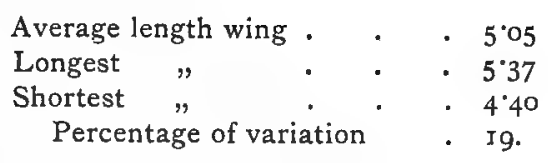

Jack Snipe-

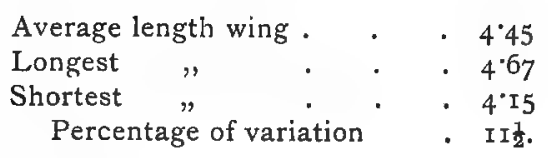

Common Snipe-

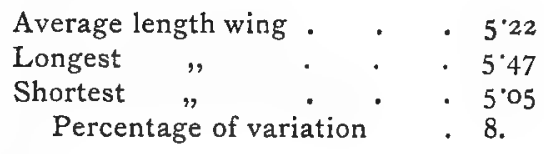

Woodcock-

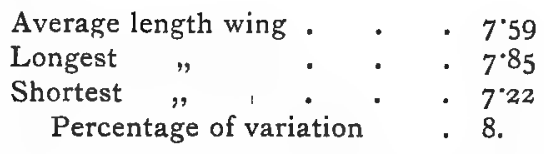

In the matter of coloration most birds show a striking constancy, variations, which are always present, being very slight-whilst some species, on the contrary, present a very remarkable range of variability; a few display the phenomenon known as discontinuous variation.

In the matter of continuous variation the Common Partridge (Perdix cinerea) and the Red Grouse afford exceptionally good subjects for study, exhibiting a truly surprising scale of gradations in coloration. More striking, perhaps, is the variation exhibited by the Arctic Skua (Stercorarius crepidatus), which displays two very distinct plumages even in the same nestingplaces, one form being sooty the other having light under parts. The white-breasted pair one with another, and with the dark forms, which also pair together. "Both extremes, and the gradations resulting from their union," says Mr. Howard Saunders, "are found breeding on our northern islands, the Faroes, Iceland, the coasts of Scandinavia [and] Russia." On Spitzbergen, however, the dark form appears to be conspicuous 
by its absence, and this seems to be true also of birds from the far north of Arctic America. In America below the Arctic Circle both forms are met with as in Great Britain. The Giant Petrel (Ossifraga gigantea) of the southern seas shows a similar variation, inasmuch as normally dark brown in colour, pure white birds are also met with, as well as every gradation of coloration between these two extremes. So far it appears, however, that the wholly white examples are only met with just north of, and within, the Antarctic Circle.

Another variable species is the little "Creeping Warbler" (Parula americana) which shows a wonderful range of variation, and one, moreover, which seems to present phases approaching each of some five other allied species- $P$. superciliosa, $P$. pitiayumi, $P$. inornata, $P$. nigrilosa and $P$. insularis, as though these were severally derived from $P$. americana.

Less is known concerning the phenomena of discontinuous variation than one would expect having regard to the number of those who devote themselves to the study of Ornithology. Nevertheless, some extremely interesting facts on this head have been placed on record.

Among British birds some good examples of this form of variation are to be met with. And perhaps the best-known instance is that furnished by the Guillemot (Lomvia troile) which sporadically appears with a ring of white around the eye, and a white streak extending from this ring backwards along the side of the head. For a long time birds so marked were regarded as representing a distinct species-the Ringed or Bridled Guillemot-but it is now generally admitted to be but a variety of the typical species. "It inhabits," says Mr. Howard Saunders, the same localities, and is always found in "company with the common species, but in far inferior numbers." On the Faroe Islands it appears not infrequently. On Handa, off the coast of Sutherland, Mr. Harvie-Brown found this variety to be abundant, as compared with other stations in Scotland, being in the proportion of one in ten or twelve; and he has many times seen the common and ringed varieties paired. And Colonel Fielden has noted the same in the Faroes and Hebrides. In the north of Iceland it is commonly met with, and there would appear to be some grounds for believing that it occurs with greater frequency in more northern latitudes. 
Further, and this is especially interesting, the allied Pacific Guillemot (Lomvia californica) also produces a precisely similar variety.

The Ruff (Machetes pugnax) when in summer dress, at any rate, affords an even more striking case. It is a matter of common knowledge that the broad frill and occipital tufts of feathers, which are assumed by the males during the period of courtship, present the most wonderful range of coloration, no two birds being exactly alike, while the extremes of coloration and pattern are most striking; but the peculiarities of each bird appear to be faithfully reproduced annually. The ruff and ear-tufts however are not the only portions of the plumage which thus set at defiance, so to speak, the general observance among birds of conformity to type, for the body plumage varies just as widely, though this fact is generally lost sight of. But however the coloration may vary, the general proportion of this ruff and "ear-tufts" remains constant. The females, however, sombrely clad, present a wonderful uniformity.

More impressive are the facts with regard to certain species of small Herons, which presenting two distinct phases-a white, and a dark phase-were for a long time regarded as so many distinct species. Perhaps the best-known instance of this curious fact is that furnished by the Reef-heron (Demigretta sacra). The typical plumage of this bird is of a deep blackishslate, but wholly white birds are common. It does not appear, however, to have been established whether these white birds ever occur where both parents are of the dark type. Blue and white birds have been seen paired together, and the offspring in such cases seem to be more or less intermediate in coloration, being streaked with blue. It is significant to note that the dark forms are darker in winter, and darkest when immature, the adults being much paler in colour.

But this remarkable dimorphism is by no means confined to this species, and it seems highly probable that we have in these instances an illustration of the lines of evolution which will ultimately end in suppression of the dark and the survival of the white forms. The evolution of the allied White Egrets has probably followed precisely similar lines.

The following facts seem, at any rate, to support this interpretation :- 
In the Pacific Heron (Notophoyx pacifica) the adult is of a glossy olive green and slate colour, blackish below, relieved by broad longitudinal streaks of white, and white tips to the feathers of the forepart of the neck. Occasionally nearly white adults are met with. From this we pass to the African whitethroated Reef-heron (Lepterodias gularis) wherein the adults are slate coloured, and the white phase occurs with more frequency. The nearly allied Indian Grey Reef-heron ( $L$. asha) is yet paler, and also develops a white phase. The Reddish Egret (Dichromanassa rufa) carries us a stage further, the general colour of the adult being of a light slaty grey, relieved by cinnamon on the head and neck. The immature birds are either bluish-grey or white. Finally, in the Blue Heron (Florida cerulea) the adults are of a bluish-slate colour, while the young birds are apparently always white. Frequently this white plumage is retained throughout life.

Whether the undoubted tendency to whiteness which is here apparent gains intensity, and ultimately becomes a dominant character, which has become favoured by selection, or whether the evolution of white species has been brought about by geographical isolation is a moot point, which demands further investigation so far as this is possible.

Apparently coming within the category of dimorphism are the curious colour aberrations known as "hepatic phases," of which good instances are furnished by the Tawny Owl and the Common Cuckoo. These species respectively not infrequently develop individuals which have excited not a little attention from the fact that they differ from the typical forms of their respective species in that the plumage is of a peculiarly red or ferruginous hue while preserving all the characteristic markings belonging to that species. So far, however, it would appear that such examples are immature. It should be mentioned, however, that a case is on record of an American Tufted Owl (Scops asio), in confinement, which passed from the grey into the red phase. Such ferruginous types are indeed among the Owls by no means uncommon, and are especially frequent in the Genus Scops. The Night-jar and the Common Snipe, among other species, also occasionally develop these furruginous types.

The Common Snipe is further remarkable in that it occasion- 
ally develops individuals of extremely dark pigmentationvelvety-black relieved by very dark brown bars. At one time such examples were regarded as representing a distinct species known as Sabine's Snipe; but later observers have shown that in reality it is not specifically distinct from the Common Snipe (Gallinago celestis). But while most of these dark forms differ from normal individuals only in their darker colour, they may therefore be regarded as melanisms. This term by no means covers all the phenomena observable in every such dark variety, inasmuch as some examples have the markings of the plumage of a totally different kind; the most conspicuous feature being the absence of the longitudinal stripes in the upper parts. Such varieties may be put down as mutative. They are, it should be noticed, more commonly obtained in Ireland than elsewhere.

This problem of the dimorphism, or of the specific distinctness of some other forms, is much more difficult to solve. Thus, according to some authorities, the Hooded and Carrion Crows are to be regarded as representing but a single dimorphic species. The late Professor Newton and Mr. Howard Saunders, two of the foremost of British Ornithologists of their day, both inclined to this view. Both forms, remarks Professor Newton in his Dictionary of Birds, inhabit Europe, but their range is very different. For while the "Hooded Crow" is, speaking generally, a summer visitant to the south-western part of this quarter of the globe, the "Carrion Crow" occupies the northeastern portion-an irregular Jine drawn diagonally from about the Firth of Clyde to the head of the Adriatic roughly marking their respective distribution. Both are essentially migrants, and hence it follows that when the Carrion Crow, as summer comes to an end, retires southward, the Grey Crow moves downward, and in many districts replaces it during the winter. Further than this it has been incontestably proved that along or near the boundary where these two birds march, they not infrequently inter-breed, and it is believed that the hybrids, which sometimes wholly resemble one or other of the parents, and at other times assume an intermediate plumage, pair indiscriminately among themselves or with the pure stock. Hence, it has seemed to some Ornithologists who have studied the subject, that these two birds, so long unhesitatingly regarded as 
distinct species, are only local races of one and the same dimorphic species.

There is no Ornithologist in Great Britain, perhaps in Europe, whose work carries more weight than that of the late Professor Newton, nevertheless, we venture to question whether the facts really justify this contention of dimorphism. Rather they seem to us to show that the Carrion and Hooded Crows are really to be'regarded as good species, but very closely allied. And in this case there is nothing strange in this inter-breeding where they overlap one another.

A precisely similar case is that of the Great Grey Shrike (Lanius excubitor) which inter-breed with two distinct but closely allied species. In the northern limit of its range, Scandinavia, L. excubitor - which is distinguished from its allies by the presence of a double white bar in the wing-meets and inter-breeds with another species, L. major, distinguished by the presence of only one bar of white in the wing. In South Russia $L$. excubitor meets with a third species, the white-winged Grey Shrike ( $L$. leucopterus), and inter-breeds therewith, producing apparently an intermediate race known as $L$. homigeri.

The "Flicker or Golden-winged Woodpecker" (Colaptes auratus) may be cited as a further illustration of inter-breeding species. A native of North America it ranges from the Atlantic Coast as far southwards as Louisiana and north to Canada. Still farther northward, to Alaska, its place, says Professor Newton, "is taken on the greater part of the Pacific side by a species which, avoiding Southern California, reaches the tablelands of Mexico-a species more brilliantly tinted, for ruby appears in its plumage instead of gold, the $C$. mexicanus or vulvicatus of authors. But in an intervening broad belt running north-westward from Texas to British Columbia there occur birds presenting almost every combination of the distinctive coloration of the two species just named. . .."

If further facts of this point are required they may be found among the Game-birds, the phenomena of intermediate races being particularly well illustrated in the case of the "Silver Pheasant".

More obscure are the facts which Professor Giglioli has brought together in what he calls The Strange Case of 
'Athene chiaradice'. Herein we have an instance of sudden variation, of mutation, of quite exceptional interest.

To be brief, the specific name Athene chiaradice was bestowed by Professor Giglioli of Florence upon a small Owl bearing traces of nestling down on its plumage which had been taken during the summer of 1899 from a nest of four at Pizzocco on the prealps of Fineli, at an altitude of 1,003 metres. Immediately after this bird came into his hands Professor Giglioli took steps to secure further specimens, but without success until July, I900, when a careful search at Pizzocco led to the discovery of a nest containing four young birds-three of which proved to be typical examples of the Little Owl Athene noctua! In I90r a third example of this peculiar form was taken at Fregona from a nest of three, the co-nestlings being of the normal type of $A$. noctua. During the summer of 1902 the last nest was discovered. This contained four young birds, three of which were of the normal $A$. noctua type. With this nest the parent birds were also captured thus setting at rest all doubts as to the parentage of this strange variety. Of these parents Professor Giglioli writes: "Although they cannot in any way be considered other than true $A$. noctua, yet they are individually and in different ways distinct from the usual $A$. noctua".

The typical Athene noctua, it may be well to remark, has pale straw-yellow irides, the upper plumage clove-brown with triangular white stripes on the head, white spots on the nape and wings, and four bars of dun-white on the tail. The under parts are dun-white streaked with brown.

The parents of the particular nestlings just referred to differed in the following respects. The male was "bigger than the average adult male $A$. noctua". "The coloration of the brown upper parts and of the blotches on the lower parts is singularly light, nearly isabelline ... (it) has hardly any white on its facial disc, which is grey; and, lastly, it is remarkable for the great number, large size, and white colour of the blotches on the top of the head, and for the extraordinary width of the rectices, the outer ones (not the broadest) measure $22 \mathrm{~mm}$., the usual width being about $16 \mathrm{~mm}$, in the adult males of $A$. noctua.

"The female is not less remarkable, but quite different; 
she is small and very dark, but the brown of the upper parts and the big blotches of the ventral feathers are tinged with rufous, and differ from the dark umber-brown of $A$. chiaradice, while they are considerably darker than the average $A$. noctua. The top of the head is as profusely spotted as in the male, more so than in the average Civetta, but the mesial light spots of each feather are very conspicuous on the dark brown ground colour. Finally, the tail feathers are unusually broad."

Now for the peculiarities of $A$. chiaradice. In the first place these all had dark brown irides, so dark as to be almost black, wherein they differed not only from their parents, but from every other species of the allied genera Nyctala, Surnia, Glaucidium and Scops, which all have yellow irides. Further, these abnormal forms differed according to Professor Giglioli in that "the tone and the pattern or style of the coloration of the plumage is absolutely different from that in $A$. noctua (the parent form) and, I may add, in any other species of that and allied genera. Thus in $A$. chiaradice the light coloured spots in both remiges and rectrices, which form transverse bands in the expanded wing in other small Owls, are replaced by longitudinal bands formed by the white margins of the outer and inner webs of those feathers." Apart from these details, it would seem, however, comparing Professor Giglioli's description with that of the normal $A$. noctua described in Yarrell's British Birds, that $A$. chiaradice differs chiefly in having the dark areas of the plumage more intensely pigmented, while the greyish areas are pure white.

Both sexes, it may be remarked, are represented in this remarkable collection of nestlings, the last nest taken containing two examples of $A$. chiaradice, and three normal nestlings. At least Professor Giglioli describes them briefly as normal, i.e., typical examples of Athene noctua, but nowhere, so far as can be discovered, does he say whether these were really normal, or whether they resembled either of the parents, which, as has been shown, were not normal. This omission is curious.

Having regard to the great interest and importance of this discovery we cannot but feel astonished that, with Professor Giglioli's approval, the only apparent source of this remarkable variation has been deliberately exterminated to adorn the galleries of the Royal Zoological Museum of Florence! For 
there seems but little doubt but that all the examples of the socalled Athene chiaradice were the progeny of the same pair of birds-themselves abnormal. Convinced. of this, they, with their last brood, though taken alive, have been deliberately slaughtered to make museum specimens, whereas one would naturally have expected that some attempt would have been made to induce the adults to breed in confinement, while a similar experiment could have been made with the offspring.

In its way as striking as any instance of mutation yet cited in these pages is the case of Shore's Woodpecker (Tiga shorei). As was first pointed out by Mr. Ogilvie Grant, this bird, in the matter of the coloration of its plumage so closely resembles another species (Chrysocolaptes gutticristatus) that the one could easily be mistaken for the other. Indeed the only ready means of discrimination lies in the fact that the last named has four and the first mentioned only three toes. Though by Ornithologists this difference in the number of the toes is regarded as justification for placing these two birds, not only in separate genera, but in separate sections of the same family-containing respectively four and three-toed genera-it would seem to be more in accord with the evidence if the Tiga shorei were to be set down as a mutational form of Chrysocolaptes gutticristatus.

With these facts before us the question naturally arises: What light, if any, do they throw on the problem of the origin of species? Will they afford any clue as to the possible origin of specific characters such as, for example, distinguish the Cole and the Marsh-tits one from another, or the different races of these two species, and of the Long-tailed Titmouse? Or to select a yet more striking illustration, of the strange permutations and combinations of colour which the various species of some genera present. Out of a possible thousand illustrations of this last kind let us take a few from the Genus Hirundo, the Common Swallow ( $H$. rustica), being well known, serving as the type. This bird, as every one knows, is of a steel-blue above, with a red forehead, a red throat, bounded by a black gorget, and a rufous-tinted breast and belly. As variants of this we have four birds regarded by many as sub-species only:-

$H$. savignii (Egypt), with deep chestnut belly ; H. erythrogaster (East Siberia, Burma, North and South America), with a 20 
rufous belly and no gorget; H.tytleri (North-East Asia, Burma), with a chestnut belly and a narrow gorget; $H$. gutturalis (East Siberia, Japan, India, Indo-Malay region, North Australia), with a white belly and no gorget. Of birds regarded as distinct species we may select $H$. lucida (Senegambia), with a red forehead, white under parts and a black gorget; $H$. dimidiata (South Africa), with no red on the forehead, a white throat and belly and only a half gorget; $H$. nigrita (West Africa), wholly steel-blue with a narrow white bar across the throat, and no tail streamers; $H$. atrocarulea (South-East Africa), which differs from the last named in having no white on the throat and long tail streamers; $H$. smithi (Africa, India), wherein the red forehead has extended backwards to form a red cap, while the rest of the plumage is blue above and white below; H. cucullata (South Africa), which has a red cap, blue upper parts and buff under parts, streaked with dusky lines. Yet other variants represented by other species might be found. Thus several species have a patch of red over the base of the tail, and this varies in extent and hue, while finally, two species having green upper parts are known.

All these are apparently descended from the Genus Phedina, wherein the upper parts are of a dull brown, and the under parts heavily streaked. In the red-rumped Mosque-swallows the species have nearly all more or less streaked under parts, and from the varying amount of red colour $\mathrm{cn}$ the heads, and the dinginess of the red on the rump of one or two species, it would seem that these are intermediate and older forms, between Phedina and the more typical species of Hirundo.

To what shall we ascribe this ringing of the changes on three or four colours? To natural selection, sexual selection, isolation, or discontinuous variation?

It would seem that this last is nearer the truth. We may suppose, in short, that these permutations and combinations begin as variations in the germ plasm, and that if slight at first, the variation having started in this, or that, new direction goes on increasing till it attains a maximum. What are the factors governing this variation we know not; but they have appa rently free play until, and unless, checked by natural selection. But this sumptuary law is not called into action unless the particular colour variation tends to throw the subject thereof into 
conflict with its environment. Herein we may find a solution of the problem of the existence of "incipient characters," so commonly urged as an objection to the theory of natural selection.

It is possible that a change of habit and habitat, even though this be slight, may be the stimulating factor in producing what we call "species". These units exist, for us, only when labelled, so to speak, by more or less tangible differentiating characters, and, so far as birds are concerned, superficial characters.

Thus the Chiff-chaff and Willow-warbler, the Reed and the Marsh-warbler, to select examples from among our native birds, are to be distinguished one from another only by experts. But they can be readily distinguished by means of their nests.

It is possible, it is worth considering, whether such changes in habit and habitat may not be at least one factor in causing germinal disturbance which sooner or later expresses itself in new combinations and permutations of colour areas, such as have been described in the Swallows, and which give rise to new "specific" characters. Later, and as a natural sequence of this change of habit and habitat, deep-seated structural changes take place, and new groups of species are thereby formed.

A peculiarly suggestive light on the evolution of species is furnished by the Great Titmouse (Parus major) and its near ally the Grey Titmouse (Parus cinereus). With the general appearance of the first-named all my readers must be familiar, for it is a common British bird; suffice it to say that its coloration is a combination of blue, black, white and yellow. The Grey Tit, on the other hand, though precisely similar in the pattern of the coloration, differs in the hue thereof, pearl grey taking the place of blue, and white of yellow. The fledgeling of the Great Tit, it is next to be noticed, differs from: the adults - both sexes being coloured alike-in being duller in hue as to the blue and yellow, while the white of the face is strongly tinged with yellow, and the black lacks the metallic: lustre, and is less in area, being absent on the side of the neck and on the breast. The fledgeling Grey Tit is practically indistinguishable. Thus it would seem that the Grey Tit has been derived from the Great Tit, the young repeating the ancestral plumage of the latter, albeit imperfectly.

In the Genera Oxynotus and Edoliiosoma- "Cuckoo-shrikes" 
-we have, in conclusion, a reversal of the usual law of plumage evolution. For herein the males are practically indistinguishable and the females quite distinct! A study of nestlings may give us the clue to this mystery.

Finally, mention must be made here of the phenomena of albinism and melanism, about which but little is yet known.

In nine cases out of ten the recorded instances of the occurrences of albino birds turn out to be merely "white varieties, as is shown by the fact that the iris and the coverings of the beak and feet retain their normal colouring. While among some species white varieties are common, as for instance among Blackbirds, in others such variations are extremely rare.

As to the causes which produce either white varieties or true albinos nothing is known; but a few curious facts have been collected which are worth recording.

White varieties of black or grey plumaged birds are relatively common, while they appear excessively rare among birds of green plumage. Between absolutely white and albino varieties and the normal plumage almost every gradation in shade may be met with, and this seems to show that the lack of colour is due to weakness in the secretion of pigment. Isabelline varieties, for example, are the natural consequence of the "watering-down," so to speak, of melanin pigments and are not infrequently met with in birds such as Rooks and Starlings, for example.

The Hon. Walter Rothschild has pointed out that most if not all green birds show yellow varieties, and this is but the natural consequence of the "watering-down" of the pigment just referred to, though at the same time it must be remarked that this green colour is not due to green pigment, but to dark melanin pigments and structural interference. White varieties of the Grey Parrot (Psittacus erithacus) have been several times recorded, but generally the red tail is retained; a specimen, however, in Mr. Rothschild's collection has a white tail with the normal grey plumage of the rest of the body. Red appears to be less easily changed. White Bullfinches, for example, retain the red of the under-surface.

Very frequently the assumption of white feathers is only partial, hence "pied" birds, where white feathers are mixed with normal plumage. 
The absence of colour, it is to be remarked, does not affect the pattern of the feathers. In white Peacocks, for example, all the characteristic markings can be traced.

Frequently birds which assume a white dress gain their normal plumage at the next moult. On the other hand, some white varieties appear to be congenital, and, moreover, to turn up in the offspring of normally coloured birds through successive generations,

The Hon. Walter Rothschild, who has paid much attention to this subject, has given some interesting illustrations of this. Thus, in the summer of I8g I four white Swallows (Hirundo mustica) were hatched in the town of Aylesbury, and were allowed to escape. In I 892 the same pair of birds reared one white bird out of an otherwise normal brood; in 1893 they produced two white, and three normal young; and in 1894 two white young-male and female-and two normally coloured birds. Another nest in I894, in the same town, also contained two white young (females) and two or three normal birds. The parents of these, Mr. Rothschild suggests, were probably related to the first pair. In 1895 this pair produced two broods, the first consisting of three white and two normally coloured birds, which all flew away on 29th June, the second of one white bird-a female now in the Tring Museum-and four normal birds.

That certain birds have a predisposition to beget white young is further illustrated by the case of a nest of four Wheatears taken at Lakenheath, Suffolk, all of which were white.

By way of contrast to these cases of pigment atrophy we have instances of melanism-intensification of pigment producing black, or nearly black varieties. One of the best instances of this is perhaps that furnished by that curious variety of the Common Snipe known as Sabine's Snipe described on p. 301 .

While so far it has been found impossible to produce white varieties, this is not the case with melanistic and other colour variations. Bullinches, as is well known, become black if fed on a diet of hemp-seed.

With black varieties, as in cases of pigment atrophy, the characteristic pattern of the feathers is preserved by each species, though this is often visible only in certain lights. 
Other colour varieties can also be produced by experiment. The cases of cayenne-fed canaries is perhaps the best-known instance of this. The cayenne has the effect of intensifying the yellow colour until it assumes a rich orange hue; but this change is only possible when the colouring matter is administered when the birds are very young. The increased colour is produced, according to Miss Newbigin-who has made a special study of animal pigments-by the intervention of a fat -apparently triolein, a constituent of red pepper. This is of interest because, as she has shown, fat pigments (lipochromes) are almost always associated with yellow and red colours. While this abnormal diet, however, in some races of canaries produces the desired orange colour, in others it results in a crimson colour, while in some no effect at all is apparent. Some white breeds of fowls are similarly affected by cayenne pepper, as was shown by the German scientist Sauermann, who administered this stimulant upon white Italian fowls, eight weeks old. Shortly after, in one case within ten days, orange-striped feathers appeared. Later the whole plumage became streaked with orange, while the breast, it is significant to note, became red. Ten birds, however, which were included in this experiment showed no change whatever.

The natives of the Amazonian region, for example, feed the Common Green Amazon Parrot (Chrysotis festiva) with the fat of large siluroid fishes, and the birds thus treated become beautifully variegated with red and yellow feathers. In the Malay Archipelago the natives of Gilolo similarly change the colour of another Parrot (Lorius garrulus), and thus produce the "Rajah" or King Lory.

"In Brazil," says Dr. Gadow, " 'contrafeitos' of the various species of Chrysotis are fashionable. These are produced by the rubbing in of the cutaneous secretion of a Toad (Bufo tinctorius) into the budding feathers of the head, which then turn out yellow instead of green." It is said that after each successive moult these artificially induced yellow feathers reappear. 


\section{CHAPTER XVIII}

\section{ACQUIRED CHARACTERS-THE PROBLEM OF PARENTAL MODI- FICATIONS}

The remarkable case of the Hoatzin and the bearing thereof on the problem of parental modification. The results of feeding experiments, and changes of light and temperature on Flamingoes and Tanagers.

MHAT living organisms vary, in all directions, is an incontrovertible fact; but the origin of these variations is still a matter for speculation. For the most part Biologists are agreed that such variations are the outward and visible signs, the expression points, so to speak, of the inherent instability of the germ plasm, which, like all living matter, being in a state of flux, can never repeat itself in all particulars as one generation succeeds another. On the other hand, there are those who believe that the varied forms of living organisms are not to be regarded as the products of an unstable germ plasm which have passed the sieve of " natural selection," but rather as the products of the somatoplasm-the adult organism -beaten into shape by the complex forces of the external world, animate and inanimate. That is to say, they hold that living matter possesses the inherent property of malleability: that whatever shape may be impressed, by use, upon this or that part of the body, that shape is inevitably transferred and added to by succeeding generations so long as the force which started the modification in question remains active. In other words, each individual that is born into the world of necessity adds both quantitatively and qualitatively to the characters "acquired" by its parents.

No evidence has yet been brought forward, however, which can be regarded as lending any weight to this contention, of the transmissibility of characters acquired during adult life, as distinct from those with which they were originally endowed.

To apply this to the case of birds. That organs are modi- 
fied by use no one disputes. A wing increases or decreases according to the amount of work exacted from it. But there is no evidence that the effects, either one way or another, of the use of this organ during the life of the individual, are transmitted to its offspring. The vestigial wings of the Ostrich tribe, the great Auk, and the Dodo are not evidence of the inherited effects of disuse, but of the cessation of the action of selection. So soon as flight became unnecessary for the continuance of life, birds with wings below the average mean stood as good a chance in the struggle for existence as those wherein the wings were larger. But, we repeat, this degree in largeness or smallness was congenital, and not transmitted as a consequence of use or disuse. The struggle for life imposes a certain minimum standard of efficiency in more or fewer characters. These characters are, or are not, inherent in the germ plasm: and on this depends the survival of the individual. The continuous elimination of birds with wings below a certain standard keeps up the efficiency of flight. So soon as this process of elimination ceases, the decay of the wing commences, though the decline may be imperceptible in any given generation. Physical characters acquired by the individual during its life-time, like knowledge, die with the individual by whom they were acquired. In a word, somatogenetic characters impressed on an individual during its lifetime are not transmissible to offspring. The only characters which can be transmitted are blastogenetic-those inherent in the germ plasm; and these have come into being through the agency of natural selection, which has operated by adopting, or rejecting, the permutations which are inevitable owing to the instability of living matter.

The following are some of the more striking of the instances which have been put forward as evidence demonstrating the truth of the doctrine of the transmissibility of "acquired characters".

Perhaps the most interesting is that brought forward by Dr. Hans Gadow, whose work as a morphologist gives added weight to his arguments.

Dr. Gadow has endeavoured to show that the very remarkable shoulder girdle and alimentary canal of that very remarkable bird, the Hoatzin (Opisthocomus cristatus), a native of 



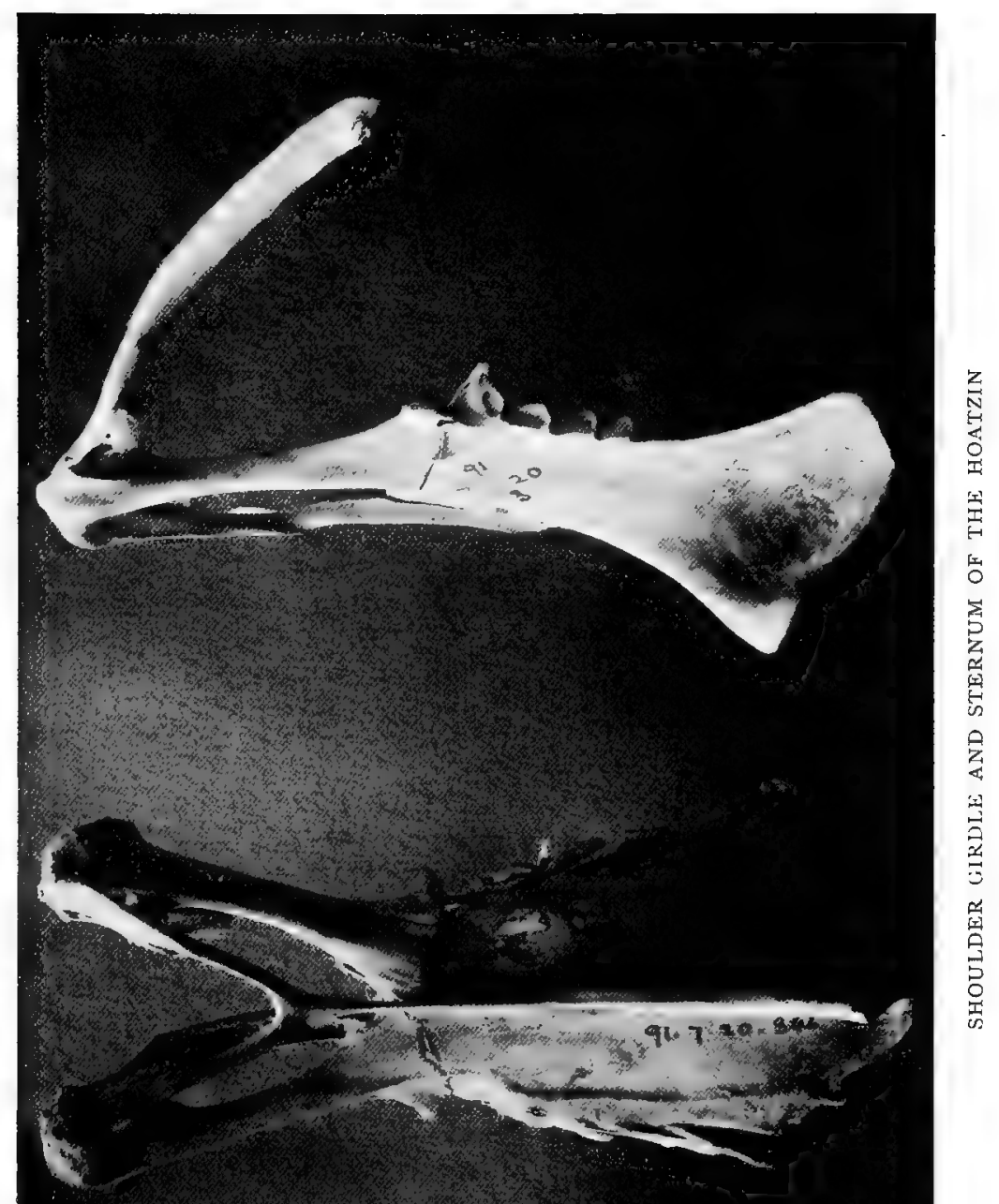


the Amazon valley, afford clear evidence of this theme-the transmissibility of acquired characters.

In this shoulder girdle (opposite) the keel of the breast-bone has become reduced to a small triangular plate at the extreme hinder end of the sternal plate, and is further peculiar in that its free edge is unusually broad, and during life is covered by a callous pad, such as is met with on the breast of the Ostrich. The furcula, or merry-thought, has been transformed so that the median spur known as the "hypocleideum" is drawn out into a long bony style fused with the sternal plate. Finally, the coracoids have fused with the sternal plate at one end, and with the free ends of the furcula at the other.

These peculiarities are, he contends, the result of the pressure exerted by the enormous crop, which is unique in character, since it has developed thick muscular walls and a horny internal layer whereby it has been enabled to assume the functions of the gizzard, which organ has, in consequence, degenerated till it is now no larger than, say, a large acorn.

The series of anatomical changes here outlined are unquestionably striking.

The broadened free edge of the sternal keel and its callous pad are set down by Dr. Gadow as the direct effect of the response to external stimulus, since this pad is used as a support to the body when the bird is at rest perched on a bough. Similarly, the peculiar modifications of the shoulder girdle are attributed to the accumulated effects of the pressure of the great muscular crop on the furcula and end of the sternal keel. But no attempt is made to account for the origin of the supposed cause of this modification of the skeleton-the change in the function and consequent increased size and weight of the crop.

The interpretation of this case, it would seem, is rather one of correlated variation. The change in the direction of the transformation of the crop, we may suppose, was the beginning of this story, which ran on to its final conclusion only. because accommodation could be found for the increased bulk by the gradual retreat of the keel of the breast-bone, no longer all-important as a support for the flight muscles since flight itself has become almost dispensed with.

And this interpretation gathers increased probability since what may well have been the initial stages in the transforma- 
tion of the skeletal parts can be seen to-day in the Gamebirds (Galliformes). Herein the keel of the sternum is much hollowed out in front, and especially so in the Turkeys, wherein the hypocleideum of the furcula is also of great length. Now in the Game-birds the crop is also of great size, and is lodged in a fashion resembling that which obtains in the Hoatzin. That is to say, it is supported, when the bird is at rest, between the arms of the furcula, and in part by the breast-muscles on either side thereof. As flight became less imperative, and the dwindling of the sternal keel more marked, more space would be at the disposal of the developing crop allowing a greater increase in size, in proportion as it took over the duties of the gizzard. If in the Turkey the size of the crop increased as the powers of flight decreased, we should have a modification of the skeleton precisely similar to that of the Hoatzin.

The Hoatzin, as is well known, is a bird whose powers of flight are extremely limited. It is believed, indeed, never to come to the ground, but to pass its whole life among trees overhanging water, and feeding upon the fruit of an astringent aroid. This peculiar food may have been possible, only because the ancestral Hoatzin had a crop which was unaffected thereby, possibly because thicker-walled and gland-secreting, whereby the process of digestion began before the food was passed on to the stomach. This being so the action of selection would be to increase the size of the crop and to decrease the size of the gizzard.

Hunter succeeded in feeding a Gull (Larus tridactylus) for a year on grain, at the end of which time the lining of the gizzard had acquired the horny surface characteristic of graineaters, while another experimenter, Holmgren, showed that the gizzard of Pigeons fed on meat lost this horny consistence, and assumed the soft character of that of a bird of prey. But no one would expect to find the offspring of such Pigeons similarly affected as a consequence of the abnormal diet of their parents. In the days of cock-fighting the combs of Gamecocks were invariably pared down, but this did not affect their male offspring. Yet it has been urged that the long tails of the Japanese "Long-tailed Fowls," which may attain a length of as much as seventeen feet, have been developed by the accumulated effects of long stimulus applied by gently and 
periodically pulling these feathers throughout the life-time of individuals during successive generations. And $\mathrm{Mr}$. J. T. Cunningham has endeavoured to show (Sexual Dimorphism in the Animal Kingdom) that all the varied ornaments of birds, whether in the shape of feathers or of horny or fleshy excrescences, have been gradually "acquired" as a consequence of the stimulus of use during successive generations. But no evidence that lends the slightest support to such an hypothesis has yet been produced.

But though no evidence has yet been brought forward which would justify belief in the transmissibility of acquired characters, there can be no sort of question but that individuals do undergo modification in this or that direction, as a consequence of the malleability, so to speak, of such organs or tissues as are subjected to particular stimuli. And some very striking facts on this head have recently been put on record with regard to the colours of certain birds, facts which go far to show that such acquisitions during the life-time of an individual are not transmitted to its offspring.

To begin with, it is well known that many brilliantly coloured birds become more or less pallid in captivity. This is especially noticeable in the case of the American Rosy Flamingo (Phonicopterus ruber). These birds invariably lose their colour in confinement and become almost white. This pallor, it has been shown, is due not to the reaction of an unfavourable climate, but is intimately associated with the metabolism of the body, a fact which has been demonstrated by experiment. $\mathrm{Mr}$. Beebe, the Curator of the Zoological Gardens of New York, appears to have been the first to demonstrate this point. "In captivity," he remarks, "these birds [American Flamingoes] fade out moult by moult, until they become almost white, like the European species. By mixing with their food a quantity of some strong but harmless dye I have had them either retain their original colour for years, or at least the fading process has been appreciably lessened." In the Gardens of the Zoological Society of London this experiment has been carried to a yet more satisfactory ending, for in place of "strong but harmless dye" these birds were turned out into a paddock where they had free access to a large pond well-stocked with small crustacea, a diet which quickly restored the lost hues. This is of particular 
interest, because it has been already shown that the characteristic colour of the flesh of salmon is due to the red colouring matter extracted from the crustacea on which it feeds. Thus, as in the case of cayenne-fed canaries, to which we have already referred (p. 3IO) pigment is not only reacquired by each individual, but may be lost and regained several times in the life-time of the same individual!

The European Flamingo (Phonicopterus roseus), it is significant to note, though feeding on a precisely similar diet, has only the wings, beak and legs vividly coloured, while the rest of the body is merely flushed with rose-pink. The Scarlet and White Ibises of Tropical America afford a precisely similar instance, the former (Eudocimus ruber) having a plumage of a gorgeous scarlet colour, which in captive birds fades moult by moult to white, and the latter, Eudocimus alba, being, as its specific name indicates, pure white, save for the beak and legs, which are red. The brilliantly coloured species then depend for their beauty upon some unstable physiological peculiarity which is not present in the less resplendent species.

Another remarkable experiment of Mr. Beebe may be mentioned in this connection. This was carried out on some Scarlet Tanagers (Pyranga erythromelas) and Bob-o-links (Dolichonyx oryzivorus) under his charge in the New York Zoological Gardens. Both species have very distinct breeding and nonbreeding (summer and winter) plumages. The first-named changes annually from scarlet and black to green and black (see p. 275), the last from buff, cream and black, strongly contrasted, to dull brownish-black and buff.

Several individuals of both species, when in full breeding plumage, were placed in small cages, and kept in a dimly lighted apartment, but well supplied with food, when, as a consequence they became very fat. A month later, when the time for the annual assumption of the winter dress arrived no change of plumage took place. In the following spring "individual Tanagers and Bob-o-links were gradually brought under normal conditions and activities with quick result; just as the wild birds in their winter haunts in South America were at that time shedding their winter garb, and assuming the more brilliant hues of summer, so the birds under my observation also moulted into the colours appropriate to the season. The old scarlet 
and black feathers fell from the Tanagers and were replaced by others of the same colour; from buff-cream and black the Bob-o-links moulted into buff, cream and black! There was no exception; the moult was from nuptial to nuptial, not from nuptial to winter plumage. The dull colours of the winter season had been skipped." Thereby, as he remarks, it is plain that the "sequence of plumage in these birds is not in any way predestined through inheritance bringing about an unchangeable succession, in the case of the Tanager, of scarlet and black green and black year after year, but that it may be interrupted by certain external factors in the environmental complex". 


\section{CHAPTER XIX}

\section{NATURAL SELECTION AS APPLIED TO BIRDS}

The theory of "Natural Selection" applied to birds. Modes of selection. Inter-specific selection. Pigs and Penguins. Skuas and natural selection. Protective coloration. Winter whitening of Ptarmigan. Mimicry among birds. Protective resemblance and aggressive resemblance. Importance of inter-specific selection on the evolution of species. Intra-selection.

7 HAT Darwin's theory of natural selection is the main factor in the evolution of species is now generally conceded; and some of the most striking of his illustrations thereof were furnished from the life-histories of birds.

This being so, one would have expected to find that, during the half-century which has now passed since the Origin of Species was given to the world, the number of additional facts bearing on this momentous question would have increased a thousand-fold. But, unhappily, strange though it be, this is not the case. Though Ornithologists profess, as a body, to accept Darwin's work, their contributions thereto are of a miserably meagre character.

Hence, then, we cannot do more in this chapter than give a brief survey of what is so far known as to the nature of the action of natural selection on birds, and the nature of the facts to be sought by future workers.

The known facts are chiefly those collected by Darwin.

We shall deal with the selection theory under three main heads :-

I. Natural selection-Inter-specific, Intra-specific, Intraorganismal.

2. Artificial selection.

3. Sexual selection.

With regard to inter-specific selection, the struggle, between different species occupying the same area, to maintain existence, 


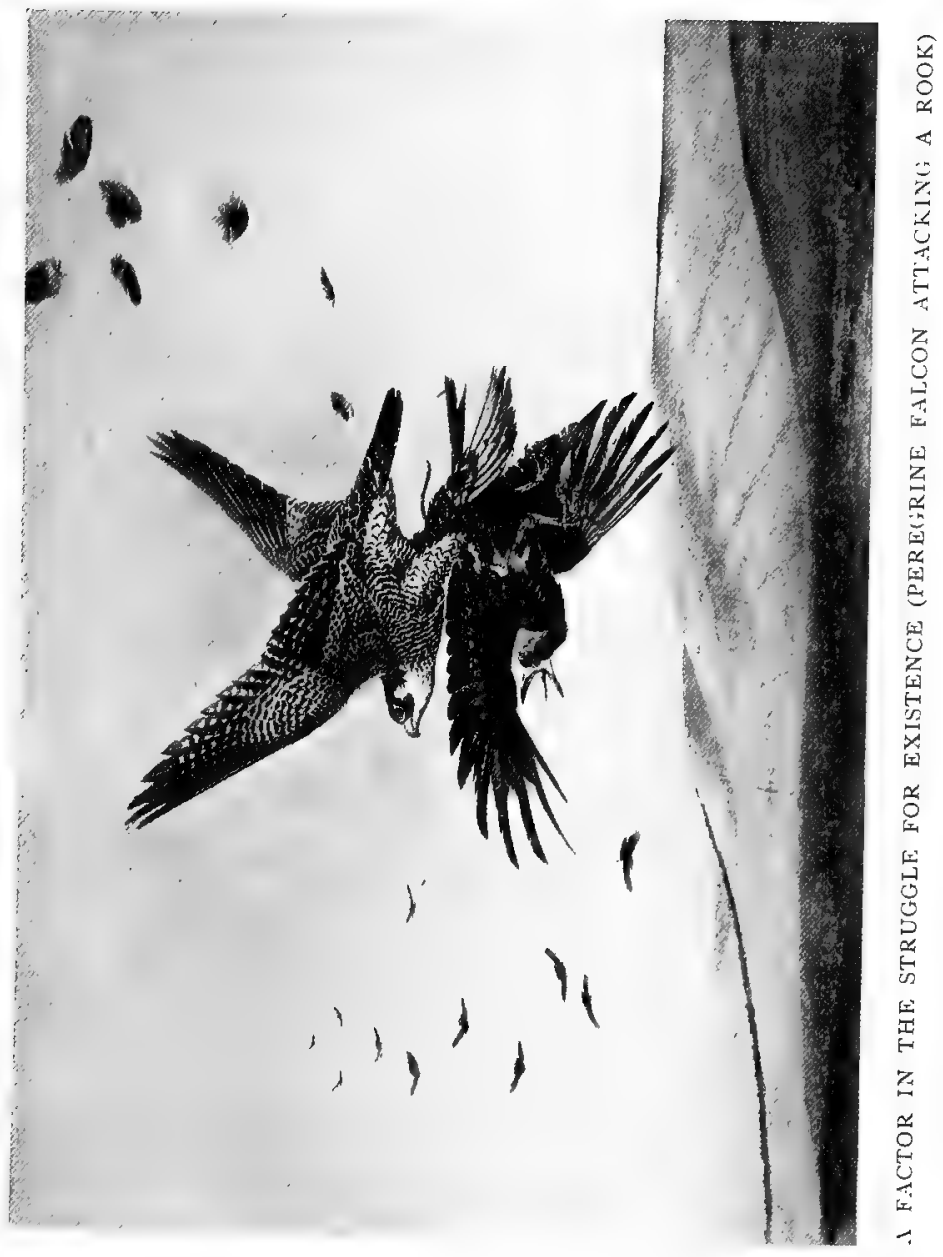


we must remark that the phenomena which are apparently due to this cause are both varied and complex, and subtly interwoven.

While in some species the victims of this struggle succumb completely, in others they escape, either by adopting new habits or by undergoing a more or less radical change in external appearance. Inability to respond to new conditions means extinction; adaptability, on the other hand, means evolution, though all evolution is not to be attributed to this cause.

Though extinction does not necessarily imply an inability on the part of the exterminated to combat the ravages of predatory species, but may be due to climatic or other causes, there are many cases on record where one species has been ousted by another over areas of greater or less extent, and this in some cases may have led to extinction.

This replacement of one species by another is well illustrated, for example, in the case of the Common Sparrow (Passer domesticus). Throughout England this pest is ousting both the House- and the Sand-martin, whole colonies of which have been dispossessed in this way; and similarly, the Purple Martin (Progne subis) is being crowded out in the United States. In like manner the Puffin (Fratercula arctica) has replaced the Manx-Shearwater (Puffinus anglorum) on some of the Islands of the Inner Hebrides. The latter, according to Yarrell's British Birds, "on St Kilda and on Pabbay . . . was formerly very common, and the young ones... . were so highly esteemed that a barrel of them formed part of the rent paid by each crofter in Mingalay to the Macneills of Barra. About a hundred years ago, however, the Puffins, which before were not numerous, began to increase very much, and drove the Shearwaters from the holes which they occupied in the cliffs : and now they have completely supplanted them, so that only a few pairs of Shearwaters are left on the Island of Pabbay." Throughout Great Britain the Jackdaw is ousting the Cornish Chough. In Greenland two forms of the Fulmar Petrel (Fulmaris glacialis) are met with, a light- and a dark-breasted form. Major (now Col.) Fielden, when visiting this region observed that the light-breasted birds domineered over the dark-breasted, which are somewhat smaller. In Australia the Common Starling (Sturnus vulgaris) was introduced some 
years ago to eat the fruit-destroying caterpillars. But they soon transferred their attentions to the fruit, and have multiplied exceedingly. Further, they have taken to evicting Kingfishers, Tree-swallows and Tree-creepers from their nests, and it is possible, within a few years, may even exterminate these feebler species. In Inaccessible Island, one of the Tristan Da Cunha group, Moseley found that feral pigs had well-nigh exterminated the Penguin (Catarrhactes chrysocome), which formerly abounded there, only a few remaining at one corner of the island, and these had contrived to survive by nesting in holes, out of reach of the pigs-a habit of nidification not practised by this'species elsewhere. Plenteous remains of these Penguins testified to their former abundance.

The great Skua, a predaceous Gull, is a bird which adds considerably to the struggle for existence among the birds amid which it dwells. Not only does it persistently-like all its relatives-pursue all other Gulls coming in from the sea, and compel them to disgorge their latest meal, but levies a heavy toll on the smaller species of Petrels, either dragging them from their burrows, or seizing them as they leave at twilight for the fishing grounds. It is exceedingly probable indeed that the nocturnal habits of these latter birds have been adopted as a more or less effectual means of escape from persecution of this kind. For, as is well known, most of the Petrels do not emerge from their underground retreats until their neighbours have retired to rest. During the breeding seasons these predatory Gulls work great havoc among the eggs and nestlings of every species within their range. In the desolate wilds of the Antarctic the same policy of rapine is pursued by McCormick's Skua, a species not easily distinguishable from the Great Skua of the northern hemisphere. This bird wages a ruthless war on the great hordes of Adelie Penguins which contrive to find in these icy regions a congenial home. Dr. E. A. Wilson, the naturalist to the British Antarctic expedition of I90I, vividly describes the audacity and cunning which these marauders display in seizing first the eggs and later the young birds. With an almost unlimited supply of victims so easily procured, this Skua would doubtless soon multiply enormously-though this increase would inevitably be ultimately reduced, in proportion as the Penguins decreased-but for the fact that they 
prey no less viciously upon the eggs and young of their own species. And this inter-necine warfare becomes intensified through the extraordinary pugnacity of their own nestlings. Never exceeding two in number in each nest, these chicks, while yet in their downy plumage, will " fight tooth and nail with one another over some trivial bit of food, locked each to the other by every claw, and fighting with loud squeals as they used their tiny beaks." "It is a noticeable fact," continues Dr. Wilson, "in connection with this bird that only one of the two hatched in a nest survives. This is connected with the tendency of the young to wander and get separated, and also with their tendency to fight, and with the instinct which teaches the parent to be chary of giving them too much nursing. The consequence of all this is that while the mother is engrossed with one, the other wanders out of reach and is sooner or later snapped up by a hungry neighbour."

Selection here certainly secures the survival of the strongest and most pugnacious individuals of each generation; and tends at the same time to preserve and increase raptorial structural characters-large claws and beak. And the Skuas are remarkable for these particular characters.

The subject of intra-specific selection among birds was very lightly touched upon by Darwin. He selected but two instances, drawing numerous others from other groups of the animal kingdom.

Under the heading "The Struggle for Life most Severe between Individuals and Varieties of the Same Species," he wrote :-

"As the species of the same genus usually have, though by no means invariably, much similarity in habits and constitution, and always in structure, the struggle will generally be more severe between them, if they come into competition with each other, than between the species of distinct genera. We see this in the recent extension over parts of the United States of one species of Swallow having caused the decrease of another species. The recent increase of the Missel-thrush in parts of Scotland has caused the decrease of the Song-thrush."

The species of Swallows were not mentioned by Darwin, and though American writers have several times quoted this passage for their several purposes, and always with tacit ap- 
proval, they have never identified these birds. Accordingly I wrote, for the purpose of this chapter, to my friend Dr. Johnathan Dwight, a distinguished American Ornithologist, asking him for confirmation of this statement, and the names of the Swallows. He replied that he had no knowledge of the fact, and further that he had every reason to believe that Darwin had been misinformed on this matter. The statement concerning the Missel-thrush is also not confirmed.

Among birds which rear two or three broods in a year it is no uncommon thing for the young of the first brood to assist in feeding those of later broods, as for example in the Common Water-hen (Gallinula chloropus) and among the Thrush tribe. On the other hand, birds which have but few young, and a relatively limited food supply, spread over a large area, drive away their young so soon as they are able to fend for themselves, as for instance among the Eagles and Ravens. Unnatural as this may seem, such conduct when more closely examined proves, on the contrary, to be extremely prudent, since the struggle for existence is lessened thereby, both for the parents and the offspring. Moreover, Eagles do not become mature for many years, so that, during this period of infertility these immature birds would seriously endanger the lives of all the subsequent broods reared by their parents, while, on attaining fertility they would still further intensify the struggle for food.

Striking as are the facts herein set down they are completely eclipsed, in interest, by those which that able naturalist Dr. A. E. Wilson has placed on record with regard to the Antarctic Penguins. And these will be found set forth in some detail in Chapter XVI.

\section{Protective Coloration}

The several instances so far quoted show selection at work in its most violent fashion-banishing, or exterminating, the weaker. But in Nature might is not always right, and the battle is not always to the strong. The persecuted contrives, not seldom, to escape by subterfuge-sometimes apparently deliberate, as by feints either of death or injury. In the cases of which we are now to speak, however, Nature has contrived to secure the survival of the otherwise defenceless by a process of selection which has had the effect of transforming the superficial 
appearance of the persecuted, whereby they have come either to resemble inanimate objects, or to assume a resemblance to species which, from one cause or another, are too respected, or too feared, to suffer molestation.

The evolution of this "apatetic" coloration, as it has been called by Professor Poulton, presents, as we have just indicated, several more or less distinct phases. And of these the colours which he calls "cryptic colours" are extremely well developed among birds; they are "colours which conceal an animal by rendering it difficult to distinguish from some part of its vegetable or mineral environment".

But these cryptic colours may serve two opposite endsthey may either conceal a bird from its enemies, when they are said to be "procryptic colours," or they may enable a predaceous species, to approach its prey unobserved, and such colours are known as "anticryptic".

Procryptic coloration has been brought to a pitch of marvellous perfection in such birds as the Bitterns, for example, but, it is to be noted, this peculiar coloration is invariably associated with posturing of some kind. The Common Bittern of Great Britain (Botaurus stellaris) —alas! no longer common-may be made to serve as an illustration of this device. Haunting reedbeds, the general hue of the plumage of this bird is buff, streaked with black in such a way that the streaks may be made to simulate the colour of the dark space between reedstems which are represented by the buff areas. On alarm the bird straightens itself out so that the head, neck and spine form one vertical line pointing skywards. Thus posed the bird remains absolutely still, till danger is past; the chances of detection amid such surroundings being infinitely remote. How difficult this disguise is to detect has been told of the Little Bittern (Ardetta involucris) of Argentina by Mr. W. H. Hudson. "One day," he says, ". . . when out shooting, I noticed one of these Herons stealing off quickly through a bed of rushes, thirty or forty yards from me: he was a foot or so above the ground, and went so rapidly, that he appeared to glide through the rushes without touching them. I fired . . . and thinking that I had killed him, I went to the spot. It was an isolated bed of rushes I had seen him in; the mud below, and for some distance round was quite bare and hard, so that it would have 
been impossible for the bird to escape without being perceived; and yet, dead or alive, it was not to be found. After vainly searching . . . for a quarter of an hour I gave over the quest . . . and was just turning to go, when, behold! there stood my Heron on a reed, no more than eight inches from me, and on a level with my knees. He was perched, the body erect, and the point of the tail touching the reed grasped by its feet; the long, slender, tapering neck was held stiff, straight and vertically; and the head and beak, instead of being carried obliquely, were also pointing up. There was not, from his feet to the tip of his beak, a perceptible curve or inequality, but the whole was the figure, the exact counterpart, of a straight, tapering rush, the loose plumage arranged to fill inequalities, and the wings pressed into the hollow sides, making it impossible to see where the body ended and the neck began, or to distinguish head from neck, or beak from head. This was, of course, a front view; and the entire under-surface of the bird was thus displayed, all of a uniform dull yellow like that of a faded rush. I regarded the bird wonderingly for some time, but not the least motion did it make. I thought it was wounded or paralysed with fear, and placing my hand on the point of its beak, forced the head down till it touched the back; when I withdrew my hand, up flew the head, like a steel spring, to its first position. I repeated the experiment many times with the same result, the very eyes of the bird appearing all the time rigid and unwinking, like those of a creature in a fit. What wonder that it is so difficult, almost impossible, to discover the bird in such an attitude! But how happened it that while repeatedly walking round the bird through the rushes I had not caught sight of the striped back, and the broad dark-coloured sides? I asked myself this question, and stepped round to get a side view, when, mirabile dictu, I could see nothing but the rushlike front of the bird! His motions on the perch, as he turned slowly or quickly round, still keeping the edge of the blade-like body before me, corresponded so exactly with my own that I almost doubted that I had moved at all. . . . I also found as I walked round him, that as soon as I got on to the opposite side and he could no longer trust himself on his perch, he whirled his body with great rapidity the other way, instantly presenting the same front as before. Finally I plucked him 
forcibly from the rush and perched him on my hand, upon which he flew only fifty or sixty yards off, and dropped into the dry grass. Here he again put into practice the same instinct so ably that I groped about for ten or twelve minutes before refinding him. . . ." Among a great number of desert birds, and birds which haunt heaths and sandy plains, the coloration harmonises remarkably, as we have already seen, with the surrounding earth. And such birds, when threatened by danger, endeavour to escape by flattening themselves out, or lying prone upon the ground, and remaining there perfectly motionless for some considerable time. The Norfolk Plover and the Courser well illustrate this. The hen Pheasant, and Partridge, and the Snipe and Woodcock are further illustrations thereof, and such instances might be enormously extended. Even birds of striking coloration, such as the Hoopoe, contrive to mask their presence when threatened. The Hoopoe, at such times, throws itself flat upon the ground, and simultaneously spreads out the wings. As a consequence, it looks so little like a living animal that it secures escape where escape seems impossible. But there are dozens of similar cases.

Instances of anticryptic coloration are hard to find among birds. They are developed, as we have already remarked, by predatory species, and for the purpose of enabling their possessors to approach their victims unawares. The best, and perhaps the only clear case, is that of the Snow Owl, which, from its white plumage, is enabled to creep up unawares upon its unsuspecting prey, which is also commonly coloured white, it must be remarked-such as Hares and Ptarmigan and Willow-grouse.

It must be pointed out, however, that the interpretation which has been placed on the significance of the winter whitening of Ptarmigan, Willow-grouse and Arctic Hares has been much challenged. And among these objectors are to be reckoned naturalists of wide experience in the field, and their dissent is based on observations which demand more attention than they have yet received.

Undoubtedly the most serious of the arguments which they have brought forward with regard to this particular coloration, is that the animals in question do not, as has been assumed, pass the winter on the surface of the snow, but in 
burrows tunnelled beneath. And these are apparently made, primarily, for the purpose of obtaining the food which lies buried beneath. Even our British Grouse-which does not, like its congener the Willow-grouse, turn white in winter-after a heavy snowfall resorts to this practice, according to Mr. Abel Chapman, who is certainly a naturalist of ripe experience. Seeking Grouse on a moor in Northumberland during the Arctic weather which prevailed in January I88I, he says in the Bird Life" of the Borders: "Yet one scans for miles that wide expanse of glistening snow, till eyes ache . . . but not a single bird is there. The Grouse, as a matter of fact, are all deepburied beneath the snow. This one presently discovers on coming across a perfect network of burrows-most nearly resembling a rabbit warren. You may have seen afar... just the head of one Grouse, the sentry on guard [though we contend that the evidence for this 'sentry-go' is of the flimsiest]. Quite as often, this precaution is neglected, and a whole pack will be asleep in their burrows, secure, they imagine, by the miles of snow-fastnesses around them.

"The site usually selected for these burrows is on some steep slope; but always where the heather is old and shaggy, and when its strong, shrub-like stalks keep the snow loose and open beneath." This habit is, he suggests, a survival of a habit once general when, during an earlier period in time, the ground was covered for months. And he urges in support of this the case of the Willow-grouse in Spitzbergen. "That race of Grouse," he writes, "enjoys but four months of life in daylight, and above ground; the remaining eight being perforce spent in snow-burrows and tunnels in the dark." Here they have provided " not merely a home, but-more important stilla full winter stock of provisions. For these early autumnal snows hold enclosed within their soft and easily excavated recesses the whole abundant crop of Arctic wild fruits and berries 'preserved' for the birds' winter needs and guarded by the frost-steeled roof above, against risk of decay."

It is possible, however, that some error in the interpretation of these facts has been made, and until further observations have been made on the habits of these birds under these conditions we prefer to suspend judgment.

But there are a number of birds which have developed still 
more remarkable phases of coloration. Herein quite harmless and passively disposed birds have developed a superficial resemblance to species which, from one cause or another, inspire fear and dread among other species; while on the other hand, there are birds which, for aggressive purposes, have assumed the guise of harmless species-wolves in sheep's clothing. That is to say then, we have here a number of species which, for particular reasons, have assumed the likeness of other birds, instead of a likeness to inanimate surroundings; they are mimics.

The evolution of this mimicry is doubted by some, the resemblance referred to being put down as accidental. Professor Poulton, however, and a great many more who have studied this matter, agree rather to regard the facts as the result of natural selection, which has given rise on the one hand to protective mimicry, and on the other to aggressive mimicry.

These two forms of coloration though "apatetic" in character are regarded by Professor Poulton as forming a separate group--pseudosematic colours. And these he divides into pseudaposematic colours-protective mimicry, and pseudepisematic colours-aggressive mimicry.

Protective mimicry, or pseudaposematic coloration, is well illustrated among birds by the Common Cuckoo (Cuculus canorus). This bird presents a really striking resemblance to a Sparrow-hawk, and thereby, it is supposed, it is enabled to carry on with ease its nefarious practice of putting its young out to nurse. Among small birds, such as are victimised by the Cuckoo, the Sparrow-hawk is greatly dreaded. So disguised then, the male Cuckoo, when his paramour is ready to dispose of an egg, hovers over spots likely to contain nests of the desired foster-parents. These threatened, as they suppose, by the bully of the country-side, at once commence to buffet him, gaining courage, in the defence of home, which at other seasons of the year they cannot command. Under this attack the pretended marauder beats an affected retreat, followed by his puny adversaries. When the pursuit has carried away the pursuers sufficiently far the female quietly slips up to the nest and then drops in her egg. On the return of the frightened birds, they either fail to notice the addition to the nest, or are indifferent, finding the eggs they left still whole. 
The Indian Cuckoo, known as the brain-fever bird (Hierococcyx varius), even more closely resembles the Indian Sparrowhawk or Shikra (Astur badius). "All the markings of the Hawk," says Mr. Frank Finn, "are reproduced in the Cuckoo which is also of about the same size, and of similar proportions in the matter of tail and wing; and both Hawk and Cuckoo having a first plumage quite different from the one they assume when adults, the resemblance extends to that too. Moreover, their flight is so much the same that unless one is near enough to see the beak, or can watch the bird settle and see the difference between the horizontal pose of the Cuckoo and the erect bearing of the Hawk, it is impossible to tell them apart on a casual view.

"The Hawk-cuckoo is parasitic on Babblers, and it has been observed that when it appears these birds absent themselves as speedily as possible, so that it has every chance of depositing its egg, which is blue like theirs, in security. Moreover, like the Drongo-cuckoo, it no doubt profits in a general way by resembling a bird much stronger than itself."

The Drongo-cuckoo (Surniculus lugubris) to which allusion has just been made, is an Indian species which bears a very striking likeness to the Drongo-shrike (Dicrurus ater), both being black and having long forked tails. The Drongo-shrike or "King Crow" is a very common bird in the East, and particularly pugnacious in disposition, successfully driving away from its haunts such predatory species as Crows and Kites. Hence the Cuckoo doubtless derives advantage from its resemblance to a bird which is held in such respect by the bullies of the region in which it lives. But the Cuckoo has pushed its likeness to the Shrike to the very bounds of impudence, for thereby it obtainswhat in any other dress it would certainly never do-access to the nest of its model, and herein it lays its eggs and there leaves them to be hatched. These pugnacious birds, so successful in keeping at bay all obviously not of their own kind, are yet by stratagem prevailed upon to rear the young of a parasite! Another Indian Cuckoo the Koel (Eudynamys), which is found also in the Malay Archipelago, is no less successful in the art of mimicry, and this, in order that it may similarly victimise a species of Starling-the Myna (Eulabes javanensis). Both sexes of the latter are black, and their young are also black. 
Now in the Cuckoo the male only is black, the female being brown. But this is of no consequence, for when these reprehensible parents desire to foist their offspring on their dupes, the male takes upon himself the task of drawing off the owners of the chosen nursery. The sequel, however, is curious. As a rule, when the male differs from the female in plumage among birds, the young resemble the female. Did this rule obtain with the young of the Myna they would speedily be destroyed by the jealous foster-parents. But it does not obtain, the young instead resemble the male parent, and don a black dress, whereby they resemble the young Mynas, and so escape detection!

But besides cases of mimicry which appear to have been evolved for the purpose of rencering parasitism possible, there are many others which have had a more worthy object-if any such could be regarded as instances of conscious mimicry, which of course is not the case. There are cases where the subjects are weak and defenceless, but' where, by assuming the guise of a pugnacious species they have escaped persecution, and lessened the severity of the struggle for existence.

The Orioles and Friar-birds of the Malay Archipelago furnish the best-known examples of this kind of mimicry. The Friar-birds are large honey-suckers, belonging to the Genus Tropidorhynchus. Dull in plumage, but armed with sharp curved beaks and strong claws, they are well able to take care of themselves, and would seem to be more or less dreaded by their neighbours, being noisy birds which go about in small flocks, and successfully drive away Crows and Hawks which venture too near their haunts. The Orioles, on the other hand, come of a very brightly coloured stock. But where they live in the same area with the Friar-birds they have assumed a similar dull coloration. "In each of the great Islands of the Austro-Malayan region," says Alfred Russel Wallace, "there is a distinct species of Tropidorhynchus (Philemon), and there is always along with it an Oriole that exactly mimics it. All the Tropidorhynchi have a patch of bare skin around the eyes, and a ruff of curious pale recurved feathers on the nape, whence their name of Friar-birds, the ruff being supposed to represent the cowl of a friar. These peculiarities are represented in the Orioles by patches of feathers of corresponding colours: while 
the different tints of the two species in each island are exactly the same. Thus in Bouru both are exactly brown; in Ceram they are both washed with yellow ochre; in Timor the undersurface is pale and the throat nearly white." So close is the resemblance between the two, that even expert Ornithologists have been deceived. The Oriole of Bouru was actually described and figured as a honey-sucker!

But what has been cited of late years as one of the most remarkable of all these instances is that of a Bulbul (Tylas) which mimics a Shrike of the Genus Xenopyrostris. These are natives of Madagascar. The Bulbul, a perfectly defenceless species, mimics the aggressive Shrike. I am sorry, however, to have to rob this instance of much of its importance, for a careful study of the skeleton of Tylas shows that it is not a Bulbul at all, but a species of Shrike, though not of the same family as the Xenopyrostris. Thus, in this case the resemblance may be rather an accidental one. The mimicry of the Friar-bird and Oriole may stand for the present at any rate, but none of the Orioles seem to have been examined by an anatomist.

We must pass now to a brief survey of the phenomena of aggressive mimicry; that is to say, of mimicry wherein an aggressive species assumes the livery of a harmless species in order that it may thereby the more easily approach its prey without exciting suspicion.

A case in point has been cited by Wallace on the authority of Mr. Osbert Salvin, an Ornithologist who, during his lifetime, had few rivals. This was furnished by a bird-eating Sparrowhawk (Accipiter pileatus), which, in the neighbourhood of Rio Janeiro, assumes a very close likeness to an insect-eating Hawk (Harpagus diodon). The latter naturally excites no fear among other birds, and consequently, its rapacious mimic is enabled to approach and seize its prey with ease. "The curious point, however, is," remarks Wallace, "that the Accipiter has a much wider range than the Harpagus, and in the regions where the insect-eating species is not found it no longer resembles it ... thus indicating that the red-brown colour [which is the character common to the two when found together] is kept true by its being useful to the Accipiter to be mistaken for the insecteating species, which birds have learnt not to be afraid of."

One of the fierce Hawk Eagles (Spizatus lanceolatus) of the 
Island of Celebes closely resembles the inoffensive Honeybuzzard (Pernis celebensis) of the same island, and this in both its immature and adult plumages.

Similarly, the South American Caracara or Curassow-hawk (Ibycter americanus) bears a wonderful resemblance to one of the Game-birds of the same region-a Curassow of the Genus Ortalis. Now the Caracara is primarily a Carrion-hawk, but will eat small birds whenever he can get them-which is generally by stealth. Like the Curassow, which he so closely resembles, he sits motionless for hours in a tree, and thinking no evil of a Curassow, small birds come and perch beside him, when they are seized before they can realise the mistake they have made!

No one supposes, of course, that these instances of mimicry in any way imply a conscious mimicry. Nor is it likely that they are the outcome of a process of selection whereby the individuals concerned assumed, by slow degrees, their ultimate likeness one to another, a likeness which has been built up out of strikingly unlike material. The case of the Oriole and the Friar-bird, for example, is not to be regarded as an instance of a brilliantly coloured bird, such as Orioles usually are, becoming slowly transformed into one of sombre hues. For it must be remembered that in its immature dress the brightest Oriole is dull. Rather we must suppose that these mimicking Orioles have survived side by side with their models the Friar-bird, be. cause they had not inherited the tendency to develop the bright colours which characterise their relatives in other lands. We must regard them, in short, as representing rather the more primitive stock from which the brightly coloured species were evolved. Any individuals which did tend to develop colour would have been weeded out through the persecution which these congenitally duller brethren escape.

The facts so far submitted have been selected with a view to demonstrating the factors which determine the avi-fauna of any given area, and the factors which govern the coloration and shapes of the individuals of that avi-fauna.

That inter-specific selection is a fact there is scarcely room for doubt. And the reality of intra-specific selection-the struggle between individuals of the same species-should be no less apparent.

The importance of the latter in the matter of the evolution 
of species is profound. Here the victors necessarily have some physical, some structural, advantage over the vanquished. They prevail because better equipped and better adapted for their environment. It was supposed that this superiority owed its existence to the selection of structural variations in the right direction. Since no two individuals of a brood are exactly alike, it seemed obvious that the variations hereby displayed would confer on some individuals a greater fitness for their environment, while in others it would have the reverse effect, and these would sooner or later disappear. The unfit, by one agency or another, in short, became weeded out.

But it is now recognised that a distinction must be drawn between individual somatic variations, variations due to feeding for example, and congenital, inborn, innate variations. That is to say, between what we may call purely individual, physical variations due more or less entirely to post-embryonic conditions, and variations which have their origin in peculiarities of the germ plasm, which are alone transmitted to offspring. Variations of this latter kind, we are now beginning to realise, have a cumulative effect; they show a decided tendency to increase in each successive generation, and are not, as was supposed, swamped by inter-crossing. The sum of all the characters essential to the survival of an individual in the struggle for existence, a struggle against the inanimate no less than the animate environment, must attain a certain minimum standard to ensure survival under the most favourable circumstances. But where the struggle becomes intensified, as by the increase of the species or competition in any form, that standard is raised, and with this comes a change in the facies of the species, or evolution.

This being so then, what is known as intra-selection must be allowed more attention than has hitherto been accorded it.

The congenital variations, to which reference has just been made, are variations which occur in the several organs, and parts of organs, which make up the individual. And these variations, as we have just remarked, once started, tend to go on increasing in each successive generation, so that the survival of this or that peculiarity, be it external or internal, follows on the same laws as the survival of this or that species. We may, in short, in following the history of the development of such and 
such a character, congenitally developed, treat that character as though it were the whole individual. Any undue development, or any deficiency of development, of this or that character may throw the whole organism out of harmony with its environment, and so bring about its destruction. Hence we must recognise an intra-organismal selection.

An admirable illustration of this principle is to be found in the curious development of the lower end of the trachea in the males of certain Anatidx. In the true Ducks-as distinct from the Geese and Swans-the lower end of the trachea, immediately above (cephalad) the right and left bronchi gives rise to a globular bulla, seen in its simplest form in the Genus Anas. In some species it arises from the right, in others from the left side of the trachea, but in all cases it is formed by a fusion of certain of the tracheal rings of which the windpipe is made up. Herein this bulla or "ampulla" has smooth, evenly ossified walls. But in many of the Diving-ducks this ampulla becomes excessively developed, and losing its rounded form takes on a more or less triangular shape, while at the same time the walls become extensively fenestrated so that the osseous portions thereof take the form of a bony skeleton or frame-work supporting an exceedingly delicate tympanic membrane, e.g., Mergansers. We have here, apparently, an hypertrophied bulla on the verge of dissolution; an interpretation the more probable since in some of the Diving-ducks, as in the Scoters (Edemia), it is wanting altogether, while in the allied Eider-ducks it is extremely reduced. In the Mergansers, by the way, there is a bulla on each side of the windpipe, that of the left side being of enormous size. Figures illustrating this point will be found on Ill. 44, p. 403 .

If a large series representing different genera and species of Ducks be examined these bullæ will be found to exhibit a most perfectly continuous evolution and devolution; and this irrespective of external characters, and apparently also of the habits of the birds; at any rate they appear to be only very roughly approximated to the bird's mode of life. As in cases of other organs, and structural peculiarities, they appear, in short, to be not very intimately associated with the problem of the struggle for existence.

The skeleton affords almost innumerable instances in sup- 
port of this contention that intra-organismal selection may proceed along lines which, though resulting in evolution, yet appear to have no relation to the struggle for existence, or to the question of the evolution of species.

Let us take one or two examples. The casque which surmounts the head of the Cassowary is composed of a mass of cancellated tissue of great delicacy, ensheathed in horn. Originally, there can be but little doubt, this ossification was purely dermal and rested upon the frontal and nasal bones. In course of its further development the base of this mass of bone fused with the mesethmoid or median partition of the orbits and nasal region. Later, by its backward extension it came to rest upon the frontals. With this relationship an absorption of the frontal so covered gradually took place until, as in the skulls of the Cassowaries of to-day, this absorption has become so complete that the hinder end of the base of this casque has actually eaten its way, as its were, into the brain case, so that it now forms a part of the actual brain covering. Thus we have a parallel case to what has happened in the formation of the carapace of the tortoises where what were sometime dermal ossifications now take the place of ribs!

Similarly, the squamosal bone in birds was originally a purely external bone, overlying the parietal, otic, lateral occipital, but in the majority of living birds it has gradually absorbed the underlying osseous tissue and has forced its way, so to speak, into the interior of the skull. Here again is a process of evolution which cannot be supposed to have any influence, or at any rate any conceivable influence, on the question of the struggle for existence and the origin of species.

The problem of intra-organismal selection then is one of great difficulty, but it is also of entrancing interest. The struggle between the parts appears to go on irrespective, in a sense, of external conditions and is yet controlled thereby. Intraorganismal selection, in short, suffers no check from external conditions until, and unless, the results of this selection puts the organism as a whole out of harmony with the condition of existence. But it is in this struggle between the parts that we must look for evidence of the origin of species. 


\section{CHAPTER XX}

\section{ARTIFICIAL SELECTION}

The evolution of the domesticated races of Pigeons, Fowls, etc. Reversion of domesticated races to the wild, ancestral type. Physiological and morphological species. Fertility and the test of species.

7 HOSE who have but a slight acquaintance with zoology, that is to say, those whose knowledge of wild animals is, by force of circumstances, limited, must always find it difficult to grasp the real meaning and full significance of the evolution theory. If, however, those thus handicapped would turn to the study of the various races of domesticated animals much that was obscure would soon become clear. In the present chapter it is proposed to deal shortly with the main results of Darwin's work in this field, in so far as birds are concerned.

As the outcome of his years of patient labour it has now become a matter of common knowledge that the various types of Pigeons, Fowls and Ducks, for example, have been created by the exercise of the breeder's art-by the selection for breeding purposes of individuals which presented any particular feature which he desired to preserve and develop. Starting, in each case, with a wild species, varieties or races thereof have been raised up which now differ more from the original parent stock than wild species and genera differ one from another, in so far as external characters are concerned.

The domesticated races of the Pigeon, for instance, have all been derived from the Rock-dove (Columba livia) still found wild in many parts of Great Britain and the mountainous parts of Europe, and ranging eastwards into India.

From this stock no less than 200 distinct races have been built up. Naturally there is a great deal of intergradation to be found in a survey of this number as a whole, but from among 
this series of forms several extremely well-marked types are to be found, such, for example, as the Carrier, Homing, Turbit, Tumbler, Runt, Fan-tail, Barb, Trumpeter and Pouter. The several peculiarities of these may be gathered from the accompanying illustration.

As to the precise origin of these nothing is known, but some are of considerable antiquity. When the earliest known descriptions of the more ancient breeds are compared with the standard types of these breeds to-day, it will be found that great changes have taken place in their appearance; changes determined by the selective action of the breeders, as they endeavoured to accentuate the several peculiarities of each breed.

The Pouter seems to have been a well-established breed so far back as $\mathrm{I} 600$, and has changed comparatively little since that time till now, a greater length of leg, and a more heavily feathered foot being the most conspicuous differences. The Fan-tail and the Jacobin Pigeons can show a similar lengthy pedigree, both breeds dating back to before 1600 . During the centuries that have elapsed the peculiar carriage of the Fan-tail has been brought into being, and the number of the tail feathers increased; while in the Jacobin the peculiar hood of reversed feathers has been greatly augmented.

These changes, we may repeat, have been brought about by selective breeding. That is to say, the breeders have selected from their stock, for mating, those which gave most promise of reproducing and exaggerating the peculiarities distinctive of their race, while such of their offspring as came short of this were destroyed. By this method some very wonderful results have been attained. Thus in the Barb and Carrier Pigeons the size of the swollen areas of soft, bare skin around the eyes and beak have always been important features; and in each succeeding generation an endeavour has been made to increase these with what result may be seen by a comparison of the heads of the wild ancestor-the Rock-dove-with that of a modern prize-winning Carrier. Similarly, in the short-faced Tumbler, shortness of beak was the desired character; and as a consequence of long-continued selection wherein only those with the shortest beaks were bred from, the beak has been reduced to such an extent that individuals are occasionally hatched whose beaks prove too short to make feeding possible! 

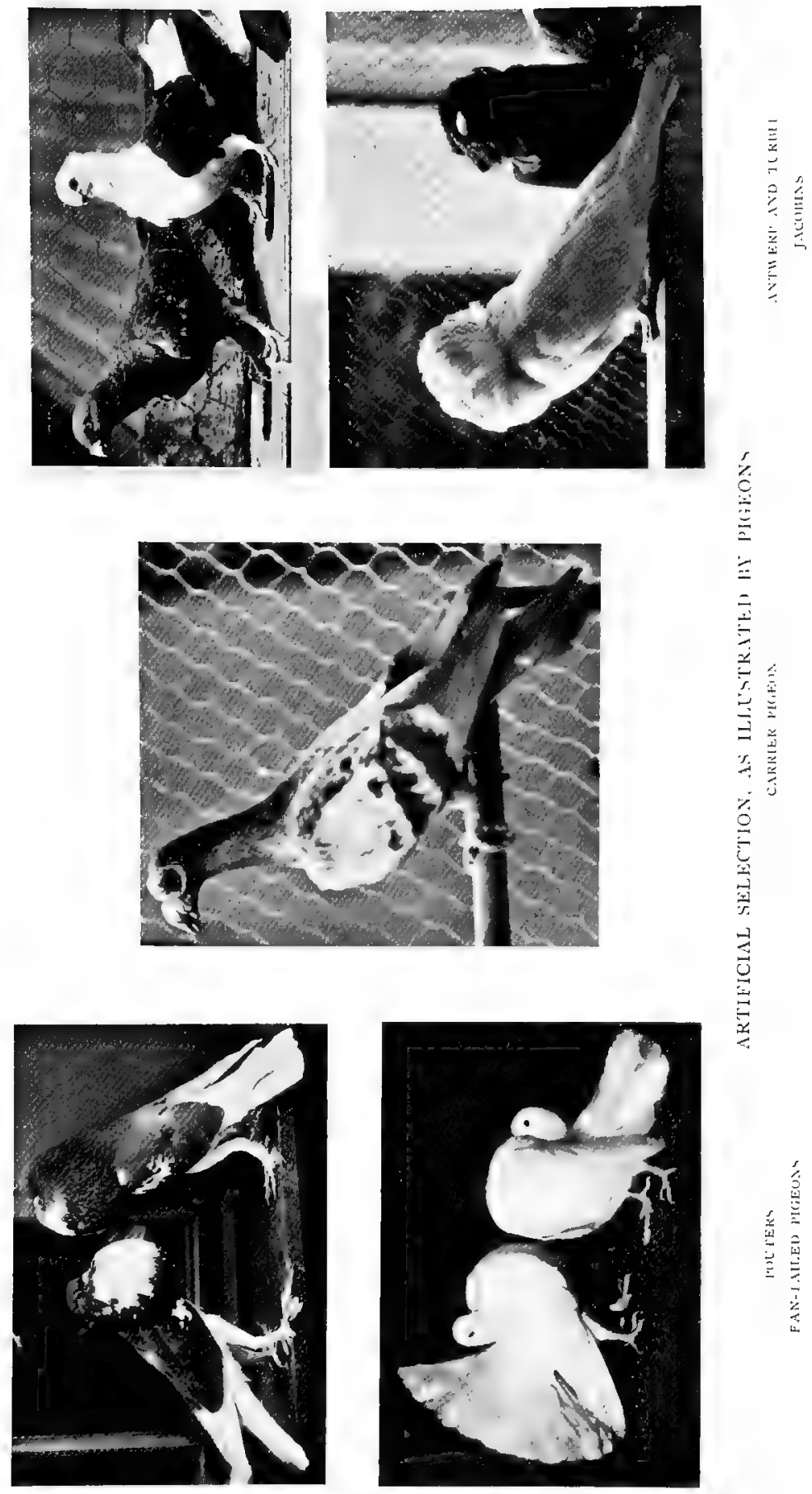

A comparison of the heads of the wild ancestor and of a prizewinning Tumbler will bring out this feature better than a long description.

But besides the external modifications of form, which are the result of man's selection, certain internal structural changes have taken place which have had no part in this deliberate scheme of modification, such as a reduction in the number of ribs, for instance, nor does it seem that this reduction can be correlated with any external characters.

As touching the origin of these breeds, of which examples are given in the accompanying illustration, it would seem that they may have arisen, in the first place, as "sports". That is to say, some more or less sudden departure in this or that direction having caught the breeder's eye, he set to work at once to perpetuate and "fix" such sport, and, by the method of selection already alluded to, gradually built up a new race.

As an illustration of this it may be mentioned that during the last decade a race of web-footed Pigeons has been established, and this not by the cumulative action of selection, that is to say, by the careful selection of those Pigeons which had the largest expanse of the normal webbing between the toes until by degrees a well-marked webbing was produced, but by mating from a single example which showed a pronounced inter-digital webbing, and careful in-breeding therefrom.

The most striking proof as to the contention that our domesticated races of Pigeons have been derived from the Rockdove is that furnished by reversion or the failure to complete the final ontogenetic stages of development. This was first demonstrated by Darwin who crossed a white Fan-tail with a black Barb, then a black Barb with a red Spot-a white bird with a red spot on the forehead and a red tail. The offspring of this cross, the mongrel Barb-fan-tail and Barb-spot, were then crossed, and their offspring developed all the characteristics of the wild Rock-dove! This reversion, it is to be noted, was complete. That is to say, it was not merely blue coloured birds that resulted-caused by a dilution of black pigment by the mating of black-pigmented birds with birds in which pigment was practically absent-but birds that reproduced all the characteristic markings of the Rock-dove, among which are 
specially to be noted the two black bars in the wings, white rump and black-barred tail.

Reversion of this kind seems to occur commonly where birds of remotely related races are mated. This, as Mr. Vernon has suggested in his work Variation in Animals, is possibly due to the fact that the characters built up by artificial selection, and superimposed upon the ancestral characters, are, in such cases of reversion, too violently antagonistic to blend, and by this

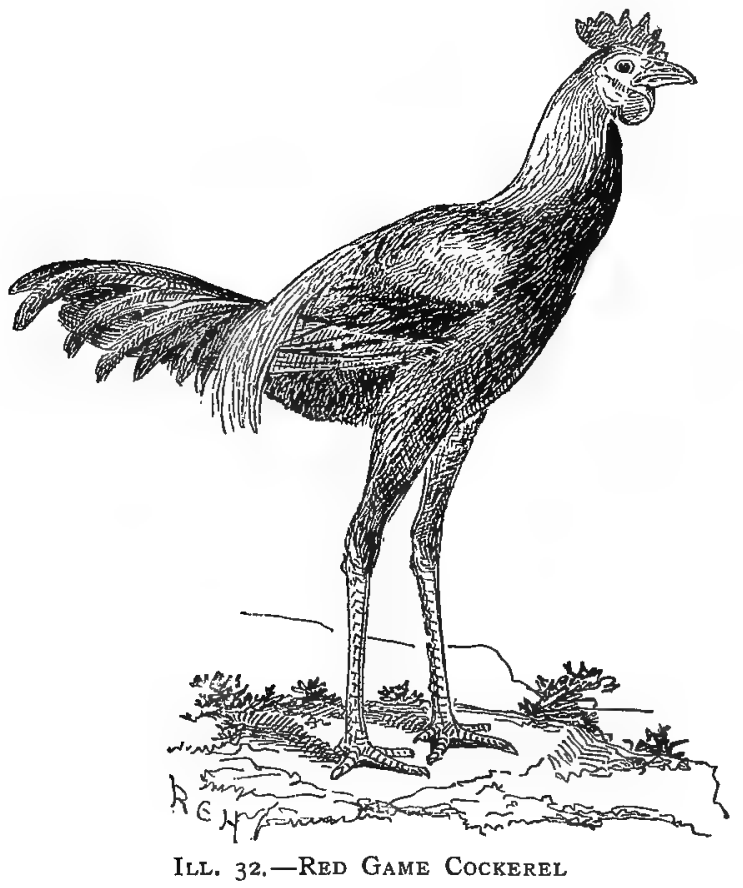

failure to combine allow the underlying ancestral characters to re-assert themselves.

From the Wild Jungle-fowl (Gallus bankiva) man has succeeded in building up a large number of domesticated varieties which, both in size, shape and coloration differ enormously one from another, and from the original, ancestral stock. Take, for example, such breeds as Plymouth-rocks, Wyandottes, Cochin-Chinas, Minorcas, Hamburgs, Spanish, Polish and Silkies, Game-fowls and Bantams. Here are black, white 
and speckled breeds, breeds in which the comb and wattles have been enormously increased-in some the comb is single, in others curiously complicated, giving rise to what are known as rose, pea, and walnut combs-and breeds in which the comb has been replaced by a huge tuft of feathers which, falling down, covers the face so as to conceal the eyes! In some races the feathering has been developed to a remarkable degree, so much so that the legs and toes are thickly covered, while even the

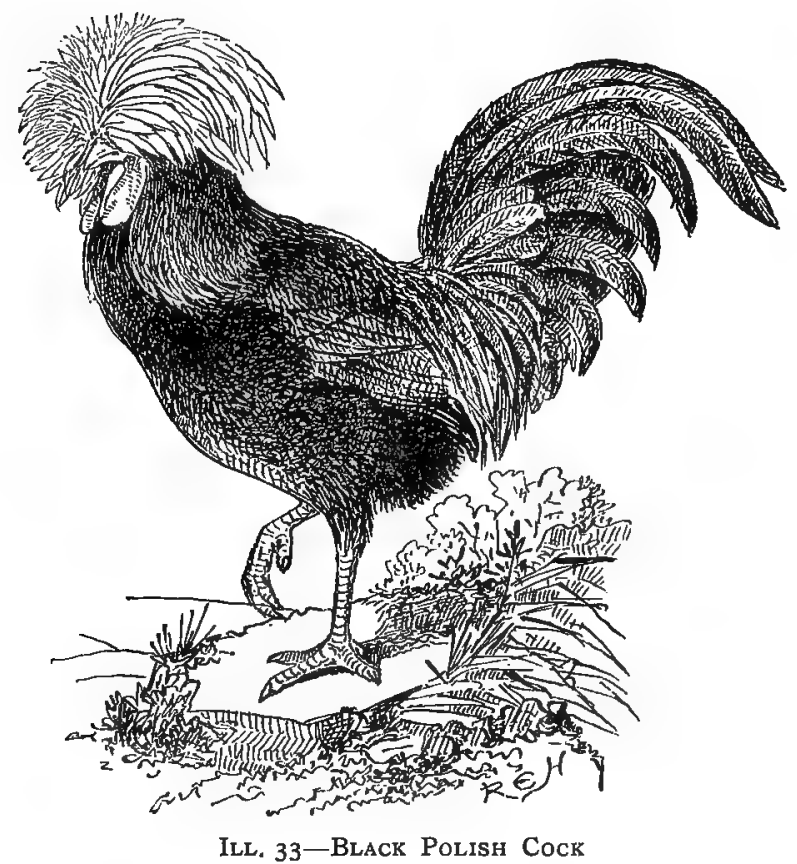

number of the toes have been increased, as in the five-toed Dorking-fowls.

The effect of the cessation of selection is well illustrated, among other things, by the coloration of the chicks. The young of the Wild Jungle-fowl, as in all the Game-birds, are striped; the young of the domesticated races of this Jungle-fowl are rarely striped, and never develop the complete markings of the chick of the parent stock. This character has no significance, no value whatever, to the young of domesticated races, and has 
never been deemed by the breeder a feature worth preserving by selection, hence it has practically disappeared.

From the wild Serin-finch, one of the commonest and best known of all our cage-birds, the Canary, has been evolved by the selective work of the breeder. And if the varieties of the Canary are less numerous than of Pigeons or Fowls, they are certainly as wonderful in the changes of external form which they display.
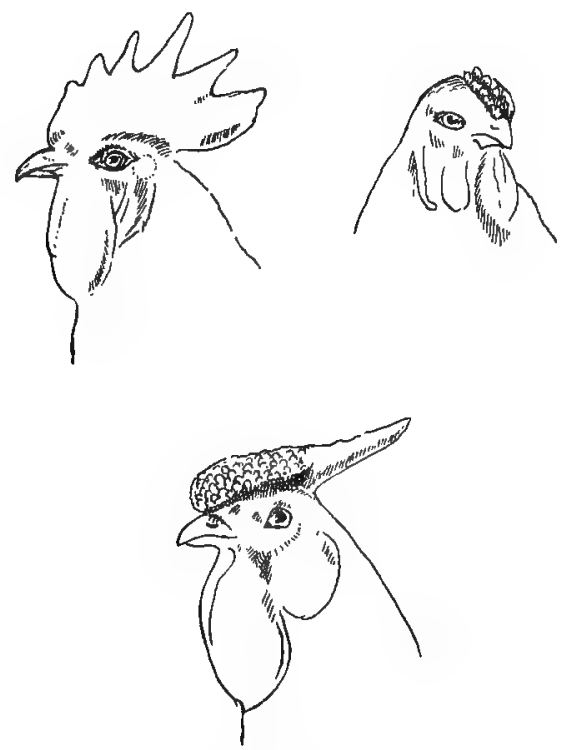

ILL. 34.-Types of ComBs

"Rose" lower, "pea" right-hand, and "single" left-hand figure.

But while Pigeons and Fowls prove singularly plastic in the hands of the breeder, some other domesticated species prove more obstinate. Ducks, Geese and Turkeys, for example, appear to be singularly conservative, and this is especially true of the Turkey, which differs but little from the wild ancestor.

While the precise origin of a large number of these breeds is unknown, in others the evolution thereof can be traced step by step, each change having been effected in response to the demands of the show-pen. In many cases, in striving after some ideal either in size, colour, markings or length of leg, 

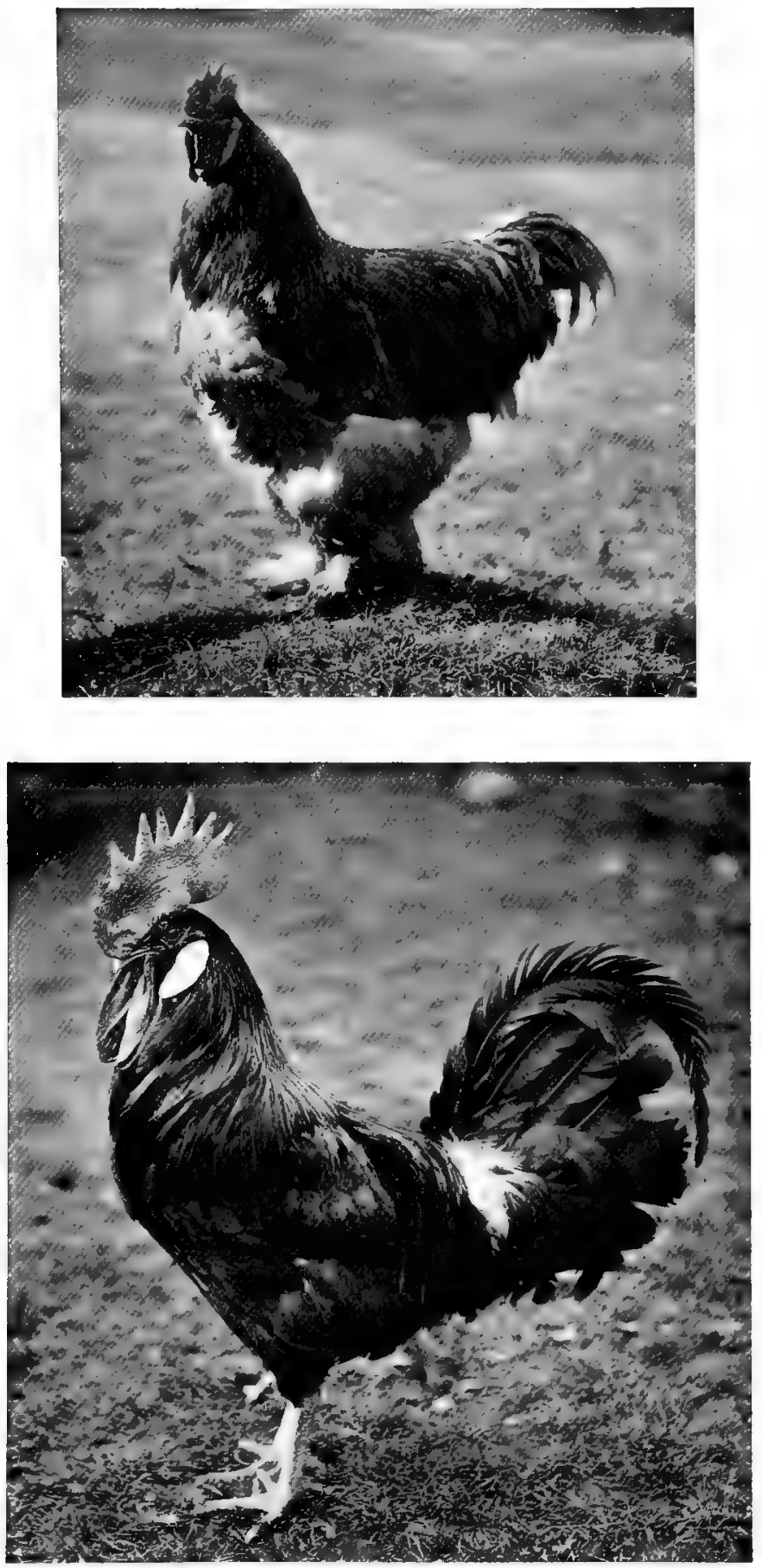

ARTIFICIAL SELECTION AS ILLUSTRATED BY VARIETIES OF THE COMMON FOWL, 
other valuable characters have been lost, since there was no reason to suppose that the development of the one could possibly affect the well-being of the other. Thus the "Gamecock" bred by our forebears for the purpose of fighting has now been changed so materially as to be quite unfit for its original purpose-supposing this were still permitted. Similarly, in the case of other breeds, prolificness has been lost in acquiring other characters which appeal only to the eye.

Man, in short, by selection, by breeding only from those birds which possessed or gave promise of the qualities he desired to improve, has been able to effect nothing short of a transformation in the case of some birds, while in others he has succeeded in changing but little.

One would suppose, however, from the statements of some writers, that the various domesticated races of, say, Pigeons or Fowls, represent the consummation of some pre-conceived standard or ideal: which is certainly not the case. In nature, as Professor Poulton has aptly remarked, Variation leads, Natural Selection follows: with domesticated races Variation leads, the Breeder follows.

Correlated variation is a factor which, however, has always been beyond his control, and has often taken place unperceived by him. In the matter of flight, most domesticated breeds have degenerated, and this is chiefly due to the influence of artificial selection-breeding from birds which showed no inclination to fly, as with Fowls and Ducks-and also, though to a less appreciable extent, to the cessation of natural selection, birds whose wings were below the minimum standard of efficiency as organs of flight, being able to transmit their tendency to degenerate wings to their offspring, because, living under artificial conditions, the struggle for existence, in the avoidance of enemies, or the search for food, has been removed.

The various domesticated races, say, of Pigeons or Fowls, which have been evolved more or less directly under human control-by artificial selection-afford, it is commonly contended, no real evidence in favour of the Darwinian theory of the origin of species by natural selection. And this because "natural" species are infertile inter se, while the domesticated races, which superficially often differ far more widely one from another than do closely allied "natural" species, are 
always fertile when crossed. Natural species are said to be physiological species, as distinct from the morphological species of the breeder. This was Huxley's contention.

But as a matter of fact presumably "physiological" species often prove, when put to the test, to be syngamic, that is to say, fertile inter se. Nowhere is this more true than among the Galli and Anatidæ, while many Passerines show the same fusibility, e.g., the Carrion and Hooded Crows (see p. 30I). The more closely, in short, any given "species" is studied the more does this supposed infertility between it and its near allies break down. We are beginning to realise that, as Sir Ray Lankester long ago contended, the old conception of species must go, and with it must go the word "species" itself. In its place he would substitute the word "forms". Modern zoology furnishes abundant evidence in favour of this view. For any given "species," if carefully studied, will be found to be divisible into a number of geographical "races," often differing one from another only in intensity of colour. The number of these races or sub-species, as they are called, are being constantly multiplied as closer scrutiny is brought to bear upon them, and as a consequence the term "species" is in proportion losing its significance.

Yet the existence of asyngamic forms-forms which, while obviously related, are yet infertile when crossed-as well as of forms with no very near allies, cannot be controverted. These are to be regarded as so many isolated geographical races whose annectent members have perished, and they might well be distinguished by some special term were it not for the fact that it is at present, and is always likely to be, impossible in the vast majority of cases to discover which are and which are not asyngamic. Undoubtedly it would be a good thing to abandon the word "species," substituting therefor some term capable of embracing within its meaning what are now called "good species" and all the variants thereof. But such a word would really have connote generic rather than specific value, as these terms are now understood, and there is little likelihood of such a drastic step being taken by the present generation of biologists. 


\section{CHAPTER XXI}

\section{SEXUAL SELECTION}

Darwin and the theory of sexual selection. The evidence on which his theory was based. Objections to the theory of Alfred Russel Wallace and of H. Eliot Howard. Sexual selection in absence of secondary sexual characters. Consciousness in display of the effect produced, or to be produced. The factors which incite display. The part which sexual selection does play.

$\mathrm{UCH}$ that concerns this chapter has already been touched upon in Chapter $\mathrm{X}$, wherein the relations of the sexes were briefly discussed. It was there shown that during the breeding season birds display very remarkable activity and excitability. This display is manifested, as a rule, by the males alone, and reaches its highest pitch in the presence of the females. With some species it takes the form of passionate outpourings of song, with others of the performance of strange antics, while in yet other cases it culminates in fierce conflicts. But whatever form such demonstrations may take, the apparent end to be attained is always the same- - the capture-either by whiles or by force-of mates.

Darwin, bringing his great intellect to bear upon these phenomena, came to the conclusion that these manifestations of sexual activity were to be regarded as the main factor, if not the only factor, in the evolution of the "secondary sexual characters" - the elaborate ornamental plumage-which characterises so many birds. The resplendent hues of the Humming-birds, the gorgeous train of the Peacock, the marvellous plumes of the Birds of Paradise, for example, were, he contended, developed by the selective activity of the females, who choose as mates those performers which pleased them or excited them most. Though, in certain cases, he argued, these wondrous plumes were the outcome of a process rather akin to natural selection, since, where mates were won by 
battle, victors would be the most vigorous males, and these, by reason of this greater vigour, would naturally develop the more beautiful plumage, as in the case of many of the Gamebirds.

He collected, to prove his contentions, a mass of most telling facts, though much of what he regarded as convincing evidence others have since endeavoured, with greater or less success, to discount.

The most striking of his arguments were those based on the displays of the Peacock and Argus Pheasants. The elaborate and gorgeous train of the one and enormously elongated and wonderful wing feathers of the other, were, he argued, developed through the selective action of the females which persistently choose to mate with the finest performers and most richly coloured.

The Peacock in display most certainly seems conscious of the gorgeous beauty of his train. As we have already pointed out, when courting he commonly approaches the female with the back of this train, which is anything but beautiful, turned towards her, till, when he judges himself sufficiently near, he swings round, and sets every one of the jewelled eyes in the wonderful fan in rapid vibration, as if to overwhelm her with his splendour. The courtship of the Golden Pheasant is no less significant. Here the wonderful collar of black and gold is swung round, sidewards-it is so spread, in fact, as to present this flaming mass of feathers in its most effective manner. And so too with the Ruff. This bird runs up to his mate, and placing himself directly in front of her, lowers his head till the beak rests upon the ground, then the frill or ruff is expanded to the full; and in this position he will remain motionless for a minute or more, commonly only to find, on looking up, that she has moved off to some distant spot, as though to show that the display of such charms moved her not at all! Yet, as we shall show, this interpretation is far from correct. The Sun-bittern (Eurypyga) again, under sexual excitement, spreads his wings in front of his body so that they form a great oval shield encircling his neck, while the tail is similarly extended, displaying a broad black semicircle behind the wings; and this apparently so as to entrance his mate with the exquisitely coloured patterns brought out by this strange 


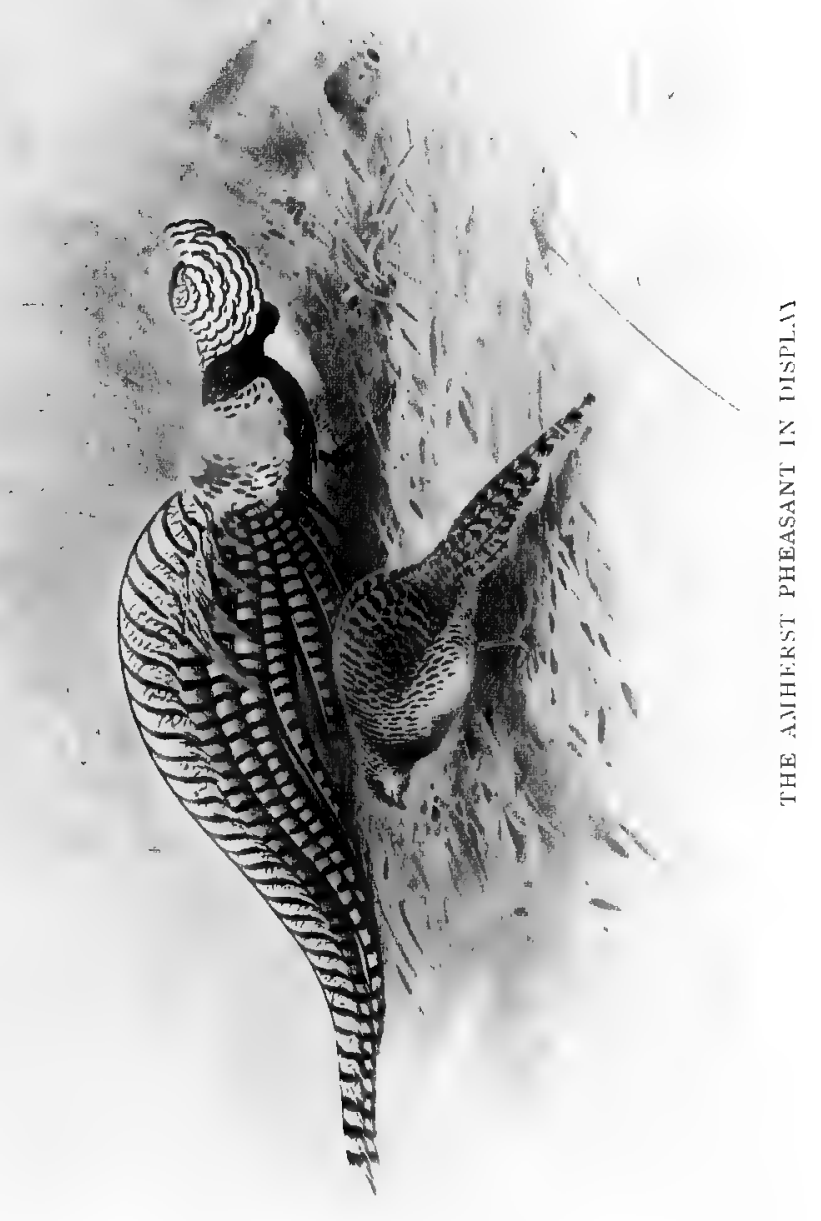



attitude. No less remarkable are the contortions of the Great Bustard, or the grotesque attitude assumed by the Turkeycock and the Amhurst Pheasant. These and other instances already quoted in Chapter X seem to indicate a consciousness on the part of the male of his striking characteristics, and a desire to overcome his mate by the display. It seems reasonable enough to assume that the females are induced thereby to pick out the finest and most resplendent performers to mate with. When such displays are made by solitary males, it is inferred that she accepts him only in the event of his pleasing her. In other words, if his display is not sufficiently animated, or his ornamentation is not sufficiently vivid to excite sexual desire, she rejects or rather ignores him. This being so, then it would follow that the peculiar characteristics of the males would tend, slowly but surely, to gain in intensity. Mr. J. G. Millais, in two remarkable monographs on the British Gamebirds and Surface-feeding Ducks, has brought together a mass of material all tending to support this view of the evolution of resplendent colours by the males. It is not necessary that the fermale should have to make her selection from a crowd of similarly displaying suitors, choosing the finest.

Further support seems to be given to this hypothesis of sexual selection by those singular cases wherein the females are more brilliantly coloured than the males; as in the Hemipodes, Painted Snipe and Phalaropes, for example. Here the females display instead of the males; and accordingly, we may suppose that unless she is a sufficiently skilled performer she will fail in exciting him to mate, and so leave no offspring.

Of many groups no evidence is forthcoming as to the methods of courtship, but some birds seem to combine other means with personal display. Thus Mr. Robert Warren, in the Birds of Ireland, says of the Sandwich Tern (Sterna cantiaca): "When the pairing season commences it is amusing to watch the absurd antics of the males trying to attract the attention of the females. At low water the Terns generally assemble on a sand-bank to rest after fishing, and there the males strut about among the females with an absurd air of importance, their heads being thrown back and their wings drooping, or almost trailing on the ground. After a time, if there is no response from the females, which generally look on 
the performance with the greatest unconcern, one of the males goes off for a time and returns with a sand-eel in his bill, after which he again struts about with wings and head in the same position, offering the sand-eel from one to another of the females as he passes along unnoticed, until at last he meets one who accepts his offering, when he sits down beside her to settle their arrangements for the season."

Having already given many instances of the courtship of birds in Chapter $X$, we may now proceed to refer to the objections which have been raised against the theory of sexual selection, and to set down a few facts in vindication thereof.

The arguments put forward by Dr. Alfred Russel Wallace and $\mathrm{Mr}$. H. Eliot Howard are each, in their way, noteworthy. And these alone will be considered here.

Dr. Wallace contends, and he has found an able champion in the naturalist De Varigny, that the brilliant colours of males are to be regarded as the outcome of excessive vigour-the method of expending the surplus energy over and above what is required for the purposes of procreation. In the females, as a rule, there is no surplus of this kind. Where such excessive vigour has been developed by females which breed, like Pheasants, in exposed situations, they have been exterminated by natural selection, their bright colours making them a mark for prowling enemies; where, however, the females nest in holes there they have acquired this extravagance of habit unchecked. No facts which support the hypothesis of excessive vigour have yet been brought forward. The dull plumage of females of say, Ducks and Pheasants, may very probably be due to the action of natural selection as suggested. But it must be remembered that there are many species wherein the females are markedly duller than the males, and wherein the sitting females cannot be regarded as exposed to danger through discovery, when in the nest, by predatory foes. The Common Sparrow affords a case in point; and many other Finches furnish similar evidence.

Furthermore, he objected to the interpretation of the evolution of the Peacock's train as given by Darwin on the grounds that it implied a rigid and uniform standard of beauty on the part of the females such as is not to be met with even in human society, since the train of the Peacock shows remarkably slight, 



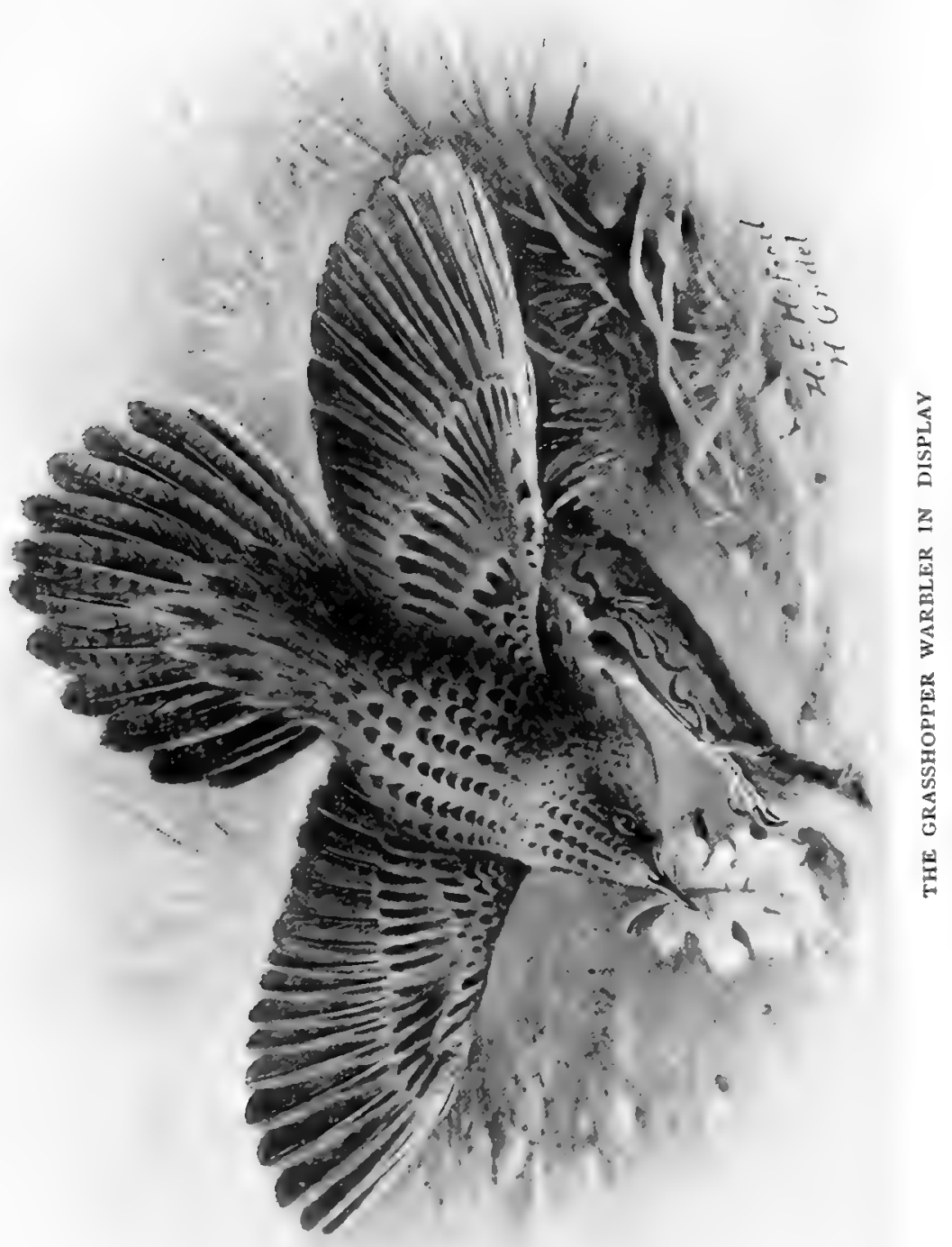


if any, variation. It is significant, in this connection, to note that the Indian and Javan Peacocks, while they resemble one another precisely in the matter of the train, they differ one from another in the shape of the head-crest and in the form of the feathers of the neck, those in the Javan bird being of unusually large size, overlapping one another like great scales, while in the Indian bird they are of a uniform colour, and so soft in texture as to lose their individuality, giving the neck a uniformly bottle-green appearance.

Much more weighty objections have been urged recently by $\mathrm{Mr}$. H. Eliot Howard, who has shown, in his remarkable History of the British Warblers, that these birds of sober hues perform, during moments of sexual exaltation, antics which in every way reflect the displays supposed to be peculiar to birds of brilliant plumage. As a case in point he takes Savi's Warbler (Locustella luscinioides) which during its moments of sexual ecstasy in the presence of the female spreads out both wings and tail, waving the latter up and down, but neither wings nor tail contain any conspicuous markings or colour, while these feathers in the Argus Pheasant are among the most wonderful among birds. But not only when courting does this little Warbler display after this fashion. He performs also when feeding the fully fledged young. Now it is assumed, this author remarks, that the resplendent feathers of the Argus Pheasant have been evolved by the selective action of the females, which, during long ages, have persistently chosen to mate only with the more vividly coloured of her suitors. Thus, by slow degrees the splendour of this bird has been built up. Mr. Howard, however, doubts the correctness of this interpretation, since precisely similar performances are associated with the courtship of the sober-hued Warblers; and further, as he points out, these antics are not confined to the period of courtship.

That there is much force in this contention must be admitted ; and to this point we shall return presently. For the moment a few other cases may be mentioned. There can be no dispute but that all birds, whether of bright hues or of sombre shades, perform what we may call "antics" of some sort whenever greatly excited, and especially during the periods of sexual activity. No better example of this could be cited than that of the Common Sparrow, whose ludicrous caperings must 
be familiar to all. In some species at any rate, it is significant that the females engage in elaborate dances when apparently under the influence of sexual excitement. This has been established, at any rate, in the case of the Greater and Lesser Birds of Paradise. These birds congregate for this purpose apart from the males, which, as we have remarked, hold dancing parties or "saccaleli" of their own. But this by the way.

To continue the tale of Mr. Howard's objections to the sexual selection theory. "The ultimate production," he says, "of the most healthy and most beautiful offspring by the selection [by the females] of certain males is, without a corresponding selection [by the males] amongst the females, impossible, and of the existence of such selection in any form there is no evidence."

But is this really so? In the first place he is arguing, apparently, solely on deductions drawn from a study of the Warblers, wherein there are little or no sexual differences, the males indeed are, in some cases, duller than the females. That the males in this group make no selection, but accept the first female that comes in their way, is surely an assumption. Further, since the theory of sexual selection as a whole is challenged, and not merely as applied to the Warblers, it is legitimate to point out that it is a further assumption to suppose that the mating of dull females with brightly coloured males would never result in a gradual increase of beauty by the males, since such increase has actually taken place in the Pheasants and Peacocks and Birds of Paradise, for example. In the Warblers he believes he has found convincing proof of the futility of the sexual selection hypothesis, since he writes : "Here, then, the impotency of sexual selection becomes apparent, for unless the females that choose the more beautiful males are themselves the more beautiful of the females, they will neutralise the effect of their own selection". The Peacock and the Bird of Paradise disprove this, or rather they show that brilliantly coloured plumage may be transmitted to the males alone-leaving the females dull coloured. We may further assume that should a vigorous cock pair with a hen of feeble constitution his male offspring will suffer. While this disparity in the coloration of the sexes obtains, Mr. Howard seems to imply that this decorative plumage of the males is transmitted through the medium of maternal impressions on 
the embryo, as is indicated in a passage wherein he alludes to our ignorance of the "influence exerted by the female on her embryo, which is profound". On this hypothesis, since she can neither discover nor control the sex of the embryo, both sexes should be coloured alike.

Finally, he concludes: "Little importance need, however, be attached to these difficulties here, since they depend upon the supposition that characters acquired by one sex can be transmitted to that sex only. For instance, if the dull-coloured female Grasshopper Warblers in a given area were to pair with the bright-coloured males, and the bright-coloured females with the dull-coloured males, the result in time would not be the continuation of these same conditions, but the gradual annihilation of the bright or dull colours." The Peacock may be cited as one of a possible hundred examples in disproof of this, and seems to show convincingly enough that this assumed commingling of characters does not take place; such commingling indeed would involve not merely brilliance of colouring but secondary sexual characters of whatever kind.

What are the factors governing the evolution of brilliant colouring we do not know; but there is evidence enough to show that this appears first in the males then in the females, and finally in the young birds-if unchecked, as to the females, by natural selection. The case of Pyrangacited in Chapter XVI, p. 275, may serve as a case in point, and numerous other instances are cited in these pages. This much must be conceded to $\mathrm{Mr}$. Howard, that sexual selection is only an indirect factor in the development of resplendent plumage, for he has shown that the peculiar phenomena associated therewith-displays-are just as fully developed in the absence of gaudy hues. Furthermore, he has shown that the females are indifferent to the most vigorous displays until they themselves become "must" so to speak-a point to which we shall refer presently.

The interpretation of the problem is probably this. Nature secures the mating of the most vigorous birds-whatever their hues-through the stimulus of parental desire which is excited by these "displays". And this parental desire, it is to be noted, is set in motion by the ripening of the sexual glands, secretions, from which-known as "hormones"-are set free, and pervading the body stimulate the nervous system, and at the same time 
the secondary sexual characters-the antlers of the stag, the mammary glands of the female, the "breeding plumage" of the bird. Where there are no obviously secondary sexual characters, as in the case of dull-coloured birds, the result is the same-a state of physical exaltation expressed in "display". Males or females wherein these "hormones" are but feebly developed, display and respond indifferently, and so cease to please the opposite sex. As Mr. Howard has pointed out, in the case of the Warblers, no amount of display on the part of the male will avail until the female has attained a like pitch of preparedness for the work of procreation. The courtship of the Ruffs and Reeves, already referred to, affords another illustration. Here it will be remembered the males for weeks spend laborious days in endeavouring to gain some responsive sign from their prospective but phlegmatic mates, yet without receiving the slightest sign of encouragement or recognition. As soon, however, as the female has become "sexually ripe," as soon as the hormones secreted by her generative glands have done their work, she herself indulges in a species of nuptial dance, waltzing round her lord, and settling down before him with her tail directed towards his head! Thus the sexual activity displayed by the male comes to mean simply that he is more ardent at this time than his mate. The advantage of this is obvious : for thereby the more vigorous males, by proclaiming their desire to pair, defeat their less vigorous rivals, who might otherwise be chosen. The earlier they can take the field, the more persistent their advances, the greater their chances of ultimate success, and this because they slowly instil a preference which cannot be overcome by later and less virile comers.

Very well. We may now consider the development of the striking secondary sexual characters which the males of so many birds exhibit. These must be regarded as on the same plane as all other structural variations-as fortuitous: and, appearing in ever so slight a degree, they can but help to increase the intensity of the display, and add to the chances of success in such males as they first appeared in. This being so, their further development is inevitable, a development which will only be checked, as we have just remarked, by natural selection. In course of time, if unchecked they be- 
come transmitted to the females, and finally to the young (p. 273).

In this last connection it is significant to notice that the young of many species of Warblers are more brilliant than their parents. From which it may be inferred that this evanescent beauty is reminiscent of an earlier adult dress, more richly coloured than that worn to-day.

It is a noteworthy fact that in nearly every large genus, or any collection of genera in any given family of birds, more or fewer lines of evolution in the development of resplendent coloration, starting from dull-coloured species, will be found. The Pigeons, Swallows, Kingfishers and Touracos may serve as illustrations of this fact, but they may be found by the score. The same law, in short, holds in regard to genera which obtains in regard to species. That is to say, in any given family, e.g., Kingfishers, one can start with a genus of dull-coloured species, some of which show evidence of incipient brilliancy, and from thence one can trace several lines of distinctive coloration-grey and white, black and white, blue and white, blue and red, and red; the several species in the respective genera, belonging to any given line of coloration-black, blue and white, or blue and red-showing various combinations of these colours whereby they are specifically distinguished. Here, too, in the dull-coloured species the sexes differ, and the young resemble the female; in the brightly coloured species, male, fermale and young are alike.

The measure of a bird's consciousness of the effect he produces, is one difficult to estimate. Can there, as a matter of fact, be any but the most vague conception in the mind-if we may use this term-of the actor of the appearance he presents to his mate? In many cases this display must be before an audience of one. There can be no model to serve as a mirror, and it is an assumption to suppose that even in the presence of such a mirror there is sufficient intelligence to make the actor realise that the model, albeit his rival, is, as it were, a reflection of himself. Yet, as may be gathered from the foregoing instances, these birds behave as if they were conscious of their appearance. To the list of illustrations let us add yet another. The Kagu (Rhinochatus jubatus) of New Caledonia, when excited, sexually or otherwise be it noted, raises the 
body so as to bring the trunk to a nearly vertical position, and the neck is brought into a line with this when the head is bent down, the beak resting among the neck feathers. The long pendant occipital crest is then raised and spread out fan-wise across the head, while the secondary quill feathers are thrust forwards, and the belly feathers are set on end. Simultaneously the bird struts up and down with a peculiar mincing gait as though swollen with importance and intending to make the most of his charms. No other bird, so far as I am aware,

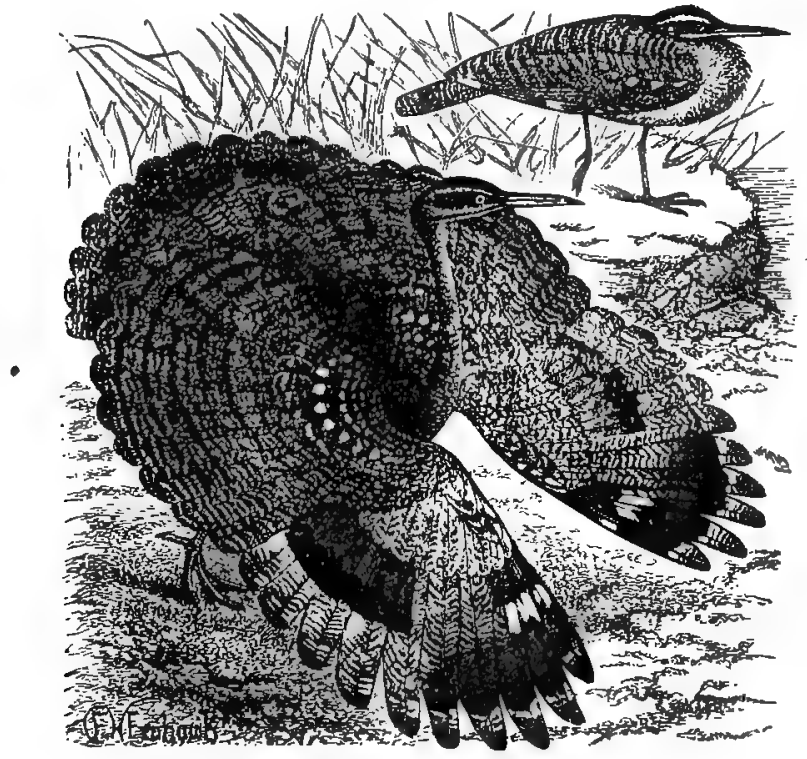

IlL. 35-The Sun-Bittern in Displax

displays after this fashion. Some of the Cranes may do so, but the fact has not been recorded.

How then stands the sexual selection theory at the present day, at any rate as applied to birds?

The evidence seems to suggest that the evolution of resplendent plumage is not to be attributed to the effect of the selective action of the female,-_to the choice, by the female, of the most effectively coloured among her suitors. This development of colour, or of decorative plumage of any kind, of secondary sexual characters in short, must be regarded, apparently, as 



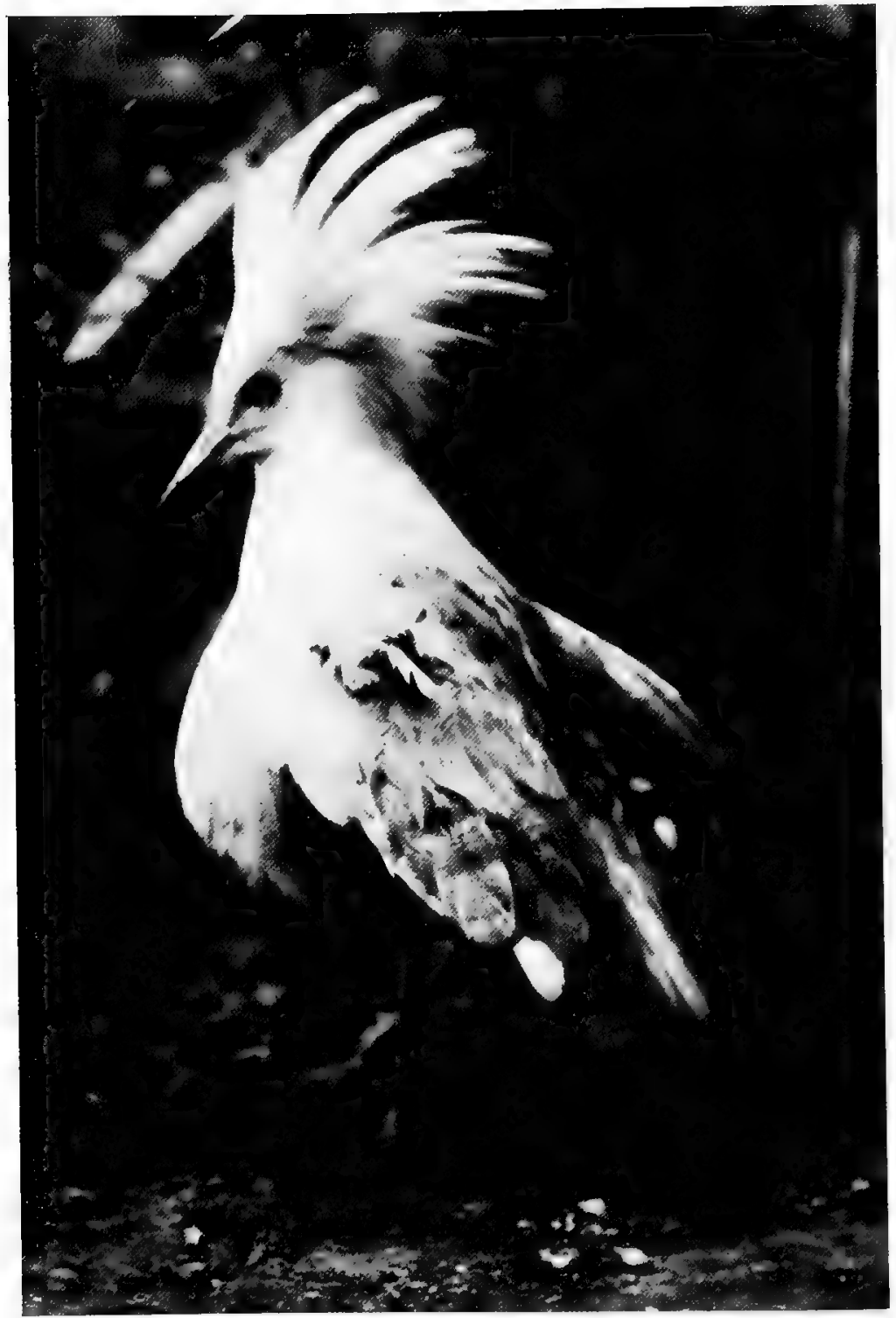

THE KAGU IN DISPLAY 
due to the unchecked growth of such characters, as they appear, apparently fortuitously, in the germ plasm. They are a byproduct of sexual selection, in the sense that they of necessity take part in the sexual demonstrations of the desire to mate. Sexual selection is answerable for the display, inasmuch as the most demonstrative birds have the best, and possibly the only, chance of securing a mate. But neither the brilliant colours nor the excessive development of feathers in this or that area, e.g., the wing feathers of the Argus Pheasant, the long streamers of certain Birds of Paradise, can be attributed to this cause. These are germinal variations which have survived, and may have attained exaggerated proportions, because they formed no obstacle to the struggle for existence, and in this they resemble all other fortuitous variations. They are no more the result of sexual selection than are the characteristic antics of say the Kagu, Sun-bird, Great Bustard, which appear to be unique. This contention seems to be borne out by the fact that birds of the most sober hues affect displays of a character precisely similar in kind to those of birds in which this display appears to be made for the sole purpose of exhibiting to the best advantage some specially modified or beautifully coloured feathers.

There can be no tradition among birds in the matter of display; no means by which each new generation can compare the-standard of perfection of that which preceded it. And this being so, the slow increments made by each generation cannot be appreciated. These secondary sexual characters, like other physical characters, pursue their development in spite of and not because of sexual selection. Their only controlling factor is natural selection. All that sexual selection does is to insist on a display of some sort, accompanied or not, as the case may be, by "embroidery". Undemonstrative birds die without offspring. Generally, of course, a non-demonstrating bird is so because of a lack of virility, and their failure to mate preserves the vigour of the race. 


\section{CHAPTER XXII}

ISOLATION-SPATIAL AND PHYSIOLOGICAL AND DETERMINATE EVOLUTION

Isolation and natural selection in evolution. Natural selection and the origin of species. Isolation and geographical distribution. Variations blastogenic. Romanes and Isolation. Physiological selection. Inter-breeding species. Island forms. Species formation in high altitudes. Discriminate isolation. Determinate evolution.

DHAT organisms possess a tendency to vary in all directions is now generally admitted as beyond dispute, nor is it denied that the only limitation to these variations, the only check upon their undue development, whereby the balance of the whole organism would be endangered, is that imposed by natural selection.

Natural selection, in other words, is charged rather with the execution of Nature's sumptuary laws-with the control or limitation of these variations-than, it would seem, with their origin and causation. And while some of these variations affect the internal policy of the organism, and are often, and indeed generally, too subtle to be readily discerned, others determine its relations to the outer world; and among these last are to be reckoned the "specific characters" of an animal, the sum of the characters by which one group of individuals possessing such and such characters in common may be distinguished from another group presenting similar but different characters.

Stable as these specific characters appear to be, under certain conditions, they can be shown to undergo more or less marked transmutations and thereby a species A may "bud off" so to speak a species B. This process of evolution can be shown to exist whether we follow the history of any given organ through a large number of different and unrelated species treating the organ as if it were an individual, or whether we 
apply this search to, say, the external characters of a large number of individuals. That is to say, whether we elect to trace the ramifications of evolution by means, say, of the study of the convolution of the intestine of fish or grain-eating birds, or whether we follow out the complexities and peculiarities of the plumage which distinguish some particular group of birds. Very well. What then are the factors which cause these changes? Are we to ascribe their origin, whether in organs or specific characters, to natural selection, or to some other factor or factors, or to a combination thereof?

That natural selection is the final arbiter of what shall survive, the sieve through which all the component parts of an organism must pass, may surely be regarded as a well-established dogma. But it by no means follows that natural selection is a factor in the origin either of species or of specific characters.

In endeavouring to account for the birth and development of specific characters, we too commonly ignore the fact that living matter is unstable, and can never reproduce itself exactly. Hence the basis of infinite variety. But each new variation may vary in its potentiality. Such as are appreciable to our eyes commonly, it would seem, tend to increase, to intensify in each generation, and, attaining their zenith, finally wane and disappear.

The evidence afforded by geographical distribution seems to show, pretty conclusively, that "Isolation" is a very powerful aid to the fostering and development of such potentially progressive variations.

This being so then, we may take it that natural selection frames her own sumptuary laws but she does not design the fashions.

Isolation, in whatever form, is, however, like natural selection, incapable of producing variations. These are innate, blastogenic, spontaneous "expression points" of the instability of protoplasm. The more any given group of animals is split up by barriers of whatever kind, the more numerous will, in course of time, become the variation on the common type. That is to say, segregation fosters the survival of variations. Natural selection suffers them, or not.

Romanes endeavoured to show, indeed, that isolation, under one of two forms-spatial or physiological-was the only possible factor in the origin of species. Though this contention 
is by no means proved, or generally admitted, a great deal of evidence may be produced to show that spatial, geographical isolation is commonly associated with the evolution of new species.

But we shall probably be near the truth in regarding natural selection as the dominant factor in evolution-as the mill of evolution; isolation is the "hopper" thereof, which is fed by spontaneous variation. By geographical isolation, for instance, more or fewer individuals temporarily escape the restrictions of natural selection imposed on the individuals occupying the area from which any given species has escaped: thereby these individuals become free to develop incipient characters hitherto held in check. Sooner or later, however, any such fresh development is again checked by natural selection, which inevitably discovers the refuge of the escaped, and imposes thereon the terms under which the newly occupied area may be held.

Romanes' hypothesis, though untenable in its entirety, is. however, most suggestive, and demands a careful examination. He contended, we may repeat, that new species arise only when more or fewer individuals of any given species become isolated, either by physical barriers or by internal, physiological changes affecting reproduction. That is to say, spatial and physiological segregation are the two prime factors in the origin of species.

Spatial, geographical isolation he perceived to be of two kinds, (I) Indiscriminate, and (2) Discriminate. When, by geological subsidences, a number of individuals of a species become cut off from the main body of the species and consequently no selection of individuals possessing certain peculiarities in common is made the isolation is Indiscriminate. This form of isolation he likens to that of the shepherd who divides a flock of sheep without regard to their special characteristics. When, however, he places all the white sheep in one fieid and all the black sheep in another, "he is isolating discriminately". And similarly, when a section of a species develops "a change of instinct determining migration to another area," or when the members of such an imaginary section all develop in common a change of habitat, or change in the choice of food, on the same area as that occupied by the main body of the species, then the segregation is discriminate. 
In the chapter on geographical distribution many instances of Romanes' "indiscriminate" isolation will be found, as for example, by the formation of islands, when, by the encroachment of the sea a section of a species becomes cut off from the parent body on the mainland. The section so isolated, as has been shown in the chapter referred to, invariably comes at last to differ, more or less markedly, from the parent species. And this because any inherent tendencies to vary in this or that direction will have a better chance of surviving, or rather perhaps because the changed conditions have introduced a new standard of selection. Here, in short, natural selection is really at work, for, from whatever cause these variations arise, only such variations as tend to bring the isolated more into harmony with their environment will survive. Or, to put it another way, any variations, whether of size, or colour, or of habit, or instinct, which tend to produce disharmony with the environment, will bring about extinction. Indiscriminate isolation merely removes the checks to the development of new characters that were enforced under the earlier conditions. And the same holds good of discriminate isolation, as when certain individuals governed by the same motives seek new quarters, or adopt new feeding habits. Isolation, then, whether discriminate or indiscriminate, certainly does play a not unimportant part in the origin of new species, but it is a secondary part. It may be likened to a new turn of the kaleidoscope. If the repressive forces of the old order are removed, new conditions are imposed. The fact that, among birds, as among other animals, island forms differ from those of the parent stock on the mainland is probably due chiefly to the influence of new conditions, and in the case of oceanic islands, to discriminate selection, or what amounts to this.

As touching physiological selection it seems clear that the potency of this factor in evolution has been overestimated. The evidence afforded by birds, at any rate, seems to afford this hypothesis but little support: and it is probable that had Romanes, in elaborating this hypothesis, sought for his evidence among birds, he would have been less insistent on the magnitude of the part it is supposed to have played in the evolution of species.

Briefly, Romanes held that new species might arise in the 
absence of such isolation agencies as physical barriers, by the development of intersterility between more or fewer sections of a species occupying a common area, and this he called "physiological selection".

"If no other form of isolation be present," he remarks, "specific divergence can only take place when some degree of cross-infertility has previously arisen between two or more sections of a species.

"When such cross-infertility has arisen it may cause specific divergence, either ( $a$ ) by allowing independent variability in each of the physiologically isolated groups; $(b)$ by becoming associated with any other cause of differentiation already operating; or $(c)$ by both of these means combined.

" As some degree of cross-infertility generally obtains between allied species, we are justified in concluding that this has been the most frequent--or at any rate the most effectivekind of isolation where the origin of species is concerned, and therefore the kind with which, in the case of species formation, natural selection, or any other cause of specific divergence, has been most usually associated."

Though among birds cross-infertility may be regarded as the general rule among certain groups, this occurs freely wherever two or more species overlap in the confines of their range.

Cross-infertility among Passerine birds is the rule, but the Gold-finch and the Hooded Crow are striking exceptions thereto. The British Gold-finch (Carduelis elegans) ranges to the east of the line of the Urals where it meets and inter-breeds with a closely similar but larger species (Carduelis major), while this last in Southern Siberia meets and inter-breeds with $C$. caniceps, a species which has no black on the crown and nape, and more white on the wing. The Hooded Crow (Corvus cor$n i x$ ) in Scotland, on the one hand, and Siberia on the other, meets and inter-breeds with the Carrion Crow (Corvus corone), the resulting hybrids showing every gradation of plumage between the two species, and on this account many Ornithologists insist that these represent but two forms of one species. There seems little justification for such a conclusion, especially since more than one species of Hooded Crow is recognised, which, like the British species just referred to, always breeds true when isolated. The British Hooded Crow ranges east- 
wards as far as the Persian Gulf, where it meets and inter-breeds with a whiter species (C. capellanus). A third species, $C$. sharpii, inhabits Afghanistan, Turkestan and Siberia as far as Tomsk. The area between that place and Krasnoyarsk-about 350 miles east- " is said," remarks Howard Saunders, "to be occupied by hybrids between this bird and a large form of Carrion Crow".

The Game-birds and the Ducks furnish yet more numerous instances, widely distinct species freely inter-breeding and producing fertile hybrids, at any rate in captivity. Thus then the theory of the infertility of closely allied species does not apply in these cases. We may assume therefore that physiological selection has played no very important part in the evolution of these specific types.

That segregation is sooner or later followed by changes in the specific characters of a species, whereby it becomes transformed into a species peculiar to the area in which it has settled, cannot well be doubted, and a few instances may make this clear.

Thus, of the nineteen species of Cassowaries known to science, one only occurs on the mainland of Australia, but seven, it is to be noted, occur on the large island of New Guinea -a fact which is not easy of explanation. The remaining eleven species are found on as many separate islands-evidently originally part of New Guinea-and represent one or other of the parent New Guinea species, transformed apparently by isolation. The Galapagos Islands tell the same story. Of forty-two species of true land-birds all but one are peculiar to these islands. But, be it noted, all are allied to birds, all the descendants of birds, found on the mainland of tropical America. These are but samples of cases where changes of the external characters have followed apparently as a consequence of isolation. Precisely similar changes are met with among species where the isolating barriers are formed, not by water, but by intervening land of a kind unsuited to the needs of the species. Birds which live at high altitudes may serve us as illustrations. Dr. Bowdler Sharpe, our gneatest living authority on the subject of the geographical distribution of birds, was the first to draw attention to this peculiar fauna of high altitudes; which presents precisely the same phenomena as the 
fauna of islands derived from the neighbouring mainland. These parallel factors of evolution have been by no means so generally recognised as they deserve to be. In the mountains of Equatorial and Eastern Africa he points out, at an altitude of 3,000 feet, on Mount Elgon, Mount Kenia, Mount Kilmanjaro and Mount Zomba in Nyassaland, and the mountains of Shoa in Abyssinia, that many peculiar birds exist and are found nowhere else in the world. For example, a species of Shrike (Lanius mackinnoni) is met with on Mount Elgon, and turns up again in the mountains of the Cameroons and only at high altitudes. Here we have an instance where isolation has not, as yet, apparently produced any superficial changes in the coloration of the bird. But the beginnings of such changes may be studied in Pinarochroa, a genus of Chats, which is represented by a series of forms, all differing slightly one from another, though so slightly as to be scarcely perceptible save to the expert. These forms have been severally collected from Mount Elgon, Kilmanjaro, Runenzori, and the mountains of Shoa at an elevation of from IO,OOO to I I,OOO feet. In the intervening lowlands, and even on the lower slopes of these mountains, these birds are never met with; they are as completely shut off as if by an ocean. One might cite dozens of similar instances. But all go to show that isolation is a factor in the production of new species.

One other instance of this kind must suffice. This is furnished by certain small birds of prey known as "Falconets" of the Genus Polioheirax. One species ( $P$. semitorquatus) inhabits Africa, a second species ( $P$. insignis) is found in the Burmese countries. These birds are selected because they are, so to speak, "ear-marked"-if we may be permitted a Hibernicism-by having, the male a grey and the female a chestnut back, showing that they must be descendants of a common ancestor which have been modified, so far as superficial characters are concerned, by isolation. One might indeed cite dozens of similar instances; but all show that isolation is at least an indirect factor in the production of new species. Now the foregoing facts are all the more remarkable because we find that a species by no means always undergoes a change when cut off from the parent stock. Isolation, in short, is, as we have hinted, only a factor, and not a cause in itself, of specific 
evolution. So much, indeed, both Darwin and Romanes have already contended, though Wallace, on the other hand, opposes this view.

The following examples well illustrate the peculiar fixity of type which some species display when isolated. One of the Pied Kingfishers (Ceryle guttuta) is met with both in Japan and the Himalayas. Though divided by thousands of miles no apparent change in the coloration of the individuals of the two areas is to be traced. The same is true of one of the crested Eagles (Spizatus orientalis), except that this bird is met with also in Formosa. Two other species, it may be remarked, are also peculiar to the Himalayas and Formosa - a Pigeon (Palumbus pulchricollis) and a red-breasted Flycatcher (Siphia superciliaris). In both species, individuals from these widely separated areas are indistinguishable.

Birds whose range may be described as cosmopolitan afford no less striking lessons on this head. The Osprey, for example, which is met with over the whole world, Arctic and Antarctic regions excepted, retains throughout its range the same superficial characters. The Barn Owl, on the other hand, which enjoys a similar range, has given rise to numerous geographical races which some choose to regard as distinct species, others as sub-species. Be that as it may, the one has changed, the other has not.

The inference that certain species have been evolved within the small areas where they are now found, by isolation, seems irresistible; the following cases of species with a yet more circumscribed habitat may be regarded as affording very striking additional evidence in favour of this hypothesis. Thus, the only known flightless Grebe (Podicipes micropterus) is confined to Lake Titicaca, Bolivia, which has an elevation of 12,644 feet. The only known flightless Cormorant (Phalacrocorax harrissi) is found on one of the Galapagos Islands off the west coast of South America. The little Humming-bird (Oreotrochilus chimborazo) is found only around the volcano of Chimborazo at an altitude of I 4,000 feet, and the nearly related $O$. pichincha from the neighbouring volcanoes of Pichincha and Cotopaxi at an elevation of 16,000 feet-living, by the way, in a world of almost continual hail, sleet and rain!-while the isolated rocks of Juan Fernandez boast two species of the 
Genus Eustephanus which are found nowhere else; the only other members of the genus occur in Chili and in Tierra del Fuego! The species on Juan Fernandez are quite distinct and remarkable for the fact that the sexes are strikingly different, while in the Chilian species they are very similar. Finally, we have the peculiar Plover known as the "Wire-bird" (Agiolitis sancto-helence), and found only on the small island of St. Helena. This list might be still further extended, but sufficient examples have surely been cited to illustrate the effects of isolation, or more properly the after effects thereof. Isolation implies change of environment, and change of environment means free play for factors hitherto held in check by the action of Nature's selection peculiar to the environment vacated. Sooner or later, as we have already remarked, natural selection again comes into play, but not until, and unless, the liberated factors assume a too luxuriant growth. But of this, more presently.

Finally, we may remark that the several species which have so far been described are so many outlying members of various Orders and Families, which have strayed into the highways or backwaters of the world-as the case may be-from more or less distant centres of distribution. And these centres are to be found scattered over more or fewer larger areas known as "zoo-geographical regions" (see Chapter IV.).

Perhaps one of the most striking illustrations of Romanes' discriminate isolation is that afforded by the curious Stork known as the "Open-bill" (Anastomus). This genus is represented by two species whose chief peculiarity lies in the remarkable form of the beak, the cutting edges of which are separated for a great part of their length by a wide gap, but this gap is met with only in fully adult birds.

Of these two species one is African (Anastomus lamelligerus) the other Indian ( $A$, oscitans). The Indian species is white relieved by black scapulars, primary coverts and quills; the tail is also black. The African species differs in many important particulars. In the first place the gap of the beak is much more marked, while the whole of the plumage is black, even in the young birds. Furthermore, the feathers of the back have undergone a curious change, terminating in spines having a glossy, bronze-like appearance. 
That these two species are descendants of a common stock there can be no question. And we may safely assume that the Indian parti-coloured species is the more primitive of the two. The Afriçan bird, then, isolated by migration, has not only intensified the peculiarities of the beak, but has further developed the striking changes of plumage just referred to. The African species, it is further to be noted, occurs throughout the whole of the continent and Madagascar, yet examples from any part of this vast range exhibit the same characters. It is true an attempt has been made to show that examples from Madagascar can be distinguished from specimens from the continent of Africa. Dr. Bowdler Sharpe insists that such distinctions cannot be admitted. The Indian species, which ranges into Ceylon and Cochin-China, exhibits a similar constancy, retaining its characteristic parti-coloured plumage.

The evolution of the African species can scarcely be put down to the influence of natural selection. But it may well be attributed to the indirect effect of discriminate isolation, whereby certain individuals, having the latent characters of the African species, were enabled to develop these innate peculiarities.

If this be admitted, we must endeavour to find some other interpretation of the peculiarities of the African species, and their persistence practically unchanged, throughout its whole enormous range. And what applies in this instance will apply also to a vast number of similar cases.

It is suggested then, that the peculiarities which distinguish the African bird are due to the removal-consequent on migration from the ancestral home-of certain restraining influences checking the further development of an inherent tendency to blackness of plumage, and an intensification of the peculiar form of the beak : a development which but for some subtle check might have become excessively developed and so brought about extinction.

This assumed inherent tendency of organs to pursue a certain definite course of evolution, once started, is known as "determinate evolution," but this factor is not regarded with general favour among evolutionists. Nevertheless, there seems very good reason for assuming that organs, like individuals, vary in their potentialities of growth; and that once started in a given direction, this growth will continue until, and unless, 
checked by natural selection. And no better instances of this can be found thav are to be met with in the skull. Take, for example, a bone like the squamosal. In the more primitive forms, like the Struthious birds, this bone is superficial, and, save in the Apteryx, does not appear on the inner wall of the brain case; and in the Penguins, the most primitive of the Neognathæ, this bone is more loosely attached to the outer wall of the skull than in any other birds. But as we proceed from the more primitive to the more specialised forms this bone is found absorbing more and more of the underlying bony tissue until finally it comes to take a large share in the formation of the inner wall of the brain case. That is to say, it passes from the position of a purely superficial bone to take up a much more intimate relation with the neighbouring bones whereby it comes, as it were, to enter into the very warp and woof of the skeleton of the cranium. In the Passeres it displays still further changes. Having long since passed from the position of a superficial scale to that of a bony plate whose entire inner surface is in contact with the brain, it has now begun to change its shape. In its more primitive condition it is roughly of the shape of a Phrygian cap; and from this shape it becomes more and more elongated, till finally it forms but a narrow crescentic band running along the outer border of the frontal and contributing to form the posterior border of the orbit.

In these changes then we have a progressive evolution resulting, apparently, from some inherent tendency within the squamosal. They cannot be influenced by, or determined by, the strains and stresses incident to the struggle for existence, for this bone, like all the cranial bones of the bird's skull, as a separate entity ceases to exist before the bird is able to fend for itself. That is to say, within a week or two of birth all the bones of the cranium have fused to form one homogeneous bony tissue. Each successive generation of birds then seems to have contributed something towards this transformation, but each stage has had to be passed through within an incredibly short space of time, and before the bird had been subjected to any of the many factors which go to make up the struggle for existence. One seems justified in concluding then that this evolution of the squamosal has taken place independent of any 
external factor, and by reason of some inherent peculiarity of growth; some variation which, once started on such and such a trend, has gone on developing that peculiarity. And what is true of this particular bone is true also of a hundred skeletal details. The changes in the relative position of the vomer, with regard to the palatines and pterygoids, and its varying stages of degeneration, ending, in many groups, by complete suppression, affords another illustration of what would seem to be a process of development and degradation independent of the action of natural selection. 


\section{CHAPTER XXIII}

\section{STRUCTURAL AND FUNCTIONAL ADAPTATIONS-SHAPE AND SYMMETRY}

The factors determining shape. The remarkable asymmetry of Owls' ears. The wing. The shoulder girdle and sternum. The pelvic girdle. The pelvic limb. Some puzzling features in the pelvis of Struthious birds. The pectineal process and its homologies. Types of feet. Feathers and adaptation to arboreal life.

$7 \mathrm{HE}$ present and succeeding chapters are intimately connected with those immediately preceding. Herein it is proposed to discuss in detail the complex problem of adaptation, and thereby the full significance of the facts of variation, acquired characters, selection and isolation, will become apparent.

Let us begin with the general problem of the shape of the bird's body, for this represents the sum of all its several adaptations.

To secure and perfect the power of flight has been the main objective in the determination of this shape; and to support the body alternately in the air or on the land, intense specialisation has become necessary. The outcome of this has been the conversion of the fore-limbs into the unique organs we call the wings, and the readjustment of the balance of the body so as to permit of its being carried, when on the ground, by the hindlimbs alone, thereby converting the bird into a biped. As a further concession to the demands of ærial locomotion the trunk has assumed a sub-conical shape, though the body, as a whole, during flight is spindle shaped, a form due to the carriage of the head and neck. In certain long-necked swimming birds this spindle shape is much attenuated, the head and neck being carried straight out, as in the Duck tribe, and the Storks and Flamingoes, for example. In other equally long-necked forms, like the Heron-which is also one of the Stork family - the head and neck are brought close to the body, thus materially shorten- 
ing the spindle and giving the same general form as in relatively short-necked types, such as Gulls and Eagles. So far, it may be remiarked, there is no explanation of the reason why birds, closely related, both structurally and genetically, such as the Herons and Storks, should assume such different forms during flight. The passage through the air is further aided by the smooth, closely fitting feathers, thereby reducing friction to a minimum.

Resuming the question of flight later, we may pass on to remark that the wings rarely serve any other purpose, during adult life, than as organs of ærial locomotion. In the case of the Penguins they serve as paddles ( $p .385$ ); and in some other instances they are armed with sharp spurs or bony bosses, and constitute formidable weapons of offence (p. I6I). When not in use the fore-limbs are held closely pressed to the sides of the body, so that, in short-winged forms, when the flank feathers overlap the free edge of the wing, no trace of the limb is visible.

Birds present a really remarkable uniformity in the matter of shape. The differences whereby one group may be distinguished from another are differences of degree only-length of beak, neck, leg or tail, peculiarities of toes and ornament, a horizontal or perpendicular carriage of the body, sum up the main variations in this matter. This uniformity of likeness is to be accounted for, as in the case of the extinct Pterodactyles and the Bats among the Mammalia, by the fact that once launched on an ærial career they become too highly specialised to adapt themselves to any new line of development. The more generalised lizards, for example, or the carnivora and ungulata among the Mammalia, offer far more variations and profound modifications of structure than can be met with among the birds. They have, in short, proved capable of adapting themselves to many different environments. And this because during the earlier stages of evolution they retained the use of the fore-limbs for general purposes, while in the case of flying animals these organs are devoted solely to the requirements of flight. The exigencies of independence for a living on this mode of locomotion curtails development in all other directions.

The fore-limbs of the bird being no longer used for the 
support of the body when on the ground the trunk has become shortened, and this shortening process is still going on. Evidence of this may be found by an examination of the skeleton, inasmuch as several pairs of the anterior ribs no longer reach the sternum, and their supporting vertebræ have in consequence been transferred to the cervical series, the length of the thoracic segment of each pair decreasing from behind forwards. A similar suppression of the ribs has taken place at the hinder end of the sternum, thus transferring thoracic vertebræ to the lumbar series. By this arrangement the hind-limb has been brought nearer the centre of gravity, but the carriage of the body is horizontal, as in quadrupedal animals. Birds which swim and dive much differ, however, in this last respect since, in some the trunk is carried obliquely, and in a few, as in the Penguins, vertically, as in man, though in these birds the femur is not markedly short.

On the other hand, the Accipitres and Striges, when at rest at least, have a vertical carriage ; but this can at any moment be transformed into the more normal horizontal attitude. The mechanics of this question must be discussed later.

Length of leg and neck largely affect the shape of the body. But there is a by no means universal correlation between these parts in the matter of length. Generally speaking, the length of the neck varies as the length of the legs. A little reflection will show that to a long-legged bird a long neck is essential, at least in the case of ground-feeding or wading types. The short-legged Swans, since much of their food is obtained from the bottom of the streams on which they live, need a long neck; and where the water is deep the food can only be obtained by a half-diving action, the forepart of the body being thrust down till the tail points vertically upwards. The "Darters" (Plotus) again have short legs and extremely long necks which are used for thrusting, spear-fashion, at the fish on which these birds feed.

In all birds the neck, whether short or long, possesses extreme mobility, more than in any other vertebrate. The fact that there are no long-legged birds with short necks, as in the Mammalia, is to be accounted for by the fact that the fore-limbs, from their specialisation, cannot be used as organs of prehension for conveying food to the mouth, or for the support of the fore- 
part of the body on the ground, as in the short-necked kangaroos, for example.

Perfect bilateral symmetry is almost universal among birds, but there are a few remarkable exceptions to this rule. Save in a single instance-the case of the Wry-billed Plover-these exceptions-afforded by certain Owls-are all superficially symmetrical. That is to say, the general contour of the bird is not affected thereby, and the asymmetry is only apparent after careful examination. In this respect, of course, it resembles the intestinal convolutions, for example. Nevertheless, it is not to be included in the same category, neither is it so easily accounted for as this intestinal coiling. On the contrary, it presents us with a problem so far unsolved, though not, perchance, insoluble.

The Owls to which reference has just been made are asymmetrical in respect to the external ear, and it will be necessary, for a proper understanding of this remarkable phenomenon, to describe certain other peculiar characters associated with, but, be it noted, by no means essential to, this asymmetry. In no bird is the aperture of this organ provided with a fleshy concha such as is found in the Mammalia : that is to say, they are earless in the ordinary sense of the term. The ear of the bird, as in the reptile, opens externally, on the side of the head, by a small aperture, which in the bird at least is almost invariably round, and, save in vultures and some few other exceptions, it is concealed by the slightly modified feathers known as the ear-coverts. In the Eagle Owls (Bubo) this aperture becomes much enlarged, and is oblong in form. In the Genus Scops this increase is still more marked, so much so, that the sclerotic plates encircling the eye become exposed (IIl. 48, F). Behind the eye there is found a large cavernous chamber at the bottom of which lies the passage to the middle ear. The modifications which we are now to describe may well have had their origin in the variations in the direction of increased size which the members of these two genera have preserved. One of the most striking features in these transformations is the development of a membranous fold or flap from the anterior border of the aperture to form an operculum or cover therefor. In the Strigidæ or Barn Owls this operculum, as may be seen in Ill. 48, E, extends both above and below the aperture, which is roughly 
quadrangular in form, and in this respect it differs from all the other species to be described. Further, in these Owls there is no asymmetry traceable; and this is also true, curiously enough, in other cases only specifically distinct from forms which present the most marked asymmetry.

In the Owls of the Genus Syrnium the aperture of the ear has increased so as to embrace the entire base of the operculum, which, when raised, exposes to view a large portion of the bony skull. In the Tawny Owl (Syrnium aluco) (IIl. 48, C, D) the aperture of the left side of the head is considerably smaller than that of the right, which exposes not only the skull wall but also a large portion of the sclerotic plates of the eye, and herein we meet with asymmetry for the first time. In the closely allied Ural Owl (Symium uralense) the ear differs in that asymmetry, if present at all, is barely perceptible. Passing now to the ears of the Genus Asio we find specialisation carried to still further limits. The aperture of the ear now extends downwards and forwards to the angle of the gape, and circles upwards and forwards to a point above the region of the middle of the eye (IIl. 48 , A, B). The operculum has now attained a relatively enormous size, and when turned forwards upon itself, reveals the greater part of the skull, and the sclerotic region of the eye, and the posterior half of the mandible. From the middle of the operculum there runs backwards a fleshy valve dividing a spacious semilunar depression-bounded in front by the eye, and behind by the post-orbital process-into two moieties differing somewhat in shape on the two sides of the head. But the chief point of interest about the cavity divided by this valve, is the fact that, on the left side of the head the passage to the middle ear opens in the floor of the chamber lying above the valve, while on the right side it will be found in the floor of the chamber below the valve and at the base of the lower jaw.

So far the modifications described are confined entirely to the plications of the skin, but in Tengmalm's Owl (Nyctala tengmalmi) the skull itself presents some important structural changes (Ill. 48, G, I, H). The membranous portion of this region, which we will examine first, differs only on the two sides of the head in that the left aperture is somewhat larger than the right. The operculum is wanting. Within this aperture, however, there will be found the most unexpected dissimilarity in the 
nature of the bony regions. Thus, on the left side of the head (IIl. 49) the combined post-orbital process and tympanic wing of the exoccipital forms a large outstanding shield extending downwards to the level of the lower jaw so as to leave a narrow chink between itself and the bony ring of sclerotic plates surrounding the eye (IIl. 49, top left-hand figure). The chink traced inwards gives way to a large chamber, in the floor of which will be found the passage to the middle ear. On the right side this chamber is wholly exposed but for a tongue-shaped plate of bone which, extending forwards to the bony rim of the eye, encloses the lower half, leaving a small triangular space lying immediately above the lower jaw (Ill. 49, top right-hand figure).

The feathers which form the periphery of the curious facial discs of these birds-and especially of the Barn Owl, Tawny and Long and Short-eared Owls-play no small part, probably, in the collection and transmission of sound waves to the middle ear. In the Barn Owl these peripheral feathers are long, narrow, curved forwards, and closely set, forming during life a trumpetshaped wing, such, for example, as one makes by placing the hand to the ear when endeavouring to catch indistinct sounds. Near the centre of the concavity of this rim, as will be seen in the figure, the aperture of the ear is placed. The arrangement of the peripheral feathers in the Tawny Owl does not differ essentially from that of the Barn Owl. In the Long and Shorteared Owls (Asionida) these feathers are arranged so that those of the uppermost segment slope downwards, while those in the lower segment of the rim slope upwards. So closely are the bases thereof packed that the supporting skin fold is drawn out so as to stand far away from the head, and so further increase the sound-catching trumpet.

The function of the operculum is by no means clear. Primarily, it seems to serve as a protection to the wall of the skull, but in the living bird it is evident that if it were slightly raised or swung outwards, much as a door on a hinge, the feathers along its free edge would, in conjunction with the peripheral disc feathers, form a sort of laterally compressed or vertically slit-shaped mouth resembling the semi-tubular ear conch of many mammals. By such an arrangement sounds can doubtless be much more easily located than is possible 
with the more normal avian apparatus: and this is a very important consideration where small living prey has to be captured on the ground during the hours of twilight.

Embryology, so far, has thrown but little light on this subject. In an embryo Long-eared Owl I found a stage exactly comparable to that which obtains in the living Scops Owl, but no trace of the operculum was then visible. The history of this region has yet to be traced.

Another curious feature is to be seen in the form of the Squamosal in the nestling skulls of the Tawny and Burrowing Owls. This bone has pursued very different lines of evolution which, moreover, do not seem to be explicable as the result of natural selection, but rather to belong to the category of character referred to elsewhere in these pages; to wit, characters due to variation in the germ-plasm, which are free to pursue their course unless, and until, checked by natural selection; that is, until they tend to hamper well-being. This point has been more fully described in my Memoirs in the Transactions of the Linnean Society, 1898.

From the problem of shape we have already passed to that. deeper one of structure, and this we will now pursue further, tracing out those peculiar modifications of the type which we may justly regard as the direct response to the demands of the environment, or to the particular needs of the animal, or, in other words, as adaptations.

The selection of these instances of adaptation must in a sense be arbitrary, inasmuch as the whole organism is but the sum of innumerable adaptations. On the theory of evolution birds are the descendants of reptiles. So the gradual shedding of the reptilian characters, or to put it another way, the gradual modification and transformation of the reptilian characters, and their transmutation into avian, are so many steps in adaptation towards the new demands of the new environment. Thus, feathers have been derived from scales by adaptation; the transformation of the ambulatory fore-limb into a wing is the result of adaptation. But we propose to use this word adaptation in its more general sense, to indicate more or less striking departures from the type. Thus commencing with what we may call the schematic bird, we have an animal clothed with feathers, having the fore-limbs modified to iorn organs adapted for arial 
locomotion, and the hind-limbs adapted to support the body in terrestrial locomotion. In considering at the commencement of this chapter some of the more striking changes of shape which birds present, this adumbration of a bird, or schematic bird, must have been, unconsciously at least, always present in the reader's mind, forming the standard of comparison. And similarly, in the further continuation of this theme, we shall discuss adaptation in this restricted sensevariations from the type.

Inasmuch as flight may be considered as one of the most striking attributes of birds, we may well commence this more detailed study of adaptation with an account of its effects on the wing, and on the structures associated therewith. The wing of the bird is an absolutely unique organ; as to its origin we can say nothing with certainty; speculations on this head are few, but they will be referred to later. Of its main features we have already treated in the introductory portion of this volume (p. I3), and we shall therefore refer here only to the modifications which are to be observed therein.

First of all, let us consider the wing as an organ of flight, and examine ( $\mathrm{r}$ ) the changes which are to be observed in the skeleton thereof, and (2) the changes in the contour of the wing as determined by the length of the flight feathers or remiges.

The modifications of the skeleton are mainly confined to the wrist and the hand. Unfortunately, we have no record of the earlier stages of the evolution of the wing, but there can be no doubt but that what we now know as the wing was originally a five-fingered organ. We meet with it for the first time in the skeleton of the Jurassic Archeopteryx, and here it has already acquired its peculiar tridactyle form. The arm and forearm differ in no respect from the same bones in modern birds, nor can the carpus be said to offer any essential points of difference. But, assuming the fossil remains of the only two specimens of Archaopteryx so far discovered to be sleletons of adult birds, it is important to notice that this complex of wrist bones remained free throughout life, while in modern birds this individuality is retained only for the first few weeks of life, as a comparison of the accompanying illustrations will show. So, too, with the bones of the middle hand or metacarpus, though 
to a much less extent. In these fossils indeed, fusion seems to have taken place, but not so completely as to obliterate the telltale sutures. The fingers differ from those of modern birds in

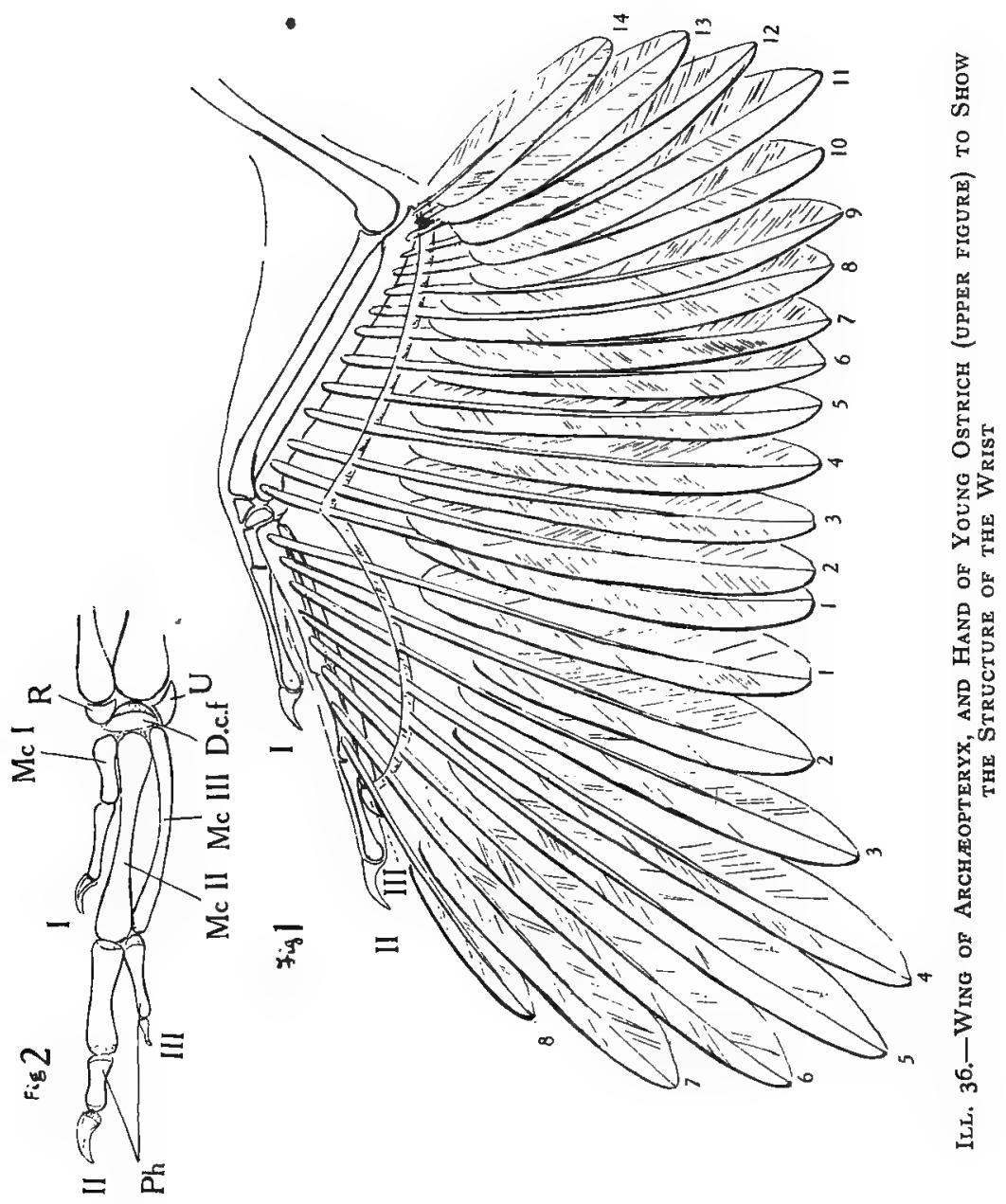

two particulars-each terminated in a large claw, and the third finger had as many as four phalanges, or separate segments, as against a single phalanx in modern birds. Claws occur today only on the thumb and second finger, and here they are 



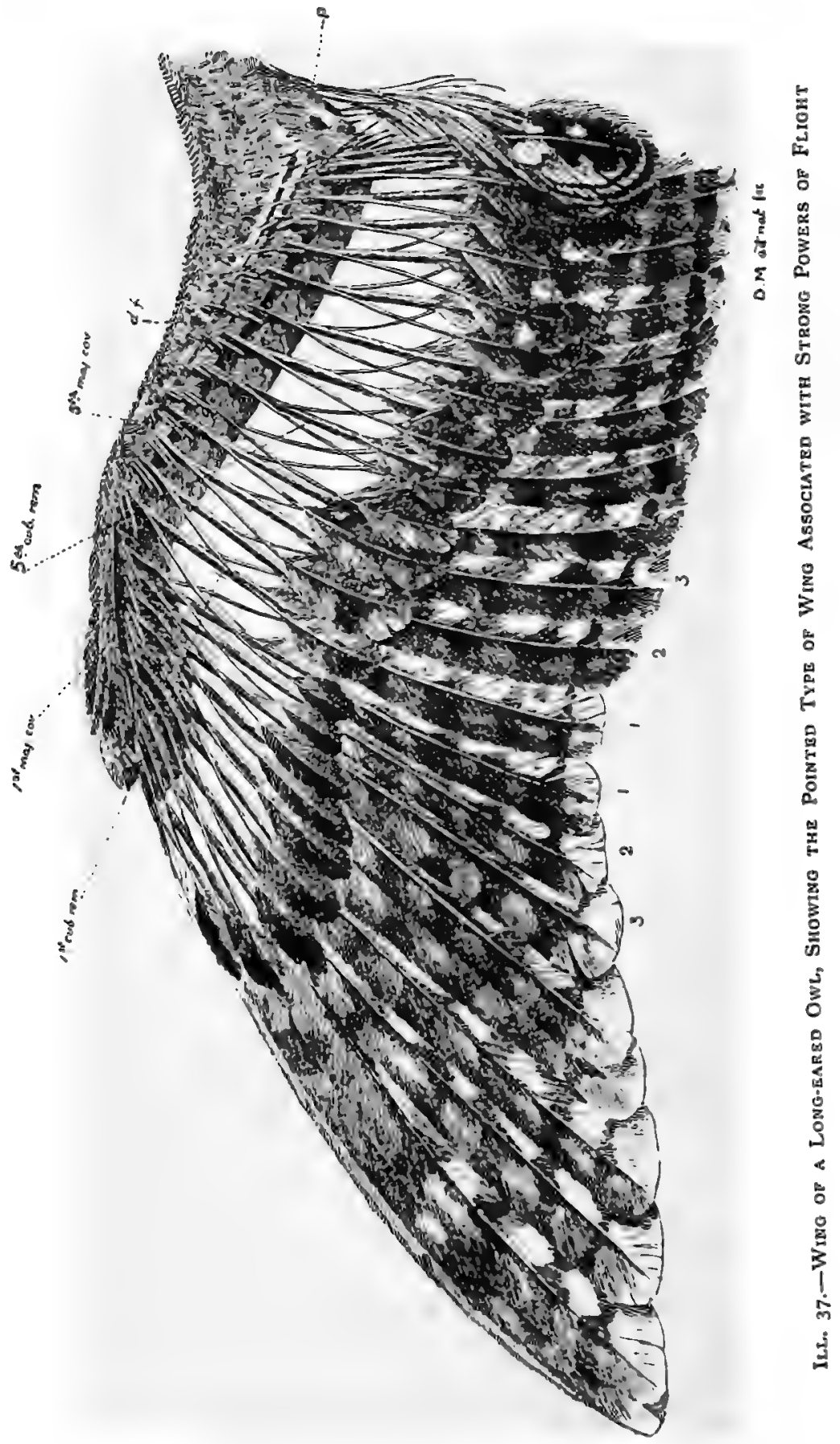


reduced to mere vestiges, save only in the remarkable Hoatzin (Opisthocomus cristatus). In this bird, as we have already pointed out, they are during the nestling period of considerable size, but later they become absorbed. Ducks and Accipitres retain vestiges of these claws throughout life; in other birds they have either become entirely suppressed on one or both digits, or they appear only during embryonic life. In the young Ostrich, however, a vestigal claw has been found on the third digit.

This reduction in the number of the digits, and the welding together which they have undergone, has resulted in the formation of what may be described as a jointed rod, eminently adapted

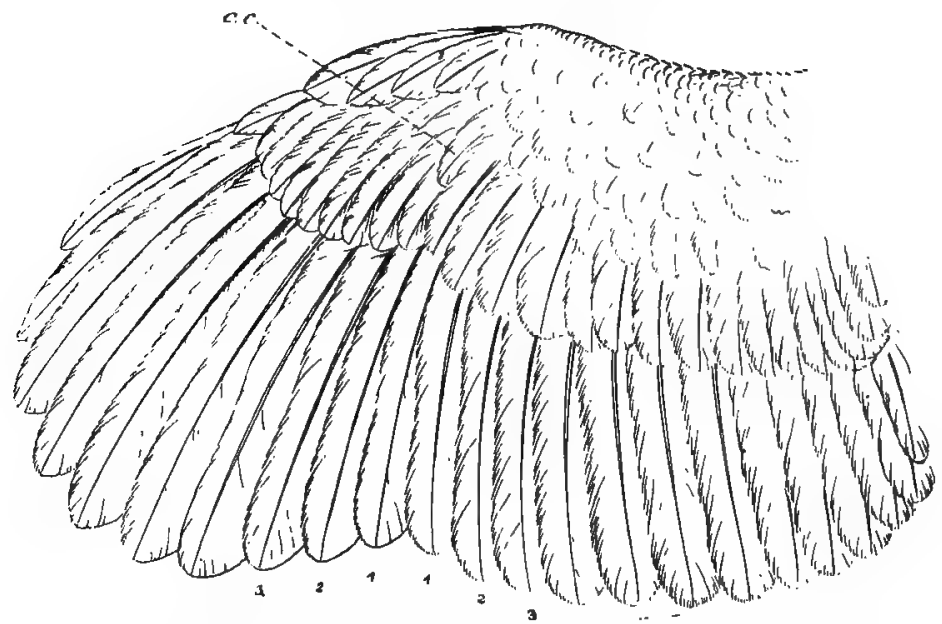

Ill. 38.-Wing of a "Wood-OWL," Showing the Rounded Type

for the support of the elastic ribbons which we call the "flight feathers," but so specialised as to be entirely useless as a support for the body-save only in a few cases where the wings are used for climbing purposes during the nestling period.

From the earliest known bird then to the present day the only changes which have taken place in the skeleton of the wing-cases of degeneration apart-have been in the shortening or lengthening of the separate segments of the limb. The most striking instances of these are to be found, curiously enough, in the two birds most renowned for their remarkable powers of flight-the Albatross and the Swift. In the former 
the arm (humerus) has attained a relatively enormous length while the hand is unusually short: in the latter these relative lengths are reversed. Yet the form of the wings in the living birds closely resemble one another, both having a very extraordinary ribbon-like contour. Although much has been written on the flight of the Albatross, and though the remarkable powers of the wing which the Swift possesses are familiar enough to us all, no close comparison or analysis of the mechanics of the flight of these two birds has yet been made. Till this is done the differences of the form of these wings must remain in the province of curious facts requiring explanation.

In some species at least, the several segments of the wing vary in their relative lengths at different stages of development, a fact which has already been demonstrated in describing the wings of the nestling Hoatzin and Common Fowl. These variations are undoubted adaptations, fulfilling different purposes during the phases of growth therein described.

The innumerable differences discernible in the wings of different groups of birds in the matter of the relative lengths of the several segments, the development of crests for muscle attachment, and so on, are all instances of adaptation, but too intricate for profitable discussion.

A brief reference may, however, be made to the difference in the contour of the wing as a whole. In birds which spend much, if not most, of their time on the wing, this organ when extended presents the form of a long, narrow, pointed blade, as in the Swift, Albatross and Frigate-bird. In those which fly but little the contour is that of a broad, much rounded, almost fanshaped plate. That this shape is correlated with the nature of the flight is demonstrated in one or two striking cases. In the Tawny Owl or Wood Owl, for example, the wing is of the short rounded type; in the Barn Owl, on the other hand, a bird which forages in the open, the wing is long. In the diurnal birds of prey similar relations are found. One might multiply instances by the score. Yet, in spite of this, systematists have unhesitatingly used the form of the wing as a factor in classification! The celebrated order Timelizda is founded upon this character alone. "Wings short and rounded, fitting close to the body!" No wonder that this "Order" contains a chaotic medley of forms. 
The shoulder girdle-the series of bony rods charged with the support of the wing-has undergone a few noteworthy changes in adapting itself to different kinds of strains. The horse-shoe shaped furcula, or merry-thought, formed by the fusion of a pair of clavicles or "collar-bones," is either U- or $\mathrm{V}$-shaped, and the latter is still further modified into a $\mathrm{Y}$-shape by the outgrowth of a discoid, or sometimes of a styliform element - the hypocleideum-at one time regarded as answering to the reptilian inter-clavicle, but now considered to have no relation to this bone. Since the sternum or breast-bone also participates directly in the special modifications due to flight it

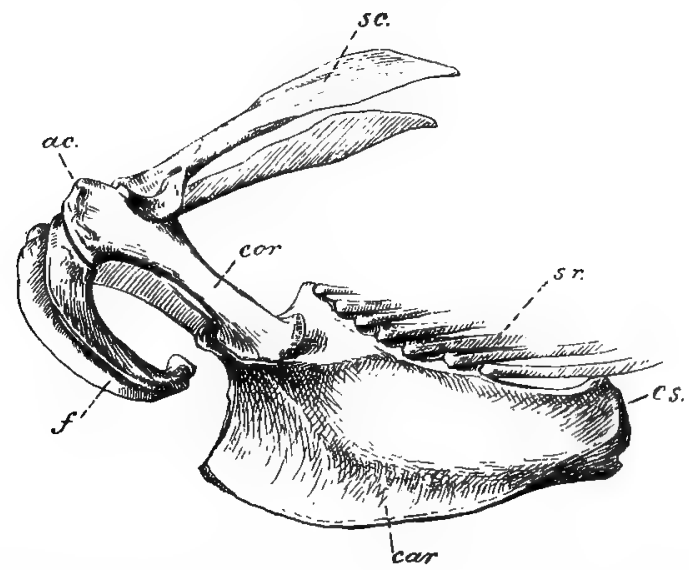

ILl. 39.-Shoutder-GIRdLe AND STERNuM of AN EAGLE

Sc. = Scapula. $\quad$ Ac. = Acrocoracoid. $\quad$ Cor. $=$ Coracoid. $\quad$ F. = Furcula. Car. = Carina. C.s. = Corpus Sterni. S.r. = sternal ribs.

will be found convenient to deal with both girdle and breastbone at the same time.

In birds of powerful and vigorous flight, such as Eagles and Falcons, the coracoids are short, broad and thick, and the furcula has the limbs wide apart, broad and strongly curved, the convexity pointing forwards; but in no case does the furcula come directly into contact with the anterior end of the carina or keel of the sternum, though the upper or free end of the furcula is closely attached to the head of the coracoid by a specially developed facet which is opposed to a similar facet on the coracoid. 
In many birds, such as Pelicans, Gannets and Cormorants, the furcula is firmly fixed, articulating, by means of special joints, with the end of the keel of the sternum below, and with the coracoids above. In the Pelicans the union with the sternum becomes still more complete, the joint between the furcula and sternal keel giving place to an actual fusion of the juxtaposed bones; and in the Frigate-birds yet further rigidity is attained by the fusion of the base of the coracoids with the end of the sternum. The advantage of this rigidity seems apparent enough in the case of the Gannets which invariably, and the Pelicans frequently, capture the fish upon which they feed by violently plunging upon their victims from a height; but the same mechanism obtains also in the Cormorants and Darters which dive only from the surface of the water, and with closed wings. Is this method of diving a recently acquired habit? In the Frigate-birds, as we have remarked, fusion has rendered all movement between the shoulder girdle and breast-bone impossible, yet these birds rarely dive; since, however, much, if not most, of their food is obtained by rapid plunges through space, as they endeavour to catch the fish disgorged by Gannets and other birds - which they harass for this purpose-before it reaches the water, it would seem that this peculiar mechanism has been developed to facilitate the rapid downward thrusting of the body through space rather than to meet the impact with the water. This view is borne out by the fact that the Eagles and Falcons also present similar modifications of this kind, the great width and breadth of the furcula compensating for the fact that it does not articulate with the keel of the sternum.

The intimate connection of the furcula with the coracoids and sternum just described is, however, by no means essential for strong and long-sustained flight, inasmuch as in the Pigeons and Sand-grouse which fly extremely well, the furcula is a very delicate bone and only slightly attached to the coracoids. In some Parrots this bone is wanting altogether, though it is admitted, of course, that Parrots are not great fliers.

As a rule a deep keel to the breast-bone (sternum) is correlated with vigorous and long-sustained powers of flight, as in the case of the Swift, Humming-bird, Sand-grouse and Pigeon, for example ; conversely, a low keel indicates a feeble flight. In the Eagles and Steganopodous birds, e.g., Gannet and Pelican, 
however, the keel is relatively shallow. But the pectoral muscles in these cases are found to have obtained increased support from the shoulder girdle. In the Gannet and Cormorant and Boatswain-birds (Phathon), for example, the keel is produced forwards to an extent unknown among other birds; while the hinder portion of the keel in these birds, and in the larger Petrels, tapers off to finally die out before reaching the end of the sternal plate. When the sternum assumes this form the coracoids are either unusually long, and provide special articular surfaces for the furcula, such as we have already described, or they are short and broad, a modification which reaches its maximum in the larger Petrels.

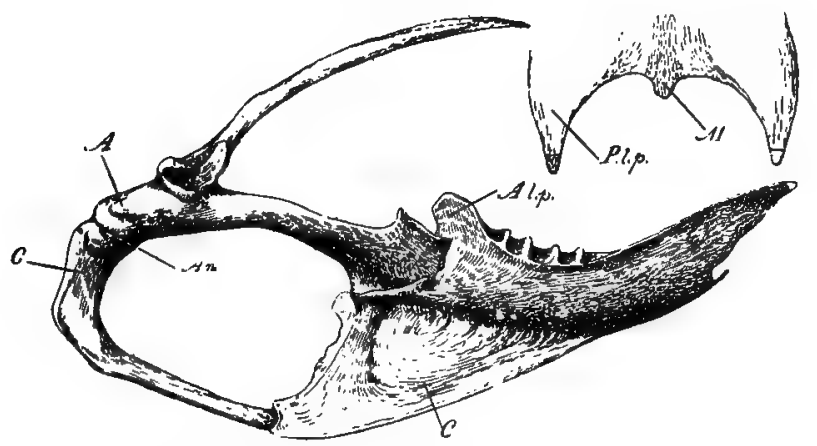

Ill, 40,-Shoulder-girdle and Sternum of a Cormorant

Economy of material seems to be striven after in the development of the sterna of birds which fly but little-in such as the Game-birds, Tinamous and Rails. In the case of the first-named, the body of the sternum is generally reduced greatly by deep notches extending far beyond the middle of the breast plate. In the Tinamous all that remains of the sternal plate is a pair of long slender processes arising on either side of the anterior border of the keel and running backwards to its termination, or beyond. In the Rails, in extreme cases, such as the Water-rails, but little of the body of the sternum remains; and in no birds of this order is the sternal plate more than moderately large.

It will have been noticed perhaps that we meet with only a rough approximation, and not a complete uniformity, of adapta- 
tion to similar mechanical requirements in the different kinds of flight. That is to say, strenuous flight, where rapidity of turning and great force in striking are required, is met by the concentration of the breast muscles far forwards. Here the necessary support is afforded either by lengthening the coracoids and strengthening the attachments of the furcula, either by articular surfaces or by fusion, or by short coracoids widely spread and of great breadth. These several modifications to attain the same end have arisen as a result of compromise: that is to say, of the transformation of the particular structural

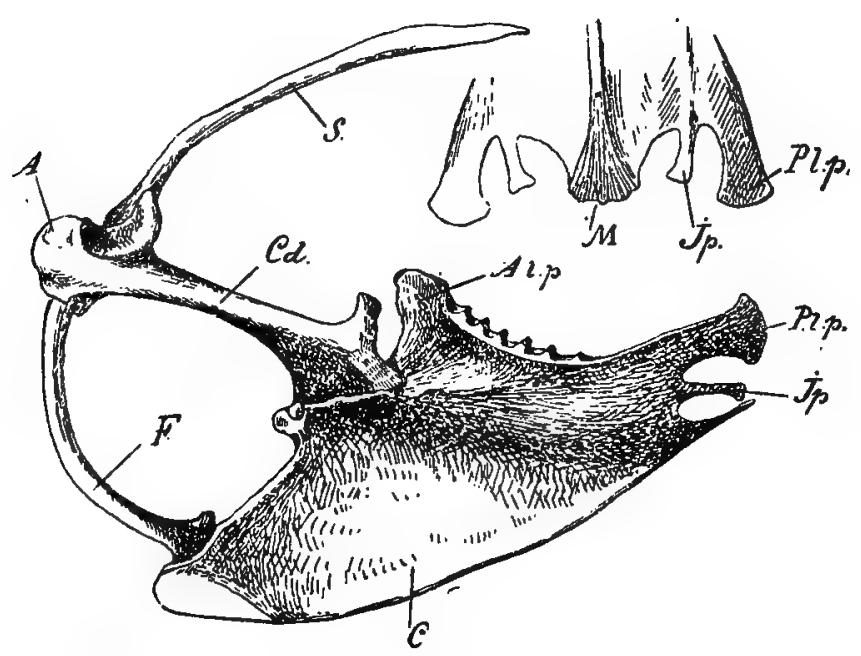

ILl. 4I,-Shoulder-GIRDLE AND STERnUM OF BoAtswain-bird

peculiarities which had already been acquired by the species before the adaptation in the new direction arose.

The results of a concentration of development in the direction of flight have affected other parts of the skeleton, but in a negative way. Thus, in birds which procure all or nearly all their food on the wing the hind-limbs become reduced by disuse, or rather by the suspension of selection, to the smallest possible limits compatible with functional existence. This is well seen in the case of the Frigate-birds, Swifts and Hummingbirds, and the Swallow tribe, for example.

Adaptations to the requirements of swimming have produced 
changes in the skeleton as striking as those which have developed in response to the needs of flight. The main features in these changes are the elongation and narrowing of the pelvis, and the backward shifting of the hind-limb.

The Ducks, Auks and Guillemots (Alcida), Cormorants, and Grebes and Divers afford the most favourable material for the study of the various phases which are to be met with in this connection.

The Cormorants, for example, belong to a group including some very diverse forms, all of which swim, though only the Cormorants and Darters procure their food by chasing their prey entirely beneath the surface of the water.

In the Boatswain-birds and Frigate-birds (Fregata) the pelvic girdle is moderately broad and has evidently undergone but little modification. It is characterised by the fact that the preacetabular ilium-that portion of the ilium lying in front of the acetabulum or socket for the thigh-bone-is longer than the post-acetabular moiety; and that the two innominate bones which make up the girdle are widely separated by long transverse processes developed by the vertebræ. In the Cormorants the post-acetabular ilium is by far the longest, while the transverse processes are extremely reduced, so that the innominate bones come to approach one another in the middle line; thus the width across the pelvis is greatly reduced.

With this elongation of the innominate and the lengthening of its posterior portion there has gone on, simultaneously, a reduction of what is known as the dorsal plane, that is, of the flattened tabular upper surface of the post-acetabular region, which reaches its climax in the Grebes and Divers.

In these forms the innominate bone has assumed the form of a long blade, divided by the socket for the femur into a short anterior and a long posterior region. This blade is closely applied to the side of a long series of fused vertebræ forming the "synsacrum" (Ill. 42, p. 387). This has also undergone profound modification, inasmuch as not only have the transverse processes of the ribs completely disappeared but the centra of the vertebræ have undergone an extensive side-to-side compression. In the complete pelvis, therefore, little more than a knife-edge is presented in a dorsal view. From the under surface it will be seen that the separate cavities for the reception of the kidneys have been entirely suppressed. 
The skeleton of the leg has undergone no less striking changes. With an extremely shortened thigh-bone, and permanently flexed at the knee joint, all that appears of the leg externally is the scale-covered tarso-metatarsus and the toes. This free portion leaves the body at its extreme hinder end, and in consequence the bird when standing carries the body erect instead of horizontal. At least this is true of the freshwater Grebes, but the marine Divers (Colymbida) can scarcely stand upon the legs, owing to the fact that the toes have lost the power of bending forwards upon the shank of the tarsometatarsus.

In the skeleton of this limb, as we have just remarked, the femur has become extremely shortened, and flattened dorsoventrally. Its lower end articulates as usual with the shaft of the tibio-tarsus, but the latter cannot be extended in the same straight line as the femur owing to the fact the cnemial crests, or bony ridges for the attachment of the muscles of the lower leg, have grown upwards to an enormous extent, so that in the Diver a deep groove has to be carved therein to receive the thighbone, as may be seen in the accompanying figure. The patella or knee cap is represented only by a vestige in the shape of a small flake of bone. In the Grebe the cnemial crest is rather less developed, but the end of the thigh-bone is gripped much as in the Divers: not, however, by the overgrowth of the cnemial crest, but by an enormous patella which is firmly held by a ligament to the crest just referred to, above which it projects some distance. Inasmuch, however, as these ligaments are elastic a certain amount of play is possible at the knee joint, sufficient to allow of the leg being straightened out far enough to make standing or even walking possible.

The tarso-metatarsus in these birds is extremely compressed from side to side presenting a knife-like edge for the cleavage of the water when swimming, and this same lateral compression is to be found in the toes, so that when the foot is closed at the end of the stroke the toes lie one behind the other so as to offer the least possible resistance in bringing the foot forwards for the next stroke.

The gradual evolution of this extremely specialised type of girdle and limb may be studied in a survey of these organs in water-birds of various types. Where swimming plays only a 


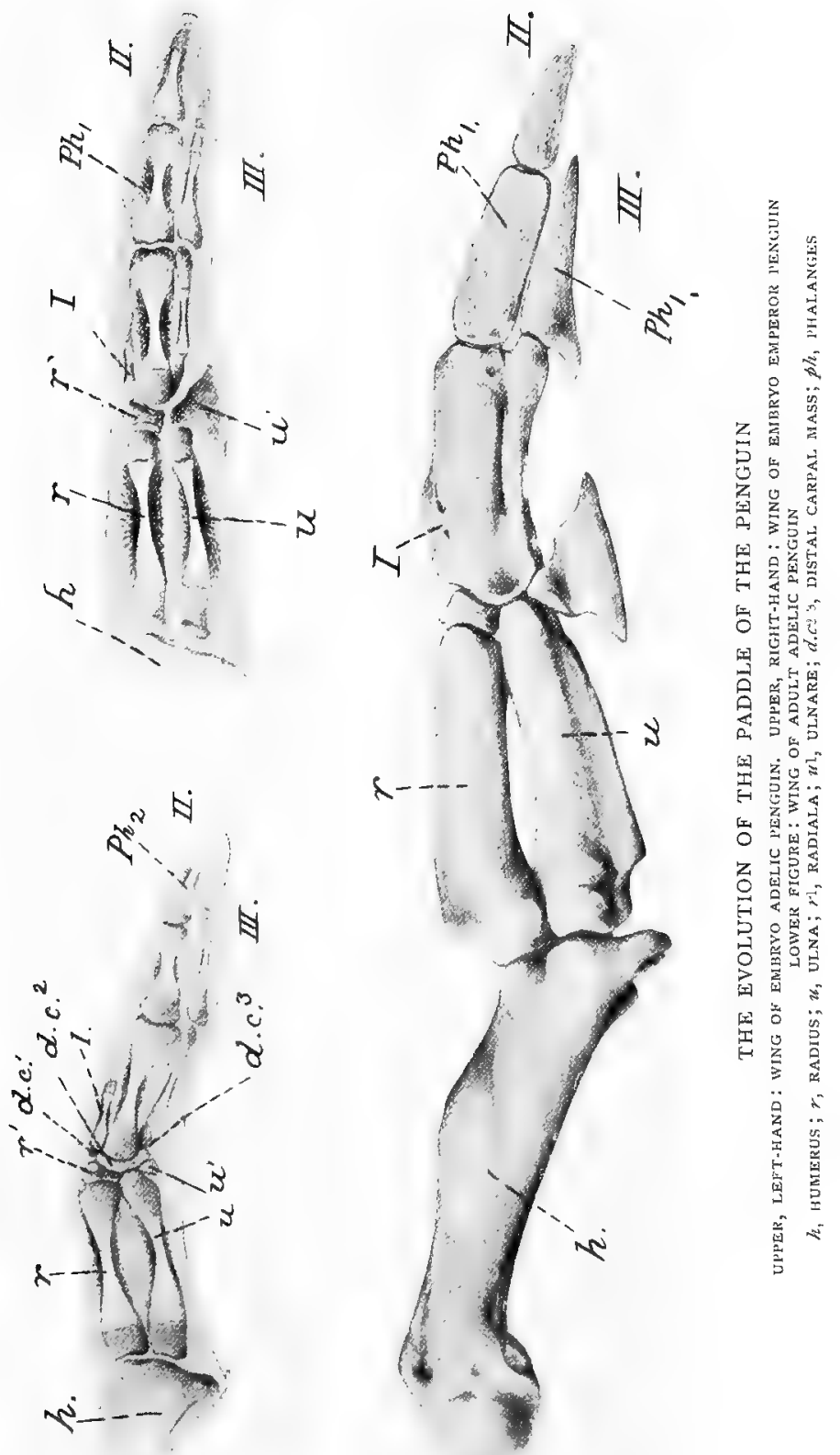
small part in the life of the bird little or no adaptation is discernible, as in the Gulls, for example, wherein the hindlimb and pelvic girdle differ in no respect from those of the Plovers. In the fresh-water Ducks, which are more aquatic, the pelvis bears evident signs of modification; in the Divingducks adaptation is still more marked, and has followed along the lines we have already indicated-the backward position of the legs and narrow pelvis, though these changes are by no means so marked as in the Grebes and Divers.

The maximum of specialisation in this direction was attained by the extinct giant Diver (Hesperornis) (Ill. I I, p. 36). In this bird the pelvic girdle had assumed all the characters presented by the Divers (Colymbide) to-day. Of the hind-limb the same may be said, save only in one particular, and that of extreme interest. The difference in question lay in the knee joint, which resembled that of the modern Grebes rather than of the Divers. It resembled the Grebes in that the patella was of enormous size, and differed therefore in that the cnemial crests were not nearly so well developed, so that the disparity in size between these was far more marked than is the case with the Grebes. Owing to the great size of this patella it was impossible for this bird to straighten the leg at the knee joint-the tibia could never have extended further than to form a right angle with the femur, and in this Hesperornis and the marine Divers agree. In Hesperornis adaptation could no further go; it represents the high-water mark of specialisation in the direction of swimming. Other features following on this specialisation will be dealt with elsewhere.

Inasmuch as in all the birds so far considered the pursuit of prey under water has resulted in more or less profound modification of the hind-limb and pelvic girdle, and a decline in the size of the wing, ending in flightlessness in the Grebe of Lake Titicaca, and in the Great Auk, and in the virtual suppression of the wing in Hesperornis, it is a matter for surprise to find that in one group-the Penguins-the incidence of selection has fallen upon the wing, ending in its transformation into a paddle, to all intents and purposes indistinguishable from that of the Cetacea and Turtles among living, and of the Ichthyosaurs and Pleiosaur among extinct, animals.

In the paddle of the adult Penguin no pollex and no flight- 
feathers are traceable; moreover, no flexion of the fore-arm or manus is possible - that is to say, the wing cannot be closed, as in wings which serve the purposes of flight. The skeleton of this wing, in the adult, reveals a great flattening and broadening, and a curious enlargement of the carpals. But in the embryo a distinct pollex is traceable, and the whole limb agrees closely with that of a typical wing, capable of fight.

The shoulder girdle displays no very remarkable features, save an enormously broad scapula; while the hind-limb, it is to be noticed, has the toes webbed and the girdle of the elongated type; as if originally the work of propelling the body fell upon the pelvic limb, as in the cases already considered. And it is significant to note that among the Auks to-day the wings are often used to accelerate progress under water. In the ancestral Penguins it would seem this auxiliary became finally the sole means of locomotion.

The extreme modification of the limbs and girdle, it is to be noticed, only occur in those types which obtain all their food beneath the surface of the water. The Coots and Water-hens, which swim well but pass much of their time and obtain much of their food on land, have undergone but little change in the direction of adaptation to swimming; it would seem indeed that these birds, before they adopted their present aquatic habitat, had sojourned long in an environment where cursorial powers of no low order were essential to existence. And this because the pelvis bears evident signs of specialisation designed to effect this end. To this fact we shall refer at the proper time. Certain near allies of these birds indeed, such as the Corn-crake, live far from water, skulking amid dense undergrowth in the driest regions.

It is generally supposed that webbed feet are essential to birds which swim; this, however, is not the case. The Coots and Water-hens, for example, are expert swimmers and divers yet the toes are free. In the former the toes are, however, provided with broad lobes of integument on either side; in the latter they are not so furnished, but are of great length and slenderness. The Gulls, near allies of the Plovers-which have free toes-have webbed feet, though they do not swim so much, nor depend so much on swimming for their livelihood as those members of the Rail tribe, the Coots and Water-hens. The 


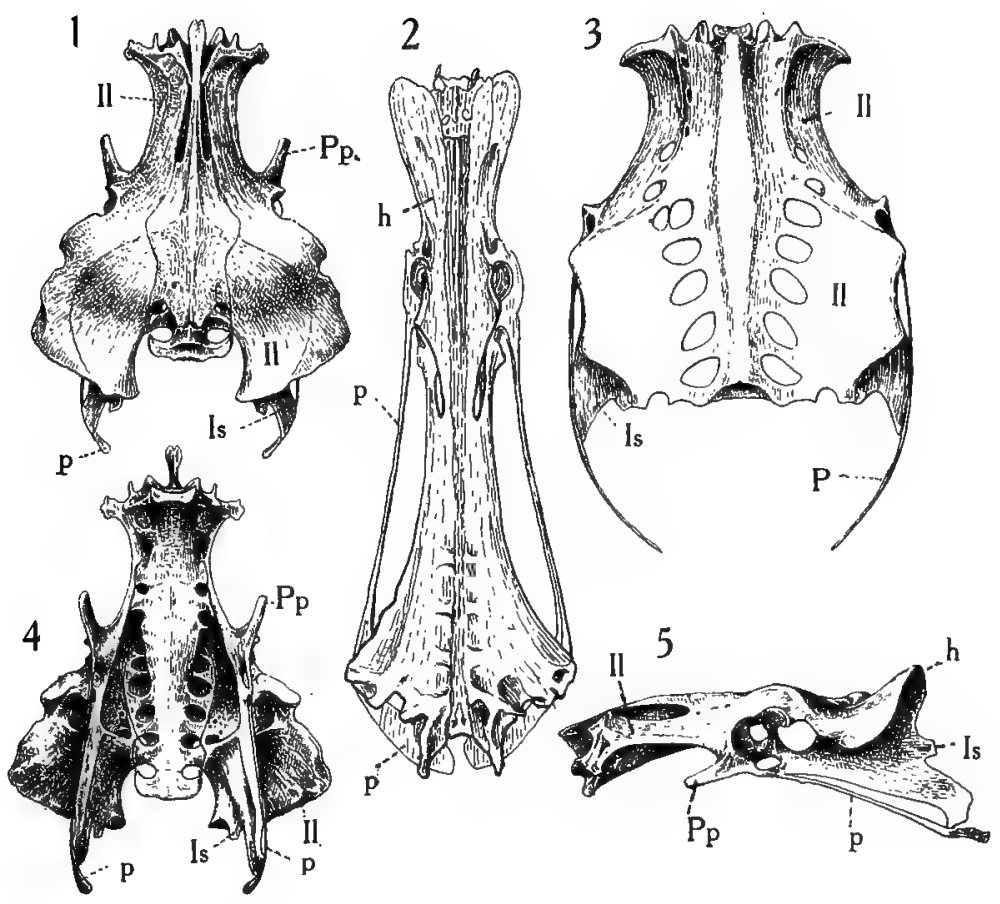

6

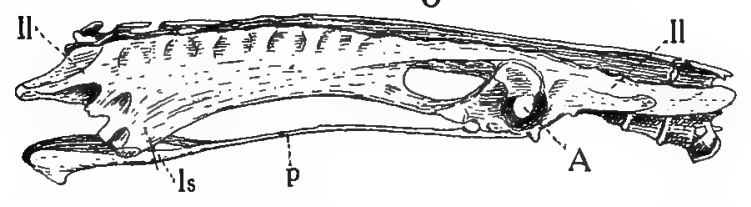

Ill. 42.-Types of Pelvic Girdles

I, 4, 5. Upper, under and side views of the pelvis of the Road-runner (Geococcy $x$ ). 2, 6, Upper and side views of the pelvis of the Red-throated Diver.

3 , Upper surface of the pelvis of a cuckoo.

P.p. $=$ Pectineal process. Il. $=$ Ilium. P. $=$ Pubis. Is. $=$ Ischium. 

Plovers, however, have the second and third toes half-webbed; in the Avocet, and some other Plovers, the third and fourth are also connected in this way. Among the Duck tribe the Screamers may be cited as forms with free toes, yet they swim much, while the intensely specialised Grebes have lobed feet like the Coots, and Phalaropes among the Plovers. To add to the complexity of this problem the Divers, which are the marine counterparts of the fluviatile Grebes, have webbed feet. Further, the Steganopodous birds are distinguished by the fact that all the toes are enclosed in a web; yet, save the diving Cormorants and Darters, none of these birds pass more time on the water than, say, the Gulls. In the Frigate-bird indeed, in which the legs are much reduced, the web of the toes has undergone considerable reduction. Such are the facts; the interpretation thereof is by no means so simple as some seem to imagine.

In seeking for evidence as to the effects of a cursorial habit we turn naturally to the pelvic girdle and limb as being the parts most likely to be affected by any adaptation tending to increase pedestrian locomotion. The conflicting character of the results obtained by a careful comparison of these parts in the most typical cursorial birds is most puzzling.

In all cases cursorial locomotion is developed at the expense of flight; and this fact is brought out with unmistakable emphasis in the case of the Ostrich tribe which are now-save only the Tinamous-absolutely flightless. But there are many species among the carinate types which, though still retaining the power of flight, pass most of their time upon the ground. This is especially true of the granivorous types-the Bustards, Game-birds, Pigeons and Sand-grouse. A very casual survey of the forms belonging to these two groups-Neognath and Palæognath-will show that, in so far as living species are concerned, the former have an unusually broad pelvis, while in the latter it is surprisingly long and narrow. The one indeed is the very antithesis of the other.

The broad type of pelvis, however, it is to be noted, is by no means rare amongthe Carinatæ, and it is especially common in the smaller Coraciiformes, such as the Kingfishers, for example. It occurs, too, among the smaller Cuckoos. Indeed it would seem almost as though this were a primitive character 
inasmuch as it is found with especial frequency among the small and more primitive forms.

It is, however, among the vegetivorous types, as we have already remarked, where the food is only to be obtained by laboriously quartering the ground on foot, that the most conspicuously broad pelvis obtains.

Two of the most striking instances of this are to be found in a Cuckoo known as the Chapparal Cock or American Road Runner (Geococcyx) and a Grouse, the Prairie-hen (Tympanuchus). Displaying a remarkable similarity in some respects, they differ materially in others. In the Grouse the postacetabular region of the ilium is enormously expanded so as to be as wide as the whole length of the pelvis, while it extends outwards and downwards on either side as a huge shelf overhanging the ischium, to an extent elsewhere unknown. In contrast with the majority of the Galli the pectineal process is conspicuous by its absence, and this fact is noteworthy.

In the Cuckoo (Geococcyx) the post-acetabular ilium, as may be seen in Ill. 42, is also extremely broad. It differs, however, from this region in the Grouse just described in that it turns first downwards, then upwards and backwards to form a cavernous space above the ischium, and in so doing effects the same purpose as the wholly downward growth in the Grouse-to wit, it affords increased surface for the attachment of the muscles of the leg. The pectineal process is here strongly developed. In both these birds the pubis is degenerate. The presence of the pectineal process is a feature of considerable importance, and is generally regarded as indicative of well-developed running powers, which are conspicuously developed in the Cuckoohence the name "road-runner". Indeed it is more expert at this form of locomotion than at flight, the wings being short and rounded.

But there are many puzzling exceptions to this rule, associating broad pelves with great powers of walking and running.

In the first place, there are many birds which have strikingly broad pelves though neither walking nor certainly running play any very conspicuous part in their life-history. Thus the Osprey (Pandion) differs from all the other Accipitrine birds in the great width of its pelvis. This fact might be attributed to the need of great muscular strength for raising 
its finny prey out of the water; but the Sea Eagles fish in a similar fashion, and the pelvis in these birds, as in the normal Accipitres, is long and narrow by comparison. Again, the Dodo and its ally the Solitaire (Pezophaps) being flightless, were entirely committed to terrestrial locomotion, yet the pelvis in these birds is relatively much narrower than in many Pigeons possessing unusually strong powers of flight. Many of the smaller Cuckoos, and many of the Coraciiformes, e.g., the Kingfishers, have very broad pelves, yet the Kingfishers certainly cannot be regarded by any stretch of imagination as pedestrians, since the legs in these birds are extremely short, and furthermore, the feet, from their peculiar shape, are entirely unfitted for walking.

Turning now to the members of the Ostrich tribe which are all, save the Tinamous, flightless, we find the giant forms divisible into two groups--those in which the pelvis is extremely broad, and those in which it is extremely narrow, so narrow as to have no parallel among Neognathine birds save the Grebes and Divers! In the Moas (Dinornis) and in Epyornis the pelvis resembles that of the Tinamous in being broad: in the Ostrich (Struthio), Rheas, Emus and Cassowaries, as well as in the pygmy Apteryx the pelvis is extremely narrow. A reference to the accompanying figures will bring out this fact better than a mere description.

The width of the pelvis, we may remark, is determined by two factors: (1) the length of the transverse processes of the vertebræ forming the synsacrum, and (2) by the development of the post-acetabular ilium to form a broad dorsal plate, the "dorsal plane".

Where the transverse processes are long, those of the sacral vertebræ are always the longest, those in front and behind gradually increasing and decreasing as they approach and leave this point. But there is not the same uniformity in the matter of the width of the dorsal plane. This may be widest across the anti-trochanters, or at any point caudad of this. Anteriorly these transverse processes may be so long as to prevent the ilia or front ends of the innominate bones coming together, though generally these plates meet one another in the middle line. It would appear that widely separated innominate bones, such as are seen in the figure of the young Boatswain-bird 
(Phethon), are indicative of a primitive condition, where these meet in front of the acetabulum of a specialised or adaptive condition. In support of this view it may be mentioned that, while in many of the Fruit-pigeons, for example, which walk but little, the innominate bones are widely separate one from another, in the great Goura Dodo and Solitaire these bones meet one another in front.

Certain extraordinary features in the pelvis of the Rhea may find brief mention in these pages, if only that they may excite further study. Briefly, then, the post-acetabular ilia have approached one another so closely that they have brought about the atrophy of so much of the vertebral column as. is embraced between them, all that remains of this being represented by mere vestiges of vertebræ. The free caudals are fairly well developed. Since in some specimens more or fewer of the vestigial caudals have disappeared, we have the unique condition of a discontinuous vertebral column! Further, in the pelvis of Rhea alone do we find the ischia meeting one another in the middle line throughout their whole length, forming a chamber enclosing the kidneys!

The effect of a cursorial habit on the legs has been chiefly to reduce the toes, first in length, then in number.

The leg of the Ostrich (Struthio) affords the most striking instance of this numerical reduction. As is well known, only the middle and outer toes now remain. Of these the middle is by far the largest; the outer indeed shows unmistakable signs of still further reduction, inasmuch as the claw has disappeared. This limb is a striking parallel to that of the horse's. But it differs in this respect, that whereas in the horse the weight of the body is borne on the terminal phalanx, in the bird all the phalanges are applied to the ground. The Bustards are extremely short-toed birds and have only three toes.

As with the pelvis, there are some curiously contradictory facts to be explained. Thus, how is it that the Moas have retained the hallux while all the other Struthious birds save Apteryx have lost it? The wings in the Moas from disuse have absolutely disappeared, yet the equally useless hind toe survived!

Though the majority of living birds spend a considerable portion of their lives amid trees or scrub, adaptations to a 
strictly arboreal life are few. Such structural modifications as we meet with chiefly affect the feet. Furthermore, as one would expect, the birds so affected are those which spend practically their whole lives in trees or amid scrub.

Such species as resort to trees merely for nesting purposes not only undergo no adaptation to facilitate perching, but they succeed in maintaining a secure foothold with feet which have completely lost one of the principal agents for grasping purposes - the hind toe. That is to say, their feet have become profoundly modified in adaptation to totally different needs, showing that they have returned to such nesting or roosting resorts after having forsaken them for countless generations.

Such abnormal perchers are, so to speak, like fish out of water, but they are extremely instructive types, and show that the greatest caution must be exercised in generalising on the habits even of the most specialised types. Thus Gannets, Cormorants, Frigate-birds, Ducks and Terns are scarcely birds one would expect to find roosting and even nesting in trees; not because, judging from the habits of the majority of the species belonging to these groups, such roosting or nestingplaces would never be selected, so much as from the fact that their structural peculiarities would seem to render them utterly unfit to use such retreats.

Thus the Gannets and Cormorants are typically cliff-haunting birds, laying their eggs on ledges, or on the ground, yet several species of Gannets and of Cormorants build in trees: the Darter invariably does so. Among the Ducks the same obtains, and so too with the Gulls, as we have already shown. It is probable that this peculiarity owes its origin to the lack of suitable nesting-places near enough to the feeding-grounds, though to-day it is practised when no such reasons obtain. These birds, in short, maintain their hold on the environment in spite of their manifest unfitness for it.

With the birds of prey, which are no less highly specialised, perching is easy: their powerful feet have become adapted to grasping prey, and can as easily therefore grasp a bough. These, then, though tree dwellers to a certain extent, have developed no adaptation to this end.

The feet of that great army of birds known as the Passeres or perching-birds, show the results of a compromise between 
walking and perching. The hind toe or hallux in these birds is long, and in the most strictly arboreal types of great size, while the three remaining toes are large and turned forwards.

But there are a number of birds which have become adapted to a strictly arboreal life, passing in this environment almost their whole lives, some indeed never leaving the forests, and these have developed feet of a peculiar type, recalling in many ways those of the chameleon. Such are the Parrots, Cuckoos, Kingfishers, Rollers, Bee-eaters, Trogons, Colies and Woodpeckers. In these the feet are used as grasping organs and but rarely for walking. Though the same end has been attained by these very different types of birds, it has been reached by different means, and this is curious. Thus in the Parrots, Cuckoos and Woodpeckers, they are yoked together in pairs, the hallux and outer pointing backwards, the second and middle toes forwards, forming what is known as the zygodactyle foot. The Kingfishers, Bee-eaters and Rollers, for example, have a syndactyle foot, wherein either all the front toes, or the middle and outer toes, are united together throughout the greater part of their length. The foot of the Trogons is unique in that the hallux and second toe turn backwards, instead of the hallux and outer toe, as in Woodpeckers and Cuckoos. In the Swifts, Humming-birds and Colies, or Mouse-birds, the hallux can be turned forwards so that all the toes point forwards. But in all these, save the zygodactyle types, the hallux is relatively small. The Owls have the outer toe reversible at will. Finally, certain Woodpeckers and one Passerine bird have reduced the number of toes to three.

The wealth of variety in these modifications is curious, inasmuch as, so far as we know to the contrary, all are modifications of a common type of foot, adapted to serve the same end.

Now it is curious to remark that after having undergone a very pronounced adaptation to an arboreal life, certain members of these groups have exchanged this environment for the ground, and in all these cases the tarso-metatarsus has undergone a very striking increase in length, as for example, in the Ground Parrakeets of the Genus Pezoporus, the Ground Hornbill, Ground Cuckoos like Geococcyx, the Dodo, the Solitaire, the Crowned Pigeon and the Tooth-billed Pigeon (Didunculus). On the other hand, by way of baffling speculation, such strictly 


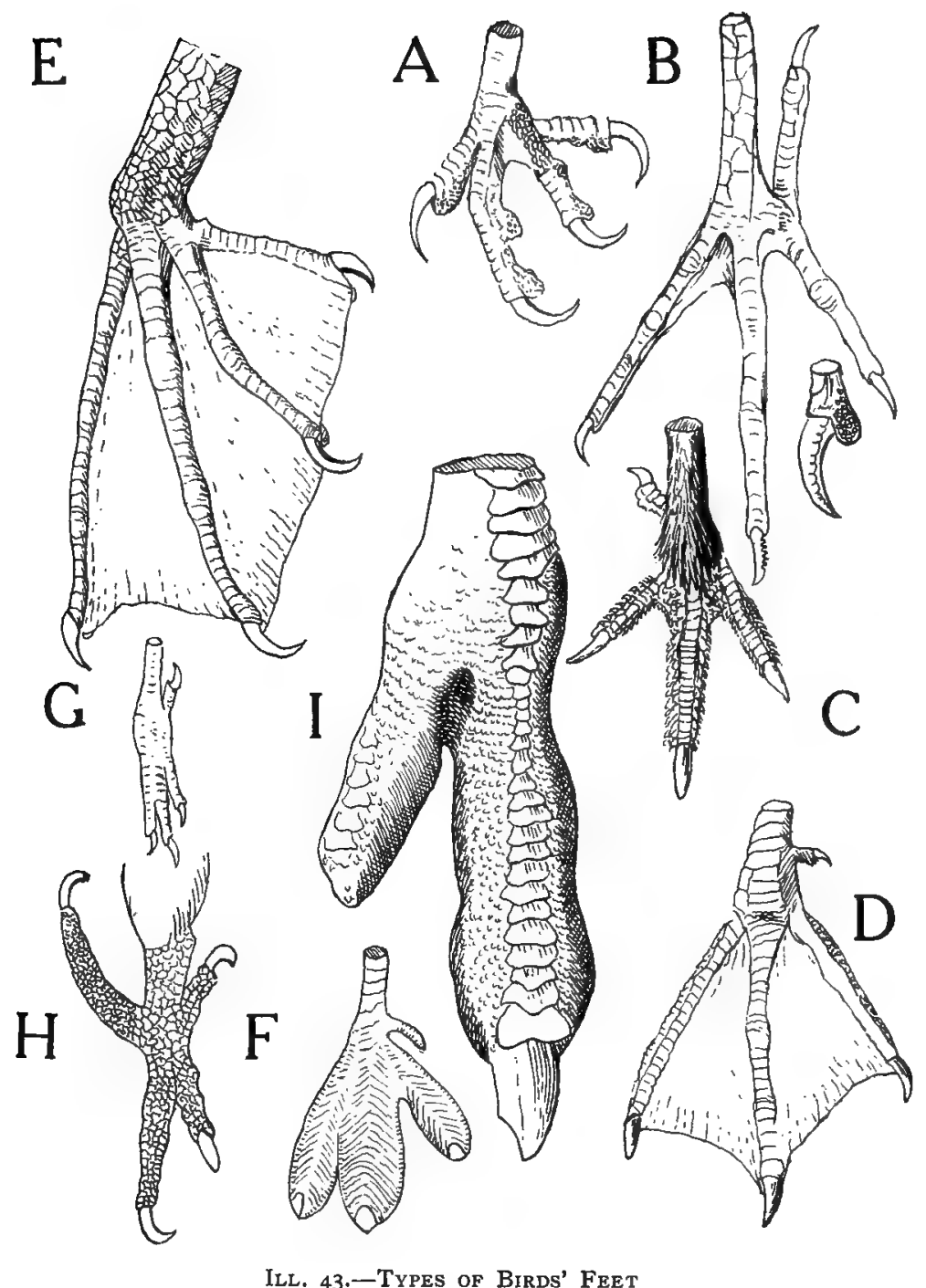

A, Sparrow-hawk. B, Heron. C, Blackcock. D, Gull. E, Cormorant. F, Grebe. G, Kingfisher. H, Parrot. I, Ostrich. 

ground-dwelling forms as Grouse and Sand-grouse have peculiarly short tarso-metatarsi, differing in this respect from all their allies wherein this segment of leg is long!

The effect of disuse, or, more correctly, the absence of selection, on the size of the hind-limbs, are nowhere more strikingly illustrated than in the Frigate-birds, Humming-birds and Swifts. All these types spend almost the whole of their waking hours on the wing, and in consequence the hind-limbs are reduced to the smallest possible size consonant with the support of the body. The Frigate-birds have retained the type of swimming foot peculiar to their allies the Gannets and Cormorants-all the toes being united in a common web-though they never dive, and rarely if ever swim; but the toes of the Swift have undergone some transformation, all the toes pointing forwards (pamprodactylus), whereby they are enabled to cling to the steep faces of cliffs or under eaves of houses while they feed their young.

The capture of swiftly moving prey, often of large size and of considerable weight, must always, in the case of birds, be effected by the legs. To render this possible considerable transformations in the hind-limb have taken place, though these are mainly confined to the tarso-metatarsus and toes. In the smaller birds of prey the feet only have undergone any marked change. In so far as the skeleton is concerned it has simply increased the size of the ungual or claw-bearing phalanges. As might be expected, all four toes are present; the hallux, so often reduced or even absent in birds which do not perch, is in birds of prey always strongly developed. In the larger birds of prey, such as the Eagles and the Great Owls, the tarsometatarsus loses its cylindrical shape and becomes transformed into a shaft flattened and twisted into long and broad ledges. These features are most marked in the great Harpy Eagles (Thrasaetus). The grip of the foot is increased by the development of fleshy bulbs (tylari) of considerable size on the undersurface of the toes, and these are especially long in the Sparrowhawks.

The armature of the feet is completed by the development of enormous claws, of which the largest is that borne on the hallux. The strength of the feet of raptorial birds is enormous. The Goshawk, for example, kills its prey by the grip of its feet. 
Where fish form the staple diet the under-surface of the toes lack the tylari just described, and instead have the skin beset by sharp denticulate horny spines, and this feature has been acquired independently by the Ospreys on the one hand and the Fishing Owls (Ketupa) on the other. This roughened surface obviously is of the highest importance in maintaining a grip on slippery creatures such as fish.

In so far as structure is concerned- the feathers change but little in response to environment. Those of aquatic birds differ but little from those of birds which never or rarely enter the water, and when this is said there is but little else to say. Their function is to subserve the purposes of flight, and of a covering. But in some cases the tail feathers are utilised to serve as the third leg of a tripod, and this obtains in the Penguins and the Woodpeckers, and one or two other climbing birds. To this end these feathers have acquired a remarkable stiffness and have the shafts pointed at the tips. By this means the Woodpecker is enabled to suppoit its body when clinging to treetrunks, or when driving holes therein for nesting purposes, or in search of food. At this time these long elastic spines are of the greatest service, affording the bird a leverage when dealing the series of powerful blows necessary to attain its ends. But it is a curious fact that the Nuthatches, which are as skilled at this work as the Woodpeckers, and as rarely leave the trunks of trees, have not acquired this peculiar form of tail, nor have they, by the way, developed the same modification of the foot as obtains in the Woodpeckers. Similarly, the aberrant Wrynecks, which agree with the Woodpeckers in having an elongate protrusible tongue and zygodactyle feet, have comparatively soft tail feathers. This is not to be explained by the fact that the Wryneck does not use its beak as a hammer, since the little Tree-creepers, which like the Nuthatches are true Passerines and therefore unrelated to the Woodpeckers, have developed spiny tails, yet they have slender curved beaks, and are therefore incapable of using the beak after the fashion of the Woodpecker. This is all the more puzzling since certain South American Passerine types, known as the Woodhewers (Dendrocolaptina) have in many species adopted the habits, and to a large extent the outward form, of the Woodpeckers, especially in regard to the spiny tail. 
There is one other point concerning the Woodpeckers and their use of the tail as a support which must be mentioned here, and that is the fact that the pygostyle, or fusion of vertebræ which terminate the tail skeleton, has its under-surface expanded to form a large disc for the purpose of affording increased support to the tail feathers. A similar support turns up again in the Falcons, and these birds use the tail for the purpose of checking their career when striking at their prey in mid-air, but in this case the disc is formed by a pair of plate-like ossicles and not by the expansion of a mass of bone. 


\section{CHAPTER XXIV}

\section{ADAPTATIONS (continued)-ORGANS OF EXTREME PERFECTION}

The significance of certain peculiar modifications of the trachea. Reciprocity in development. The apparent over-elaboration of organs as illustrated by Woodpeckers and Kingfishers. Diastataxy.

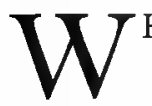

HILE structural peculiarities can in the majority of cases undoubtedly be interpreted as adaptation to particular ends, there remain a very considerable number of cases where cause and effect are by no means so obvious. It is proposed here to examine a few of the more striking of this nature is broad outline, selecting for the purpose some very remarkable instances furnished by the windpipe.

In addition to its respiratory functions it serves also as the organ of voice. This, as we have already seen (p. I66) in the birds, is placed at the lower instead of the upper end of the trachea, and in the course of its evolution has assumed certain peculiarities characteristic of different groups of birds. In the light of what follows it would appear that these differences arose as congenital variations rather than as direct responses to any particular stimuli, and this because the special but precisely similar cases now to be considered do not appear to support current interpretations as to their purpose and origin.

Briefly, the particular tracheal peculiarities to which we now refer are regarded as specially developed mechanical devices, or as resonators, as the case may be, for producing sounds beyond the range of species not so provided. But it cannot be said that a closer study tends to confirm this opinion, although in many cases it may appear to do so.

Thus the Cassowaries have perhaps the simplest form of syrinx of all birds, being entirely without modification for voice production; yet these birds give vent to a considerable variety of sounds, and when excited make a noise that has been aptly 
compared to a deep roar. In the closely allied Emus, on the other hand, the front of the windpipe, near the middle of the neck, presents a series of rings which fail to meet in the middle line, leaving a long and fairly wide slit. Through this aperture the lining membrane of the tube emerges to form a large sac lying immediately beneath the skin, and the sac can be inflated at will. As the Emu makes a very remarkable booming or hollow drumming sound, such as might be made by beating on a large wooden tub or barrel, it is supposed that the sac is the instrument for the production of the sound, but the Cassowary contrives to do as much without any such aid. Possibly by acting as a resonator, it helps to increase the volume of the sound. But we have no direct evidence that such is the case, and the significance of this will appear presently.

In many birds, and these in no way related forms, the windpipe becomes enormously lengthened, so that in consequence it has to be stowed away in coils, and this is done in one of three ways-either these coils run between the surface of the breast muscles and the skin, or they are received into a cavity in the keel of the breast-bone, or they are stowed away beneath the lungs (II1. 6, pp. I7, I 8). Generally these modifications obtain in the males only, sometimes in both sexes, and more rarely in the female only. As an instance of superficial coiling we may take the case of the Semipalmated Goose (Anseranas), in which, in the males only, the windpipe is coiled beneath the skin of the upper part of the breast, the coils varying in number, and lying sometimes to one side and sometimes to the other, the coracoid bone of that side being modified to accommodate the coils. The males of the Curassows, and both sexes of a species of Penelope (Penelope jacucaca), have the windpipe coiled away beneath the skin, the coils extending as far back as the end of the sternum. Although there are many species of Penelopes, $P$ jacucaca alone is so modified. Further, the males of the Manucode Bird of Paradise have an enormous tracheal coil (IIl. 23), covering the whole surface of the breast. Thus this character has been independently acquired in several widely distinct forms, but the sounds made by these birds do not appear to be more remarkable than in allied species of these several groups which have normal windpipes. In the Crested Guineafowls (Guttera), and in both sexes, the windpipe forms a loop 
which fits into a hollow in the symphysis of the furcula, but the voice of this bird is not peculiar.

In the Storks the bronchi are of remarkable length, and in the Black Stork (Ciconia nigra) take an $\Omega$-shape twist before entering the lungs, while in one species of Spoon-bill (Platalea), and in the Tantalus Stork (Tantalus ibis), the trachea is coiled up into an 8-shaped loop, but these birds are practically silent.

In both sexes of the Whooper, Trumpeter and Bewick's Swans and in some Cranes the windpipe is received into the keel of the breast-bone, which has been enlarged to form a hollow chamber for its reception. Here again we have a precisely similar modification independently acquired by two very distinct groups, but differing in this-that in the Swans the loop of the windpipe passes under the furcular symphysis, while in the Cranes it passes above this, as may be seen in Ill. 23. Here the coils seem undoubtedly to be used for the purpose of increasing the volume of the voice, but the Cranes so provided do not appear to call more loudly than species not so furnished.

Among the Ducks some very remarkable modifications are to be met with, and these show a very interesting series of increasing complexity. In the Common Mallard (Anas boschas) for example, the lower end of the trachea develops on its left side a large osseous, thin-walled, bulbous chamber immediately over the bronchus, while the right side of the tube remains unmodified. Varying chiefly in size, this same chamber will be found in the males only of all the fresh-water surface-swimming Ducks, and is generally regarded as an important factor in the production of the voice. If this be true it is curious that in the Mallard, for example, the males have but a low hoarse note, while the call of the female-which lacks this resonating chamber, if such it is-is loud. In the Diving-ducks this chamber becomes enormously increased in size, and changes much in shape. No longer spherical, it becomes now discoid, consisting of an osseous ring of bone, wider at the base than the top, and supporting a tense but delicate sheet of membrane. Usually, the centre of the disc is crossed by an arcuate bar, which looks as though it had been developed for the sake of strengthening the disc. It is more probable, however, that this bar and the short "stays" of bone between the outer rim and the bar, are the last remnants of a continuous wall of bone such 
as obtains in the fresh-water Ducks. In other words, this bulb is undergoing a process of degeneration as a consequence of hypertrophy. A reference to the figures below will afford a better idea of these structures than a lengthy description.

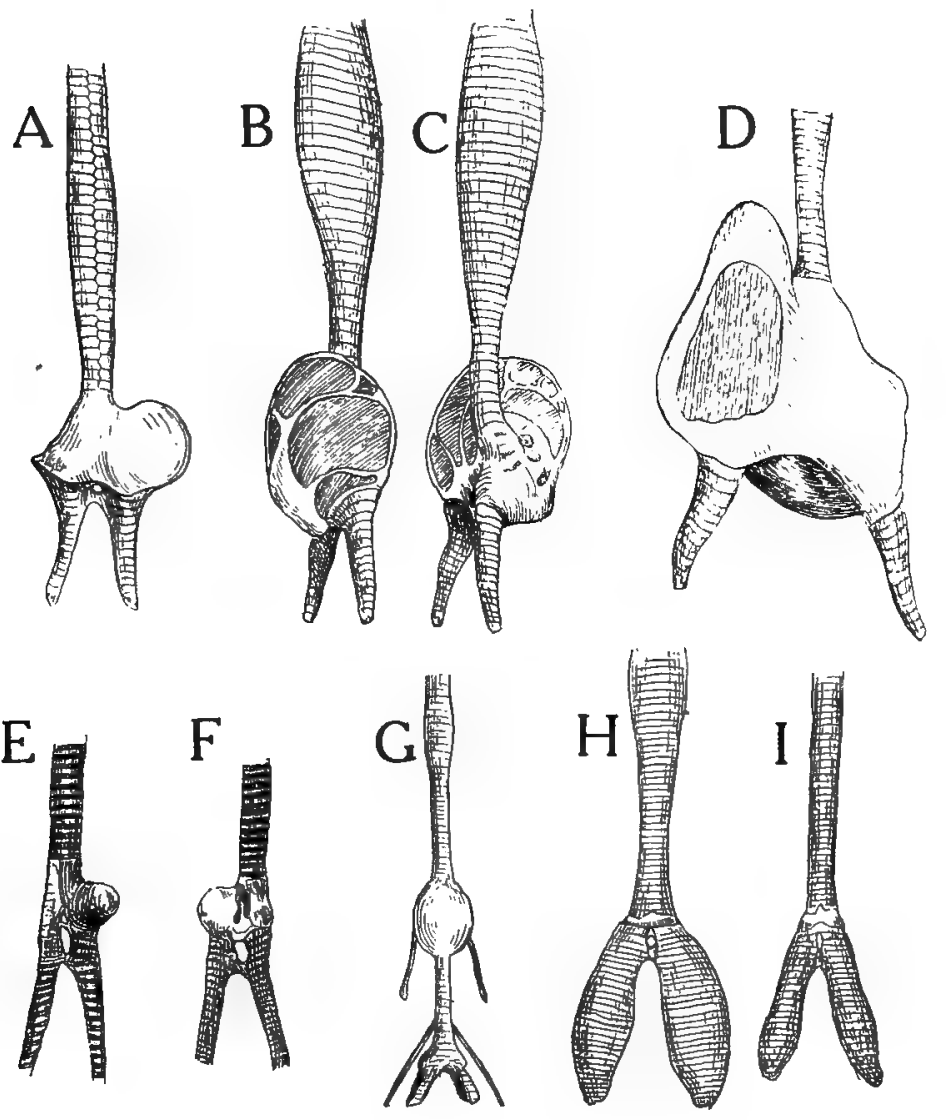

ILL. 44.-TYPES OF SYRINX

A, Mallard. B, C, Pochard. D, Goosander. E, F, Steller's Eider. G, Velvet Scoter. H, I, Common Scoter (male left-hand, female right-hand figure).

In the Mergansers this structure reaches its maximum size and is supplemented by a smaller tympanum on the right side. The Mergansers bring us a further complication, in the shape of bulbous swellings of the middle of the windpipe. Thus in the Red-breasted Merganser (Mergus serrator) the male has the 
middle of the trachea considerably enlarged to form a long, fusiform swelling, while in the Goosander (Mergus merganser) there are in the male two such swollen areas, and one, be it noted, in the female. The trachea of the male Velvet Scoter (Edemia fusca) is still more remarkable. In this bird the bulb at the end of the trachea is wanting, but the tube, near its lower third, becomes abruptly swollen to form a large spherical chamber, made up of tracheal rings fused together to form a homogeneous wall, while immediately below the larynx is a second chamber, this, however, being formed outside the tracheal tube and with which it communicates through special apertures, as may be seen in Ill. 44 .

What purpose do these structures serve? If as a resonator for increasing the sound of the voice then it is curious that in many Ducks the female, which has no resonator, has the louder voice, as in the case of the Mallard, for example. Ducks with precisely similar resonators have absolutely different calls. The coiled tubes of the Curassows, Swans and Cranes, on the other hand, certainly do seem to act directly upon the voice, producing a loud trumpeting sound, yet the similarly convoluted windpipe of two species of the Painted Snipe does not appear to have any vocal function at all. In the Painted Snipe (Rhynchea), be it noted, the convolutions are met with only in the females, but these, as in some other species to which reference has already been made, are large and more resplendent than the males, which, as in all such cases, undertake the charge of the eggs and young. The elaboration of these organs is, in short, something of a mystery. They seem to come within the category of what have been called "organs of extreme perfection," since unnecessary energy seems to have been expended in developing structures which appear in some cases at least to serve no purpose. If indeed they be resonators, then it is more remarkable that the majority of species contrive to make louder sounds without the aid of such contrivances, while among birds with similarly elaborated windpipes some produce a sonorous kind of music, others no remarkable sound at all.

The Passerine birds provide a parallel. Here the elaborate arrangement of muscles and tracheal rings which form the syrinx have resulted in the evolution of an organ of song, of great perfection, as witness such performers as the Nightingale, 
Blackcap, Skylark, Thrush and Mocking-bird. This being so, it is somewhat remarkable that a very large proportion of what are technically known as "song"-birds should have no song, yet in them the syrinx and its muscles appear to be as perfectly developed as in the master performers! How is it that these muscles have not degenerated from disuse? Why are they maintained in a condition of useless perfection? The Crow and the Jay are conspicuous examples of songless song-birds, yet the organ of voice is, so far as we can see, as perfect as in the Nightingale. Similarly, the females of the Nightingale,

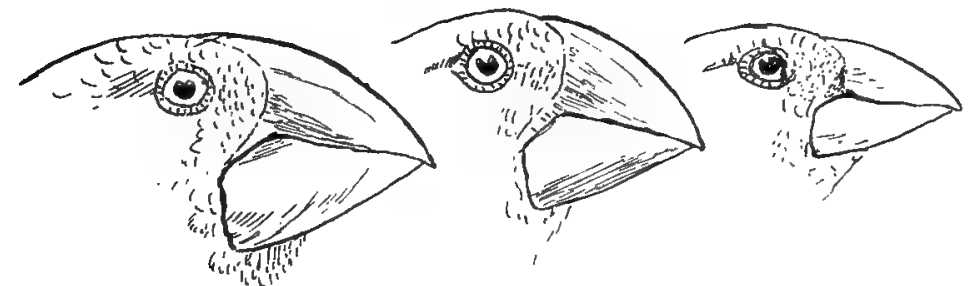

G.magnirostris

G.strenua

G. Fortis
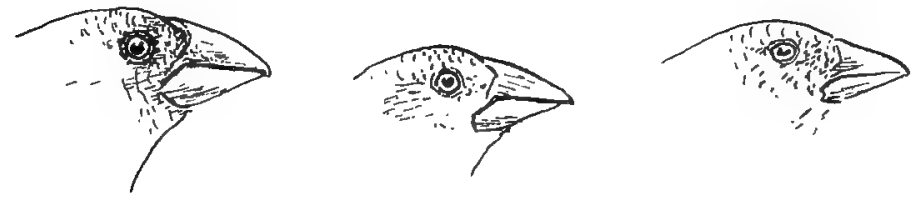

G.Fortis

G. Fulginosa

G.parvula

\section{Forms of the beak in the genus Geospiza}

ILL. 45

Thrush and other performers have the syrinx apparently as perfect as in their mates, yet they sing not.

Finally, there remain two other cases of apparently meaningless structures associated with the windpipe that demand notice here.

In the Blackcock (Lyrurus tetrix) there is found, at the lower end of the trachea in the males, a relatively enormous pair of oval bodies-one on either side of the windpipe-having a convoluted outer surface and an almost unique structure in 
that it is made up of a tissue of a "mucous" character such as is met with elsewhere only in the umbilical cord connecting the mammalian foetus with the parent. So far the purpose of these bodies is quite unknown.

No less puzzling is the median septum which runs up the middle of the tracheal tube in birds so widely distinct as Humming-birds and Petrels, Spoon-bills and Penguins. Possibly it is the last vestige of a sometime double trachea which has now fused, inasmuch as a similar septum is found in all embryonic birds. This, except in the cases just quoted, becomes completely absorbed, save only that portion which remains to form the "pessulus".

There are other similar instances of structures which appear to be preserved in a high state of efficiency, but whose functions are so far unknown, or but imperfectly understood; but, in so far as birds are concerned, the modifications of the windpipe are the most striking.

What may be called the principle of reciprocity in development is nowhere more perfectly illustrated than in the case of the tunnelling of the keel of the sternum by the windpipe, or by the cup-shaped receptacle formed, it is assumed, by the pressure of the windpipe on the symphysis of the clavicle, in the case of the Guinea-fowls of the Genus Guttera. The phenomena here exhibited appear hitherto to have been passed without comment, yet it is certainly remarkable that this keel, elsewhere among birds a thin plate of bone, should in these Swans and Cranes have developed into a cavernous receptacle, involving also the body of the sternum forming the roof of this space. What are the factors which have brought about the formation of this curious chamber? The theory of natural selection here seems inardequate; while the theory of mutation involving the sympathetic variation of two such dissimilar structures seems no more helpful.

For the capture of ants and other insects the Woodpeckers have developed a protrusible tongue-agreeing therein with many ant-eating mammalia-and powerful salivary glands. Yet, without any such elaborate apparatus one of the Kingfishers (Halcyon cyanoleucus) of Liberia, which, after the fashion of his people, is almost tongueless, contrives to subsist on ants without any special apparatus for their capture! 

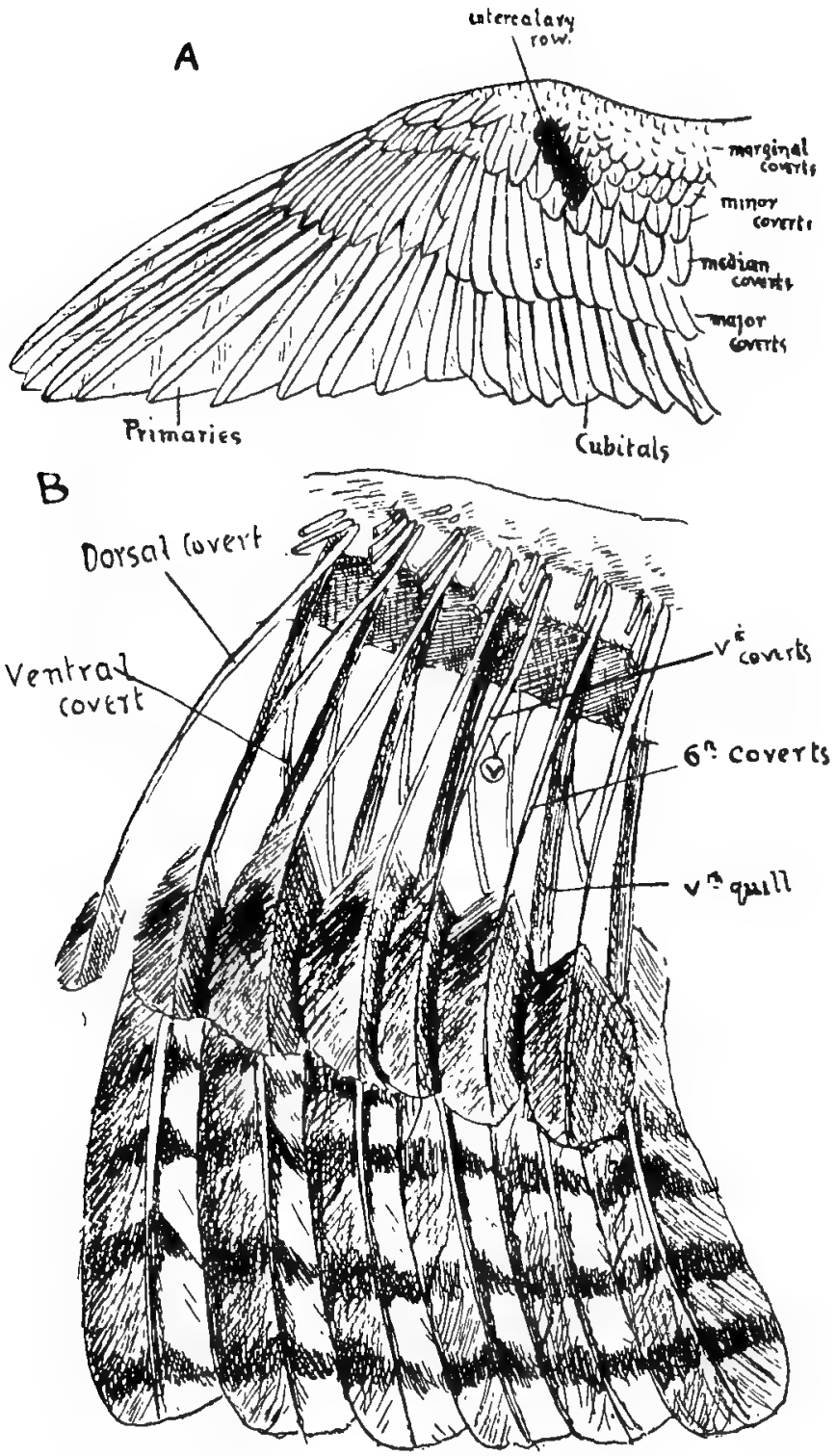

ILL. 46

A, The upper surface of the wing of a Little Stint (Tringa minuta) to show $(a)$ the difference between the "distal" and "proximal" overlap-the former shown by the major, the latter by the median coverts-and $(b)$ the "faulting " which results in the formation of an "intercalary row" in diastataxic wings.

B, Upper surface of a portion of the forearm of an Owl to show the diastataxic condition of the wing. 

Here again is another instance of apparent over-elaboration in Nature. We say apparent advisedly, for the fact that so many widely different creatures have developed a highly complex lingual mechanism for the capture of insect food shows that these exceptions require further study.

By way of contrast we may site the case of the Red-headed Woodpecker (Melanerpes erythrocephala), which, like its congeners, possesses a protrusible tongue ostensibly for the capture of insect prey, yet lives at any rate very largely, on eggs of other birds, even entering hen-roosts in its quest for these delicacies! Furthermore, and perhaps as a natural sequence, it devours young birds, which are killed by a blow on the head with the dagger-like bill, and through the hole thus made the tongue is thrust for the purpose of sucking out the brains! It is recorded that, in Ohio, a colony of Swallows, represented by some dozens of nests, was so completely raided that not a single young one was reared! Occasionally frogs are eaten, perhaps by way of varying the diet. We must assume that this strange departure has been but recently made, for as yet the elaborate mechanism characteristic of the Woodpecker shows no signs of degeneration.

Finally, mention must be made of that most puzzling and elusive phenomenon known as Diastataxy, a name coined by Dr. Chalmers Mitchell to designate the apparent absence of the fifth secondary remex which is met with in nearly all Neognathine birds save the Passeres, which have, in consequence, what Dr. Mitchell calls a eutaxic wing. Some Families of birds, as among Pigeons and Kingfishers, present both forms : the Galli are all eutaxic, the nearly related Megapodes diastataxic; the Cranes are diastataxic, but some of the aberrant types are eutaxic, and so on. In diastataxic wings, as shown in the accompanying illustration, all the major coverts of the forearm, save the fifth pair, embrace a quill, the fifth pair do not.

Embryology, however, seems to prove that this absence of a quill, or aquintocubitalism, as it was called by earlier writers, is due to the torsion and shifting of the feather papillæ, and hence the curious "intercalary row" of wing coverts shown in our illustration.

A considerable body of facts have been collected with regard 
to this puzzling subject, and some of these have brought to light stages which show that where eutaxic wings are met with in diastataxic groups-Pigeons, Kingfishers, Swifts—this eutaxy has been secondarily acquired. The primitive was undoubtedly eutaxic. This view is not, however, held by the author just quoted.

The subject presents many difficulties in the way of investigation, and so far seems to defy solution. Hence it is but briefly referred to here, by way of adding to the number of structural characters which seem outside the pale of the action of selection, which seem in short to have no relation to the problem of the struggle for existence, for it is commonly assumed that all tangible characters owe their existence to this factor. Those who desire to inquire further into this mystery will find all the information so far gathered together in two papers published in vol. xxvii. of the Journal of the Linnean Society by Mitchell and Pycraft. 


\section{CHAPTER XXV}

ADAPTATIONS (continued)-THE ALIMENTARY CANAL AND VAS. CULAR SYSTEMS

The form of the beak in relation to the food. Modifications of the tongue. The alimentary canal. Modifications of the crop and gizzard. The convolutions of the intestines. Peculiarities of the vascular system.

$7 \mathrm{HOUGH}$ it may seem like drawing attention to a truism to point out the fact that there is an intimate relation between the form of the beak and the nature of the food, yet, in a work like the present, nothing should be taken for granted. Moreover, although this correlation is true in general principle it is not absolutely true, since the shape of the beak in many cases by no means proclaims the nature of the food, beaks of the same shape having been independently acquired to fulfil very different purposes; while, on the other hand, birds not even remotely related have evolved similar beaks to attain similar ends.

Some groups, as in the Gallinaceous birds and the birds of prey, for example, present a great uniformity in this matter, others as wide a range of variety; closely allied species of the same genus may even present a very striking range of form, as, for example, in the case cited by Darwin in his Voyage of the Beagle, where he describes and figures the bills of the Genus Geospiza, a small group of Finches inhabiting the Galapagos (Ill. 45). The Larks supply a similar instance. Here the smaller and weaker beaks are used for picking up small seeds which are either easily crushed or are swallowed whole, while the more powerful jaws have been evolved for the purpose of crushing large and hard-shelled seeds and fruit stones; thus no source of food of this kind is wasted. The Hawfinches appear to be unique in that the beak-sheath has developed, in the region of the gape, tumid swellings with striated surfaces. A pair of these occur on the lower jaw, which work against a 
large cushion of similar structure borne by the palate. This crushing mill recalls the large flat-topped teeth of the extinct Placodont reptiles or the crushing apparatus of some fishes. The jaws of the aberrant Opisthocomus are provided with rows of cone-shaped tubercles running along a ridge just inside the cutting edges of the jaws. These horny "teeth" enable the bird to feed upon the fruit of an aroid, and thus, in so far to escape competition in the struggle for food, since other birds without developing a similar armature must leave these fruits untouched.

The same facts meet one whatever group of birds is examined. Where the supply of any particular kind of food is practically inexhaustible, there will be found a large number of species all having the same type of beak. But it would seem that, sooner or later, either because the feeding area becomes inadequate to support the increased numbers crowded upon it, or from idiosyncrasies of taste, some individuals begin to change their diet, selecting food neglected by the majority, and this forms the basis for a new line of evolution. Whether this begins by the selection of small variations capable of facilitating the capture of the new food or of mutations, the result is the same. The Plover tribe furnishes a good object-lesson on this subject.

In the typical Plovers the beak is short and slightly swollen at the tip. Therewith the birds pick up small mollusca, crustacea, and worms and other aquatic organisms. In some, as in the Turnstones (Strepsilas), the beak acquires a great density and becomes pointed. It is used for the purpose of capturing small crustacea which lurk under stones at low tide. Using the beak as a lever the bird raises, and finally overturns the stone, seizing whatever may have been in hiding before escape is possible-hence the name "Turnstone". In the closely allied and larger Oyster-catcher (Ostralegus) the beak has increased enormously both in length and density, and is now used for breaking open the shells of the larger molluscs, such as mussels (Mytilus).

Yet other long-billed Plovers are the Curlews and Snipes. The former, like the Ibises-birds belonging to the Stork family, and not even distantly related to the Plovers-have downwardly curved beaks which are used as forceps to drag out small crustacea, molluscs, and so on, from their hiding-places; 
while the latter use the beak as a probe, thrusting it far down into the mud in search of worms until the prey is touched. For this purpose a high degree of specialisation has become
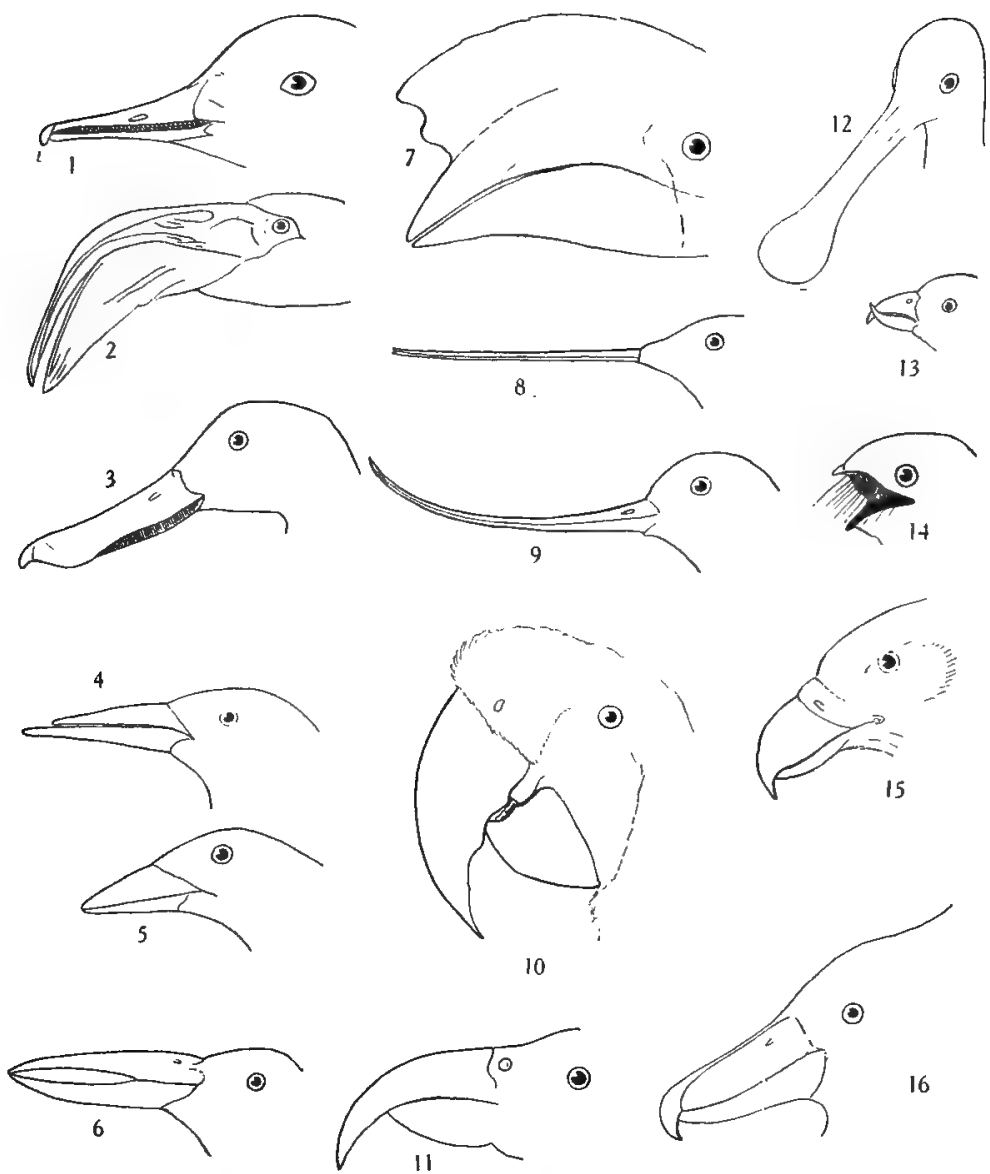

(-)

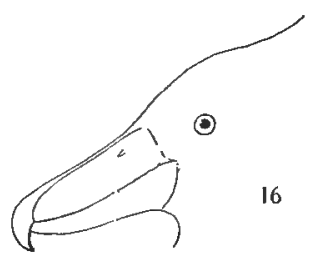

ILL. 47.-TYPES OF BeAKs

I, Merganser. 2, Flamingo. 3, Shoveller. 4, Scissor-bill (adult). 5, Scissorbill (young). 6, Anastomus. 7, Hornbill. 8, Humming-bird. 9, Avocet. ro, Parrot. II, Parrot. I2, Spoon-bill. '13, Cross-bill. I4, Nightjar. I5, Eagle. I6, Balæniceps.

necessary, and the beak has accordingly become richly supplied with nerves ending in small pits at the tip of the beak. But this is not all. As it would be impossible for such a long 
and elastic organ to move away the mass of soil surrounding the whole beak, a mechanism has been evolved whereby the tips only of the jaws are opened sufficiently wide to allow of the worm being grasped. The mechanism in question is simple, and may be briefly described as follows: The beak of the Snipe is formed by the elongation of the premaxilla and the extension forwards of the narial fossa to within a short distance of the tip of the beak. Thus is formed an upper and a lower pair of lateral rods of great slenderness and elasticity. By the contraction of muscles attached to the quadrate bones the pair of inferior bars are thrust forwards, and this results in forcing the tip of the beak upwards. The relaxation of the muscle brings the curled-up tip down again so as to close upon the worm and hold it securely until brought to the surface. This form of beak, seen in perfection in the Snipes and Woodcocks, apparently had its origin in the short bill seen in the Dunlin, Stints and Sandpipers, for example.

Few groups of birds show the influence of the quest for food more admirably than the members of the Goose tribe, using this term in its widest sense. The most ancient of this group is undoubtedly represented by the Screamers of South America (p. 48). The beak of these birds resembles that of a Fowl in shape, and is used similarly for picking up seeds and other vegetable matter on land, varied with succulent water-plants obtained when on the water. These birds, as we have remarked, are probably the ancestors, or near allies of the ancestors, of the Goose tribe, and, it may be remembered, though aquatic in habits, have no webs to the toes. The next stage in the evolution of the more typical Anserine bird we get in the Black and White Goose, or Semi-palmated Goose (Anseranas), wherein the toes are half-webbed, and the beak has assumed a Goose-like form, having the edges of the jaws provided with horny lamellæ; while the tongue has become thick and fleshy and fringed with horny processes. The development of this peculiar form of tongue, and of the horny processes along the jaws, enable the bird to avail itself of the rich stores of food in the shape of insects and other organisms which teem in the water. These are captured by taking large quantities of water into the mouth and expelling it by means of the fleshy tongue, the lamellæ of the jaws acting as a rough 


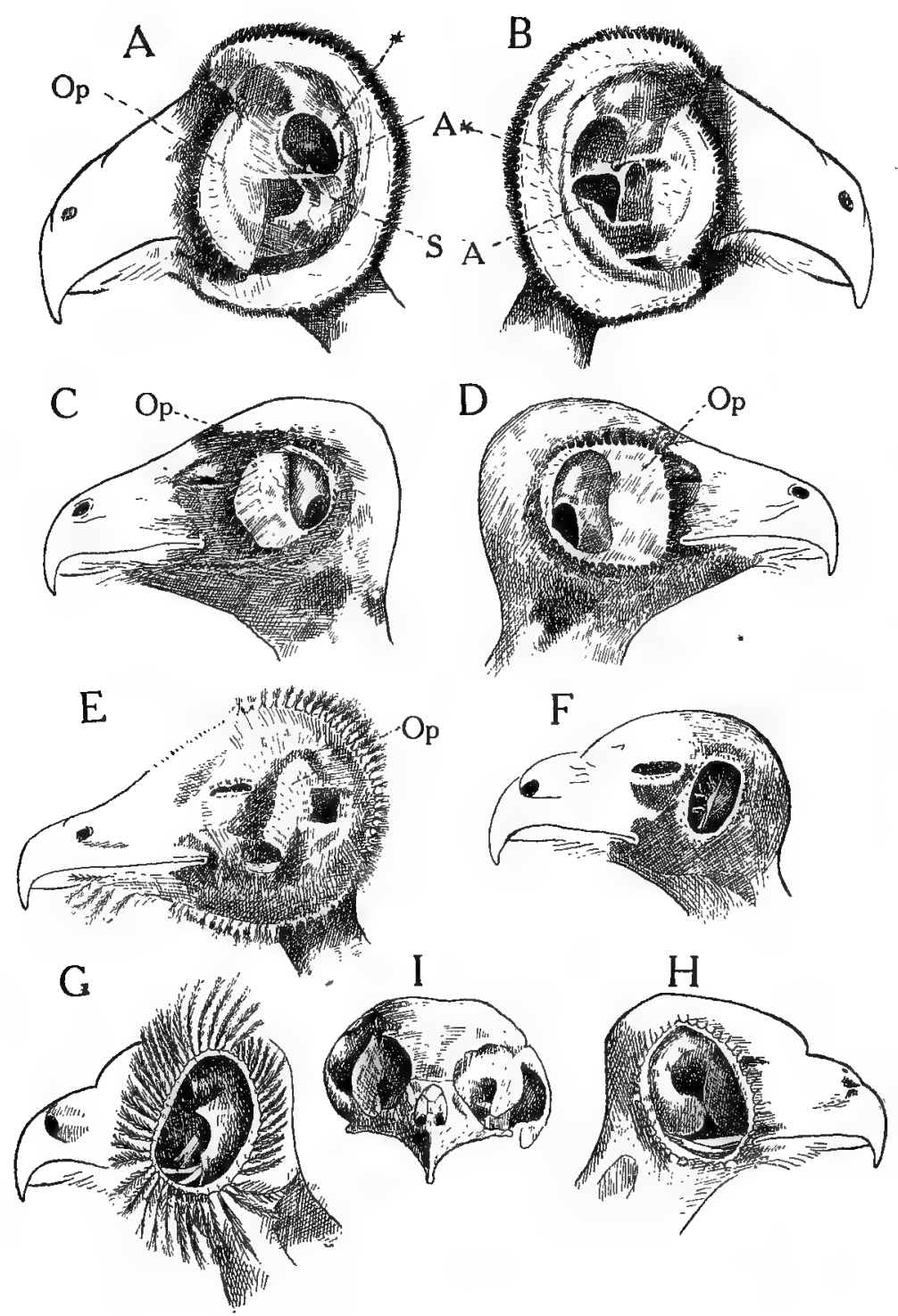

IlL. 48.-EAR Apertures OF The OWLS 

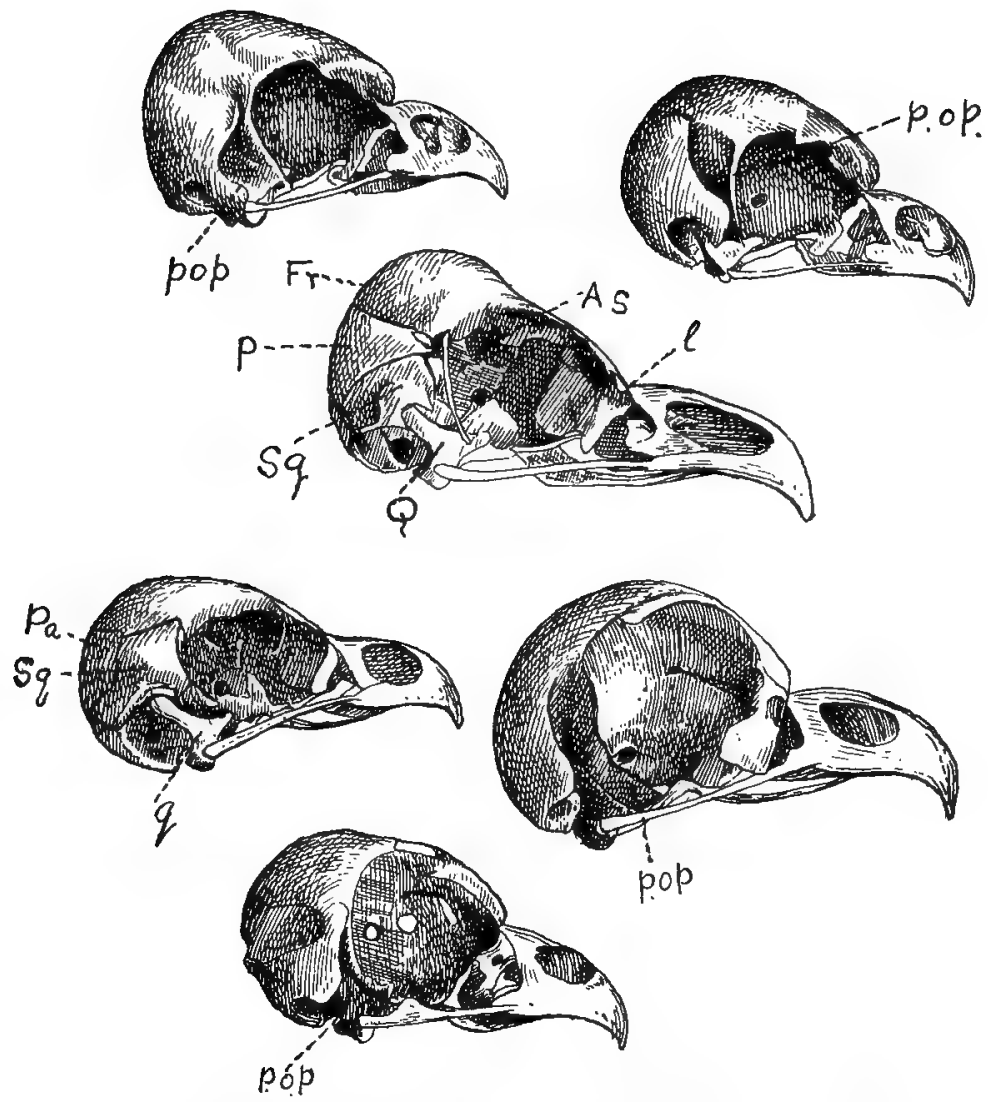

Ill. 49.-Skulls of OWLS Showing the Asymmetry of the SkUll of TENGmal,m's OWL, and The Curious Differences in the Form of THE Squamosal in the Young Tawny OWl (eentre figures) and Young BurrowING OwL (to left and below). 

strainer. In the Swans these structures are carried a step further: but they attain their highest perfection in the Ducks, reaching the maximum development in the Shoveller where these lamella are relatively of enormous length, recalling the baleen plates of certain whales. Some of the Ducks have further modified the structure of the beak. Thus the Blue Duck of New Zealand (Hymenolamus) has developed membranous folds on each side of the upper jaw, and these probably have some relation to the capture of insect larvæ on which this bird is said to live. The Mergansers have long, narrow beaks, the edges of which are armed with sharp, backwardly directed tooth-like processes adapted for the capture of fish (Ill. 47, p. 4I3). In these birds the tongue differs conspicuously from that of other Ducks, being less fleshy, and only feebly provided with the lateral processes so characteristic of the Ducks.

While the serrations of the beak in the Diving-ducks and Geese bear a rough semblance to horny conical teeth, in some birds these serrations take the form either of a series of fine needle-like points, as in the Darters (Plotus), for example, or of a number of extremely minute and sharp-pointed notches, as in the Sun-birds. But between these two extremes many intermediate types are to be met with.

Where the food has to be torn or finely divided we find the beak short, hooked and pointed, as in the Carrion-feeding Vultures, the Hawks, Eagles, Owls, and the Shrikes, and it presents a similar shape in the rodent Parrots which feed upon fruits and other vegetable matter. Thus it will be seen that the superficial resemblance which beaks may present is a dangerous guide as to questions of affinity.

The beaks of Parrots illustrate in an even more striking manner than in the case of the Finches (p. 405) how close may be the relation between the form of the jaws and the nature of the food.

In these birds the whole structure of the skull has been transformed to facilitate the manipulation of food. In the first place the upper jaw articulates with the frontal bones by means of a hinge, while the palatine bones have been enormously developed so as to form deep blades of bone set on edge and terminating at the base of the premaxilla. The details 
of the mechanism of the beak have not yet been completely worked out; but suffice it to say when the pterygoids are thrust forward the movement is passed on to the palatines, and these by their forward movement thrust the upper jaw upwards by its hinge. The under side of the hook of the jaw is traversed by fine striations, having a characteristic arrangement in different groups. These impart a roughness to the beak useful in holding slippery and hard-shelled seeds. In the small Parrakeets, e.g., Melopsittacus undulatus (Budgerigar) this beak, as is well known, is very small and inconspicuous. From this we may pass through a gradually increasing series to the huge beak of the Macaws, terminating in the enormous jaws of the Black Cockatoo (Microglossus aterrimus). This bird, says Wallace, "has a rather.small and weak body, long weak legs, large wings, and an enormously developed head . . . armed with a sharp-pointed hooked bill of immense size and strength. ... The tongue is a curious organ, being a slender fleshy cylinder of a deep red colour, terminated by a horny black plate, furrowed across and somewhat prehensile. . . . It eats various fruits and seeds, but seems more particularly attached to the kernel of the kanary-nut, which grows on a lofty forest tree (Canarium commune), abundant in the islands where this bird is found; and the manner in which it gets at these seeds shows a correlation of structure and habits which would point out the 'Kanary' as its special food. The shell of this nut is so excessively hard that only a heavy hammer will crack it: in shape it is somewhat triangular and the outside is quite smooth. The manner in which the bird opens these nuts is very curious. Taking one endways in its bill and keeping it firm by a pressure of the tongue, it cuts a transverse notch by a lateral sawing motion of the sharp-edged lower mandible. This done, it takes hold of the nut with its foot, and biting off a piece of leaf retains it in the deep notch of the upper mandible, and again seizing the nut, which is prevented from slipping by the elastic tissue of the leaf, fixes the edge of the lower mandible in the notch, and by a powerful nip breaks off a piece of the shell. Again taking the nut in its claws, it inserts the very long and sharp point of the bill and picks out the kernel, which is seized hold of, morsel by morsel, by the extensile tongue. Thus every detail of form and structure in 
the extraordinary bill of this bird seems to have its use, and we may easily conceive that the Black Cockatoos have maintained themselves in competition with their more active and more numerous white allies, by their power of existing on a kind of food which no other bird is able to extract from its stony shell."

Other instances of this competition are to be had in plenty among the Parrots. The large bills of the Hyacinthine Macaws (Ara hyacinthinus) of Central Brazil, like the beak of the Black Cockatoo, are used for breaking open hard nuts, in the present case palm-nuts, the shells of which are so dense as to be difficult to break with a heavy hammer, yet they are said to be crushed by the beaks of these birds. Thus then the beaks of these Parrots recall the marvellous crushing power of the jaws of the hyæna, which in strength exceed those of the lion.

Again some Parrots, such as the Banksian Cockatoo (Calaptorhynchus banksii) and those of the Genus Platycercus live largely on insect larvæ. The slender-billed Cockatoo (Lichmetis nasica) of Australia, differs from that of other Parrots in that the upper jaw is long, slender and only slightly decurved; and this modification enables the bird to dig for grass roots and bulbs. Now it is instructive to note that a very similar modification of the beak has taken place in a Parrot restricted to Chili--the slight-billed Paroquet (Henicognathus leptorhynchus) and this bird also lives mainly on grass roots. This being so, it seems strange that the Owl-parrot or Kakapo (Stringops) of New Zealand, which also feeds largely on grass, should have a normal Parrot's beak. But this habit may have been recently adopted, and it is certainly true that the diet of this strange bird is supplemented to a very considerable extent by fruits and seeds. When eating grass it is said to nibble after the fashion of a rabbit, and for such a method of trituration the more normal beak is admirably adapted.

The large family of the Lories and some other Parrots live almost exclusively on insects and honey, and for this purpose have developed a quite peculiar tongue, described on p. 429. Professor Moseley, writing of the little Swainson's Paroquet, remarks that it "gathers so much honey from the flowers, that it fairly pours out of the bird's beak when it falls shot to the ground". 
The Parrots, we might mention, are the only birds which universally hold their food in the foot while it is being eaten; and it will be found, moreover, that with certain exceptions the left foot is invariably used for this purpose. The little Owl (Athene noctua) is perhaps the only other bird of similar habits. The Hobby among the Accipitres uses the feet for a similar purpose, but only when in mid-air.

There is a remarkable diversity in the shape of the beak among the fruit-eating birds. In the case of the Parrots hard seeds and nuts form the staple diet; the exceptions to this rule are obviously recent changes of habit which have not yet greatly affected the bill. In the Toucans and Hornbills it is of enormous size, so much so as to give these birds the appearance of being terribly overweighed by their bills. As a matter of fact, however, these enormous jaws are really of astonishing lightness, especially in the Toucans. A section through the bill of one of these birds shows that the horny beak-sheath is extremely thin, and covers a lattice-work of bone of extreme delicacy, resembling filigree work, the interstices of which are filled with air.

While the bill of the Toucan is remarkable for the brilliancy of its colours that of the Hornbill is scarcely less so for its bizarre ornamentation, which takes the form of a casque of varying shape. In some species this casque is furthermore peculiar in that it is open in front, giving a strangely unfinished appearance to this ornament. What is still more strange is the fact that this opening leads directly into a mass of cancellated tissue. The casque of the Helmet-Hornbill (Rhinoplax vigil) presents something of a mystery, inasmuch as it is composed of a mass of ivory-like density, and of great thickness. What can be the use of this structure? It has been suggested that the bird uses it as a hammer for breaking open hardshelled nuts, and certainly it is a fact that the face of this mass is bruised as if it were put to some such use. Further, the fossæ or cavities which lodge the cerebral hemispheres of the brain, and of the optic lobes, and the septum which dips down between the two cerebral hemispheres in the middle line are unusually thickened, as though to protect the brain from the effects of violent shocks. To deaden the force of such shocks the horny mass is backed by a bony network of props directed forwards and meeting its base at right angles. These mechani- 


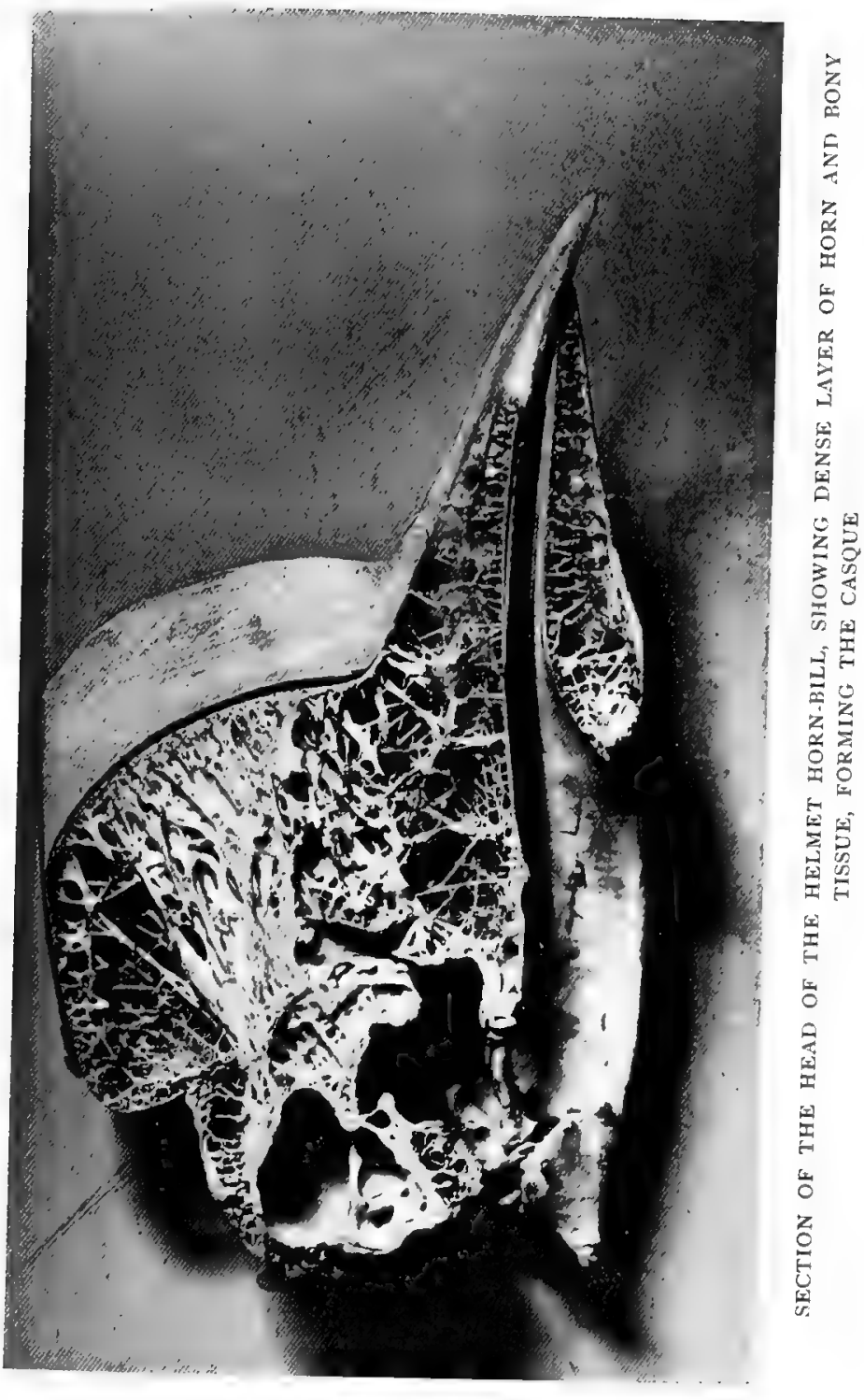



cal contrivances to resist and deaden shock all point exclusively to the correctness of the surmise as to the use of this "hammer".

Both Hornbills and Toucans live chiefly on fruit, but the former display a fondness for insect food. The great length of the beak of the Toucan has been explained by Bates in his Travels on the Amazons. "It is," he says, "to enable [it] to reach and devour fruit whilst remaining seated, and thus to counterbalance the disadvantage which the heavy body and gluttonous appetite would otherwise give it in the competition of allied groups of birds. The relation between the extraordinarily lengthened bill of the Toucan and its mode of obtaining food is therefore precisely similar to that between the long neck and lips of the giraffe and the mode of browsing of the animal. The bill of the Toucan can scarcely be considered a very perfectly formed instrument for the end to which it is applied ... but nature appears not to invent organs at once for the functions to which they are now adapted, but avails herself here of one already existing structure or instinct, there of another, according as they are handy, when need for further modification arises."

With the Trogons and Barbets we must complete our review of fruit-eating birds. Here the beak is extremely short and wide, giving the bird an enormous gape, only exceeded by certain insectivorous birds, such as Swallows and Night-jars, which, it will be remembered, seize their prey upon the wing. Now it is in a precisely similar way that the Trogon plucks its fruit. "Their method of obtaining food," says Bates, "is to station themselves quietly on low branches in the gloomy shade of the forest and eye the fruits on the surrounding trees, darting off as if with an effort every time they wish to seize a mouthful, and returning to the same perch."

The peculiar habits of feeding displayed by the Toucan and Trogon are the result of adaptation to the peculiar requirements of their environment. Flowers and fruit on the crowns of large trees of South American forests grow chiefly on the small endtwigs which will not bear any considerable weight. All animals therefore which feed on fruit or insects lurking in flowers, must have some means of reaching their food at a distance. Monkeys contrive to do this by their long arms, or must swing by their 
tails; Humming-birds suspend themselves in mid-air before the flowers while they extract therefrom honey and insects: but the dull and heavy Toucan is obliged to adopt the tactics just described.

The insectivorous birds display no less variety in the shape of the bill. In many of the small perching birds, such as the Robin and Wagtail, it is small, and differs but little in shape from that of many seed-eaters. In others, as in the Tree-creepers, it is long, slender and decurved. The former piclos up insects when at rest, the latter has to hunt for them amid the crevices of the bark of trees. In the Jacamars it is long and pointed, as in the fish-eating Kingfishers, In the Flycatcher it is short, broad and greatly depressed: these birds catch their prey as it flies. In the Swallows, Swifts and Night-jars, the beak is reduced to its smallest possible dimensions and the gape deeply cleft so that in the Night-jar the angle of the mouth extends backwards to terminate below the eyes; and these all capture small insects in mid-air, rushing along at great speed. In the case of these swift-winged birds there can be no doubt but that the peculiar form of the bill is a direct adaptation to the capture of insect food. Not so, however, is the case of the large number of Kingfishers which live entirely on insect prey far from water. The beaks of these birds are as certainly special adaptations for the capture of small fish. But it is easy here to see how the changed diet came about, inasmuch as even the most confirmed fish-eaters eat largely of the small crustacea and aquatic insect lavæ which abound in streams. From prey of the latter kind it is but a step to an exclusively insect diet which can be obtained independently of the presence of streams. That this is so we may gather from the fact that these insectivorous types capture their victims exactly as their relatives capture fish-by darting suddenly upon them from a sallying point to which they return.

The enormous mouths of the aberrant Night-jars known as "Frog-mouths" would appear to have been acquired before they lapsed into the sluggish habits of to-day. They feed, like Night-jars, on insects, but these are captured not while the bird is on the wing, but by hunting among the branches of the trees. These birds appear to vary their diet with fruit and small mammals. This last fact is important as indicating the incipient 
stages in the development of the Owls (see p. 439), which live now on the flesh of the higher vertebrates. The step from an insectivorous diet to a diet of the flesh of vertebrates is but a short one, and vice versâ. Indeed many confirmed "flesheaters" live occasionally on insects. For example, I have commonly found the stomach of the Short-eared Owl (Asio brachyotus) crammed with the Common Dor-beetle (Geotrupes vernalis).

While the modifications hitherto described are all of a kind that are characteristic of a large number of species, and differ only in degree one from another, there are a few which are unique, that is to say, they are met with only in a single species, or at most in three or four. In some of these the correlation between the method of feeding and the shape of the beak is evident, in others no such insight is possible.

The little Wry-billed Plover of New Zealand is an instance where this correlation can be plainly seen. In this bird (Anarhynchus frontalis) the beak is drawn out to a fine point and curves sharply to the right, a formation which enables the bird to pick up small crustacea lurking under stones between tidemarks. So nice is the adjustment between this structural modification and the habit of feeding that the bird invariably, when hunting, walks round the stone left to right! Further, the black band which encircles the breast is broadest on its left, or exposed side, and this because the band is a device adopted for protective purposes, enabling the bird more closely to resemble its surroundings! No less remarkable is the beak of the Scissorbill (Rhyndops nigra). This bird is hardly to be separated from the Terns (Sterna), yet the beak is absolutely unlike that of any other known bird, the lower jaw being much longer than the upper (I1l. 47, p. 4I 3 ), and both being flattened to the thinness of a knife-blade from the gape forwards! In feeding, the Scissor-bill skims along the surface of the water with the lower blade thrust into the stream. By this plan toll is taken of shoals of small fishes swimming at the top of the water, the fish being caught up as by a pair of shears as the bird passes over them. In the nestling (Ill. 47, p. 4I 3), it is to be remarked, the jaws are of equal length.

A species of Stork known as the "Open-bill" (Anastomus) p. 362 has the upper and lower jaws curiously bowed so as to 
leave a large open space along the middle of their cutting edges (IIl. 47, p. 4I3). This bird feeds largely upon shell-fish, and according to some the remarkable space just described is caused by the wearing away of the edges of the beak by the hard shells. This explanation, however, will not bear the test of investigation.

In the great Whale-headed Stork (Balceniceps rex) of the Nile the beak is enormously widened and inflated (Ill. 47, p. 4I 3), and a similar modification has been acquired by one of the Night-herons of the Genus Cancroma, and, strangely enough, by the Shoe-billed Kingfisher (Clytoceyx rex). So far, there appears to be no explanation of the remarkable peculiarity, as it is not known that these birds subsist upon any particular prey different from that pursued by Herons and Kingfishers with normal beaks. The fact that there is a general resemblance in the nature of the prey of the normal Storks and Kingfishers makes this recurrence of similar types of beaks in the Whale-headed Stork and the Shoe-billed Kingfisher of New Guinea the more extraordinary.

One of the most remarkable cases of adaptation yet brought to light is surely that of the Huia-bird of New Zealand. In this species the beak of the male is short and but slightly curved, while that of the female is rather more than twice as long and much decurved. These birds live on wood-boring grubs, of which the supply is never probably more than sufficient. It would seem then that Nature has, so to speak, ensured a sufficiency for each by bestowing upon the one a short beak capable of chiselling away the more decayed parts of the tree, and on the other a long probe, wherewith the desired morsels may be dragged out from holes in sounder wood which would resist the blows of a beak.

The tongue in birds presents a wider range in structural variations than is to be met with among any other group of vertebrates. As an organ of touch it is used only in a few rare cases, nor does it appear to be commonly used in the selection of food by taste; in Parrots it is certainly so employed, and possibly in some other groups.

In the majority of birds it is small, provided at the back with a number of small pointed processes directed towards the throat, while at the tip it is horny. In birds which swallow 
their food whole, and of large bulk, it becomes reduced to a mere nodule, as in the Cormorant and Gannet. This vestigial condition, however, is not correlated with this particular method of feeding, since in the Stork, Ibis and Spoon-bill, which feed on small animals, this organ is equally degenerate, so that the probable explanation of its decay in such forms is to be attributed to lack of use. In the majority of cases adaptation to the needs of the animal is clearly traceable. Thus among raptorial birds which feed on living prey the tongue is fleshy and somewhat spoon-shaped, and this is true also of the Owls, while in their allies the Night-jars it is quite degenerate. In the Carrion-feeding Vultures again we meet with the same parallels, since in both the Old and New World types, which are certainly not nearly related, we find a tongue of a perfectly unique shape in that it is long, trough-like, and provided along its upper edges-which are turned inwards-with well-defined serrations. So far, however, there are no recorded observations to show how this peculiar tongue is used. Similarly, the Anserine birds and the aberrant Stork (Phoenicopterus), have developed tongues of a very remarkable character obviously in response to their peculiar feeding habits. Presenting numerous minor variations of shape among different genera of Ducks and Geese, it is in nearly all extremely thick and fleshy, fringed along the sides with fine lamella or horny teeth, as the case may be; the lamellæ occur in Surface-feeding Ducks, the horny teeth in the Geese and Swans which feed on weeds. In the fish-eating Ducks, as the red-breasted Mergansers, the tongue is less fleshy, provided with fine bristle-like lamellæ along each side, and with horny conical papillæ over the dorsal surface, and these serve to hold the slippery prey; but the tip of the tongue in all these Anserine birds is horny and scoopshaped.

The tongue is rarely protrusible in birds, and only in those which, like certain mammals, use this organ instead of the jaws for the capture of prey. Coated with a sticky saliva secreted by an enormous pair of glands situated on each side of the head, this organ is thrust out into the midst of colonies of ants and withdrawn covered with victims. By this means the bird is enabled to secure the largest possible amount of food with the least possible labour. With an ordinary insect diet when the prey is secured one at a time, such an arrangement would 
be actually disadvantageous, since the labour expended in thrusting out the tongue and secreting the saliva would be out of all proportion to the capture made. But the development and perfection of this peculiar method of feeding was, so to speak, worth while, inasmuch as it enables these birds to avail themselves of a supply of food inaccessible to ordinary birds; while at the same time it can as easily secure spiders, larvæ and other insect food, fruit and seeds, as its less-favoured neighbours by means of its beak in the usual fashion, and indeed during a large part of the year it is compelled to adopt a mixed diet of this kind. Further, even among Woodpeckers many feed but seldom, and some apparently never, upon ants, but in these cases the mechanism of the tongue is less perfect. This mechanism, and one or two features associated therewith, compels at least a short examination.

Varying in perfection in accordance with the use to which it is put, it reaches its highest development in the Genus Colaptes, though in our British Green Woodpecker (Gecinus viridis) it is scarcely less complete. This extensibility then is gained by the elongation of the hyoid bones-a pair of long rods passing backwards from the base of the tongue immediately under the head. In the genera in question these rods are of enormous length, extremely slender and very elastic. Continuing their backward course they pass upwards on to the top of the head, where they meet, and passing forwards in a deep groove in the skull continue their course, turning to the right-occasionally to the left-and passing into the right nasal fossa. In Colaptes they then turn downwards and run along the floor of the olfactory chamber to the end of the beak. By means of the muscles attached thereto these rods can be pulled backwards, downwards and forwards, and thus the tongue is thrust out, the salivary glands simultaneously pouring out their sticky secretion over the exposed portion. This is armed with varying devices of backwardly directed barbs and hairs, which serve two different purposes. The longest tongues have few barbs along their edges, and are used mainly for the capture of ants. Apparently for the sake of increasing the thickness of the salivary coating on the back of the tongue a rough surface is provided by means of a large number of tiny recurved, and backwardly directed processes. The hairy and downy Woodpeckers, on the other hand, 


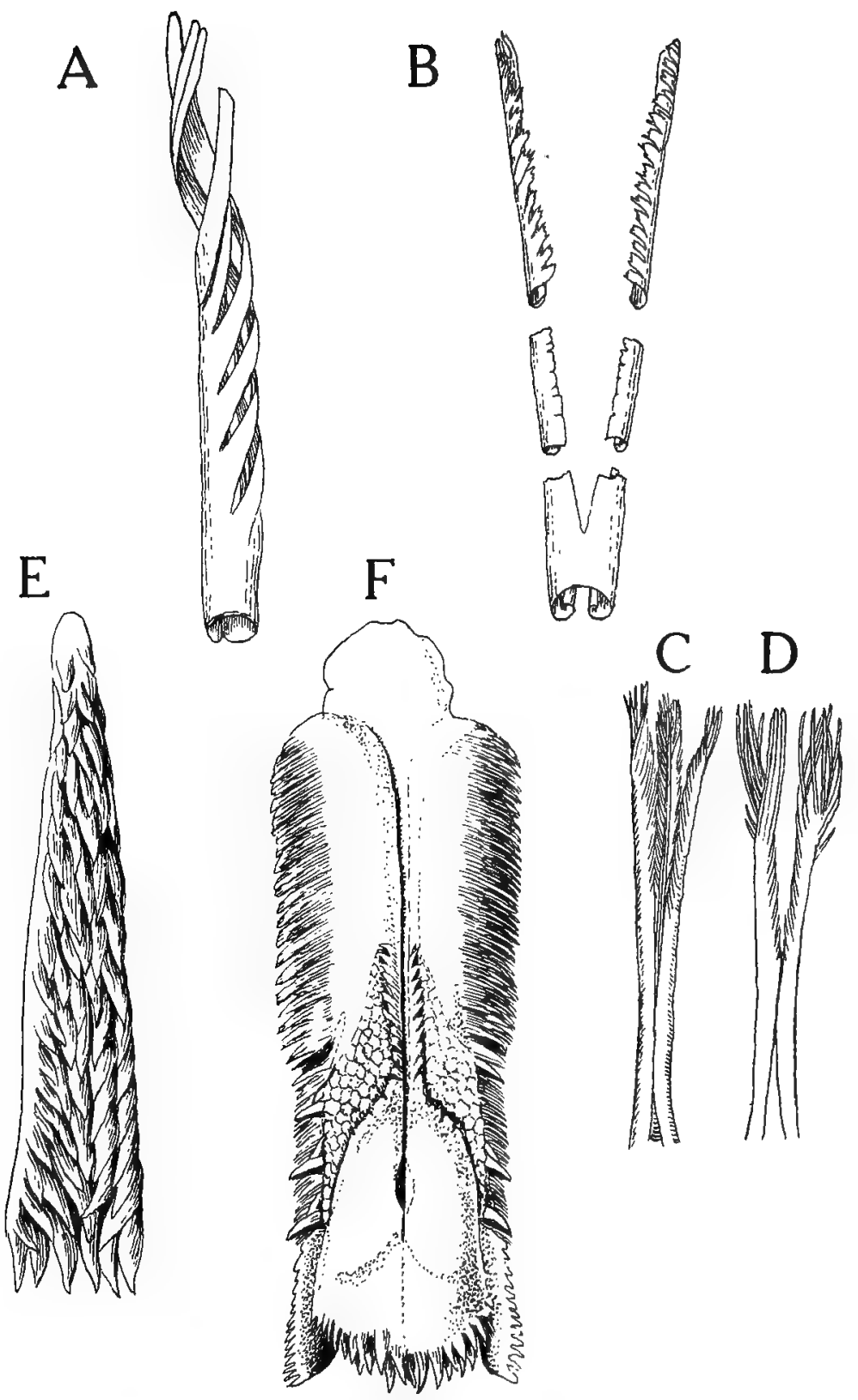

ILL. 50.--TYPES OF TONGUES

A, Anthrothreptes malaccensis. 'B, Anthrothreptes subcollaris. C, Australian Honey-sucker. D, Honey Creeper (Arthiola). E, Penguin. F, Swan. A and $\mathrm{B}$ after Gadow. $\mathrm{C}$ to $\mathrm{F}$ after Lucas. 

have short tongues armed on each side with barbs admirably adapted for spearing larvæ and dragging them from their hiding-places. Still shorter is the tongue of the American "Sapsucker" (Sphyrapicus varius), and this is furnished with numerous short hair-like processes on each side, near the tip, whose purpose seems to be to draw up by capillary attraction the sap of trees on which this bird largely feeds; though with this juice considerable numbers of insects, attracted by the flow of sap, are also taken.

The tongues of Humming-birds and "Honey-eaters" and Sun-birds are even more remarkable. Owing to their small size no slight skill is required to make out their structure, and much of our knowledge on this subject is due to the labours of Dr. Hans Gadow of Cambridge, and an American anatomist, $\mathrm{Mr}$. F. A. Lucas. They have shown that in the Humming-birds the tongue is of great length and cleft for half its length. The upper edges of the two branches curl inwards so as to form two tubes. When the bird is engaged in extracting honey from flowers this portion of the tongue is worked rapidly backwards and forwards, and the juice which is forced by this means into the tubes is withdrawn either by the formation of a vacuum at the back of the mouth, or by pressing the tongue against the roof thereof and so squeezing out the liquid. It is probable, however, that this mechanism is devised rather for the capture of insects which have gathered in the nectaries of the flower than for the honey itself, inasmuch as large quantities of insects are always found in the stomachs of these birds. But the tongue of "Honey-eaters," such as the Australian and Hawaiian honey-suckers, are more perfectly adapted for honey gathering. Here the tip is cleft, and each branch may be again split so that this organ terminates in four or eight small spiral branches formed by the splitting up of each branch into hairlike processes. This tip appears to have been derived from a simple form wherein the edges of the tongue curled up to meet one another in the middle line so as to form a tube as in the Sun-birds of the Genus Hemignathus. Complex as these honey-gathering tongues may be-though in no case is the extraction of sweet juices the only function of the tongue-they may all be derived from the typical avian tongue which at its 
tip is always horny and generally frayed, especially so after much wear. That is to say, the tongue in birds has an inherent tendency to become frayed along its edge, and in some cases this tendency has been increased by selection, until the complex structures just described have been built up.

It is not easy to discover what determines the apparent correlation between the form of the tongue and the nature of the food, which is so often met with; and any attempt to solve the riddle is met with contradictions. Thus in the Penguins it is long and pointed, and has the upper surface completely studded with long, backwardly directed conical processes, and thereby differ most conspicuously from the Grebes and Divers, and the Auks, Puffins and Guillemots; all these have similar tongues, long, pointed and smooth, and all, like the Penguins, live mainly on fish. The Emperor and Adelié Penguins of the Antarctic, however, live largely on cuttle-fish, and crustacea form the staple diet of the Adelié Penguins, according to Dr. Wilson, the naturalist of the Discovery expedition. Yet the tongue in all the species of this aberrant group presents the same peculiar character. Thus the variations in the nature of the diet are correlated with differences in the form of the tongue in the Woodpeckers, but show no such adjustment in the case of the Penguins. The Petrels again differ but little, so far as records show, in the nature of their food, yet in their tongues they present great variations, though in no case does this organ present any very remarkable peculiarities. This fact is the more striking since in the Genus Prion the beak has become remarkably broadened and flattened and provided along its edges with lamellæ, recalling those of the Ducks, yet the tongue has not acquired a similar resemblance to that presented by these birds.

\section{The Alimentary Canal}

It is a point of considerable interest to note that the various modifications presented by the alimentary canal are, in their way, as numerous and as striking as those presented by the beak and tongue. Though there is a manifest resemblance in the structure of the digestive organs, according to whether the diet is of an animal or vegetable nature, yet we meet with a wonderful variety in the details of the several adaptations for 
the disposal of these very different food-stuffs included under the general head of flesh and vegetable. More than this, we are confronted here with a number of exceptions to the general rule, and with apparently unnecessary complexities of structure, as when, without apparent rhyme or reason, an elaborate mechanism has been evolved to deal with a perfectly normal diet, such as is disposed of with ease in all other cases without any special modification.

In many birds the cesophagus or gullet is dilated in the region of the furcula or merry-thought; but slightly in some, while in others, as in the Pigeons and Game-birds, there is formed a relatively enormous chamber. In the Pigeons this is symmetrical and bilobed, but in the Game-birds it forms a single globular cavity with a very thin wall. In birds of prey the crop is only slightly developed, a temporary chamber, the lumen of the gullet, contracting when its store of food has passed; the same is true also of many fish-eating birds. In the great majority of birds there is no crop, and between this complete absence and the huge chamber of the Pigeon there is every possible gradation. Its walls contain no special digestive glands, except in the case of the Hoatzin (p. 3 I 3), and its precise function may well form a subject for future investigators. It would seem to fulfil, in the case of the Pigeons, Game-birds and many of the small seed-eating, perching birds, the same purpose as the ruminating stomach of mammals. That is to say, it enables a large store of food to be taken in rapidly and carried away to some secluded spot for digestion. In animals which have to seek their food in open situations where they are at the mercy of prowling carnivores, such a device is of immense importance. Thus, then, we may take it, that this highly specialised crop has arisen by the action of natural selection, which has increased the size of this organ by selecting for survival those birds which possessed favourable variations in the direction of an increased capacity in this normally enlarged area of the gullet. Those in which the size of this region of the gullet tended rather to decrease, or to remain stationary, became naturally more exposed to the attacks of their enemies since they had to return oftener to the danger area to take in fresh supplies of food.

The extraordinarily thick fleshy mass which surrounds the stomach or "gizzard" of fruit and grain-eating birds presents 28 
some noteworthy and puzzling variations. Usually the inner surface of such a gizzard is faced with apposed horny pads, between which the food is comminuted by being ground up with small stones, the pads exercising an alternate up and down motion. In the Nicobar Pigeon these horny pads have become ossified, while in two closely allied Fruit Pigeons yet another plan has been adopted. Thus, in the Fiji Fruit Pigeon (Carpophaga latrans) the inner lining of this organ is beset with conical horny bosses, or tubercles, set closely together, while in an allied species, Phenorhina goliath, this modification is carried still further by ossification of the tubercles. Apparently these peculiar modifications have been brought about to enable these birds to digest fruits encased by an unusually hard outer coat, the Carpophaga living on the fruit of a species of onocarpus which bears a curious "corky" fruit of the size of a walnut.

In the Jambu Fruit Pigeons of the Genus Ptilopus, of which there are several species, the interior of the gizzard is so fashioned as to form four crushing pads, arranged so that, in a cross section, the cavity of the gizzard is cruciform. So far no facts concerning the food of these birds have come to light which enable any explanation to be given of this unique arrangement.

The Darters again, close allies of the Cormorants, present peculiar modifications of the gizzard, all the more remarkable because they differ in no respect from the Cormorants in the nature of their food-living fish. In the last-named birds the gizzard is that of a normal fish-eating bird, thin-walled and capacious. In the Darters this is quite otherwise, and what is still more remarkable is the fact that the several species of Darters differ among themselves in the complexity of the modifications in question. Thus in the American Darter (Plotus anhinga), the first portion of the stomach or proventriculus is peculiar in that the digestive glands thereof are gathered together so as to enclose a chamber into which their secretions are poured, while the hinder end of the stomach, that corresponding to the gizzard in other birds, is doubled back upon the central portion and lined with long hair-like structures resembling cocoa-nut fibre, and about half an inch long. The function of this hairy mat seems to be to prevent bones and other solid particles from gaining admittance into the intestine. In an 
allied species, Levaillant's Darter, the proventricular end of the stomach is not specially remarkable; but there is a similar pyloric chamber guarded by hairs, which, however, have a quite different arrangement, forming a conical plug immediately in front of the entrance to the gut. Curiously enough, this plan of guarding the gateway to the intestine has been adopted also by the South American "Turkey-buzzard" (Cathartes aura). Here the hairs are of various lengths, and range in colour from black to greenish-yellow. No other birds of prey seem to have found it necessary to adopt a similar device, just as no other fish-eating birds have copied the Darters in this respect. The independent development of a structure so peculiar in birds which are not genetically related is a point of considerable interest.

The presence of these hairs in the gizzard recalls the fact that in the Common Cuckoo the gizzard is lined throughout with hairs, but these prove on examination to be purely extraneous, being the matted hirsute covering of the caterpillars- "woolly bears"- and other species on which this bird feeds. No other bird can eat these caterpillars on account of the formidable nature of their covering, yet structurally nothing has yet been discovered in the structure of the stomach of the Cuckoo which explains why these birds, and these alone, are able to make such caterpillars their special prey.

Certain species of Tanagers, a group of birds hardly to be distinguished from Finches, have contrived to dispense with a gizzard altogether. The species in question belong to the Genera Euphonia and Chlorophonia. In these birds the glandular proventriculus, or fore-stomach, opens into the gut, from which, however, it is separated by a narrow non-glandular zone representing the last of the gizzard. This peculiar arrangement at present furnishes an unsolved problem, for these birds do not appear to differ in the nature of their food from other Tanagers and Finches with normal gizzards.

Passing now to the intestines we shall find that these also present a number of puzzling variations for future workers to interpret. For much of our knowledge on this head we are indebted to the philosophical investigations of Dr. Chalmers Mitchell. We are concerned here, however, only with such features as bear upon the problem of adaptation. 
Thus, then, there is a definite relation between the length and thickness of the gut and the nature of the food. In Granivorous birds the gut is of great length, and this may be traced to the fact that the food is difficult to digest and is mixed with a large amount of indigestible material, so that much time and a large surface for the action of the digestive juices are necessary for the conversion of the ingested material into food. Birds which feed on fish similarly require a gut of great length, and in these birds the walls of the intestines are much thickened, probably as a protection against injury by sharp bones. Though fish is popularly regarded as a most nutritious diet, it must be remembered that birds have to eat their captures raw, and it has been shown that in uncooked fish no less than 70 per cent. is wasted.

Frugivorous birds have short thin-walled intestines. Here, as Dr. Mitchell points out, the nutritive substances are in forms which render them capable of rapid and fairly complete absorption, and the organic salts present stimulate osmosis, or the passage of the digested matter through the walls of the intestine into the blood. The ease of absorption makes a relatively large surface unnecessary, and the large calibre of the gut not only diminishes the outflow from the blood caused by the presence of organic salts, but it decreases the danger of violent purging.

Such are the general principles, but the variety displayed by the coilings of these intestines within the body cavity is infinite. The fact that unrelated types often resemble one another, while others present sudden and remarkable variations, makes the study of the intestinal tract one of great difficulty; at the same time it furnishes most valuable data to those who desire to investigate the problem of the evolution of the various systems of the body apart from the evolution of the organism as a whole.

The diverticulum, which represents the last vestige of the yolk-sac, is in some birds completely lost, in others it remains as a vestige throughout life, while yet again in others it has become transformed into a gland and takes on a new function, apparently intimately correlated with the development of the cæca.

The cæca are blind diverticula of the intestine placed at 
the point where the small intestine passes into the rectum. Their presence, or absence, from a systematic point of view, is of some importance. A heritage from reptilian ancestors, of moderate length and thin-walled in the more primitive forms, they may become reduced to mere vestiges; or one, or both, may even disappear completely, while in some cases they have become enormously developed, having their cavities divided by spirally arranged septa, as in Chauna and some of the Rails and Cranes, or produced into large bulbous sacs having the external wall produced into papillate hollow outgrowths, as in the Martineta Tinamou (Calodromas elegans) (p. 23). Originally they were probably digestive in function, and in many birds they still remain so, serving for the dissolution of cellulose.

Where the diet is largely insectivorous or vegetivorous the cæca are large; while a carnivorous or piscivorous, and especially a frugivorous diet, leads to their reduction or complete disappearance. The Passerine birds, which exhibit great variety in their choice of food, have small cæca which have become transformed into glandular organs.

In spite of this generalisation, however, the study of the colic cæca of birds is one of great complexity, and bristling with contradictions, as Dr. Mitchell in his brilliant memoir has shown. Thus the Passerine birds affect all diets, yet display but one type of cæca. The Owls and Accipitrine birds have an almost identical diet, the larger forms being carnivorous the smaller insectivorous, yet the Owls have very large, flask-shaped cæca, while in the Hawks they are vestigial or absent. The Game-birds and Pigeons have a similar diet, yet the former have large cæca, partly digestive and partly secretory or excretory in function; while in the latter they are vestigial, or absent, or reduced, but transfused into glandular organs; the Gulls feed on fish and garbage and have the cæca vestigial or absent, while in the Skuas - which are also Gulls-they are large, thinwalled and digestive in function.

Thus, then, the evolution of the alimentary canal by no means follows that of the organism as a whole. That is to say, it runs along lines of its own governed by factors by no means yet understood.

While the various structural peculiarities which have been described with regard to the alimentary system are commonly 
regarded as so many more or less well-marked illustrations of adaptation to function, the similar modifications of type revealed by a study of the vascular system are more difficult of interpretation, and with a brief reference to these this chapter rrıust close.

The carotid arteries in birds, as in other vertebrates, are typically two in number. But in many species one or other of these arteries-right or left-atrophies, the remaining vessel increasing in size in consequence. Yet again, as in certain Parrots, the right carotid follows its normal course, along the hypophyseal canal formed by the neck vertebræ, while the left runs superficially along with the corresponding pneumogastric and jugular vein. In the Ground Hornbill both carotids have this peculiarity, and are also of remarkably small calibre, their work apparently being largely performed by the vertebral arteries, which are unusually large. According to one authority indeed the carotids are here reduced to the condition of imperforate cords.

Where only one carotid is present a vestige of the missing artery is commonly found in the shape of a short canal leading from the innominate artery to the persistent carotid. In the Flamingo, for example, the left carotid only is present, the right being represented only by a short tube leading from the right innominate artery into the single carotid trunk. In the Cockatoos (Cacatua) the left is similarly curtailed. But in the Passerine birds where the left carotid only is present the remnant of the right has entirely disappeared. In the Bittern, on the other hand, there is but a single carotid, but the bases of the originally separate vessels are of equal size at their origin from their respective innominate arteries. So far no explanation of these vagaries appears to be forthcoming.

The main artery of the thigh in birds shows similar variations. In most birds this is the femoral, but in some it is the ischiadic. The Cuckoos of the Genus Centropus exhibit both variations. Here, as in the case of the carotids, no interpretation has yet been found; and the evolution of these peculiarities seems indeed to have come about without regard to the struggle for existence. 


\section{CHAPTER XXVI}

\section{CONVERGENT EVOLUTION AND PARALLEL DEVELOPMENT}

The evolution of the Owls and diurnal birds of prey. Night-jars and Owls. Swifts and Swallows. The Cariama, Cranes and Storks. The Plover tribe and the Rails. Gulls and Petrels. The Diving Petrels and the Auks. The remarkable transformation of the skeleton in the Auks and Diving Petrels. Homoplasy a factor in the evolution of birds. The problem of the New World Vultures.

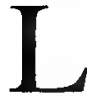

ET us now proceed to examine in some detail a few of the more striking instances of "convergence" as it occurs among birds.

Perhaps the most striking instance is that afforded by the birds of prey, which may be described under the general term of Hawks and Owls.

Until comparatively recent times these were regarded as intimately related. And since the Hawk tribe hunt by day while the Owls choose rather the twilight hours for their marauding expeditions, they were divided by the older Ornithologists into two groups-the Diurnal and Nocturnal birds of prey. To-day no one conversant with Ornithology would agree to regard such an association as an expression of genetic relationship. The more or less nocturnal Owls are now invariably recognised as near allies of the crepuscular Night-jars, and descended in consequence from the great Coraciiform stem of the avian tree. The Hawks, Eagles, Falcons and so on, on the other hand, are undoubtedly allied to the Pelargiform or Stork-like birds.

The common resemblances which the two groups share are due entirely to adaptation to the requirements of a raptorial life, and nowhere is this fact more marked than in the skeleton. Strange though it may appear, the bony framework is more plastic, yields more completely to the moulding influences of the environment, than do the muscular and visceral systems. 
Osteologically the Hawks and Owls bear a most remarkable likeness one to another, so much so that on this evidence alone it is doubtful whether the two groups could be separated. That is to say, they would be regarded simply as divergent branches of a common stock. The evidence of the soft parts, however, is conclusive. - Without entering into minute details, it will be sufficient here to mention one or two of the more important characters on which the independence of the two stocks is established.

For example, Gadow has pointed out that the Owls (Striges) cannot have been derived from the diurnal birds of prey ( $A c c i$ pitres) since they have no ambiens muscle, although the structure of the foot is practically the same as that of the Accipitres which possess an ambiens. Another item in the case disproving the common origin of the two types, according to the author just quoted, is the fact that the Accipitres have only vestiges of the cæca, or blind gut, while in the Owls the cæca are of considerable size-being tubular in shape and dilated at their extremities, as in the Night-jars (Caprimulgi). The existence of these organs in the Owls, if derived from the Accipitres, is, he contends, inexplicable, since though both being carnivorous, we must suppose that the flesh diet in one case had preserved, or even increased these organs, while in the other it had reduced them. But this argument loses its cogency when we reflect that in the closely allied Swifts and Night-jars we have a precisely parallel case. Both are insectivorous, yet the Swifts have no cæca, while in the Night-jars they are largely developed. Stranger still, among the Night-jars cæca are wanting in the Genus Egotheles, though the birds of this genus do not differ in their diet from say Caprimulgus, the British Night-jar, where they are large and functional! The character of the convolutions of the intestine is of more importance in this matter. In the Accipitres the gut is of great length, especially in the case of the fish-eaters: and specialisation has taken place, as Mitchell has shown, in other ways. In the Owls the gut is comparatively short and primitive in the nature of its convolutions. These agree with those of the Caprimulgi, whilst the Accipitrine birds agree with the Storks in this matter.

This marked difference in the convolution of the intestines is a point of considerable interest. In the shortness of the gut 
and great size of the cæca the Owls agree with the insectivorous Caprimulgi-Night-jars. Thus the gut has remained apparently unchanged by the flesh diet which the Owls have adopted, while the skeleton has undergone a really profound change, thus showing that while extensive structural alterations were necessary for the capture of vertebrate terrestrial prey, practically no changes were necessary for its digestion! The same rule does not apply to the Hawks, since the gut shows many evidences of specialisation, though derived from a flesh-eating stock. Though both Hawks and Owls have acquired the same skeletal peculiarities in adaptation to the requirements of a raptorial life, the assimilation of this prey has curiously enough demanded but little in the way of adaptation.

The muscular systems of the Owls and Hawks, like the intestines, differ widely. The former have the type prevailing among the Caprimulgi, the latter the type of the Storks. But there is no need to go on piling up instances of this kind, enough has been shown to prove the independence of the two groups despite their similarity to-day.

In one instance the Accipitrine birds have approached the Owls. Perhaps the most striking of these is the case of the Harrier which has developed the same peculiar disc-like arrangement of the feathers of the face which give the Owls their characteristic appearance. On this account the older naturalists regarded the Harriers as the natural transition from the Hawks to the Owls. The second instance is furnished by the outer toe, which in the Owls is reversible, or capable of being turned backwards. The Osprey, and some other Hawks, possess a similar freedom of movement in this toe.

To appreciate the extent of the modification which the framework of the Owl has undergone, the skeleton of one of these birds should be compared with that of one of the Caprimulgi; for choice that of the "Frog-mouth" Podargus, inasmuch as the species of this genus have adopted a partial flesh diet. Although many points of difference would at once become obvious on such a comparison, the most striking would be the change in the form of the hip girdle and the greatly increased length and size of the legs and toes, which in the Owl have become grasping organs of enormous power.

One Caprimulgine character the Owl has over-exaggerated 
-that is, the peculiarly "felted" character of the feathers, and especially of the wing feathers. The "quills" of the Owl are of great breadth, and the barbs or rami thereof are of considerable length and elasticity, while the radii or barbules are provided with specially elongated "fila" on the upper surface which serve to ensure a perfectly noiseless flight-a very important thing in birds which hunt their prey by twilight.

A naturalist shown an Owl and a Hawk for the first time would assuredly regard them as closely allied. Supposing him to have procured the specimens for himself in the field, he would, from his observations on their habits, attribute the peculiar softness of the Owl's plumage to the need of a silent flight, enabling the bird to hunt near the earth during twilight. Harsh plumage creating a whirring sound would infallibly give warning to the victims before capture became possible. It would only be after a careful comparison of the details of structure in the two types that he would discover the fact that the resemblance was due to adaptation, and it would not be till he had gone still further into the matter that he could decide whether this resemblance was due to parallel development or to homoplasy.

Adaptation to a raptorial life has similarly transformed the South American Cariama, ${ }^{1}$ one of the Gruiformes. But the resemblance here is not so much to the typical "bird of prey," such as the Hawk or Eagle, as to an aberrant and primitive member of the Accipitres-the Secretary-bird (Serpentarius secretarius) of South Africa. Long-legged, and long-necked, there is little in this bird to suggest relationship with the true Accipitres at first sight, save the form of the beak. The internal anatomy of this bird, however, leaves no room for doubt as to its relationship. Compared with the Cariama, one cannot help remarking that a kind of reciprocal convergence has taken place here, inasmuch as the long neck and legs of the Secretarybird may well be regarded as Crane-like. By this standard the only Accipitrine character of the Cariama is the hooked beak!

But the Secretary-bird is-in so far as external appearance is concerned-as it were, linked to the main Accipitrine chain

1 There are really two species of Cariama, or "Seriema," representing as many genera. 
by certain "annectent" forms known as "Carrion-hawks"; and these, by a parity of reasoning, join together also the Cariama.

The Carrion-hawks, which number several species, are natives of South America. They are really close allies of the Falcons, but, as might be supposed from the connection here, they are long-legged birds which run much upon the ground, in which particulars they differ conspicuously from true Falcons.

So close is the resemblance between these forms-Cariamas, Secretary-birds and Carrion-hawks-that Ornithologists so distinguished as Dr. Sharpe have regarded them as close allies, uniting them to form a single sub-family!

The dissecting knife has, however, severed the union, and at the same time made it necessary to find an explanation of the strange likenesses. This now appears to be found in "Convergence". These several types may be called "homoplasts"; they are the outcome of the working of "homoplasy".

None obtain their food after the fashion of the true Hawks -by seizing swiftly moving prey by the feet while on the wing; but all hunt comparatively slowly moving animalssnakes, mice, frogs, large insects, etc. ; and many subsist partly on Carrion. This accounts for the long legs and relatively short toes-the latter indeed in the Secretary-bird are very short. Living on terrestrial prey easily overtaken by running, the legs have in consequence gradually lengthened, and the necks have had to keep pace therewith.

Hardly less striking is the resemblance between the Crane and Stork tribe. So real is this that only those with some knowledge of Ornithology can distinguish the one from the other. Yet, here again, is an instance of homoplasy, and not of parallelism. The two groups have independent origins, and have acquired this resemblance to one another by the action of "similar forces or environment" on parts which are exactly or nearly alike.

The familiar White Stork, or still better, the Common Heron, may serve as a type of the Stork tribe-birds with long, pointed beaks, and long neck and legs. In the same terms one may describe the Cranes, though a few species have short beaks.

Though superficially so much alike, and though both affect the same haunts-swamps and fens-the food they seek there is different. The Stork appears to require an animal diet 
exclusively-frogs, fish, water-voles, and so on ; but the Crane, on the other hand, seems to prefer a vegetable diet; and to procure this large flocks will betake themselves to corn-fields wherever these are to be found. These birds are not, however, entirely vegetivorous, for frogs and lizards are greedily devoured; fish, however, they do not appear to eat.

Another striking instance of convergent evolution is furnished by a small and very remarkable family of the Plover tribe-the Parridæ. Extending over a wide geographical area, inasmuch as representatives are to be met with in Australia, South America, India, China, Ceylon and Africa, they yet all present a very un-plover-like appearance, and a strong resemblance to the Rallidæ, a family allied to the Cranes.

The Plovers, we may remark, are small, medium-sized, short-toed wading birds, frequenting beaches, and marsh and fen land, but keeping strictly to open country. Many swim with ease, though they appear but rarely to resort to this exercise.

The Rails and Water-hens are birds which should need no description here. Dwellers in the country know them well, and even in great cities like London the Water-hens at least may be seen daily in all the larger public parks, where indeed they have shaken off the reserve and secretiveness which are their natural habit, and walk boldly in the open. Timid and retiring in a wild state, these birds are not easily approached. In their haunts they differ from the marsh-loving Plovers in that they hide amid' the densest cover the reeds afford. When they come abroad they prefer to take to the water. Contrasting strongly with the Plovers in the great length and slenderness of the toes, these birds yet swim and dive well, though, be it noted, the toes are not webbed. This elongation of the toes renders it possible to walk with ease over floating water-weeds where insect prey abounds. ${ }^{\mathrm{I}}$

Thus, then, the Plovers and Rails contrive to live in harmony in the same regions. This brings us to our objective the evolution of the Parridæ. There are several species in this

${ }^{1}$ It might be supposed, perhaps, from this description that the Plovers and Rails were all aquatic or semi-aquatic in habit. This is not the case; a few species in each group have become dwellers on dry uplands, like the Landrail; or sandy wastes, like the Thick-knee (p. 54). 
family, which are known commonly as "Jacanas". By most systematists placed with the Rails, they are now known to be Plovers which have assumed the fashion of a Rail in response to the demands of a like environment. The Rail-like characters are chiefly to be observed in the great length of the toes, which is still further increased by claws of enormous length and great slenderness. Unlike the Plovers and like the Rails these birds pass their lives mainly on the water, and running about over the surface of floating aquatic weeds.

The Brazilian Jacana (Parra nigra) resembles our Waterhen (Gallimula chloropus) in the development of a bare fleshy shield on the forehead; but this shield is yet more reminiscent, both in appearance and structure, with the similar skin-folds which occur around the base of the beak in certain Plovers of the Genus Lobivanellus and Hoplopterus, which birds the Jacanas still further resemble in the possession of powerful spurs in the carpal or wrist-joint. The largest and most beautiful, however, of all the ten species of Jacanas is the Indian Jacana or Waterpheasant, Hydrophasianus chirurgus. Certain peculiar characters of this and other members of the family are described elsewhere.

The Cranes (Gruiformes) and Plover tribe (Charadriiforme's) are undoubtedly closely allied groups, and each contain within their ranks many aberrant and puzzling types. Each has produced forms resembling members of the opposite group. One instance of this kind we have already examined in the case of the Jacanas, which, though indubitable Plovers, have come to bear a very close resemblance to the Rails. Yet another is furnished by the Norfolk Plover or Thick-knee (Edienemus crepitans) which bears an unmistakable likeness to the Bustards, so much so that systematists have endeavoured by various compromises to reconcile this fact. The difficulty has generally been met by placing the Bustards-which belong undoubtedly to the Crane tribe-with the Plover tribe, using this term in a broad sense.

The case is an interesting one, and shows clearly the results of adaptation to environment. The Plover in question on the one hand, the Bustards on the other, are descendants of fen and marsh-haunting ancestors, and have exchanged this milieu for dry arid plains. What are the factors which brought about 
this migration we of course cannot say, but it is not difficult to imagine members of each group using the higher and drier surrounding country as a temporary resort, and ultimately forsaking the older haunts to found new colonies where competition perchance was less keen. At the present day, for example, many of the Plover tribe pass at least part of the year on the uplands, and the remainder by the sea or in the marshes. The long legs of these two convergent forms, originally developed to enable their possessors to wade in search of food, are now used as an aid to escape enemies before resorting to flight. In the matter of the toes certain changes have taken place in response to the new environment: originally of moderate length, so as to support the weight of the body in soft places, they have now become much shortened, thereby forming more perfectly a cursorial function.

As touching the sea-haunting habits of the Plover tribe. As might be expected, some species rarely leave this habitat, such as the aberrant Crab-plovers (Dromas) of E. Africa, Madagascar and S. India, for example; while the curious and aberrant Chionis or "Kelp-pigeon" of the Antarctic is even more maritime. "It feeds," says Darwin, "on sea-weed and shells on the tidal rocks. Although not web-footed, from some unaccountable habit, it is frequently met with far out at sea. This small family of birds is one of those which, from its varied relations to other families, although at present offering only difficulties to the systematic naturalist, ultimately may assist in revealing the grand scheme, common to the present and past ages, on which organised beings have been created."

If this much-to-be-desired culmination has not yet been reached, an approach thereto, which he probably at that time did not foresee, has been made, inasmuch as these birds furnish an undoubted link in the chain of evolution of the Auk tribe. No one supposed, when Darwin wrote the words just quoted, that the Auks were related to the Plovers. To-day this is recognised as a fact; but the lines along which the transformation took place, and the nidus from which they arose has always been a difficult problem. But there can be little room for doubt but that they arose, if not from this family, at least from some ancestral Plover having similar habits to those of the "Kelp-pigeon". Presently the peculiar features of the Auk 
tribe will be discussed, and it would be well to bear in mind these facts.

It would be well now to take a few cases of convergence from what we may call the "ærial" types on the one hand, and the aquatic types on the other.

Of the first kind the Swallows and Swifts furnish very striking examples. Representatives of both happily occur in Great Britain, and are indeed to be counted among our commonest summer visitants. So nearly alike are these two forms that by the ordinary observer they are merely regarded as different species of a common type. As a matter of fact the nearest allies of the Swifts are the Night-jars, to which certain exotic forms bear a close likeness; while the Swallows are members of a totally different order. What are their nearest allies is still a moot point, but they belong to the great group known collectively as the "Passeres". Too well known to need a detailed description here, it will be sufficient to draw attention to the fact that this resemblance of quite unrelated forms is due to adaptation to the requirement of catching living insect prey on the wing. In the Night-jars, which are crepuscular, the mouth is of enormous size; in the allied Swifts and the unrelated Swallows the mouth is also of great size, but is not so exaggerated a feature. All these capture insect prey while travelling at great speed through the air. The legs in all these forms have become exceedingly reduced, so much so that some of the Swifts find it extremely difficult to take flight from a level surface, sometimes indeed impossible. The wings, on the other hand, have become more or less pointed and ribbon-like when extended, but they differ much one from another when closely examined. Thus the Swift has an extraordinarily short arm and forearm and a hand of great length; in the Swallow, on the other hand, the arm and forearm are not conspicuously short, neither is the hand specially long.

To the Swifts and Swallows, in times past, have been added a third group known as the Pratincoles. This alliance was made on the supposition that, bearing a very real resemblance to these birds, both in form and habit, they must of course be related. We know now that this is not the case. The Pratincoles have been proved to be aberrant members of the Plover 
tribe-birds far enough removed from any possible relationship either to the Swifts or the Swallows.

No less remarkable in this connection are the Gulls and the Petrels, the Auk tribe and the Divers.

To begin with the two first-named groups. Until comparatively recently these were regarded as close allies. Even to-day there may be found some who are still of opinion that this is the case. Certainly the close resemblance which certain of the Petrels, e.g., the Fulmar Petrel (Fulmaris glacialis), present to the Gulls lends colour to this view. Superficially the readiest way of distinguishing the one from the other is by means of the shape and position of the nostrils and the character of the beak-sheath.

In the Petrels the rhamphotheca is compound, that is to say, the horny sheath of both upper and lower jaws is made up of several pieces; while the nostrils take the form of tubular apertures opening either on the ridge of the culmen or on each side thereof. In the Gulls the nostrils are slit-like, and placed midway down the beak. Furthermore, in the absence of a nasal septum the right and left narial apertures merge into one.

A brief survey of the morphology of the two groups is however sufficient to show at once that they are absolutely distinct. The Petrels are scions of an ancient stock not very distantly removed from the Stork tribe (Ciconiiformes). The Gulls, on the other hand, are unquestionably a highly specialised branch of the Plover group (Charadriiformes) and related therefore to the Cranes (Gruiformes).

The close superficial resemblance between the groups is to be attributed entirely to homoplasy-the action of a like environment on similar parts of similar organisms. Both types are aquatic, and seek their prey on the wing; and both feed on fish and carrion. The Petrels are essentially marine forms; the Gulls are not so uniformly wedded to the sea, many species ascending rivers, and breeding inland on meres and similar situations. The Petrels lay white eggs, those of the Gulls are of the typical Plover type, so much so indeed, that it was on this account that their affinities with the Plovers was first suspected.

The effects of their environment are well illustrated by these two groups. The Gulls, as we have just remarked, are by no 
means confined to the sea. The common Black-headed Gull, for example, during the autumn and winter months, contrives to pick up a living by following the plough in search of worms. For at least six months in the year they are to be found in considerable numbers up the Thames, many miles from its mouth, proving a source of infinite pleasure to the jaded toilers of the great city.

But with the Petrels this is otherwise. They may be said never to leave the sea save for breeding purposes. Many species are crepuscular. As might be expected, in consequence of their strictly marine habits, this group exhibits a series of gradations presenting an increasing specialisation to this habitat. The more generalised fly well, and swim comparatively little. These have relatively short bodies and long legs and wings, such as the Fulmar (Fulmaris glacialis), Storm-petrel (Thallasidroma pelagica) and the Fork-tailed Petrel (Cymochorea leucorrhoa) for example. From these we may pass to a long-bodied, shortlegged type, such as our Manx Shearwater (Puffinus anglorum), or the Dusky Shearwater (Puffinus obscurus). In these birds the wings are relatively shorter, and the legs placed further backwards. The former character has followed a lessened use of the power of flight, the latter an increased use of the limbs in swimming ; and these birds pass most of their time on the water, and can dive well, though they appear to resort but rarely to the latter practice. The long-legged species are not known to dive. That this swimming type possessing some powers of diving, and commonly found far from land, should have given rise to a yet more perfect diving form is not surprising. This is found in the little Diving Petrels of the Genus Pelecanoides. These birds, of which there are three species, would rather, at first sight, be regarded as some species. of Auk-a highly specialised Plover to be described immediately -than as Petrels. Moseley, in his Voyage of the Challenger, describes these birds as so numerous in Royal Sound, Kerguelen's Land, that the water, on two occasions, "was covered. with these birds in flocks extending over acres, which were: black with them ". They dive, he says, with extreme rapidity, and when frightened, get up and flutter along close to the water, and drop and dive again.

As touching the Auks and Divers. The Auks-by which 
term we include the Guillemots, Razor-bills and Puffins-are, as we have already remarked, neither more nor less than highly specialised Plovers. Derived probably from a stock which obtained a living entirely from rock-pools and beaches, and later from the sea itself by swimming and diving, the body became more and more transformed to facilitate the pursuit of very active prey under water. We say very active prey advisedly, because certain of the Duck tribe are equally skilled as divers, but they have undergone far less striking modifications, and this apparently because they seek, not agile fish, but algæe and mollusca. At the same time it is significant to note that the modifications which these Ducks present are similar in character to those of the Auks.

The most striking of the changes which the Auks and their kind have undergone are to be found in the thoracic vertebræ, hip-girdle and ribs.

The first-named have developed relatively enormous spines (hypapophyses) on their under surfaces, and many of these have the free end spread out into $L$-shaped processes. These spines afford attachment for highly developed muscles necessary for imparting impetus to the dive. The hip girdle has become drawn out, so to speak, posteriorly, so that the ischia, and especially the pubes, form long backwardly directed rods. The hindermost ribs have become enormously elongated so as to touch the free ends of the pubes, and thus form a sort of cage for the viscera. How great is this extension of the ribs can best be appreciated by a comparison of the figure of the trunk :skeleton of the aberrant Plover Chionis. This species, a native of Arctic regions, has been selected as it is a very ancient form, strictly marine in habitat, and probably nearer the ancestral Plover than the more familiar birds of this genus.

These changes in the trunk are evidently the outcome of adaptation to an aquatic life. To secure the greatest possible speed in the pursuit of an active prey under water the trunk thas become elongated, thereby placing the legs nearer the hinder end of the body, and imparting greater speed and power to the stroke.

While in the matter of the elongation of the ribs, as will be shown presently, the Auks have exceeded the yet more specialised Divers, in so far as the legs are concerned they have 



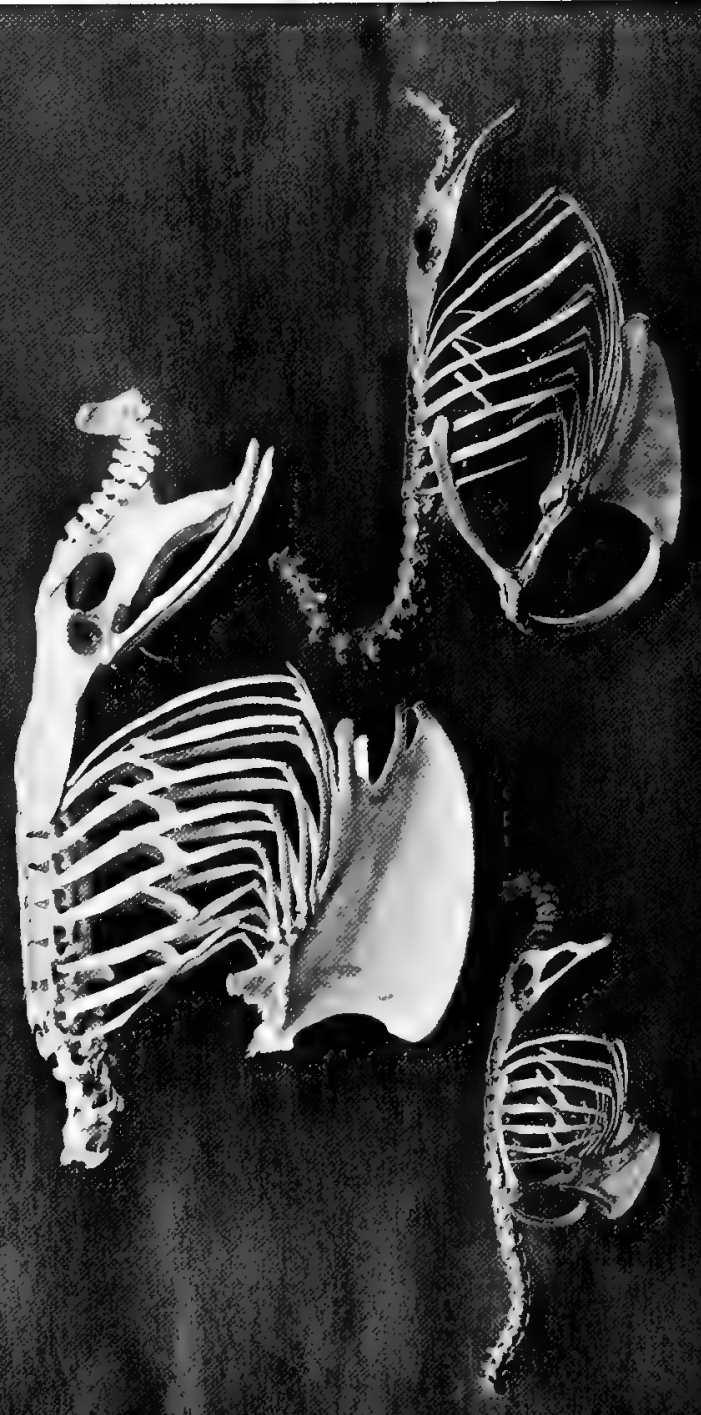

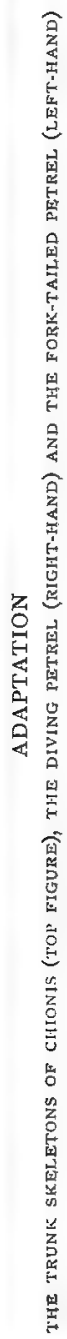





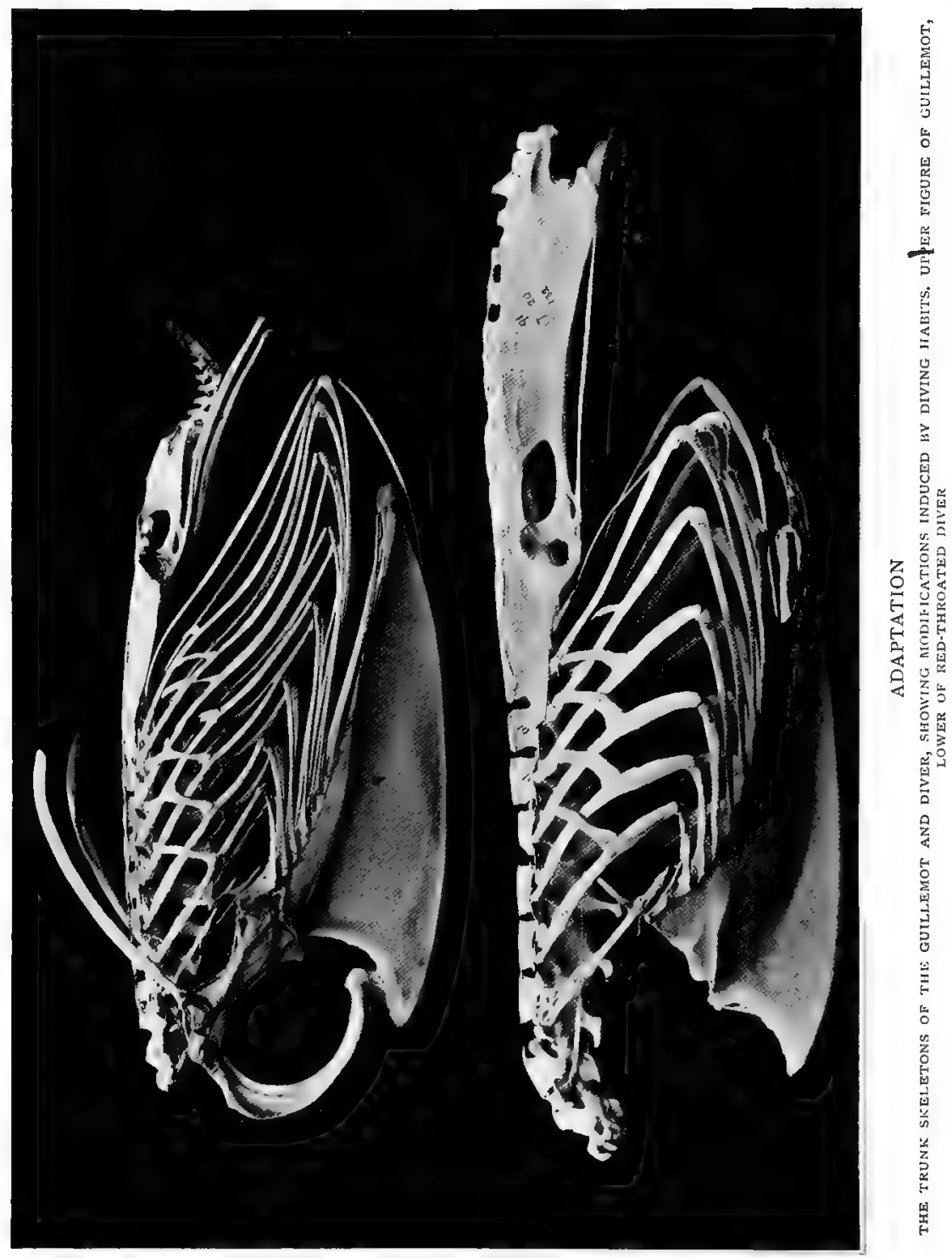


changed the more typical Plover-type mainly in the shortening of the tarso-metatarsal bones. The femur or thigh-bone is yet as long as in the more normal Plover. This fact is one of considerable interest, affording another link in the chain we are endeavouring to forge to show that change of habits is slow to alter the deep-seated structures of an animal. In the little Diving-Petrels we had an instance of a bird which superficially was much more like an Auk than a Petrel. Yet, in spite of this superficial resemblance, the skeleton has but little changed. The Auks appear to have sojourned on the ocean wastes far longer, and in consequence have become more perfectly adapted to this environment.

The Auks and the Divers, like the Gulls and the Petrels, were universally believed to be intimately related forms. Yet we know now that they are in no way related. The Divers represent a very ancient group, now almost extinct. They are possibly descendants, or, at any rate, very nearly allied to the giant Hesperornis of the cretaceous epoch.

Unlike the Diving-Petrels and the Auks, the latter and the Divers (Colymbi) have acquired a more than superficial likeness; for the skeletons of the two types present parallels which, while they leave little room for doubt as to their interpretation, at the same time appear to show conclusively that capture of prey under water dates back to an indefinitely long period; and this is especially true of the Divers, which, among birds that fly, have reached the high-water mark of specialisation to this end.

As in the Auks, the body has become markedly elongated and depressed, and thereby more perfectly adapted for swimming. The legs, in the living bird, seem to leave the body at its extreme hinder end. This fact is due, not to a shifting backwards of the acetabulum - the socket of the hip girdle for the articulation of the thigh-bone-but to structural peculiarities of the leg itself, all of which contribute towards securing efficiency in swimming, but at the same time render the limb practically useless as an organ of locomotion on land.

Let us briefly survey these "expression points" of evolution. The thigh-bone (femur) has been transformed into a much depressed and extremely short bone, and can be rotated forwards as in other birds. The freedom of movement, however, at the knee-joint has been curtailed in a manner unique among 
birds. This has come about by the upgrowth in a semicircle of the articular surface of the tibia so as to grasp the end of the femur in a close embrace, absolutely preventing the leg being straightened. Thus, the tibia in the living bird is permanently flexed on the femur at more or less of a right angle. In swimming when the thigh is brought forwards for the commencement of the stroke the leg-shank is brought to a position at right angles to the long axis of the body; at the end of the stroke it lies parallel with the long axis thereof. But this tibia is still further remarkable for the enormous development of the cnemial crest which rises far above the level of the thighbone. The patella, in consequence, has become reduced to a mere scale, partaking in shape of the form of the crest behind which it lies. This huge crest affords attachment to powerful swimming muscles.

In the hind-limb of the lacustrine Grebes we find a midway stage in the development of this remarkable joint. Here a similar tibial semicircular socket is formed, not, however, by the semicircular growth of the tibial articular surface, but by a large patella which allows of a little more movement. As a consequence the Grebes can walk, though with difficulty, on land; the Divers, as we have already remarked, cannot. On land these birds can sit upright, but locomotion can only be effected by lying along the belly and shoving the body forward by means of the feet. As in the Divers, the cnemial processes are enormously developed, though they do not attain, relatively, so large a size, and are overtopped by the great pyramidal patella, which in the Divers has become suppressed by the great cnemial crest.

The tarso-metatarsus and the toes, which together make the foot, is in both Divers and Grebes extremely compressed, offering little more than a knife-edge to the water when swimming. In both Grebes and Divers the outer toes are so arranged as to fold up one behind the other at the end of the stroke when the leg is being brought forwards. The outer toe is the longest in both forms. The Divers are web-footed, but in the Grebes broad lobes along each toe take the place of webs. This is really a very curious fact and demands closer scrutiny. It has already caused comment, some inclining to the belief that the Grebes are-and on this account-really more nearly 


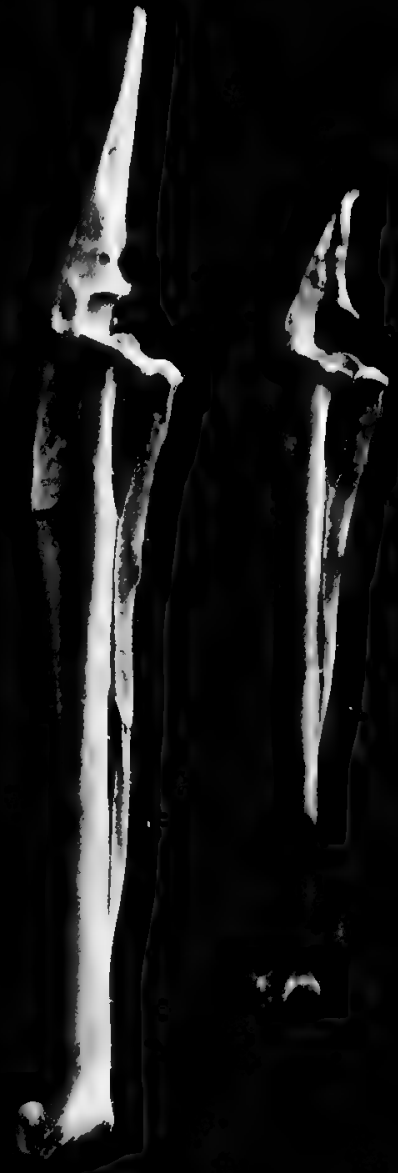

ADAPTATION

SHANK OF THE LEG OF THE RED-THROATEN DIVER (LEFT-HAND) AND OF THE GREAT CRESTED GREBE (RIGHT-HAND) TO SHOW THE GREAT SPUR ABOVE THE KNEE JOINT 

allied to the Coots and Water-hens, which are also lobe-footed. There is, however, little of real value in this contention.

That homoplasy should play a very important part in the evolution of the Class Aves is only what might be expected from the uniformity of structure which these animals present.

The factors which are concerned in the production of these homoplasts are by no means so easily detected as some would have us believe. Doubtless they are the same as obtained in other cases of adaptation to environment, but this assurance leaves the key to the problem still undiscovered.

"When," says Sir Ray Lankester, "identical or nearly similar forces, or environments, act on two or more parts of an organism which are nearly or exactly alike, the resulting modifications of the various parts will be exactly or nearly alike. Further, if instead of similar parts in the same organism, we suppose the same forces to act on parts in two organisms, which parts are exactly or nearly alike, and sometimes homogenetic, the resulting correspondences called forth in the several parts of the two organisms will be nearly or exactly alike. . . ." As generally interpreted these forces, or environments, act by selecting variations favourable to the maintenance of life in the particular environment in question.

Thus, variations tending to increase the length of the body and shift the legs backwards have been selected in birds which swim and dive much; the selection of variations which tended to lengthen the legs and strengthen the toes and claws has transformed the limbs of the Owls from normal perching limbs to organs fitted for grasping and holding living prey, and so on.

According to some, these variations are more or less fortuitous: that is to say they are not stimulated in any way by the environment. Others, however, like Professor Osborn, hold that in every animal there are fundamental predispositions to vary in certain directions, predispositions which are aroused under certain exciting causes. But this hypothesis, judging by the evidence now before us, seems to prove too much. Perchance a satisfactory solution may be found in a compromise. This assumes a potentiality to respond directly to any long-sustained stimulus. Many will see in this last explanation a virtual concession to the theoretical doctrine of the transmission of acquired characters. Nevertheless, it does not necessarily imply this. 
There certainly seems to be some show of evidence that habit precedes structure. The case of the Diving Petrel (Urinatrix) will serve as an illustration. Though superficially this bird so closely resembles the little Auk (Alca alle), yet, in its skeleton, it has undergone but little modification of the normal Petrel type. The Pluvialine Alcidæ, e.g., Guillemot and Auk, have apparently, from a longer course of moulding, greatly modified the skeleton of the trunk, and to a less extent of the legs. The marine Divers (Colymbida) and lacustrine Grebes have from a yet longer sojourn in their respective environments suffered still further changes; but all the types in question have developed the same general features, as of course was to be expected.

Before closing this chapter a brief reference must be made to the opposite side of this picture, wherein is presented a number of equally remarkable phenomena illustrating that interesting phase of evolution known as parallel development.

Parallel development differs from convergent development in this, that whereas in the latter, forms not even remotely related have come to assume a superficially identical appearance, in the former that resemblance is due to a common descent, albeit remote, before heterogeneity had well begun. Often this parallelism is worked out in regions of the earth far distant one from another, and always before the several characteristics which distinguish the living descendants of this primitive stock had assumed their final trend; that is to say, while these characteristics were yet in a nascent condition so that the differences which obtain between what we now call the parallel forms are to be regarded as so many "expression points" of environmental influence-of selection-and of the struggle between the several parts of the organisms involved, as a consequence of their early separation and long isolation.

It is an open question whether the New and Old World Vultures are to be regarded as convergent or parallel types. The Old World Vultures are unquestionably Accipitrine; but it is not so certain that their doubles of the New World are descendants of nascent Accipitres, or are offshoots from the Gruiform stem, or, as the late Professor Garrod held, of the Ciconiform stem. Forbes hinted at a descent from the Petrels, and in many parts, especially the cranial characters, there are striking resemblances thereto. 


\section{INDEX}

A

Accipitres, descent of, 49 .

Acquired characters, 3 II.

Africa and South America, continuity of, 77 .

Air-sacs, number of, I7.

- naso-pharyngeal, I8.

- of Bustard, I8, I48, I55.

- - Adjutant, r8, 156 .

- - Emu, r9, I66.

- origin of, Ig.

- of Musk Duck, Ig.

- Frigate-Bird, I50.

- - Ruffed Grouse, I55.

Albinism, 308.

Anastomus, remarkable beak of, 362 .

Anseres, origin of, 49.

Antarctica, existence of, 76 .

Aquintocubitalism, meaning of, 409 .

Archæopteryx, characters of, 35, 4I.

- wing of, $263,266,374$.

- tail of, 266.

- feathers of, 269 .

Arctic sub-region, birds of, 64 .

Arteries, transformation of, 438 .

Asymmetry, instances of, 369 .

Asyngamic forms, 342 .

Auks, evolution of, 450 .

- systematic position of, 55 .

Australian region, birds of, 72 .

Aves, numerical strength of, 60 .

\section{B}

Barbets, peculiar distribution of, 78 .

Beak, modifications of, 4II.

Birds, characters of, I, 5, 30 .

- flightless, $37,69,73,123$.

- descent of, 38,56 .

- classification of, 48 .

- Ethiopian, 65.

- extinct, $6 \mathrm{~g}$.

- Neotropical, 75.

- fossil, 77 .

- size in relation to latitude, 85 .

- effect of climate on, 86.
Birds, effect of storms on, 87 .

- fertilising flowers, I06.

- seed dispersal by, ro8.

- checks upon reptiles, II5.

- enemies of, ri6.

- destroyed by crabs, xI6, II7.

- - pigs, II7.

- parasitic, 127, 132 .

- sharing burrows with reptiles, 127.

- polyandrous, I34.

- gregarious habits, I35.

- strange sleeping postures, $\mathrm{r} 39$.

- food-storing, I40.

- struggle for existence, 140.

- tournaments of, 156 .

- weapons of, 160 .

- dances of, I6I.

- song of, 165.

- music of, I66.

- windpipes of, $\mathrm{r} 6 \mathrm{~g}$.

- reversal of sexual rôle in, I7I.

- ancient types of, 174 .

- origin of nests, $174-93$.

- burrowing, I75.

- nests of, 176 .

- eggs of, 195.

- brooding habits of, 213 et seq.

- striped colours of, 252.

Bittern, coloration of, 322 .

Black Cock, display of, ${ }_{57}$.

Bower-birds, strange habits of, I64.

Bustard and Bee-eaters, I25.

- characters of, 53 .

- display of, I55.

\section{C}

Cæca, forms of, $2 \mathrm{I}$.

Canary, origin of, $34^{\circ}$.

Caracara, causes of increase of, II4.

Cariama, transformation of, 442 .

Carrion-hawk. See Caracara.

Cassowaries, specific forms of, 359 .

Coloration, effect of light on, $8 \mathrm{I}$. - moisture on, 82,84 .

- striped, meaning of, 252.

- protective, 322. 
Coloration, procryptic, 323 .

- cryptic, 323.

- apatetic, 323-27.

- anticryptic, 325.

- resplendent, evolution of, 35I.

Convergent evolution, 439 .

Coraciomorphæ, oldest of, 59 .

Correlated variation, 34I.

Coverts, arrangement of, 14 .

Cow-bird, parasitic habits, 132 .

Cranes, characters of, 53.

- dances of, $\mathbf{I 6 2}$.

Cuckoos, parasitic, 128, 13 r.

\section{D}

Dabchick, care of young of, 224.

Dancing, 163 .

Diastataxy, meaning of, 409.

Digestive system, Ig.

Dimorphism, 299.

Dippers, distribution of, 78 .

Display of Argus, $x_{45}$.

- - Bird of Paradise, 147.

- Bustard, I55.

- - Black Cock, 157.

- - Ruff, I59.

- - Sun Bittern, 344, 352.

- Warblers, 347.

- - Kagu, 35I.

- meaning of, 349 .

Distribution, forms of, 78 .

Divers, evolution of, $45 \mathrm{I}$.

Dodo, extinction of, I2I.

\section{E}

Ecdysis, peculiar forms of, 28r, 285. Eclipse plumages of Game-birds and Ducks, 277.

Eggs of Cuckoo, r28 et seq.

- peculiarities of, 196 .

- coloration of, 198 et seq.

- white, 205 .

- structure of, 2 ro.

Egrets and Elephants, I25.

Ethiopian sub-region, birds of, 65 .

Evolution, convergent, 439 .

- parallel, 454 .

Extermination of British birds, IIg.

Extinction of Great Auk, I20.

- - Dodo, I2r.

- - Solitaire, I22.

- Labrador Duck, I22.

- - Cormorant, I22.

- Moa, I23.
F

Feathers, kinds of, 5 , Ir.

- structure of, 6 .

- abrasion of, 8r, 28o, 284 .

Feeding young, methods of, 225 .

Feet, forms of, 386,395 .

Flamingo, change of colour in, 315.

Flight, altitude of, 96 .

- speed of, 96 .

Food, influence on colour, 3 I5.

Fowls, breeds of, 338 .

Frigate-birds, parasitıc habits of, 127 .

- remarkable display of, 155.

\section{G}

Galliformes, composition of, 50 .

Gizzard, work of, 20.

- peculiarities of, 20 .

Glands, absence of, I5.

Gold-crests, peculiar distribution of, 78 .

Grebe, flightless, 36r.

Gregarious habits, formation of, I35 et seq.

Gruiformes, types of, 52 .

Gullet, modifications of, 432 .

Gulls, affinities of, 55 .

- predaceous habits of, 320 .

\section{H}

Habit in relation to structure, 454 .

Hangnests, aberrant nesting habits of, 132.

Hearing, sense of, 29 .

Heart, structure of, 25 .

Heel-pads of nestlings, 26I.

Hemipodes, reversal of sexual rôle in, I 7I.

Hepatic phases, 300.

Hesperornis, characters of, 37 .

- pelvic girdle of, $3^{85}$.

- leg of, 385 .

Hoatzin, remarkable nesting habits, 238.

- structural peculiarities of, 3 r2.

- affinities of, 450 .

Homing instinct, I03.

Homoplasy, 448,453 .

Hornbill, Helmet, use of casque, 422.

- strange nesting habits, $2 \times 5$.

Hunting in concert, 139 .

\section{I}

Ichthyornis, peculiarities of, 37 .

Indian region, birds of, 69 .

Interbreeding, 30I. 
Intestines, regions of, 20.

- convolutions, $2 \mathrm{I}$.

- peculiarities of, $2 \mathrm{r}$.

- and adaptation, 435.

Intraorganismal selection, 333 .

Isolation areas, ignificance of, 79 .

- and evolution, 354.

- - variation, 355.

- - fixity of type, $36 \mathrm{I}$.

- indiscriminate, 357 .

\section{$\mathbf{K}$}

Kea, killing sheep, II4.

L

Lungs, structure of, $\mathbf{7}$.

\section{M}

Madagascar, extinct birds of, 69 .

Megapodes, nest of, 217, 218, 248.

Melanism, 308.

Migration, seasonal, $9 \mathbf{I}$.

- routes, 92.

- al titude during, 95.

- and lighthouses, 97.

- causes of, 99 .

- interpretation of, ro3.

- and geographical races, $\mathrm{IO}_{4}$.

Mimicry, 327.

Moult, forms of, 279.

Muscular system, peculiarities of, 26 , 27.

Mutations, 303.

\section{N}

Natural selection and evolution, 356 .

Nearctic region, confines of, 74 .

Neossoptyles, II, 27 I.

Neotropical region, birds of, 75 .

Nervous system, 27 .

Nestling down, Io, II, 27 r.

- bright colours in, 233.

- conditions of, at hatching, 235.

- development of, 243.

- wings of, 244 .

Nests as receptacles for nests, 126 .

- types of, I76 et seq.

- origin of, 194 .

Night-jars, evolution of, 440 .

Nutcracker, irruption of, 99 .

Nuthatch, peculiar distribution, 78 . 29 *
Offspring, care of, 223.

Oil-gland, use of, $15, \mathrm{x} 6$.

Organs of extreme perfection, 404 .

Ostriches and $Z$ ebras, r24.

Owls and vole plague, II3.

- changed nesting habits of, II7.

- mutational form of, 303 .

-- asymmetrical ears of, $36 \mathrm{~g}$.

- evolution of, 439 .

Oxpecker and cattle, I24.

\section{$\mathbf{P}$}

Palate, avian, peculiarities of, 43,46 .

Pallas's Sand-grouse, irruption of, 98 .

Parasitism, I27.

Passeres, characters of, 56 .

- descent of, 60.

Pelvic girdle, peculiarities of, 33,383 , 385,389 .

- limb, peculiarities of, 34 .

Penguins, descent of, 48 .

- southern origin of, 77 .

- paddle of, 385 .

Petrels, descent of, $4^{8}$.

- lamellated beaks of, 50 .

- convergence in, $44^{8}$.

- transformation of 454 .

Pheasants, distributiơnal centre of, 70 .

Physiological selection, 357 .

Pigeon, passenger, vast hordes of, 135 .

Pigeons, descent of, 55,56 .

- domestic, evolution of, 335 .

Play of birds, 290.

Plovers, forms of, 53-55.

Plumage, effect of weathering on, 80 .

- disintegration of, 80 .

- intensification of colour in, 8r.

- bleaching in, $8 \mathrm{I}, 82$.

- effect of moisture on, 82 .

- winter whitening of, 84 .

- displays of, 144 .

- phases of, 269, 271, 276.

- " eclipse," 277.

Powder-down, II.

Prepennæ, I0, 27 I.

Preplumulæ, 10, 27I.

Pro-aves, characters of, 38 .

Pterylosis, I2.

Pygostyle, structure of, 266 .

- peculiarities of, 399 .

\section{$\mathbf{Q}$}

Quails, primitive coloration of, 259 .

- rapid maturity of, 269 . 
Rails, ancient characters of, 52 .

Rhea and Guanacos, I24.

Ruff, display of, 159 .

\section{$\mathbf{S}$}

Sand-grouse, descent of, 55,56 .

- irruption of, 98 .

- care of young, 225.

Screamers, archaic characters of, 48,50 .

Selection, interspecific, 3 I8.

- intraspecific, 321 .

- intraorganismal, 333.

- artificial, 335.

- sexual, 343.

- natural, 356 .

- physiological, 357.

Shoulder-girdle, forms of, 379 .

Skeleton, characters of, 16,30 .

Skuas, predatory habits of, II8, 320.

Skull, characters of, 30 .

Smell, characters of, 29.

Snipe, "bleating " of, I7o.

Species, origin of, 305.

- evolution of, 307 .

- physiological, 342 .

Squamosal, evolution in, 372 .

Steganopodous birds, descent of, 48 .

Storks, types of, 48 .

Striped coloration, significance of, 252.

Struthious birds, fossil forms of, 77 .

Swallow, migration route, 92 .

\section{$T$}

Tail, evolution of, 266 .

- feathers, uses of, 398 .

Tanager, change of colour in, 3 I6.

Tinamous, 5 r.

Tongues, forms of, 420,426 .

Tournaments, kinds of, 156 .

Turnices, 5 I.
U

Uropygium, I5, 16.

\section{V}

Variation, continuous and discontinuous, $29 r$.

Vertebræ, peculiarities of, 33 .

\section{$\mathbf{W}$}

Warblers, order of migration of, 99 . display of, 347 .

Weapons, uses of, $x 60$.

White eggs, meaning of, 205.

- plumage, significance of, 325 .

Windpipes, modifications of, 401 et seq.

Wing, feathers of, 13,377 .

- spurs of, I6I.

- sounds made by, $x$ 7o.

- claws of, 250.

- skeleton of, 373 et seq.

Woodcock carrying young, 225, 230.

Woodpecker, method of storing nuts, 140.

- - - grasshoppers, I42.

- - obtaining sap, I42.

- plumage, phases of, 273.

- interbreeding of, 302.

- mutation in, 305 .

- changed habits of, 409 .

\section{$\mathbf{Y}$}

Young, methods of feeding, 225.

- neglect of, 232.

- striped coloration of, 252.

\section{$\mathbf{z}$}

Zoo-geographical regions, 63 . 

ABERDEEN : THE UNIVERSITY PRESS 





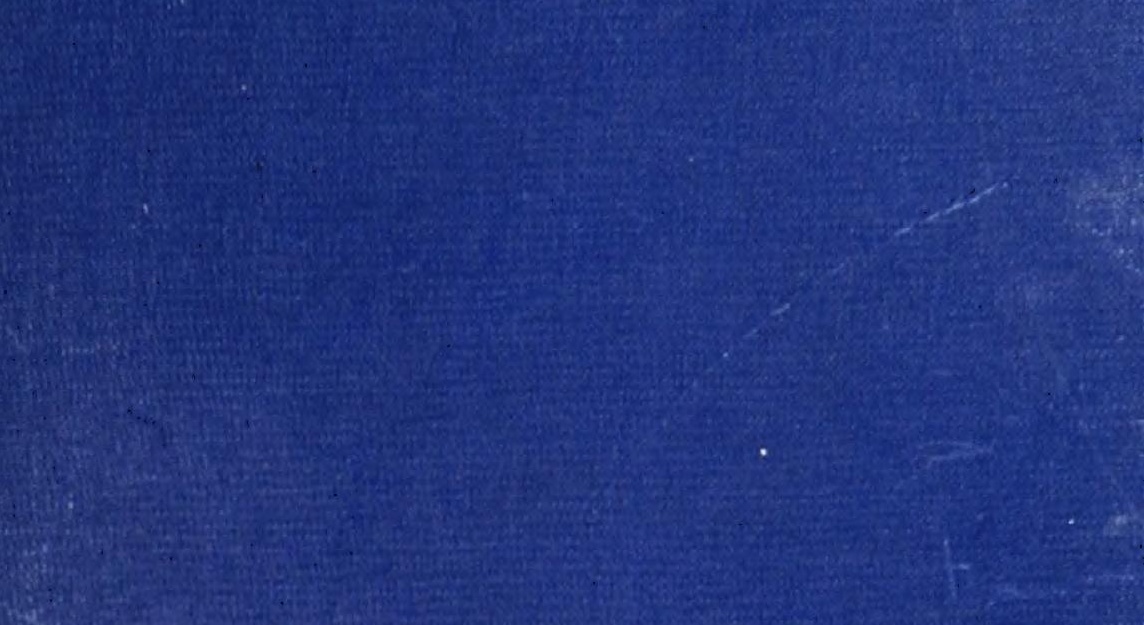

Pit.

Aivicy

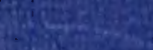

anding

(i.)

浆

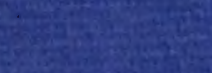

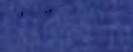

c.s.

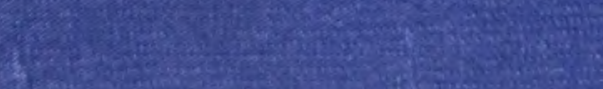

